UNIVERSIDAD NACIONAL DE LA PLATA

FACULTAD DE CIENCIAS NATURALES Y MUSEO

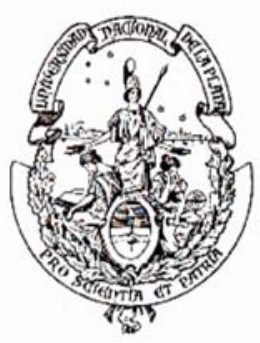

\title{
GEOLOGÍA Y GEOQUÍMICA DEL SKARN SAN MIGUEL, SISTEMA DE TANDILIA, PROVINCIA DE BUENOS AIRES
}

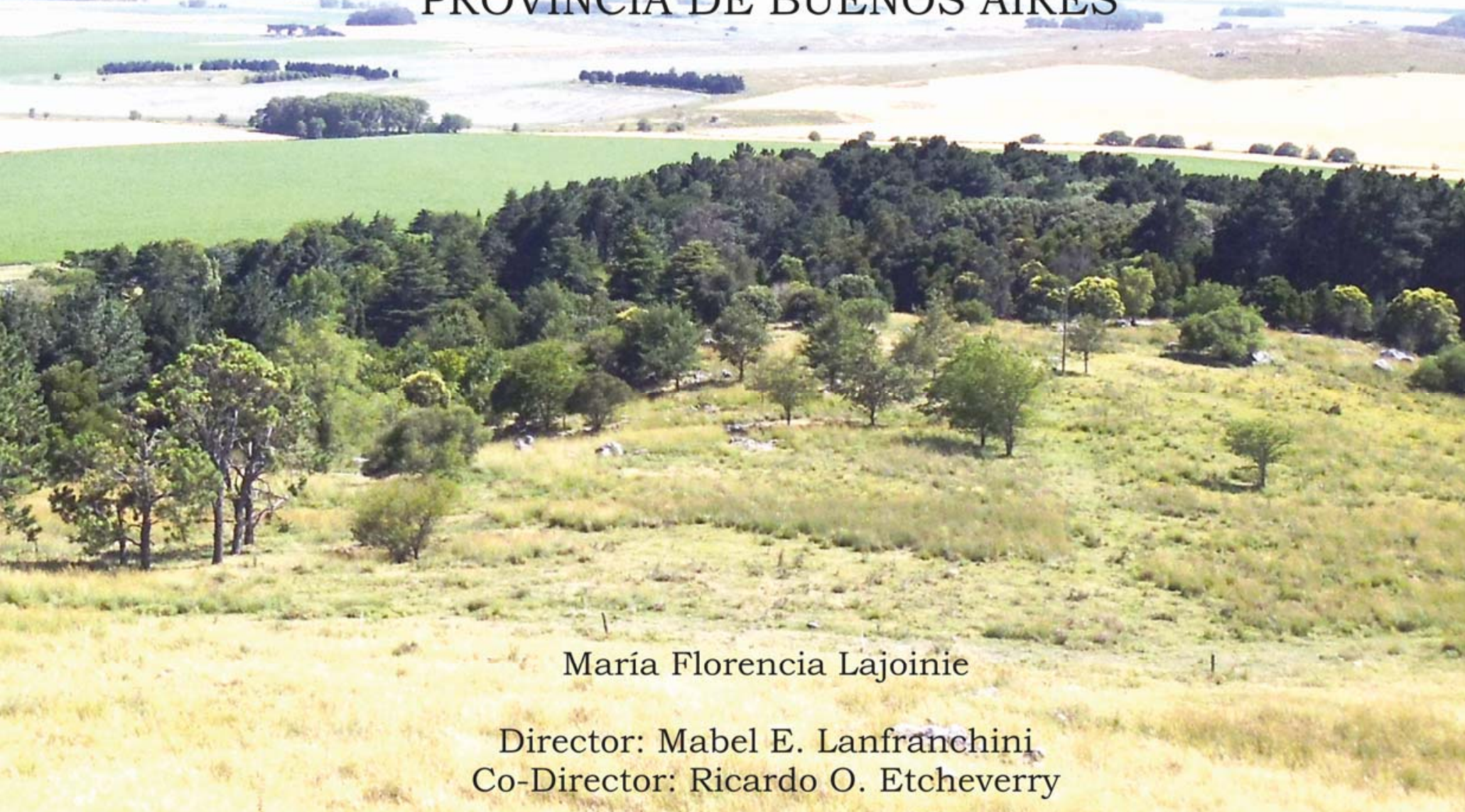

LA PLATA, 2015<smiles>CCCCC1CCCCC1</smiles> 
"La mayoría de nosotros somos expertos en prestar atención a todo lo que no tenemos, a todo lo que no somos, a todo lo que no hemos logrado, a todo lo que no se nos ha cumplido. Ahora, deberíamos volvernos expertos en lo que sí tenemos, en lo que sí somos, en lo que hasta ahora hemos conquistado, en aquello que se nos ha hecho realidad. Es cierto que hay mucho por lograr, por ser y por hacer, pero en el camino hacia ello no perdamos la visión inmediata y la oportunidad de estar agradecidos en este momento".

(Autor desconocido) 


\section{AGRADECIMIENTOS}

Deseo expresar mi más profundo agradecimiento a todas aquellas personas que me han acompañado, personal y profesionalmente, en esta hermosa etapa de mi vida.

A mi querida y admirada Directora de Tesis Dra. Mabel E. Lanfranchini, por su compañía, consejos y amistad. Su guía a través de estos años me ha enseñado que se puede trabajar mucho, con felicidad y disfrutando de cada uno de los pasos de un proceso. A mi querido CoDirector de Tesis Dr. Ricardo O. Etcheverry, por confiar en mí y haberme dado la posibilidad de realizar este trabajo de Tesis Doctoral. Su paciente guía ha sido de mucha importancia durante el desarrollo de esta Tesis.

A la Dra. María Elena Canafoglia por su enorme ayuda durante la realización de los diferentes análisis de minerales e interpretación de los resultados, al Dr. Clemente Recio por los análisis de isótopos estables y por su aporte en los diferentes trabajos publicados y al Dr. Raúl de Barrio por su colaboración general.

Al Director del Instituto de Recursos Minerales Dr. Isidoro Schalamuk y a mis compañeros de trabajo, muy especialmente, a mis compañeras de oficina Lic. Cecilia Cábana y Lic. Marcela Curci, por recibirme con tanto afecto y a la Lic. Andrea Ramis por nuestras largas conversaciones.

A los dueños de las estancias San Miguel, La Concordia y Siempre Verde por su buena predisposición y trato cordial en cada una de las visitas que realizamos al área de estudio.

A todos mis amigos, especialmente al Lic. Marcos Machioli Grande y a la Lic. Mariana Bodaño quienes me han aportado su ayuda, alegría y compañía.

A mis padres Nilda y Carlos, les estaré eternamente agradecida por tanto amor. Soy quien soy gracias a ustedes.

Por último quiero agradecer a mi compañero de vida Hernán de la Cal, quien estuvo a mi lado durante todo el transcurso de esta Tesis. Transitó conmigo cada uno de los momentos, ofreciéndome su ayuda incondicional en las campañas, en la lectura de los trabajos y en otras tantas cosas más. Sin él nada hubiese sido igual. 
A mi amor Hernán.

A mis padres Nilda y Carlos y a mis hermanos Mauricio y Francisco.

A Branca, Magma, Michín, Rocco, Claudia y Malm. 


\section{INDICE}

RESUMEN

Páginas

ABSTRACT

CAPÍTULO 1

\section{“OBJETIVOS Y METODOLOGÍA DE}

TRABAJO"

\subsection{Introducción}

1.1.1 Antecedentes de la zona de estudio

1.2 Objetivos

1.3 Metodología de trabajo 12

1.3.1 Tratamiento de imágenes satelitales y

cartografia

1.3.2 Trabajo de campo 13

1.3.3 Estudios de gabinete y laboratorio $\quad 14$

1.4 Bibliografia

CAPÍtULO 2 “GEOLOGÍA REGIONAL"

2.1 Introducción 23

2.2 Geología del Cratón del Río de la Plata

2.3 Geologia de las Sierras Septentrionales

2.3.1 Basamento ígneo metamórfico 28

2.3.2 Cubierta sedimentaria 30

2.3.3 Evolución tectónica de las Sierras

Septentrionales

2.4 Geologia del área de Tandil $\quad 35$

2.4.1 Evolución tectónica del área de Tandil 41

2.5 Bibliografia

CAPÍtulo 3 “GEOLOGÍA LOCAL" 
3.A.1 Gneis biotítico y migmatitas 56

3.A.1.1 Caracterización geológica 56

3.A.1.2 Petrografia $\quad 62$

3.A.1.2.1 Petrografia de los xenolitos 68

3.A.1.3 Geoquímica $\quad 71$

3.A.1.4 Discusión de los resultados 76

3.A.2 Mármol 80

3.A.2.1 Introducción 80

3.A.2.2 Petrografía 82

3.A.2.3 Caracterización geoquímica del mármol 84

3.A.2.3.1 Geoquimica de roca total 86

3.A.2.3.2 Isótopos estables $\quad 87$

3.A.2.4 "Evento Lomagundi-Jatuli": Carbonatos 90

marinos del Paleoproterozoico

3.A.2.5 Discusión 93

$\begin{array}{ll}\text { 3.A.3 Bibliografia } & 97\end{array}$

CAPÍTULO 3.B "ROCAS ÍGNEAS DEL BASAMENTO DEL ÁREA DE SAN MIGUEL"

3.B.1 Introducción 104

3.B.2 Cerro Guacho 104

3.B.2.1 Introducción 104

3.B.2.2 Caracterización geológica y petrográfica 105

3.B.2.3 Caracterización geológica y petrográfica 108 de los cuerpos pegmatoideos

3.B.2.3.1 Turmalina 111

3.B.2.3.2 Resultados de estudios sobre cristales $\quad 112$ de turmalina

3.B.2.3.3 Discusión y consideraciones genéticas $\quad 115$

3.B.3 Cuerpos tonalíticos 117

3.B.3.1 Introducción 117

3.B.3.2 Caracterización petrográfica 118

3.B.4 Caracterización geoquímica de las 119 unidades antes descriptas

3.B.5 Diques 126 
3.B.5.1 Introducción 126

3.B.5.2 Caracterización geológica de los diques $\quad 127$

3.B.5.3 Petrografia de los diques 133

3.B.5.4 Caracterización geoquímica de los $\quad 139$

diques

3.B.5.5 Discusión y conclusiones 145

3.B.6 Bibliografia 148

\section{CAPÍTULO 4}

"SKARN SAN MIGUEL: CARACTERÍSTICAS

GEOLÓGICAS, MINERALÓGICAS Y QUÍMICAS"

4.1 Introducción 153

4.2 Skarn San Miguel 154

4.2.1 Estancia San Miguel: sectores 156

noroccidental y nororiental

4.2.2 Estancia San Miguel: sector sur $\quad 179$

4.2.3 Estancia La Concordia 184

4.2.4 Estancia Siempre Verde 186

4.3 Geoquímica del skarn San Miguel 190

4.3.1 Elementos mayoritarios y trazas 191

4.3.2 Tierras Raras 199

4.3.3 Balance de masas 203

4.3.4 Composición química de las vetillas 211

4.3.5 Clasificación del skarn San Miguel 212

4.4 Discusión y análisis de los resultados 215

4.5 Comparación con el skarn Punta Tota 219

4.5.1 Descripción del skarn Punta Tota 219

4.5.2 Comparación entre los skarns Punta Tota 221

y San Miguel

4.6 Bibliografia 223

CAPÍTULO 5 "NATURALEZA DE LOS FLUIDOS

FORMADORES DEL SKARN: COMPOSICIÓN Y

CONDICIONES P-T" 
5.1 Introducción 227

5.2 Caracterización y análisis de las 227 inclusiones fluidas

5.2.1 Petrografia de las inclusiones fluidas 227

5.2.2 Microtermometría de inclusiones fluidas 235

5.2.2.1 Metodología 235

5.2.2.2 Resultados $\quad 237$

5.3 Análisis de Isótopos Estables 243

5.3.1 Resultados 244

5.3.1.1 Termometria 246

5.3.1.2 Estimación del $\delta^{18} \mathrm{O}$ del fluido 246

5.4 Vesubianita como estimador de 248 temperatura

5.4.1 Introducción 248

5.4.2 Resultados 249

5.4.3 Discusión y conclusiones 251

5.5 Geotermómetro granate-clinopiroxeno 252

5.6 Discusión 255

5.7 Conclusiones 259

$\begin{array}{ll}5.8 \text { Bibliografia } & 260\end{array}$

CAPÍTULO 6 "DISCUSIÓN Y CONCLUSIONES"

6.1 Introducción 263

6.2 Discusión 263

6.2.1 Evolución del basamento del área de San 263

Miguel

6.2.2 Modelo genético del skarn San Miguel 273

$\begin{array}{ll}6.3 \text { Conclusiones } & 279\end{array}$

6.4 Bibliografia 282 


\section{RESUMEN}

En el área de San Miguel $\left(37^{\circ} 33^{\prime} 27^{\prime \prime}\right.$ - $37^{\circ} 36^{\prime} 13^{\prime \prime}$ S y $59^{\circ} 20^{\prime} 34^{\prime \prime}$ $59^{\circ} 24^{\circ} 52$ “) afloran rocas metamórficas e ígneas pertenecientes al basamento de las Sierras Septentrionales de la provincia de Buenos Aires denominado Complejo Buenos Aires. Las metamorfitas consisten en: gneises biotíticos migmático, migmatitas, xenolitos de anfibolitas y mármoles a los cuales se asocia la presencia de un skarn (skarn San Miguel). Las rocas ígneas están representadas por un cuerpo granítico, fuertemente metamorfizado, que constituye el Cerro Guacho, un cuerpo de composición tonalítica que aflora en el casco de la Estancia San Miguel y en el cerro Los Angelitos (Ea. Siempre Verde) y diversos diques de naturaleza tanto ácida como intermedio-básica. En la presente Tesis Doctoral se exponen los resultados de los estudios y análisis realizados sobre los tipos litológicos antes mencionados, enfocados particularmente a definir la génesis del skarn San Miguel.

El gneis biotítico migmático presenta un bandeado $\left(\mathrm{S}_{1}\right)$ con rumbo general $\mathrm{N} 35^{\circ} \mathrm{E}$ y una composición mineralógica integrada por microclino, plagioclasas (oligoclasa-andesina), cuarzo y biotita. Las migmatitas se exhiben como diferenciados, dentro del mismo gneis, con estructura estromática de igual rumbo que $\mathrm{S}_{1}$ o con estructuras menos frecuentes como movilizados brechoides o boudines. Sus leucosomas están constituidos por cuarzo, plagioclasa (oligoclasa) y feldespato potásico tipo microclino. También se presentan leucosomas más voluminosos de límites difusos que además de la mineralogía antes mencionada incluyen granate con una composición $\mathrm{Alm}_{72} \operatorname{Prp}_{13} \mathrm{Sp}_{12} \mathrm{Gro}_{3}$. Análisis químicos indican que el gneis deriva de un protolito sedimentario con características de un wacke o grauvaca y que las migmatitas se habrian formado a partir de la fusión parcial del gneis a través de la descomposición de la biotita en presencia de plagioclasas y cuarzo. Esto generó una fase granatífera, con feldespato potásico y un fundido granítico peraluminoso en desequilibrio, con bajo contenido en Th 1,50 a 2,71 ppm) y en $\operatorname{Zr}$ (42 a $154 \mathrm{ppm}$ ), aunque variable en este último, y baja relación $(\mathrm{La} / \mathrm{Yb})_{\mathrm{N}}$, menor a 55,85. Teniendo en cuenta que parte de los cuerpos de leucosomas son concordantes con el bandeamiento del gneis y que los cristales de cuarzo de los mismos presentan extinción ondulosa, podríamos decir que la migmatización comenzó a producirse durante la fase deformacional donde el gradiente de presión habría favorecido la migración del fundido antes de reequilibrarse. Dicha fase deformacional corresponde al Ciclo Transamazoniano de 
acuerdo a la edad de $2.200 \mathrm{Ma}$, aproximadamente, estimada para este tipo de rocas en el área de Tandil.

Incluidos en el gneis y en algunos leucosomas, se han identificado xenolitos de anfibolitas que tienen una asociación mineral: hornblenda + plagioclasa \pm titanita \pm apatita \pm minerales opacos (facies anfibolita) con signos de retrogradación, principalmente en los bordes de los mismos, como reemplazos pseudomórficos de biotita y cristalización de actinolita. Dichos fragmentos han sido interpretados como remanentes de la ruptura de cuerpos rígidos de composición máfica en respuesta a la alta tasa de deformación que afectó a toda el área de Tandil.

El mármol estudiado aflora en tres sectores: dos de ellos en la Ea. San Miguel y uno en la Ea. Siempre Verde. Se encuentra hospedado en el gneis biotítico y está intruido por numerosos filones graníticos cuyos espesores varian entre 5 centímetros y 1 metro. Presenta una asociación mineral calcita + diópsido + cuarzo, que indica un grado metamórfico en facies anfibolita alta $\left(716^{\circ} \mathrm{C}\right)$, en concordancia con las anteriores rocas metamórficas. Determinaciones de $\delta^{13} \mathrm{C}(\mathrm{de}+5 \%$ o a $+6 \%$ ) y de $\delta^{18} \mathrm{O}$ (con una distribución bimodal de $+14 \%$ y $+17 \%$ ) indican que si bien existe un descenso en los valores especialmente de $\mathrm{O}$ a medida que nos acercamos al contacto con los filones graníticos, los mismos corresponden a valores típicos para carbonatos de origen marino. Considerando los valores positivos del $\mathrm{C}$ y el hecho de que estos carbonatos se depositaron con anterioridad a los 2.200 Ma, podrian ser incluidos dentro de los depositados durante el "evento Lomagundi-Jatuli" definido a nivel mundial, siendo ésta la primera mención en Argentina.

La intrusión de los leucosomas graníticos en el mármol propició el metasomatismo a partir del cual se formó el skarn San Miguel. Este proceso favoreció el desarrollo de paragénesis minerales calcosilicáticas, con un patrón zonal caracterizado por las zonas de: (1) wollastonita-vesubianita, (2) granateclinopiroxeno, (3) clinopiroxeno, en facies de exoskarn, y las zonas de (4) granateclinopiroxeno, (5) clinopiroxeno-plagioclasa cálcica, en facies de endoskarn. Esta mineralogía indica que la fase fluida original poseía una baja proporción de $\mathrm{CO}_{2}$ (vesubianita + grosularia limitada a $X_{\mathrm{CO} 2}<0,05$ y vesubianita + wollastonita a $X_{\mathrm{CO} 2}$ $<0,01)$. En este sentido, análisis de inclusiones fluidas (IF) alojadas en minerales del skarn indicaron un sistema acuoso predominantemente $\mathrm{NaCl}-\mathrm{H}_{2} \mathrm{O} / \mathrm{NaCl}-\mathrm{KCl}$ $\mathrm{H}_{2} \mathrm{O}$, de baja salinidad $(<7 \%$ en peso eq. $\mathrm{NaCl}$ ) y con una temperatura de homogeneización entre 250 y $320^{\circ} \mathrm{C}$. Otros estudios geotemométricos permitieron 
arribar a temperaturas de equilibrio isotópico del orden de 351 a $553^{\circ} \mathrm{C}$, superiores a las temperaturas de homogeneización determinadas a partir de las IF. Si tenemos en cuenta que la cristalización de los minerales analizados se produjo (de acuerdo al contexto geológico) bajo un régimen de metamorfismo regional, esta diferencia podria deberse a que las IF, a diferencia de los equilibrios isotópicos, son sensibles a la presión del sistema y requieren, en este caso, una corrección superior a los $100^{\circ} \mathrm{C}$.

Fases retrógadas se manifiestan como reemplazos de minerales de las paragénesis prógradas del siguiente modo: diópsido por tremolita y clorita y granate por clinozoisita, desarrollando texturas de desequilibrio térmico como coronas de retrogradación y pseudomorfismo. Además, se identificaron apatita, titanita y escasos cuarzo y calcita como minerales intersticiales o neoformados. La retrogradación también se observa en el desarrollo de vetillas compuestas por cuarzo (vetillas grises) y clinozoisita (vetillas rosadas) que cortan a las zonas prógradas y representan la circulación de los últimos fluidos silíceos y acuosos remanentes del sistema.

En el Cerro Guacho aflora un granito de grano medio a fino que se intruyó en el gneis biotítico arrastrando en su ascenso xenolitos máficos y fragmentos de gneis. Su clasificación tectónica, mediante estudios geoquímicos, es similar a la del resto de los granitos del área de Tandil, que poseen características transicionales entre granitos sin-colisionales y de arco volcánico. El mismo fue interpretado como el resultado de la fusión de corteza continental durante el episodio de colisión continental. En este mismo sector el estudio de cuerpos pegmatoideos portadores de turmalina, fue de mucha utilidad en la definición del origen ígneo del granito del Cerro Guacho. Una roca tonalítica que aflora en el Cerro Los Angelitos y en la Ea. San Miguel pone de manifiesto, a través de las relaciones de corte, que su formación es posterior al gneis y a los leucosomas. Su tamaño de grano es medio a grueso y en algunos sectores presenta foliación que junto con la presencia de migmatitas, indica un ambiente meso a catazonal. Tanto la tonalita como el granito antes mencionado no presentan relación de contacto, en afloramiento, con el skarn San Miguel. Geoquímicamente también posee características transicionales entre granitos sincolisionales y de arco volcánico. Esta roca podría estar asociada a anatexis de cuerpos básicos o a fusión parcial en la corteza inferior-media. 
Adicionalmente se definieron diques granítico-granodioríticos y un dique andesítico-basáltico. Estos cuerpos intruyen a todas las unidades antes descriptas por lo que representan el evento más joven dentro de la evolución ígneometamórfica del área. Los primeros corresponden a granitos calco-alcalinos, metaluminosos con tendencia a la peraluminosidad, con una signatura geoquímica que los ubica en una zona de transición entre granitos sin-colisionales y de arco volcánico, en coincidencia con los granitos del área de Tandil. Estas características coinciden con los granitoides de alta $\mathrm{SiO}_{2}$ que son los últimos residuos en cristalizar y tienen además de agua, volátiles ricos en aluminio. Análisis petrográficos y geoquímicos, especialmente de Tierras Raras, revelaron importantes similitudes entre ellos, indicando que estos diques podrian derivar del mismo fundido granítico que se emplazó a través de un sistema de fallas de rumbo NO-SE coincidente con el dominio tectónico C (definido en la región). Estos diques graníticos corresponden a la primera mención de este tipo de cuerpos en el ámbito de las Sierras Septentrionales y se habrian formado por el emplazamiento de fundidos anatécticos resultantes del reciclado de la corteza continental.

Por otra parte, el dique andesítico-basáltico es calcoalcalino de potasio medio y se emplazó en una zona de cizalla con una orientación similar a la de los diques graníticos, siendo sometido a un proceso de milonitización evidenciado por la presencia de una foliación milonítica y porfiroclastos de plagioclasa con bordes deformados y recristalizados. Según las relaciones geoquímicas $(\mathrm{La} / \mathrm{Yb})_{N}$ y $(\mathrm{La} / \mathrm{Sm})_{N}$ obtenidas, este dique posee afinidad con los correspondientes a la suite calcoalcalina presentes en la región, los cuales derivan de la fusión parcial de material mantélico ocurrida hace unos 2000 Ma.

Los procesos antes mencionados que determinaron la formación de las rocas que afloran en el área de San Miguel pueden ser explicados, teniendo en cuenta además estudios realizados por otros autores, en el contexto tectónico de una cuenca de retroarco asociada a una subducción corteza oceánica-corteza continental que tuvo lugar en estadios previos al Ciclo Tranzamazoniano. 


\begin{abstract}
In the San Miguel area, located between $37^{\circ} 33^{\prime} 27^{\prime \prime}-37^{\circ} 36^{\prime} 13^{\prime \prime} \mathrm{S}$ and $59^{\circ} 20^{\prime} 34^{\prime \prime}-59^{\circ} 24^{\prime} 52^{\prime \prime} \mathrm{W}$, metamorphic and igneous rocks belonging to the Sierras Septentrionales basement, called Buenos Aires Complex, crop out. The metamorphic rocks are migmatic biotitic gneisses, migmatites, amphibolite xenoliths and a marble associated to the presence of a skarn (San Miguel skarn). The igneous rocks are represented by a metamorphosed granitic body, which constitutes the Guacho Hill, a tonalitic body that crops out in the San Miguel farm and in the Los Angelitos Hill (Siempre Verde farm), and a dike set of acidic and intermediate-basic composition. The present work shows the results of studies and analyses of the lithologic types listed above, particularly focused on defining the genesis of the San Miguel skarn.
\end{abstract}

The migmatic biotitic gneiss shows a planar anisotropic fabric of compositional banding type orientated in a $N 35^{\circ} \mathrm{E}$ direction and a mineral composition consisting of microcline, plagioclase (oligoclase-andesine), quartz and biotite. The migmatites are exhibited as differentiated bodies with stromatic structure, with the same direction $\mathrm{S}_{1}$ or with less frequent structures as breccia mobilized and boudins. Their leucosomes are composed of quartz, plagioclase (oligoclase) and potasic feldspar (microcline type). Also, more voluminous leucosomes with diffuse limits and garnet $\left(\mathrm{Alm}_{72} \operatorname{Prp}_{13} \mathrm{Sp}_{12} \mathrm{GrO}_{3}\right)$, in addition to the above mentioned mineralogy, are described. Chemical analysis indicate that the gneisses derived from a sedimentary protolith with characteristics of a wake or greywacke while the migmatites would have formed from the partial melting of gneisses through decomposition of biotite in the presence of quartz and plagioclase. This process generated a garnetiferous phase, with potassic feldspar and a peraluminous granitic melt in imbalance, low in Th (1.50 to $2.71 \mathrm{ppm})$ and $\mathrm{Zr}$ (42$154 \mathrm{ppm})$, although variable in the second one and with low $(\mathrm{La} / \mathrm{Yb})_{\mathrm{N}}$ ratio $(<55.85)$. Considering that some of the leucosome bodies are concordant with the orientation of the compositional banding gneisses and their quartz crystals present undulose extinction, it can be interpretated that the migmatization began during the deformational phase where the pressure gradient would have favored the migration of the melt before reaching equilibrium. This deformational phase corresponds to the Transamazonian cycle according to the age of 2200 Ma approximately estimated for this type of rocks in the Tandil area. 
Included into the gneisses and in some leucosomes, amphibolite xenoliths have been identified. They are composed of hornblende + plagioclase \pm titanite \pm apatite \pm opaque minerals (amphibolite facies). These xenoliths show evidences of retrogradation as pseudomorphic replacements of biotite and crystallization of actinolite, mainly at their edge. These fragments have been interpreted as remainings of the breakdown of rigid bodies of mafic composition in response to the high rate of deformation that affected the entire area of Tandil.

The studied marble crops out in three sectors: two of them in the San Miguel farm and the other one in the Siempre Verde farm. It is hosted in the biotite gneiss and it is intruded by numerous thin concordant bodies of granitic composition whose thicknesses vary between $5 \mathrm{~cm}$ and 1 meter. It presents a mineral assemblage quartz + calcite + diopside, indicating high amphibolite grade metamorphic facies $\left(716^{\circ} \mathrm{C}\right)$, consistent with the estimated grade in the previously mentioned metamorphic rocks. Determinations of $\delta^{13} \mathrm{C}\left(+5 \%\right.$ o to $+6 \%$ o) and $\delta^{18} \mathrm{O}$ (with a bimodal distribution of $+14 \%$ o and $+17 \%$ o) indicate that there is a decrease especially in the values of $\mathrm{O}$, close to the contact with granitic bodies; they correspond to typical values for carbonates of marine origin. Considering the positive values of $\mathrm{C}$ and the fact that these carbonates were deposited previously to $2200 \mathrm{Ma}$, they could be included within those deposited during the "LomagundiJatuli event" which was defined globally. This is the first mention of these types of carbonate rocks in Argentina.

The intrusion of the granitic leucosomes into the marble propitiated the metasomatism that formed the San Miguel skarn. This process favored the development of a calc-silicate mineral paragenesis with a zonal pattern characterized by the zones of: (1) wollastonite-vesuvianite, (2) garnet-clinopyroxene, (3) clinopyroxene, in exoskarn facies, and the zones of: (1) garnet-clinopyroxene, (2) clinopyroxene-calcitic plagioclase, in endoskarn facies. This mineralogy indicates that the original fluid phase has a low $\mathrm{CO}_{2}$ content (vesuvianite + grossular limited to $<0.05$ and vesuvianite + wollastonite to $<0.01$ ). In this sense, analysis of fluid inclusions (FI) hosted in skarn minerals indicated a predominantly aqueous $\mathrm{NaCl}$ $\mathrm{H}_{2} \mathrm{O} / \mathrm{KCl}-\mathrm{NaCl}-\mathrm{H}_{2} \mathrm{O}$ system, low salinity $(<7 \quad$ wt\% eq. $\mathrm{NaCl})$ and with a homogenization temperature between 250 and $320^{\circ} \mathrm{C}$. Other geothermometrystudies allowed to stablish isotopic equilibrium temperatures of about $351-553^{\circ} \mathrm{C}$, higher than homogenization temperatures determined from the FI. Tacking into account that the mineral crystallization occurred (according to the geological context) under a regime of regional metamorphism, this difference can be explained 
considering that FI, unlike isotopic equilibrium, are sensitive to the system pressure and require a correction over $100^{\circ} \mathrm{C}$.

Retrograde phases form coronas and replace pseudomorphically the prograde mineral assemblages as follows: diopside by chlorite and tremolite and garnet by clinozoisite. In addition, apatite, titanite and scarce quartz and calcite, are recognized interstitial or neoformed minerals. Retrogradation was also seen in the development of quartz (gray) and clinozoisite veinlets (pink), which intersect the prograde zones and represent the circulation of the last remaining siliceous and aqueous fluids of the system.

The granite that crops out at the Guacho Hill has a medium-fine grain size. It is intruded into the biotitic gneiss and contains mafic xenoliths and fragments of the same gneiss. Its tectonic classification, by geochemical studies, is similar to the rest of the granites of the area of Tandil, which have transitional characteristics between syncollisional and volcanic-arc granites. The origin of this granite was interpreted as the result of the melting of continental crust during a episode of continental collision. In the same sector, the study of pegmatoid-bodies bearing tourmaline was very useful to define the igneous origin of the granite of the Guacho Hill. Tonalitic rock, that crops out in the Los Angelitos Hill and in the San Miguel farm, show field evidences that they formed later than the gneiss and the leucosomes. They have medium-coarse grain size and in some sectors the fact of been foliated together with the presence of migmatites, indicates a meso-catazonal environment.

Additionally, granitic-granodioritic dikes and a basaltic-andesitic dike were observed. These bodies intruded all the units described above; therefore, they represent the youngest event in the igneous-metamorphic evolution of the area. The first ones correspond to calc-alkaline, metaluminous granites and granodiorites, with a peraluminous tendency and have a syn-collisional to volcanic arc geochemical signature, in coincidence with the granites of Tandil. These characteristics match with high $\mathrm{SiO}_{2}$ granitoids that represent the latest residue in crystallizing and are, in addition, water rich in aluminum and volatiles. The petrographic and geochemical analysis, especially rare earth elements, show significant similarities between them, indicating that these dikes could be derived from the same granitic melt, which was emplaced through a NW-SE trending fault system, coincident with the $\mathrm{C}$ tectonic domain defined for the region. This is the first mention of this type of carried out granitic dikes in the Sierras Septentrionales 
that were formed by the emplacement of anatectic melts resulting from the recycling of continental crust.

Moreover, the calc-alkaline-medium potassium basaltic-andesite dyke, was emplaced in a shear zone with a similar orientation to that indicated to the granitic dikes, and was subjected to mylonitization. This process is evidenced by the presence of a mylonitic foliation and porphyroclasts of plagioclase with deformed and recrystallized edges. According to the geochemical relationships $(\mathrm{La} / \mathrm{Yb})_{\mathrm{N}}$ and $(\mathrm{La} / \mathrm{Sm})_{\mathrm{N}}$ obtained, this dike has affinity with those of the calc-alkaline suite in the region, which derived from partial melting of the mantelic material that occurred about 2000 Ma.

The processes mentioned above, which determined the formation of the rocks that crop out in the San Miguel area, can be explained, considering also studies carried out by other authors, in the tectonic context of a back-arc basin associated with an oceanic-continental crust subduction which took place in previous stages at the Transamazonian Cycle. 


\subsection{INTRODUCCIÓN}

La palabra skarn proviene del sueco antiguo y era usada por los mineros de la región de Pelberg (Suecia central) para referirse a la ganga silicatada asociada a unos depósitos de magnetita (Geijer y Magnusson 1952). Este término fue utilizado por primera vez en la literatura científica por Tornebohm (1875 y 1882) refiriéndose a los "groenskarn" (skarn verde) o "skarnstein" (roca de skarn) para describir rocas con granate y piroxeno de los depósitos de Norberg y Langban, Suecia.

Posteriormente, autores como Newberry (1980 y 1998), Meinert y Newberry (1981), Einaudi et al. (1981), Burt (1982), Meinert (1992), Lentz (2005) y Meinert et al. (2005) ampliaron la bibliografia con gran cantidad de investigaciones y nuevas publicaciones sobre este tipo de roca, redefiniendo el término skarn como "rocas metamórficas regionales o de contacto constituidas por silicatos de $\mathrm{Ca}, \mathrm{Mg}$ y $\mathrm{Fe}$ derivados de un protolito correspondiente a calizas y dolomías en el cual se han introducido, metasomáticamente, grandes cantidades de $\mathrm{Si}, \mathrm{Al}, \mathrm{Fe}$ y $\mathrm{Mg}$. Los procesos metasomáticos son muy variados e involucran la participación de fluidos magmáticos, metamórficos y meteóricos”. De esta forma las paragénesis tipo skarn involucran la cristalización de minerales calcosilicatados tales como diópsido, wollastonita, granate (andradita o grosularia), actinolita y vesubianita, entre los más frecuentes.

Habitualmente los skarns están asociados a procesos de mineralización y en algunos casos pueden presentarse como depósitos económicamente rentables.

En el territorio de la República Argentina afloramientos de este tipo de rocas se restringen principalmente a sectores emplazados en las Sierras Pampeanas, Precordillera, Cordillera Principal y Patagónica y en algunos sectores de la Cuenca Neuquina. Muchos de estos son portadores de mineralizaciones de $\mathrm{Fe}, \mathrm{Cu}$ e incluso $\mathrm{Au}$, por lo que fueron explotados irregularmente (algunos hasta la actualidad). 


\subsubsection{Antecedentes de la zona de estudio}

El skarn San Miguel se encuentra situado entre las localidades de Barker y Azucena, a 33 kilómetros al sur de la ciudad de Tandil, provincia de Buenos Aires. Representa un evento geológico singular en el área de Tandil, Sierras Septentrionales de la provincia de Buenos Aires, debido a la escasez de este tipo de rocas en este ámbito. El denominado skarn forma parte de las rocas basamentales pertenecientes al Complejo Buenos Aires (Marchese y Di Paola 1975 y Dalla Salda et al. 2005) el cual comprende un conjunto de rocas metamórficas e ígneas de dificil diferenciación. Las metamorfitas más abundantes son gneises, migmatitas graníticas y en menor proporción anfibolitas, esquistos y mármoles. Las rocas ígneas comprenden un conjunto de cuerpos graníticos a tonalíticos y un extenso enjambre de diques de composición ácida, intermedia y básica (Echeveste y Fernández 1994, Fernández y Echeveste 1995, Iacumin et al. 2001 y Teixeira et al. 2002). En general, los contactos entre las diferentes unidades litológicas son dificiles de reconocer ya que se encuentran cubiertos por derrubio cuaternario. Así, tal como sucede en muchas otras localidades de las Sierras Septentrionales, los destapes realizados para la explotación de rocas de aplicación, en labores a cielo abierto, permiten el reconocimiento de perfiles artificiales donde se visualizan las diferentes relaciones de corte e intersección de las unidades litológicas.

Los antecedentes bibliográficos de estudios geológicos del skarn San Miguel son escasos y fueron iniciados por Villar Fabre (1956), quien menciona por primera vez la existencia de calizas metamórficas intruídas por granitos, al efectuar el levantamiento geológico de la Hoja 33q: Barker (donde se indica la presencia de una cantera de carbonato de calcio). Muy poco tiempo después Teruggi et al. (1958) citan la presencia de calizas cristalinas en la cantera San Manuel, al norte de Barker, referencia que por su ubicación geográfica y descripción geológica general correspondería a la cantera San Miguel. Estos autores describen la existencia de tres o cuatro lentes de caliza alineadas e intercaladas en una roca granítica pegmatoide, citando además una paragénesis compuesta por diópsido-grosularia- 
wollastonita. En la década del 60, Villar Fabre y Quartino (1966) y Quartino y Villar Fabre (1967) llevaron a cabo los primeros estudios petrológicos del skarn San Miguel, caracterizando facies de endo y exoskarn conjuntamente con procesos de asimilación del granito que intruye las calizas. Recientemente, de Barrio et al. (2009) realizaron estudios mineraloquímicos y tipificaron preliminarmente al skarn como cálcico.

Las escasas investigaciones realizadas en torno al skarn San Miguel, generan una serie de interrogantes respecto a su génesis y a sus implicancias en la evolución del basamento de las Sierras Septentrionales, que incentivaron la realización de la presente Tesis Doctoral.

\subsection{OBJETIVOS}

El objetivo general de esta investigación consistió en postular un modelo geológico-evolutivo para el basamento ígneo-metamórfico del área de San Miguel, Sistema de Tandilia (Buenos Aires), con énfasis en el skarn homónimo.

Con el fin de alcanzar el objetivo general mencionado, se plantearon los siguientes objetivos específicos:

-Describir en forma detallada las características geológicas y geoquímicas de las rocas del área de estudio, poniendo énfasis en las unidades ígneometamórficas que pudieron tener relación con la formación del skarn San Miguel.

-Realizar una cartografia detallada de la zona de estudio conjuntamente con esquemas y perfiles transversales que muestren la morfologia del skarn.

-Analizar las características de los eventos metamórficos que actuaron en la zona y su relación con la formación del skarn.

-Definir la presencia de estructuras y su vinculación con la tectónica regional de las Sierras Septentrionales, más específicamente con las del área de Tandil. 
-Realizar el estudio petrológico, mineraloquímico y geoquímico de los distintos afloramientos del skarn, con el fin de determinar las etapas evolutivas de la génesis de este depósito y tipificarlo.

-Caracterizar los fluidos vinculados a los procesos de desarrollo del skarn, desde el punto de vista fisico-químico. Definir la o las fuente/s de los fluidos. -Establecer la potencialidad metalogénica del área de estudio.

-Definir el modelo genético de la formación del skarn San Miguel en contexto con el marco geológico regional.

\subsection{METODOLOGÍA DE TRABAJO}

\subsubsection{Tratamiento de imágenes satelitales y confección de cartografia}

Con anterioridad a las tareas de campo se confeccionó un mapa base, a partir del procesamiento de imágenes satelitales (principalmente ASTER), fotografias aéreas e información topográfica disponible: Hoja Topográfica 33q 1:100000 y 1:50000, Villa Cacique, Buenos Aires, actualizada por el Servicio Nacional Minero Geológico (1974); Mapa Geológico de Tandilia (Iñiguez et al. 1989); Mapa Geológico de la Región de Tandil (Dalla Salda et al. 1988 y 2005); Mapa Geológico de Barker (Leveratto y Marchesse 1983, modificado por Poiré y Spalletti 2005) y detalles de la zona con Google Earth. En el tratamiento de las imágenes satelitales se identificaron los distintos afloramientos que luego fueron mapeados en el campo. Las fotografias aéreas y las cartas topográficas fueron escaneadas y geo-referenciadas en coordenadas Gauss Krüger con datum WGS84 Faja 5 y se rectificaron para eliminar la deformación cónica utilizando un programa de procesamiento digital de imágenes. La geo-referenciación se realizó mediante puntos de control como caminos y estancias de la Hoja Topográfica 33q Villa Cacique. Con todo lo anterior se realizó un mosaico digital a escala 1:5000. Este producto final se exportó a un SIG (Sistema de Información Geográfica) donde se confeccionó el mapa geológico y topográfico del área, superponiendo en distintas capas la información plani-altimétrica y los datos geológicos y estructurales obtenidos. Este mapa se utilizó en el campo 
como base del levantamiento geológico para realizar el mapeo de detalle de los sectores de interés. Finalmente la edición del mapa se realizó a través de una herramienta informática de diseño gráfico.

\subsubsection{Trabajo de campo}

Debido a la cercanía de la zona de estudio, se ejecutaron 8 campañas cortas que totalizaron 40 dias de trabajo en los que se realizaron el reconocimiento y cartografia de las diversas unidades geológicas aflorantes en el área. A partir de estas tareas, se llevó a cabo el muestreo de las distintas unidades ígneas y metamórficas, con detalle en el depósito de skarn, con el fin de realizar estudios petrológicos y químicos. Posteriormente se confeccionaron dos perfiles transversales al skarn, desde la roca granítica menos afectada por el metasomatismo, cortando las distintas zonas del skarn, hasta la roca carbonática más fresca. Se realizó simultáneamente una toma sistemática de muestras de cada litología y de las diferentes zonas del skarn.

Uno de los grandes desafios que presentó la zona de estudio, fue poder establecer las relaciones de contacto entre las distintas unidades litomorfológicas, sobre la base de los escasos afloramientos con poca continuidad, debido al gran desarrollo de suelos y vegetación que caracteriza la región. Para ello se realizó un exhaustivo trabajo descriptivo de detalle en el destape de la cantera ubicada en la estancia San Miguel, donde se obtuvieron las principales relaciones que luego se extrapolaron a los nuevos hallazgos de cuerpos de skarn, para obtener así su delimitación areal y zonación facial. Cabe destacar que estos cuerpos de roca se encuentran parcialmente cubiertos o presentan un intenso grado de alteración meteórica.

Finalmente se obtuvo un mapa geológico de las principales unidades ígneo-metamórficas sobre la base del mapa geológico-topográfico a escala 1:5000 y esquemas de mayor detalle. 


\subsubsection{Estudios de gabinete y laboratorio}

-Confección de una base de datos bibliográficos: Se efectuó una recopilación y análisis del material bibliográfico y cartográfico disponible, a los fines de construir una base de datos principalmente estratigráficos, geocronológicos y geotectónicos.

- Petrografía de secciones delgadas: Se realizó un total de 97 secciones delgadas que incluyeron muestras del skarn y de otras rocas del área de estudio. A partir de las mismas se realizó una descripción de texturas, estructuras y mineralogía de estas rocas para clasificarlas preliminarmente.

Los estudios petrográficos y mineralógicos han sido complementados con datos obtenidos a partir de una serie de técnicas instrumentales y analiticas:

-Análisis por microsonda electrónica: Mediante el análisis por microsonda electrónica, se obtuvo la composición química de granates, piroxenos, vesubianita, plagioclasas (típicos de la paragénesis calcosilicática) que permitió, por un lado, la clasificación del skarn San Miguel dentro de una de las categorias de skarns existentes en la literatura, y por otro, determinar una zonación dentro del mismo. La obtención de la composición de estos minerales también fue sumamente útil en la determinación de las condiciones físico-químicas de la formación del skarn. Los estudios se realizaron con una microsonda electrónica marca Cameca, modelo Camebax SX 100, en el laboratorio de microanálisis del Servicio de Ciencia y Técnica de la Universidad de Oviedo, España. Los análisis se realizaron con aceleración de corriente $20 \mathrm{kv}$ e intensidad $20 \mathrm{nA}$ y diámetro de haz de 1 a 2 $\mu \mathrm{m}$. Los estándares naturales utilizados fueron: albita para $\mathrm{Na}$ y $\mathrm{Si}, \mathrm{Al}_{2} \mathrm{O}_{3}$ para $\mathrm{Al}, \mathrm{MgO}$ para $\mathrm{Mg}$, andradita para $\mathrm{Ca}$, ortosa para $\mathrm{K}, \mathrm{Mn}$ y Ti para $\mathrm{Mn}$ y $\mathrm{Ti}$, magnetita para $\mathrm{Fe}, \mathrm{NiO}$ para Ni y cromita para $\mathrm{Cr}$.

-Difracción de rayos $X$ : Los análisis de espectros obtenidos por difracción de rayos X (DRX) se efectuaron en el Museo de Ciencias Naturales de la ciudad 
de La Plata, mediante un difractómetro Philips PW1710, con radiación CuKa $(\lambda=1,5378 \mathrm{~nm})$ y con velocidad de barrido $60^{\circ} / \mathrm{h}$.

- Microscopía electrónica: La microscopía electrónica de barrido, en centro y borde de cristales sueltos, se realizó con un ESEM (FEI Quanta 200), con filamento de tungsteno, en el Servicio de microscopia, LIM-Facultad de Ingeniería, Universidad Nacional de La Plata. Para las determinaciones semicuantitativas EDS por microanálisis se utilizó un EDAX Detector Apollo 40 (LIMF-UNLP). Las mediciones fueron realizadas en vacío y a dos presiones distintas.

-FTIR: La Espectroscopía Infrarroja (FTIR) fue efectuada en un espectrofotómetro Bruker Equinox 55, en el CEQUINOR-CONICET-UNLP, utilizando la técnica de pastilla de $\mathrm{KBr}$ en un rango de frecuencia comprendido entre 4000 y $400 \mathrm{~cm}^{-1}$.

Para calcular las fórmulas minerales se utilizaron los siguientes métodos:

Granate: El cálculo de la fórmula estructural y la discriminación de $\mathrm{Fe}^{+2} / \mathrm{Fe}^{+3}$, fue realizado sobre la base de 12 oxígenos, siguiendo la metodología propuesta por Droop (1987).

Piroxeno: La fórmula estructural y la discriminación de $\mathrm{Fe}^{+2} / \mathrm{Fe}^{+3}$, se calculó sobre la base de 6 oxígenos, siguiendo los criterios de Droop (1987).

Vesubianita: El cálculo de la fórmula estructural fue realizado sobre la base de 76 aniones $\left(\mathrm{O}^{=}, \mathrm{OH}^{-}, \mathrm{F}^{-}, \mathrm{Cl}^{-}\right)$por fórmula unidad siguiendo los criterios de Groat et al. (1992) y teniendo en cuenta la fórmula general:

$$
\mathrm{X}_{19} \mathrm{Y}_{13} \mathrm{~T}_{0-5} \mathrm{Z}_{18} \mathrm{O}_{68} \mathrm{~W}_{10}
$$

Donde:

$\mathrm{X}=$ es un catión $\left(\mathrm{Na}^{+}, \mathrm{K}^{+}, \mathrm{Ca}^{+2}, \mathrm{Ba}^{+2}\right)$ de coordinación cúbica.

$\mathrm{Y}=$ corresponde a un catión cuyo radio varía entre 0,5 y $0,8 \AA \AA\left(\mathrm{Mn}^{+2}, \mathrm{Ni}^{+2}\right.$, $\left.\mathrm{Mg}^{+2}, \mathrm{Fe}^{+2}, \mathrm{Cr}^{+3}, \mathrm{Al}^{+3}, \mathrm{Ti}^{+4}\right)$ ubicado en coordinación octaédrica.

$\mathrm{T}=$ representa especies $\mathrm{B}$ o $\mathrm{P}$ en coordinación trigonal planar y tetraédrica respectivamente, si bien no está perfectamente especificado en la fórmula. $Z=$ corresponde a $\mathrm{Si}^{+4}$ y ocasionalmente a $\mathrm{Al}^{+3}$ en coordinación tetraédrica. 
$\mathrm{W}=$ son grupos aniónicos $\left(\mathrm{OH}^{-}, \mathrm{F}^{-}, \mathrm{Cl}^{-}\right)$.

Ilmenita: La reconstrucción de su fórmula estructural se realizó para 6 oxígenos siguiendo el criterio de Deer et al. (1996) y la discriminación de $\mathrm{Fe}^{+2} / \mathrm{Fe}^{+3}$, según la metodología propuesta por Droop (1987).

Turmalina: De acuerdo a la fórmula general de la especie sobre la base de 31 aniones $\left(\mathrm{O}^{=}, \mathrm{OH}^{-}, \mathrm{F}^{-}\right)$por fórmula unidad, según Hawthorne y Henry, (1999):

$$
\mathrm{XY}_{3} \mathrm{Z}_{6}\left(\mathrm{~T}_{6} \mathrm{O}_{18}\right)\left(\mathrm{BO}_{3}\right)_{3} \mathrm{~V}_{3} \mathrm{~W}
$$

Se realizó la reconstrucción de la fórmula de acuerdo a los análisis semicuantitativos.

Siendo:

$\mathrm{X}=\mathrm{Na}^{+1}, \mathrm{Ca}^{+2}$, vacante. Según Henry et al. (2011), este sitio también puede incluir $\mathrm{K}^{+1}$.

$\mathrm{Y}=\mathrm{Li}^{+1}, \mathrm{Fe}^{+2}, \mathrm{Mg}^{+2}, \mathrm{Mn}^{+2}, \mathrm{Al}^{+3}, \mathrm{Cr}^{+3}, \mathrm{Fe}^{+3}, \mathrm{~V}^{+3}, \mathrm{Ti}^{+3}$.

$\mathrm{Z}=\mathrm{Mg}^{+2}, \mathrm{Al}^{+3}, \mathrm{Fe}^{+3}, \mathrm{~V}^{+3}, \mathrm{Cr}^{+3}$.

$\mathrm{T}=\mathrm{Si}^{+4}, \mathrm{Al}^{+3}, \mathrm{~B}^{+3}$.

$\mathrm{B}=\mathrm{B}^{+3}$, vacante.

$\mathrm{V}=\mathrm{OH}^{-}, \mathrm{O}^{-2}$.

$\mathrm{W}=\mathrm{OH}^{-}, \mathrm{F}^{-}, \mathrm{O}^{-2}$.

- Geoquímica de roca total: Se determinó la composición química de las rocas del área mediante la cuantificación de elementos mayoritarios, minoritarios, traza y Tierras Raras. Sobre la base de los estudios petrográficos se seleccionaron muestras representativas para cada tipo litológico identificado. Parte de estas muestras fueron trituradas y pulverizadas a malla 200 en un molino de anillos, para ser analizadas geoquímicamente en el Laboratorio ALS Patagonia S.A. (Argentina). Los elementos mayoritarios $\left(\mathrm{SiO}_{2}, \mathrm{TiO}_{2}\right.$, $\mathrm{Al}_{2} \mathrm{O}_{3}, \mathrm{Fe}_{2} \mathrm{O}_{3}, \mathrm{MnO}, \mathrm{MgO}, \mathrm{CaO}, \mathrm{Na}_{2} \mathrm{O}, \mathrm{K}_{2} \mathrm{O}, \mathrm{y} \mathrm{P}_{2} \mathrm{O}_{5}$ ) fueron determinados por espectroscopía de fluorescencia de rayos $\mathrm{X}$, mediante la rutina ME-XRF12, en la que las muestras fueron primero calcinadas y disueltas con $50 \%$ $\mathrm{Li}_{2} \mathrm{~B}_{4} \mathrm{O}_{7}-50 \% \mathrm{LiBO}_{2}$ y finalmente fundidas a $1050-1100^{\circ} \mathrm{C}$ hasta la obtención de una perla. Los patrones utilizados fueron SARM-39 y SARM-45. 
Elementos como Ba, Cr, Rb, Cs, Ga, Hf, Nb, Y, Sr, Sn, Ta, Th, U, V, W, Zr y REE se determinaron mediante la rutina ME-MS81, la misma consistió en mezclar 0,20g de muestra con $0,90 \mathrm{~g}$ de $\mathrm{LiBO}_{2}$ y fusionar a $1000^{\circ} \mathrm{C}$. El preparado resultante se enfrió y disolvió en $100 \mathrm{ml}$ de $\mathrm{HNO}_{3}$ al $4 \%-\mathrm{HCl}$ al $2 \%$. Esta solución fue analizada por una combinación de espectrometría de emisión de plasma (ICP) y espectrometría de masas (MS). Los patrones utilizados fueron OREAS-45, OREAS-14 y SY-4.

Los resultados de dichos análisis fueron graficados en distintos diagramas binarios y ternarios ampliamente utilizados en la bibliografia con el fin de realizar diferentes clasificaciones geoquímicas. Para ello los elementos mayoritarios fueron recalculados al 100\% en base anhidra.

-Inclusiones fluidas: El análisis de inclusiones fluidas primarias, secundarias y pseudosecundarias, tuvo como objetivo realizar determinaciones microtermométricas, que permitieron establecer salinidad, temperatura y composición de los fluidos que interactuaron con la roca carbonática, así como la variación de estos parámetros en el espacio y en el tiempo. Para ello se realizaron mediciones microtermométricas en aproximadamente 100 inclusiones fluidas hospedadas en granate, piroxeno, vesubianita y cuarzo que fueron cuidadosamente mapeadas y clasificadas de acuerdo a los criterios de Roedder (1984) y Nash (1976). Estas mediciones fueron realizadas en secciones bipulidas (30-100 $\mu \mathrm{m}$ de espesor). Los estudios termométricos de las inclusiones fluidas se realizaron en el Departamento de Geologia de la Universidad de Buenos Aires en una platina Chaixmeca de calentamiento por medio de una resistencia y enfriamiento por nitrógeno líquido, instalada en un microscopio Leica.

-Isótopos estables: Se seleccionaron muestras especificas de minerales del mármol y del skarn para realizar estudios de isótopos estables. Parte de los resultados $\delta^{18} \mathrm{O}$ obtenidos de los minerales del skarn se utilizaron para confeccionar pares geotermométricos y así calcular la temperatura de cierre isotópico entre pares minerales en equilibrio. De esta forma se determinó $\delta^{18} \mathrm{O}$ en granates, piroxenos, wollastonita, vesubianita y calcita, y $\delta^{13} \mathrm{C}$ en 
calcita del mármol y del skarn. Las determinaciones isotópicas de $\delta^{13} \mathrm{C}$ y $\delta^{18} \mathrm{O}$ se realizaron en el Servicio de Isótopos Estables de la Universidad de Salamanca (España) mediante la utilización de un espectrómetro de masas de fuente gaseosa, modelo SIRA-II, fabricado por VG-Isotech, equipado con cold finger, para análisis de muestras pequeñas y sistema múltiple de admisión de muestras. Los cristales de cada uno de los minerales analizados fueron separados y concentrados en forma manual bajo lupa binocular para su posterior tratamiento. La extracción de $\mathrm{CO}_{2}$ de las calcitas se realizó mediante reacción con $\mathrm{H}_{3} \mathrm{PO}_{4}$ al $103 \%$ a $25^{\circ} \mathrm{C}$ durante 12 horas. Para el tratamiento de los cristales de silicatos (granate, piroxeno, wollastonita y vesubianita) se emplearon metodologías convencionales de acuerdo a Clayton y Mayeda (1963). Las relaciones isotópicas se expresan a través de la notación normal como valores delta por mil $(\delta \%)$, con un error analítico de $\pm 0,2$ por mil para $\delta^{13} \mathrm{C}$ y $\delta^{18} \mathrm{O}$. Los resultados están dados con relación al estándar SMOW (Standard Mean Ocean Water) para el $\delta^{18} \mathrm{O}$ y con relación al estándar PDB (Pee Dee Belemnite) para el $\delta^{13} \mathrm{C}$. La información obtenida fue analizada y volcada en distintos diagramas que permitieron observar las variaciones en las proporciones isotópicas de las zonas del skarn y también permitieron determinar algunas particularidades del protolito carbonático. 


\subsection{BIBLIOGRAFİA}

Burt, D.M. 1982. Skarn deposits. Historical bibliography through 1970. Economic Geology 77: 755-763.

Clayton, R.N. y Mayeda, T.K. 1963. The use of bromine pentafluoride in the extraction of oxygen from oxides and silicates for isotopic analysis. Geochimica et Cosmochimica Acta 27: 43-52.

Dalla Salda, L.H., Bossi J. y Cingolani, C.A. 1988. The Rio de la Plata cratonic region of southwestern Gondwana. Episodes 11: 263- 269.

Dalla Salda, L.H., de Barrio, R.E., Echeveste, H. y Fernández, R. 2005. El basamento de las Sierras de Tandilia. En de Barrio, R.E., Etcheverry, R., Caballé, M.F. y Llambías, E.J. (eds.) Geologia y Recursos minerales de la Provincia de Buenos Aires. Relatorio del $26^{\circ}$ Congreso Geológico Argentino, 32-50, La Plata.

de Barrio, R.E., Lanfranchini, M.E., Etcheverry, R.O., Martín-Izard, A., Tessone, M.O. y Paz, M. 2009. Geological and geochemical evolution of the San Miguel skarn, Tandilia Belt, Buenos Aires Province, Argentina. 24th International Applied Geochemistry Symposium, Fredericton 281-284, Canada.

Deer, W.A., Howie, R.A. y Zussman, J. 1996. Rock-forming Minerals, Volume 1A, Second Edition, 919p. Orthosilicates, Longman, London.

Droop, G.T.R. 1987. A general equation for estimating $\mathrm{Fe}^{+3}$ concentration in ferromagnesian silicates and oxides from microprobe analysis, using stoichiometric criteria. Mineralogical Magazine 51: 431-435.

Echeveste, H.J. y Fernández, R.R. 1994. Asociaciones de óxidos y sulfuros en diques básicos de las Sierras de Tandil, provincia de Buenos Aires. Revista del Museo de La Plata 11: 99-118.

Einaudi, M.T., Meinert, L.D. y Newberry, R.J. 1981. Skarn deposits. Economic Geology 75th Anniversary Volume: 317-391.

Fernández, R.R. y Echeveste, H.J. 1995. Caracterización geoquímica y petrológica de diques del Sistema de Tandilia, provincia de Buenos Aires, Argentina. Jornadas Geológicas y Geofísicas Bonaerenses, Actas 1, 329-337, Buenos Aires.

Geijer, P. y Magnusson, N.H. 1952. The iron ores of Sweden. En Blodel, F. y Marvier, L. (eds.) Symposium sur les gisements de fer du monde. $19^{\circ}$ Congreso Geológico Internacional, 477-499, Alger. 
Google Earth (2007). Foto de satélite de Barker, provincia de Buenos Aires, Argentina. Consulta: 30 de septiembre de 2013, http://earth.google.com.

Groat, L.A., Hawthorne, F.C. y Ercit, T.S. 1992. The chemistry of vesuvianite. Canadian Mineralogist 30: 19-48.

Hawthorne, F.C. y Henry, D.J. 1999. Classification of the minerals of the tourmaline group. European Journal of Mineralogy 11: 201-215.

Henry, D.J., Novák, M., Hawthorne, F.C., Ertl, A., Dutrow, B.L., Uher, O. y Pezzotta, F. 2011. Nomenclature of the tourmaline-supergroup minerals. American Mineralogist 96: 895-913.

Iacumin, M., Piccirillo, E., Girardi, V., Teixeira, W., Bellieni, G., Echeveste, H., Fernández, R., Pinese, J. y Ribot, A. 2001. Early Proterozoic Calc-Alkaline and Middle Proterozoic Tholeiitic Dyke Swarms from Central-Eastern Argentina. Petrology, Geochemistry, Sr-Nd Isotopes and Tectonic Implications. Journal of Petrology 42: 2109-2143.

Iñiguez Rodriguez, A.M., Del Valle, A., Poiré, D., Spalletti, L. y Zalba, P. 1989. Cuenca Precámbrica Paleozoico inferior de Tandilia, Provincia de Buenos Aires. En Chebli, G., Spalletti, L.A. (eds.) Cuencas sedimentarias argentinas. Instituto Superior de Correlación Geológica, Universidad Nacional de Tucumán, Serie Correlación Geológica 6: 245-263, Tucumán.

Leveratto, M.A. y Marchese, H.G. 1983. Geología y estratigrafia de la Formación La Tinta (y homólogas) en el área clave de Sierra de La Tinta-Barker-Villa Cacique-Arroyo Calaveras, Provincia de Buenos Aires. Revista de la Asociación Geológica Argentina 38: 235-247.

Lentz, D.R. 2005. Mass-balance Analysis of Mineralized Skarn Systems: Implications for Replacement Processes, Carbonate Mobility and Permeability Evolution. SGA 2005, Mineral Deposit Research, Meeting the Global Challenge 1: 421-424, Beijing.

Marchese, H.G. y Di Paola, E. 1975. Miogeosinclinal Tandil. Revista de la Asociación Geológica Argentina 30: 161-179.

Meinert, L.D. 1992. Skarn and skarn deposits. Geoscience Canada, 19.

Meinert, L.D. y Newberrv, R.J. 1981. Skarn deposits. Economic Geology 75th Anniversary Volume: 317-39.

Meinert, L.D., Dipple, G.M. y Nicolescu, S. 2005. World skarn deposits. Economic Geology 100th Anniversary Volume: 299-336. 
Nash, J.T. 1976. Fluid inclusion petrology-data from porphyry copper deposits and application to exploration. U. S. Geology Survey Professional Paper 907-D.

Newberry, R.J. 1980. The Geology and Chemistry of Skarn Formation and Tungsten Deposition in the Central Sierra Nevada, California. Tesis doctoral, Universidad de Stanford (inédita), Stanford.

Newberry, R.J. 1998. W and Sn-Skarn deposits. En Lentz, D.R. (ed.) A 1998 status report, in Mineralised Intrusion-Related Skarn Systems. Short course series 26. Mineralogical Association of Canada: 289-335, Canada.

Poiré, D.G. y L.A. Spalletti. 2005. La cubierta sedimentaria precámbrica/paleozoica inferior del Sistema de Tandilia. En de Barrio, R.E., Etcheverry, R.O., Caballé, M.F. y Llambías, E.J. (eds.) Geología y Recursos Minerales de la provincia de Buenos Aires. Relatorio del $16^{\circ}$ Congreso Geológico Argentino: 51-68, La Plata.

Quartino, B. y Villar Fabre, J. 1967. Geología y petrología del basamento de Tandil y Barker, provincia de Buenos Aires, a la luz del estudio de localidades críticas. Revista de la Asociación Geológica Argentina 22: 223-251.

Roedder, E. 1984. Fluid Inclusions. Mineralogy Society of America. Reviews in Mineralogy, 12, 644p.

Servicio Nacional Minero Geológico. 1974. Hoja Topográfica 33q Villa Cacique, provincia de Buenos Aires, escala 1:100000, Buenos Aires.

Teixeira, W., Pinese, J., Iacumin, M., Girardi, V., Piccirillo, E., Echeveste, H., Ribot, A, Fernández, R., Renne, P.R. y Heaman, L.M. 2002. Calc-alkaline and tholeiitic dyke swarms of Tandilia, Río de la Plata craton, Argentina: U-Pb, $\mathrm{Sm}-\mathrm{Nd}$, and $\mathrm{Rb}-\mathrm{Sr}{ }^{40} \mathrm{Ar} /{ }^{39} \mathrm{Ar}$ data provide new clues for intraplate rifting shortly after the TransAmazonian orogeny. Precambrian Research 119: 329353.

Teruggi, M.E., Mauriño, V., Limousin, T. y Schauer, O. 1958. Geología de las Sierras de Tandil. Revista de la Asociación Geológica Argentina 13: 185-204.

Tornebohm, A. 1875. On largerforljden inom Norbergs Malmfalt. Geology for Stockholm Forth 2: 329-335.

Tornebohm, A. 1882. Geologische Ubersichskarte der Statthalterschaft Vermland in Masstab 1:400.000 Nebst Beschreibung. Sumary Report by E. Cohen, 33 p., Stockholm. 
Villar Fabre, J. 1956. Descripción geológica de la Hoja 33q, Barker (provincia de Buenos Aires). Dirección Nacional de Minería (inédito), 109-130, Buenos Aires.

Villar Fabre, J. y Quartino, B. 1966. Exomorphic and endomorphic effects from marble-contaminated granite contacts in the "San Miguel" quarry, Barker, Province of Buenos Aires, Argentina. American Journal of Science 264: 310320. 


\section{CAPÍTULO 2}

\section{GEOLOGÍA REGIONAL}

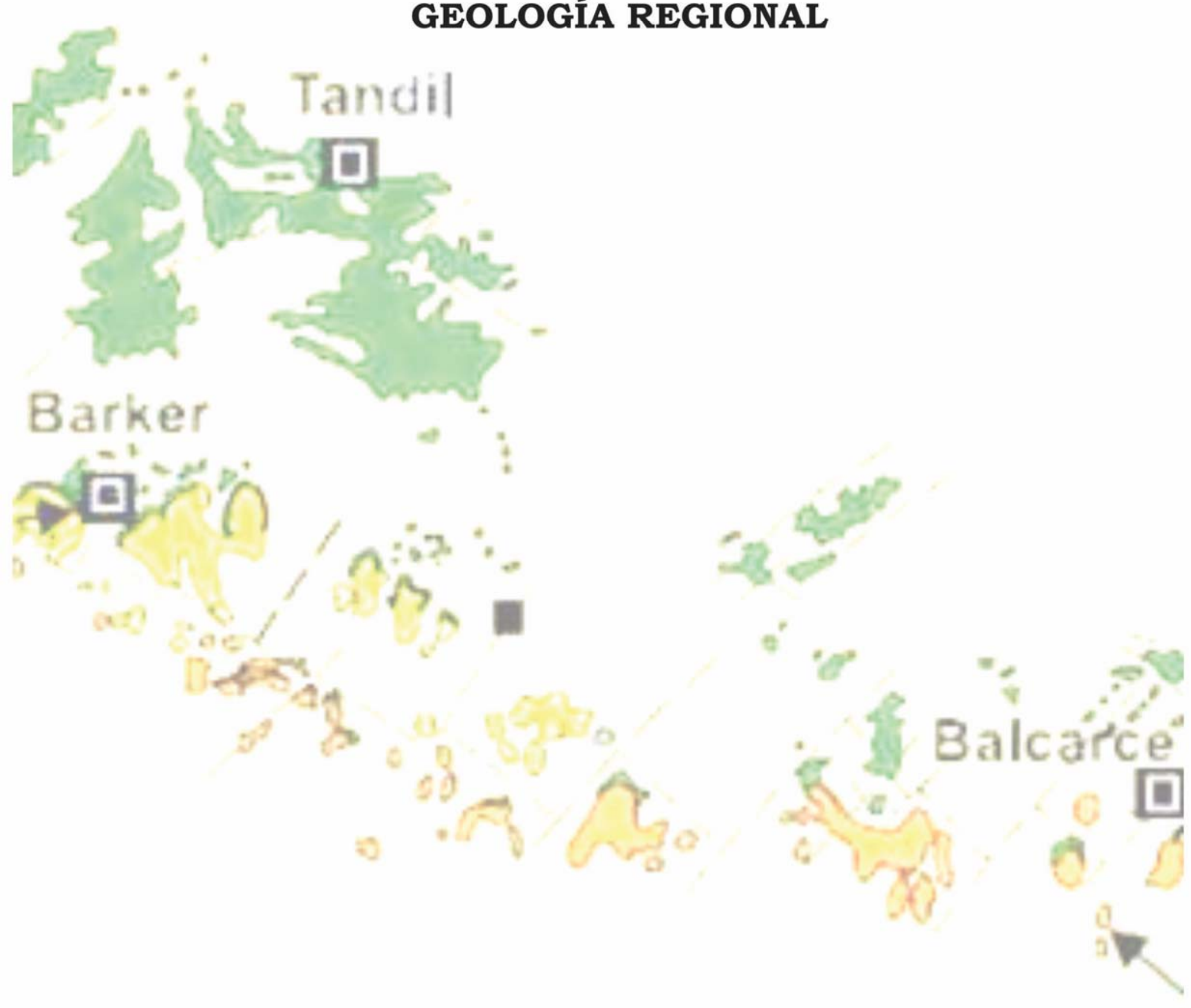




\subsection{INTRODUCCIÓN}

El área de estudio se encuentra ubicada en el ámbito de las Sierras Septentrionales de la provincia de Buenos Aires (Harrington 1956) también conocidas como Sistema de Tandilia (Nágera 1940). Estas sierras comprenden un conjunto de elevaciones que dejan parcialmente al descubierto al Precámbrico más antiguo de Argentina, que junto con los afloramientos ubicados en el oeste de la República Oriental del Uruguay y los de la isla Martín García (Río de La Plata) conforman la unidad conocida como Cratón del Río de la Plata (Almeida 1971).

El basamento cristalino de las Sierras Septentrionales, denominado Complejo Buenos Aires (Marchese y Di Paola 1975), corresponde a una típica asociación ígneo-metamórfica compuesta por gneises granítico-tonalíticos, migmatitas, anfibolitas y plutones graníticos a tonalíticos y en menor proporción por mármoles, esquistos y diques de composición ácida, intermedia y básica.

El presente capítulo tiene como finalidad ofrecer una síntesis de la geología regional, una descripción de las principales unidades litológicas y una caracterización de los episodios de deformación que afectaron a la región en la cual se encuentra el skarn San Miguel.

\subsection{GEOLOGÍA DEL CRATÓN DEL RÍO DE LA PLATA}

El Cratón del Río de la Plata, (CRLP Fig. 2.1, Almeida 1971, Rapela et al. 2007 y Cingolani 2010) se encuentra conformado por unidades ígneas y metamórficas cubiertas casi en su totalidad por rocas sedimentarias de edad neoproterozoico-cámbrica, por sedimentos y basaltos de la cuenca del Paraná y en otros sectores por sedimentos modernos. Este Cratón se encuentra afectado por dos ciclos orogénicos mayores que son el Transamazoniano, que transcurrió entre los 2200-1700 Ma, y el Brasiliano, 
ocurrido entre los 1000-500 Ma (Dalla Salda et al. 1988, Pimentel y Fuck 1992, Bossi et al. 1993 y Hartmann et al. 2002a).

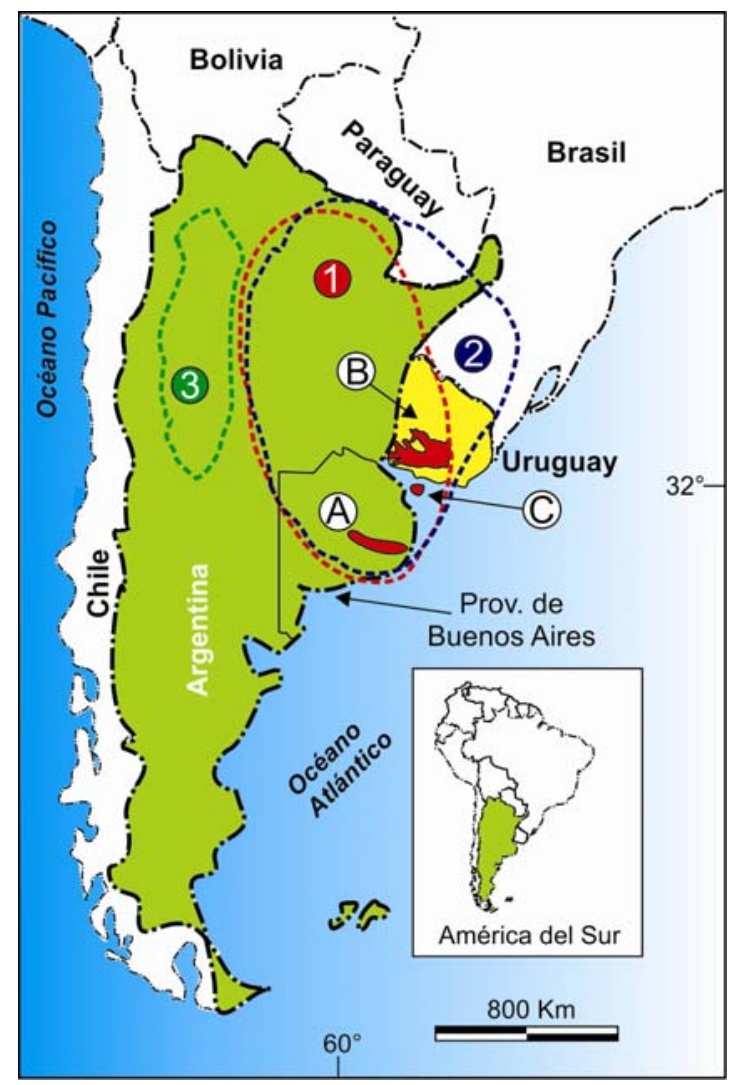

Figura 2.1: Mapa de ubicación de los afloramientos del Cratón del Río de la Plata. (A) Sierras Septentrionales de la provincia de Buenos Aires, (B) Terreno Piedra Alta y (C) Isla Martín García. (1) Límite del CRLP de acuerdo a las interpretaciones de Oyhantçabal et al. (2010) y de Rapela et al. (2011). (2) Límite del CRLP propuesto por Gaucher et al. (2011). (3) Límites del orógeno Pampeano de acuerdo a Rapela et al. (2007).

El extremo más occidental del Cratón está en contacto con las Sierras Pampeanas en Argentina como se observa en la Fig. 2.1 (Booker et al. $2004 \mathrm{y}$ Rapela et al. 2007). El límite oriental, el único expuesto, aflora en Uruguay y según Gaucher et al. (2011) llegaría hasta el Terreno Nico Pérez, que limita con el Terreno Cuchilla Dionisio (Gaucher et al. 2009) a través de la zona de cizalla Sierra Ballena (Oyhantçabal et al. 2010) (Fig. 2.2). Sin embargo, de 
acuerdo a Oyhantçabal et al. (2010) y Rapela et al. (2011) el Terreno Nico Pérez es de edad arqueno-mesoproterozoica y se habría amalgamado al CRLP recién durante el Neoproterozoico (Bossi y Cingolani 2009 y Oyhantçabal et al. 2010) por lo que no sería parte de este Cratón. De esta forma el límite oriental del CRLP sería el Terreno Piedra Alta a través de la zona de cizalla de Sarandí del Yí que lo separa del Terreno Nico Pérez y del Cinturón Dom Feliciano. Este último es el resultado de la colisión del CRLP con el Cratón de Kalahari durante el ciclo Brasiliano (Oyhantçabal et al. 2010). Los afloramientos más australes del CRLP, se encuentran en Argentina: en la Isla Martín García (Figs. 2.1 y 2.2) y en las Sierras Septentrionales de la provincia de Buenos Aires o Sistema de Tandilia (Fig.2.1).

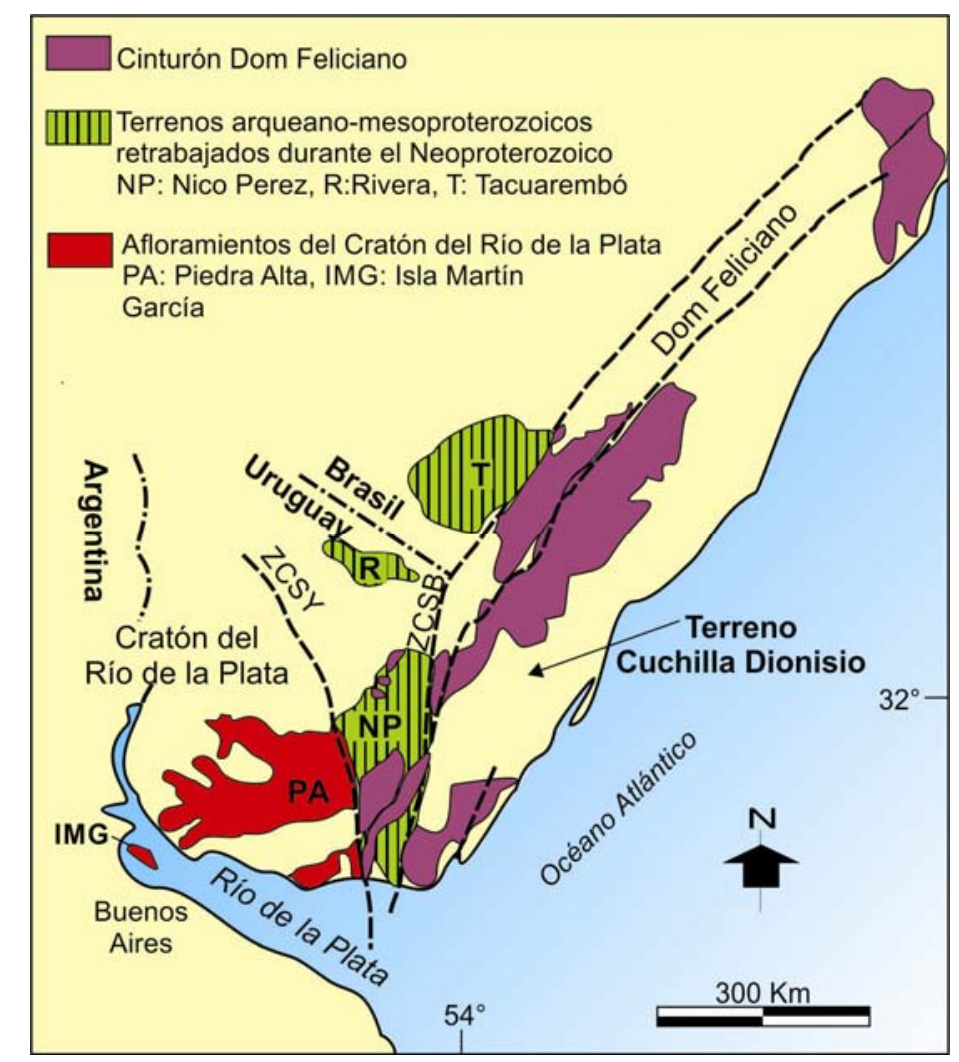

Figura 2.2: Mapa geológico esquemático de los afloramientos del Cratón del Río de la Plata en el sur de Brasil y Uruguay, junto con los terrenos neoproterozoicos, cinturones y principales zonas de cizalla. Modificado de Basei et al. (2005), Bossi y Cingolani (2009) y Oyhantçabal et al. (2009). ZCSY: Zona de cizalla Sarandí del Yí, ZCSB: Zona de cizalla Sierra Ballena. 


\subsection{GEOLOGÍA DE LAS SIERRAS SEPTENTRIONALES}

Las Sierras Septentrionales de la provincia de Buenos Aires (Fig. 2.3), tal como fue mencionado anteriormente, corresponden a los asomos más australes del CRLP. Estas Sierras fueron descriptas y estudiadas por numerosos autores como Villar Fabre (1954), González Bonorino (1954), Teruggi y Kilmurray (1975 y 1980) y más recientemente por Cingolani y Dalla Salda (2000), Dalla Salda et al. (2005) y Cingolani (2010). Se encuentran ubicadas en la región centro-este de la República Argentina y comprenden un conjunto de serranías con rumbo NO-SE que se extiende a lo largo de $350 \mathrm{Km}$ de longitud desde Olavarría hasta Mar del Plata. Su ancho máximo es de $60 \mathrm{Km}$ en la región central (Dalla Salda et al. 2005), hasta unos pocos kilómetros en ambos extremos. Su altura máxima, de alrededor de 500 m.s.n.m, también se encuentra en la parte central del cordón. Las Sierras limitan al norte con la Cuenca del Salado (conformada por unidades mesozoicas a cenozoicas) y al sur con la Cuenca de Claromecó (constituida por unidades neoproterozoicas a paleozoicas); ambas cuencas están cubiertas por relleno moderno (Fig. 2.4). La Sierras no son un cordón continuo ya que están atravesadas por valles que determinan la división general de las mismas en tres sectores principales que reciben los nombres de las poblaciones más importantes. De oeste a este, como se observa en la Fig. 2.3, las áreas son: Azul (NO), Tandil (centro) y Balcarce (SE).

El relieve de la región está controlado por el tipo litológico presente, siendo en general un relieve redondeado y suave donde predomina la erosión de rocas ígneo-metamórficas, en tanto que hacia el sur se torna abrupto y escarpado donde afloran las unidades de la cubierta sedimentaria. 


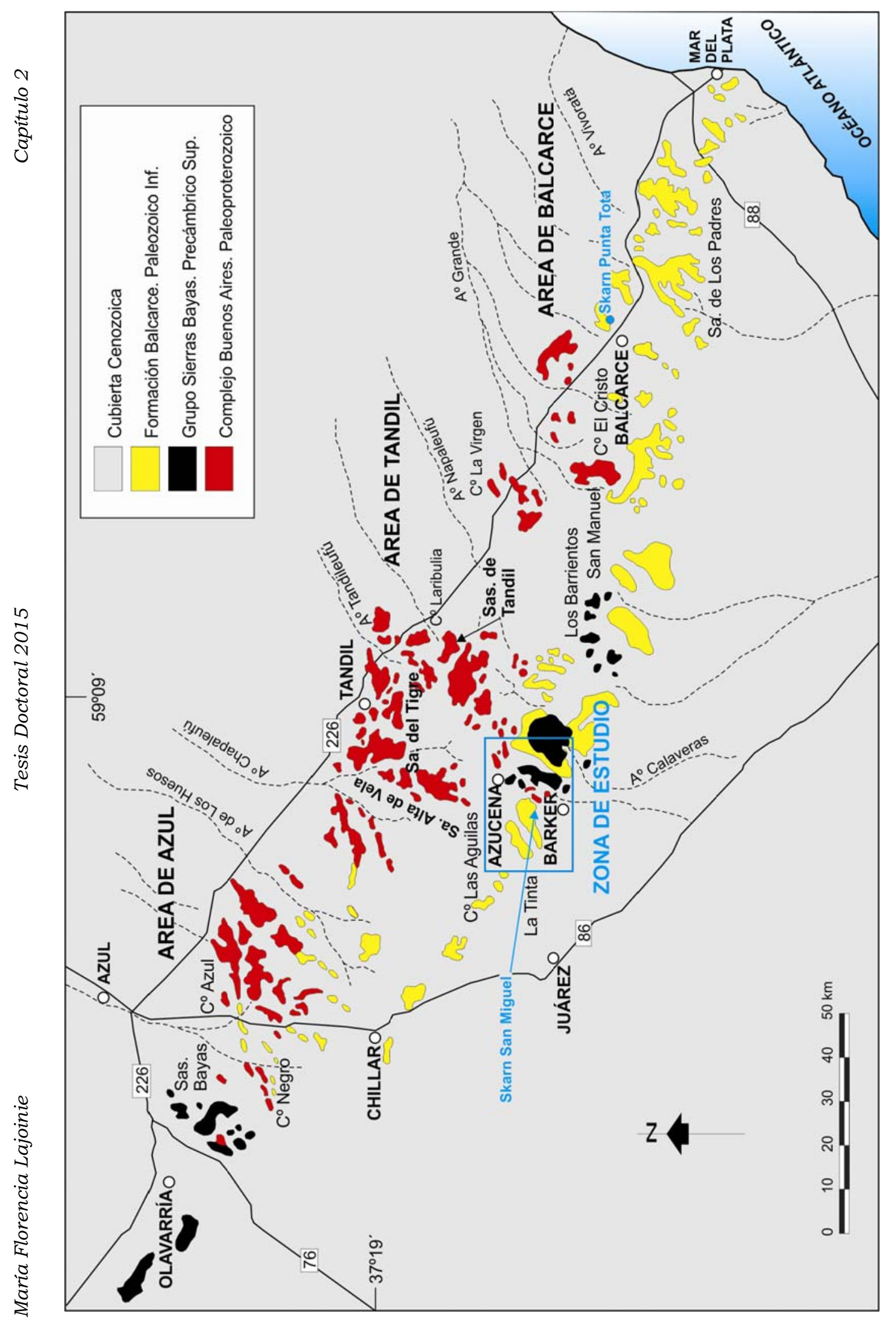

กิ

苗

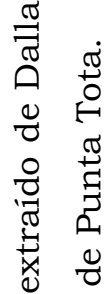

के

穵

告 $\sum_{0}$

ติ

$\approx 8$

晃

อ. 气

๘ี

웅

e

శ్

吾

品

थ

营

记

ब $\frac{\pi}{2}$

ช

$8 \%$

:

${ }_{\infty}$

बू ब

$\sum^{\pi}$

लें

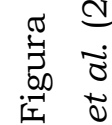




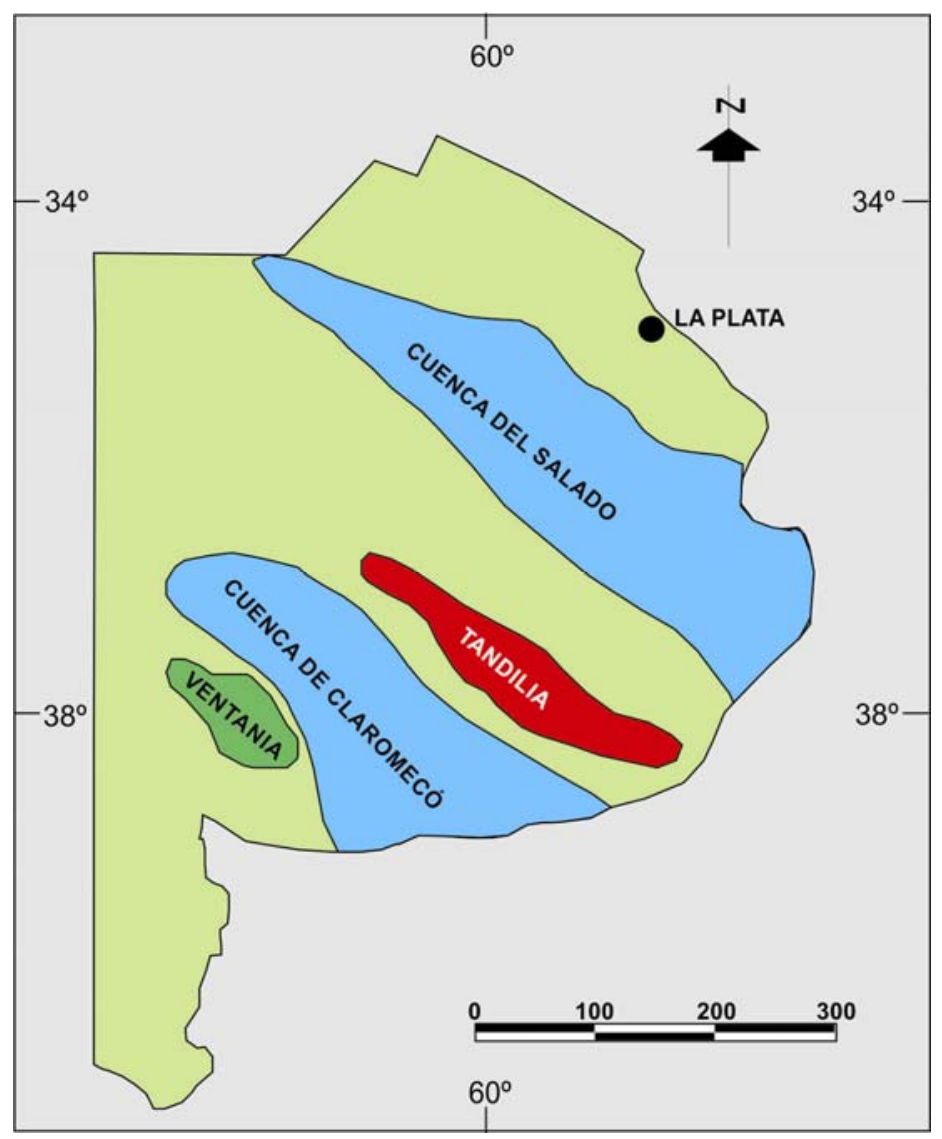

Figura 2.4: Esquema de ubicación y límites de las cuencas del Salado y de Claromecó, que limitan con Tandilia (Sierras Septentrionales) y Ventania (Sierras Australes).

\subsubsection{Basamento ígneo metamórfico}

El basamento de las Sierras Septentrionales denominado Complejo Buenos Aires (Marchese y Di Paola 1975) aflora principalmente en el sector norte de las sierras (Fig. 2.3) y corresponde a una típica asociación ígneometamórfica compuesta por gneises granítico-tonalíticos, migmatitas, anfibolitas, escasos mármoles, plutones graníticos a intermedios y diques de composición ácida, intermedia y básica (Dalla Salda et al. 2005 y Cingolani 2010). Las rocas metamórficas son abundantes en el área de Balcarce y en menor medida en Tandil. Los gneises biotíticos y gneises biotíticogranatiferos de Balcarce han sido datados en 2.176, 2.073 y $2.163 \mathrm{Ma}$ (Cingolani et al. 2002 y Hartmann et al. 2002b). Las migmatitas son 
comunes en varias localidades de Azul, Tandil y Balcarce, siendo las más habituales las variedades cuarzo-feldespáticas con granates neoformados (Dalla Salda et al. 2005). Las anfibolitas se encuentran presentes como lentes o nódulos dentro de otras rocas metamórficas e ígneas y están compuestas por plagioclasas, anfiboles y cuarzo.

Los mármoles son escasos y se han identificado en Punta Tota, Sierra de Bachicha, cerca de la ciudad de Balcarce (Delpino 2000 y Delpino y Dristas 2008) y en el área de San Miguel, al SO de la ciudad de Tandil (Fig. 2.3) asociados al skarn homónimo (Villar Fabre y Quartino 1966, Quartino y Villar Fabre 1967, de Barrio et al. 2009 y Lajoinie et al. 2013).

Fajas miloníticas, mencionadas por primera vez por Backlund (1913) y rocas de zona de falla también han sido descriptas por González Bonorino et al. (1956) y Teruggi y Kilmurray (1975 y 1980); las mismas serian derivadas de granitoides y se encuentran más intensamente desarrolladas en varias y amplias fajas de corte en las sierras de Azul y Tandil (Dalla Salda 1981). Las metavolcanitas mencionadas por Lema y Cucchi (1981) y Dristas (1983), también serian parte de las rocas basamentales así como las rocas metamórficas de bajo grado (metacherts, metagrauvacas y metabasitas) de la Formación El Cortijo, sólo expuestas en la región de Tandil, interpretadas como de filiación oceánica (Teruggi et al. 1988 y Ramos 1999) y relicto de una posible sutura (Chernicoff et al. 2014).

Los granitoides, predominantemente paleoproterozoicos, poseen edades K-Ar entre 2.200 y 2.000 Ma (Hart et al. 1966 y Halpern et al. 1970), $\mathrm{U}-\mathrm{Pb}$ SHRIMP de 2.170 Ma (Cingolani et al. 2002 y Hartman et al. 2002a) y Rb-Sr entre 2.154 \pm 28 y $1.770 \pm 88$ Ma (Hart et al. 1966, Halpern et al. 1970, Varela et al. 1988, Linares y González 1990 y Pankhurst et al. 2003). Presentan una gran variabilidad en cuanto a composición mineral y textura. Las relaciones con la roca de caja son difíciles de reconocer e interpretar ya que en su mayoría son rocas metamórficas parcial a totalmente migmatizadas (Dalla Salda et al. 2005). En el área de Tandil se reconoce un amplio sector de afloramientos de tonalitas, granodioritas y granitos que 
presenta características afines a un arco magmático generado durante la orogenia paleoproterozoica en el ciclo Transamazoniano (Dalla Salda et al. 1988). Este basamento está intruido por un extenso enjambre de diques reunidos en dos grupos: los diques más antiguos, de $\sim 2.000$ Ma (Teixeira et al. 2002) pertenecientes a una suite calcoalcalina (Fernández y Echeveste 1995 e Iacumin et al. 2001) y los más jóvenes, con edades U-Pb (ID TIMS) de $1.588 \pm 11 \mathrm{Ma}$ y $1.587,5 \pm 3,4 \mathrm{Ma}$ (Teixeira et al. 2013), que son máficos y tholeíticos (Echeveste y Fernández 1994 e Iacumin et al. 2001).

\subsubsection{Cubierta sedimentaria}

Está constituida esencialmente por rocas silicoclásticas y carbonáticas que afloran al sur de las Sierras (Fig. 2.3). De base a techo conforman: (a) el Grupo Sierras Bayas integrado por la Formación Villa Mónica, Diamictita Colombo, Formación Cerro Largo, Formación Las Águilas-Olavarría y Formación Loma Negra (Dalla Salda e Iñiguez 1979, Zalba 1988, Poiré et al. 1984 y Poiré 1993) que comprenden una sucesión calcáreo-silicoclástica con una edad comprendida entre los 900 y 543 Ma (Poiré 1987, Gómez Peral et al. 2007 y Gómez Peral 2008), (b) la Formación Cerro Negro (Iñiguez y Zalba 1974), calcáreo-silicoclástica (pelitas y margas) de edad neoproterozoicocámbrica (de acuerdo a su contenido fosilifero, Gómez Peral et al. 2005) y (c) la Formación Balcarce también silicoclástica asignada al Ordovícico-Silúrico Inferior (Teruggi et al. 1958, Seilacher et al. 2002, Poiré et al. 2003, Zimmermann y Spalletti 2009 y Cingolani 2010).

Estas sucesiones corresponden a un paleoambiente sedimentario de plataforma. Su mejor exposición es en los sectores cercanos a OlavarríaSierras Bayas, Barker y Balcarce, donde se encuentran los estratos tipo de las Formaciones que las constituyen.

Iñiguez et al. (1989) realizaron un exhaustivo cuadro estratigráfico por sectores (Fig. 2.5), con las correspondientes correlaciones entre las diferentes unidades litoestratigráficas de la región, que fue posteriormente modificado por Poiré y Spalletti (2005). 


\begin{tabular}{|c|c|c|c|c|c|c|c|}
\hline \multirow{2}{*}{$\begin{array}{c}\text { ERAS } \\
\text { PERIODOS }\end{array}$} & \multicolumn{6}{|c|}{ UNIDADES ESTRATIGRÁFICAS } & \multirow{2}{*}{$\begin{array}{l}\text { SECUEN- } \\
\text { CIAS DEPO- } \\
\text { SICIONALES }\end{array}$} \\
\hline & \multicolumn{2}{|r|}{ AZUL } & \multicolumn{2}{|c|}{ TANDIL } & \multicolumn{2}{|c|}{ BALCARCE } & \\
\hline $\begin{array}{l}\text { CÁMBRICO- } \\
\text { SILÚRICO } \\
\text { INF. }\end{array}$ & \multicolumn{2}{|c|}{$\begin{array}{c}\text { Formación } \\
\text { Balcarce }\end{array}$} & \multicolumn{2}{|c|}{$\begin{array}{c}\text { Formación } \\
\text { Balcarce }\end{array}$} & \multicolumn{2}{|c|}{$\begin{array}{c}\text { Formación } \\
\text { Balcarce }\end{array}$} & Batán \\
\hline \multirow{5}{*}{ 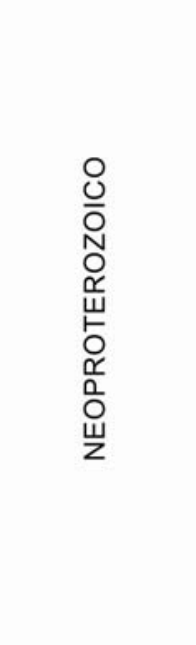 } & $\begin{array}{l}\mathrm{F} \\
\mathrm{C} \in\end{array}$ & ormación & & $\begin{array}{l}\text { ormación } \\
\text { erro Negro }\end{array}$ & $\begin{array}{l}\text { Diamictita } \\
\text { Sierra del } \\
\text { Volcán }\end{array}$ & $\begin{array}{c}\text { Formación } \\
\text { Punta } \\
\text { Mogotes }\end{array}$ & $\begin{array}{l}\text { La } \\
\text { Provi- } \\
\text { dencia }\end{array}$ \\
\hline & \multirow{4}{*}{$\begin{array}{l}\text { Grupo } \\
\text { Sierras } \\
\text { Bayas }\end{array}$} & $\begin{array}{l}\text { Formación } \\
\text { Loma Negra }\end{array}$ & \multirow{4}{*}{$\begin{array}{l}\text { Grupo } \\
\text { Sierras } \\
\text { Bayas }\end{array}$} & $\begin{array}{c}\text { Formación } \\
\text { Loma Negra }\end{array}$ & & & $\begin{array}{c}\text { Villa } \\
\text { Fortabat }\end{array}$ \\
\hline & & $\begin{array}{c}\text { Formación } \\
\text { Olavarria }\end{array}$ & & $\begin{array}{l}\text { Formación } \\
\text { Las Águilas }\end{array}$ & & & Dian \\
\hline & & 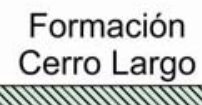 & & $\begin{array}{l}\text { Formación } \\
\text { Cerro Largo }\end{array}$ & & & Malegni \\
\hline & & $\begin{array}{l}\text { Formación } \\
\text { Villa Mónica }\end{array}$ & & $\begin{array}{l}\text { Formación } \\
\text { Villa Mónica }\end{array}$ & & & Tofoletti \\
\hline $\begin{array}{l}\text { PROTERO- } \\
\text { ZOICO }\end{array}$ & & & & & & & \\
\hline
\end{tabular}

Figura 2.5: Cuadro estratigráfico y secuencial de la cubierta sedimentaria de las Sierras Septentrionales de la provincia de Buenos Aires. Extraído de Poiré y Spalletti (2005).

Estos últimos autores definen así, cinco ciclos sedimentarios vinculados genéticamente con cambios del nivel del mar, de tal manera que cada secuencia queda limitada por discordancias erosivas de carácter regional. Dentro de la cobertura sedimentaria se han reconocido dos niveles de diamictitas, uno entre la Formación Villa Mónica y la Formación Cerro Largo denominada Diamictita Colombo y otra en la base de la Formación Balcarce denominada Diamictita Sierra del Volcán (área de Balcarce) (Spalletti y Del Valle 1984). La importancia de esta última, radica en que según su posición estratigráfica y edad (Ordovícico Superior), podría ser correlacionada con un importante evento glacial en el sur de Sudamérica y 
Sudáfrica. Además de estas evidencias, las similitudes de la cobertura sedimentaria del Cratón del Río de la Plata con las formaciones del Grupo Nama del suroeste de África, fueron utilizadas como elementos en la reconstrucción del borde suroccidental de Gondwana durante el Neoproterozoico (Germs 1972, Dalla Salda 1979, 1980, 1982 y Dalla Salda et al. 1988).

\subsubsection{Evolución tectónica de las Sierras Septentrionales}

Siguiendo la subdivisión del Precámbrico sugerida por la IUGS (Brito Neves 2009), Cingolani (2010) realiza un esquema de la evolución tectónica de las Sierras Septentrionales, el cual puede resumirse en los siguientes episodios:

- Estadio 1 (Neoarqueano-Sideriano), según evidencias geoquímicas, petrológicas e isotópicas, se registra el inicio de una subducción que involucra bloques continentales neoarqueanos $(2,5-2,6 \mathrm{Ga})$, que hasta ese momento habrian tenido una historia independiente. Según Teruggi et al. (1988) y Ramos (1999) estos bloques corresponderian a los terrenos de Buenos Aires, El Cortijo y Tandilia (Fig. 2.6a). Este episodio tectónico, según evidencias isotópicas de U-Pb SHRIMP en circones fue llamado por Hartmann et al. (2002a) como el "Orógenia de las Encantadas". Recientemente Chernicoff et al. (2014), interpretan sobre la base de estudios geofísicos una sutura que denominaron "Sutura del Cortijo" ubicada entre los terrenos de Tandil y Balcarce (estos últimos también según denominación de estos autores), indicando que en algún momento del Neoarqueano estos habrian sido terrenos separados por un sistema de rift que generó entre ambos una cuenca con depósitos marinos (Fig. 2.7). 


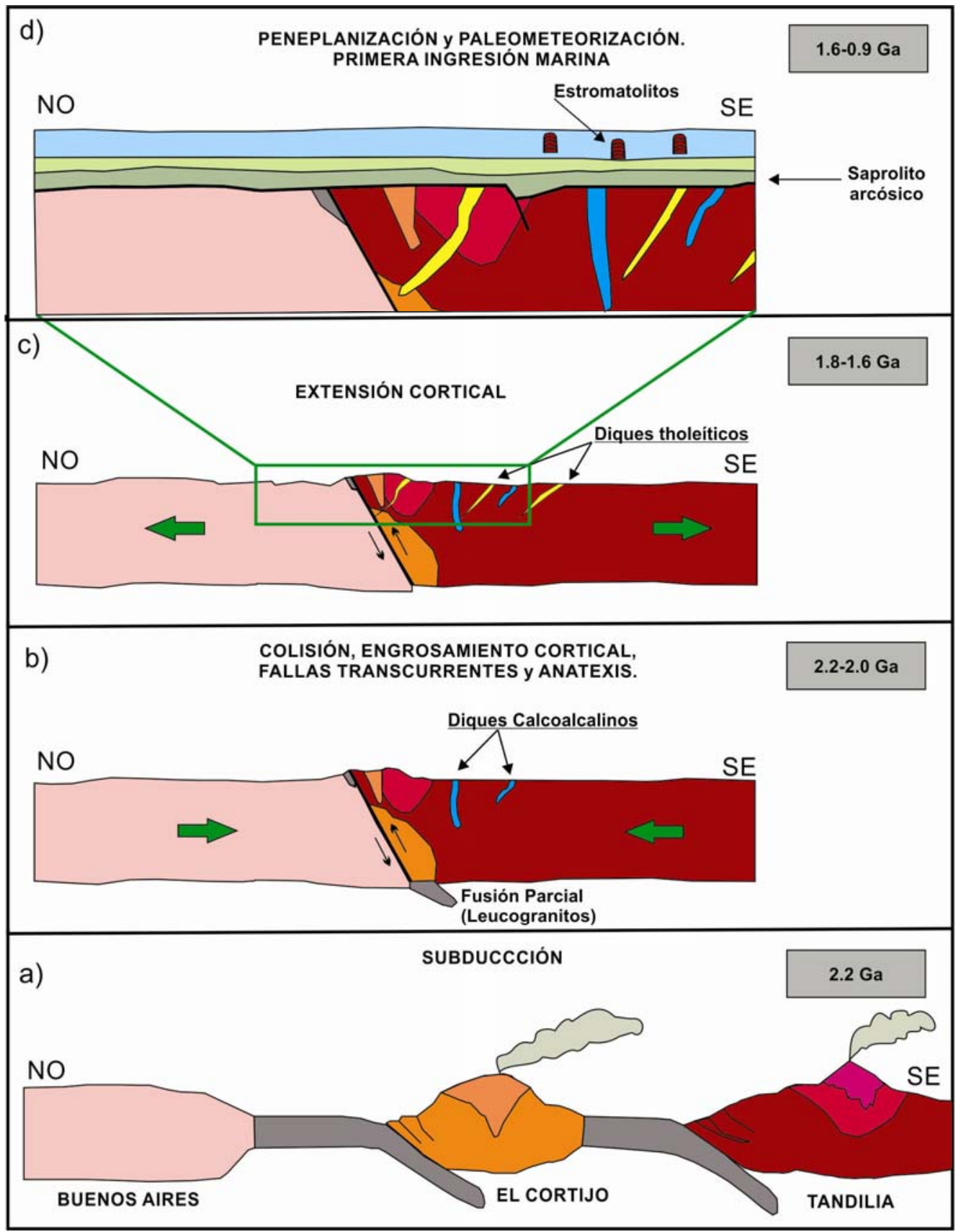

Figura 2.6: Los esquemas a-d, corresponden a secciones esquemáticas que muestran la evolución tectónica del basamento de las Sierras Septentrionales, extraído de Cingolani (2010). La misma consiste en: a) episodios de subducción y colisión (Teruggi et al. 1988 y Ramos 1999), b) engrosamiento cortical, fallamiento y anatexis, c) extensión (Dalla Salda et al. 2006) y d) comienzo de la depositación de la cubierta sedimentaria en sucesivas ingresiones marinas (Iñiguez et al. 1989). 
- Estadio 2 (Rhyaciano temprano-tardío), este estadio es interpretado como un episodio de colisión continente-continente, como sugieren la presencia de fajas miloníticas y relictos de corteza oceánica asociada a un presunto engrosamiento de la corteza. La colisión provocó fallamiento, el cuál favoreció los procesos de anatexis de las rocas corticales. Como consecuencia de dicha anatexis, se produjo el emplazamiento de plutones en una corteza metamorfizada y deformada. Las colisiones generadas por el cierre de un sistema de subducción ocurrieron entre Tandilia y el terreno de Buenos Aires o entre Tandilia y Balcarce (Fig. 2.7, Chernicoff et al. 2014). E1 emplazamiento de diques calco-alcalinos se asocia a los procesos distensivos generados por la colisión continental (Fig. 2.6b). Hartmann et al. (2002a) llama a este estadio como el "Orógenia Camboriú".

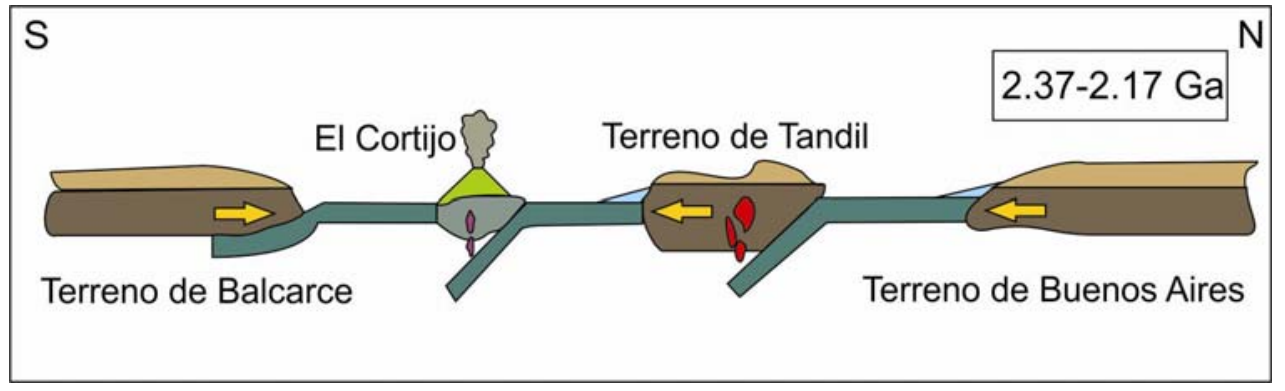

Figura 2.7: Esquema sobre la base de la interpretación de Chernicoff et al. (2014). Estos autores indican para el Neoarqueano-Paleoproterozoico la presencia de dos cuencas, una entre los terrenos de Balcarce y Tandil y otra entre este último terreno y el terreno de Buenos Aires.

- Estadio 3 (Orosiniano-Statheriano), estadio extensional con generación de leucogranitos post-colisionales y emplazamiento de diques tholeíticos (Fig. 2.6c).

- Estadios 4, 5 y 6 (Mesoproterozoico-Neoproterozoico tardío), el basamento ígneo - metamórfico sufre un período de peneplanización, paleometeorización y probablemente episodios de hidrotermalismo. En este sentido, Dristas y Martínez (2007) describieron niveles ricos en 
hierro de origen hidrotermal en el tope de la Formación Villa Mónica y en la base de la Formación Cerro Largo.

Durante el Neoproterozoico tardío se registra la primera transgresión marina que genera depósitos silicoclásticos y de dolomías estromatoliticas. Separadas de las anteriores por una superficie de no conformidad, se registran los depósitos silicoclásticos y carbonáticos de una segunda transgresión marina. Luego se genera una superficie de regresión, representada por un karst con depósitos de hierro y fósforo, el cual fue descripto por Leanza y Hugo (1987), Poiré y Gaucher (2007) y Gómez Peral et al. (2007). Posteriormente, se registra un nuevo episodio transgresivo hacia el final del Neoproterozoico, caracterizado por depósitos silicoclásticos (Fig. 2.6d).

- Estadio 7 (Neoproterozoico-Cámbrico), de acuerdo a Iñiguez et al. (1989), se registra un importante fallamiento en respuesta a un esfuerzo en sentido suroeste. En consecuencia, el basamento paleoproterozoico fue afectado por un fallamiento que generó un arreglo de bloques ascendidos y descendidos, donde en estos últimos se preservó la cobertura sedimentaria neoproterozoica.

- Estadio 8 (Ordovícico-Silúrico?), posteriormente al ascenso de los bloques se produjo la erosión de la superficie ascendida y finalmente un evento transgresivo que generó los depósitos que cubrieron las secuencias antes mencionadas. Un depósito de diamictita es la evidencia del evento glacial en el Hirnantiano.

Hacia el Paleozoico Superior, se genera una reactivación de las fallas (Pérmico Superior), a partir de la cual el Sistema de Tandilia se ha mantenido como una zona elevada (Zalba et al. 2007) y tectónicamente inactiva.

\subsection{Geologia del área de Tandil}

En el siguiente apartado se realiza un detalle de la geología del área de Tandil (sector central), dado que la zona de estudio queda comprendida en este ámbito dentro de las Sierras Septentrionales (Fig. 2.8). En este sector se 
ubican importantes afloramientos del basamento cristalino, donde los granitoides se distribuyen en dos áreas preferenciales (Dalla Salda et al. 1992): I) a lo largo de una faja septentrional de rumbo este-oeste que tiene como centro la ciudad de Tandil, y II) en un sector austral circunscripto a la Sierra del Tigre y al tercio sur de la Sierra Alta de Vela. La faja septentrional, asociada a rocas miloniticas, se caracteriza por una gran variación composicional entre tonalítica y granítica. Estos granitoides parecen formar parte de un cuerpo mayor constituido por agrupaciones de plutones de menor tamaño, emplazados en varias fases. Los Cerros Tandileufú (canteras San Luis, Tandileufú y San Lino) y Los Nogales exhiben rocas tonaliticas, particularmente en la cantera San Luis estas rocas se asocian a granitos, granodioritas y a milonitas grises. Hacia el oeste, en la cantera Tandileufú, en el extremo norte del cerro homónimo, reaparecen las tonalitas grises también asociadas a granitos; alli la milonitización es abundante y los granitos son más heterogéneos ya que muestran zonas de grano más grueso ricas en feldespato potásico alternando con otras más finas. Las variaciones composicionales son de contactos netos pero no muestran relaciones de intrusividad. En la cantera San Lino se reconocen granitoides grises claros y oscuros, estos últimos son de composición tonalítica y están contenidos en espesas fajas de milonitas. En el área del Cerro Los Nogales, las tonalitas, se asocian a abundantes aplitas y pegmatitas de texturas granudas con hornblenda, tremolita y biotita. Presentan plagioclasa de tipo andesina, cuarzo intersticial (ameboidal y xenoblástico), escaso microclino y epidoto (zoicítico o pistacítico). 


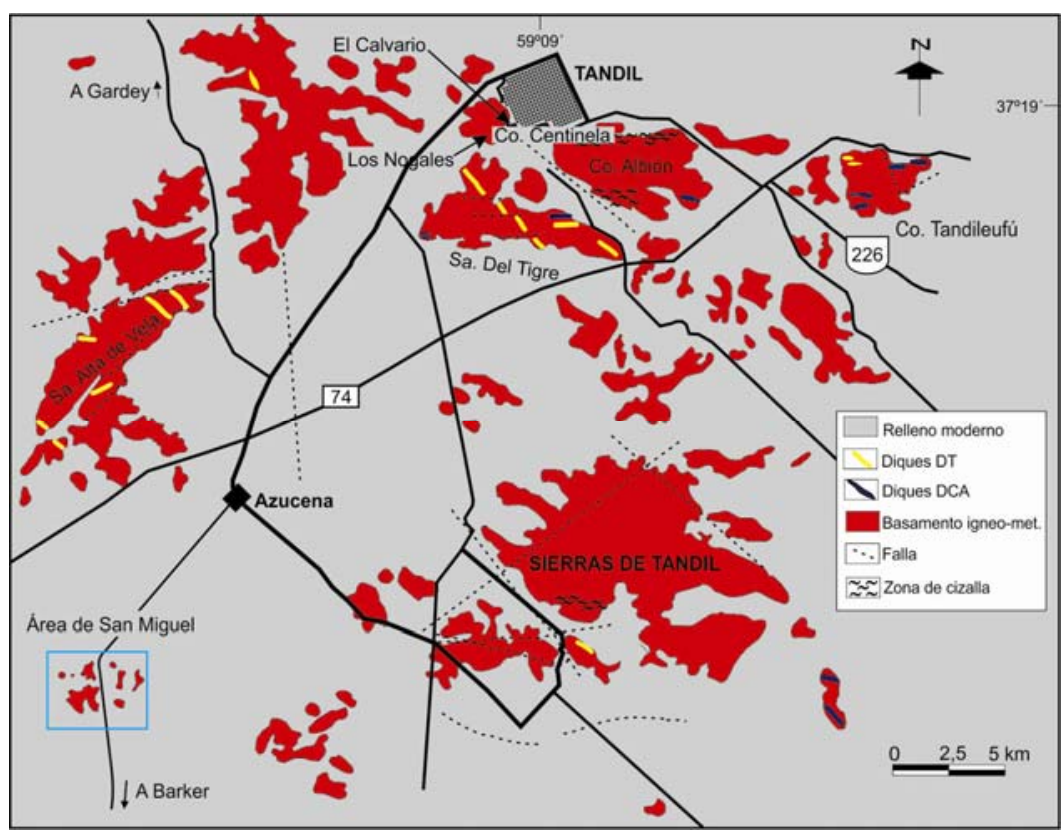

Figura 2.8: Mapa geológico del área de Tandil mostrando los principales afloramientos del basamento ígneo-metamórfico, el enjambre de diques calcoalcalinos (DCA) y tholeíticos (DT) y las principales zonas de falla. Además se ubica el área de estudio (San Miguel). Modificado de Dalla Salda et al. (1988 y 2006). La ubicación de los diques fue tomada de Iacumin et al. (2001).

En el sector austral, los granitos afloran en la Sierra del Tigre y en el sur de la Sierra Alta de Vela. Presentan, en general, coloraciones grises o rosadas, textura granuda a porfiroide y tamaño de grano fino a medio.

Las tonalitas de El Calvario y alrededores de la ciudad de Tandil tienen edades de 2.234, 2.166, 2.183 y $2.228 \mathrm{Ma}, \mathrm{U}-\mathrm{Pb}$, SHRIMP (Cingolani et al. 2002). Estas edades, sobre todo las determinadas en granitoides, son predominantemente paleoproterozoicas (Varela et al. 1988, Linares y González 1990, Cingolani et al. 2002, Hartmann et al. 2002b y Pankhurst et al. 2003). Estos granitoides se encuentran emplazados en metamorfitas, parcial a casi totalmente migmatizadas, presentando en consecuencia relaciones de campo frecuentemente dificiles de establecer. El Cuadro 2.1 comprende un resumen de las principales determinaciones radiométricas en rocas del basamento de la zona. 
Las rocas metamórficas afloran en distintos sectores del área de Tandil como en Cerrillos de La Ribulia (sur de Tandil) donde se identificaron rocas metavolcánicas ácidas, a veces porfiroblásticas (Teruggi y Kilmurray 1980) similares a las descriptas en el Cerro Tandileufú, Cerro San Luis y Sierra Alta de Vela (Lema y Cucchi 1981).

Las anfibolitas son comunes en esta región y se presentan como intercalaciones delgadas o cuerpos nodulares aislados, en general de dimensiones reducidas, con estructura masiva o bien anisótropa de tipo bandeado. Su composición mineral es: plagioclasas, hornblenda, epidoto, cuarzo y micas (biotita y/o clorita). Las evidencias de campo parecen sostener que existen dos ciclos de distinta edad, uno pre-gnéisico y otro posterior previo a los granitos más tardíos.

En un perfil al sudoeste del Cerro Centinela, Quartino y Villar Fabre (1967) describieron brechas de metabasitas antiguas muy deformadas dentro de rocas gnéisicas.

Las migmatitas heterogéneas son frecuentes en Tandilia, con leucosomas cuarzo-feldespáticos y granates neoformados. Están deformadas $\mathrm{y}$ a menudo pasan transicionalmente a gneises $\mathrm{u}$ otras variedades de migmatitas. 


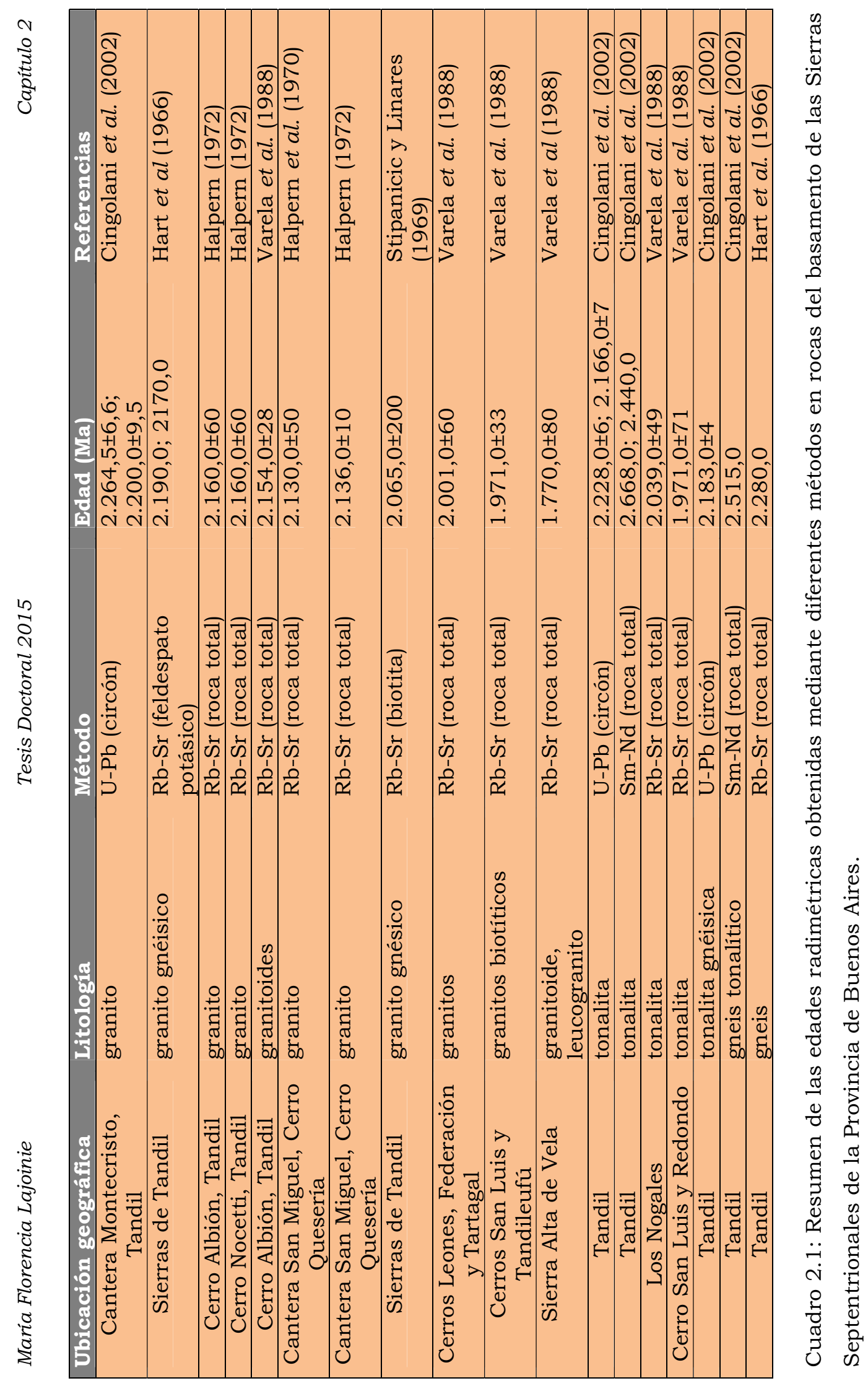


I

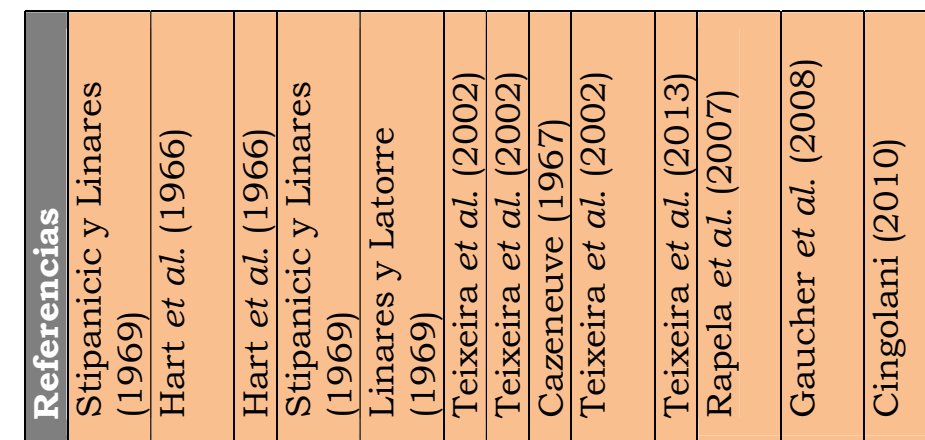




\subsubsection{Evolución tectónica del área de Tandil}

El reconocimiento de estructuras en este basamento representa uno de los aspectos de mayor dificultad debido al bajo nivel de exposición de las rocas. Actualmente y como resultado de los estudios realizados por numerosos autores se sabe que la estructuración del Complejo Buenos Aires se conformó durante más de un episodio de deformación generados durante dos ciclos geotectónicos regionales (Transamazoniano y Brasiliano). Estos generaron estructuras complejas agrupadas por Teruggi et al. (1973 y 1974) en "dominios tectónicos". El dominio A (Fig. 2.9) sería el más antiguo, posiblemente anterior a los $2.200 \mathrm{Ma}$, y se habria desarrollado durante un primer evento deformacional asociado a un metamorfismo de bajo grado (facies esquistos verdes) que generó plegamientos sinmetamórficos con ejes E-O (Teruggi et al. 1973) y fábricas planares de igual rumbo (S1). El dominio tectónico B (Fig. 2.9) muestra trenes de pliegues con ejes NE-SO, lineación mineral y una fábrica planar (S2) de igual orientación, conformados durante un segundo evento deformacional alrededor de los $2.000 \mathrm{Ma}$ que estaría asociado también a un segundo episodio metamórfico de mayor grado entre facies esquistos verdes alta hasta anfibolitas e incluso localmente granulitas; éste es considerado el principal evento metamórfico. Litológicamente corresponde a migmatitas de folias melanocráticas biotíticas $y$ folias leucocráticas cuarzo-feldespáticas, bien definidas y plegadas.

Finalmente un tercer evento metamórfico en facies esquistos verdes desarrolla una foliación NO-SE (S3). Esta estructuración, denominada dominio tectónico $\mathrm{C}$, se encuentra limitada a fajas de poco desarrollo y pliegues de igual orientación que deforman la foliación del dominio B (Fig. 2.9). Los planos estructurales de este último dominio han controlado la inyección de diques básicos y en reducidos sectores también ácidos. 


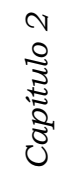

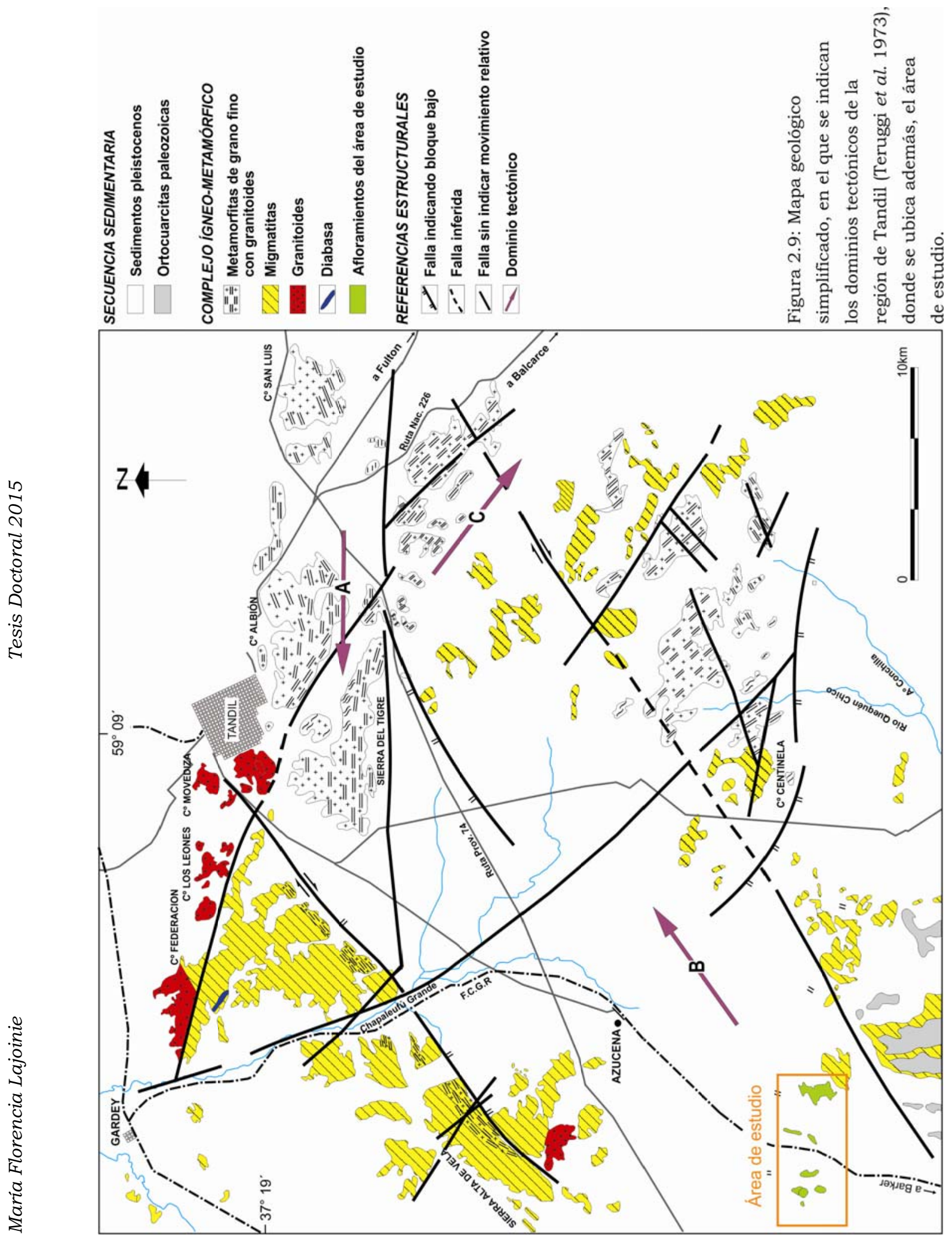




\subsection{BIBLIOGRAFÍA}

Almeida, F.F.M. 1971. Geochronological division of the Precambrian of South America. Revista Brasileira de Geociencias 1: 13-21.

Backlund, H. 1913. Algunas observaciones sobre rocas notables procedentes de Olavarria (Provincia de Buenos Aires). Dirección General de Minería, Geología e Hidrología, Boletín serie B, 2, Buenos Aires.

Basei, M.A.S., Frimmel, H.E., Nutman, A.P., Preciozzi, F. y Jacob, J. 2005. A connection between the Neoproterozoic Dom Feliciano (Brazil/Uruguay) and Gariep (Namibia/South Africa) orogenic belts-evidence from a reconnaissance provenance study. Precambrian Research 139: 195-221.

Booker, J.R., Favetto, A. y Pomposiello, M.C. 2004. Low electrical resistivity associated with plunging of the Nazca flat slab beneath Argentina. Nature 429: 399-403.

Bossi, J., Preciozzi, F. y Campal, N. 1993. Predevoniano del Uruguay Parte 1: Terreno Piedra Alta. Dinamige, Montevideo, 1-50.

Bossi, J. y Cingolani, C. 2009. Extension and general evolution of the Río de la Plata Craton. En Gaucher, C., Sial, A.N. Halverson, G.P. y Frimmel, H.E. (eds.) Neoproterozoic-Cambrian tectonics, global change and evolution: A focus on southwestern Gondwana. Developments in Precambrian Geology. Elsevier 16: 73-85.

Brito Neves, B. 2009. The Paleoproterozoic in the South-American continent: Diversity in the geologic time. Journal of South American Earth Sciences 32: 270-286.

Cazeneuve, H. 1967. Edades isotópicas del basamento de la provincia de Buenos Aires. Revista Ameghiniana 1: 3-10.

Chernicoff, C.J., Zappettini, E.O. y Peroni, J. 2014. The Rhyacian El Cortijo suture zone: Aeromagnetic signature and insights for the geodynamic evolution of the southwestern Rio de la Plata craton, Argentina. Geoscience Frontiers 5: 4352.

Cingolani, C.A. 2010. The Tandilia System of Argentina as a southern extension of the Río de la Plata Craton: An overview. International Journal of Earth Science 100: 221-242. 
Cingolani, C.A. y Dalla Salda, L.H. 2000. Buenos Aires cratonic region. En Cordani, U., Milani, E., Thomaz Filho, A., Campos, D. (eds.) Tectonic evolution of South America. 31st International Geological Congress, 139-146, Río de Janeiro.

Cingolani, C.A., Hartmann, L.A., Santos, J.O.S. y McNaughton, N.J. 2002. U-Pb SHRIMP dating of zircons from the Buenos Aires Complex of the Tandilia Belt, Río de la Plata Craton, Argentina. 15 Congreso Geológico Argentino 1: 149154.

Dalla Salda, L. 1979. Nama and La Tinta Groups, a common Southern AfricaAmerica basin?. Bulletin Chamber of Mines Precambrian Research Unit, University of Cape Town 17 Annual Report 113-128, Cape Town.

Dalla Salda, L. 1980. Some relationship between the cratonic areas of the Rio de la Plata, South America and the western Kalahari, Africa. Bulletin Chamber of Mines Precambrian Research Unit, University of Cape Town 17 Annual Report 88-111, Cape Town.

Dalla Salda, L. 1981. Tandilia, un ejemplo de tectónica de transcurrencia de basamento. Revista de la Asociación Geológica Argentina 36: 204-207.

Dalla Salda, L. 1982. Nama-La Tinta y el inicio de Gondwana. Acta Geológica Liloana 16: $23-28$.

Dalla Salda, L.H. e Iñiguez, A.M. 1979. La Tinta, Precámbrico y Paleozoico de Buenos Aires. 7th Congreso Geológico Argentino 1: 539-550, Neuquén.

Dalla Salda, L.H., Bossi, J. y Cingolani, C. 1988. The Rio de la Plata cratonic región of Southwestern Gondwana. Episodes 11: 263-269.

Dalla Salda, L.H., Franzese, J.R. y Posadas, V.G. 1992. The 1800 Ma myloniteanatectic granitoid association in Tandilia, Argentina. Basement Tectonics 7: 161-174.

Dalla Salda, L.H., de Barrio, R.E., Echeveste, H. y Fernández, R. 2005. El basamento de las Sierras de Tandilia. En de Barrio, R.E., Etcheverry, R., Caballé, M.F. y Llambias E.J. (eds.) Geología y Recursos minerales de la Provincia de Buenos Aires. Relatorio del $26^{\circ}$ Congreso Geológico Argentino, 32-50, La Plata.

Dalla Salda, L.H., Spalletti, L.A., Poiré, D.G., de Barrio, R., Echeveste, H. y Benialgo, A. 2006. Tandilia. En Temas de Geología Argentina 1. Serie de correlación Geológica 21:17-46, San Miguel de Tucumán.

de Barrio, R.E., Lanfranchini, M.E., Etcheverry, R.O., Martin-Izard, A., Tessone, M.O. y Paz, M. 2009. Geological and geochemical evolution of the San Miguel 
skarn, Tandilia Belt, Buenos Aires Province, Argentina. 24th International Applied Geochemistry Symposium, Fredericton, 281-284, Canada.

Delpino, S.H. 2000. Evolución metamórfica del sector nororiental del basamento de Tandilia, Argentina: Metamorfismo en facies granulita y anatexis cortical. Tesis Doctoral, Universidad Nacional del Sur (inédita), 180p., Bahía Blanca.

Delpino, S.H. y Dristas, J.A. 2008. Dolomitic marbles and associated calc-silicates, Tandilia belt, Argentina: Geothermobarometry, metamorphic evolution, and PT path. Journal of South American Earth Sciences 23: 147-175.

Dristas, J. A. 1983. Petrología de una meta-riolita en la Sierra del Tigre, Tandilia. Revista de la Asociación Geológica Argentina 38: 192-200.

Dristas, J.A. y Martínez, J.C. 2007. Hydrothermal low temperature Late Proterozoic unconformity-related hydrothermal iron deposits, in the northern Barker area (Tandilia Ranges, Argentina). Neues Jahrbuch für Geologie und Palaöntologie, Stuttgart 246:267-281.

Echeveste, H.J. y Fernández, R. R. 1994. Asociaciones de óxidos y sulfuros en diques básicos de las Sierras de Tandil, provincia de Buenos Aires. Revista del Museo de La Plata 11: 99-118.

Fernández, R. R. y Echeveste, H. J. 1995. Caracterización geoquímica y petrológica de diques del Sistema de Tandilia, provincia de Buenos Aires, Argentina, Jornadas Geológicas y Geofísicas Bonaerenses, Actas 1: 329-337, Buenos Aires.

Gaucher, C., Finney, S., Poiré, D., Valencia, V., Grove, M., Blanco, G., Pamoukaghlian, L. y Gómez Peral, L. 2008. Detrital zircon ages of Neoproterozoic sedimentary successions in Uruguay and Argentina: Insights into the geological evolution of the Río de la Plata Craton. Precambrian Research 167: 150-170.

Gaucher, C., Frimmel, R.E. y Germs, G.J.B. 2009. Tectonic events and palaeogeographic evolution of southwestern Gondwana in the Neoproterozoic and Cambrian. En Gaucher, C., Sial, A.N., Halverson, G.P. y Frimmel, H.E. (eds.) Neoproterozoic-cambrian Tectonics, Global Change and Evolution: A Focus on Southwestern Gondwana, Developments. Precambrian Geology 16: 295-316.

Gaucher, C., Frei, R., Chemale, F., Frei, D., Bossi, G., Martinez, G., Chiglino, L. y Cernuschi, F. 2011. Mesoproterozoic evolution of the Rio de la Plata Craton in 
Uruguay: At the heart of Rodinia?. International Journal of Earth Sciences 100: 2-3.

Germs, G. J. B. 1972. New shelly fossils from Nama Group, South West Africa. American Journal of Science 272: 752-761.

Gómez Peral, L.E. 2008. Petrología y diagénesis de las unidades sedimentarias precámbricas de Olavarría, Provincia de Buenos Aires. Tesis doctoral, Universidad Nacional de La Plata (inédita), 619 p., La Plata.

Gómez Peral, L. E., Poiré, D.G. y Canalicchio, J.M. 2005. Clastos fosfáticos en la Formación Villa Mónica, Neoproterozoico inferior, Sistema de Tandilia, Argentina. $16^{\circ}$ Congreso Geológico Argentino. Actas 3: 125-132, La Plata.

Gómez Peral, L., Poiré, D.G., Strauss, H. y Zimmermann, U. 2007. C-O Isotope data and diagenetic constraints of the Neoproterozoic Sierras Bayas Group, (SW Gondwana), Argentina. Chemical Geology 237: 127-146.

González Bonorino, F. 1954. Geología de las Sierras Bayas, partido de Olavarría, provincia de Buenos Aires, MOP. LEMIT, Serie 2, 55: 5-37, La Plata.

González Bonorino, F., Zardini, R., Figueroa, M. y Limousin, T. 1956. Estudio geológico de las Sierras de Olavarría y Azul (provincia de Buenos Aires) LEMIT, MOP, Serie 2, 63: 5-22, La Plata.

Halpern, M. 1972. Geochronologic Evolution of Southern South America. Simposio Internacional de Sistemas Carbonífero e Permiano America do Sul. Academia Brasileira de Ciencias 44: 149-160, San Pablo, Brasil.

Halpern, M., Umpierre Urquhart, M. y Linares, E. 1970. Radiometric ages of crystalline rocks from southern South America, as related to Gondwana and Andean geologic provinces. 4th Upper Mantle Symposium, 345-356, Buenos Aires.

Harrington, H. 1956. Argentina. En Jenks, W. F. (ed.) Handbook of South American Geology. Geological Society of American, Memoir 65: 129-165, Nueva York.

Hart, S.R., Krogh, T.E., Davis, G.L., Aldrich, L.T. y Munizaga, R. 1966. A geochronological approach to the continental drift hypothesis. Carnegie Institute Washington Yearbook 65: 57-59.

Hartmann, L.A., Santos, J.O.S., Bossi, J., Campal, N., Schipilov, A. y McNaughton, N.J. 2002a. Zircon and titanite U-Pb SHRIMP geochronology of Neoproterozoic felsic magmatism on the eastern border of the Río de la Plata Craton, Uruguay. Journal of South American Earth Science 15: 229-236. 
Hartmann, L.A., Santos, J.O.S., Cingolani, C.A. y McNaughton, N.J. 2002b. Two Paleoproterozoic Orogenies in the Evolution of the Tandilia Belt, Buenos Aires, as evidenced by zircon U-Pb SHRIMP geochronology. International Geology Review 44: 528-543.

Iacumin, M., Piccirillo, E., Girardi, V., Teixeira, W., Bellieni, G., Echeveste, H., Fernández, R., Pinese, J. y Ribot, A. 2001. Early Proterozoic Calc-Alkaline and Middle Proterozoic Tholeiitic Dyke Swarms from Central-Eastern Argentina. Petrology, Geochemistry, Sr-Nd Isotopes and Tectonic Implications. Journal of Petrology 42: 2109-2143.

Iñiguez, A.M. y Zalba, P. 1974. Nuevo nivel de arcillas en la zona de Cerro Negro, partido de Olavarría, provincia de Buenos Aires. Anales del Lemit 264: 95100.

Iñiguez, A.M., del Valle, A., Poiré, D.G., Spalletti, L.A. y Zalba, P.E. 1989. Cuenca precámbrica-paleozoica inferior de Tandilia, provincia de Buenos Aires. En Chebli, G y Spalletti, L.A. (eds.) Cuencas Sedimentarias Argentinas, 245-263, Tucumán.

Lajoinie, M.F., Lanfranchini, M.E., Etcheverry, R.O. y Recio, C. 2013. Zonación mineral vinculada a procesos geoquímicos en el skarn San Miguel, Sierras Septentrionales de la provincia de Buenos Aires. Revista de la Asociación Geológica Argentina 70: 402-412.

Leanza, H.A. y Hugo, C. 1987. Descubrimiento de fosforitas sedimentarias en el Proterozoico superior de Tandilia, Buenos Aires, Argentina. Revista de la Asoción Geológica Argentina 42: 417-428.

Lema, H. y Cucchi, R. 1981. Hallazgo de meta-vulcanitas en el Cerro Tandileufú, Provincia de Buenos Aires. Revista de la Asociación Geológica Argentina 36: $1-103$

Linares, E. y González, R. 1990. Catálogo de edades radimétricas de la República Argentina 1957-1987. Publicaciones Especiales de la Asociación Geológica Argentina, serie B.

Linares, E. y Latorre, C.O. 1969. Datación por el método potasio-argón de algunas rocas ígneas argentinas. Informe Comisión Nacional Energía Atómica (inédito), Buenos Aires, Argentina.

Marchese, H.G. y Di Paola, E. 1975. Miogeosinclinal Tandil. Revista de la Asociación Geológica Argentina 30: 161-179. 
Nágera, J.J. 1940. Historia física de la provincia de Buenos Aires, 1. Tandilia. Universidad Nacional de La Plata, Facultad de Humanidades y Ciencias de la Educación. Biblioteca de Humanidades, 24 p., La Plata.

Oyhantçabal, P., Siegesmund, S. y Wemmer, K. 2009. The Sierra Ballena shear zone in the southernmost Dom Feliciano Belt (Uruguay): Evolution, kinematics, and deformation conditions. International Journal of Earth Science 99: 12271246.

Oyhantçabal, P., Siegesmund, S. y Wemmer, K., 2010. The Río de la Plata Craton: A review of units, boundaries, ages and isotopic signatures. International Journal of Earth Science 100: 201-220.

Pankhurst, R.B., Ramos, A. y Linares, E. 2003. Antiquity of the Rio de la Plata Craton in Tandilia, southern Buenos Aires province, Argentina. Journal of South American Earth Science 16: 5-13.

Pimentel, M.M. y Fuck, R.A. 1992. Neoproterozoic crustal accretion in central Brazil. Geology 20: 375-379.

Poiré, D.G. 1987. Mineralogía y sedimentología de la Formación Sierras Bayas en el núcleo Septentrional de las sierras homónimas, partido de Olavarría, provincia de Buenos Aires. Tesis Doctoral, Universidad Nacional de La Plata (inédita), 271 p., La Plata.

Poiré, D.G., 1993. Estratigrafia del Precámbrico sedimentario de Olavarría, Sierras Bayas, provincia de Buenos Aires, Argentina. $10^{\circ}$ Congreso Geológico Argentino y $3^{\circ}$ Congreso de Exploración de Hidrocarburos, Actas 2: 1-11, Mendoza.

Poiré, D.G., del Valle, A. y Regalía, G.M. 1984. Trazas fósiles en cuarcitas de la Formación Sierras Bayas (Precámbrico) y su comparación con las de la Formación Balcarce (Cambro-Ordovícico), Sierras Septentrionales de la provincia de Buenos Aires. $9^{\circ}$ Congreso Geológico Argentino, Actas 4: 249266, Río Negro.

Poiré, D.G., Spalletti, L.A y del Valle, A. 2003. The Cambrian-Ordovician siliciclastic platform of the Balcarce Formation (Tandilia System, Argentina): facies, trace fossils, palaeoenvironments and sequence stratigraphy. Geologica Acta 1: 4160.

Poire, D.G. y Spalletti, L.A. 2005, La cubierta sedimentaria Precambrica-Paleozoica Inferior del Sistema de Tandilia. En de Barrio, R.E., Etcheverry, R.D., Caballé, 
M.E. y Llambias, E. (eds.) Geologia y Recursos Minerales de la Provincia de Buenos Aires. $16^{\circ}$ Congreso Geologico Argentino, Relatorio, 4: 51-68, La Plata. Poiré, D.G. y Gaucher, C. 2007. Lithostratigraphy and correlations of two Neoproterozoic basins from the Río de la Plata Craton, SW-Gondwana. En Proceedings of 3rd symposium on Neoproterozoic-early Palaeozoic events in southwestern Gondwana, Programme and Short Papers, Stellenbosch.

Quartino, B. y Villar Fabre, J. 1967. Geología y petrología del basamento de Tandil y Barker, provincia de Buenos Aires, a la luz del estudio de localidades críticas. Revista de la Asociación Geológica Argentina 22: 223-251.

Ramos, V.A. 1999. Rasgos estructurales del territorio argentino. 1 Evolución Tectónica de la Argentina. En Caminos, R. (ed.) Geología Argentina. Instituto de Geología y Recursos Minerales, Subsecretaria de Minería, Buenos Aires. Anales 29-24: 715-784.

Rapela, C.W., Pankhurst, R.J., Casquet, C., Fanning, C.M., Baldo, E.G., GonzálezCasado, J.M., Galindo, C. y Dahlquist, J. 2007. The Rio de la Plata Craton and the assembly of SW Gondwana. Earth Science Reviews 83: 49-82.

Rapela, C.W., Fanning, C.M., Casquet, C., Pankhurst, R.J., Spalletti, L., Pain, D. y Baldo, G.E. 2011. The Río de la Plata Craton and the adjoining PanAfrican/brasiliano terranes: Their origins and incorporation into south-west Gondwana. Gondwana Research 20: 673-690.

Seilacher, A., Cingolani, C.A. y Varela, R. 2002. Ichnostratigraphic correlation of Early Paleozoic sandstones in North Africa and Central Argentina. En Salem, M. y Oun, K. (eds.) Geology of Northwest Libya. Earth Science Society of Lybia 1: 275-292.

Spalletti, L.A. y del Valle, A. 1984. Plataformas Silicoclásticas. En Bossi, G. (ed.) Ambientes y modelos sedimentarios. Boletín sedimentológico 4: 161-187.

Stipanicic, P.N. y Linares, E. 1969. Edades radimétricas determinadas para la República Argentina y su significado geológico. Boletín Academia Nacional de Ciencias 47: 51-96, Córdoba, Argentina.

Teixeira, W., Pinese, J., Iacumin, M., Girardi, V., Piccirillo, E., Echeveste, H., Ribot, A, Fernández, R., Renne, P.R. y Heaman, L.M. 2002. Calc-alkaline and tholeiitic dyke swarms of Tandilia, Rio de la Plata Craton, Argentina: U-Pb, $\mathrm{Sm}-\mathrm{Nd}$, and $\mathrm{Rb}-\mathrm{Sr}{ }^{40} \mathrm{Ar} /{ }^{39} \mathrm{Ar}$ data provide new clues for intraplate rifting shortly after the Transamazonian Orogeny. Precambrian Research 119: 329353. 
Teixeira, W., D’Agrella-Filho, M.S., Hamilton, M.A., Ernst, R.E., Girardi, V.A.V., Mazzucchelli, M. y Bettencourt, J.S. 2013. U-Pb (ID-TIMS) baddeleyite ages and paleomagnetism of 1.79 and $1.59 \mathrm{Ga}$ tholeiitic swarms, and position of the Rio de la Plata Craton within the Columbia Supercontinent. Lithos 174: 157-174.

Teruggi, M.E., Mauriño, V.E., Limousin, T.A. y Schauer, O. 1958. Geología de las Sierras de Tandil. Revista de la Asociación Geológica Argentina 13: 185-204

Teruggi, M.E., Kilmurray, J.O. y Dalla Salda, L.H. 1973. Los dominios tectónicos de la región de Tandil. Anales de la Sociedad Científica Argentina 295: 81-94.

Teruggi, M. E., Kilmurray, J.O., Rapela, C.W. y Dalla Salda, L.H., 1974. Diques básicos en las Sierras de Tandil. Revista de la Asociación Geológica Argentina 24: 41-60.

Teruggi, M.E. y Kilmurray, J.O. 1975. Tandilia. $6^{\circ}$ Congreso Geológico Argentino. Relatorio Geología de la provincia de Buenos Aires: 55-77.

Teruggi, M.E. y Kilmurray, J.O. 1980. Sierras Septentrionales de la provincia de Buenos Aires. Geología Regional Argentina. Academia Nacional de Ciencias, Córdoba 2: 919-956.

Teruggi, M.E., Leguizamón, M.A. y Ramos, V.A. 1988. Metamorfitas de bajo grado con afinidades oceánicas en el basamento de Tandil: Su implicancia geotectónica, provincia de Buenos Aires. Revista de la Asociación Geológica Argentina 43: 366-374.

Varela, R., Cingolani, C.A. y Dalla Salda, L.H. 1988. Geocronología rubidio-estroncio en granitoides del basamento de Tandil, provincia de Buenos Aires, Argentina. Segundas Jornadas Geológicas Bonaerenses (Bahía Blanca). Comisión de Investigaciones Científicas de la provincia de Buenos Aires, 291-305, La Plata.

Villar Fabre, J.F. 1954. Resumen geológico de la hoja 32q, sierras de Tandil. Revista de la Asociación Geológica Argentina 9: 109-130.

Villar Fabre, J. y Quartino, B. 1966. Exomorphic and endomorphic effects from marble-contaminated granite contacts in the "San Miguel" quarry, Barker, Province of Buenos Aires, Argentina. American Journal of Science 264: 310320.

Zalba, P.E. 1988. Clasificación de las arcillas de las Sierras Septentrionales de la provincia de Buenos Aires. CETMIC, Publicación especial.

Zalba, P.E., Manassero, M., Laverret, E.M., Beaufort, D., Meunier, A., Morosi, M. y Segovia, L. 2007. Middle Permian telodiagenetic processes in Neoproterozoic 
sequences, Tandilia System, Argentina. Journal of Sedimentary Research 77: 525-538.

Zimmermann, U. y Spalletti, L.A. 2009. Provenance of the Lower Palaeozoic Balcarce Formation (Tandilia System, Buenos Aires Province, Argentina): Implications for palaeogeographic reconstructions of SW Gondwana. Sedimentary Geology 219: 7-23. 


\section{CAPÍTULO 3}

\section{GEOLOGÍA LOCAL}

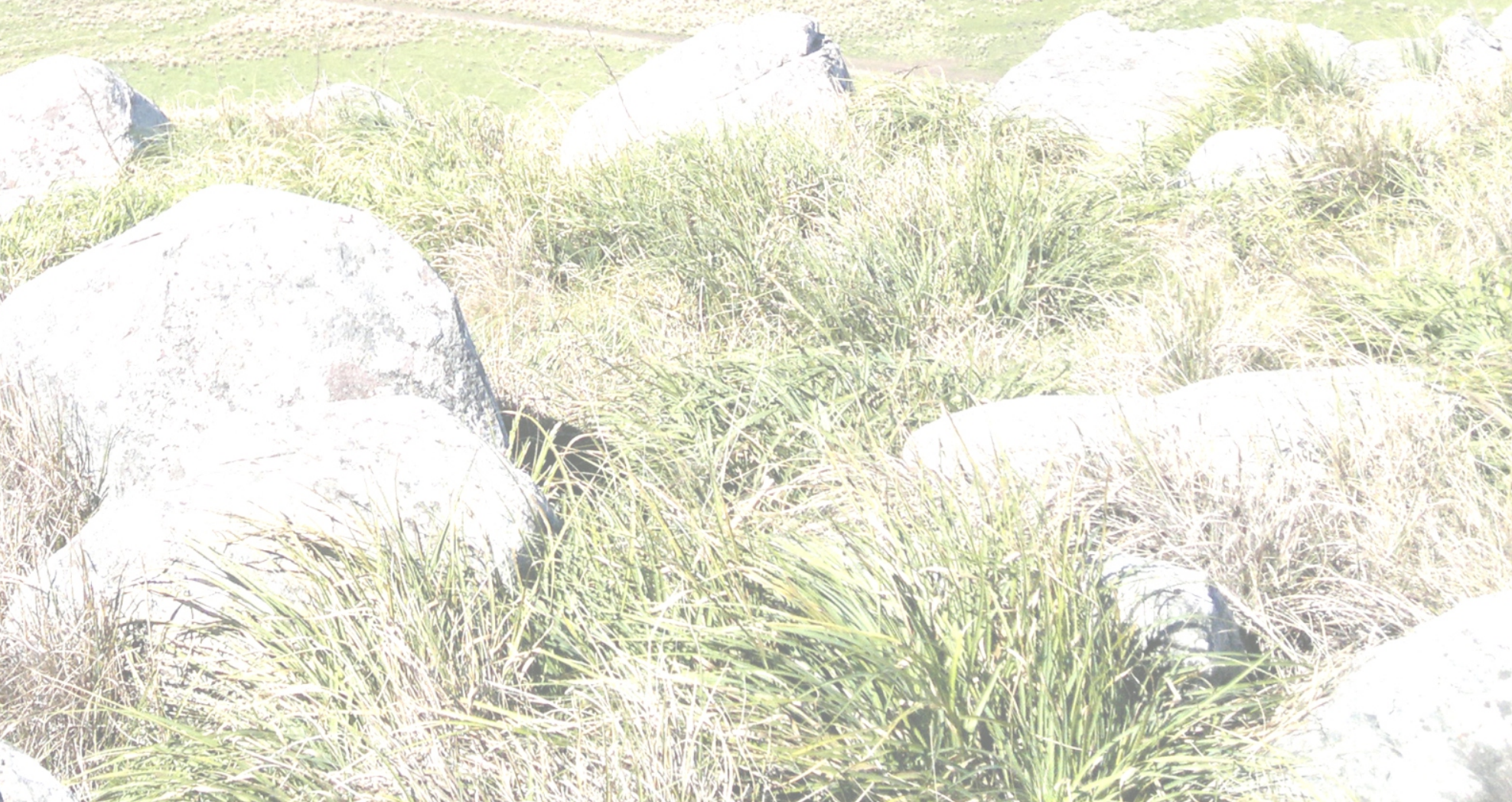




\subsection{INTRODUCCIÓN}

El skarn San Miguel se expone en un área situada entre las localidades de Barker y Azucena, a $33 \mathrm{Km}$ al SSO de la ciudad de Tandil. Sus coordenadas geográficas, teniendo como centro una cantera inactiva donde aflora el skarn son: $37^{\circ} 33^{\prime} 45,42^{\prime \prime}$ latitud sur y 59 $21^{\prime} 45,22^{\prime \prime}$ longitud oeste. El área, denominada también San Miguel, incluye los afloramientos ubicados en las estancias: San Miguel (los más importantes), La Concordia y Siempre Verde (Fig. 3.1).

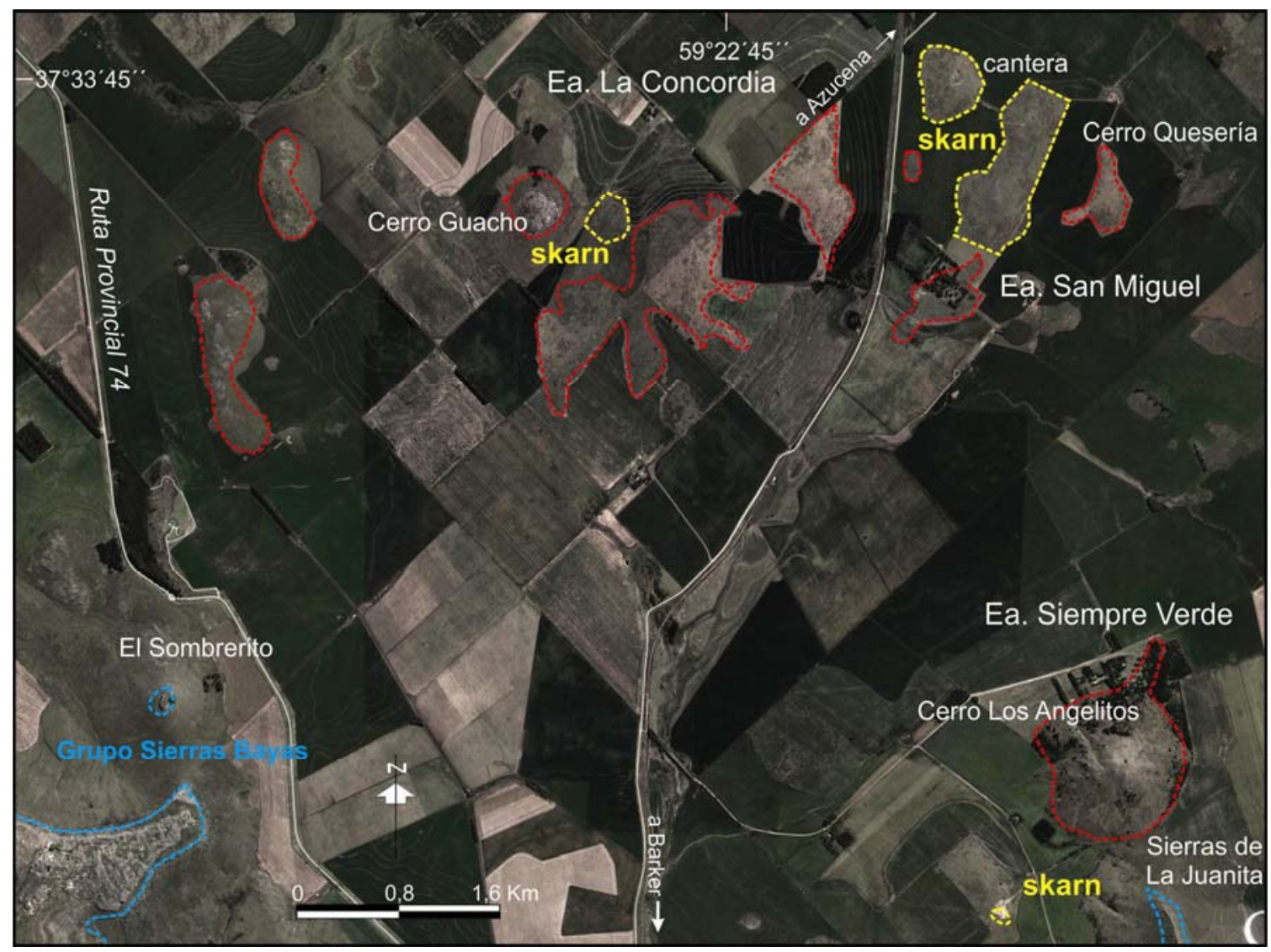

Figura 3.1: Mapa de ubicación del área de San Miguel. Se destaca en el mismo, la ubicación de los afloramientos del skarn (en amarillo) y de los del basamento estudiado (en rojo). Además se ubican los afloramientos de la cobertura sedimentaria, Grupo Sierras Bayas (en celeste). 
$\mathrm{El}$ acceso a dicha zona puede ser a través de tres caminos que desde la ciudad de Tandil (como punto de referencia) hacia el sur son: la Ruta Provincial 74, pasando por la localidad de Azucena y continuando 10 kilómetros por un camino vecinal aproximadamente en dirección sur, la Ruta Provincial 74 hasta el kilómetro 243 y luego por un camino vecinal en dirección sureste, o ingresando desde Barker hacia el norte.

Este sector corresponde a los asomos más australes del basamento en el área, ya que hacia el sur, éste se encuentra cubierto por rocas sedimentarias del Grupo Sierras Bayas cuyos primeros afloramientos constituyen el Cerro el Sombrerito y las Sierras de La Juanita (Fig. 3.1). El basamento está representado por a) rocas metamórficas como gneises biotíticos, migmatitas con diferentes estructuras y un mármol al cual se asocia el skarn San Miguel, y b) rocas ígneas que corresponden a un cuerpo granítico, fuertemente metamorfizado, que constituye el Cerro Guacho, otro de composición tonalítica que aflora en el casco de la Estancia San Miguel y en el cerro Los Angelitos (Ea. Siempre Verde) y diversos diques de naturaleza tanto ácida como intermedio-básica (Fig. 3.2a y b).

Siendo que un skarn es el resultado de procesos de metasomatismo ocurridos entre un protolito carbonático y fluidos silíceos fue necesario estudiar todos los cuerpos silíceos que podrian haber estado involucrados en la formación del skarn, haciendo la salvedad que la pobre exposición de los mismos y la discontinuidad de los afloramientos dificulta dicha tarea. En el presente capítulo se aborda la geología del área de interés poniendo énfasis en los distintos tipos de rocas metamórficas e ígneas que se asocian al skarn con la finalidad de determinar el marco geológicometamórfico-genético de las rocas del área. Con el propósito de unificar las metodologías de estudio este capítulo consta de dos secciones: A, en la que se analizan las rocas metamórficas y B en la que se estudian las rocas igneas. 


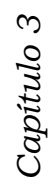

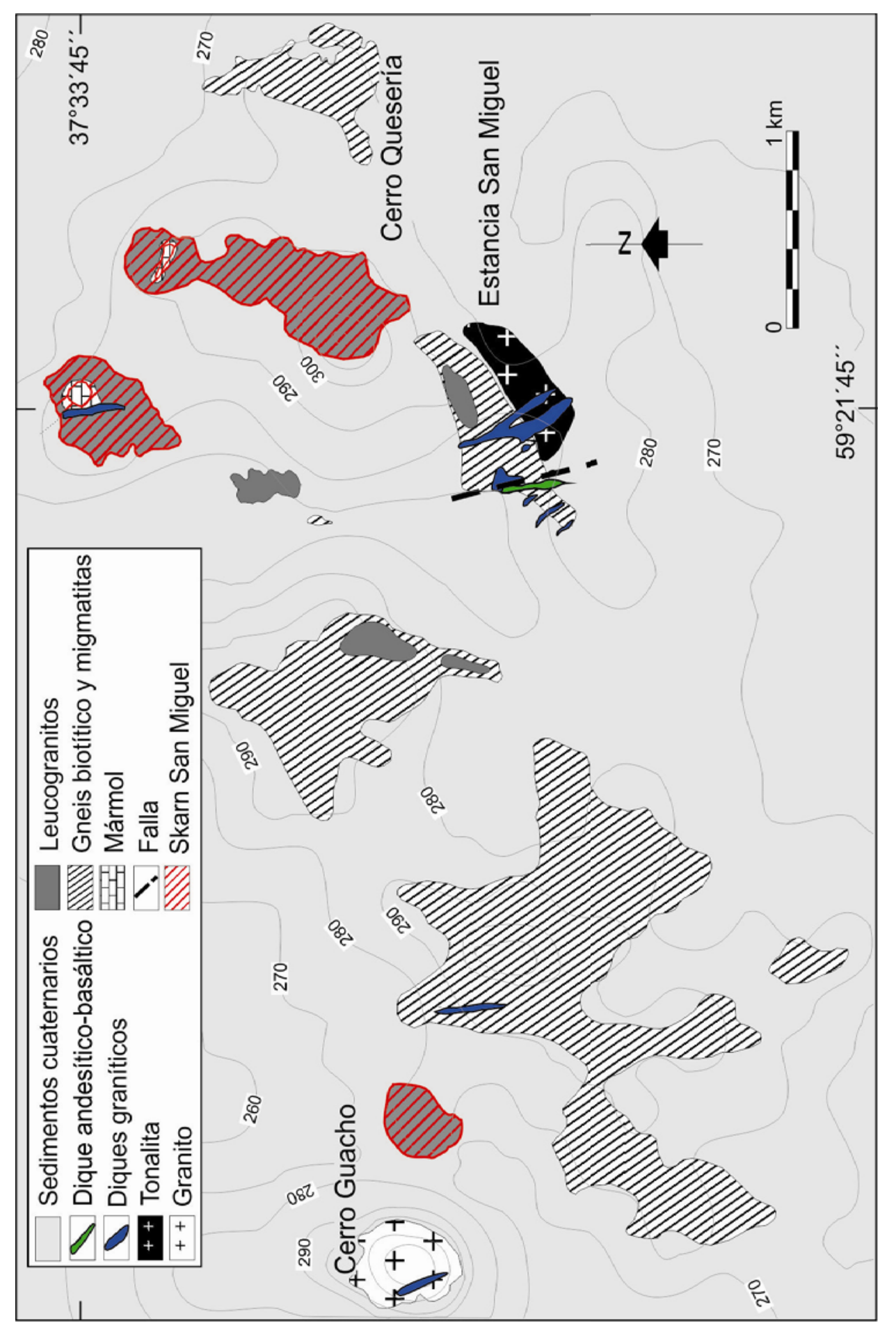
임

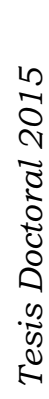

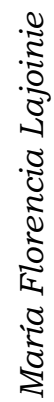

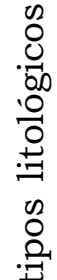

呿

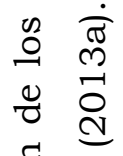

:

?

뜽

है

율

\&

$\nabla 2$

离 :

횽

\&

.

d.

总跑

$\sum \sqrt{2}$

ฮี

ले है

范 


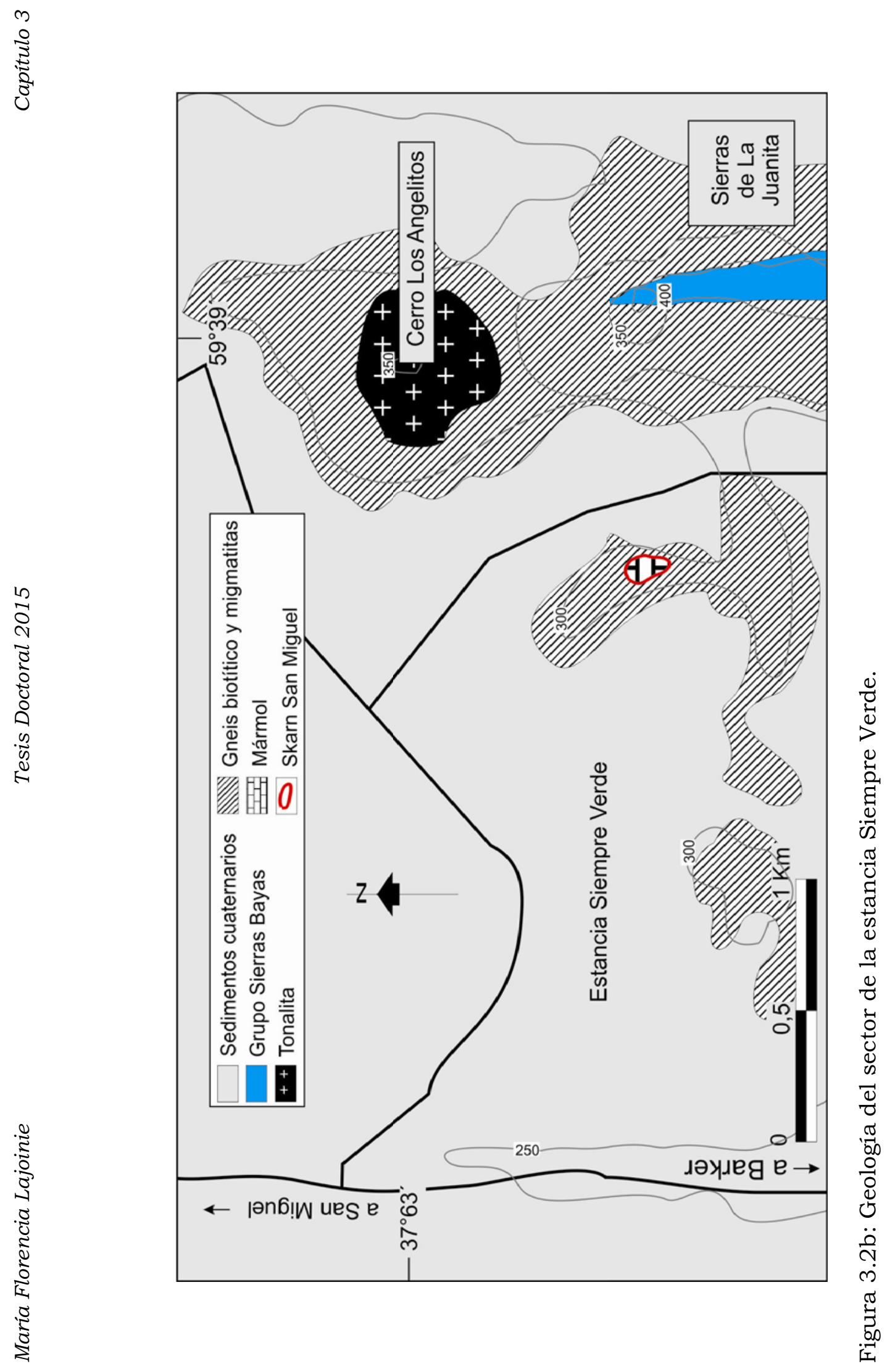




\section{CAPÍTULO 3.A}

\section{ROCAS METAMÓRFICAS DEL BASAMENTO}

\section{DEL ÁREA DE SAN MIGUEL}




\section{A.1 GNEIS BIOTÍTICO-MIGMÁTICO Y MIGMATITAS}

\section{A.1.1 Caracterización geológica}

La roca de mayor distribución areal (Fig. 3.2a y b) corresponde a un gneis biotítico migmático que aflora al oeste de los principales afloramientos del skarn San Miguel, en las cercanías del Cerro Guacho (Ea. La Concordia) y Cerro Los Angelitos (Ea. Siempre Verde), sí como también en el casco de la Ea. San Miguel y en el Cerro Quesería. Este último, se ubica al este del skarn y corresponde a un afloramiento de forma irregular de 0,8 kilómetros de longitud máxima en dirección N-S y un ancho medio de 0,4 kilómetros en dirección E-O. La importancia de este afloramiento radica en que una de las edades absolutas obtenidas en el área de estudio fue determinada a partir de rocas de composición granítica de este sector. Dicha determinación, corresponde a una edad $\mathrm{Rb}-\mathrm{Sr}$ de $2.130 \pm 50 \mathrm{Ma}$ (Halpern et al. 1970) que indica por primera vez de forma absoluta que el basamento del área de estudio es predominantemente paleoproterozoico. De acuerdo a los estudios realizados en la presente tesis, las rocas datadas corresponden a sectores del gneis biotítico migmático que presentan escasa a nula foliación, por lo que dicha edad correspondería a la edad del principal evento metamórfico ocurrido en la región.

En términos generales, este gneis presenta una coloración heterogénea con tonalidades claras y oscuras, enmascaradas en afloramiento por la intensa meteorización de la superficie de las rocas (Fig. 3.A.1a). Posee tamaño de grano medio a grueso, textura equigranular a inequigranular seriada y fábrica anisótropa planar de tipo bandeado composicional $\mathrm{S}_{1}$, dada por la alternancia de bandas claras y oscuras con una dirección dominate $\mathrm{N} 35^{\circ} \mathrm{E}$ (Fig. 3.A.1b). Las bandas claras son de color blanquecino, poseen espesores de aproximadamente 2-3 centímetros y están constituidas por cuarzo, feldespato alcalino y plagioclasas. Estas bandas claras se diferencian con dificultad, en afloramiento, de los leucosomas de las migmatitas estromáticas que se describirán a continuación. Por otro lado, las bandas oscuras son de color negro a gris oscuro, poseen un ancho de 
aproximadamente 4 centímetros y presentan abundante biotita además de los minerales antes mencionados, aunque en menor proporción (Fig.3.A.1c y d).
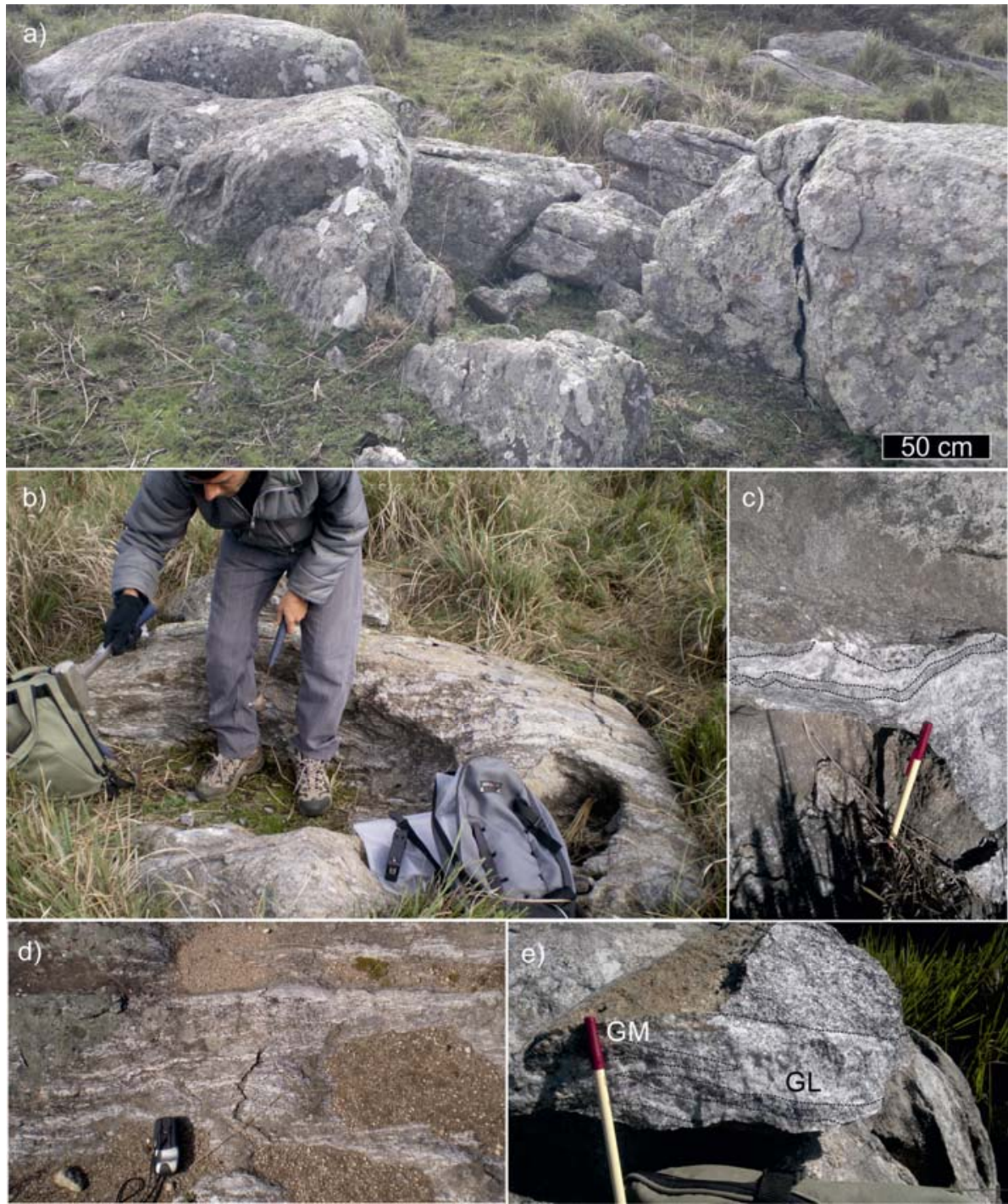

Figura 3.A.1: a) Aspecto de los afloramientos del gneis biotítico migmático. b) Estructura del gneis en afloramiento. c y d) Detalle del bandeado composicional constituido por bandas claras y oscuras. Algunas bandas claras corresponden a leucosomas. e) Detalle de los sectores con menor proporción de biotita que genera la consecuente pérdida del bandeado composicional. $\mathrm{GL}=$ sectores del gneis leucocrático, GM= sectores del gneis melanocrático, correspondiente a las laminillas con biotita. 
En otras zonas estas bandas oscuras se tornan discontinuas y algo difusas debido a la disminución en la cantidad de biotita que desarrolla pequeñas laminillas discontinuas que mantienen la orientación del bandeado $\mathrm{S}_{1}$ (Fig.3.A.1e).

Las migmatitas del área de San Miguel se manifiestan como sectores asociados al gneis biotítico (Fig. 3.2a y b) que desarrollan estructuras generadas por procesos de fusión parcial. Según la clasificación de Mehnert (1968), que tiene en cuenta la relación entre neosoma y paleosoma, las migmatitas presentan estructuras estromáticas con bandas paralelas a la foliación $\mathrm{S}_{1}$ del gneis, por lo que en estos casos resulta sumamente dificil diferenciar ambas litologías (Fig. 3.A.2a). En determinados afloramientos las migmatitas desarrollan otras estructuras como movilizados brechoides (Fig. 3.A.2b) y boudines (Fig. 3.A.2c). El neosoma se compone de un leucosoma de color blanquecino constituido por cuarzo, feldespato potásico y plagioclasas, con tamaño de grano grueso y variable y un melanosoma de límites difusos con tamaño de grano medio y mayor proporción de biotita (Fig. 3.A.2d). En otros sectores en contacto con los gneises y migmatitas se observan cuerpos migmáticos más voluminosos, de límites difusos y fábrica isótropa de aspecto leucocrático, con granate (Fig. 3.A.3a). En afloramiento son de difícil identificación y es por eso que en los primeros trabajos, estos sectores eran considerados como parte del mismo gneis que era clasificado como un gneis granatífero-biotítico (Fig. 3.A.3b). En términos generales presentan coloración blanquecina a grisácea, tamaño de grano medio a grueso y textura inequigranular, dada por la presencia de porfiroblastos de granate de coloración pardo rojiza de hasta 1 centímetro de diámetro (algunos presentan un importante grado de oxidación), y una matriz de feldespato potásico, cuarzo y plagioclasas de tamaño medio (Fig. 3.A.3c). 

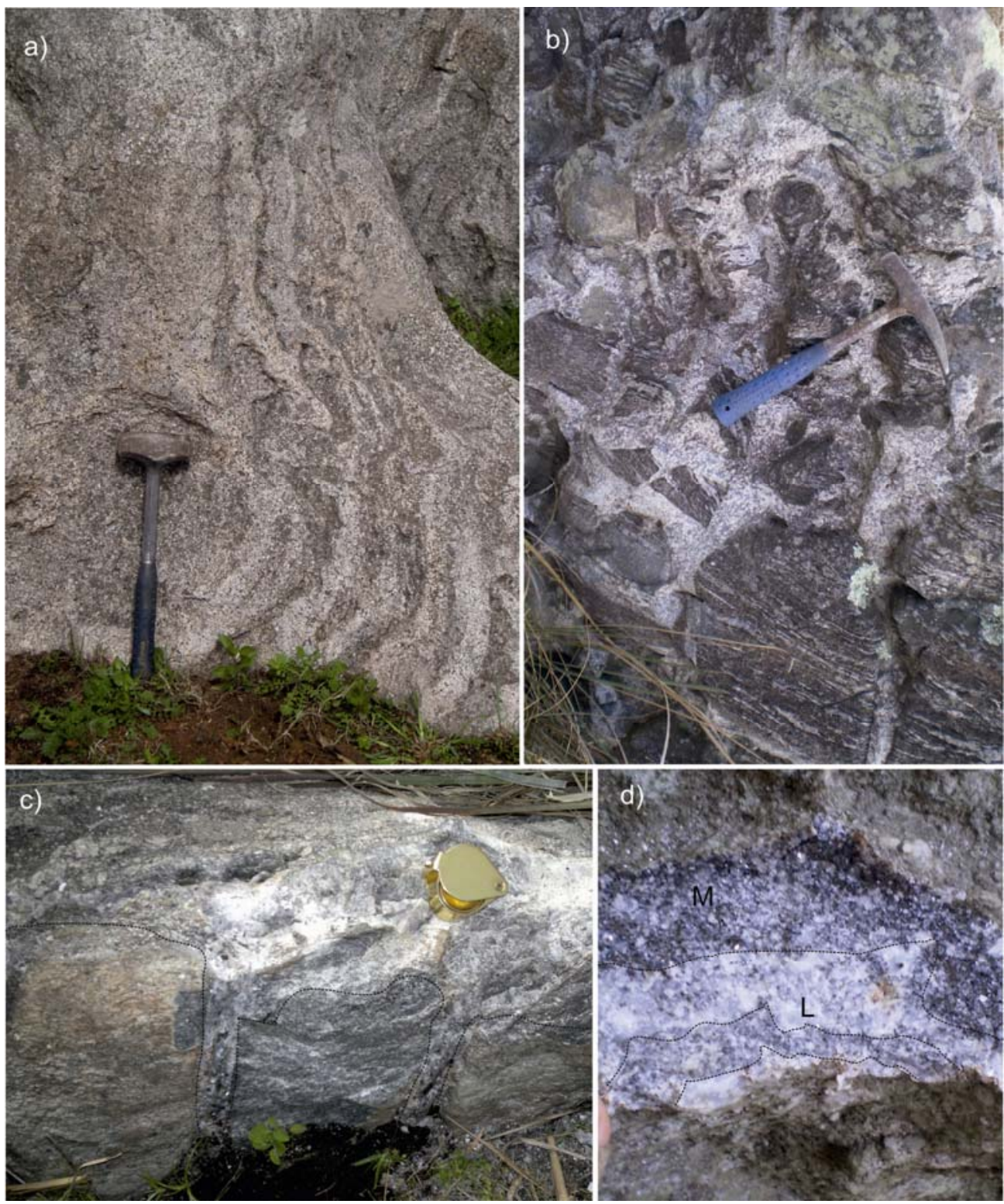

Figura 3.A.2: a) Afloramiento de la migmatita con estructura estromática. b) Migmatita con estructura brechoide. c) Sector de la migmatita con estructuras tipo boudines. d) Detalle de leucosoma (L) y melanosoma (M).

En algunos afloramientos del gneis y también de las migmatitas, como en los ubicados al oeste del Cerro Guacho y al sur del casco de la estancia San Miguel (Fig. 3.2a), se han identificado xenolitos de coloración gris oscura, tamaño de grano fino y con una fábrica que en algunos casos es masiva y en otros anisótropa. 

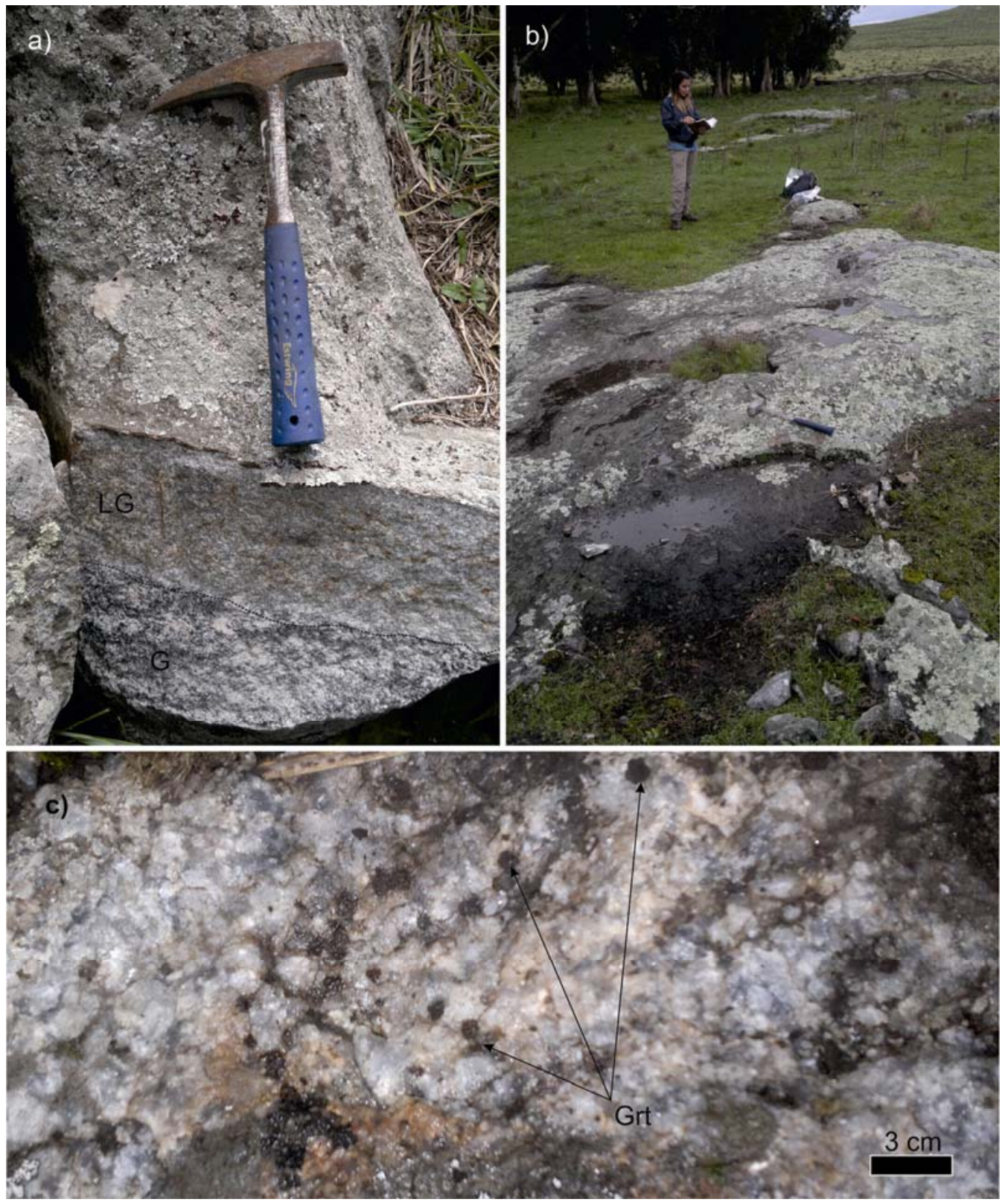

Figura 3.A.3: a) Cuerpo leucocrático (LG) con granate intruyendo al gneis biotítico (G). b) Aspecto de los afloramientos de los cuerpos leucocráticos con granate, a diferencia del gneis los mismos presentan formas redondeadas sin estructuras visibles. c) Detalle de la textura de un leucosoma granatífero. Abreviatura mineral Siivola y Schdmit (2007).

Su mineralogía compuesta de abundantes minerales melanocráticos de hábito prismático hace pensar que podrian corresponder a xenolitos de 
una roca máfica (Fig. 3.A.4a). Los mismos poseen diversas morfologias entre elongadas y equidimensionales de bordes netos y angulosos (Fig. 3.A.4b).
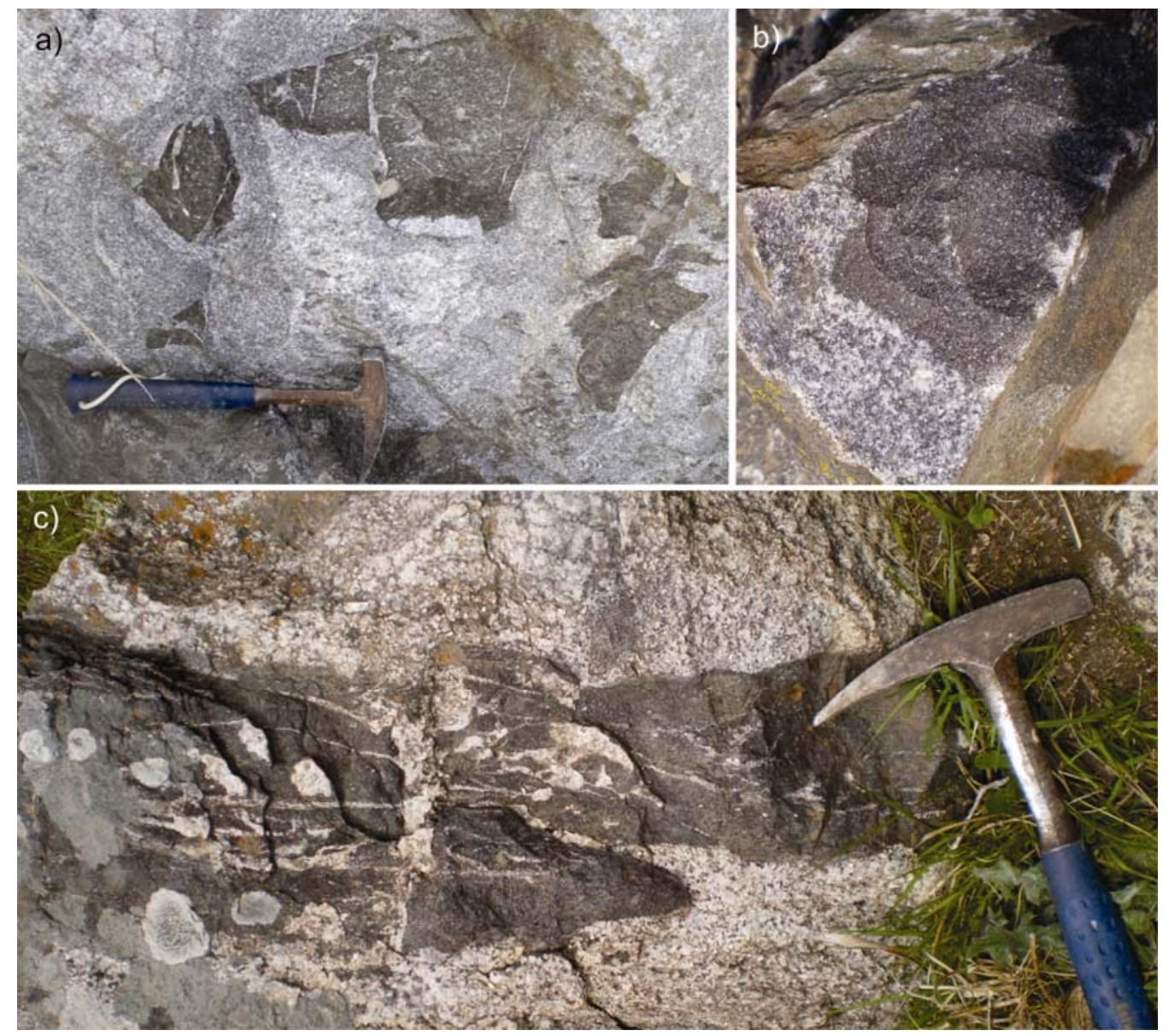

Figura 3.A.4: a) Xenolitos de color gris oscuro a negro rodeados por la roca de caja en cuyos bordes se observa la deformación de la fábrica. b) Detalle del tamaño de grano fino de los xenolitos y del grano medio y textura granosa de la roca de caja. c) Xenolito elongado y atravesado por numerosas vetillas de cuarzo.

Los equidimensionales presentan tamaños que varian entre 10 y 30 centímetros de diámentro mientras que los elongados registran hasta 60 centímetros de longitud máxima. Algunos se encuentran atravesados por pequeñas vetillas de cuarzo, sobre todo aquellos que presentan fábrica anisótropa (Fig. 3.A.4c). Estos xenolitos serán abordados a través de la 
petrografia, ya que su por su tamaño de grano fino su estudio en muestra de mano es limitado.

\section{A.1.2 Petrografia}

Al microscopio, el gneis, posee tamaño de grano medio a grueso entre 0,2 y 3 milimetros y textura inequigranular seriada. Las bandas claras presentan una mineralogía constituida principalmente por plagioclasa tipo oligoclasa (determinada por el método de Michel Lévy), feldespato potásico y en menor proporción por cuarzo (Fig. 3.A.5a y b). Los cristales de plagioclasa y feldespato potásico son abundantes, desarrollan morfologias subhedrales con longitudes máximas de 2 milímetros y presentan una leve alteración a sericita y a minerales del grupo de las arcillas. Los individuos de plagioclasa evidencian deformación plástica, que se observa en la curvatura y ahusamiento del maclado primario (Fig. 3.A.5b). El cuarzo es poco abundante y posee tamaño de grano variable entre medio y grueso y bordes irregulares. Registra deformación evidenciada por su extinción ondulosa, bandas de deformación, y en algunos sectores subgranos, manifestando también procesos de recuperación (Fig. 3.A.5a). Las bandas oscuras están integradas por abundante cantidad de biotita, y en menor proporción, plagioclasa tipo oligoclasa-andesina (determinada por el método de Michel Lévy), feldespato tipo microclino y escaso cuarzo. Las biotitas se observan bien desarrolladas con longitudes máximas de 1 milímetro y en su mayoría orientadas en forma paralela al bandeamiento composicional (Fig. 3.A.5c y d). Presentan inclusiones de circones de 0,02 milimetros y una leve cloritización (Fig. 3.A.5c). Si bien las biotitas son abundantes, en ciertos sectores disminuye su abundancia notablemente provocando una reducción en el espesor de las bandas oscuras, a menos de 0,5 centímetros e inclusive su desaparición. 


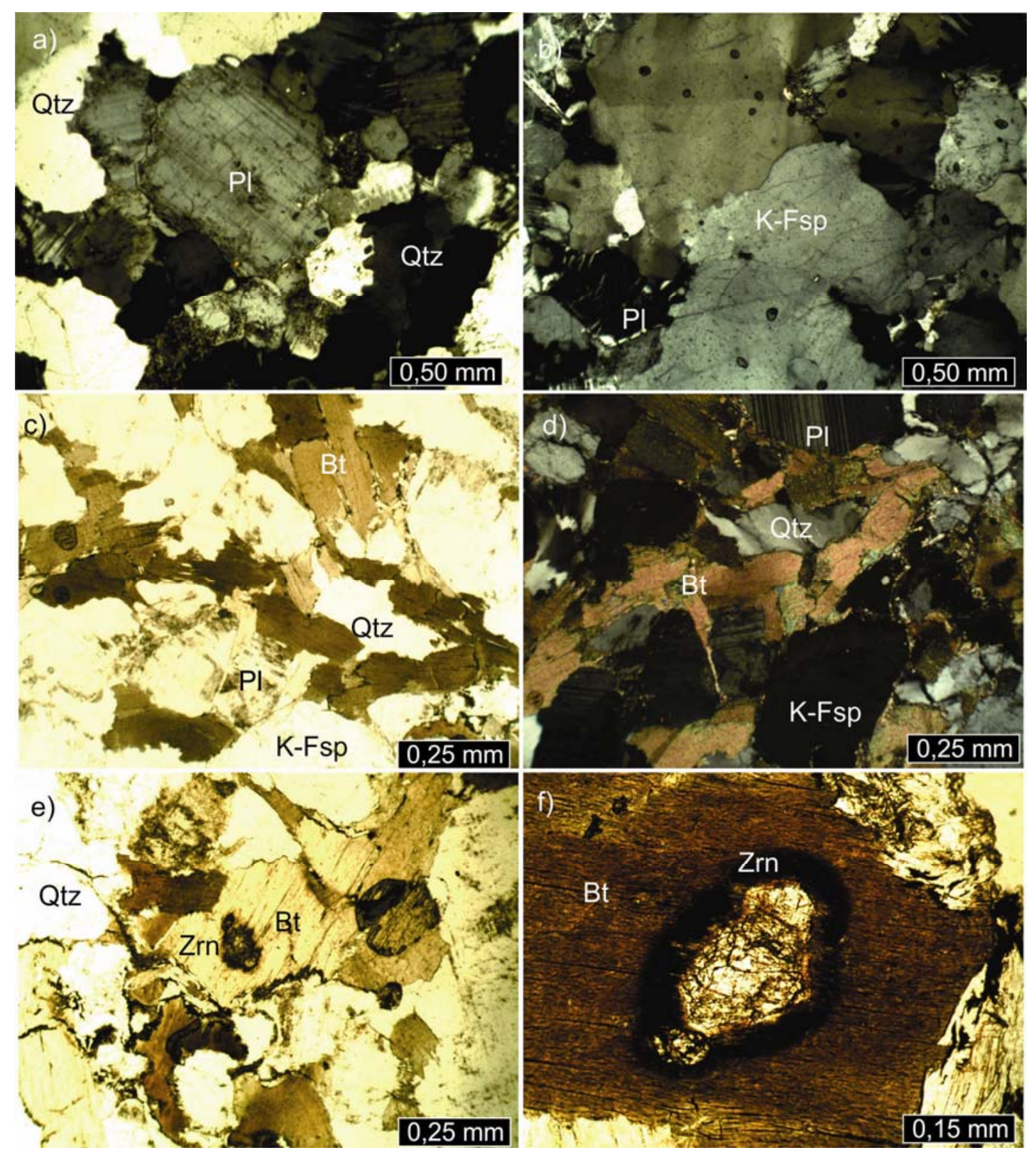

Figura 3.A.5: Aspecto microscópico del gneis biotítico, a y b) corresponden a las bandas claras, ambas con analizador para que puedan apreciarse las características de los minerales y c y d) bandas oscuras sin y con analizador, donde se observa la presencia de cristales de biotita orientados. e y f) detalles de los sectores oscuros donde se observan grandes cristales de circón dentro de cristales de biotita, con desarrollo de halos pleocroícos. Abreviaturas minerales según Siivola y Schmid (2007). 
Si bien las migmatitas presentan estructuras diferentes en afloramiento, al microscopio sus leucosomas muestran similares características, distinguiéndose dos facies principales: leucocráticas y leucocráticogranatíferas. Las facies leucrocráticas presentan tamaño de grano medio a grueso entre 0,1 y 3 milímetros y fábrica isótropa.

$\mathrm{Su}$ mineralogía está constituida principalmente por cuarzo, feldespato potásico tipo microclino y plagioclasas (Fig. 3.A.6a y b). Se han encontrado escasos individuos de biotita en forma intersticial sumamente desferrizados y en algunos casos reemplazados por clorita. El cuarzo presenta bordes de grano irregulares con tamaños que varian entre 0,5 y 3 milimetros, extinción ondulosa y textura tipo "tablero de ajedrez" por el desarrollo de subgranos tabulares o cuadrados (Fig. 3.A.6c). En algunos sectores se han detectado uniones triples a $120^{\circ}$ de cristales de cuarzo (Fig. 3.A.6d). El microclino presenta su típico maclado en enrejado y pertitas en venas. La plagioclasa, tipo oligoclasa, posee extinción ondulosa, maclas deformadas y núcleos alterados a sericita y a minerales del grupo de las arcillas al igual que algunos feldespatos potásicos (Fig. 3.A.6b). Además, la presencia de 'bulging' de gran amplitud entre cristales de plagioclasa indican alta movilidad de los límites de grano (migración de borde de grano) y los contactos lobulados entre cristales de cuarzo y plagioclasa, también indican deformación dúctil de alta $\mathrm{T}^{\circ}$ (Fig. 3.A.6d).

Las facies leucocrático-granatíferas, poseen tamaño de grano medio variable entre 0,2 y 6 milímetros, presentan textura inequigranular y fábrica isótropa. Su mineralogía está constituida por: cuarzo, plagioclasas, microclino, granate y escasa biotita. Los cristales de cuarzo, de tamaño variable entre 0,1 y 2 milimetros, cuentan con desarrollos anhedrales y bordes de grano irregulares (Fig.3.A.7a y b). Además se encuentran deformados mostrando extinción ondulosa, signos de recuperación como bandas de deformación y subgranos y posible migración de borde de grano como evidencia de recristalización dinámica. La plagioclasa (oligoclasa) presenta tamaños máximos de 0,6 milimetros, hábitos poco desarrollados y maclas ahusadas, como evidencia de deformación (Fig. 3.A.7a y b). El 
microclino posee tamaños entre 0,5 y 3 milimetros, desarrolla cristales con morfologías irregulares y se observa con su maclado típico en enrejado, presentando además pertitas e inclusiones de cuarzo (Fig. 3.A.7b). Los cristales de granate tienen una composición obtenida por microsonda electrónica (Cuadro 3.A.1a y b), que varía entre almandino72-70, piropo 14-07 y espesartina $18-12$, con contenidos menores a 3,6\% del resto de los componentes (uvarovita+ andradita+ grosularia).

\begin{tabular}{|c|c|c|c|c|c|c|c|c|}
\hline \multicolumn{9}{|c|}{ Muestra $\mathrm{m} 3$} \\
\hline \multirow[b]{2}{*}{ \%peso } & \multicolumn{4}{|c|}{ Grt1 } & \multicolumn{4}{|c|}{ Grt2 } \\
\hline & P1 & P2 & P3 & P4 & P1 & P2 & P3 & P4 \\
\hline $\mathrm{SiO}_{2}$ & 36,72 & 36,99 & 37,07 & 37,08 & 37,00 & 37,06 & 37,08 & 36,99 \\
\hline $\mathrm{TiO}_{2}$ & 0,00 & 0,00 & 0,03 & 0,02 & 0,00 & 0,02 & 0,06 & 0,04 \\
\hline $\mathrm{Al}_{2} \mathrm{O}_{3}$ & 20,39 & 20,73 & 20,83 & 20,82 & 20,68 & 20,80 & 20,64 & 20,56 \\
\hline $\mathrm{Cr}_{2} \mathrm{O}_{3}$ & 0,00 & 0,00 & 0,03 & 0,04 & 0,01 & 0,00 & 0,00 & 0,00 \\
\hline $\mathrm{Fe}_{2} \mathrm{O}_{3 \mathrm{rec}}$ & 1,37 & 1,33 & 0,81 & 1,05 & 1,26 & 1,28 & 1,20 & 1,29 \\
\hline $\mathrm{FeO}_{\text {rec }}$ & 31,36 & 31,79 & 31,31 & 31,36 & 31,02 & 31,07 & 31,18 & 31,17 \\
\hline MnO & 7,74 & 5,42 & 5,51 & 5,60 & 5,92 & 5,95 & 5,95 & 5,81 \\
\hline MgO & 1,66 & 2,83 & 3,50 & 3,45 & 3,42 & 3,47 & 3,44 & 3,45 \\
\hline $\mathrm{CaO}$ & 1,21 & 1,24 & 0,93 & 0,86 & 0,82 & 0,86 & 0,84 & 0,82 \\
\hline NiO & 0,00 & 0,01 & 0,00 & 0,03 & 0,00 & 0,00 & 0,00 & 0,00 \\
\hline $\mathrm{Na}_{2} \mathrm{O}$ & 0,01 & 0,02 & 0,01 & 0,00 & 0,02 & 0,02 & 0,01 & 0,01 \\
\hline $\mathrm{K}_{2} \mathrm{O}$ & 0,01 & 0,01 & 0,01 & 0,00 & 0,00 & 0,00 & 0,00 & 0,00 \\
\hline Total & 100,47 & 100,37 & 100,04 & 100,51 & 100,15 & 100,43 & 100,40 & 100,14 \\
\hline \multicolumn{9}{|c|}{ Cationes por unidad de fórmula, sobre la base de 12 oxigenos } \\
\hline Si & 2,993 & 2,988 & 2,991 & 2,984 & 2,990 & 2,990 & 2,983 & 2,991 \\
\hline Al & 0,007 & 0,012 & 0,009 & 0,016 & 0,010 & 0,010 & 0,017 & 0,009 \\
\hline $\mathbf{F e}^{+3}$ & 0,000 & 0,000 & 0,000 & 0,000 & 0,000 & 0,000 & 0,000 & 0,000 \\
\hline Suma & 3,000 & 3,000 & 3,000 & 3,000 & 3,000 & 3,000 & 3,000 & 3,000 \\
\hline Al & 1,952 & 1,961 & 1,972 & 1,968 & 1,960 & 1,957 & 1,941 & 1,952 \\
\hline $\mathrm{Cr}$ & 0,000 & 0,000 & 0,000 & 0,000 & 0,000 & 0,000 & 0,000 & 0,000 \\
\hline $\mathbf{T i}$ & 0,000 & 0,000 & 0,000 & 0,000 & 0,000 & 0,000 & 0,000 & 0,000 \\
\hline Mg & 0,202 & 0,353 & 0,420 & 0,414 & 0,411 & 0,418 & 0,413 & 0,416 \\
\hline $\mathrm{Fe}^{+3}$ & 0,084 & 0,080 & 0,049 & 0,063 & 0,076 & 0,077 & 0,103 & 0,078 \\
\hline $\mathrm{Fe}^{+2}$ & 2,138 & 2,147 & 2,112 & 2,111 & 2,096 & 2,085 & 2,097 & 2,107 \\
\hline Mn & 0,541 & 0,370 & 0,376 & 0,388 & 0,405 & 0,409 & 0,405 & 0,398 \\
\hline $\mathbf{C a}$ & 0,106 & 0,107 & 0,080 & 0,074 & 0,071 & 0,073 & 0,072 & 0,071 \\
\hline $\mathbf{N i}$ & 0,000 & 0,001 & 0,000 & 0,002 & 0,000 & 0,000 & 0,000 & 0,000 \\
\hline $\mathbf{N a}$ & 0,001 & 0,002 & 0,002 & 0,000 & 0,003 & 0,003 & 0,001 & 0,001 \\
\hline $\mathbf{K}$ & 0,001 & 0,001 & 0,009 & 0,000 & 0,000 & 0,000 & 0,000 & 0,000 \\
\hline suma & 5,025 & 5,022 & 5,020 & 5,020 & 5,022 & 5,022 & 5,032 & 5,023 \\
\hline Total & 8,025 & 8,022 & 8,020 & 8,020 & 8,022 & 8,022 & 8,032 & 8,023 \\
\hline & & & Porcent & ajes mole & culares & & & \\
\hline almandino & 71 , & 72,0 & 70,6 & 70,6 & 70,230 & 69,800 & 70,186 & 70,407 \\
\hline piropo & & $11, \varepsilon$ & $14, \mathrm{C}$ & $13,8^{\prime}$ & 13,802 & 14,016 & 13,826 & 13,906 \\
\hline espesartina & 18 , & 12,4 & 12,5 & 12,9 & 13,571 & 13,711 & 13,563 & 13,298 \\
\hline Uvt+Adr+Grs & & 62 & 2,6 & 2,4 & 2,397 & 2,473 & 2,423 & 2,389 \\
\hline Suma & 100 & $00 \quad 100$ & 100 , & $00 \quad 100$, & 100,00 & 100,00 & 100,00 & 100,00 \\
\hline
\end{tabular}


Cuadro 3.A.1a: Valores representativos de análisis químicos por microsonda electrónica de distintos cristales de granate de los leucosomas. El contenido de $\mathrm{Fe}$ en granate $\left(\mathrm{Fe}^{2+} \mathrm{y} \mathrm{Fe}^{3+}\right)$ fue recalculado según Droop (1987). Los contenidos de $\mathrm{P}_{2} \mathrm{O}_{5}$ se encuentran por debajo del límite de detección por lo que no se incluyen en el cuadro. Abreviaturas minerales según Siivola y Schmid (2007).

\begin{tabular}{|c|c|c|c|c|c|c|c|c|}
\hline \multicolumn{9}{|c|}{ Muestra m4 } \\
\hline \multicolumn{9}{|c|}{ Grt 1} \\
\hline \%peso & P1 & P2 & P3 & P4 & P5 & P6 & P7 & P8 \\
\hline $\mathrm{SiO}_{2}$ & 37,28 & 37,31 & 37,26 & 36,83 & 37,16 & 37,22 & 36,86 & 37,22 \\
\hline $\mathrm{TiO}_{2}$ & 0,02 & 0,00 & 0,03 & 0,04 & 0,00 & 0,00 & 0,03 & 0,02 \\
\hline $\mathbf{A l}_{2} \mathbf{O}_{3}$ & 20,79 & 20,79 & 20,80 & 20,77 & 20,50 & 20,73 & 20,67 & 20,83 \\
\hline $\mathrm{Cr}_{2} \mathrm{O}_{3}$ & 0,00 & 0,00 & 0,00 & 0,00 & 0,00 & 0,00 & 0,03 & 0,00 \\
\hline $\mathrm{Fe}_{2} \mathrm{O}_{3 \text { rec }}$ & 1,34 & 2,05 & 1,29 & 1,82 & 1,27 & 1,26 & 2,16 & 0,84 \\
\hline $\mathrm{FeO}_{\text {rec }}$ & 31,74 & 31,10 & 31,07 & 30,72 & 31,15 & 31,11 & 30,71 & 31,24 \\
\hline MnO & 5,45 & 5,94 & 6,03 & 6,16 & 5,98 & 5,98 & 6,05 & 5,88 \\
\hline MgO & 3,26 & 3,51 & 3,50 & 3,34 & 3,47 & 3,47 & 3,44 & 3,42 \\
\hline $\mathrm{CaO}$ & 1,12 & 0,87 & 0,86 & 0,83 & 0,76 & 0,85 & 0,80 & 0,85 \\
\hline $\mathrm{NiO}$ & 0,06 & 0,00 & 0,00 & 0,05 & 0,00 & 0,00 & 0,00 & 0,00 \\
\hline $\mathrm{Na}_{2} \mathrm{O}$ & 0,02 & 0,03 & 0,02 & 0,03 & 0,02 & 0,02 & 0,04 & 0,03 \\
\hline $\mathbf{K}_{2} \mathbf{O}$ & 0,00 & 0,00 & 0,00 & 0,00 & 0,00 & 0,00 & 0,00 & 0,01 \\
\hline Total & 100,90 & 101,40 & 100,80 & 100,40 & 100,20 & 100,50 & 100,50 & 100,30 \\
\hline \multicolumn{9}{|c|}{ Cationes por unidad de fórmula, sobre la base de 12 oxígenos } \\
\hline Si & 2,99 & 2,98 & 2,99 & 2,97 & 3,00 & 2,99 & 2,97 & 3,00 \\
\hline Al & 0,01 & 0,02 & 0,01 & 0,03 & 0,00 & 0,01 & 0,03 & 0,00 \\
\hline $\mathrm{Fe}^{+3}$ & 0,00 & 0,00 & 0,00 & 0,00 & 0,00 & 0,00 & 0,00 & 0,00 \\
\hline Suma & 3,00 & 3,00 & 3,00 & 3,00 & 3,00 & 3,00 & 3,00 & 3,00 \\
\hline Al & 1,96 & 1,94 & 1,96 & 1,95 & 1,95 & 1,96 & 1,94 & 1,97 \\
\hline $\mathbf{C r}$ & 0,00 & 0,00 & 0,00 & 0,00 & 0,00 & 0,00 & 0,00 & 0,00 \\
\hline $\mathbf{T i}$ & 0,00 & 0,00 & 0,00 & 0,00 & 0,00 & 0,00 & 0,00 & 0,00 \\
\hline Mg & 0,39 & 0,42 & 0,42 & 0,40 & 0,42 & 0,42 & 0,41 & 0,41 \\
\hline $\mathrm{Fe}^{+3}$ & 0,08 & 0,12 & 0,08 & 0,11 & 0,08 & 0,08 & 0,13 & 0,05 \\
\hline $\mathrm{Fe}^{+2}$ & 2,13 & 2,08 & 2,09 & 2,07 & 2,10 & 2,09 & 2,07 & 2,10 \\
\hline Mn & 0,37 & 0,40 & 0,41 & 0,42 & 0,41 & 0,41 & 0,41 & 0,40 \\
\hline $\mathbf{C a}$ & 0,10 & 0,07 & 0,07 & 0,07 & 0,07 & 0,07 & 0,07 & 0,07 \\
\hline $\mathbf{N i}$ & 0,00 & 0,00 & 0,00 & 0,00 & 0,00 & 0,00 & 0,00 & 0,00 \\
\hline $\mathbf{N a}$ & 0,00 & 0,01 & 0,00 & 0,00 & 0,00 & 0,00 & 0,01 & 0,00 \\
\hline $\mathbf{K}$ & 0,00 & 0,00 & 0,00 & 0,00 & 0,00 & 0,00 & 0,00 & 0,00 \\
\hline Suma & 5,03 & 5,04 & 5,03 & 5,04 & 5,03 & 5,03 & 5,04 & 5,02 \\
\hline Total & 8,03 & 8,04 & 8,03 & 8,04 & 8,03 & 8,03 & 8,04 & 8,02 \\
\hline \multicolumn{9}{|c|}{ Porcentajes moleculares } \\
\hline almandino & 71,30 & 69,90 & 69,80 & 69,90 & 70,20 & 70,00 & 69,80 & 70,40 \\
\hline piropo & 13,00 & 14,10 & 14,00 & 13,60 & 13,90 & 13,90 & 13,90 & 13,70 \\
\hline espesar & 12,40 & 13,50 & 13,70 & 14,20 & 13,70 & 13,60 & 13,90 & 13,40 \\
\hline Uvt+Adr+Grs & 3,20 & 2,50 & 2,50 & 2,40 & 2,20 & 2,50 & 2,30 & 2,50 \\
\hline Suma & 100,0 & 100,00 & 100,00 & 100,00 & 100,00 & 100,00 & 100,00 & 100,00 \\
\hline
\end{tabular}


Cuadro 3.A.1b: Valores representativos de análisis químicos por microsonda electrónica de distintos cristales de granate de los leucosomas. El contenido de $\mathrm{Fe}$ en granate $\left(\mathrm{Fe}^{2+}\right.$ y $\left.\mathrm{Fe}^{3+}\right)$ fue recalculado según Droop (1987). Los contenidos de $\mathrm{P}_{2} \mathrm{O}_{5}$ se encuentran por debajo del límite de detección por lo que no se incluyen en el cuadro. Abreviaturas minerales según Siivola y Schmid (2007).

Se observan fracturados y con reemplazos de biotitas de tamaño muy pequeño que desarrollan coronas de retrogradación. Los cristales de biotita son muy escasos y se observan en forma intersticial o como reemplazo del granate con un avanzado estado de desferrización (Fig. 3.A.7 a y d).

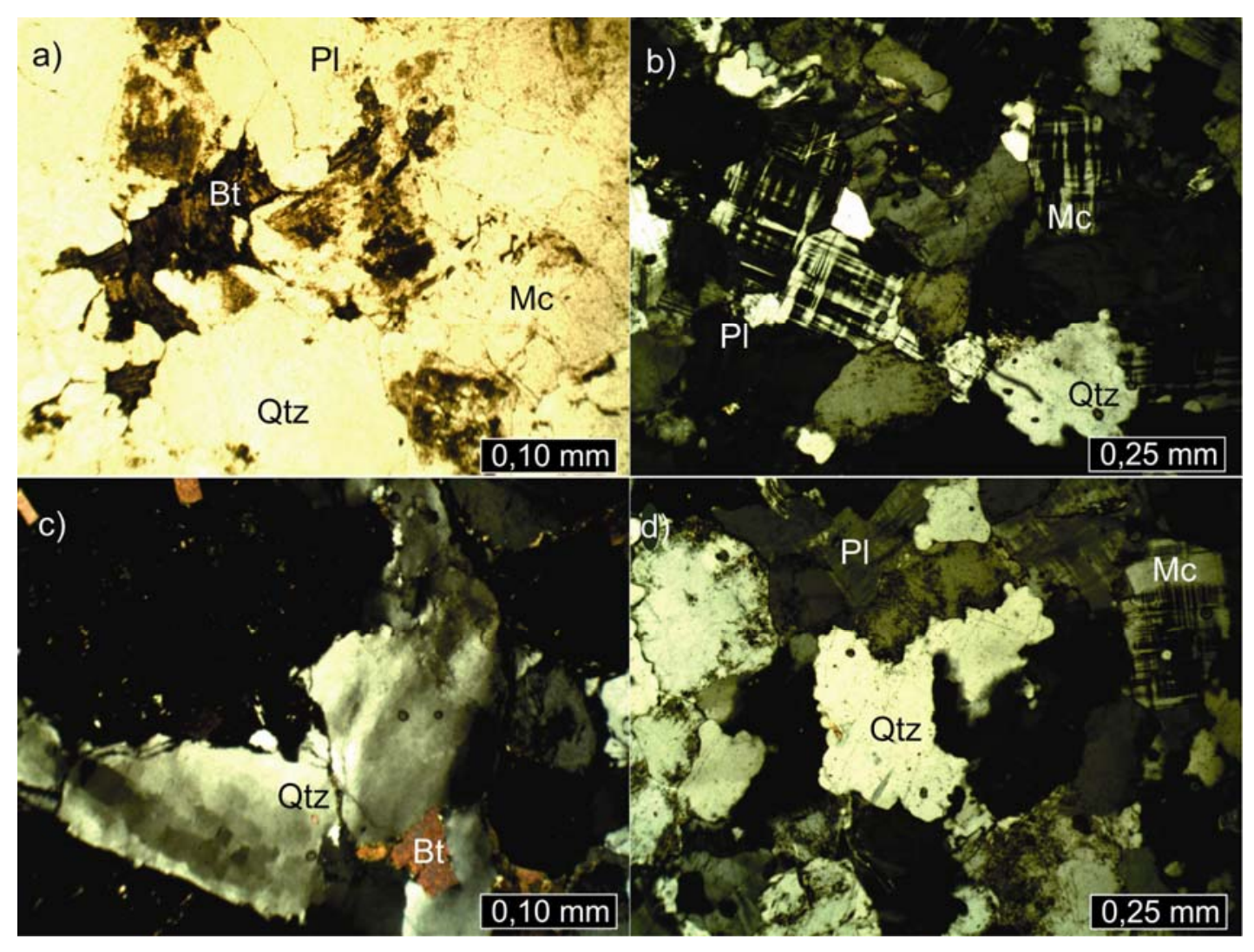

Figura 3.A.6: Aspecto miscroscópico de los leucosomas. a) Mineralogía sin analizador, se observa biotita intersticial. b) Mineralogía con analizador, donde se observa maclado en enrejado en microclino y polisintético en plagioclasas. c) Extinción ondulosa en cristales de cuarzo. d) Con analizador, cuarzo con bordes irregulares, con migración de borde de grano, rodeado de microclino y plagioclasas levemente alteradas. Abreviaturas minerales según Siivola y Schmid (2007). 


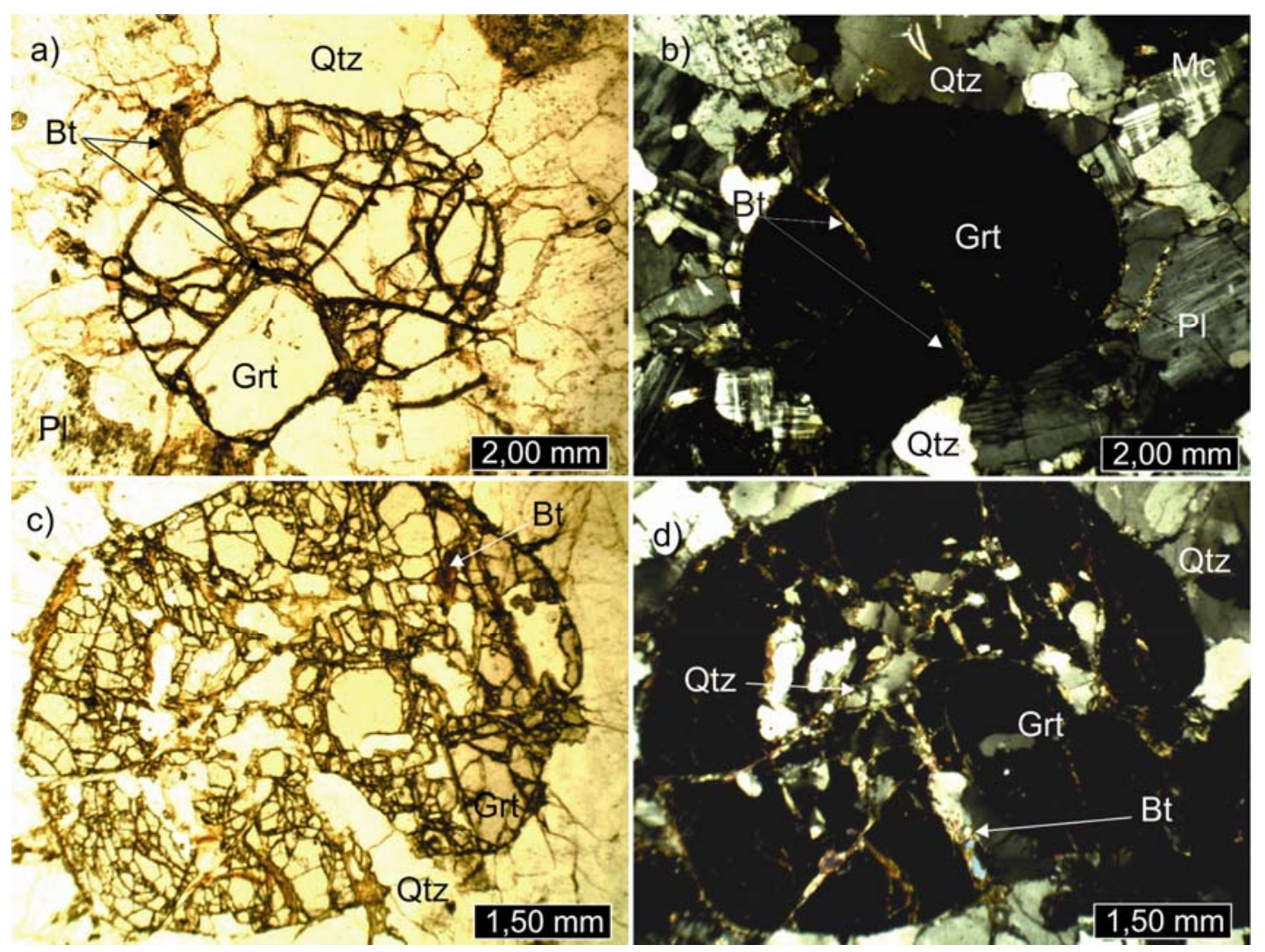

Figura 3.A.7: Leucosomas granatiferos. a y b) porfiroblastos de granate, fracturados y con reemplazo de biotita en los bordes. c y d) poiquiloblastos de granate con inclusiones de cuarzo, presentando el mismo reemplazo por biotita que los porfiroblastos. Abreviaturas minerales según Siivola y Schmid (2007).

\section{A.1.2.1 Petrografia de los xenolitos}

Se han identificado fragmentos de roca de distintos tamaños que varian entre 15 y 30 centímetros, incluidos dentro del gneis biotítico y de algunos leucosomas. Estos fragmentos o xenolitos poseen formas variadas y corresponden a una roca de tonalidad oscura a verdosa, con fábrica anisótropa (en la mayoría de los casos), textura levemente porfirica y con una mineralogía muy contrastante con respecto a la de las rocas hospedantes que poseen abundante cuarzo.

En las Figs. 3.A.8a y b se observa el contacto entre un xenolito y la roca de caja, sin y con analizador, en el que se manifiesta el contraste entre la mineralogía, textura y tamaño de grano de ambas rocas. La mineralogía 
del xenolito consiste en anfiboles, biotita, cuarzo, plagioclasas y como accesorios titanita, apatita y minerales opacos (Fig. 3.A.8c y d).
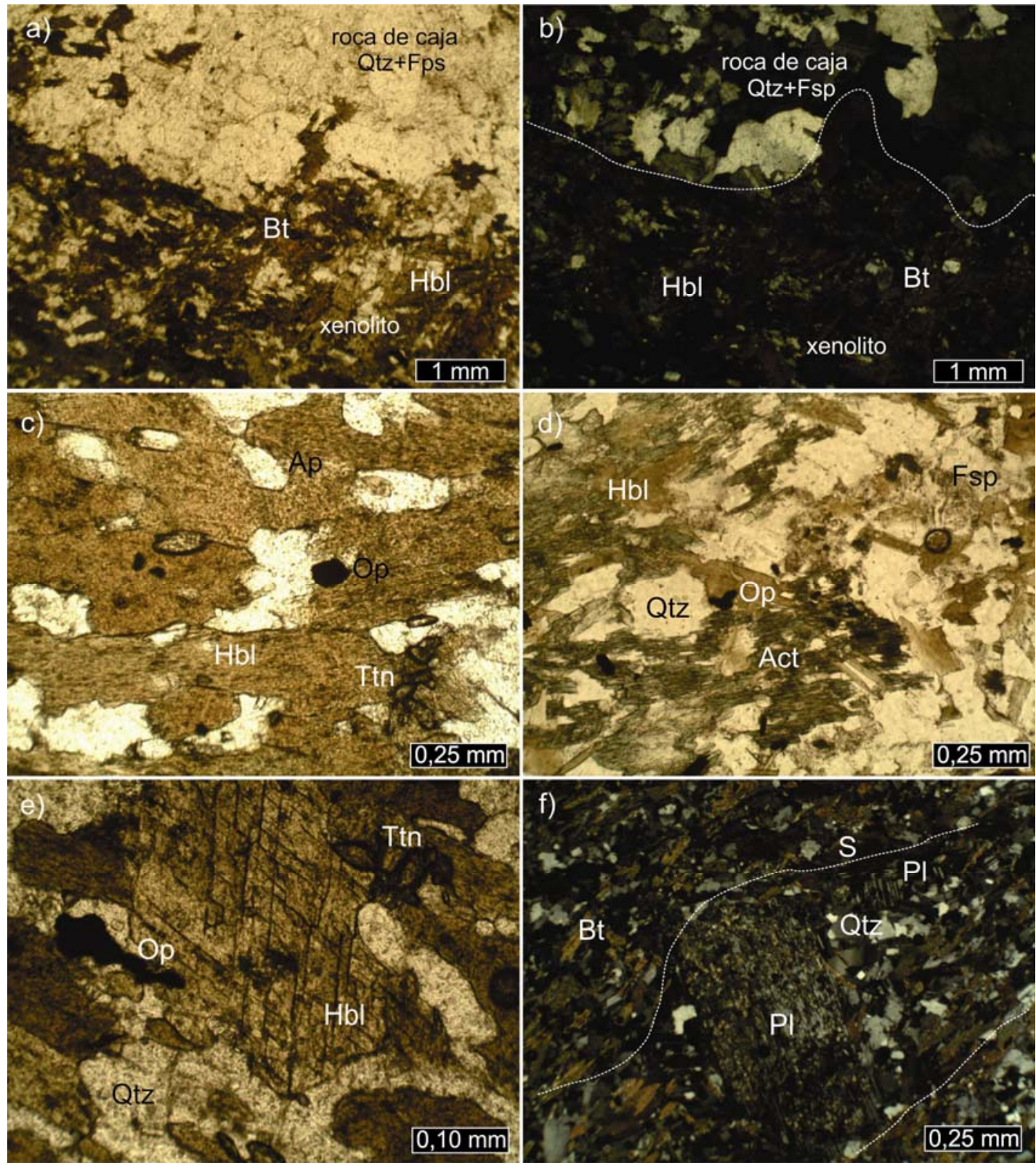

Figura 3.A.8: Aspecto microscópico de los xenolitos. a y b) Contacto entre el xenolito (margen inferior de la foto) y la roca de caja (margen superior de la foto), sin analizador y con analizador respectivamente. c) Mineralogía de la roca en el centro de los xenolitos sin analizador; predominantemente constituida por cristales de hornblenda cuyos prismas se encuentran orientados. d) Mineralogia de los bordes 
de los xenolitos sin analizador; se observan los reemplazos de hornblenda por actinolita y biotita y el aumento en la abundancia de minerales como cuarzo y feldespato. e) Sección basal de un cristal de horblenda rodeado de cuarzo y minerales opacos, el mismo se encuentra entre secciones prismáticas orientadas. f) Porfiroblasto de plagioclasa ubicado en los bordes del xenolito, con inclusiones y reemplazos por minerales hidratados y rodeado por una matriz deformada (S) con mayor proporción de biotita, cuarzo y plagioclasa. Abreviaturas minerales según Siivola y Schmid (2007).

Se observan dos tipos de anfiboles, por un lado cristales de hornblenda con desarrollo euhedral, hábito prismático y pleocroísmo de castaño oscuro a castaño claro amarillento y por otro, posible actinolita con hábito fibroso y pleocroísmo en tonos verdosos (Fig. 3.A.8d). Ambos minerales presentan una orientación preferencial que es responsable de la fábrica anisótropa, tipo lineación mineral. Esto justifica la abundancia de secciones basales típicas de anfibol con clivaje en dos direcciones formando ángulos oblicuos (Fig. 3.A.8e), identificadas en diversos sectores de los cortes. Además los cristales de hornblenda presentan reemplazos pseudomórficos por biotita, predominantemente en los sectores periféricos del xenolito, donde además se observa la mayor abundancia de actinolita (Fig. 3.A.8d). Los cristales de cuarzo que se disponen entre los prismas de anfiboles poseen extinción ondulosa y bordes irregulares (Fig. 3.A.8f). Los cristales de plagioclasa son escasos pero presentan tamaños en dos modas principalmente, una de tamaño pequeño (0,1 milimetros), anhedrales con su típico maclado polisintético, mejor representada en la matriz, y otra con tamaño de grano de 0,5 milímetros que está representada por porfiroblastos con hábitos subhedrales a euhedrales, también con maclado polisintético (Fig. 3.A.8f). Estos últimos minerales son más abundantes también hacia los bordes de los xenolitos donde la roca comienza a perder su fábrica anisótropa, quizá por interacción con la roca de caja (Fig. 3.A.8f). 


\section{A.1.3 Geoquímica}

Con el fin de caracterizar geoquímicamente las rocas metamórficas del área y de definir su origen se realizaron análisis de elementos mayoritarios, traza y REE de dos muestras del gneis biotítico ( $\mathrm{gn}_{1}$ y $\left.\mathrm{gn}_{2}\right)$ y de cuatro muestras de las migmatitas, dos correspondientes a las facies leucocráticas $\left(\begin{array}{llllll}\mathrm{m}_{1} & \mathrm{y} & \mathrm{m}_{2}\end{array}\right)$ y dos a las facies leucocrático-granatíferas $\left(\begin{array}{llll}\mathrm{m}_{3} & \mathrm{y} & \mathrm{m}_{4}\end{array}\right)$. Los resultados de los análisis químicos se muestran en el Cuadro 3.A.2.

La clasificación general se realizó mediante el diagrama de Middlemost (1994), en el mismo se observa que las muestras grafican en los campos de granodiorita y granitos (Fig.3.A.9a). Cabe destacar que los gneises ( $\mathrm{gn}_{1}$ y gn gn presentan una composición química que los ubica entre el campo de los granitos $\left(\mathrm{gn}_{1}\right)$ y de las granodioritas ( $\left(\mathrm{gn}_{2}\right)$, y los leucosomas son en general graníticos $\left(\mathrm{m}_{1}, \mathrm{~m}_{3} \mathrm{y} \mathrm{m}_{4}\right)$, con excepción de $\mathrm{m}_{2}$ que también es granodiorítico. La clasificación normativa (CIPW, Cuadro 3.A.3), mediante la utilización del diagrama de Barker (1979), indica que las muestras corresponden mayoritariamente a monzonitas cuarzosas, a excepción de la muestra $\mathrm{m}_{2}$ que se asigna a granodiorita (Fig.3.A.9b). Si bien los resultados son similares a los obtenidos mediante la clasificación de acuerdo a los óxidos mayoritarios, las relaciones $\mathrm{Ab} / \mathrm{An}$ indican que los leucosomas contienen más anortita normativa.

Mayor información se obtuvo de los contenidos en elementos traza y $\mathrm{REE}$, para su tratamiento los primeros fueron normalizados a la composición de la corteza superior (Taylor y MacLennan 1981) y los últimos se normalizaron a condrito según Sun y McDonought (1989). Además, se incorporó una muestra correspondiente al NASC que es la composición de las Lutitas Compuestas de Norteamérica, según Gromet et al. (1984). Con esta última se espera definir la composición del protolito de las rocas metamórficas de la región. 


\begin{tabular}{|c|c|c|c|c|c|c|c|}
\hline Muestra & $g n 1$ & gn2 & $m 1$ & $m 2$ & $\mathrm{m3}$ & $m 4$ & NASC \\
\hline $\mathrm{SiO}_{2}$ & 71,0 & 70,3 & 73,0 & 70,1 & 71,6 & 75,7 & \\
\hline $\mathrm{TiO}_{2}$ & 0,3 & 0,2 & 0,3 & 0,0 & 0,1 & 0,0 & \\
\hline $\mathbf{A l}_{2} \mathrm{O}_{3}$ & 15,1 & 15,6 & 15,3 & 17,1 & 15,3 & 13,5 & \\
\hline $\mathrm{Cr}_{2} \mathrm{O}_{3}$ & 0,0 & 0,0 & 0,0 & 0,0 & 0,0 & 0,0 & \\
\hline $\mathrm{Fe}_{2} \mathrm{O}_{3 \text { total }}$ & 3,3 & 2,9 & 2,5 & 1,1 & 2,4 & 1,0 & \\
\hline MgO & 1,0 & 0,6 & 0,7 & 0,2 & 0,1 & 0,1 & \\
\hline MnO & 0,0 & 0,0 & 0,0 & 0,0 & 0,0 & 0,0 & \\
\hline $\mathrm{CaO}$ & 2,8 & 2,8 & 3,2 & 5,3 & 2,1 & 2,2 & \\
\hline $\mathrm{Na}_{2} \mathrm{O}$ & 3,7 & 4,3 & 4,0 & 4,5 & 4,6 & 3,5 & \\
\hline $\mathbf{K}_{2} \mathbf{O}$ & 2,7 & 2,1 & 1,3 & 0,8 & 2,9 & 2,9 & \\
\hline $\mathbf{P}_{2} \mathrm{O}_{5}$ & 0,1 & 0,1 & 0,0 & 0,2 & 0,0 & 0,0 & \\
\hline LOI $* 1000$ & 0,4 & 0,5 & 0,6 & 1,2 & 0,4 & 0,7 & \\
\hline Total & 100,4 & 99,5 & 100,9 & 100,5 & 99,5 & 99,6 & \\
\hline $\mathbf{B a}$ & 1030,0 & 294,0 & 627,0 & 214,0 & 3,0 & 860,0 & \\
\hline $\mathbf{C r}$ & 220,0 & 190,0 & 150,0 & 210,0 & 1,0 & 130,0 & \\
\hline Cs & 2,6 & 1,9 & 1,8 & 1,3 & 672,0 & 0,8 & \\
\hline $\mathbf{G a}$ & 18,4 & 18,6 & 17,6 & 20,7 & 0,8 & 14,8 & \\
\hline Hf & 3,8 & 4,8 & 3,7 & 1,0 & 0,9 & 4,6 & \\
\hline $\mathbf{N b}$ & 4,3 & 3,9 & 4,3 & 0,6 & 0,2 & 0,2 & \\
\hline $\mathbf{R} \mathbf{b}$ & 72,0 & 67,1 & 44,9 & 26,6 & 0,6 & 60,9 & \\
\hline Sn & 1,0 & 1,0 & 1,0 & 1,0 & 3,3 & 1,0 & \\
\hline $\mathbf{S r}$ & 405,0 & 470,0 & 828,0 & 545,0 & 57,6 & 332,0 & \\
\hline $\mathbf{T a}$ & 0,3 & 0,3 & 0,2 & 0,1 & 1,8 & 0,1 & \\
\hline Th & 15,8 & 44,6 & 1,5 & 1,5 & 481,0 & 1,5 & \\
\hline $\mathbf{U}$ & 1,1 & 1,9 & 0,5 & 0,4 & 0,1 & 1,0 & \\
\hline $\mathbf{V}$ & 24,0 & 27,0 & 40,0 & 6,0 & 2,7 & 6,0 & \\
\hline $\mathbf{W}$ & 12,0 & 12,0 & 10,0 & 14,0 & 0,1 & 9,0 & \\
\hline $\mathbf{Y}$ & 7,1 & 12,0 & 4,1 & 3,4 & 0,9 & 13,3 & \\
\hline $\mathbf{Z} \mathbf{r}$ & 140,0 & 170,0 & 130,0 & 42,0 & 8,0 & 154,0 & \\
\hline La & 53,0 & 124,0 & 30,2 & 14,8 & 1,1 & 9,7 & 38,0 \\
\hline $\mathrm{Ce}$ & 105,0 & 249,0 & 51,8 & 23,9 & 3,0 & 16,7 & 80,0 \\
\hline $\mathbf{P r}$ & 10,9 & 26,2 & 5,1 & 2,5 & 0,1 & 1,7 & 1,0 \\
\hline Nd & 39,2 & 92,8 & 16,9 & 9,0 & 17,9 & 5,3 & 34,0 \\
\hline Sm & 6,5 & 13,6 & 2,1 & 1,4 & 11,4 & 0,9 & 6,0 \\
\hline Eu & 1,2 & 1,4 & 1,5 & 0,9 & 1,7 & 1,2 & 1,0 \\
\hline Gd & 4,0 & 7,0 & 0,9 & 0,9 & 0,5 & 1,5 & 5,00 \\
\hline $\mathbf{T b}$ & 0,4 & 0,7 & 0,2 & 0,1 & 1,0 & 0,3 & 0,70 \\
\hline Dy & 1,6 & 3,0 & 0,8 & 0,6 & 33,8 & 1,9 & 5,00 \\
\hline Ho & 0,3 & 0,5 & 0,2 & 0,1 & 16,1 & 0,5 & 0,90 \\
\hline Er & 0,6 & 1,1 & 0,4 & 0,2 & 120,0 & 1,9 & 3,00 \\
\hline Tm & 0,1 & 0,2 & 0,1 & 0,0 & 0,1 & 0,3 & 0,40 \\
\hline $\mathbf{Y b}$ & 0,4 & 0,9 & 0,4 & 0,2 & 12,0 & 3,0 & 3,00 \\
\hline Lu & 0,0 & 0,1 & 0,1 & 0,0 & 2,4 & 0,5 & 0,40 \\
\hline Eu* & 32,11 & 63,56 & 9,06 & 6,69 & 8,96 & 6,81 & 30,45 \\
\hline Eu/Eu & 0,67 & 0,40 & 2,98 & 2,49 & 1,74 & 3,10 & 0,63 \\
\hline $\mathbf{L a / Y b}$ & 100,01 & 95,72 & 55,45 & 55,85 & 22,94 & 6,88 & 9,20 \\
\hline
\end{tabular}

Cuadro 3.A.2: Resultados de análisis geoquímicos de muestras del gneis biotítico (gn1 y gn2), leucosomas (m1 y m2) y leucosomas granatíferos (m3 y m4). Los óxidos mayoritarios están expresados en \% en peso, los elementos traza y tierras raras en ppm. NASC, composición de las Lutitas Compuestas de Norteamérica (Gromet et al. 1984). El número de decimales está determinado por la exactitud de medición del elemento. 


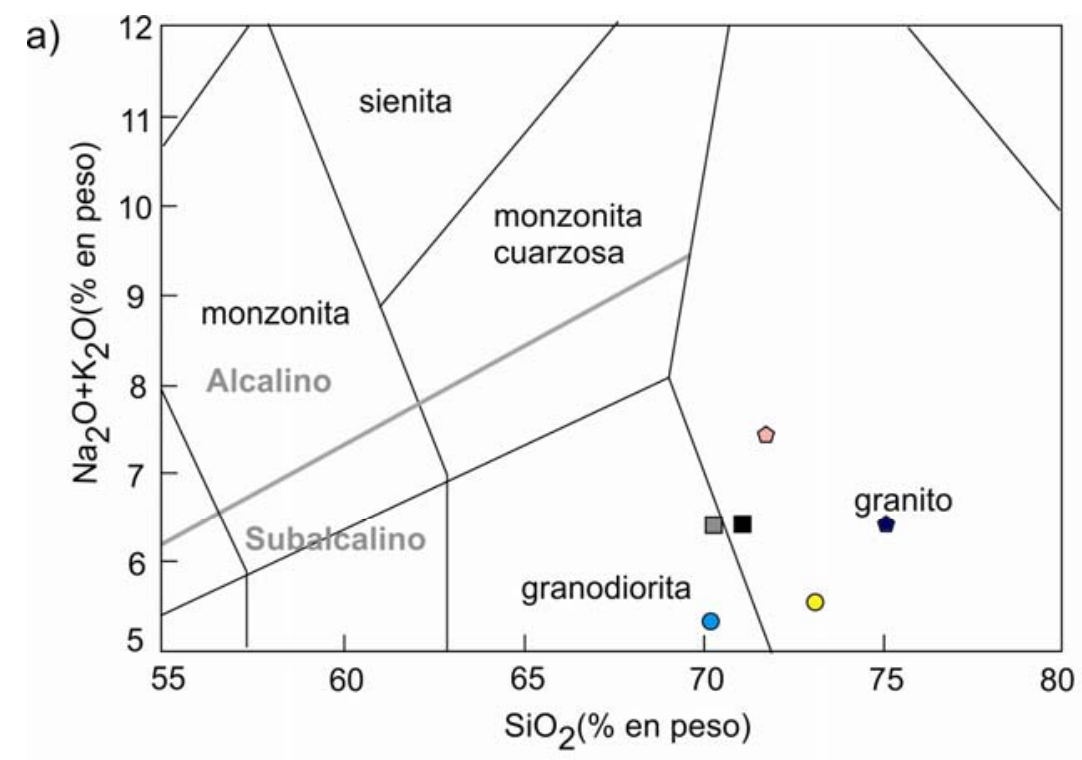

b)

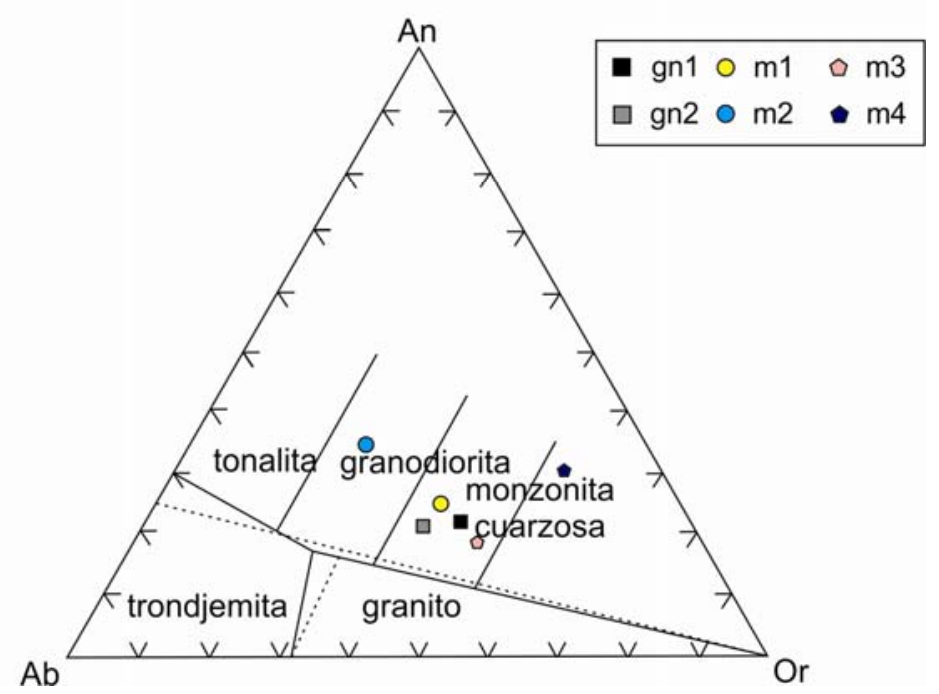

Figura 3.A.9: a) Diagrama de clasificación de Middlemost (1994) para rocas ácidas. b) Diagrama de clasificación normativa, Barker (1979).

El análisis de los contenidos de elementos traza del gneis que se observan en el diagrama multielemento (Fig. 3.A.10), muestra para los LILEs contenidos de $\mathrm{Rb}$ de 67,1 a 72 ppm, Sr de 405 a 470 ppm y Ba entre 294 y $1030 \mathrm{ppm}$, de este último se destaca su gran variabilidad entre ambas 
muestras del gneis. Por otro lado los HFSE presentan valores de $\mathrm{Zr}$ poco variables (140-170 ppm), Th elevado y variable (15,8-44,6 ppm), Nb bajo (3,9-4,3 ppm) y Ce variable (105-249 ppm).

\begin{tabular}{|lrrrrrr|}
\hline minerales & gn $\mathbf{1}$ & \multicolumn{1}{c}{$\mathbf{g n 2}$} & $\mathbf{m} \mathbf{1}$ & \multicolumn{1}{c}{$\mathbf{m} \mathbf{2}$} & \multicolumn{1}{c}{$\mathbf{3}$} & \multicolumn{1}{c}{$\mathbf{4}$} \\
cuarzo & 29,99 & 29,39 & 28,24 & 29,68 & 35,98 & 34,45 \\
plagioclasa & 45,2 & 50,88 & 49,98 & 62,77 & 43,31 & 50,52 \\
ortosa & 16,25 & 12,35 & 17,26 & 4,85 & 18,08 & 8,63 \\
corindón & 0,98 & 1,28 & 0,74 & 0 & 0,7 & 1,05 \\
diópsido & 0,00 & 0,00 & 0,00 & 0,73 & 0,00 & 0,00 \\
hipersteno & 5,93 & 4,71 & 2,92 & 1,28 & 1,56 & 4,2 \\
ilmenita & 0,49 & 0,4 & 0,09 & 0,04 & 0,04 & 0,47 \\
magnetita & 0,96 & 0,87 & 0,7 & 0,3 & 0,32 & 0,71 \\
apatita & 0,23 & 0,14 & 0,12 & 0,37 & 0,05 & 0,02 \\
circón & 0,03 & 0,03 & 0,01 & 0,01 & 0,03 & 0,03 \\
cromita & 0,04 & 0,04 & 0,03 & 0,04 & 0,03 & 0,03 \\
enstatita & 2,88 & 1,89 & 0,25 & 0,42 & 0,31 & 2,03 \\
forsterita & 3,04 & 2,82 & 2,66 & 0,86 & 1,25 & 2,17 \\
anortita & 13,06 & 13,22 & 13,47 & 23,78 & 11,39 & 15,86 \\
albita & 32,13 & 37,65 & 13,79 & 38,98 & 31,91 & 34,65 \\
\%An & 21,25 & 20,91 & 30,25 & 35,17 & 18,55 & 26,81 \\
\%Ab & 33,75 & 39,23 & 16,03 & 40,46 & 33,54 & 36,34 \\
\%Or & 26,46 & 19,53 & 38,77 & 7,17 & 29,45 & 14,59 \\
\%Q & 32,79 & 31,71 & 29,57 & 30,50 & 36,95 & 36,80 \\
\%P & 49,43 & 54,93 & 52,34 & 64,51 & 44,48 & 53,97 \\
\%Or & 17,77 & 13,33 & 18,07 & 4,98 & 18,56 & 9,22 \\
\hline
\end{tabular}

Cuadro 3.A.3: Minerales normativos, norma CIPW. Además se incorporaron los resultados de los índices utilizados en los diagramas ternarios An-Ab-Or y Q-P-Or (Barker 1979).

El contenido de REE de estas mismas muestras presenta diseños con pendientes negativas que indican un enriquecimiento en LREE respecto a las HREE $\left(\mathrm{La}_{\mathrm{N}} / \mathrm{Yb}_{\mathrm{N}}\right.$ entre 95,7 y 100,1) y una anomalía negativa en Eu (Eu/Eu* entre 0,40 y 0,67). Si comparamos el diseño del patrón de las pelitas del NASC con el de las muestras de gneis, vemos que son similares aunque las segundas presentan mayor enriquecimiento en LREE y un empobrecimiento en HREE (Fig.3.A.11). 


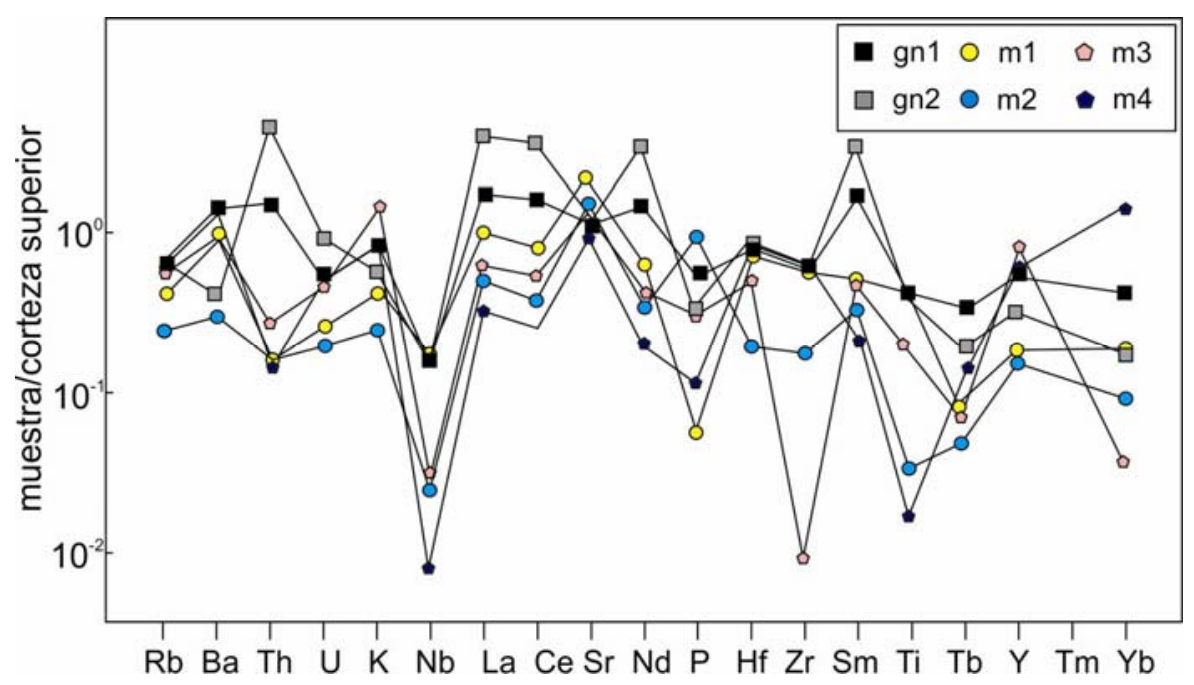

Figura 3.A.10: Diagrama multielemento de trazas, normalizado a condrito (Sun y McDonought 1989).

En estos mismos diagramas se graficaron los contenidos de trazas (Fig.3.A.10) y REE (Fig. 3.A.11) de los leucosomas de las migmatitas. En cuanto a los elementos traza se observan valores en Th bajos entre 1,50 y 2,71 ppm y valores de $\mathrm{Zr}$ variables entre 42 y $154 \mathrm{ppm}$. Como se observa en la Fig. 3.A.11, el diseño de los REE en los leucosomas es similar al de los gneises pero con una fuerte anomalía positiva en $\mathrm{Eu}\left(\mathrm{Eu} / \mathrm{Eu}^{*}\right.$ entre 1,74 y 3,10) y con relaciones $\mathrm{La}_{\mathrm{N}} / \mathrm{Yb}_{\mathrm{N}}$ de 55,44 - 55,85 (leucosomas) y de 22,94 6,88 (leucosomas granatíferos).

Con el fin de completar la caracterización del protolito de las rocas metamórficas se graficaron las muestras en el diagrama de Herron (1988), donde mayoritariamente las mismas se ubican en el campo de wackes menos $\mathrm{m}_{1}$ que queda incluida en los campo de arenisca lítica y $\mathrm{m}_{4}$ en el de las arcosas, (Fig.3.A.12a). Las áreas grises corresponden a la composición de los protolitos de gneises de Balcarce estudiados por Delpino (2000). Como se observa una de ellas coincide con los campos de wackes y areniscas líticas, al igual que los protolitos de los gneises estudiados, mientras que la otra coincide con los campos de pelitas y pelitas ricas en Fe. Finalmente las relaciones normativas Q-Ab-Or de las muestras de los leucosomas, se 
graficaron en un diagrama triangular donde se proyectan los campos de fundidos anatécticos generados experimentalmente (Fig. 3.A.12b). En el mismo, la mayoría de las muestras de los leucosomas quedan comprendidas en el campo A, la $\mathrm{m}_{3}$ en la zona de superposición de los 3 campos y $\mathrm{m}_{2}$ cae fuera de todos los campos.

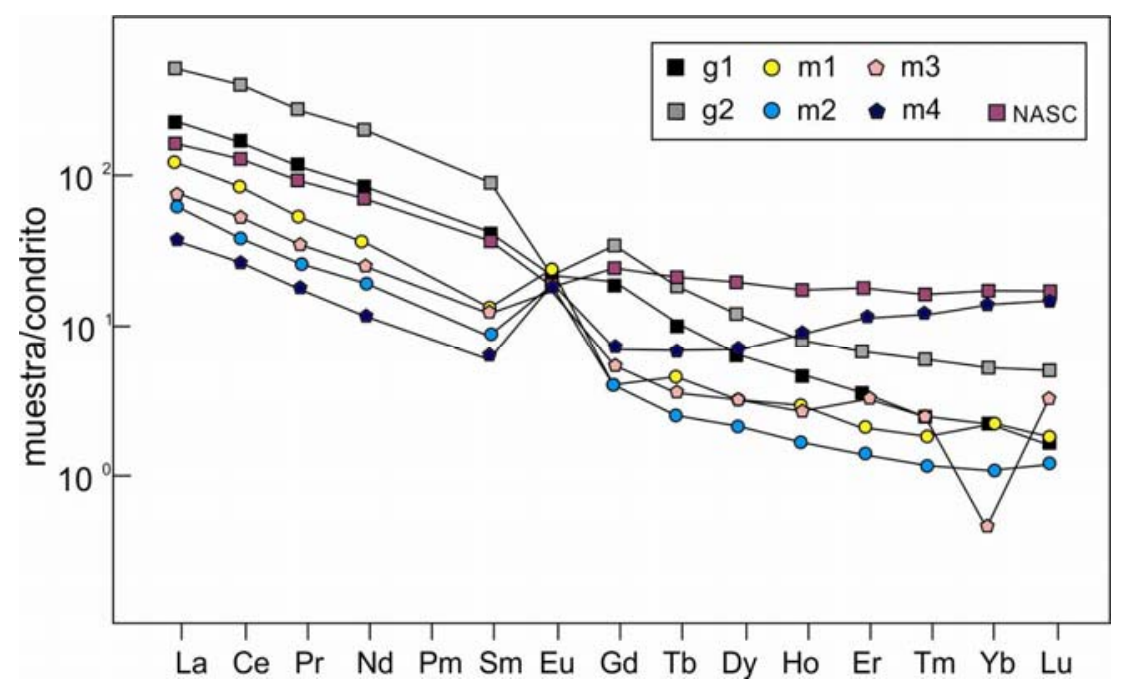

Figura 3.A.11: Diagrama spider de tierras raras, normalizado a condrito (Sun y McDonought 1989). Además se incorporó una muestra del NASC (Lutitas Compuestas de Norteamérica), Gromet et al. (1984).

\section{A.1.4 Discusión de los resultados}

Las rocas metamórficas del basamento que se exponen en el área de San Miguel, corresponden principalmente a gneises biotíticos y migmatitas con diferentes estructuras.

El gneis biotítico presenta una fábrica anisótropa planar tipo bandeado $\left(\mathrm{S}_{1}\right)$ con rumbo general $\mathrm{N} 35^{\circ} \mathrm{E}$ y posee una composición mineralógica integrada por microclino, plagioclasas (oligoclasa-andesina), cuarzo y biotita. Las migmatitas se exhiben como diferenciados dentro del mismo gneis con estructura estromática de igual rumbo que $\mathrm{S}_{1}$ o con estructuras menos frecuentes como movilizados brechoides o boudines. Sus leucosomas están constituidos por cuarzo, plagioclasa (oligoclasa) y 
feldespato potásico tipo microclino. También se presentan leucosomas de límites difusos que además de la mineralogía antes mencionada incluyen granate con una composición $\mathrm{Alm}_{72} \operatorname{Prp}_{13} \mathrm{Sp}_{12} \mathrm{Grs} 3$, similar a la establecida por Delpino (2000) para los segregados granatiferos generados por fusión parcial del gneis descripto en el basamento que aflora en la Sierra de Bachicha, Balcarce $\left(\operatorname{Alm}_{71} \operatorname{Prp}_{7} \operatorname{Sp}_{7} \operatorname{Grs}_{15}\right)$.

a)

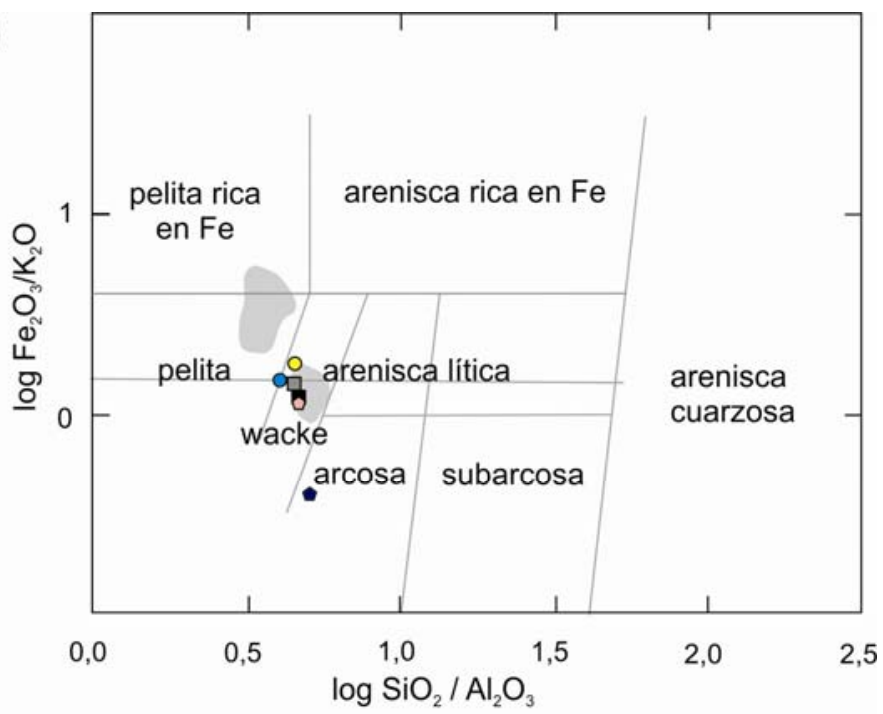

b)

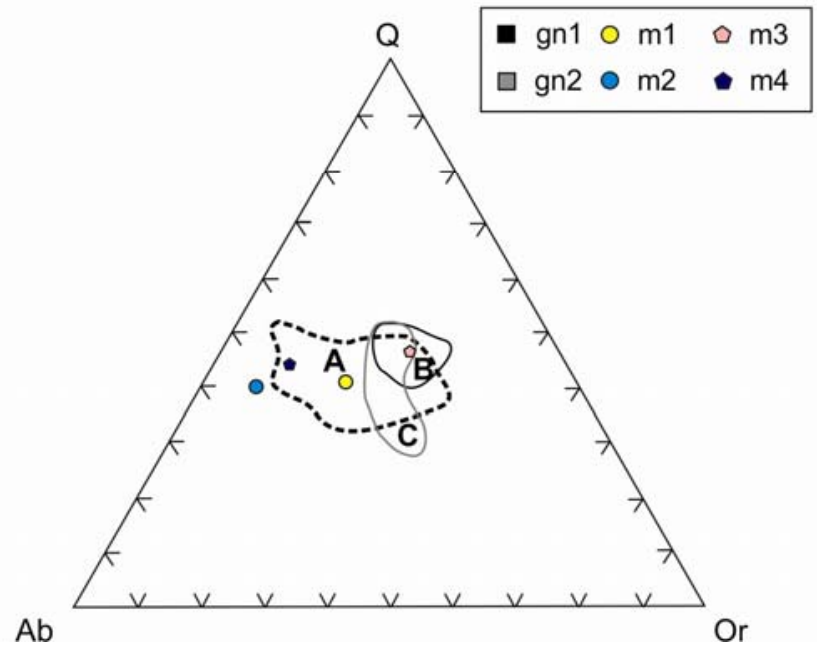

Figura 3.A.12: a) Diagrama de Herron (1988), clasificación de protolitos de rocas metamórficas. b) Diagrama de relaciones normativas Q-Ab-Or. Campo A, Winkler, (1979), Winkler y von Platen (1961); campo B, Holtz y Johannes (1991) y campo C, Montel y Vielzeuf (1997). 
Incluidos en el gneis y en parte de los leucosomas, se han identificado xenolitos de anfibolitas con una asociación mineral hornblenda + plagioclasa \pm titanita \pm apatita \pm opacos con signos de retrogradación, sobre todo en los bordes de los mismos, como reemplazos pseudomórficos de biotita y la cristalización de actinolita. De acuerdo a las características estructurales y mineralógicas, esta roca se trataría de una anfibolita en facies anfibolitas con rasgos de retrogradación a esquistos verdes. Esta retrogradación podría asociarse a la hidratación generada por los fluidos acuosos liberados a partir las rocas metamórficas hospedantes, que actuaron preferentemente sobre los bordes del xenolito, manteniendo la asociación del pico metamórfico en el centro de los mismos. Este tipo de xenolitos máficos y los procesos de biotitización de la hornblenda fueron descriptos por Quartino y Villar Fabre (1967) en xenolitos incluidos en gneises, en un perfil ubicado al SO del Cerro Centinela a unos 30 kilómetros del área de estudio. Dichos fragmentos han sido interpretados como remanentes de la ruptura de cuerpos rígidos de composición máfica en respuesta a la alta tasa de deformación que afectó a toda el área de Tandil.

Los análisis químicos de las rocas antes mencionadas indican que el gneis es de composición granodiorítica a granítica y que los diferenciados leucocráticos son graníticos a monzoníticos cuarzosos. Estos últimos presentan una composición Q-Ab-Or normativa que queda comprendida dentro del campo de los fundidos anatécticos producidos experimentalmente (Winkler 1979), indicando que los mismos podrían haberse formado a partir de la anatexis de gneis biotítico. Sólo una muestra queda fuera de estos campos, la correspondiente a facies leucocráticas $\left(\mathrm{m}_{2}\right)$ que pese a no identificarse tan cercana al skarn reconocido presenta diópsido normativo y además mayor cantidad de plagioclasas que podrían estar manifestando la presencia de mármol no expuesto en otros sectores del área. Su mayor contenido en plagioclasa también podría deberse a la presencia de material restítico o participación de materiales de composición más básica (Delpino 2000) El análisis de los contenidos de REE indica una particular correlación entre el gneis y las migmatitas basada en sus anomalias de Eu, negativa 
para el primero y positiva para las segundas. La anomalía negativa del gneis estaría sugiriendo que éste ha sido sometido a fusión y pérdida de minerales, fundamentalmente de biotita y plagioclasas. La comparación entre el contenido de REE de este gneis y el de las lutitas del NASC revela ciertas similitudes que podrian indicar que el protolito del gneis habria sido una roca sedimentaria pelítica. Si bien existen algunas diferencias con el patrón del NASC, hay que resaltar que el gneis biotítico presenta pérdida de material y además considerando el diagrama de Herron (1988), se puede inferir que el protolito podría no ser exactamente una roca pelítica sino una roca con características más parecidas a un wacke o grauvaca (Dott 1964). En este sentido, Delpino (2000) determina esta misma composición para los protolitos de los gneises que afloran en el área de Balcarce, aunque algunos muestran composiciones más pelíticas.

Rocas metamórficas derivadas de un protolito pelítico (o de similares características) pueden fundirse parcialmente a través de tres tipos de reacciones: 1) descomposición de plagioclasa en presencia de una fase fluída, 2) descomposición de muscovita, y 3) descomposición de biotita. La primera reacción ocurre solamente si hay agua libre en el sistema y genera un fundido de composición trondhjemítica o tonalítica (Patiño Douce 1996, Patiño Douce y Harris 1998, Castro et al. 2000). En cambio tanto la desestabilización de muscovita como de biotita se produce en condiciones anhidras dando lugar a fundidos de composición granítica $\mathrm{y}$ fases peritécticas refractrarias como granate, ortopiroxeno o cordierita entre otros (Thompson 1982, Le Breton y Thompson 1988 y Patiño Douce y Johnston 1991). En este caso la desaparición de la biotita en los leucosomas descriptos y la cristalización de granate predominantemente almandínico, estaría indicando que los fundidos se habrian generado por la descomposición de biotita en presencia de plagioclasas y cuarzo, generando esta fase granatífera, con feldespato potásico y un fundido granítico peraluminoso. De los patrones de REE observados se deduce que el principal control sobre la anomalía de Eu de los leucosomas lo ejercen las plagioclasas 
y en donde está presente también el granate, siendo que estos poseen una anomalía marcadamente positiva de este elemento.

Otras características de este fundido están determinadas por el bajo contenido en Th (1,50 a 2,71 ppm) y en $\operatorname{Zr}(42$ a $154 \mathrm{ppm})$, aunque variable en este último, y por la baja relación $(\mathrm{La} / \mathrm{Yb})_{\mathrm{N}}$ que es menor a 55,85 en todos los casos. Según Watt y Harley (1993) dichas características se ajustan a las de fundidos en desequilibrio; que se generan cuando el líquido es extraído antes de reequilibrarse con la restita. De acuerdo a estos autores los fundidos en desequilibrio no se generan a altas temperaturas, sin embargo los leucosomas de las migmatitas del área de San Miguel han incorporado feldespato, que requiere temperaturas cercanas a los $800{ }^{\circ} \mathrm{C}$ (Watt y Harley 1993). Teniendo en cuenta que parte de los cuerpos de leucosomas son concordantes con el bandeamiento del gneis y que los cristales de cuarzo de los mismos presentan extinción ondulosa, podríamos decir que la migmatización comienza a producirse durante la fase deformacional donde el gradiente de presión podría haber favorecido la migración del fundido antes de llegar al 8\% de fusión establecido para superar el "umbral de percolación de líquido" inclusive siendo menor al 5\% (Hand y Dirks 1992). De esta forma el fundido habría migrado antes de reequilibrarse generando finalmente estos cuerpos de límites difusos que no guardan relación con la dirección de foliación dominante.

\section{A.2 MÁRMOL}

\section{A.2.1 Introducción}

En el área de trabajo aflora uno de los dos mármoles, reconocidos hasta el momento, que forman parte del basamento de las Sierras Septentrionales. El otro mármol identificado se expone en Punta Tota (Fig. 2.3) y corresponde a un mármol dolomítico cuya asociación progradante forsterita + calcita + dolomita + clinopiroxeno + espinelo evidencia un pico metamórfico en facies granulita $\left(750-800{ }^{\circ} \mathrm{C}\right)$, según Delpino (2000) y 
Delpino y Dristas (2008). Éste se encuentra asociado a rocas ígneas graníticas y tonalíticas y a metamorfitas de alto grado como migmatitas, granulitas, gneises biotítico-granatíferos y anfibolitas conformando en el basamento una secuencia estratificada. Este mármol, de tonalidades verdosas, aparece como intercalaciones de 50 centímetros a 2 metros de espesor en forma concordante con las anfibolitas, en cuyos contactos se observa una mineralogía que corresponde a una paragénesis tipo skarn, evidenciando la acción de procesos metasomáticos.

El mármol de San Miguel presenta tres afloramientos principales: dos de ellos en la Ea. San Miguel y uno en la Ea. Siempre Verde (Fig.3.2 a y b). Se encuentra hospedado en el gneis biotítico e intruido por numerosos filones cuyos espesores varian entre 5 centímetros y 1 metro (Fig. 3.A.13a y b). El mármol posee tamaño de grano medio a grueso y una mineralogía compuesta principalmente por calcita y en menor proporción por pequeños cristales de piroxeno de color verde (Fig. 3.A.14). Los filones presentan una mineralogía constituida por cuarzo, plagioclasas, feldespato potásico y clinopiroxeno (estos filones serán tratados en el capítulo 4). Dicho mármol se encuentra involucrado en la formación del skarn, de esta forma su caracterización geológica y geoquímica tiene como finalidad conocer el protolito a partir del cual se formó el skarn San Miguel.

Además, en este mismo apartado se realiza una comparación entre este mármol y otros con edades similares que se depositaron durante un período temporal caracterizado por una fuerte anomalía positiva en $\delta^{13} \mathrm{C} y$ $\delta^{18} \mathrm{O}$ denominado "Evento Lomagundi-Jatuli" (Karhu y Holland 1996). Dicha comparación suma importante información para la ubicación temporal de la formación del protolito del mármol de San Miguel. 


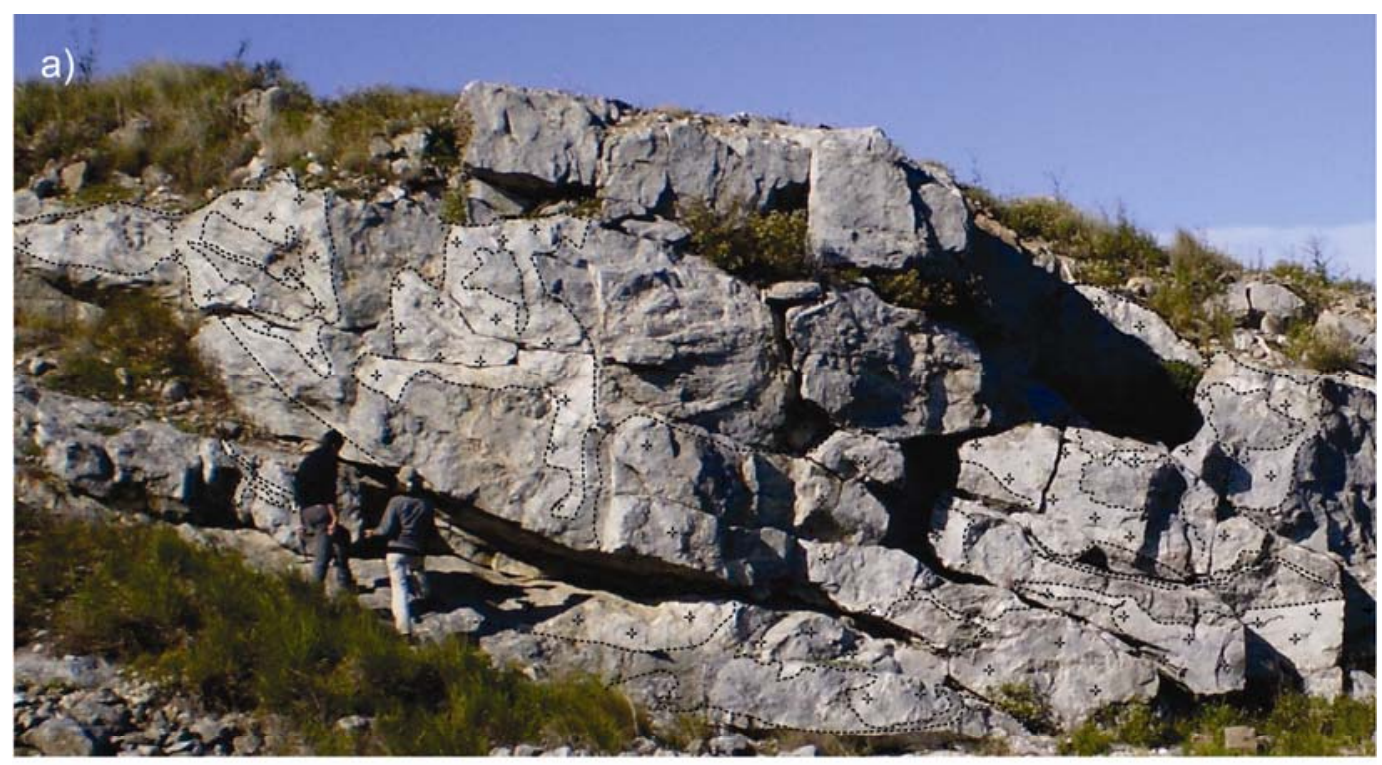

b)

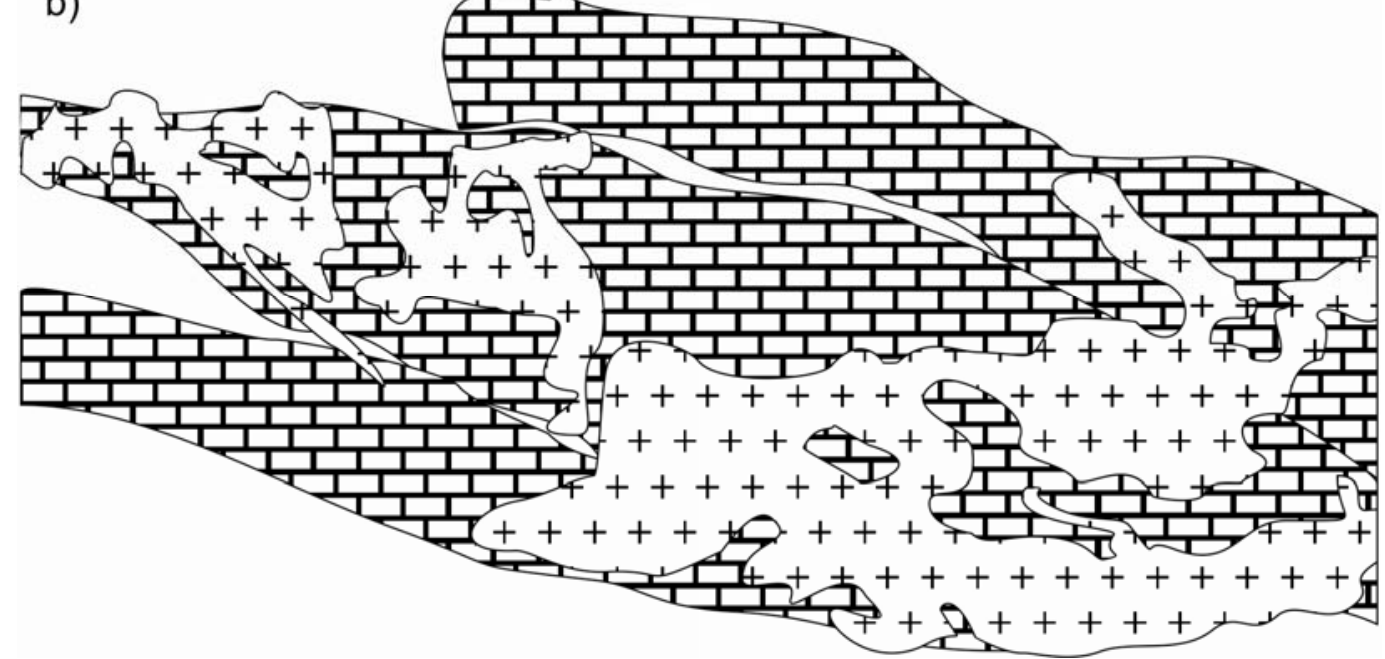

Figura 3.A.13: a) Vista del frente de la cantera principal del área de San Miguel donde se expone de mejor manera tanto el mármol como los filones que lo intruyen. b) Sección esquemática simplificada de las relaciones entre el mármol y las intrusiones graníticas.

\section{A.2.2 Petrografia}

El mármol presenta una coloración blanquecina a grisácea, con tamaño de grano variable de algunos milimetros a 2-3 centímetros (Fig. 3.A.14). Su mineralogía está conformada en su mayoría por calcita (cerca del 
$80 \%$ de la muestra), cantidades menores de clinopiroxeno de tipo diópsido (Cuadro 3.A.4) y escaso cuarzo.

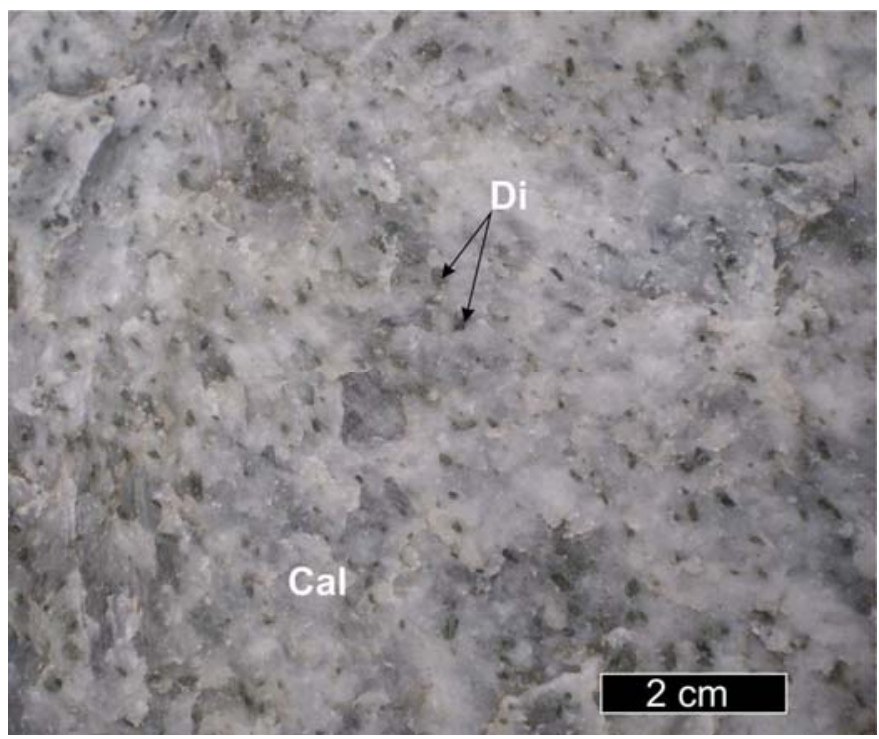

Figura 3.A.14: Aspecto mesoscópico del mármol con abundante calcita y pequeños cristales de color verde (diópsido). Abreviaturas minerales según Siivola y Schmid (2007).

Los cristales de calcita se manifiestan euhédricos, límpidos y con evidencias de deformación como extinción ondulosa y maclas ahusadas (Fig. 3.A.15a y b). Además, se observa recristalización de la calcita en franjas y la presencia de cristales alargados y seudopoligonales, bordes de maclas y contactos lobulados, que indicarian migración de bordes de grano (Fig. 3.A.16a y b). Todo esto, junto con la curvatura y hogeneización por sectores, indicarian deformación dúctil de la calcita. El diópsido es de color verde oscuro, desarrolla cristales de 3-4 milimetros de longitud media (Fig. 3.A.15b) y su abundancia es muy variable, registrándose sectores que poseen alrededor del $20 \%$ de este mineral y otros con menos del 10\%. Algunos cristales se encuentran parcialmente reemplazados por clorita y tremolita (Fig. 3.A.16a). Los escasos cristales de cuarzo tienen un tamaño promedio de 0,5 milimetros, se disponen en forma aislada y presentan extinción ondulosa (Fig. 3.A.16b). Hacia los contactos con los filones graníticos se observan las 
paragénesis metasomáticas típicas de skarn como granate + piroxeno y wollastonita + piroxeno en la zona más periférica del mármol (Lajoinie et al. 2013). Este último piroxeno, a diferencia del presente en el mármol tiene una coloración verde clara y es más translúcido, por estar menos reemplazado por clorita y tremolita. Está presente sólo en los contactos con los filones graníticos.

\begin{tabular}{|l|r|c|l|}
\hline \multicolumn{1}{|c|}{ Óxido } & \multicolumn{1}{c|}{$\%$} & catión & c.p.u.f \\
\hline $\mathbf{S i O}_{\mathbf{2}}$ & 52,00 & $\mathbf{S i}^{+\mathbf{4}}$ & 1,94 \\
$\mathbf{A l}_{\mathbf{2}} \mathbf{O}_{\mathbf{3}}$ & 1,20 & $\mathbf{A l}^{+\mathbf{3}}$ & 0,05 \\
$\mathbf{F e O}$ & 4,30 & $\mathbf{F e}^{+\mathbf{2}}$ & 0,13 \\
$\mathbf{M g O}$ & 14,00 & $\mathbf{M g}^{+\mathbf{2}}$ & 0,78 \\
$\mathbf{C a O}$ & 28,50 & $\mathbf{C a}^{+\mathbf{2}}$ & 1,14 \\
Total & 100,00 & Suma & 4,04 \\
\hline \multicolumn{4}{|c|}{ Fórmula mineral aproximada: } \\
Ca,55 Mgo,38 $\mathbf{F e}_{\mathbf{0}, \mathbf{0 6}} \mathbf{S i}_{\mathbf{1 , 9 2}} \mathbf{A l}_{\mathbf{0 , 0 4}} \mathbf{O}_{\mathbf{6}}$ \\
\hline
\end{tabular}

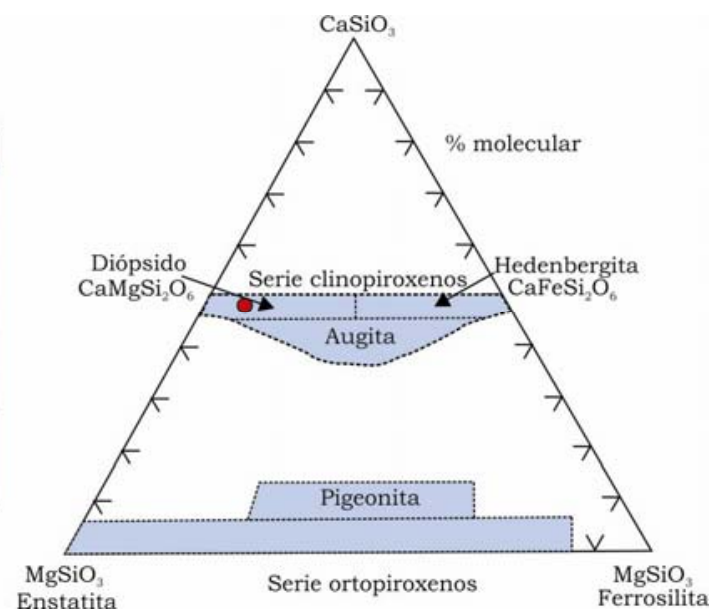

Cuadro 3.A.4: Composición química promedio y fórmula mineral aproximada de cristales de clinopiroxeno del mármol, obtenida mediante un análisis EDAX (se asume al hierro total como $\mathrm{FeO}$ ). De forma complementaria, dicha composición fue ploteada en el diagrama triangular (Klein y Hurlbut 1999) ubicado a la derecha del cuadro. El punto rojo indica que el mineral corresponde a la serie clinopiroxeno diópsido-hedenbergita (mayoritariamente diópsido).

\section{A.2.3 Caracterización geoquímica del mármol}

Los análisis químicos y las determinaciones de isótopos estables (C y O) fueron realizados en muestras obtenidas de una sección transversal al contacto roca granítica-roca carbonática, tal como se grafica en la Fig. 3.A.17. En ésta, además se indica la ubicación y denominación de cada muestra. Así, se realizó una caracterización geoquímica del mármol y un análisis de las variaciones, generadas por metasomatismo, en la composición química y en las relaciones de isótopos estables $\delta^{13} \mathrm{C}$ y $\delta^{18} \mathrm{O}$ en cristales de calcita y $\delta^{18} \mathrm{O}$ en individuos de diópsido. 

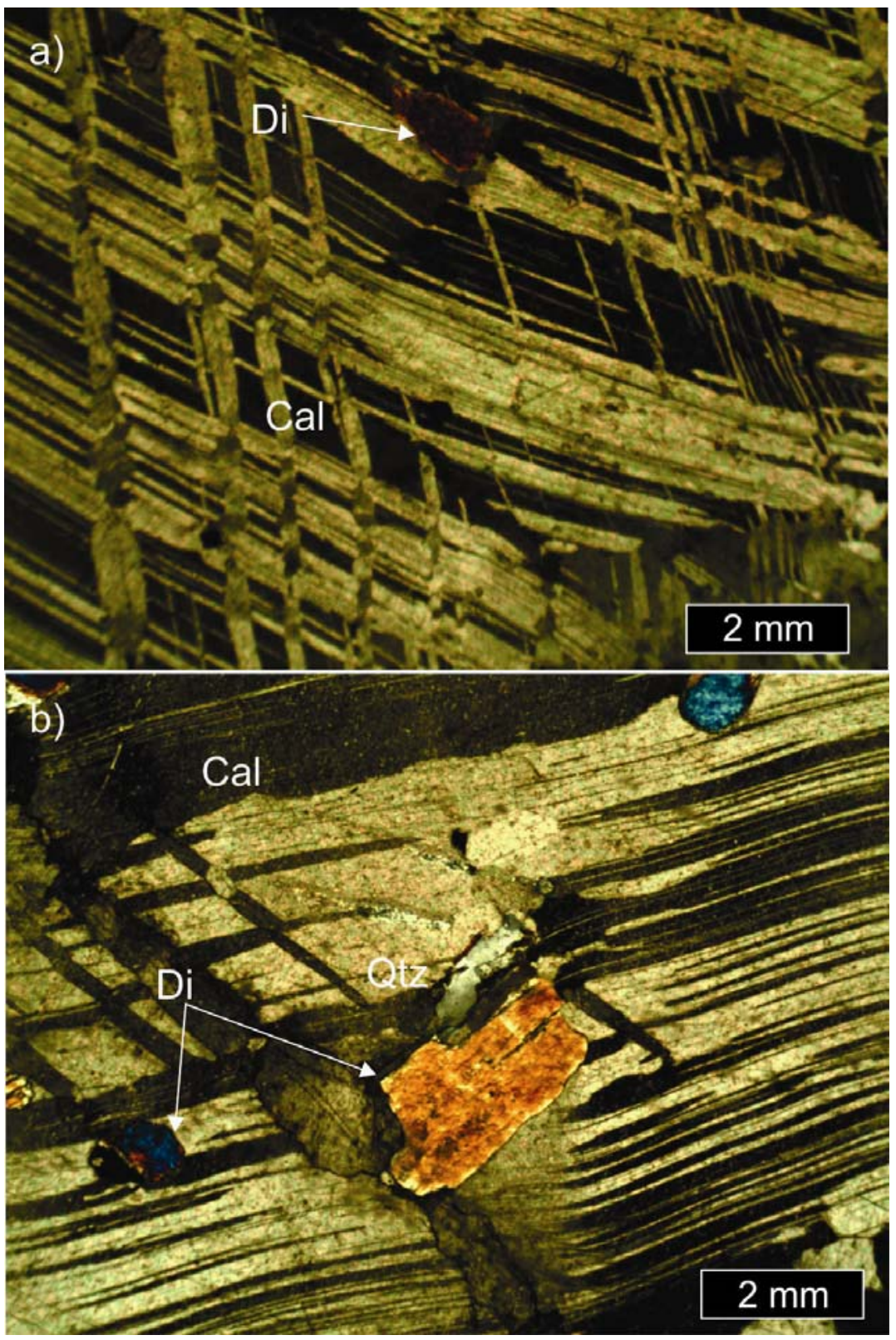

Figura 3.A.15: Vista microscópica del mármol. a) Maclas deformadas en cristal de calcita y pequeño cristal de diópsido, con analizador. b) Maclas ahusadas en cristal de calcita, pequeños cristales de diópsido y cuarzo con extinción ondulosa, con analizador. Abreviaturas minerales según Siivola y Schmid (2007). 

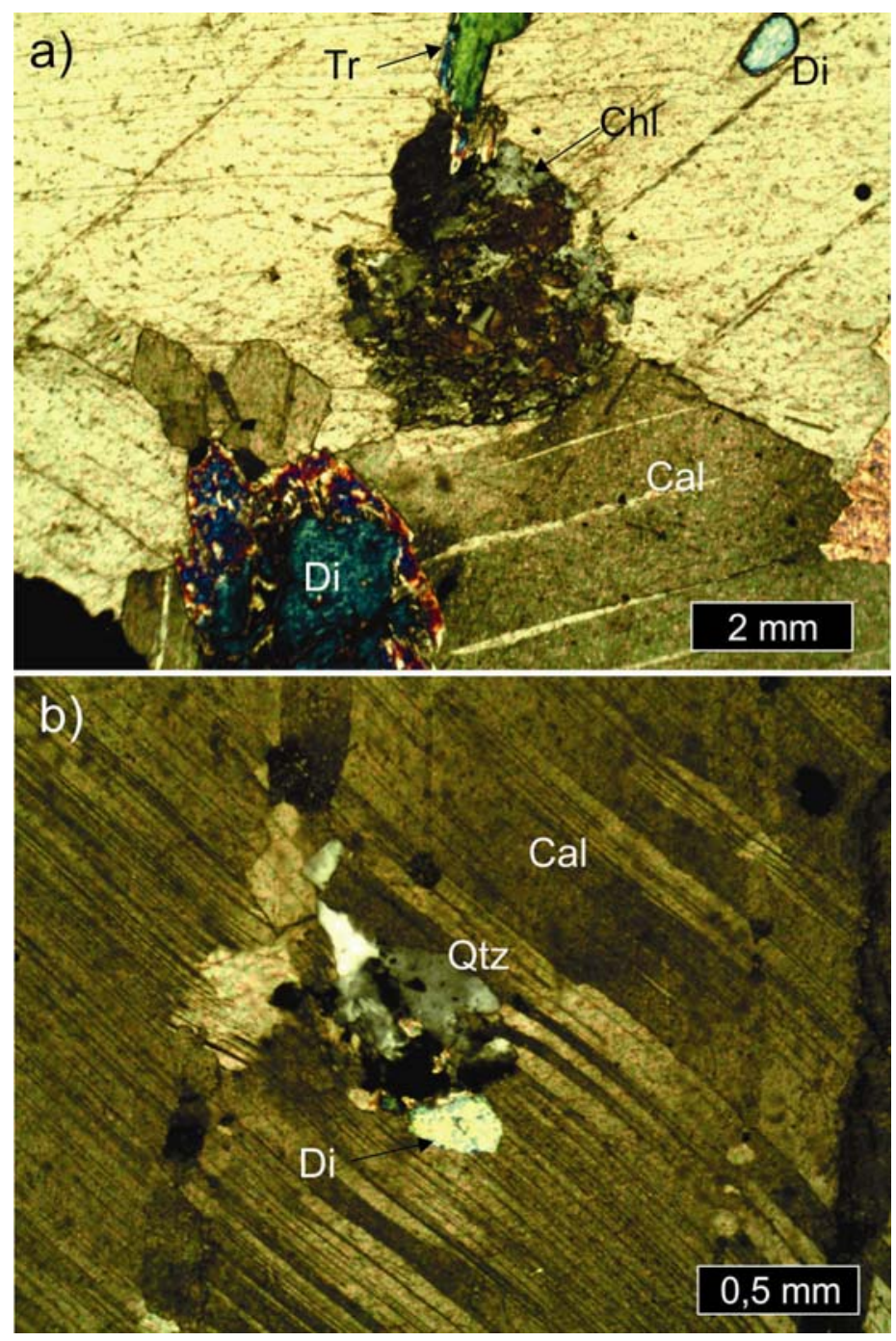

Figura 3.A.16: a) Cristales de diópsido en matriz de calcita, reemplazados por clorita y tremolita, con analizador. b) Pequeños cristales de cuarzo con extinción ondulosa, agrupados con cristales de diópsido, con analizador. Abreviaturas minerales según Siivola y Schmid (2007).

\section{A.2.3.1 Geoquimica de roca total}

Los resultados de los análisis químicos (Cuadro 3.A.5) indican que estos mármoles presentan contenidos altos de $\mathrm{CaO}$ (52,90 a 54,70\%), en concordancia con la gran cantidad de calcita identificada en muestras de mano y al microscopio. Bajos tenores de $\mathrm{SiO}_{2}$ (1 a 4\%), $\mathrm{MgO}(0,62$ a 1,10\%), $\mathrm{Fe}_{2} \mathrm{O}_{3 \text { Total }}(0,13$ a $0,66 \%)$ y $\mathrm{Al}_{2} \mathrm{O}_{3}(0,06$ a $0,69 \%)$ se atribuyen a la presencia 
de cristales de diópsido y cuarzo. En cuanto a los elementos minoritarios se puede destacar la gran variabilidad en el contenido de $\mathrm{Ba}$, de 1080,0 a 10,4 ppm, mientras que los de $\mathrm{Sr}$ presentan valores similares para todas las muestras, comprendidas entre 191,5 y 115,0 ppm.

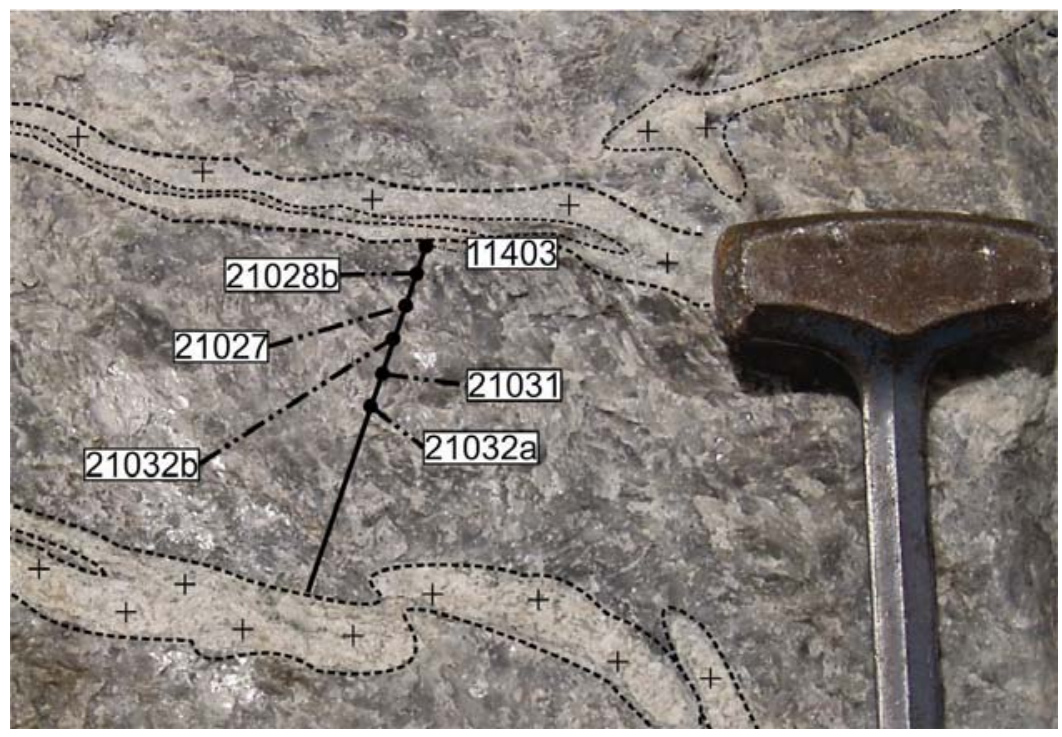

Figura 3.A.17: Vista del mármol intruido por filones graníticos, donde se indica la ubicación y nomenclatura de las muestras analizadas.

\section{A.2.3.2 Isótopos estables}

Los valores de $\delta^{18} \mathrm{O}$ obtenidos en cristales de calcita del mármol oscilan entre $+17,12$ y $+13,84 \%$ o (SMOW), mientras que los de $\delta^{13} \mathrm{C}$ varian entre $+5,42$ y $+4,26 \%$ o $(\mathrm{PDB})$, como se indica en el Cuadro 3.A.6. En el diagrama $\delta^{13} \mathrm{C}$ vs $\delta^{18} \mathrm{O}$ (Bowman 1998) de la Fig. 3.A.18, la gráfica de estos resultados indica la evolución del fluido en equilibrio isotópico con la calcita. También se destaca en esta figura la existencia de una correlación entre los registros isotópicos y las distancias al contacto mármol-roca granítica, en la que los valores más positivos de $\delta^{13} \mathrm{C}$ y $\delta^{18} \mathrm{O}$ se corresponden con las muestras ubicadas a mayor distancia del mencionado contacto. 


\begin{tabular}{|c|c|c|c|}
\hline Muestra & $21028 b$ & 11403 & $21032 b$ \\
\hline $\mathrm{SiO}_{2}$ & 4,57 & 4,16 & 1,62 \\
\hline $\mathrm{TiO}_{2}$ & 0,01 & 0,03 & $<0,01$ \\
\hline $\mathbf{A l}_{2} \mathbf{O}_{3}$ & 0,46 & 0,69 & 0,06 \\
\hline $\mathrm{Fe}_{2} \mathrm{O}_{3 \text { Total }}$ & 0,66 & 0,37 & 0,13 \\
\hline MgO & 1,10 & 0,62 & 0,65 \\
\hline Mno & 0,01 & 0,01 & 0,01 \\
\hline $\mathrm{CaO}$ & 52,90 & 53,30 & 54,5 \\
\hline $\mathrm{Na}_{2} \mathrm{O}$ & 0,05 & 0,10 & 0,04 \\
\hline $\mathbf{K}_{2} \mathbf{O}$ & 0,01 & 0,02 & 0,01 \\
\hline $\mathbf{P}_{2} \mathbf{O}_{5}$ & 0,07 & 0,09 & 0,07 \\
\hline LOI & 40,40 & 40,50 & 42,95 \\
\hline Total & 100,27 & 100,03 & 100,05 \\
\hline Sr & 191,5 & 166,5 & 115,0 \\
\hline $\mathbf{B a}$ & 85,4 & 1080,0 & 10,4 \\
\hline $\mathbf{R b}$ & $<0,2^{*}$ & 0,4 & $<0,2^{*}$ \\
\hline Th & 0,33 & 0,59 & 0,12 \\
\hline $\mathbf{U}$ & 0,19 & 0,15 & 0,08 \\
\hline Ta & $<0,1^{*}$ & 0,1 & $<0,1^{*}$ \\
\hline $\mathbf{Z r}$ & 2 & 14 & $<2 *$ \\
\hline Hf & $<0,2^{*}$ & $0,3^{*}$ & $<0,2^{*}$ \\
\hline $\mathbf{Y}$ & 6,3 & 9,6 & 3,3 \\
\hline $\mathbf{C r}$ & 10 & 10 & $<10^{*}$ \\
\hline Ga & 0,6 & 0,8 & $<0,1$ \\
\hline W & $<1^{*}$ & 1 & $<1^{*}$ \\
\hline La & 4,0 & 4,8 & 1,3 \\
\hline $\mathrm{Ce}$ & 3,8 & 5,1 & 0,8 \\
\hline Pr & 0,65 & 0,87 & 0,2 \\
\hline Nd & 2,7 & 3,4 & 0,9 \\
\hline Sm & 0,45 & 0,73 & 0,16 \\
\hline Eu & 0,17 & 0,15 & 0,04 \\
\hline Gd & 0,57 & 0,87 & 0,19 \\
\hline Tb & 0,08 & 0,11 & 0,03 \\
\hline Dy & 0,47 & 0,75 & 0,27 \\
\hline Ho & 0,11 & 0,17 & 0,05 \\
\hline Er & 0,29 & 0,5 & 0,15 \\
\hline Tm & 0,02 & 0,06 & 0,01 \\
\hline $\mathbf{Y b}$ & 0,17 & 0,31 & 0,11 \\
\hline $\mathbf{L}$ & 0,02 & 0,03 & $=0,01$ \\
\hline
\end{tabular}

Cuadro 3.A.5: Resultados de los análisis químicos de distintos sectores del mármol de San Miguel. Nota: Los óxidos mayoritarios están expresados en \% en peso, los elementos minoritarios y traza en ppm. El número de decimales depende de la exactitud del método para la detección del elemento. * Por debajo del límite de detección.

En la misma gráfica se incluyen, además, los datos promedio de $\delta^{13} \mathrm{C} y$ $\delta^{18} \mathrm{O}$ de calcitas ígneas y de carbonatos marinos, los cuales manifiestan que 
la recristalización provocada por procesos metasomáticos genera mayores descensos en $\delta^{18} \mathrm{O}$ que en $\delta^{13} \mathrm{C}$.

\begin{tabular}{|ccrr|}
\hline Muestra & $\mathbf{8}^{1 \mathbf{1}} \mathbf{O}_{\text {cal }}$ & $\mathbf{8}^{13} \mathbf{C}_{\text {cal }}$ & $\mathbf{8}^{1 \mathbf{1}} \mathbf{O}_{\text {clpx }}$ \\
$\mathbf{2 1 0 3 2 a}$ & $+17,12$ & $+5,42$ & $+14,7$ \\
$\mathbf{2 1 0 3 1}$ & $+16,80$ & $+5,39$ & $\mathrm{n} / \mathrm{d}$ \\
$\mathbf{2 1 0 3 2 b}$ & $+16,80$ & $+5,06$ & $\mathrm{n} / \mathrm{d}$ \\
$\mathbf{2 1 0 2 7}$ & $+13,96$ & $+5,05$ & $\mathrm{n} / \mathrm{d}$ \\
$\mathbf{2 1 0 2 8 b}$ & $+13,91$ & $+4,95$ & $+9,4$ \\
$\mathbf{1 1 4 0 3}$ & $+13,84$ & $+4,26$ & $\mathrm{n} / \mathrm{d}$ \\
\hline
\end{tabular}

Cuadro 3.A.6: Resultados de isótopos estables obtenidos de cristales de calcita y clinopiroxeno del mármol. Los datos $\delta^{18} \mathrm{O}$ de calcita y clinopiroxeno se expresan en SMOW (Standard Mean Ocean Water) y los valores $\delta^{13} \mathrm{C}$ de calcita en PDB (Pee Dee Belemnite), $\mathrm{n} / \mathrm{d}=$ no determinado.

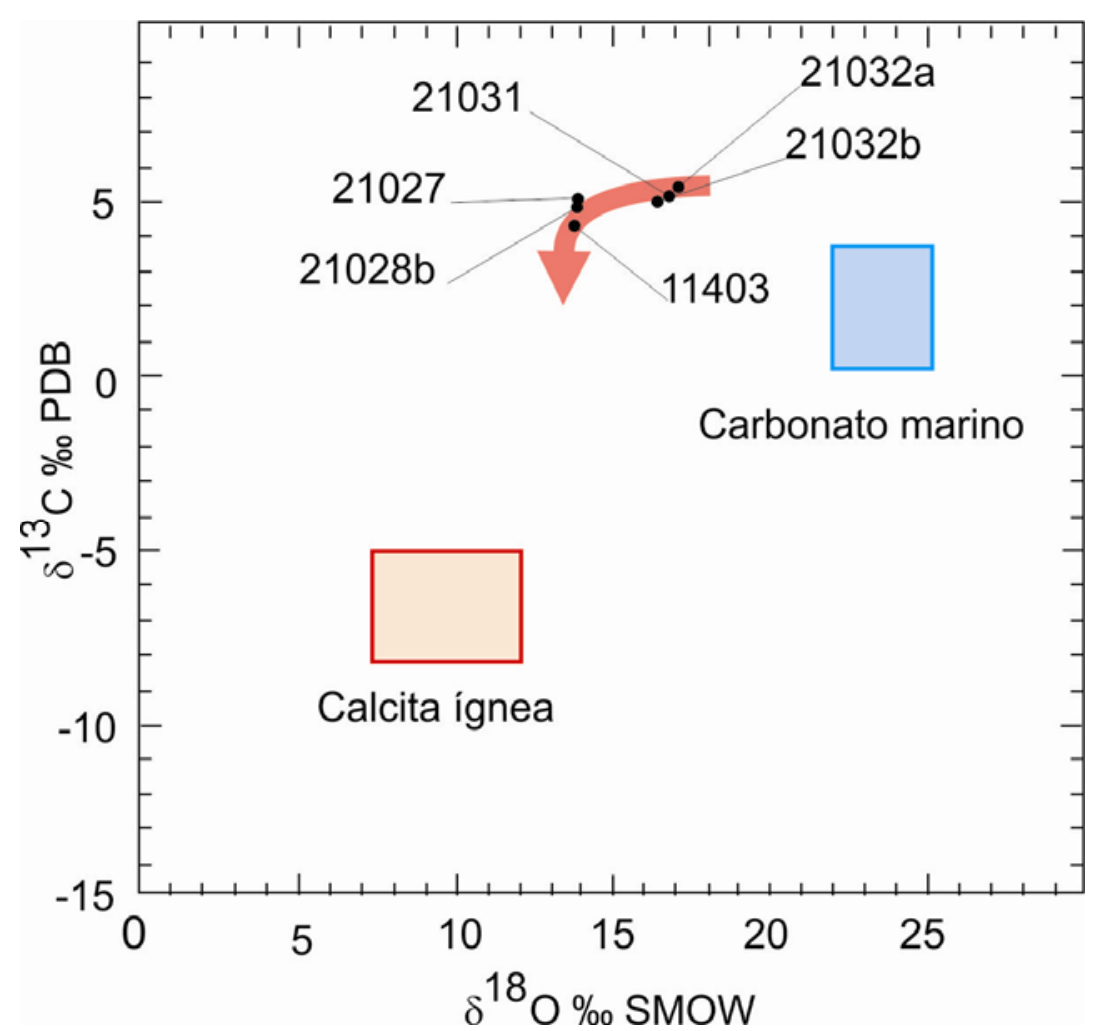

Figura 3.A.18: Diagrama $\delta^{18} \mathrm{O}$ vs $\delta^{13} \mathrm{C}$ según Bowman (1998). En el mismo se encuentran graficados los valores obtenidos de calcitas del mármol. Los recuadros e 
corresponden a los valores típicos de calcita ígnea (recuadro rosado) y carbonato marino (recuadro celeste).

Con el fin de establecer la variación isotópica entre los diópsidos provenientes del mármol y los de la fase metasomática (contacto roca granítica-mármol), se analizaron los fraccionamientos isotópicos de $\delta^{18} \mathrm{O}$ de ambos tipos de diópsido, arrojando valores promedio de $+14,7 \%$ o para el primero y de $+9,4 \%$ para el segundo. Estos mismos valores de $\delta^{18} \mathrm{O}$ de diópsido se emplearon conjuntamente con los obtenidos de calcita en paragénesis con el diópsido, para determinar la temperatura del equilibrio isotópico mediante el geotermómetro calcita-diópsido, según Valley (2003). Se obtuvieron temperaturas de $716^{\circ} \mathrm{C}$ para el par mineral presente en el mármol y de $451^{\circ} \mathrm{C}$ para el proveniente de la zona de contacto, registrando una diferencia de $265^{\circ} \mathrm{C}$ entre ambas zonas.

\section{A.2.4 "Evento Lomagundi-Jatuli": Carbonatos marinos del Paleoproterozoico}

Los primeros estudios de isótopos estables realizados en carbonatos marinos del Grupo Lomagundi en Zimbawe, depositados entre los 2400 y los $2000 \mathrm{Ma}$ aproximadamente, develaron una importante anomalía positiva en los valores de $\delta^{13} \mathrm{C}$ (Schidlowski et al. 1975 y 1976). Dicha anomalia, denominada "evento Lomagundi-Jatuli" (Karhu y Holland 1996), fue registrada posteriormente en otros carbonatos también de edad paleoproterozoica, bien preservados o inclusive con procesos de metamorfismo sobreimpuestos. Importantes avances en el estudio de este evento fueron realizados en el Escudo de Fennoscandia (Noruega, Finlandia y Suecia) por Baker y Fallick (1989), Karhu (1993) y en Norte América por Schidlowski et al. (1983), Mirota y Veizer (1994) y Bekker et al. (2003 y 2006). Otros afloramientos investigados corresponden a aquellos situados en los Cratones de Kapvaal y Sudáfrica, África (Schidlowski et al. 1976, Gauthier-Lafaye y Weber 1989, Master et al. 1990, Buick et al. 1998 y 2003, Bekker et al. 2001, Schröder et al. 2008); en el Cratón de San Francisco, Brasil (Bekker et al. 2003, Maheshwari et al. 2010); en el Cratón de Aravalli, 
India (Maheshwari et al. 1999, 2002 y 2010) y en el Cratón de Pilbara y Yilgarn, Australia (Lindsay y Brasier 2002), Fig. 3.A.19.

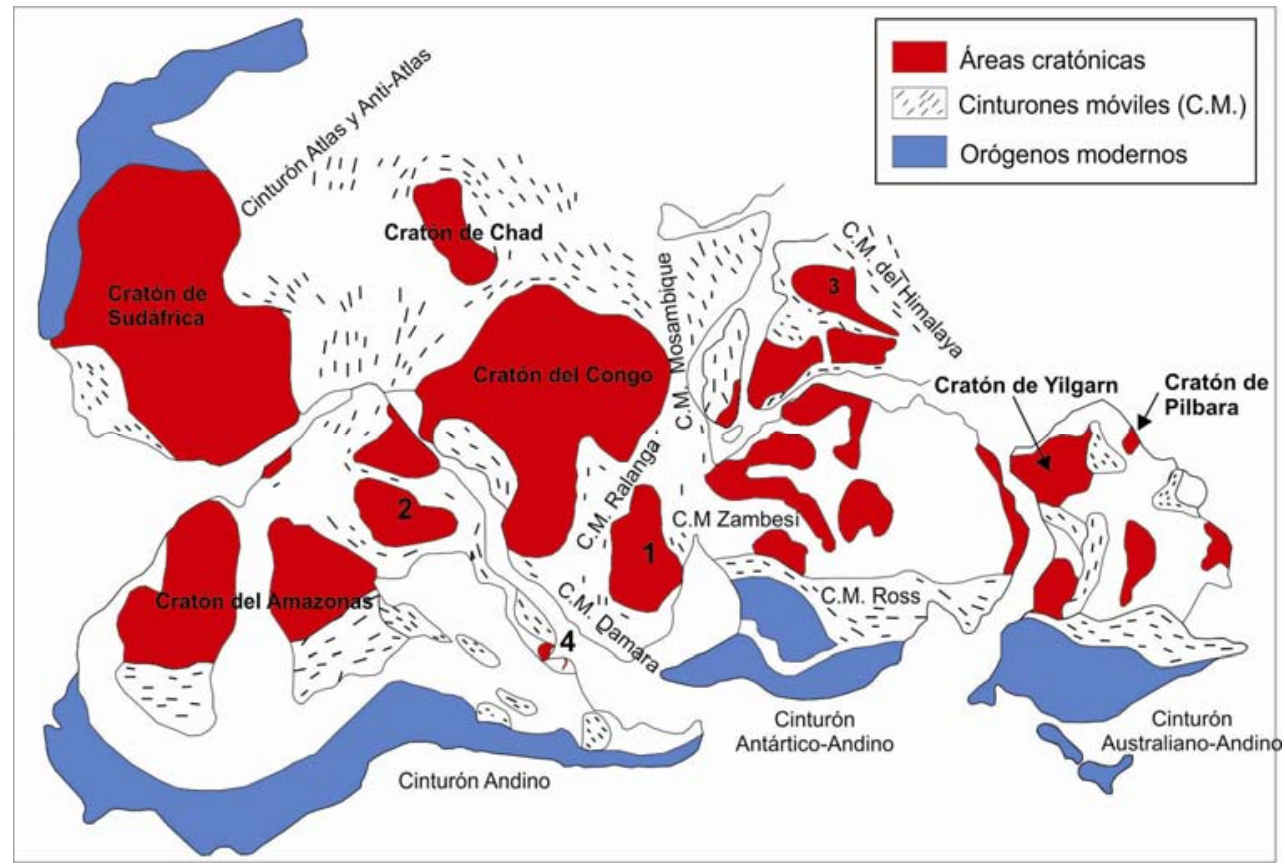

Figura 3.A.19: Esquema de Gondwana, donde se observa la distribución de los cratones arqueanos-paleoproterozoicos, cinturones móviles y orógenos más jóvenes (modificado de Trompette 1994). 1-Cratón de Kapvaal, 2-Cratón de San Francisco, 3-Cratón de Aravalli y 4- Cratón del Río de la Plata.

Típicamente estos carbonatos poseen valores de $\delta^{18} \mathrm{O}$ cercanos a $+20 \%$ o (Melezhik et al. 2005) y de $\delta^{13} \mathrm{C}>1 \%$ o hasta incluso valores de $+28 \%$ o (Grupo Lomagundi, Melezhik et al. 2005). Si bien el inicio y duración del evento sigue siendo tema de investigación, la recopilación de los estudios estratigráficos y quimioestratigráficos indica que el mismo comenzó antes de los 2.200 Ma, poco tiempo después de la glaciación Huroniana 2.450-2.220 Ma (Young et al. 2001) y finalizó a los 2.110-2.060 Ma (Bekker et al. 2008), extendiéndose por más de 300 Ma (Karhu y Holland 1996, Melezhik et al. 2005 y 2007). Durante este período se identifica un incremento en la producción de $\mathrm{C}$ orgánico, que luego fue liberado y oxidado en los océanos y 
en la atmósfera. Esto aumentó los niveles de O de la atmósfera generando importantes modificaciones tanto en el ambiente como en los procesos biológicos (Karhu y Holland 1996). De esta forma los estudios de caracterización y de distribución espacial y temporal de los carbonatos depositados durante el "evento Lomagundi-Jatuli" sigue siendo una herramienta fundamental para el entendimiento de los procesos que generaron una de las modificaciones más importantes en el ciclo del C a nivel mundial durante el Paleoproterozoico.

Recientemente esta anomalía fue reconocida por Maheshwari et al. (2010) en el Terreno Piedra Alta, Cratón del Río de la Plata (CRLP), Fig. 2.2. Estos carbonatos predominantemente dolomíticos, se encuentran ubicados en el Cinturón San José (Bossi et al. 1993 y 1998, Bossi y Cingolani 2009) como parte de la sucesión sedimentaria que corresponde a la Formación Paso Severino (Bossi 1966). Dicha unidad se encuentra intruida por cuerpos granodioríticos datados en $2.074 \pm 6 \mathrm{Ma}$ (Hartmann et al. 2002). Estas rocas carbonáticas registran un amplio rango de valores de $\delta^{13} \mathrm{C}$ que van de $-5 \%$ a $+11,6 \%$ o. Si bien los valores positivos de $\delta^{13} \mathrm{C}$ son típicos de los carbonatos paleoproterozoicos, los negativos estarian asociados a la remineralización de la materia orgánica en ambientes diagenéticos tempranos, ricos en materia orgánica (Maheshwari et al. 2010). Es decir, los valores negativos serian producto de la actividad metabólica de organismos marinos que fraccionaron los isótopos de $\mathrm{C}$ antes de devolverlos al medio como elementos inórgánicos y que luego fueron precipitados como carbonatos.

En la Fig. 3.A.20, se grafican las determinaciones de $\delta^{13} \mathrm{C}$ del mármol de San Miguel junto con las correspondientes a los registros mundiales de carbonatos depositados durante el "evento Lomagundi Jatuli". En esta gráfica puede observarse que los valores $\delta^{13} \mathrm{C}$ de los mármoles estudiados quedan comprendidos en los determinados para aquellos carbonatos depositados durante el mencionado evento. 


\section{A.2.5 Discusión}

Los mármoles de San Miguel forman parte de las rocas que constituyen el basamento de las Sierras Septentrionales, al igual que los estudiados por Delpino (2000) y Delpino y Dristas (2008), en Punta Tota. La paragénesis mineral calcita + diópsido + cuarzo, reconocida en el mármol de San Miguel, indica que los procesos metamórficos alcanzaron facies anfibolita alta, teniendo en cuenta que la temperatura de la isograda del diópsido está determinada en $\sim 650^{\circ} \mathrm{C}$, para una presión cercana a los 8 Kbars (Bucher y Frey 2002).

1- Fm. Fecho du Funil(Bekker et al. 2003)

2- Fm. Paso Severino(Maheshwari et al. 2010)

3- Grupo Lomagundi (Schidlowsky et al. 1976)

4- Fm. Juderina (Lidnsay y Brasier 2002)

5- Grupo Pretoria (Buik et al. 2003)

6- Grupo Aravalli (Maheshwari et al. 1999)

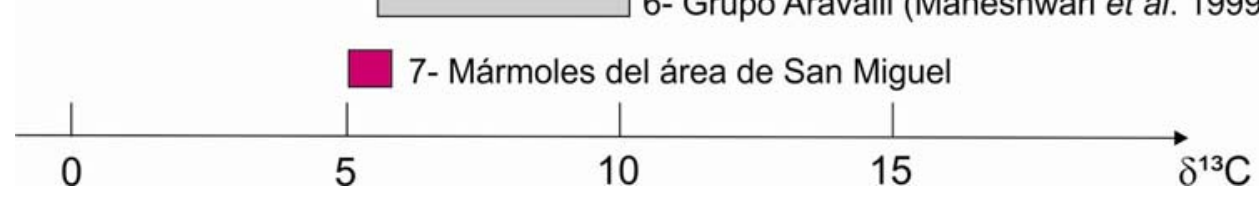

Figura 3.A.20: Variación de los registros de $\delta^{13} \mathrm{C}$ y edades de los carbonatos de diversas unidades pertenecientes a los distintos cratones: 1- $\mathrm{Pb}-\mathrm{Pb} 2,11 \pm 0,1 \mathrm{Ga}$ (Babinski et al. 1995); 2- U-Pb 2,14 \pm 7 Ga (Santos et al. 2003); 3- Pb-Pb 2,17 Ga (Woodhead y Hergt 1997); 4- Rb-Sr 2,26 Ga (Hamilton 1977); 5- Pb-Pb 2,07 a 2,15 Ga (Deb y Thorpe 2004) y 5- Rb-Sr, mayor a 2,13 \pm 50 Ga (Halpern et al. 1970).

La ausencia de dolomita y la presencia de pequeños cristales de cuarzo estarian indicando que el protolito habría sido un carbonato con una asociación mineral compuesta mayoritariamente por calcita y en menor proporción por cuarzo y escasa dolomita, como los protolitos que grafican en el campo 2a en la Fig. 3.A.21. Esto mismo se evidencia en los análisis 
químicos del mármol que presentan altos valores de $\mathrm{CaO}$ y bajos contenidos de $\mathrm{MgO}$.

El origen de las rocas carbonáticas a partir de las cuales se formó el skarn San Miguel no había sido determinado hasta el momento, ya que por su antigüedad y por los procesos de recristalización y metasomatismo sobreimpuestos sus características originales han sido modificadas. Normalmente los carbonatos de un skarn están empobrecidos en ${ }^{13} \mathrm{C}$ y ${ }^{18} \mathrm{O}$ respecto al carbonato original (Shieh y Taylor 1969), ya que en condiciones de equilibrio el $\mathrm{CO}_{2}$, liberado en las reacciones de descarbonatación, está enriquecido en estos isótopos (Bowman 1998). Sin embargo, hay un máximo de empobrecimiento en ${ }^{18} \mathrm{O}$ admisible, pues incluso la roca descarbonatada presenta contenidos elevados en oxígeno (el conocido como "límite calcosilicatado", Valley 1986), de modo que el descenso en $\delta^{180}$ no será mayor a $2-4 \%$ o. Los datos analíticos obtenidos (Cuadro 3.A.3) indican $8^{13} \mathrm{C} \approx$ $+5 /+6 \%$, y $\delta^{18} \mathrm{O}$ con una distribución bimodal de $+14 \%$ o $+17 \%$, de modo que mientras el oxígeno es diferente al de un carbonato marino (típicamente $\delta^{18} \mathrm{O}>+25 \%$ ), el $\delta^{13} \mathrm{C}$ no ha sufrido descensos notables (Fig. 3.A.18).

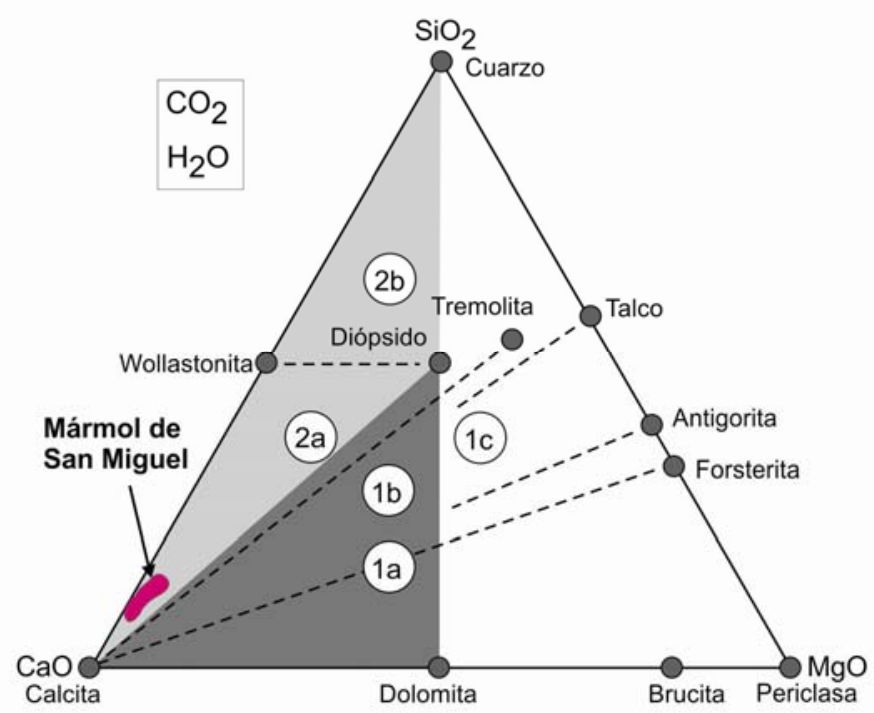

Figura 3.A.21: Diagrama quimiográfico del sistema $\mathrm{CaO}-\mathrm{MgO}-\mathrm{SiO}_{2}$, proyectado desde $\mathrm{CO}_{2}$ y $\mathrm{H}_{2} \mathrm{O}$ (Bucher y Frey 2002). Los mármoles dolomíticos están 
representados en los campos $1 \mathrm{a}, 1 \mathrm{~b}$ y $1 \mathrm{c}$; los calcosilicáticos en los campos $2 \mathrm{a}$ y $2 \mathrm{~b}$. El protolito del mármol de San Miguel queda comprendido en el campo 2a.

Por otro lado se observa una importante anomalía positiva y una disminución en los valores de $\delta^{13} \mathrm{C}$ de $+5,42$ a $+4,26 \%$ y de $\delta^{18} \mathrm{O}$ de $+17,85$ a $+13,84 \%$ o medida que nos acercamos al contacto con los filones graníticos.

Los carbonatos paleoproterozoicos depositados durante el "evento Lomagundi-Jatuli", tal como se mencionó anteriormente, fueron reconocidos en numerosas unidades carbonáticas pertenecientes a distintos cratones del mundo, debido a la presencia de una importante anomalia positiva en los valores de $\delta^{13} \mathrm{C}$ y de $\delta^{18} \mathrm{O}$. Si bien muchos de estos carbonatos se conservan inalterados otros presentan evidencias de procesos diagenéticos e inclusive metamórficos. De acuerdo a los estudios realizados por Melezhik et al. (2001), los valores de $\delta^{13} \mathrm{C}$ y de $\delta^{18} \mathrm{O}$ pueden mantenerse prácticamente inalterados aún bajo condiciones de facies anfibolita, dependiendo de las características de la roca carbonática y de las condiciones de metamorfismo. Los valores de $\delta^{18} \mathrm{O}$ del mármol de San Miguel son algo más bajos que los esperados para los carbonatos paleoproterozoicos cuyo promedio es de aproximadamente $+20 \%$ (Melezhik et al. 2005). Teniendo en cuenta la asociación mineral presente, se podría postular que el descenso registrado en este isótopo al igual que en el $\mathrm{C}$, sobre todo hacia el contacto con los filones graníticos, estaría asociado a la formación de calcosilicatos a través de reacciones de desvolatilización (Valley 1986) generadas durante el proceso metamórfico y el posterior proceso metasomático. En este sentido, el accionar como buffer de los carbonatos sería el que provoca un menor descenso de los valores $\delta^{13} \mathrm{C}$ explicando su menor variabilidad. Entre los calcosilicatos antes mencionados, se destacan los valores de $\delta^{18} \mathrm{O}$ del diópsido que permitieron establecer una importante diferencia entre dos poblaciones de este mineral (distal y proximal al contacto con los filones). Estos valores fueron usados conjuntamente con los de $\delta^{18} \mathrm{O}$ de calcita (en paragénesis) permitiendo establecer dos pares geotermométricos: (1) calcitadiópsido distal que arrojó temperaturas del orden de $\operatorname{los} 716^{\circ} \mathrm{C}$, en 
concordancia con el mencionado grado de facies anfibolita alta y (2) calcitadiópsido proximal que resultó en temperaturas que rondan los $451^{\circ} \mathrm{C}$, correspondientes al proceso metasomático.

Finalmente, teniendo en cuenta que los núcleos del mármol estudiados se encuentran alojados en un gneis biotítico, cuyas edades absolutas son de $2.176 \mathrm{Ma}$, resulta evidente que la edad del protolito sería aún mayor. Esto último sumado a que los elevados valores positivos de $\delta^{13} \mathrm{C}$, obtenidos de estos mármoles, concuerda con los registros mundiales de carbonatos paleoproterozoicos (Fig. 3.A.20), indicaría que los mármoles del área de San Miguel derivan de un protolito correspondiente a un carbonato marino depositado durante el "evento Lomagundi-Jatuli". 


\section{A.3 BIBLIOGRAFÍA}

Babinski, M., Chemale, J.R.F. y Van Schmus, W.R. 1995. The $\mathrm{Pb} / \mathrm{Pb}$ age of the Minas Super-group carbonate rocks, Quadrilátero Ferrífero, Brazil. Precambrian Research 72: 235-245.

Baker, A.J. y Fallick, A.E. 1989. Heavy Carbon in 2-Billion-Year-Old Marbles from Lofoten-Vesteralen, Norway. Implications for the Precambrian Carbon-Cycle. Geochimica et Cosmochimica Acta 53: 1.111-1.115.

Barker, F. 1979. Trondhjemite: Definition, enviroment and hypotheses of origin. En Barker, F. (ed.) Trondhjemites, dacites and related rocks. Elsevier, Amsterdam: 1-12.

Bekker, A., Kaufman, A.J., Karhu, J.A., Beukes, N.J., Swart, Q.D., Coetzee, L.L. y Eriksson, K.A. 2001. Chemostratigraphy of the Paleoproterozoic Duitschland Formation. South Africa: implications for coupled climate change and carbon cycling. American Journal of Science 301: 261-285.

Bekker, A., Sial, A.N., Karhu, J.A., Ferreira, V.P., Noce, C.M., Kaufman, A.J., Romano A.W. y Pimentel, M.M. 2003. Chemostratigraphy of carbonates from the Minas Supergroup, Quadrilatero Ferrifero (Iron Quadrangle), Brazil: a stratigraphic record of early Proterozoic atmospheric, biogeochemical and climatic change. American Journal of Science 303: 865-904.

Bekker, A., Karhu, J.A. y Kaufman, A.J. 2006. Carbon isotope record for the onset of the Lomagundi carbon isotope excursion in the Great Lakes area, North America. Precambrian Research 148: 145-180.

Bekker, A., Holmden, C., Beukes, N.J., Kenig, F., Eglington, B. y Patterson, W.P. 2008. Fractionation between inorganic and organic carbon during the Lomagundi $(2.22-2.1 \mathrm{Ga})$ carbon isotope excursion. Earth Planet. Science Letter 271: 278-291.

Bossi, J. 1966. Geología del Uruguay. Colección Ciencias №2. Departamento de publicaciones de la Universidad de la República, Montevideo, Uruguay.

Bossi, J. y Cingolani, C. 2009. Extension and general evolution of the Río de la Plata Craton. En Gaucher, C., Sial, A.N. Halverson, G.P. y Frimmel, H.E. (eds.) Neoproterozoic-Cambrian tectonics, global change and evolution: a focus on southwestern Gondwana, Developments in Precambrian Geology. Elsevier, Amsterdam 16: 73-85. 
Bossi, J., Preciozzi, F. y Campal, N. 1993. Predevoniano del Uruguay Parte 1: Terreno Piedra Alta. Dinamige, Montevideo: 1-50.

Bossi, J., Ferrando, L., Montaña, J., Campal, N., Morales, H., Gancio, F., Schipilov, A. Piñeyro, D. y Sprechmann, P. 1998. Carta geológica del Uruguay, Escala 1:500.000. Geoeditores, Montevideo.

Bowman, J.R. 1998. Stable-Isotope systematics of skarns. En Lentz, D.R. (ed.) Mineralized Intrusion Related Skarn Systems. Mineralogical Association of Canada. Short Course 26: 99-145, Québec.

Bucher, K. y Frey, M. 2002. Petrogenesis of Metamorphic Rocks. Springer-Verlag, Berlin Heidelberg, 341 p., Nueva York.

Buick, I.S., Uken, R., Gibson, R.L. y Wallmach, T. 1998. High $\delta^{13} \mathrm{C}$ Paleoproterozoic carbonates from the Transvaal Supergroup, South Africa. Geology 26: 875878.

Buick, I.S., Williams, I.S., Gibson, R.L., Cartwright, I. y Miller, J.A. 2003. Carbon and $\mathrm{U}-\mathrm{Pb}$ evidence for a Palaeoproterozoic crustal component in the Central Zone of the Limpopo Belt, South Africa. Journal of Geological Society of London 160: 601-612.

Castro, A., Corretge, L. G., El-Biad, M., El-Hmidi, H., Fernandez, C. y Patiño Douce, A. 2000. Experimental constraints on Hercynian anatexis in the Iberian Massif, Spain. Journal of Petrology 41: 1471-1488.

Deb, M. y Thorpe, R.A. 2004. Geochronological constraints in the Precambrian Geology of Rajasthan and their metallogenic implications. En Deb, M. y Goodfellow, W.D (eds.) Sediment-Hosted Lead - Zinc Sulphide Deposits, Narosa Publishing House: 246-263, New Delhi.

Delpino, S.H. 2000. Evolución metamórfica del sector nororiental del basamento de Tandilia, Argentina: metamorfismo en facies granulita y anatexis cortical. Tesis Doctoral, Universidad Nacional del Sur (inédita), 180p., Bahía Blanca.

Delpino, S.H. y Dristas, J.A. 2008. Dolomitic marbles and associated calc-silicates, Tandilia belt, Argentina: Geothermobarometry, metamorphic evolution, and P-T path. Journal of South American Earth Sciences 23: 147-175.

Dott, R.H. Jr. 1964. Wacke, Graywacke and Matrix. What approach to Immature Sandstone Classification? Journal of Sedimentary Research 34: 625-623.

Droop, G.T.R. 1987. A general equation for estimating $\mathrm{Fe}^{+3}$ concentration in ferromagnesian silicates and oxides from microprobe analysis, using stoichiometric criteria. Mineralogical Magazine 51: 431-435. 
Gauthier-Lafaye, F. y Weber, F. 1989. The Francevillian (Lower Proterozoioc) uranium ore deposits of Gabon. Economic Geology 84: 2267-2285.

Gromet, L.P., Dymek, R.F., Haskin, L.A. y Korotev, R.L. 1984. The "North American shale composite": Its compilation mayor and trace elements characteristics. Geochimica et Cosmochimica Acta 48: 2469-2498.

Halpern, M., Umpierre Urquhart, M. y Linares, E. 1970. Radiometric ages of crystalline rocks from southern South America, as relate to Gondwana and Andean geologic provinces. 4th Upper Mantle Symposium, Petrologia y Volcanismo: 345-356, Buenos Aires.

Hamilton, J. 1977. Isotope and trace element studies of the Great Dyke and Bushveld mafic phase and their relation to Early Proterozoic magma genesis in southern Africa. Journal of Petrology 18: 24-52.

Hand, M. y Dirks, P.H.G.M. 1992. The influence of deformation on the formation of axial-planar leucosomes and the segregation of small melt bodies within the magmatitic Napperby Gneis, Central Australia. Journal of Structural Geology 14: 591-604.

Hartmann, L.A., Santos, J.O.S., Cingolani, C.A. y McNaughton, N.J. 2002. Two Paleoproterozoic Orogenies in the Evolution of the Tandilia Belt, Buenos Aires, as evidenced by zircon U-Pb SHRIMP geochronology. International Geology Review 44:528-543.

Herron, M.M. 1988. Geochemical classification of terrigenous sands and shales from core or log data. Journal of sedimentary Petrology 58: 820-829.

Holtz, F. y Johannes, W. 1991. Genesis of peraluminous granites I. Experimental investigation of melt compositions at 3 and $5 \mathrm{~kb}$ and various $\mathrm{H}_{2} \mathrm{O}$ activities. Journal of Petrology 32: 935-958.

Karhu, J.A. 1993. Palaeoproterozoic evolution of the carbon isotope ratios of sedimentary carbonates in the Fennos-candian Shield. Geological Survey of Finland bulletin 371:1-87.

Karhu, J.A. y Holland, H.D. 1996. Carbon isotopes and rise of the atmospheric oxygen. Geology 2: 6-9.

Klein, C. y Hurlbut, C.S. 1999. Manual of Mineralogy (after Dana J.D., 21th edition), John Wiley \& Sons, 681p., New York.

Lajoinie, M.F., Lanfranchini, M.E., Etcheverry, R.O. y Recio, C. 2013. Zonación mineral vinculada a procesos geoquímicos en el skarn San Miguel, Sierras 
Septentrionales de la provincia de Buenos Aires. Revista de la Asociación Geológica Argentina 70: 402-412.

Le Breton, N. y Thompson, A.B. 1988. Fluid-absent (deshydration) melting of biotite in metapelites in the early stages of crustal anatexis. Contributions to Mineralogy and Petrology 99: 226-237.

Lindsay, J.F. y Brasier, M.D. 2002. Did global tectonics drive early biosphere evolution? Carbon isotope record from 2.6 to $1.9 \mathrm{Ga}$ carbonates of Western Australian basins. Precambrian Research 114: 1-34.

Maheshwari, A., Sial, A.N. y Chittora, V.K. 1999. High $\delta^{13} \mathrm{C}$ Paleoproterozoic carbonates from the Aravalli Supergroup, Western India. International Geology Review 41: 949-954.

Maheshwari, A., Sial, A.N., Chittora, V.K. y Harsh, B. 2002. A positive $\delta^{13}$ Ccarb anomaly in Paleoproterozoic carbonates of Aravalli Craton,Western India; "Support for a global isotopic excursion". Journal Asian Earth Science 21: 59-67.

Maheshwari, A., Sial, A.N., Gaucher, C., Bossi, J., Bekker, A., Ferreira, V.P. y Romano, A.W. 2010. Global nature of the Paleoproterozoic Lomagundi carbon isotope excursion: A review of occurrences in Brazil, India, and Uruguay. Precambrian Research 182: 274-299.

Master, S., Verhagen, B.T. y Duane, M.J. 1990. Isotopic signatures of continental and marine carbonates from the Magondi Belt, Zimbabwe: implications for the global carbon cycle at 2,0 Ga. En 23rd Earth Science Congress of Geological Society of South Africa. Abstracts 346-348, Cape Town.

Mehnert, K. R. 1968. Migmatites and the origin of granitic rocks, 391 p., Amsterdam.

Melezhik, V.A., Gorokhov, I.M., Fallick, A.E. y Gjelle, S. 2001. Strontium and carbon isotope geochemistry applied to dating of carbonate sedimentation: an example from high-grade rocks of the Norwegian Caledonides. Precambrian Research 108: 267-292.

Melezhik, V.A., Fallick, A.E. y Kuznetsov, A.B. 2005. Palaeoproterozoic, rift-related, 13C-rich, lacustrine carbonates, NW Russia-Part 2: Global isotope signal recorded in the lacustrine dolostones. Transactions of the Royal Society of Edinburgh Earth Science 95: 423-444. 
Melezhik, V.A., Huhma, H., Condon, D.J., Fallick, A.E. y Whitehouse, M.J. 2007. Temporal constraints on the Paleoproterozoic Lomagundi-Jatuli carbon isotopic event. Geology 35: 655-658.

Middlemost, E.A.K. 1994. Naming materials in magma/igneous rock system. Earth Science Review 37: 215-224.

Mirota, M.D. y Veizer, J. 1994. Geochemistry of Precambrian Carbonates. Aphebian Albanel Formations, Quebec, Canada. Geochimica et Cosmochimica Acta 58: 1735-1745.

Montel, J.M. y Vielzeuf, D. 1997. Partial melting of metagreywackes, Part II. Compositions of minerals and melts. Contributions to Mineralogy and Petrology 128: 176-196.

Patiño Douce, A.E. 1996. Effects of pressure and $\mathrm{H}_{2} \mathrm{O}$ content on the compositions of primary crustal melts. Transactions of the Royal Society of Edinburgh. Earth Science 87: 11-21.

Patiño Douce, A.E. y Johnston, A.D. 1991. Phase equilibria and melt productivity in the pelitic system: implications for the origin of peraluminous granitoids and aluminous granulites. Contributions to Mineralogy and Petrology 107: 202218.

Patiño Douce, A.E. y Harris, N. 1998. Experimental constraints on Himalayan anatexis. Journal of Petrology 39: 689-710.

Quartino, B. y Villar Fabre, J. 1967. Geología y petrología del basamento de Tandil y Barker, provincia de Buenos Aires, a la luz del estudio de localidades críticas. Revista de la Asociación Geológica Argentina 22: 223-251.

Santos, J.O.S., Hartmann, L.A., Bossi, J., Campal, N., Schipilov, A., Piñeyro, D. y McNaughton, N.J. 2003. Duration of the Transamazonian and its correlation within South America based on U-Pb SHRIMP geochronology of the la Plata Craton, Uruguay. International Geology Review 45: 27-48.

Schidlowski, M., Eichmann, R. y Junge, C.E. 1975. Precambrian sedimentary carbonates: carbon and oxygen isotope geochemistry and implications for the terrestrial oxygen budget. Precambrian Research 2: 1-69.

Schidlowski, M., Eichmann, R. y Junge, C.E. 1976. Carbon istope geochemintry of the Precambrian Lomagundi carbonate province, Rhodesia. Geochemical et Cosmochemical Acta 40: 449-455.

Schidlowski, M., Hayes, J.M. y Kaplan, I.R. 1983. Isotopic inferences of ancient biochemistries: carbon, hydrogen and nitrogen. En: Schopf, J.W. (ed.) Earth's 
Earliest Biosphere: Its Origin and Evolution. Princeton University Press, 149186, Princeton.

Schröder, S., Bekker, A., Beukes, N.J., Strauss, H. y van Niekerk, H.S. 2008. Rise in seawater sulphate concentration associated with the Paleoproterozoic positive carbon isotope excursion: evidence from sulphate evaporites in theç 2.2-2.1Gyr shallow marine Lucknow Formation, South Africa. Terra Nova 20: 108-117.

Shieh, Y.N. y Taylor Jr., H.P. 1969. Oxygen and carbon isotope studies of contact metamorphism of carbonate rocks. Journal of Petrolology 10: 307-331.

Siivola, J. y Schmid, R. 2007. List of Mineral Abbreviations. Recommendations by the IUGS Subcommission on the Systematics of Metamorphic Rocks: Web version 01.02.07. www. bgs.ac.uk/scmr/home.html.

Sun, S. y McDonough, W.F. 1989. Chemical and isotopic systematic of oceanic basalts: Implications for mantle composition and processes. En Saunders A.D. y Norry, M.J. (eds.) Magmatism in the Ocean Basins. Blackwell Scientific, 313-345, Boston.

Taylor, S.R. y McLennan, S.M. 1981. The composition and evolution of the continental crust: Rare earth element evidence from sedimentary rocks. Philosophical Transactions of the Royal Society of London 301: 381-399.

Thompson, A.B. 1982. Deshydration melting of pelitic rocks and the generation of $\mathrm{H}_{2} \mathrm{O}$-undersaturated granitic liquids. American Journal of Science 282: 1567-1595.

Trompette, R. 1994. Geology of Western Gondwana (2000-500 Ma). Pan-AfricanBrasiliano aggregation of South America and Africa. Rotterdam Bakelma, 350 p.

Valley, J.W. 1986. Stable isotope geochemistry in metamorphic rocks. En Valley, J.W., Taylor, H.P. y O'Neil, J.R. (eds.) Stable Isotopes in High Temperature Geological Processes. MSA Reviews in Mineralogy 16: 445-490, Washington.

Valley, J.W. 2003. Oxygen isotopes in zircon. En Hanchar, J.M. y Hoskin, P.W.O. (eds.) Zircon, Reviews in Mineralogy and Geochemistry 53: 343-385.

Watt, G.R y Harley, S.L. 1993. Accessory phase controls on the geochemistry of crustal melts and restites produced during water-unsaturated partial melting. Contributions to Mineralogy and Petrology 114: 550-566.

Winkler, H.G.H. 1979. Petrogénesis de rocas metamórficas. H. Blume Ediciones, 346 p., Madrid. 
Winkler, H.G.H y von Platen, H. 1961. Experimentelle Gesteinsmetamorphose-V. Experimentelle Anatektischer Schmelzen und ihre Petrogenetische Bedeutung. Geochimica et Cosmochimica Acta 24: 250-265.

Woodhead, J.D. y Hergt, J.M. 1997. Application of the double spike technique to $\mathrm{Pb}$-isotope geochronology. Chemical Geology 138: 311-321.

Young, G.M., Long, D.G.F., Fedo, C.M. y Nesbitt, H.W. 2001. Paleoproterozoic Huronian basin: product of a Wilson cycle puntuacted by glaciations and a meteorite impact. Sedimentary Geology 141: 233-250. 


\section{CAPÍTULO 3.B}

\section{ROCAS IGNEAS DEL BASAMENTO}

\section{DEL ÁREA DE SAN MIGUEL}

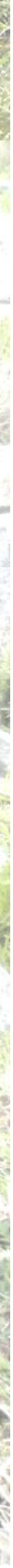




\section{B.1 INTRODUCCIÓN}

En el presente apartado se exponen los resultados de los estudios realizados sobre los cuerpos ígneos mencionados en el inicio del capítulo 3. Estos corresponden: al granito que constituye el Cerro Guacho, la tonalita del casco de la estancia San Miguel y del Cerro Los Angelitos (estancia Siempre Verde) y a un conjunto de diques ácidos y uno intermedio básico, presentes en el área.

El objetivo es definir las características geológicas y la relación de intrusión de dichos cuerpos con las rocas metamórficas (capítulo 3.A).

\section{B.2 CERRO GUACHO}

\section{B.2.1 Introducción}

El Cerro Guacho constituye uno de los puntos más elevados del área de San Miguel, con una altura de 320 m.s.n.m y $45.000 \mathrm{~m}^{2}$ de superficie expuesta (Fig. 3.1 y 3.2a), que llama la atención no sólo por su altura y morfología redondeada sino también por su desvinculación aparente con el resto de los afloramientos ya que se encuentra enteramente rodeado por suelos (Fig. 3.B.1).

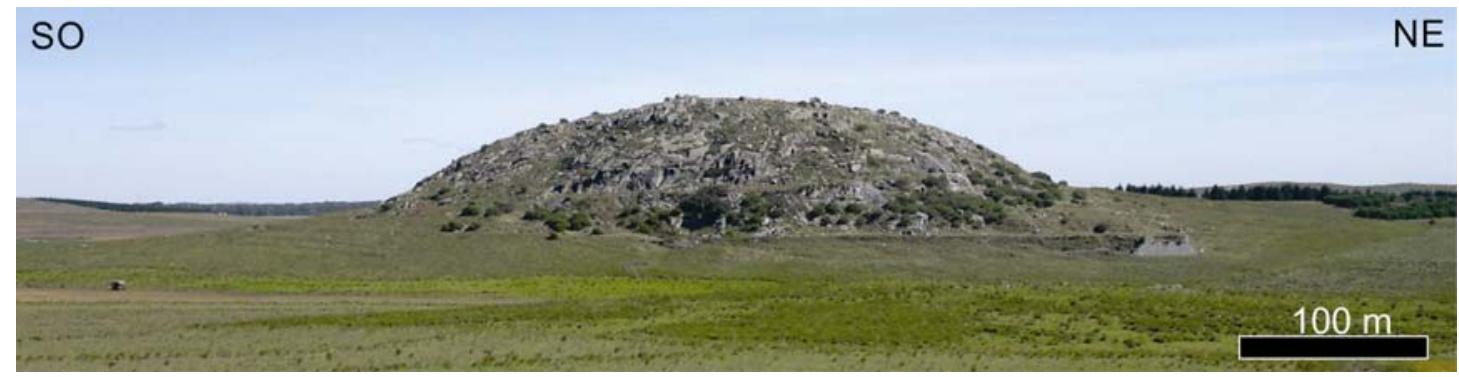

Figura 3.B.1: Vista del Cerro Guacho tomada desde la estancia San Miguel. Su morfología redondeada irrumpe entre los suelos cultivados. En el flanco derecho de la imagen se distingue un antiguo muro construido con el mismo material que se movilizaba en la cantera durante la época de explotación. 
En éste afloran rocas ígneas de composición granítica con evidencias de deformación, intruidas por vetas pegmatoideas con turmalina y por un dique granítico de 2 metros de espesor con rumbo general NO-SE, que será descripto en el apartado 3.B.4.

En el sector norte del cerro se inició, a comienzos del siglo XX la explotación de material granítico, actividad que se mantuvo aproximadamente hasta 1940, fecha en la que se interrumpió, perdurando inactiva hasta la actualidad (Fig. 3.B.2a y b). Esta explotación tenía como finalidad la producción de bloques para la posterior confección de adoquines y postes; se efectuaba mediante la utilización de barrenos (Fig. 3.B.2b) y también en forma manual. Funcionaba con un sistema de vagonetas que descendian por gravedad desde la cantera hasta el lugar de embarque ferroviario. Teniendo en cuenta que la superficie del laboreo ronda los $10.000 \mathrm{~m}^{2}$, se estima que se extrajeron aproximadamente $40.000 \mathrm{~m}^{3}$ de roca.

Se identificaron dos variedades litológicas explotadas, una corresponde a un granito de coloración grisácea con tamaño de grano medio y la otra variedad corresponde a un gneis biotítico que constituye la roca de caja del cuerpo ígneo, la cual ya fue descripta en el capítulo 3.A.2

\section{B.2.2 Caracterización geológica y petrográfica}

En este cerro aflora predominantemente una roca con textura microgranular, de aspecto masivo y color gris oscuro (Fig. 3.B.3a). En sectores periféricos del cuerpo ígneo, se observan xenolitos de una roca bandeada correspondiente a la roca de caja (gneis biotítico) y xenolitos de coloración oscura que ya se han descripto en el interior del gneis en el capitulo 3.A (Fig. 3.B.3b). La roca predominante, posee una mineralogía principalmente constituida por cuarzo, feldespato potásico, plagioclasas y escasa biotita (Fig. 3.B.4a y b). El cuarzo es el principal constituyente, presenta cristales de tamaños entre 0,5 y 1 milimetros, bordes irregulares y lobulados y evidencias de procesos de deformación como extinción ondulosa y bandas de deformación (Fig. 3.B.4b). 

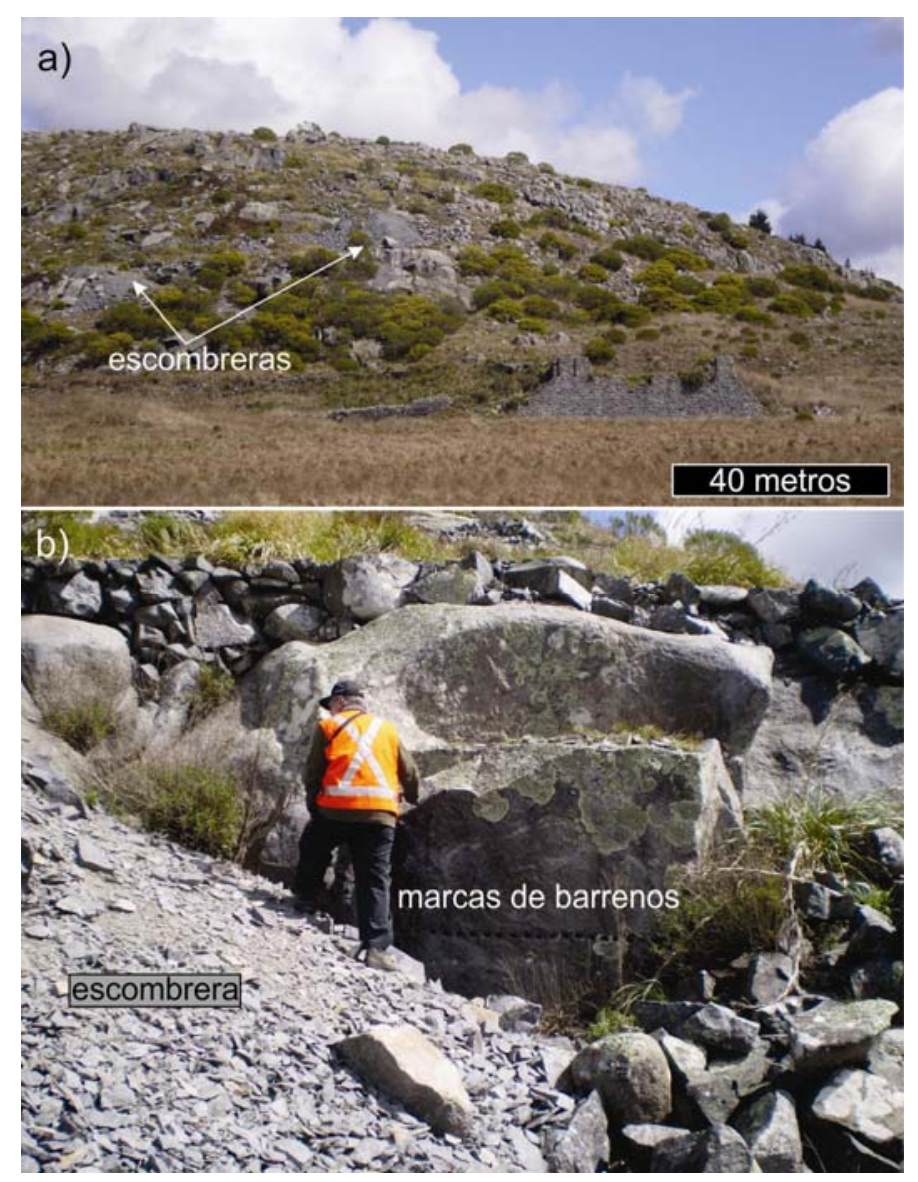

Figura 3.B.2: a) Vista del flanco explotado del cerro, con los sectores de escombreras. Aún permanecen de pié muros construidos con material de la explotación utilizados como contención ante posibles derrumbes. b) En las escombreras pueden verse las perforaciones correspondientes a los barrenos.

El feldespato potásico posee tamaños similares al cuarzo entre 0,8 y 1,2 milimetros, con desarrollos anhedrales, macla tipo Carlsbad y una incipiente alteración arcillosa (Fig. 3.B.4b). Los cristales de plagioclasas son escasos, anhedrales y con macla polisintética (Fig. 3.B.4b). Su composición aproximada por el método de Michel-Lévy es anortita $18^{-24}$, correspondiente a una oligoclasa. Al igual que el feldespato potásico las plagioclasas presentan una leve alteración a minerales de la familia de las arcillas. La biotita es escasa y crece de forma intersticial, por lo que no desarrolla hábitos muy definidos. Posee un color castaño característico y pleocroísmo a castaño 
claro y en algunos casos una moderada desferrización y pérdida de color (Fig. 3.B.4a).
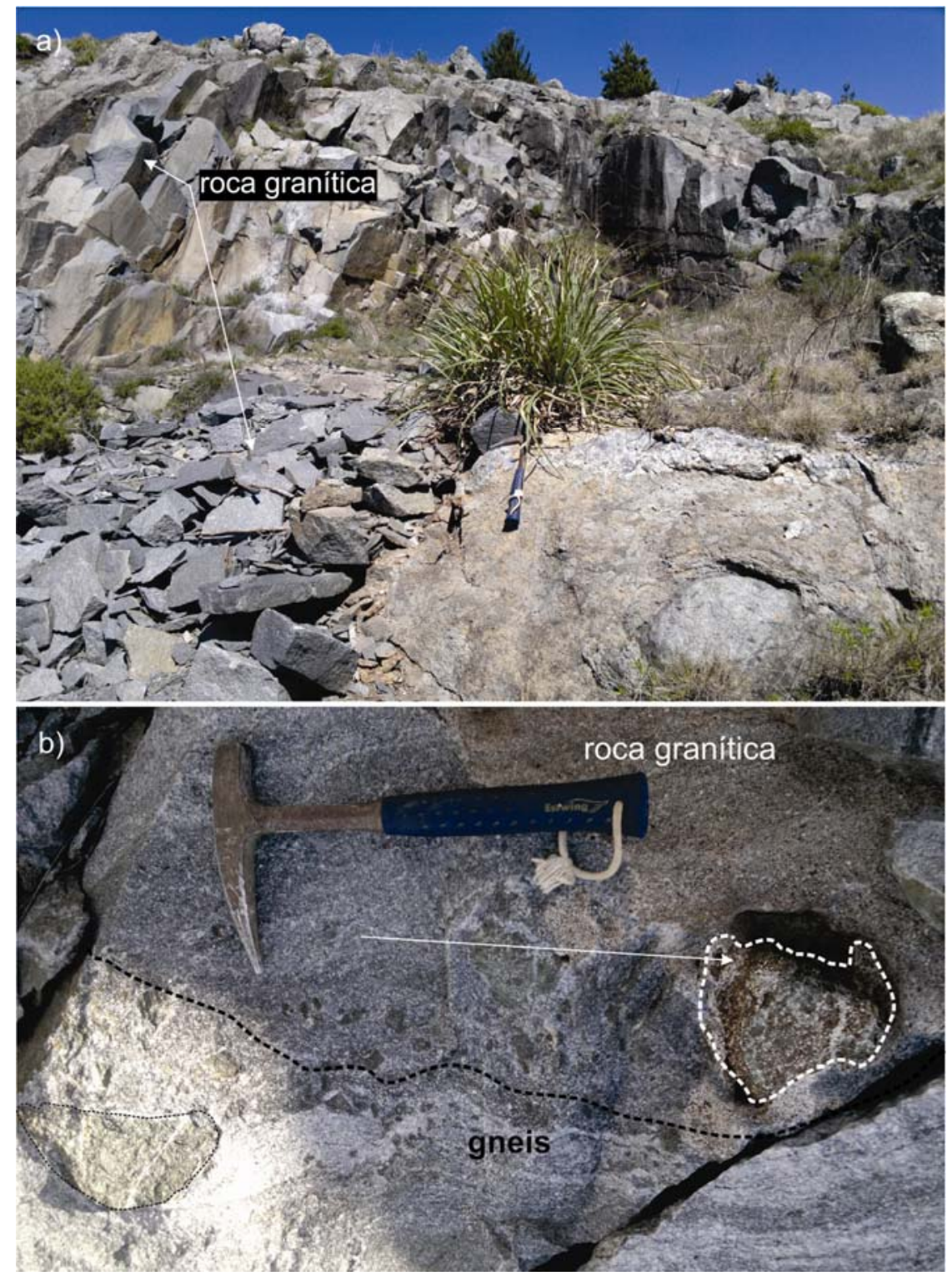

Figura 3.B.3: a) En uno de los antiguos sectores de explotación puede observarse la roca granítica de color gris utilizada para fabricar los adoquines y postes. b) La roca granítica intruye al gneis biotítico migmático (capítulo 3.A) que en este sector también presenta xenolitos máficos. 


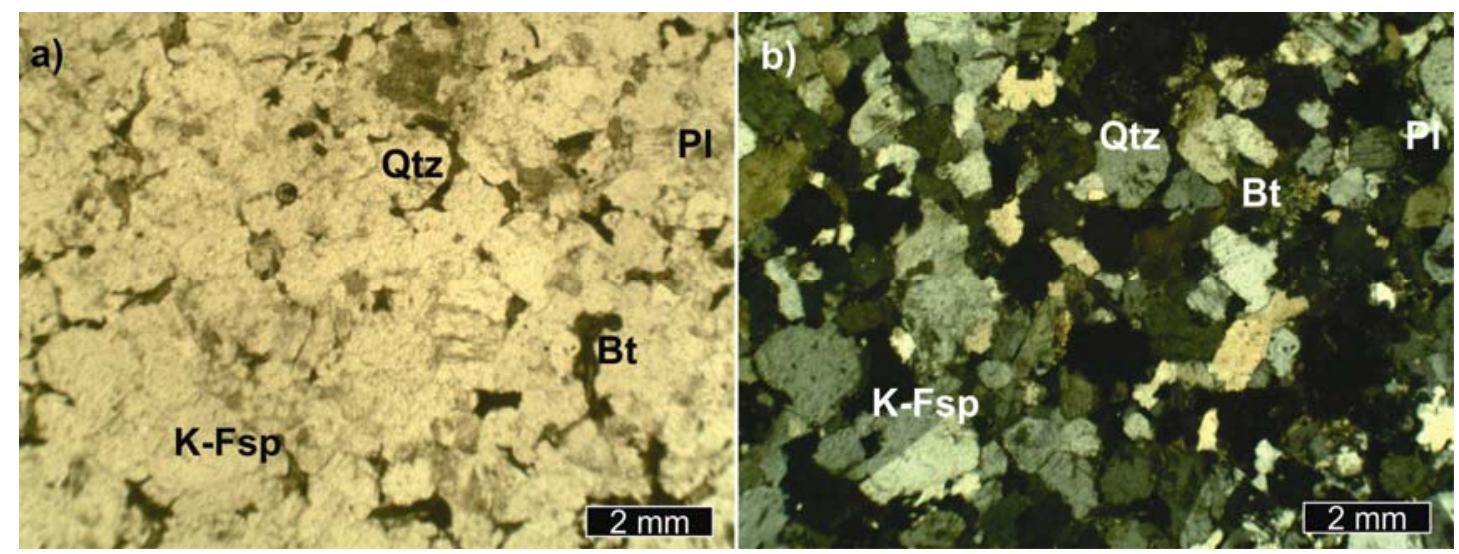

Figura 3.B.4: a) Aspecto microscópico y mineralogía de la roca granítica que aflora en el Cerro Guacho, sin analizador, se puede observar el desarrollo intersticial de la biotita que además se encuentra desferrizada. b) Con analizador se ve la morfología irregular de los cristales de cuarzo. Los feldespatos potásicos presentan macla de Karlsbad y las plagioclasas macla polisintética. Abreviaturas minerales según Kretz (1983) y Siivola y Schmid (2007).

\section{B.2.3 Caracterización geológica y petrográfica de los cuerpos pegmatoideos}

Se identificaron cuerpos feldespático - cuarzosos de aspecto vetiforme, portadores de turmalina que presentan de 2 a 3 metros de longitud y un espesor variable entre 20 y 50 centímetros (Fig. 3.B.5a). Estos se disponen en forma subhorizontal en el flanco noroccidental del Cerro Guacho. En dicho sector se localiza una cantera de granito inactiva, la cual facilita el reconocimiento de las relaciones de corte entre los cuerpos pegmatoideos y la roca granítica cuyas coordenadas son $37^{\circ} 34^{\prime} 15^{\prime \prime}$ sur y $59^{\circ} 23^{\prime} 27^{\prime \prime}$ oeste (Fig. 3.B. $5 \mathrm{~b}$ y c).

La mineralogía de estos cuerpos está representada fundamentalmente por feldespato alcalino tipo microclino y en menor proporción por cuarzo, plagioclasas y turmalina (Fig. 3.B.5d). Los cristales de la asociación mineral tienen un tamaño variable, entre algunos milimetros y 5-6 centímetros, correspondiendo los individuos más grandes a microclino. A escala mesoscópica se reconocen dos tipos de feldespatos, uno de color gris oscuro de mayor tamaño y otro más pequeño de tonalidad blanquecina (Fig. 3.B.5d). 

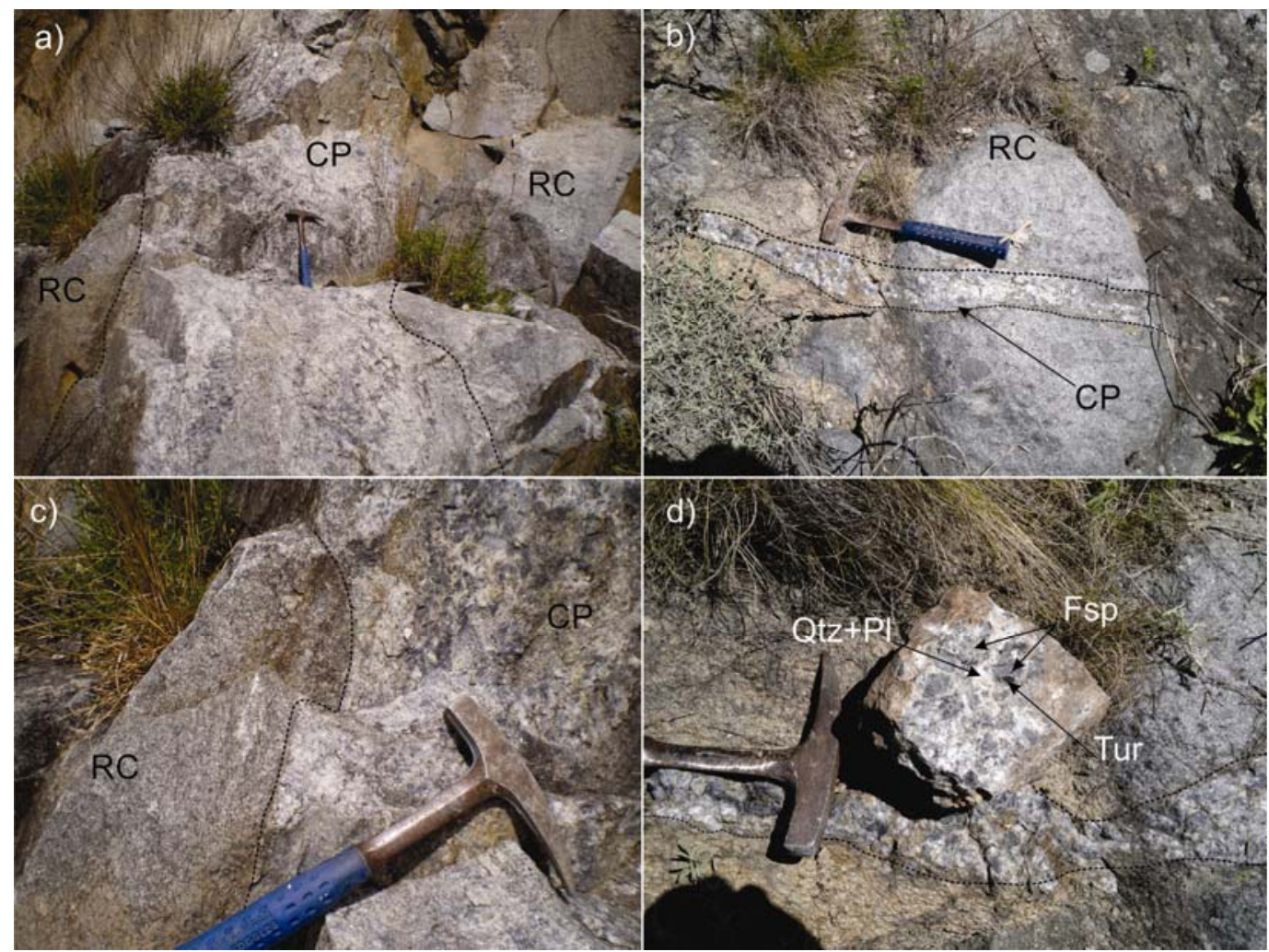

Figura 3.B.5: Cuerpos pegmatoideos. a) Uno de los cuerpos pegmatoideos (CP) intruido en la roca granítica ( $\mathrm{RC})$. b) Cuerpo de aspecto vetiforme de menor espesor, en la foto puede observarse la diferencia granulométrica con la roca de caja. c) Detalle del contacto entre el cuerpo pegmatoideo y la roca granítica. d) Aspecto mesoscópico del cuerpo pegmatoideo donde se indica la mineralogía constituida por cuarzo, plagioclasa, turmalina y feldespato potásico de color gris oscuro. Abreviaturas minerales según Siivola y Schmid (2007).

Al microscopio se observa la mineralogía constituída por microclino, cuarzo, plagioclasa y turmalina (Fig. 3.B.6a y b). El microclino posee macla en enrejado, bordes irregulares y texturas pertíticas y mirmequíticas (Fig. 3.B.6b y c). El cuarzo es ahumado, muy escaso y posee extinción ondulosa (Fig. 3.B.6b, c y d). Las plagioclasas son poco abundantes y desarrollan cristales pequeños incluidos en individuos de microclino (Fig. 3.B.6c y d). Las turmalinas son anhedrales con pleocroísmo marcado entre castaño 
oscuro y claro, sin zonación (Fig. 3.B.6e y f) y crecen en forma intersticial entre los cristales de microclino, o como coronas de reemplazo sobre el feldespato.

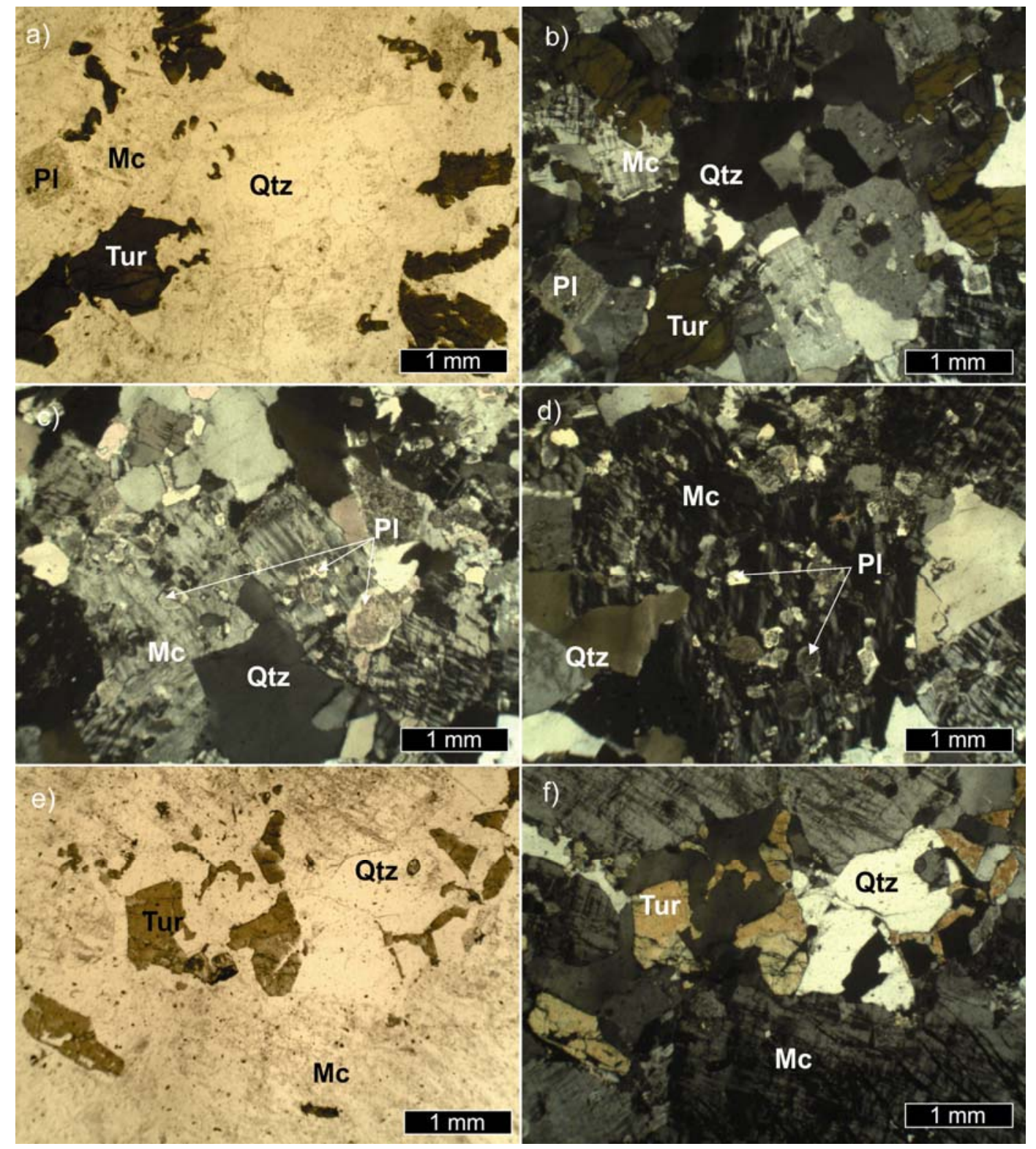

Figura 3.B.6: Aspecto microscópico de los cuerpos vetiformes con turmalina. a y b) Mineralogía y textura de las vetas, sin y con analizador, respectivamente. c y d) Grandes cristales de microclino con macla en enrejado e inclusiones de cristales de plagioclasas y cuarzo con bordes irregulares y leve extinción ondulosa, con analizador. e y f) Cristales de turmalina anhedrales, con pleocroísmo de castaño a 
verde amarillento, sin y con analizador respectivamente. Como se observa en la imagen crecen en forma intersticial o como coronas de reemplazo. Abreviaturas minerales según Siivola y Schmid (2007).

\section{B.2.3.1 Turmalina}

Las turmalinas son minerales accesorios comunes en rocas ígneas y metamórficas (London et al. 1996). Sin embargo no habían sido estudiadas hasta el momento en rocas pertenecientes al basamento de las Sierras Septentrionales de la provincia de Buenos Aires. Las turmalinas pueden registrar y preservar cambios químicos durante su cristalización, así el estudio de este mineral, permite realizar consideraciones sumamente importantes desde el punto de vista genético (Henry y Guidotti 1985; Dutrow y Henry 2000). Por este motivo, la caracterización petrográfica, mineralógica y química de los cristales de turmalina identificados en cuerpos pegmatoideos con aspecto vetiforme relevados en el Cerro Guacho, tiene como objetivo determinar los procesos responsables de la formación de este mineral. De este modo, se podrá avanzar en el estudio y entendimiento de las complejas relaciones existentes entre los procesos ígneos y metamórficos en la zona de estudio.

Estos silicatos, poseen una fórmula general (según Hawthorne y Henry 1999):

\section{$X \mathrm{Y}_{3} \mathrm{Z}_{6}\left(\mathrm{~T}_{6} \mathrm{O}_{18}\right)\left(\mathrm{BO}_{3}\right)_{3} \mathrm{~V}_{3} \mathrm{~W}$}

Siendo:

$\mathbf{X}=\mathrm{Na}^{+1}, \mathrm{Ca}^{+2}$, vacante. Según Henry et al. (2011), este sitio también puede incluir $\mathrm{K}^{+1}$.

$\mathbf{Y}=\mathrm{Li}^{+1}, \mathrm{Fe}^{+2}, \mathrm{Mg}^{+2}, \mathrm{Mn}^{+2}, \mathrm{Al}^{+3}, \mathrm{Cr}^{+3}, \mathrm{Fe}^{+3}, \mathrm{~V}^{+3}, \mathrm{Ti}^{+3}$.

$\mathbf{Z}=\mathrm{Mg}^{+2}, \mathrm{Al}^{+3}, \mathrm{Fe}^{+3}, \mathrm{~V}^{+3}, \mathrm{Cr}^{+3}$.

$\mathbf{T}=\mathrm{Si}^{+4}, \mathrm{Al}^{+3}, \mathrm{~B}^{+3}$

$\mathbf{B}=\mathrm{B}^{+3}$, vacante.

$\mathbf{V}=\mathrm{OH}^{-}, \mathrm{O}^{-2}$. 
$\mathbf{W}=\mathrm{OH}^{-}, \mathrm{F}^{-}, \mathrm{O}^{-2}$.

Poseen numerosas propiedades significativas, entre las cuales se destacan: su estabilidad en un amplio rango de presión y temperatura, su resistencia a la alteración física y química, su variabilidad composicional y su capacidad de intercambiar iones con fluidos externos (Henry y Dutrow 1996).

Su cristalización puede deberse a distintos procesos geológicos. Según Pesquera y Velasco (1997) el reemplazo metasomático de ciertos silicatos preexistentes puede generarse por la saturación de fluidos acuosos cargados en boro, durante los últimos estadios de consolidación de un magma granítico. La introducción de boro en la etapa neumatolítica produce el reemplazo de minerales ígneos, donde las biotitas y feldespatos son los primeros minerales en ser reemplazados por turmalina, mientras que el cuarzo permanece estable (Deer et al. 1996). Si el reemplazo es completo, la asociación final de la roca será cuarzo + turmalina. Por otro lado, Slack (1993) y Peng y Palmer (1995) proponen que la turmalina se forma por removilización de fluidos ricos en boro, durante procesos metamórficos, metasomáticos e hidrotermales.

\section{B.2.3.2 Resultados de los estudios sobre cristales de turmalina}

Los difractogramas efectuados presentan picos máximos e intensidades en: 2,58 (100\%); 3,99 (90\%); 2,95 (70\%) correspondientes al PDF 43-1464, variedad Chorlo (Fig. 3B.7).

La micrografia de la Fig. 3.B.8 muestra la morfología prismática de un cristal de la especie estudiada. En la misma se observan secciones triangulares redondeadas y fractura concoidal, características típicas de este mineral. 


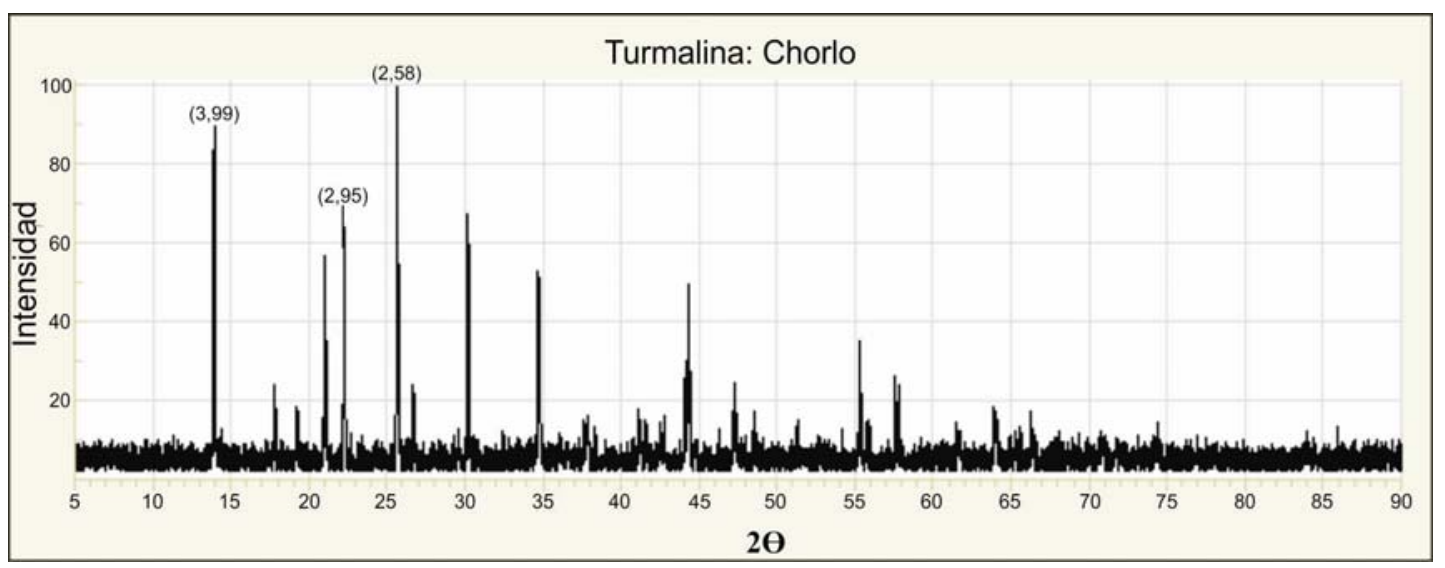

Figura 3.B.7: Difractograma de cristales de turmalina. Se observa que los picos característicos corresponden a la variedad Chorlo.

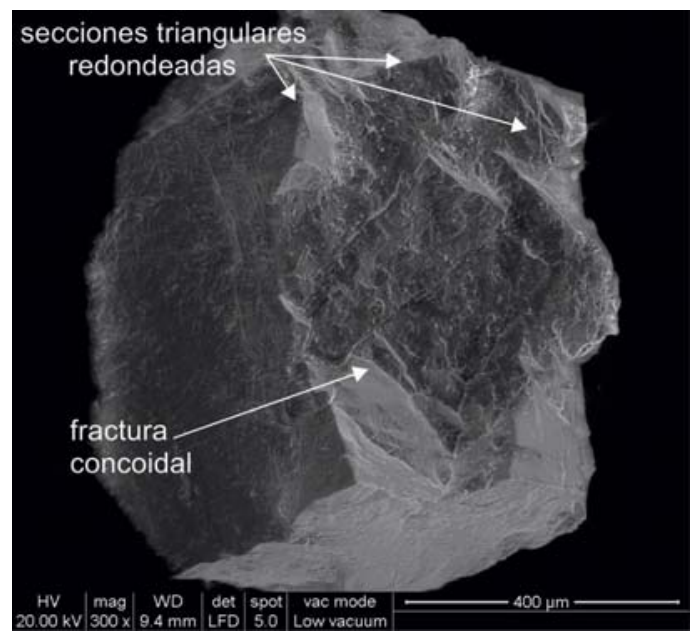

Figura 3.B.8: Fotomicrografia de un cristal de turmalina obtenida mediante un microscopio electrónico de barrido. Obsérvense las secciones triangulares redondeadas y la fractura concoidal, características típicas de este mineral.

El estudio de espectroscopia FTIR (Fourier Transform Infrared espectrocopy) ha permitido observar la influencia de las sustituciones catiónicas sobre los enlaces químicos. El espectro de la Fig. 3.B.9 se caracteriza por las débiles bandas en 3746 y $3655 \mathrm{~cm}^{-1}$, asignadas a vibraciones del agua. La ancha banda centrada en $3436 \mathrm{~cm}^{-1}$ es debida a grupos $(\mathrm{OH})^{-}$y puentes de $\mathrm{H}$ del $\mathrm{H}_{2} \mathrm{O}$. La señal en $1616 \mathrm{~cm}^{-1}$ se corresponde con la deformación angular del $\mathrm{H}_{2} \mathrm{O}$. La zona de $1400 \mathrm{~cm}^{-1}$ se caracteriza por presentar tres bandas 
seguidas, siendo la central en $1375 \mathrm{~cm}^{-1}$ la de mayor intensidad. Ésta se puede atribuir a la presencia de grupos boratos $\left(\mathrm{BO}_{3}\right)^{-3}$, donde los estiramientos B-O se localizan en 1350-1240 $\mathrm{cm}^{-1}$ (Farmer 1974). En la zona de $1200-1000 \mathrm{~cm}^{-1}$ se localizan las bandas de los estiramientos de los enlaces $\mathrm{Si}-\mathrm{O}$, grupos $\left(\mathrm{SiO}_{4}\right)^{-4}$, la misma está caracterizada por un hombro en $1078 \mathrm{~cm}^{-1}$ y un máximo en $988 \mathrm{~cm}^{-1}$, para las variedades de chorlo esta señal se ha reportado en 1077-983 $\mathrm{cm}^{-1}$ (Blanco 1988). En este rango aparecen también las vibraciones del Al-O en posición tetraédrica cuando hay reemplazo de Si por Al.

La zona comprendida entre 800 y $500 \mathrm{~cm}^{-1}$ del espectro es la más difícil de asignar con precisión, dado que en ella se encuentran las señales de las deformaciones angulares de las especies de $\mathrm{Si}$, así como el reemplazo de $\mathrm{Si}$ por $\mathrm{Al}$ en posición tetraédrica, los estiramientos del enlace $\mathrm{M}-\mathrm{O}$ (particularmente cationes bivalentes en coordinación octaédrica), las vibraciones del $\mathrm{H}_{2} \mathrm{O}$ y grupos $\mathrm{OH}$, así como los modos de red. Es destacable que en el rango comprendido entre $550-470 \mathrm{~cm}^{-1}$ aparece una banda intensa que ha sido atribuida a iones trivalentes en posiciones octaédricas, que pueden asignarse a los modos de vibración del Al (Blanco 1988; Farmer 1974).

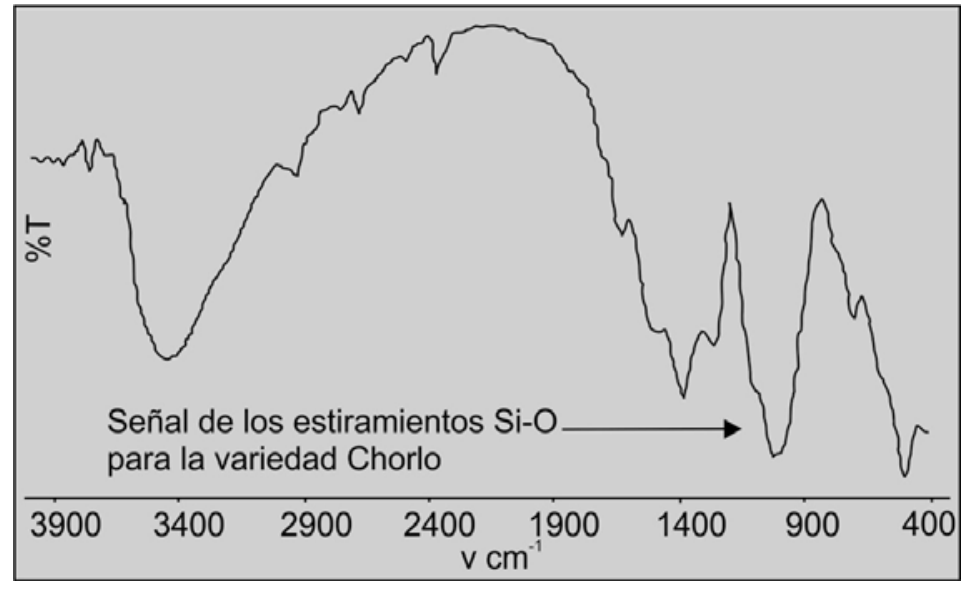

Figura 3.B.9: Espectro FTIR obtenido de los cristales de turmalina. 
Los resultados de los análisis químicos realizados se indican en la Cuadro 3.B.1, como datos promedio de cristales sin zonación y que arrojaron composiciones similares.

\begin{tabular}{|lr|}
\hline Óxidos & Porcentaje \\
$\mathbf{N a O}$ & 1,94 \\
$\mathbf{M g O}$ & 5,28 \\
$\mathbf{A l}_{\mathbf{2}} \mathbf{O}_{\mathbf{3}}$ & 38,69 \\
$\mathbf{S i O}_{\mathbf{2}}$ & 42,01 \\
$\mathbf{K}_{\mathbf{2}} \mathbf{O}$ & 0,36 \\
$\mathbf{C a O}$ & 0,99 \\
$\mathbf{T i O}_{2}$ & 1,02 \\
$\mathbf{F e O}_{\text {(total) }}$ & 9,71 \\
Total & 100,00 \\
\hline
\end{tabular}

Cuadro 3.B.1: Contenido promedio de óxidos de las turmalinas expresado en \% en peso.

\section{B.2.3.3 Discusión y consideraciones genéticas}

Los estudios de DRX permitieron definir que la especie estudiada corresponde al grupo espacial $\mathrm{R} 3 \mathrm{~m}$, variedad Chorlo.

El análisis del espectro obtenido por FTIR confirmó la presencia de grupos $\mathrm{OH}$ en el sitio $\mathrm{V}$ y de $\left(\mathrm{BO}_{3}\right)^{-3}$ en el sitio $\mathrm{B}$, por las intensas señales identificadas en las zonas de $3400 \mathrm{~cm}^{-1}$ y $1400 \mathrm{~cm}^{-1}$, respectivamente.

Si bien la presencia de Li no ha podido ser determinada, se asume un contenido inferior a 0,5 átomos por unidad de fórmula en el sitio Y, conforme a los datos bibliográficos para la especie determinada (Henry et al. 2011), en concordancia con los altos tenores en boro.

Sobre la base de los resultados obtenidos y los datos químicos promedio se pudo aproximar la fórmula química de la especie:

\section{$\left(\mathrm{Na}_{0,7} \mathrm{~K}_{0,1,} \mathrm{Ca}_{0,2}\right)\left(\mathrm{Li}_{<0,5} \mathrm{Fe}_{1,2} \mathrm{Mg}_{<1,2} \mathrm{Ti}^{+3}{ }_{0,3}\right) \mathrm{Al}_{6}\left[\mathrm{Al}_{0,5} \mathrm{Si}_{5,5}\left(\mathrm{BO}_{3}^{-3}\right)_{3}\right](\mathrm{OH}, \mathrm{F})_{4}$}

Según Henry y Guidotti (1985) existe una relación entre la variedad de turmalina y el tipo de roca de la cual deriva. En los diagramas de la Fig. 
3.B.10 propuestos por estos autores, se ha graficado la composición de las turmalinas estudiadas, ubicándose en el campo 2, correspondiente a granitoides, aplitas y pegmatitas pobres en Li. Así se interpreta que los cuerpos vetiformes estudiados portadores de turmalina evidencian un origen ígneo.

Esta hipótesis genética es respaldada por los estudios petrográficos de los cuerpos pegmatoideos, donde la presencia de coronas de turmalina sobre cristales de microclino, representan el reemplazo ocurrido en los últimos estadios de cristalización magmática por la saturación en boro de los fluidos ígneos (Deer et al. 1996).

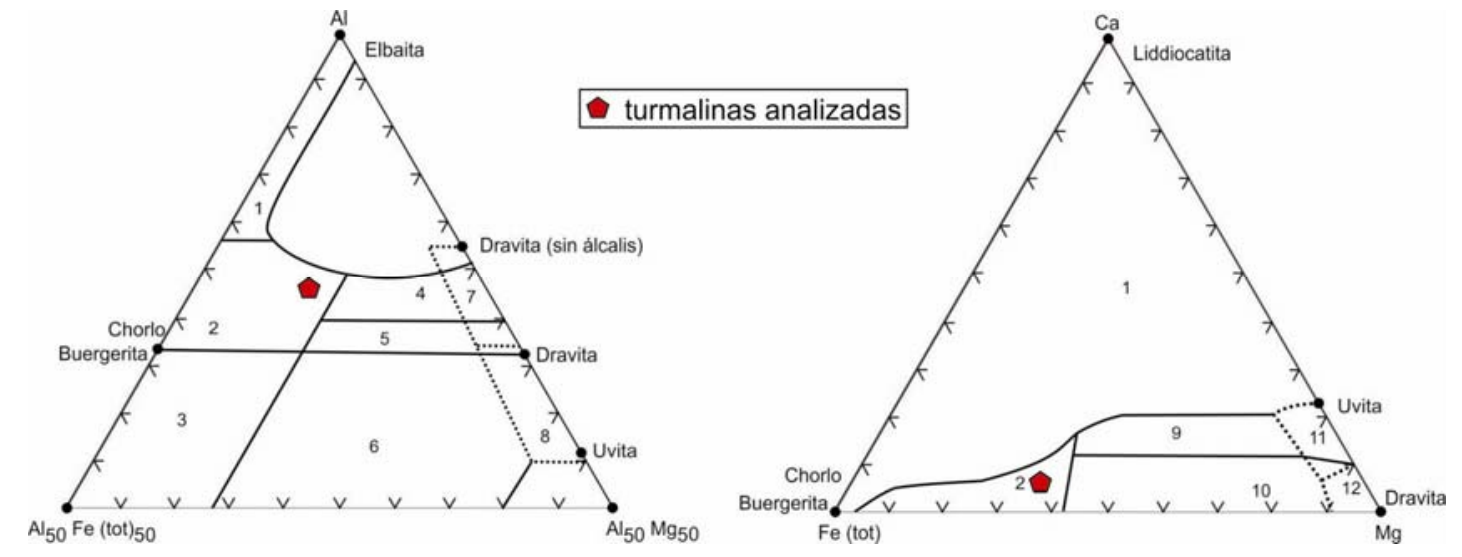

Figura 3.B.10: Diagramas de clasificación de Henry y Guidotti (1985). Campos: 1Granitoides, aplitas y pegmatitas ricas en Li, 2-Granitoides, aplitas y pegmatitas pobres en $\mathrm{Li}$, 3-Rocas cuarzo-turmalínicas ricas en $\mathrm{Fe}^{+3}$, 4-Metapsamitas y metapelitas saturadas en Al, 5-Metapsamitas y metapelitas no saturadas en Al, 6Metapelitas, rocas calcosilicatadas y cuarzo-turmalínicas ricas en $\mathrm{Fe}^{+3}$, 7Metaultramafititas ricas en $\mathrm{Ca}$, 8-Metacarbonatos y metapiroxenitas, 9-Metapelitas y metapsamitas ricas en Ca y rocas calcosilicatadas, 10-Metapelitas pobres en Ca, metapsamitas y rocas cuarzo-turmalínicas, 11-Metacarbonatos y 12Metaultramafititas. 


\section{B.3 CUERPOS TONALÍTICOS}

\section{B.3.1 Introducción}

Este tipo de rocas aflora en dos sectores dentro del área de estudio: en el casco de la estancia San Miguel y en el cerro Los Angelitos (estancia Siempre Verde), Fig. 3.2a y b. El primero es un afloramiento pequeño constituido por varios asomos de aspecto redondeado (Fig. 3.B.11a), ubicados al sur de los correspondientes al skarn. El conjunto totaliza unos 500 metros de longitud máxima en dirección NE-SO y un ancho máximo de 200 metros en dirección casi perpendicular a la anterior. Las alturas registradas alcanzan los 280 a 290 m.s.n.m. Este afloramiento se encuentra hacia el NO en contacto con el gneis biotítico migmático al cual intruye y con los leucosomas granatíferos descriptos en el capítulo 3.A (Fig. 3.2a), mientras que el resto de sus límites se pierde bajo la cobertura de suelos. Además, se encuentra intruido por cuerpos diqueiformes que se describirán en un apartado a continuación. Mesoscópicamente posee una textura granular y dado su tamaño de grano medio pueden identificarse fácilmente minerales como cuarzo, plagioclasas, biotita y anfíboles (Fig. 3.B.11b). En pocos sectores desarrolla una leve foliación que consiste en un bandeado composicional.

El otro afloramiento (Cerro Los Angelitos) posee dimensiones mayores (Fig. 3.B.11c), con una superficie total de $530 \mathrm{~m}^{2} \mathrm{y}$ una altura máxima de 380 m.s.n.m (Fig. 3.2b). Se encuentra en las cercanías del afloramiento de skarn ubicado más hacia el sur, y también se presentan intruyendo al gneis biotítico (Fig. 3.2a). No se ha identificado en afloramiento la relación espacial con el skarn San Miguel. 

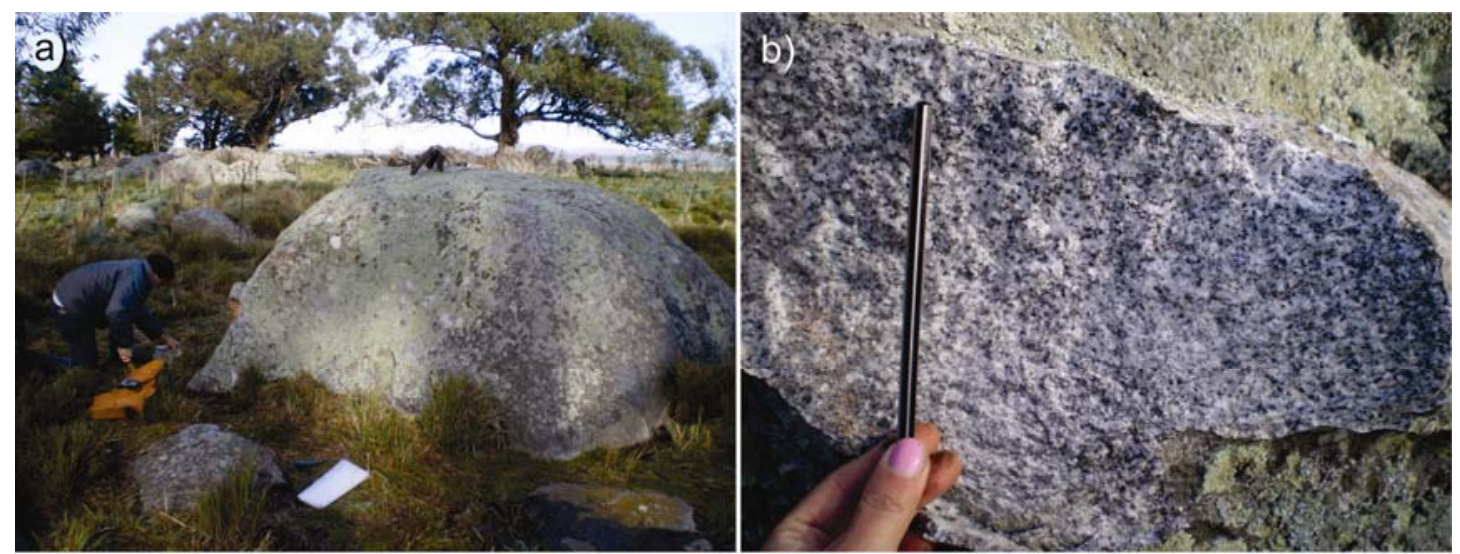

c)

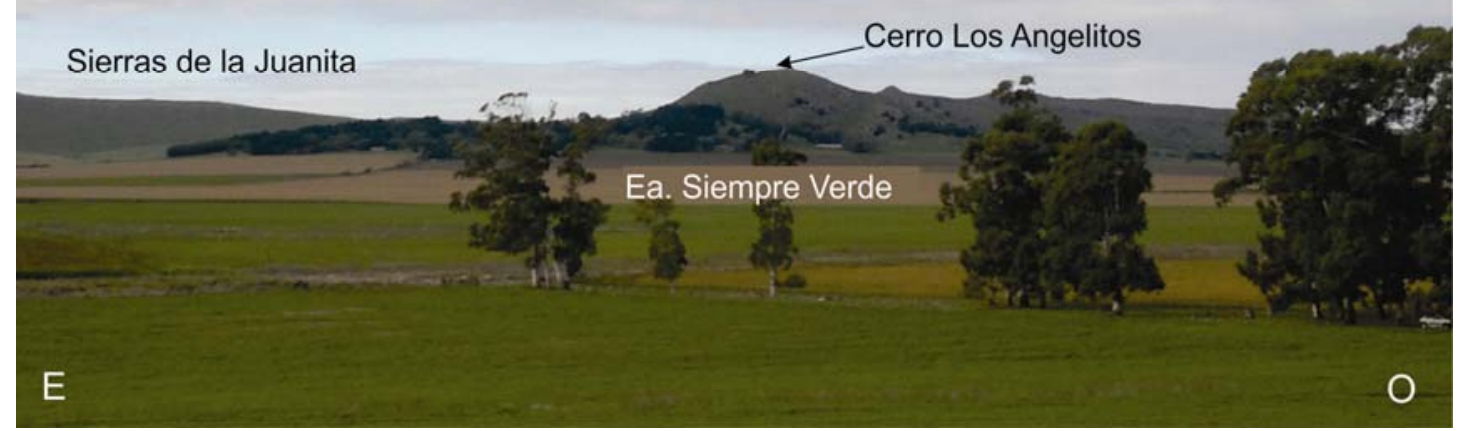

Figura 3.B.11: a) Aspecto de los afloramientos de la tonalita en el casco de la estancia San Miguel. b) Tonalita en muestra de mano, donde puede observarse su textura granular y su mineralogía compuesta por minerales leucocráticos y melanocráticos. c) Vista desde la estancia San Miguel del Cerro Los Angelitos donde también aflora la tonalita. En el fondo de la imagen las Sierras de la Juanita, correspondientes a los primeros afloramientos de la cobertura sedimentaria.

\section{B.3.2 Caracterización petrográfica}

Esta roca posee una coloración heterogénea entre blanquecina y gris oscura debida a la presencia de minerales leucocráticos y melanocráticos (Fig. 3.B.11b). Su textura es granular con tamaño de grano medio que ronda los 0,5-2 milímetros (Fig. 3.B.12a). Su mineralogía se compone de plagioclasas, cuarzo, anfibol de tipo hornblenda, biotita, escaso feldespato potásico y como accesorios circón y opacos (Fig. 3.B.12a y b). Los cristales de plagioclasas presentan desarrollos anhedrales a subhedrales, tamaños entre 0,5 y 1 milímetros (Fig. 3.B.12b), maclado polisintético y un leve 
reemplazo por minerales de las arcillas (Fig. 3.B.12a y c). La composición aproximada, estimada mediante el método de Michel-Lévy, es anortita55-75 (correspondiente a una labradorita). Los cristales de cuarzo presentan tamaños que rondan los 0,5 milimetros, poseen bordes irregulares y extinción ondulosa en la mayoría de los cristales (Fig. 3.B.12b). La hornblenda es de color verdoso levemente castaño, pleocroíca y posee, en general, hábito prismático poco desarrollado en cristales de 1,2 a 1,7 milimetros de largo, mientras que en algunos sectores presenta desarrollos esqueletales con inclusiones de cristales de cuarzo y plagioclasa (Fig. 3.B.12a). Los individuos de biotita son de color castaño rojizo y poseen halos pleocroicos debidos a la presencia de circones (Fig. 3.B.12a y c). Además, presentan en secciones basales, inclusiones aciculares de rutilo con macla de sagenita (Fig. 3.B12a). Los accesorios como el circón se encuentran tanto en cristales de biotita como en sectores con cuarzo y feldespato y manifiestan en todos los casos tamaños menores a 0,5 milimetros (Fig. 3.B.12d). Los opacos encontrados fueron interpretados como minerales oxidados asociados a la desferrización de la biotita.

\section{B.4 CARACTERIZACIÓN GEOQUÍMICA DE LAS UNIDADES}

Con el fin de realizar una completa caracterización y clasificación de las rocas que conforman las unidades antes descriptas, se realizaron análisis de elementos mayoritarios, trazas y tierras raras. Se seleccionaron dos muestras de cada unidad denominadas cg1 y cg2 (granito del Cerro Guacho) y t1 y t2 (tonalita), los resultados de dichos análisis se muestran en el Cuadro 3.B.2. Los porcentajes de óxidos mayoritarios fueron recalculados a $100 \%$ en base anhidra, como se recomienda para la confección de los distintos gráficos utilizados. 

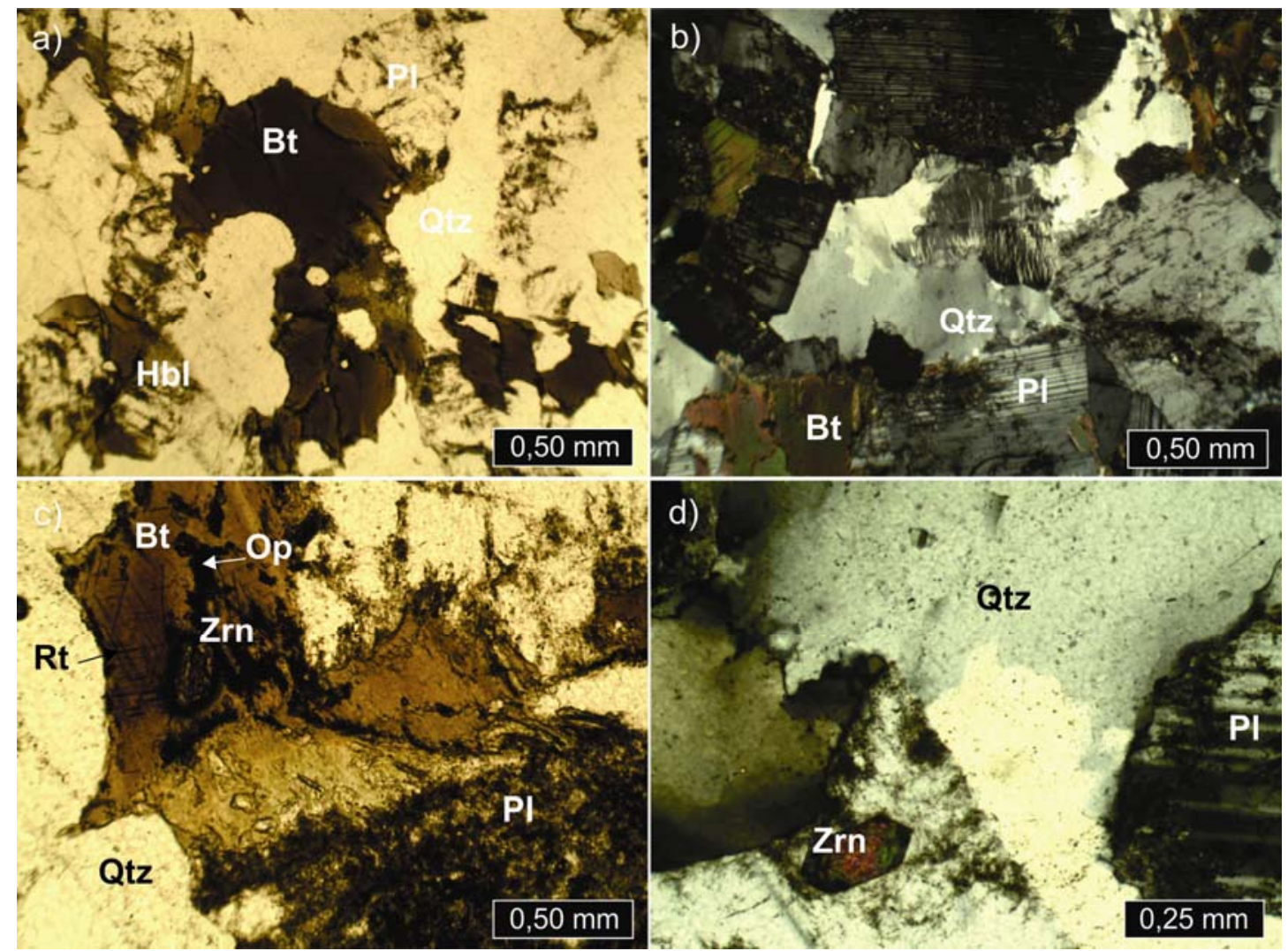

Figura 3.B.12: a) Aspecto microscópico de la tonalita sin analizador, donde se observa la textura granular y la mineralogía constituida por plagioclasa, cuarzo, biotita y hornblenda. b) Con analizador se observan la extinción ondulosa de los cristales de cuarzo y el maclado polisintético en las plagioclasas de desarrollo suhedral, estas últimas poseen una leve alteración a minerales de la familia de las arcillas. c) Cristales de biotita con inclusiones de rutilo, con macla de sagenita y halos pleocroícos por la presencia de circón, sin analizador. d) Cristal euhedral de circón, rodeado de plagioclasa levemente alterada y cuarzo anhedral, con analizador. Abreviaturas minerales según Kretz (1983) y Siivola y Schmid (2007).

Según la clasificación general de Irvine y Baragar (1971) que utiliza la relación $\mathrm{SiO}_{2}$ vs $\mathrm{Na}_{2} \mathrm{O}+\mathrm{K}_{2} \mathrm{O}$ las muestras estudiadas del Cerro Guacho quedan comprendidas en los campos subalcalinos de monzogranitos y las de tonalita, de acuerdo a lo esperado petrográficamente, en el de las de tonalitas (Fig. 3.B.13). También se utilizó la clasificación normativa Ab-AnOr de Barker (1979), norma CIPW (Cuadro 3.B.3). 


\begin{tabular}{|c|c|c|c|c|}
\hline Muestra & $\mathrm{t1}$ & t2 & $\operatorname{cg} 1$ & $\operatorname{cg} 2$ \\
\hline $\mathrm{SiO}_{2}$ & 63,00 & 64,20 & 72,30 & 71,00 \\
\hline $\mathrm{TiO}_{2}$ & 0,56 & 0,67 & 0,28 & 0,33 \\
\hline $\mathbf{A l}_{2} \mathbf{O}_{3}$ & 15,95 & 15,95 & 15,10 & 15,00 \\
\hline $\mathrm{Cr}_{2} \mathrm{O}_{3}$ & 0,04 & 0,04 & 0,03 & 0,03 \\
\hline $\mathrm{Fe}_{2} \mathrm{O}_{3}$ & 6,58 & 6,08 & 2,41 & 2,41 \\
\hline MnO & 0,07 & 0,09 & 0,04 & 0,02 \\
\hline MgO & 2,22 & 2,15 & 0,90 & 1,20 \\
\hline $\mathrm{CaO}$ & 4,79 & 4,69 & 2,25 & 2,55 \\
\hline $\mathrm{Na}_{2} \mathrm{O}$ & 3,55 & 3,45 & 4,38 & 3,87 \\
\hline $\mathbf{K}_{2} \mathbf{O}$ & 1,91 & 1,91 & 2,51 & 2,23 \\
\hline $\mathbf{P}_{2} \mathbf{O}_{5}$ & 0,12 & 0,17 & 0,10 & 0,10 \\
\hline LOI & 1,09 & 1,14 & 0,93 & 0,98 \\
\hline Total & 99,88 & 100,54 & 101,23 & 99,72 \\
\hline $\mathbf{B a}$ & 645 & 664 & 544 & 504 \\
\hline $\mathbf{C r}$ & 233,00 & 250 & 240 & 197 \\
\hline Cs & 4,60 & 4,76 & 21,2 & 22 \\
\hline Ga & 20 & 21,3 & 25,5 & 24,3 \\
\hline Hf & 4,7 & 4,6 & 4,1 & 4,1 \\
\hline $\mathbf{N b}$ & 6,9 & 7,6 & 4,8 & 4,3 \\
\hline $\mathbf{R b}$ & 88,2 & 89,7 & 168 & 154 \\
\hline Sn & 2 & 2 & 4 & 3 \\
\hline Sr & 503 & 554 & 246 & 258 \\
\hline $\mathrm{Ta}$ & 0,4 & 0,6 & 1 & 1 \\
\hline Th & 6,03 & 6,99 & 9,05 & 8,89 \\
\hline $\mathbf{U}$ & 0,79 & 0,82 & 2,95 & 2,01 \\
\hline $\mathbf{v}$ & 58,7 & 60 & 20 & 22 \\
\hline w & 12 & 14 & 14 & 17 \\
\hline $\mathbf{Z r}$ & 177 & 189 & 147 & 134 \\
\hline La & 39,9 & 41,7 & 28,5 & 27,7 \\
\hline $\mathrm{Ce}$ & 78 & 79,2 & 47,4 & 48 \\
\hline Pr & 9,01 & 8,97 & 4,68 & 4,66 \\
\hline Nd & 34 & 35,1 & 15,6 & 16 \\
\hline Sm & 6,22 & 6,07 & 2,35 & 2,07 \\
\hline Eu & 1,29 & 1,38 & 0,68 & 0,65 \\
\hline Gd & 4,43 & 4,64 & 1,33 & 1,33 \\
\hline Tb & 0,61 & 0,62 & 0,17 & 0,17 \\
\hline Dy & 3,01 & 3,21 & 0,69 & 0,54 \\
\hline Ho & 0,44 & 0,54 & 0,1 & 0,1 \\
\hline Er & 1,19 & 1,21 & 0,25 & 0,25 \\
\hline Tm & 0,15 & 0,18 & 0,04 & 0,04 \\
\hline $\mathbf{Y b}$ & 1,02 & 1,22 & 0,21 & 0,2 \\
\hline Lu & 0,13 & 0,16 & 0,01 & 0,01 \\
\hline $\mathbf{Y}$ & 14,7 & 15,3 & 3,1 & 3,1 \\
\hline
\end{tabular}

Cuadro 3.B.2: Resultados de análisis geoquímicos de muestras de la tonalita de San Miguel (t1 y t2) y del granito del Cerro Guacho (cg1 y cg2). Los óxidos mayoritarios están expresados en \% en peso, los elementos minoritarios y traza en ppm. El número de decimales depende de la exactitud del método para la detección del elemento. 


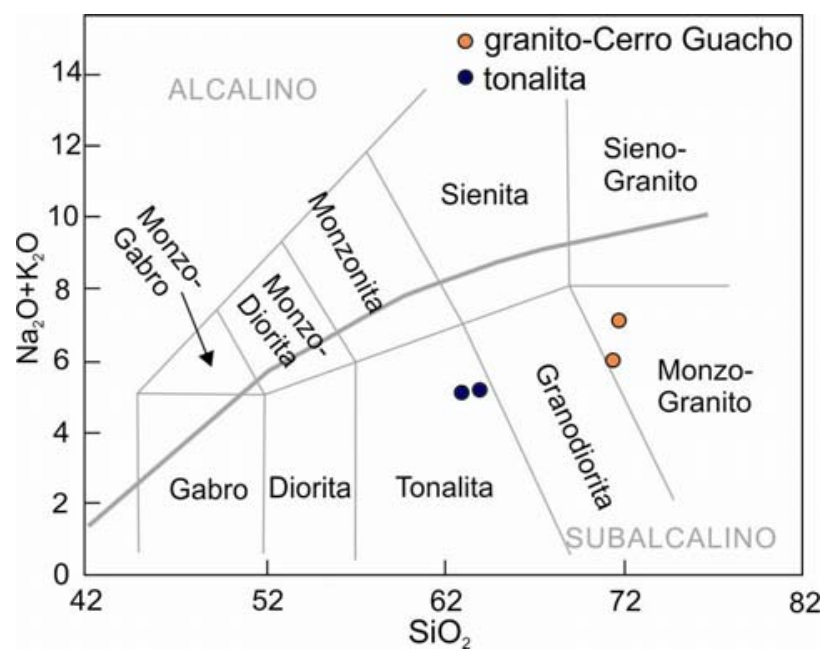

Figura 3.B.13: Diagrama de clasificación para rocas plutónicas (Irvine y Baragar 1971). En el mismo se graficaron las muestras correspondientes a la roca granítica del Cerro Guacho (cg1 y 2) y a la tonalita (t1 y t2).

\begin{tabular}{|lllll|}
\hline minerales & $\mathbf{c g} \mathbf{1}$ & $\mathbf{c g} \mathbf{2}$ & $\mathbf{t 1}$ & $\mathbf{t 2}$ \\
\hline cuarzo & 30,54 & 33,01 & 21,39 & 17,46 \\
plagioclasa & 48,63 & 46,54 & 52,18 & 54,02 \\
ortosa & 15,60 & 14,13 & 11,41 & 10,59 \\
corindón & 0,82 & 1,20 & 0,00 & 0,00 \\
diópsido & 0,00 & 0,00 & 0,06 & 0,00 \\
hipersteno & 3,50 & 4,15 & 11,50 & 3,24 \\
ilmenita & 0,30 & 0,36 & 1,29 & 3,83 \\
magnetita & 0,36 & 0,37 & 1,78 & 0,00 \\
hematita & 0,00 & 0,00 & 0,00 & 0,45 \\
apatita & 0,19 & 0,20 & 0,39 & 0,36 \\
circón & 0,02 & 0,03 & 0,04 & 0,02 \\
cromita & 0,02 & 0,02 & 0,06 & 0,03 \\
Total & 99,98 & 100,01 & 100,10 & 100,00 \\
\%An & 16,27 & 19,95 & 34,46 & 34,12 \\
\%Ab & 59,43 & 56,76 & 47,59 & 47,32 \\
\%Or & 24,30 & 23,29 & 17,95 & 18,56 \\
\hline
\end{tabular}

Cuadro 3.B.3: Clasificación normativa CIPW de las muestras de granito y tonalita. 
De acuerdo a este diagrama las muestras cg corresponden a trondhjemitas y granodioritas y las muestras $\mathrm{t} 1 \mathrm{y}$ t2, a tonalitas (Fig. 3.B.14).

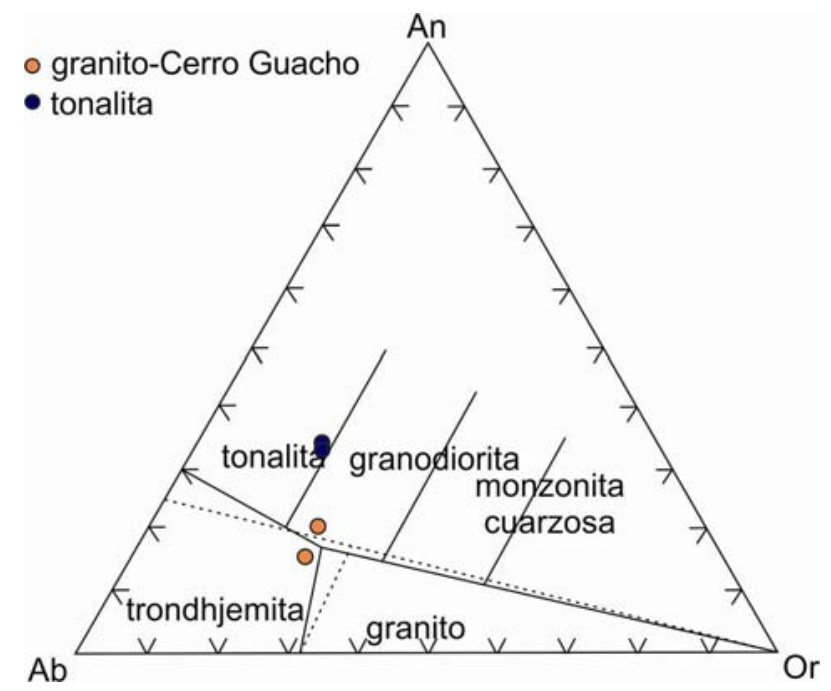

Figura 3.B.14: Diagrama de clasificación normativa Ab-An-Or (Barker 1979). Los valores graficados fueron obtenidos mediante la norma CIPW.

Estas muestras fueron graficadas en diagramas de discriminación tectónica (Fig. 3.B.15a y b). El correspondiente a Pearce et al. (1984), que utiliza la relación $\mathrm{Nb}-\mathrm{Y}$, indica que todas las rocas analizadas se disponen en el campo de granitos sin-colisionales y de arco volcánico (Fig. 3.B.15a). En cambio en el gráfico de la Fig. 3.B.15b Ta-Yb, de Pearce et al. (1984), que permite mayor discriminación, las muestras del granito del Cerro Guacho se disponen en el campo de los granitos sin-colisionales, mientras que las de la tonalita en el de granitos de arco volcánico.

Para el análisis completo de trazas y tierras raras, se realizaron dos gráficas una de elementos traza normalizados a la composición de la corteza (Fig. 3.B.16) según Taylor y McLennan (1981) y otra de tierras raras normalizadas a condrito (Fig. 3.B.17) según Sun y McDonough (1989). 

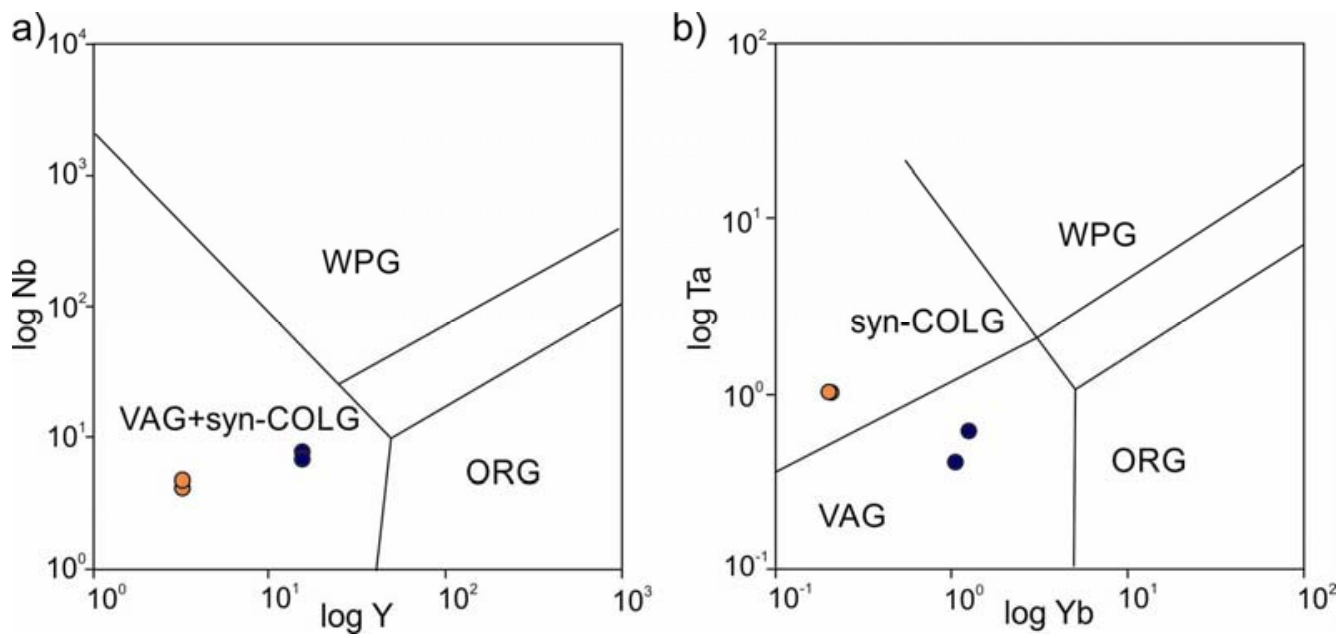

Figura 3.B.15: Diagramas de clasificación tectónica según Pearce et al. (1984). Granitos de intraplaca (WPG), granitos orogénicos (ORG), granitos de arco volcánico (VAG) y granitos sincolisionales (syn-COLG). a) Relación logarítmica $\mathrm{Nb}$ - Y. b) Relación logarítmica Ta-Yb. La segunda gráfica permite determinar que las muestras del granito del Cerro Guacho poseen mayor afinidad con los granitos sincolicionales y la tonalita con los de arco volcánico. Referencias en la Fig. 3.B.14.

En la primera (Fig. 3.B.16), se observa que las muestras del granito por un lado y las de la tonalita por otro poseen contenidos tan similares de trazas que no es posible diferenciar las muestras del mismo tipo litológico. Además, existe una importante similitud en los patrones de distribución de los elementos traza del granito y de la tonalita, ambos con anomalías negativas en $\mathrm{Nb}$ y $\mathrm{Tb}$ y anomalía positiva en Hf. Entre las diferencias más destacables podemos mencionar el mayor contenido en $\mathrm{Rb}$ del granito, su anomalía positiva en $\mathrm{U}$, mientras que la tonalita posee anomalía negativa en este elemento pero positiva en Sm.

En el diagrama de tierras raras, se vuelve a manifestar la superposición de las muestras de igual tipo litológico pero también importantes similitudes en los diseños o patrones de las tierras raras entre las muestras de granito y tonalita. Las muestras del granito presentan menor contenido de todas las tierras raras que las de tonalita y un empobrecimiento en Lu. Las rocas tonalíticas poseen una leve anomalía 
negativa en Eu mientras que las graníticas evidencian una anomalía positiva en este mismo elemento.

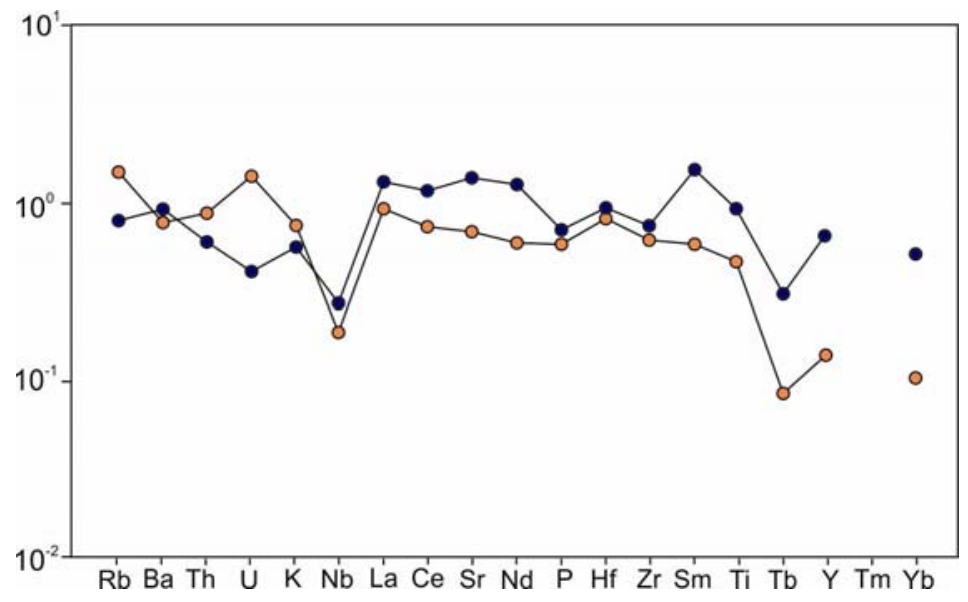

Figura 3.B.16: Diagrama de elementos traza, normalizado a la composición de la corteza superior (Taylor y MacLennan 1981). Referencias en la Fig. 3.B.13.

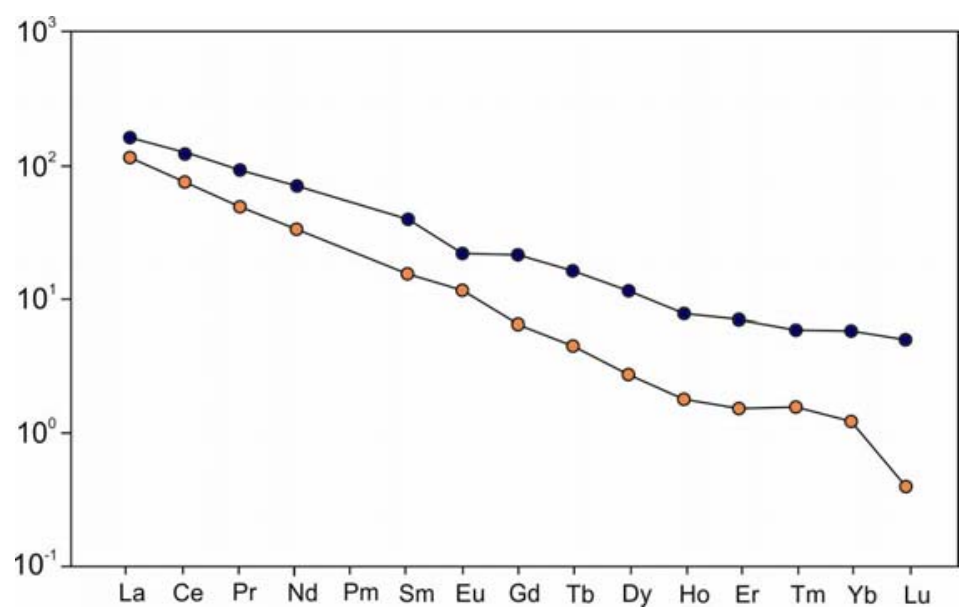

Figura 3.B.17: b) Diagrama de tierras raras normalizadas a condrito (Sun y McDonough 1989). Referencias en la Fig. 3.B.14. 


\section{B.5 DIQUES}

\section{B.5.1 Introducción}

La presencia de enjambres de diques en zonas cratónicas representa una importante herramienta de correlación entre diferentes unidades tectónicas, ya que brinda información para la interpretación de procesos geodinámicos, así como para la reconstrucción de paleocontinentes (Baer y Heimann 1995).

El basamento de las Sierras Septentrionales hospeda un extenso sistema de diques proterozoicos que fue estudiado por numerosos autores (Villar Fabre 1955, Quartino y Villar Fabre 1967, Teruggi et al. 1974, Lema y Cucchi 1981, Dristas 1983, Kilmurray et al. 1985, Echeveste y Fernández 1994 y Fernández y Echeveste 1995). Estos diques fueron reunidos en dos grandes grupos: aquellos emplazados durante el Proterozoico temprano y otros en el Proterozoico medio. Los primeros, de composición andesítica y riolítica, afloran en las Sierras de Tandil, Sierra del Tigre, Cerro Albión y especialmente en el Cerro Tandileufú (Fig. 2.8). Poseen una edad de 2.000 $\mathrm{Ma}$ (obtenida en biotita por el método ${ }^{40} \mathrm{Ar} /{ }^{39} \mathrm{Ar}$, Teixeira et al. 2002) y corresponden a un volcanismo bimodal perteneciente a una asociación calcoalcalina (Fernández y Echeveste 1995 y Iacumin et al. 2001). Estos diques se emplazaron durante una etapa transtensional en el ciclo Transamazoniano (Iacumin et al. 2001). Los más jóvenes, cuya edad es de $1.600 \mathrm{Ma}$, (Teixeira et al. 2002), son máficos y tholeíticos (Echeveste y Fernández 1994, Iacumin et al. 2001); comprenden dos tipos de diques: a) de diabasa que afloran en las Sierras de Azul y Tandil (Fig. 2.3) y b) basálticos de alto $\mathrm{TiO}_{2}$ que sólo afloran en las Sierras de Tandil (Teruggi et al. $1974 \mathrm{y}$ 1988). El emplazamiento de los diques más jóvenes está asociado a un proceso extensivo durante la etapa post-colisional del ciclo Transamazoniano (Dalla Salda et al. 1988 y 1992).

En este apartado se realiza la caracterización petrológica y geoquímica de los diques ubicados en el área de San Miguel (Lajoinie et al. 2014). 
Además, se comparan estos nuevos afloramientos con los distintos grupos de diques ubicados en sus proximidades, con el fin de asignarlos a uno de los dos grandes eventos de emplazamiento de diques caracterizados por los autores antes mencionados.

\section{B.5.2 Caracterización geológica de los diques}

Los diques del área de San Miguel afloran en tres sectores, los cuales fueron denominados para su descripción: nororiental, suroriental y occidental (Fig. 3.B.18).

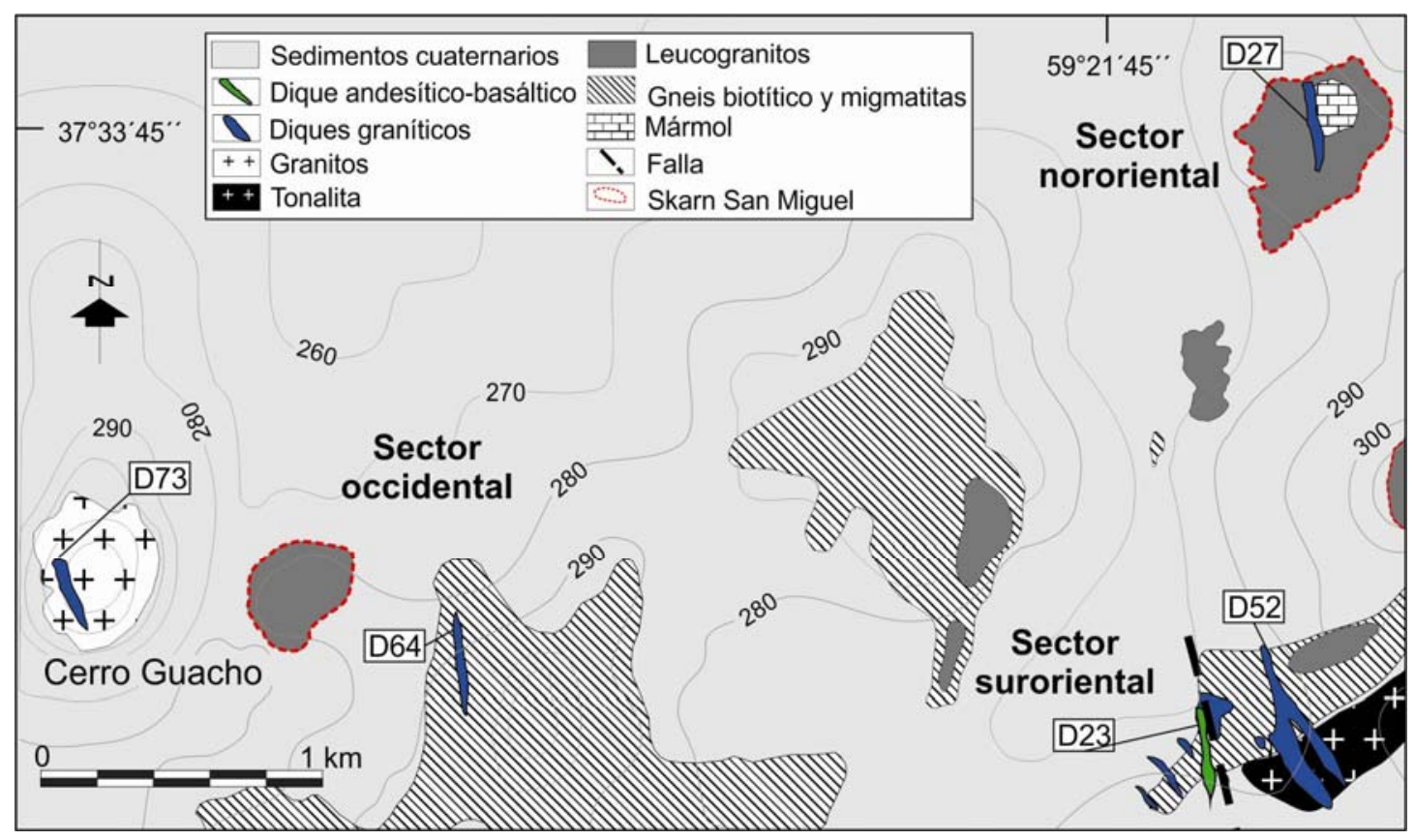

Figura 3.B.18: Mapa geológico del área de San Miguel con la ubicación de los diques que afloran en la zona en cada uno de los sectores y la nomenclatura de las muestras (Lajoinie et al. 2014).

Recientemente se han identificado otros afloramientos de cuerpos de similares características en las cercanías del cerro Los Angelitos y al oeste de la estancia La Concordia, a los que serán descriptos a continuación. Los 
mismos se encuentran actualmente en estudio y serán motivo de futuras contribuciones científicas.

\section{Sector nororiental}

En esta zona, la presencia de una cantera deja al descubierto la morfologia interna del skarn San Miguel (de Barrio et al. 2009 y Lajoinie et al. 2013), el cual se encuentra intruido por un dique de composición granítica (Villar Fabre y Quartino 1966 y Quartino y Villar Fabre 1967) aproximadamente vertical con rumbo general $\mathrm{N} 15^{\circ} \mathrm{O}$ (Fig. 3.B.19a). Si bien los afloramientos son escasos, la cantera muestra una sección completa del dique de hasta 2 metros de espesor (Fig. 3.B.19a y b). Se reconocen aquí sus contactos netos y escasas evidencias de metasomatismo, representados por la presencia de apatita y epidoto en los sectores marginales del mismo (Fig. 3.B.19c). Su color gris oscuro contrasta con las coloraciones de tonalidades más claras del skarn (Fig. 3.B.19d y e). Su textura es granular a levemente porfiroide, con tamaño de grano medio. Está compuesto por cuarzo, plagioclasas, feldespato potásico y biotita. Hacia el norte de este destape se identifican pequeños afloramientos saltuarios de morfologia redondeada de este mismo dique, que se extiende a los largo de 4 a 5 metros (Fig. 3.B.19f).

\section{Sector suroriental}

Se reconocen varios afloramientos de un dique granítico de similares características al descripto en la zona de la cantera. Se destacan dos afloramientos mayores cuyos rumbos generales son $\mathrm{N} 35^{\circ} \mathrm{O}$ y $\mathrm{N} 25^{\circ} \mathrm{O}$ (Fig. 3.B.20a y b), junto con numerosos asomos de menor tamaño, parcialmente cubiertos y en apariencia desvinculados espacialmente entre sí (Fig. 3.B.20c). Si bien las relaciones de campo no son completas, este dique está en contacto con la roca ígnea de composición tonalítica que aflora inmediatamente al este y con el gneis biotítico migmático y los leucosomas granatiferos, que asoman al oeste del mismo (Fig. 3.B.18) 

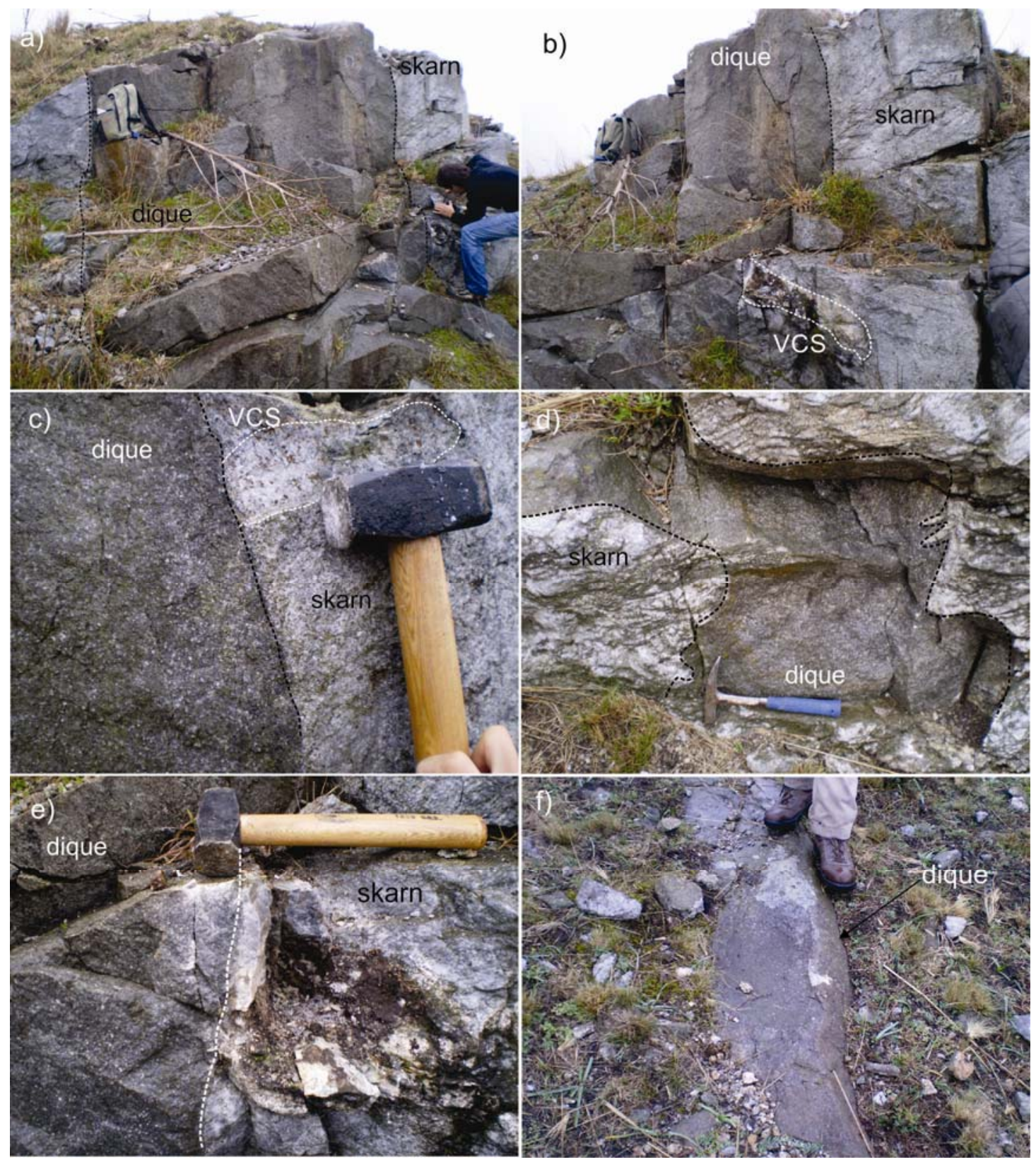

Figura 3.B.19: Dique granítico, sector nororiental. a y b) Vista en afloramiento del dique en la cantera principal donde aflora el skarn San Miguel, cortando vetillas con calcosilicatos (VCS). c) Detalle del contacto entre el dique y el endoskarn. d) Contacto del dique con un sector más bandeado que podría corresponder a una migmatita. e) Detalle de uno de los afloramientos donde se observa como el dique corta o intruye al skarn. f) Afloramientos naturales del dique, nótese su aspecto redondeado y masivo. 

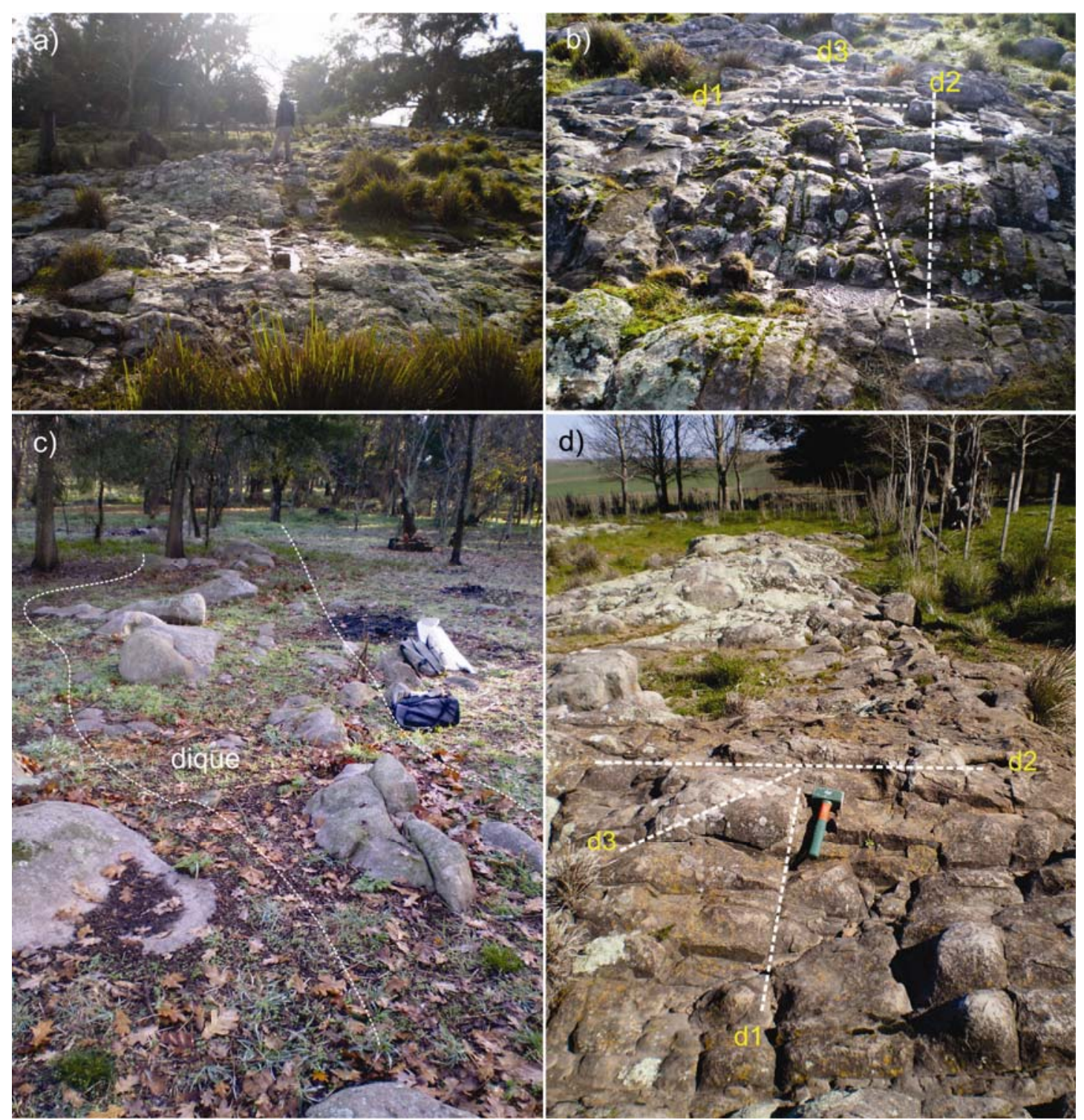

Figura 3.B.20: Dique granítico del sector suroriental. a y b) Afloramientos mayores, donde se observan los distintos sistemas de diaclasas. c) Afloramientos menores, menos diaclasados y con similar apariencia que los afloramientos del dique nororiental. e) Detalle de las familias de diaclasa d1, d2 y d3 en orden cronológico.

Los afloramientos con superficies redondeadas por la meteorización; presentan diaclasamiento muy marcado, sobre todo los dos mayores, donde se registran tres sistemas de diaclasas cuyos rumbos son $\mathrm{N} 45^{\circ} \mathrm{E}(\mathrm{d} 1), \mathrm{N} 35^{\circ} \mathrm{O}$ (d2) y $\mathrm{N} 15^{\circ} \mathrm{O}(\mathrm{d} 3)$, como se observa en la Fig. 3.B.20a, b y d. La d2 es la más frecuente e intercepta a la d1. El sistema d3 corta a los anteriores y es el de menor abundancia pero mayor continuidad. En este sector se reconoció una 
labor de destape que exhibe un frente de 30 metros de longitud, en el cual se observa una zona de cizalla vertical a subvertical con rumbo $\mathrm{N} 35^{\circ} \mathrm{O}$. Esta zona se encuentra intensamente fracturada, deformada y con una fuerte tinción rojiza provocada por la presencia de óxidos e hidróxidos de hierro (Fig. 3.B.21a). Esta deformación afecta a la roca de caja, gneis biotítico, que en este sector también presenta xenolitos máficos de variados tamaños y formas (Fig. 3.B.21b) y también al dique granítico que presenta planos de fractura en los que se observan superficies estriadas y pulidas (Fig. 3.B.21c). En este sector aflora entre las anteriores rocas, un cuerpo diqueiforme de coloración gris más oscura, emplazado en planos de fractura del dique granítico, cuyo espesor aproximado es de un metro (Fig. 3.B.21d). Hacia el sur se identificaron varios afloramientos menores de este mismo cuerpo con un rumbo que varía entre $\mathrm{N}-\mathrm{S}$ y $\mathrm{N} 15^{\circ} \mathrm{O}$ que totalizan una longitud de 15 metros. Este dique está conformado por una roca negra a gris oscura con un tamaño de grano muy fino, constituida mayoritariamente por cristales de anfibol de tipo hornblenda, pero que en afloramiento muestra una fuerte tinción rojiza (Fig. 3.B.21d), que se atribuye a procesos de meteóricos de oxidación.

\section{Sector occidental}

Se identificaron dos diques graníticos, uno en el Cerro Guacho y otro extenso y continuo de aproximadamente 100 metros de longitud al este de este cerro (Fig. 3.B.18). El primero se emplaza en la roca ígnea plutónica de composición granítica constituyente del Cerro Guacho y presenta una longitud de 4 metros con rumbo $\mathrm{N}^{\circ} \mathrm{O}$ (Fig. 3.B.22a). El afloramiento se encuentra muy diaclasado y afectado por las tareas de extracción realizadas en una cantera ubicada en este cerro. Su mineralogía está compuesta por microclino, plagioclasas, cuarzo y escasa biotita. El segundo dique se emplaza en el gneis biotítico migmático, aunque el contacto entre ambos no puede observarse bien debido a la cobertura de suelos (Fig. 3.B.22b). 


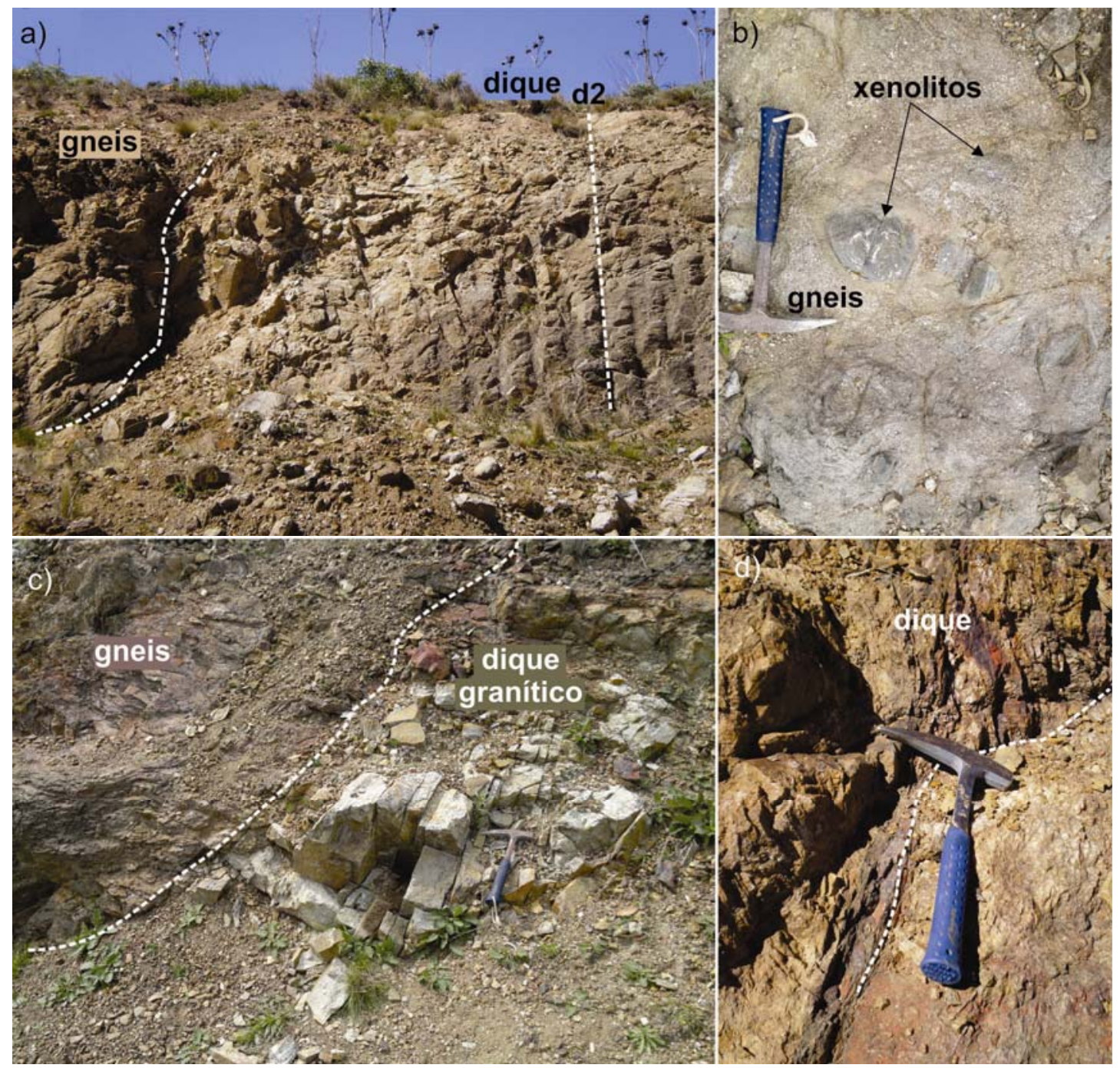

Figura 3.B.21: Cantera, zona de cizalla y meteorización intensa. a) Frente norte donde afloran el dique granítico diaclasado y el gneis (roca de caja) ambos afectados por meteorización. b) Xenolitos máficos incluidos en el gneis biotítico migmático. c) Contacto entre el gneis y el dique granítico, nótese la diferencia del estado de meteorización y deformación. d) Afloramiento del contacto entre el cuerpo diqueiforme de coloración gris oscura y la roca de caja, ambos presentan una fuerte tinción rojiza.

$\mathrm{Su}$ rumbo es $\mathrm{N} 15^{\circ} \mathrm{O}$, es aproximadamente subvertical y presenta diaclasamiento en dos direcciones, una $\mathrm{N} 40^{\circ} \mathrm{O}$ y otra menos manifiesta $\mathrm{N} 45^{\circ} \mathrm{E}$. La roca que compone este dique presenta, al igual que los diques 
graníticos antes mencionados, textura granular con tamaño de grano medio y una mineralogía compuesta por cuarzo, feldespato potásico, plagioclasas y biotita.
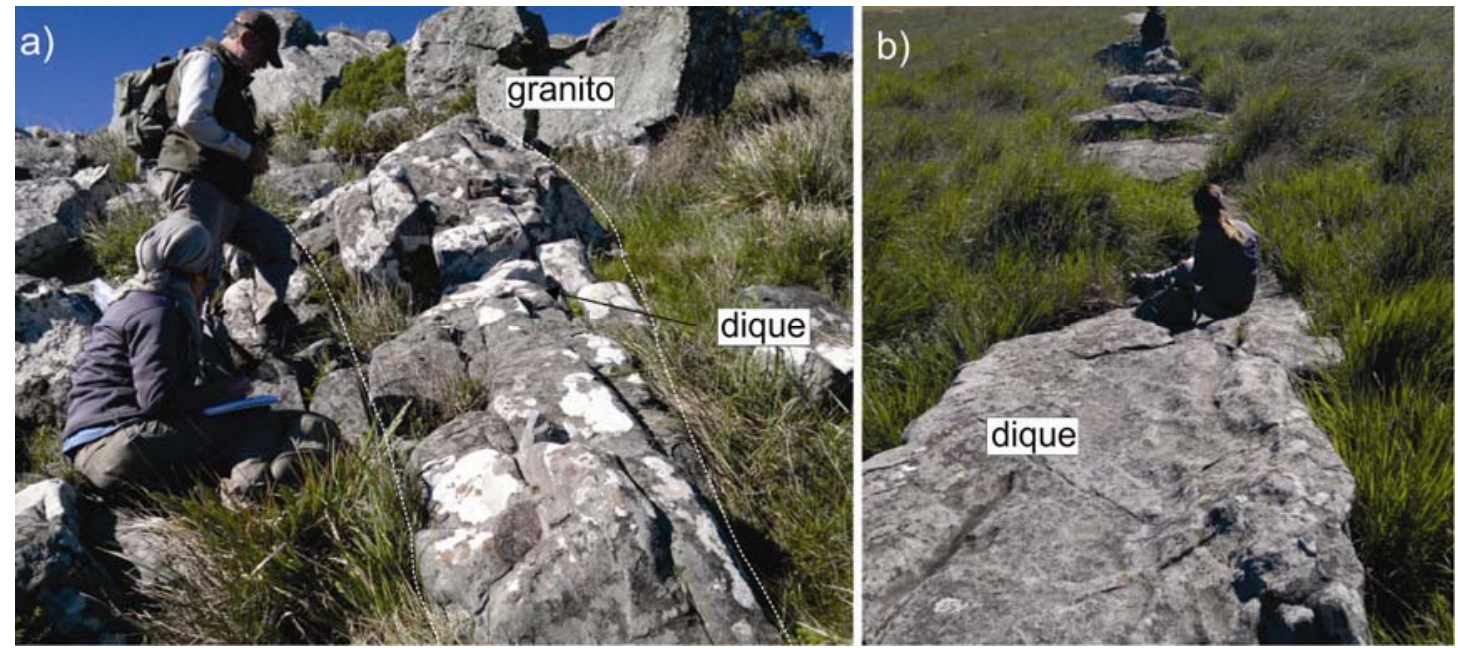

Figura 3.B.22: Diques del sector occidental. a) Dique granítico en el Cerro Guacho. b) Dique granítico emplazado en el gneis biotítico. Este contacto es inferido ya que no hay afloramientos del mismo debido al profuso desarrollo de suelos.

\section{B.5.3 Petrografia de los diques}

Al microscopio, el dique nororiental y el del sector occidental emplazado en el Cerro Guacho, presentan una mineralogía compuesta por cuarzo (50-55\%), plagioclasa sódica (15-20\%), feldespato potásico (20-25\%), biotita (5-10\%) y como mineral accesorio circón. Poseen textura granular a levemente porfiroide con un tamaño de grano medio que varía entre 0,8 y 2 milimetros (Fig. 3.B.23a y g), siendo las plagioclasas los minerales de mayor tamaño. Los cristales de cuarzo evidencian procesos de deformación, dados por la presencia de microestructuras como extinción ondulosa y bandas de deformación (Fig. 3.B.23b y h). Al mismo tiempo, otros cristales presentan signos de recuperación (presencia de subgranos) y recristalización dinámica. Las plagioclasas presentan desarrollo euhedral a subhedral y una composición general, determinada por el método de Michel-Lévy, entre albita y oligoclasa (anortita05-12). Algunas poseen núcleos con coloración verdosa, 
producto de la alteración a epidoto, lo que podría indicar una composición más cálcica (Fig. 3.B.23c); por otro lado, también muestran rasgos de deformación intracristalina como maclas ahusadas (Fig. 3.B.23b). Los feldespatos potásicos están representados por microclino de hábito poco definido (subhedrales), presentando zonas reemplazadas por sericita y arcillas (Fig. 3.B.23a y b). Las biotitas son euhedrales y se encuentran desferrizadas, con una consecuente pérdida de color en los cristales (Fig. 3.B.23a). En los sectores periféricos del dique nororiental se observan crecimientos de cristales de epidoto y apatita, con desarrollos euhedrales (Fig. 3.B.23d, e, y f) que corresponden a minerales neoformados, probablemente por la incorporación metasomática de calcio del exoskarn (Lajoinie et al. 2013).

El dique granítico suroriental y el del sector occidental emplazado en el gneis biotítico, también presentan similares características a las descriptas para los diques anteriores. Poseen textura granular, con tamaño de grano medio a fino entre 0,7 y 1 milimetro, con una mineralogia constituida por cuarzo (40\%), plagioclasas (25-30\%), feldespato potásico (25\%) y biotita (0$10 \%$, como se observa en la Fig. 3.B.24a y d. Estos minerales exhiben las mismas texturas de deformación intracristalina (especialmente en cuarzo y feldespato) y recristalización de tipo dinámica (Fig. 3.B.24b y e). Sin embargo en estos diques la plagioclasa es más abundante y su composición general, determinada por el método de Michel-Lévy, es más cálcica (anortita15-23), correspondiente a una oligoclasa. El feldespato potásico presenta desarrollo subhedral y es de tipo microclino en el dique suroriental mientras que en el dique del sector occidental muestra un maclado tipo Carlsbad y texturas mirmequíticas (Fig. 3.B.24b y e). En ambos diques el feldespato potásico presenta sericitización generada por los procesos de alteración (Fig. 3.B.24c y f). La biotita es escasa, presenta crecimiento intersticial y posee una leve cloritización (Fig. 3.B.24a y d). 

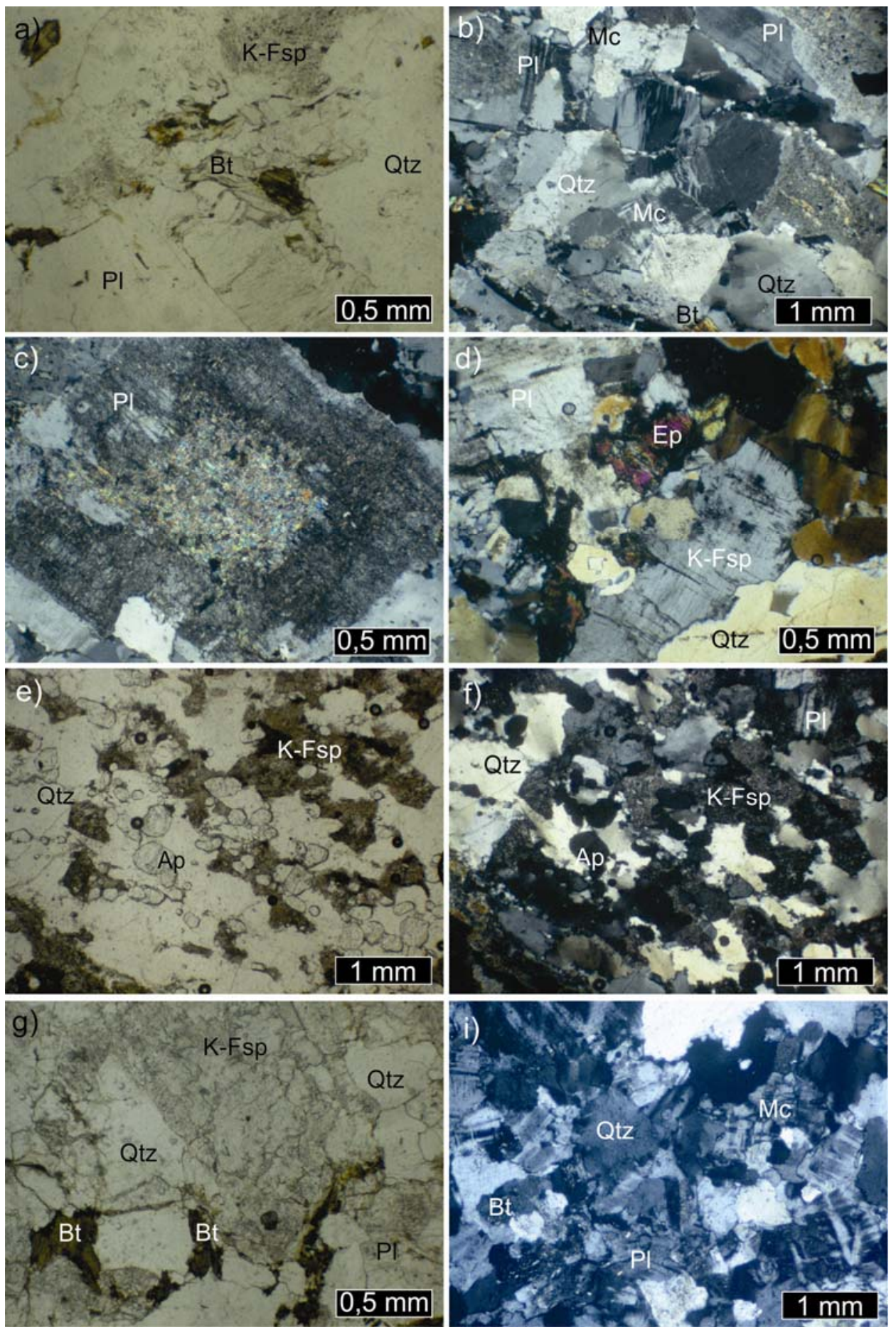

Figura 3.B.23: a) Textura microscópica y mineralogía vista sin analizador, del dique nororiental. b) Aspecto microscópico de los minerales vista con analizador y microestructuras de deformación en cristales de cuarzo. c) Cristal de plagioclasa zonado y alterado. d) Cristales de epidoto, generados como consecuencia del 
metasomatimo, con analizador. e y f) Cristales de apatita, con nicoles paralelos y cruzados, respectivamente. g) Aspecto microscópico y mineralogía, sin analizador, del dique occidental emplazado en el Cerro Guacho. h) Microestructuras de deformación en cristales de feldespato y cuarzo, con nicoles cruzados. Abreviaturas de minerales según Kretz (1983) y Siivola y Schmid (2007).

Los minerales accesorios son circón y titanita, ambos de tamaño muy pequeño (inferior a 0,1 milímetros), el primero está asociado a los sectores con biotita.

En el sector suroriental se reconoció un dique conformado por una roca de coloración gris oscura a negra, que vista al microscopio presenta grano fino a muy fino y textura inequigranular tipo porfírica. Está compuesta por una matriz de grano muy fino $(0,1$ milimetros), que en algunos sectores evidencia una ligera orientación de los minerales que la componen. Está constituida por plagioclasa, anfibol de tipo hornblenda parcialmente reemplazado por tremolita, biotita y clorita, escaso cuarzo y minerales opacos (Fig. 3.B.25a y b). Los fenocristales son de plagioclasa, poseen tamaños que varian entre 1 y 2 milímetros. Tienen un desarrollo euhédrico, poseen maclas tipo polisintética y Carlsbad y una marcada zonación (Fig. 3.B.25b y c). Esta zonación queda resaltada por la presencia de "inclusiones" o pequeños cristales de anfibol especialmente en los bordes de la mayoría de los fenocristales, donde se observan uno o dos "anillos" de extinción diferencial, lo que indica un cambio composicional en las plagioclasas, asociado a episodios de desequilibrio durante su cristalización (Fig. 3.B.25c). En fenocristales aislados, estas inclusiones se concentran en sus núcleos. En otros sectores del mismo dique se observa evidencias de procesos de deformación que se manifiesta a través de una marcada orientación preferencial en la matriz, paralela a planos de disolución por presión, bien definidos y a la presencia de porfiroclastos de plagioclasa (Fig. 3.B.25d). En menor cantidad se presentan porfiroclastos de hornblenda, los cuales se encuentran levemente deformados, exhibiendo morfologías sigmoidales (Fig. 3.B.25d); dicho rasgo junto con la presencia de planos de disolución por presión evidencian un insipiente proceso de milonitización 
(Fig. 3.B.25d y e). Finalmente se desarrolló un estadio de deformación frágil que generó microfracturación en dos direcciones bien definidas que son perpendiculares entre sí y forman ángulos de $45^{\circ}$ con los planos de disolución, y una tercer posible microfracturación casi paralela a esta última (Fig. 3.B.25f).
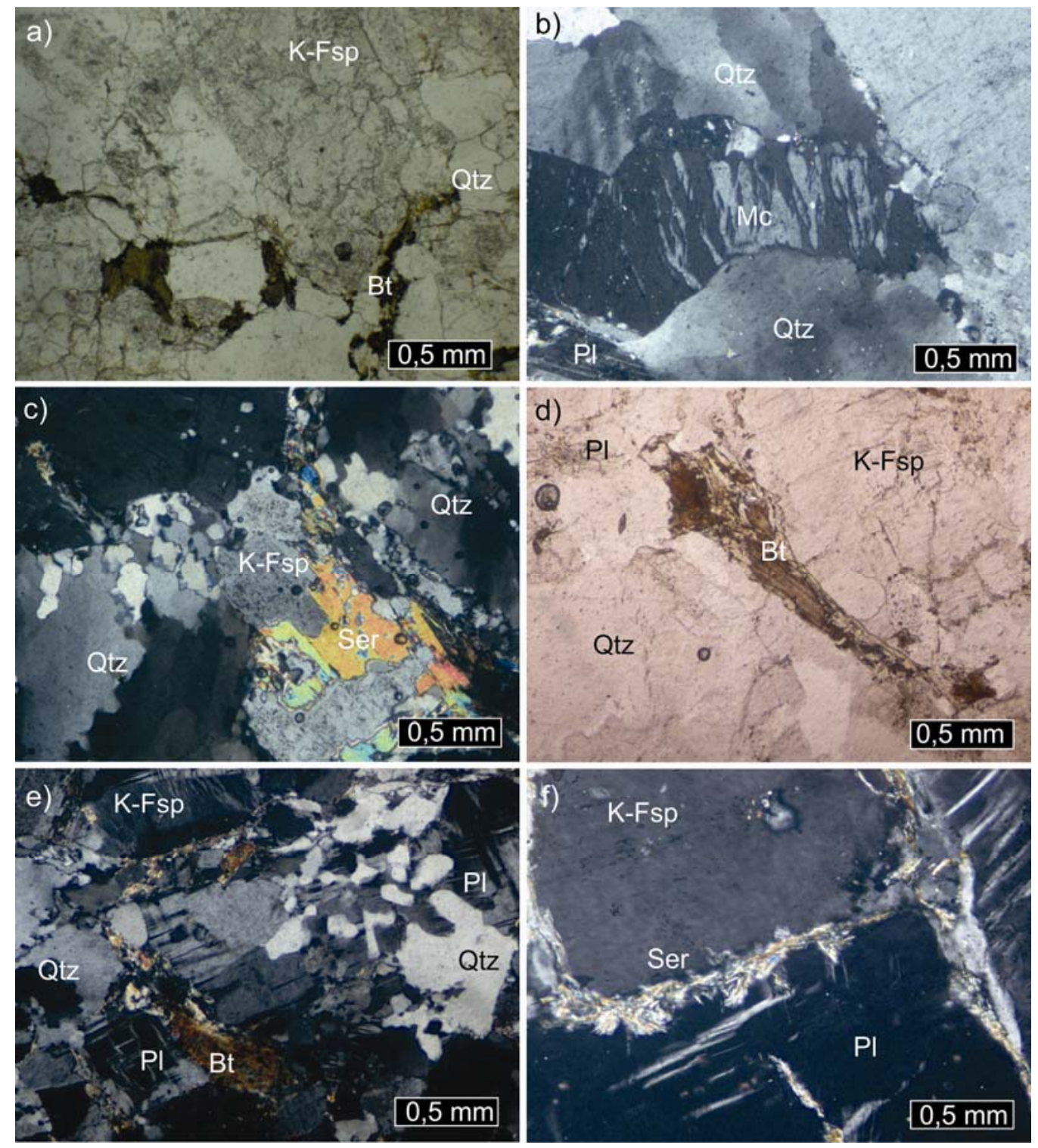

Figura 3.B.24: a) Textura microscópica y mineralogía sin analizador, del dique del sector suroriental. Los cristales de biotita presentan una pérdida de color. b) Aspecto microscópico con analizador, donde se pueden apreciar las 
microestructuras de deformación en los cristales de cuarzo y microclino. c) Cristal de feldespato potásico visto con analizador, rodeado de cuarzo recristalizado (subgranos), parcialmente reemplazado por sericita. d) Textura microscópica y mineralogía, sin analizador, del dique occidental emplazado en el gneis biotítico, donde se observa el crecimiento intersticial de cristales de biotitas desferrizadas. e y f) Microtexturas de deformación en cuarzo (con extinción ondulosa) y en feldespato (con maclas ahusadas), con analizador. Algunos feldespatos presentan textura mirmequítica. Abreviaturas de minerales según Kretz (1983) y Siivola y Schmid (2007).
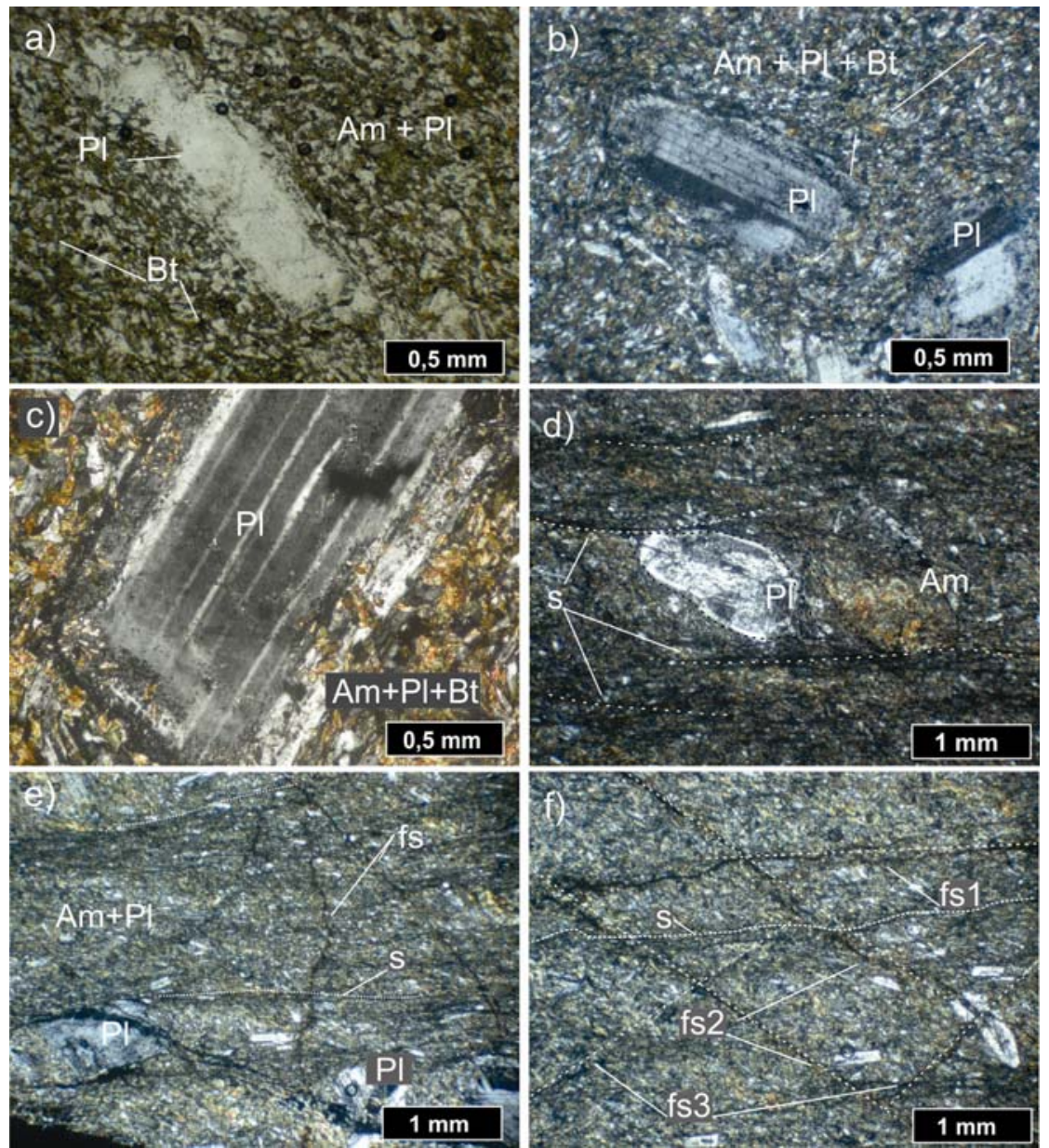

Figura 3.B.25: a) y b) Textura microscópica y mineralogía del dique intermediobásico, sin y con analizador, respectivamente. c) Fenocristal de plagioclasa zonado, rodeado por la matriz holocristalina, con analizador. d) Porfiroclastos deformados de hornblenda y plagioclasa, rodeados por una matriz que presenta una fábrica anisótropa planar con una insipiente foliación milonítica. e) Relación angular entre 
la foliación milonítica (s) y los planos de fractura posteriores (fs). f) Relación angular entre los planos de fractura. Abreviaturas de minerales según Siivola y Schmid (2007)

\section{B.5.4 Caracterización geoquímica de los diques}

Con el objeto de realizar una adecuada tipificación geoquímica de los diques, se realizaron análisis químicos de roca total incluyendo concentraciones de los elementos mayoritarios, traza y Tierras Raras de las muestras extraídas de cada sector; los resultados analiticos se muestran en el Cuadro 3.B.4. Los porcentajes de óxidos mayoritarios fueron recalculados a $100 \%$ en base anhidra, como se recomienda para la confección de los distintos gráficos utilizados.

\section{Elementos mayoritarios}

La muestra D23 corresponde al dique de composición intermediobásica y las otras a los diques graníticos, del sector nororiental (D27), suroriental (D52) y occidental (D64 y D73), como se indica en la Fig. 3.B.18. En los diagramas se graficaron además, los datos geoquímicos de muestras procedentes de diques andesítico-basálticos de la región de Tandil (cercanos al área de estudio) emplazados en la Sierra Alta de Vela y en las Sierras de Tandil (Iacumin et al. 2001). Los mismos fueron separados en diques tholeíticos (DT) y diques calco-alcalinos (DCA), debido a la gran importancia de esta diferenciación en la interpretación de su génesis. También se graficaron otros datos geoquímicos de rocas graníticas (GT) de la región de Tandil (Dalla Salda et al. 1988, Dalla Salda y Franzese 1989), y se compararon con las signaturas geoquímicas de los diques graníticos del área de San Miguel. Para la clasificación general de los diques intermedio-básicos se utilizó el diagrama binario $\mathrm{K}_{2} \mathrm{O}-\mathrm{SiO}_{2}$ de Peccerillo y Taylor (1976), que se observa en la Fig. 3.B.26a, donde la muestra D23 grafica en el campo calcoalcalino de potasio medio, junto a las muestras de los DCA. 


\begin{tabular}{|c|c|c|c|c|c|}
\hline Muestra & D-27 & D-52 & D-23 & D-64 & D-73 \\
\hline Coordenada & 5556280 & 5556308 & 5556162 & 5554509 & 5553640 \\
\hline G-K & 5842817 & 5841514 & 5841446 & 5841684 & 5841779 \\
\hline $\mathrm{SiO}_{2}$ & 76,7 & 72,8 & 54,5 & 76 & 72,1 \\
\hline $\mathrm{TiO}_{2}$ & 0,08 & 0,24 & 0,64 & 0,08 & 0,34 \\
\hline $\mathbf{A l}_{2} \mathbf{O}_{3}$ & 12,6 & 13,65 & 15,4 & 13,15 & 14,6 \\
\hline $\mathrm{Cr}_{2} \mathrm{O}_{3}$ & 0,021 & 0,032 & 0,017 & 0,04 & 0,02 \\
\hline $\mathrm{Fe}_{2} \mathrm{O}_{3}$ & 1,1 & 1,66 & 12,6 & 0,94 & 2,55 \\
\hline MgO & 0,09 & 0,33 & 4,94 & 0,13 & 0,53 \\
\hline MnO & 0,035 & 0,022 & 0,164 & 0,02 & 0,04 \\
\hline $\mathrm{CaO}$ & 0,61 & 1,42 & 5,69 & 0,8 & 1,63 \\
\hline $\mathrm{Na}_{2} \mathrm{O}$ & 3,46 & 3,16 & 2,49 & 3,62 & 3,97 \\
\hline $\mathbf{K}_{2} \mathbf{O}$ & 4,58 & 4,75 & 1,23 & 4,72 & 3,94 \\
\hline $\mathbf{P}_{2} \mathbf{O}_{5}$ & 0,017 & 0,047 & 0,178 & 0,01 & 0,08 \\
\hline LOI 1000 & 0,6 & 0,65 & 1,94 & 0,5 & 0,75 \\
\hline Total & 99,91 & 98,85 & 99,90 & 100,05 & 100,7 \\
\hline $\mathbf{B a}$ & 153,5 & 722 & 677 & 236 & 1080 \\
\hline $\mathrm{Cr}$ & 180 & 210 & 120 & 260 & 200 \\
\hline Cs & 12,5 & 5,85 & 2,78 & 4,77 & 3,98 \\
\hline $\mathbf{G a}$ & 19,1 & 18,8 & 17,5 & 16,7 & 19 \\
\hline Hf & 5,1 & 4,8 & 2,8 & 3 & 6,1 \\
\hline $\mathbf{N b}$ & 13,3 & 9,1 & 5,2 & 8 & 7,7 \\
\hline $\mathbf{R b}$ & 352 & 244 & 51,5 & 254 & 144 \\
\hline Sn & 6 & 3 & 1 & 2 & 3 \\
\hline Sr & 41,4 & 201 & 255 & 67,5 & 213 \\
\hline $\mathbf{T a}$ & 1,9 & 0,7 & 0,4 & 0,7 & 0,6 \\
\hline Th & 16,45 & 18,45 & 4,9 & 15,65 & 12,45 \\
\hline $\mathbf{U}$ & 5,04 & 3,22 & 0,98 & 4,42 & 2,68 \\
\hline $\mathbf{v}$ & 9 & 16 & 121 & 14 & 30 \\
\hline $\mathbf{w}$ & 12 & 13 & 3 & 18 & 14 \\
\hline $\mathbf{Z r}$ & 120 & 170 & 100 & 78 & 245 \\
\hline $\mathbf{L a}$ & 35 & 50,9 & 22,8 & 19,3 & 47,2 \\
\hline $\mathrm{Ce}$ & 79,5 & 104 & 44,8 & 40,8 & 87,9 \\
\hline Pr & 8,55 & 11,1 & 5,28 & 4,87 & 9,45 \\
\hline Nd & 30,1 & 38,8 & 20,1 & 16,4 & 29,4 \\
\hline Sm & 6,43 & 6,28 & 3,57 & 3,56 & 4,37 \\
\hline Eu & 0,16 & 0,61 & 1,00 & 0,21 & 0,85 \\
\hline Gd & 5,1 & 3,66 & 3,28 & 2,67 & 2,85 \\
\hline $\mathbf{T b}$ & 0,77 & 0,51 & 0,49 & 0,39 & 0,43 \\
\hline Dy & 4,55 & 2,76 & 3,25 & 2,44 & 2,38 \\
\hline Ho & 0,83 & 0,5 & 0,68 & 0,44 & 0,49 \\
\hline Er & 2,39 & 1,33 & 2,11 & 1,11 & 1,17 \\
\hline $\mathrm{Tm}$ & 0,34 & 0,18 & 0,31 & 0,19 & 0,21 \\
\hline $\mathbf{Y b}$ & 2,3 & 1,24 & 2,2 & 0,96 & 1,22 \\
\hline Lu & 0,34 & 0,17 & 0,35 & 0,16 & 0,23 \\
\hline $\mathbf{Y}$ & 24,7 & 13,8 & 18,5 & 12,7 & 12,5 \\
\hline Eu/Eu* & 0,08 & 0,35 & 0,87 & 0,19 & 0,69 \\
\hline $\mathbf{L a} / \mathbf{Y b}$ & 27,88 & 10,34 & 7,04 & 13,65 & 22,88 \\
\hline $\mathrm{La} / \mathrm{Sm}$ & 3,39 & 5,06 & 3,98 & 3,38 & 5,74 \\
\hline
\end{tabular}

Cuadro 3.B.4: Resultados de análisis geoquímicos de los diques aflorantes en el área de San Miguel. Los óxidos mayoritarios están expresados en \% en peso, los 
elementos traza y REE en ppm. El número de decimales depende de la exactitud del método para la detección del elemento. Coordenada G-K (Gauss Kruger).

La Fig. 3.B.26b grafica la relación entre el Índice de Saturación en Alúmina (ISA, Shand 1927, que diferencia los magmas metaluminosos de los peraluminosos) y el Índice Agpaítico (que separa los magmas en subalcalinos y peralcalinos). Como puede observarse las cinco muestras estudiadas se disponen en el campo de magmas subalcalinos, pero la D23 lo hace en el cuadrante subalcalino-metaluminoso y las correspondientes a D27, D52, D64 y D73 en el cuadrante subalcalino - peraluminoso.

Las rocas de los diques estudiados fueron clasificadas mediante una serie de diagramas ampliamente utilizados en la literatura geológica. En el diagrama "Total Alkali - Silica" - TAS (Le Maitre 2002) de la Fig. 3.B.26c, la muestra D23 queda comprendida en el campo de las andesitas basálticas junto con las muestras de los diques de composición intermedio-básica de la región de Tandil, que corresponden al evento más antiguo de emplazamiento de diques (Iacumin et al. 2001). De igual manera las muestras D27, D52, D64 y D73 fueron graficadas en el diagrama de Middlemost (1994), donde D27 y D64 corresponden a granitos, mientras que D52 y D73 son granodioritas (Fig. 3.B.26d).

\section{Elementos traza y Tierras Raras}

Como los diques del área de San Miguel presentan evidencias petrográficas de procesos de metamorfismo y alteración posteriores a su cristalización, es conveniente utilizar diagramas de clasificación sobre la base de determinados elementos traza inmóviles, dado que los mismos no experimentan grandes cambios con los procesos acaecidos con posterioridad a la formación de la roca (Rollinson 1993). Teniendo en cuenta la utilidad de ciertos elementos traza como parámetros de discriminación de ambientes tectónicos, se emplearon distintos diagramas según el tipo de roca. 
a)

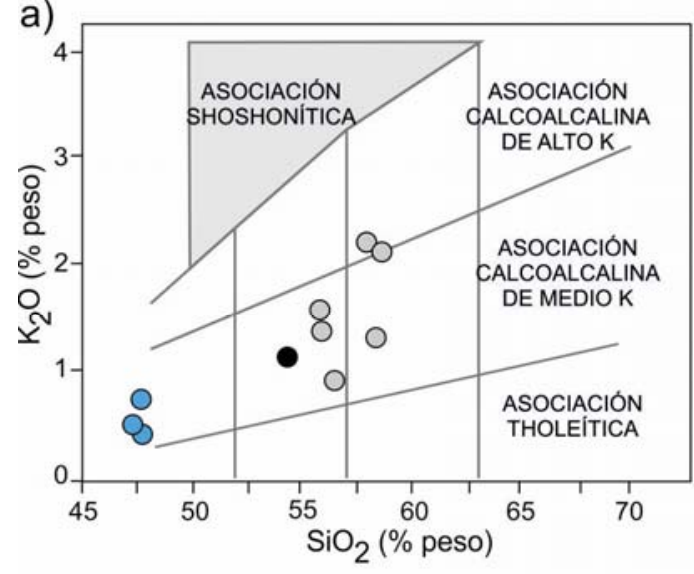

c)

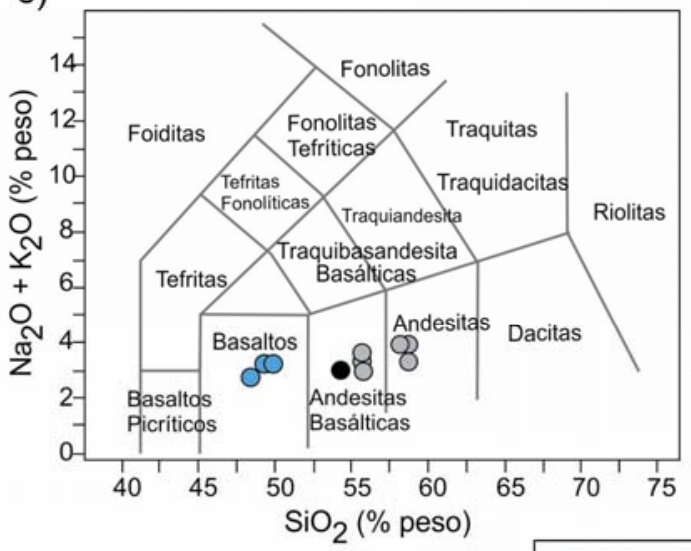

b)

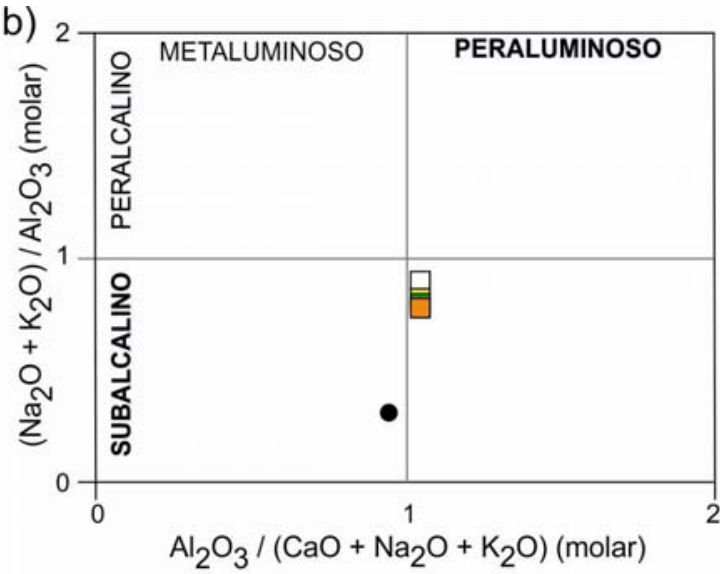

d)

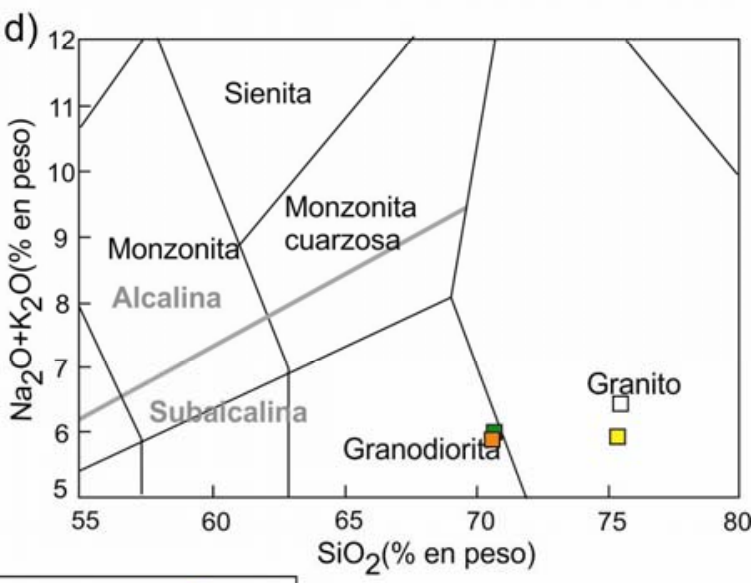

$\begin{array}{lll}\mathrm{O} \text { DT } \bullet \mathrm{D} 23 & \square \mathrm{D} 27 & \square \mathrm{D} 64 \\ \mathrm{O} \text { DCA } & \square \mathrm{D} 52 & \square \mathrm{D} 73\end{array}$

Figura 3.B.26: a) Diagrama binario $\mathrm{K}_{2} \mathrm{O}-\mathrm{SiO}_{2}$ de Peccerillo y Taylor (1976). b) Índice de Saturación en Alúmina (Shand 1927) vs. Índice Agpaítico. c) Diagrama TAS (Le Maitre 2002). d) Diagrama TAS, para rocas plutónicas de Middlemost (1994). DT y DCA muestras tomadas de Iacumin et al. (2001).

Para los diques graníticos se usó el diagrama propuesto por Pearce et al. (1984), donde se observa que las muestras D27, D52, D64 y D73 corresponden a una transición entre granitos sincolisionales y arco volcánico al igual que los granitos del área de Tandil, Fig. 3.B.27a (Dalla Salda et al. 1988, Dalla Salda y Franzese 1989).

Para los diques intermedio-básicos (DCA, DT y D23), de acuerdo al diagrama triangular Ti/100-Zr-3Y (Fig. 3.B.27b) propuesto por Pearce y 
Cann (1973), D23 corresponde a basalto calco-alcalino, al igual que los DCA, mientras que los DT plotean en el campo de los basaltos de intraplaca.
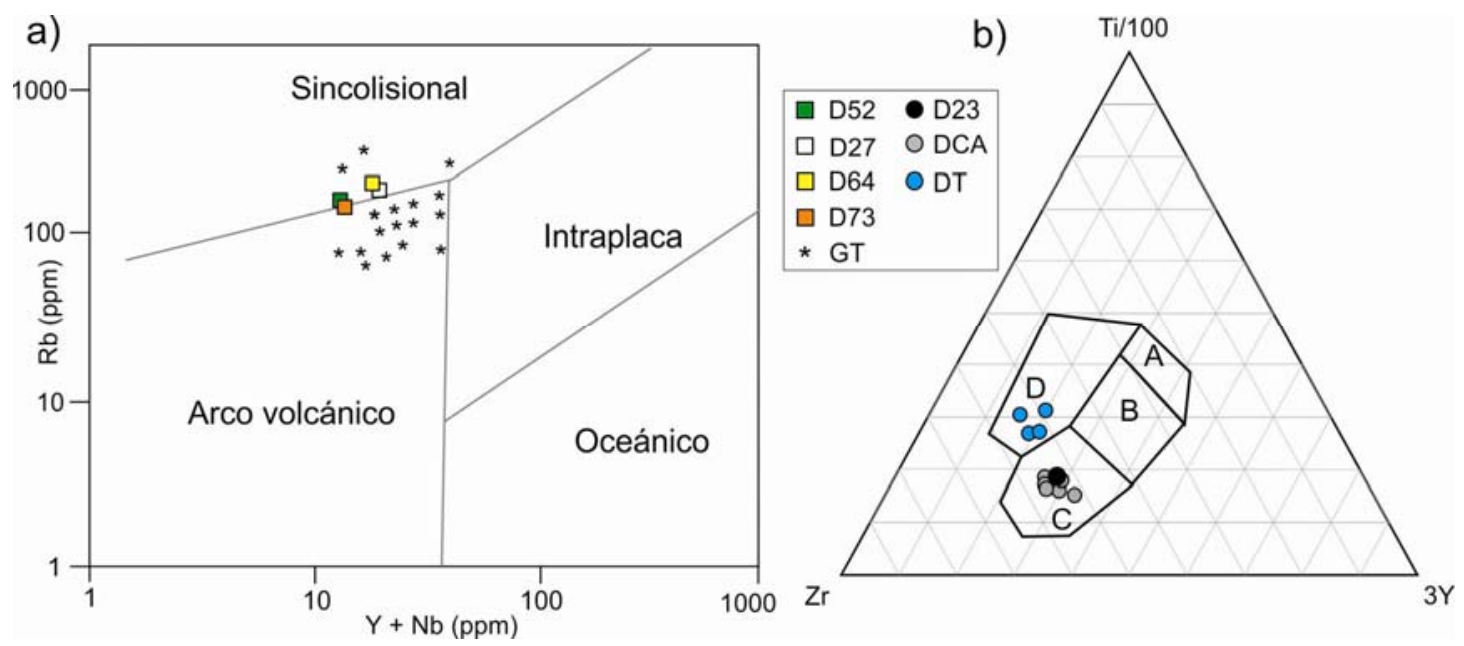

Figura 3.B.27: a) Diagramas de discriminación tectónica. a) Diagrama binario propuesto por Pearce et al. (1984). b) Diagrama triangular propuesto por Pearce y Cann (1973). DT y DCA muestras tomadas de Iacumin et al. (2001) y GT tomadas de Dalla Salda (1988) y Dalla Salda y Franzese (1989). Basalto tholeítico de arco de isla (A), MORB (B), basalto calco-alcalino (C) y basalto de intraplaca (D).

\section{Diagramas multielementos}

Se realizaron dos gráficos, uno de Tierras Raras normalizado a condrito (Fig. 3.B.28a, Sun y McDonough 1989) y otro diagrama extendido de elementos traza normalizado al manto primitivo (Fig. 3.B.28b) de acuerdo a Wood et al. (1979). En el primero se incluyeron también tres muestras de los diques estudiados por Iacumín et al. (2001), dos correspondientes a los tholeíticos (DT) y una a los calcoalcalinos (DCA). En la figura 3.B.28a se observa un diseño con pendientes negativas para todas las muestras, los diques graníticos poseen casi el mismo diseño pero con diferentes anomalías de Eu. La muestra D23 presenta el mismo diseño que los DCA, con un enriquecimiento en ETR livianas (LREE), mientras que los DT tienen un diseño mucho más plano debido a que no presentan enriquecimiento en LREE, como en los anteriores. La anomalía de $\mathrm{Eu}$ de los diques fue 
cuantificada mediante la fórmula $\mathrm{Eu} / \mathrm{Eu}^{*}=\mathrm{Eu}_{\mathrm{N}} /\left(\mathrm{Sm}_{\mathrm{N}} \mathrm{x} \mathrm{Gd}_{\mathrm{N}}\right)^{1 / 2}$, la cual arrojó valores de 0,08; 0,35; 0,19 y 0,69 para D27, D52, D64 y D73 respectivamente y un valor de 0,87 para D23.

El grado de evolución de los fundidos está indicado por los valores de ETR totales (en ppm): 201,06 para D27; 235,86 para D52; 106,20 para D64; 200,65 para D73 y 128,88 para D23. El grado de fraccionamiento de las rocas (que se refleja en las pendientes) se calculó con la relación (La/Yb) $)_{N}$, la cual arrojó valores de 27,$88 ; 10,34 ; 13,65 ; 22,38$ y 7,04 para D27, D52, D64, D73 y D23, respectivamente. Para los DT esta relación es de 1,55 y para los DCA es igual a 10,00 (Iacumin et al. 2001). La relación (La/Sm) $\mathrm{N}$ (Schilling et al. 1983), que evidencia el grado de fraccionamiento de las tierras raras livianas de las rocas correspondientes a los diques respecto al manto primitivo, arrojó para la muestra D23 un valor de 3,98, mientras que esta relación (también calculada con datos de Iacumin et al. 2001) es de 1,01 para los DT y de 3,19 para los DCA. Para los diques graníticos se calculó la misma relación, obteniéndose valores de 3,39; 5,06; 3,38 y 5,74 (para D27, D52, D64 y D73).

En el diagrama de la figura 3.B.28b, normalizado al manto primitivo (Wood et al. 1979), se observa como la tendencia del dique D23 es a acercarse a la distribución de tierras raras de los diques calcoalcalinos (DCA) y a diferenciarse un poco más de los diques tholeíticos (DT). Los DT tienen concentraciones menores de $\mathrm{Ba}, \mathrm{La}, \mathrm{Ce}$ y $\mathrm{Nd}$, pero mayor cantidad de $\mathrm{Ti}$, en comparación con los DCA y D23 (Fig. 3.B.28b y c). Si bien la D23 presenta grandes similitudes con los DCA, la primera tiene contenidos ligeramente menores de $\mathrm{Rb}, \mathrm{K}, \mathrm{Nb}$ y $\mathrm{P}$, asociado al grado de alteración meteórica que presenta este dique.

De igual forma se calculó la relación $(\mathrm{Zr} / \mathrm{Ti})_{\mathrm{N}}$, dando valores de 1,71; 1,88 y 0,78 (para D23, DCA y DT respectivamente), siendo la anomalía de Ti mayor en los dos primeros y prácticamente nula en el último. 

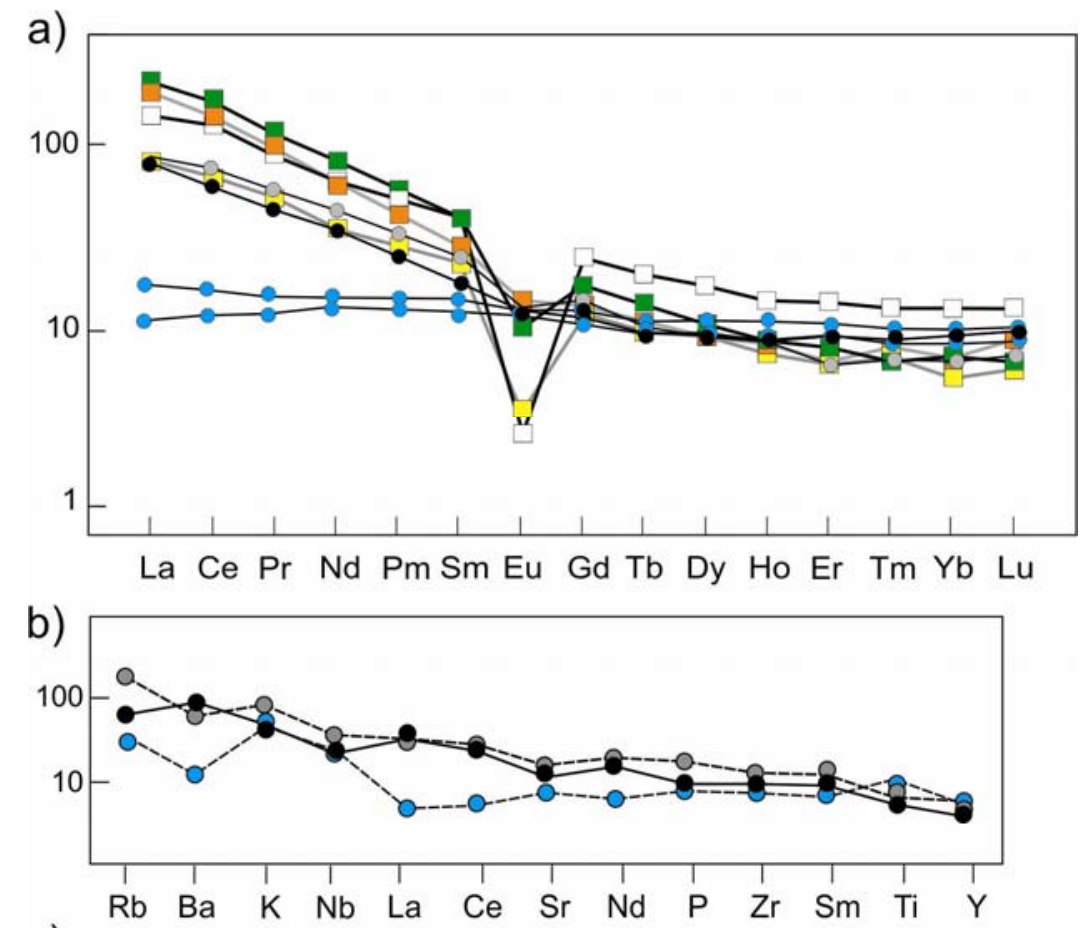

c)

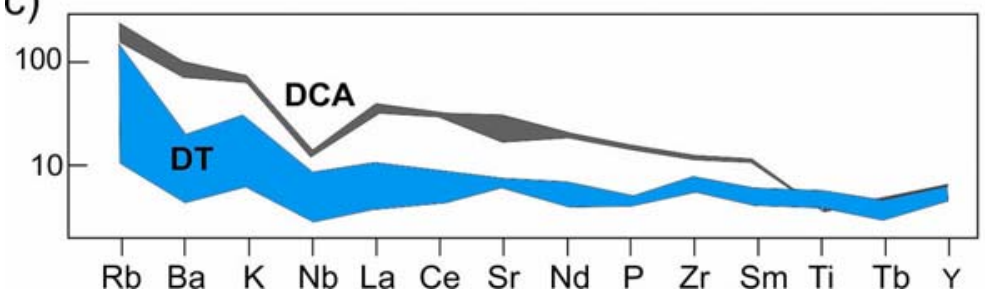

Figura 3.B.28: Diagramas multielementos. a) Normalizado a condrito (Sun y McDonough 1989). b) Normalizado al manto primitivo (Wood et al. 1979). c) Tendencias de los diques DT y DCA estudiados por Iacumin et al. (2001). Referencias en la Fig. 3.B.27.

\section{B.5.5 Discusión y conclusiones parciales}

Los estudios petrográficos y geoquímicos permitieron diferenciar dos tipos litológicos en los diques del área: (1) granítico y (2) andesítico-basáltico. El primero corresponde a granitos y granodioritas, de similar mineralogía, pero con una variación en la abundancia y composición de las plagioclasas. Según los diagramas de clasificación geoquímica y discriminación tectónica, son granitos calco-alcalinos, metaluminosos con tendencia a la peraluminosidad, con una signatura geoquímica que los ubica en un zona de 
transición entre los granitos sin-colisionales y de arco volcánico, en coincidencia con los granitos del área de Tandil. Si bien desde el punto de vista geoquímico, los altos valores de $\mathrm{Rb}$ son los esperados para los granitos tipo-S (entre 244 y 352 ppm), según Christiansen y Jeffrey (1996), el ISA indica que los valores de $\mathrm{Al}_{2} \mathrm{O}_{3}$ son levemente menores a los esperados para granitos típicamente peraluminosos. Esto acompañado con la ausencia de minerales como muscovita o polimorfos del aluminio, hace pensar que estos granitos serian, en realidad, metaluminosos con una tendencia a la peraluminosidad, considerando que en muchas ocasiones los granitoides con alta $\mathrm{SiO}_{2}$ son los últimos residuos en cristalizar y tienen además de agua, volátiles ricos en aluminio lo que podría obliterar este valor. En el análisis de los diagramas multielementos se observa una distribución con pendientes negativas para estos diques en la que se destaca un enriquecimiento en LREE y anomalías negativas de Eu. Esta anomalía es menor en las granodioritas, probablemente debido a la mayor proporción de plagioclasa respecto a los granitos. Estos diques serian preliminarmente comparables con filones capa graníticos emplazados al SO del cerro Centinela (Tandil), en la foliación de una roca gnéisica (Quartino y Villar Fabre 1967). Presentan similitudes petrográficas y geoquímicas, sugiriendo que podrian derivar del mismo fundido granítico aunque con diferente modo de emplazamiento. En el área de estudio la coincidencia de los rumbos e inclinaciones que poseen los diques se debe a que su emplazamiento estuvo controlado por un mismo sistema de fracturas preexistente de rumbo preferencial NO - SE.

Por otra parte el dique andesítico-basáltico es calcoalcalino de potasio medio. Se encuentra emplazado en una zona de cizalla con una orientación similar a la de los diques graníticos, por lo que presenta rasgos característicos de deformación frágil-dútil como el desarrollo de una foliación milonítica insipiente y porfiroclastos con bordes deformados. Los porfiroclastos, principalmente de plagioclasa, presentan una fuerte zonación, que en la mayoría de los casos se debe a desequilibrios químicos durante su cristalización. Según las relaciones geoquímicas $(\mathrm{La} / \mathrm{Yb})_{N}$ y $(\mathrm{La} / \mathrm{Sm})_{N}$ 
obtenidas, este dique evidencia afinidad con los calcoalcalinos estudiados por Iacumin et al. (2001) para los cuales Teixeira et al. (2002) determinan una edad de $2000 \mathrm{Ma}$. En el mismo sentido, el diagrama multielementos normalizado al manto primitivo (Wood et al. 1979) muestra similar enriquecimiento para algunos LILEs ( $\mathrm{Ba}$ y Sr) y LREE (La y Ce) en D23 y en los diques calcoalcalinos. Dicho enriquecimiento podría deberse a la asimilación del material cortical que experimentan los magmas calcoalcalinos en su ascenso a través de una corteza engrosada. En este sentido, Iacumin et al. (2001), proponen que los diques calcoalcalinos que se emplazaron a los $2000 \mathrm{Ma}$, derivan de la fusión parcial de material mantélico, afectado por metasomatismo a partir de la interacción con material cortical.

En sintesis, sobre la base de las relaciones de campo, los análisis petrológicos, geoquímicos y los datos geocronológicos disponibles en la región investigada, se concluye que el dique andesítico-basáltico se emplazó a través de un sistema de planos de debilidad reactivado que afectó al gneis y al dique granítico. De esta forma si al dique andesítico-basáltico se le asigna una antigüedad de $\sim 2000 \mathrm{Ma}$, los graníticos tendrían una edad entre los 2000 y $2200 \mathrm{Ma}$, considerando la edad máxima determinada para el basamento que aflora en el área de estudio (Rapela et al. 2007, Gaucher et al. 2008 y Cingolani 2010).

Finalmente, los diques del área de San Miguel representan evidencias de complejos procesos tectonomagmáticos desarrollados en un lapso de unos $200 \mathrm{Ma}$, de gran importancia para la historia evolutiva del Cratón del Río de la Plata. 


\section{B.6 BIBLIOGRAFÍA}

Baer, G. y Heimann, A. 1995. Physics and Chemistry of Dikes. A.A. Balkema, 339 p., Rotterdam.

Barker, F. 1979. Trondhjemite: Definition, enviroment and hypotheses of origin. En Barker, F. (ed.) Trondhjemites, dacites and related rocks. Elsevier, Amsterdam, 1-12.

Blanco, M. 1988. Espectros de infrarrojo en Turmalinas. Acta Geológica Hispánica 23: 283-290.

Christiansen, E.H. y Jeffrey, D.K. 1996. Trace Element in Silicic Magmas: a Metallogenic Perspective. En Wyman, D.A. (ed.) Trace Element Geochemistry of Volcanic Rocks: Applications for Massive Sulphide Exploration. Geological Association of Canada, Short Course Notes 12: 115-151.

Cingolani, C.A. 2010. The Tandilia System of Argentina as a southern extension of the Río de la Plata Craton: An overview. International Journal of Earth Science 100: 221-242.

Dalla Salda, L.H. y Franzese, J.R. 1989. Los granitoides de Tandil. Primeras Jornadas Geológicas Bonaerenses, Actas 1: 845-861, Buenos Aires.

Dalla Salda, L.H., Bossi, J. y Cingolani, C.A. 1988. The Rio de la Plata cratonic region of southwestern Gondwana. Episodes 11: 263-269.

Dalla Salda, L.H., Franzese, J.R. y Posadas, V.G. 1992. The 1800 Ma myloniteanatectic granitoid association in Tandilia, Argentina. Basement Tectonics 7: 161-174.

de Barrio, R.E., Lanfranchini, M.E., Etcheverry, R.O., Martín-Izard, A., Tessone, M.O. y Paz, M. 2009. Geological and geochemical evolution of the San Miguel skarn, Tandilia Belt, Buenos Aires Province, Argentina. 24th International Applied Geochemistry Symposium 281-284, Canada.

Deer, W.A., Howie, R.A. y Zussman, J. 1996. An introduction to the Rocks Forming Minerals (2nd ed.). Longman, London, 696 p.

Dristas, J.A. 1983. Petrología de una metariolita en la Sierra del Tigre, Tandilia. Revista de la Asociación Geológica Argentina 38: 192-200.

Dutrow, B. y Henry, D.J. 2000. Complexly zoned fibrous tourmaline: a record of evolving magmatic and hydrothermal fluids. Canadian Mineralogist 38: 131143. 
Echeveste, H.J. y Fernández, R.R. 1994. Asociaciones de óxidos y sulfuros en diques básicos de las Sierras de Tandil, provincia de Buenos Aires. Revista del Museo de La Plata 11: 99-118.

Farmer, V.C. 1974. Infrared spectra of minerals. En Farmer, V.C. (ed.) Mineralogical Society Monograph No. 4. Mineralogical Society, London, 399 p.

Fernández, R.R. y Echeveste, H. J. 1995. Caracterización geoquímica y petrológica de diques del Sistema de Tandilia, provincia de Buenos Aires, Argentina. Jornadas Geológicas y Geofísicas Bonaerenses, Actas 1: 329-337, Buenos Aires.

Gaucher, C., Finney, S., Poiré, D., Valencia, V., Grove, M., Blanco, G., Pamoukaghlian, L. y Gómez Peral, L. 2008. Detrital zircon ages of Neoproterozoic sedimentary successions in Uruguay and Argentina: Insights into the geological evolution of the Río de la Plata Craton. Precambrian Research 167: 150-170.

Hawthorne, F.J. y Henry, D.J. 1999. Classification of the minerals of the tourmaline group. European Journal of Mineralogy 11: 201-216.

Henry, D.J. y Dutrow, B.L. 1996. Metamorphic tourmaline and its petrologic applications. En Grew, E.S. y Anovitz, L.M (eds.) Boron: Mineralogy, Petrology, and Geochemistry. Reviews in Mineralogy and Geochemistry 33: 503-557.

Henry, D.J. y Guidotti, C.V. 1985. Tourmaline as a petrogenetic indicator mineral: an example from the staurolite grade metapelites of NW Maine. American Mineralogist 70: 1-15.

Henry, D.J., Novák, M., Hawthore, F.C, Erti, A., Duthrow, B.L., Ther, O y Pezzota, F. 2011. Nomenclature of the tourmeline-supergroup minerals. American Mineralogist 96: 895-913.

Iacumin, M., Piccirillo, E., Girardi, V., Teixeira, W., Bellieni, G., Echeveste, H., Fernández, R., Pinese, J. y Ribot, A. 2001. Early Proterozoic Calc-Alkaline and Middle Proterozoic Tholeiitic Dyke Swarms from Central-Eastern Argentina. Petrology, Geochemistry, Sr-Nd Isotopes and Tectonic Implications. Journal of Petrology 42: 2109-2143.

Irvine, T.N. y Baragar, W.R.A. 1971. A guide to the chemical classification of the common volcanic rocks. Canadian Journal of Earth Sciences 8: 523-548. 
Kilmurray, J.O., Leguizamón, M.A. y Ribot, A. 1985. Los diques de diabasa del noroeste de las Sierras de Azul, Provincia de Buenos Aires. Primeras Jornadas Geológicas Bonaerenses: 863-866.

Kretz, R. 1983. Symbols for rock-forming minerals. American Mineralogist 68: 277279.

Lajoinie, M.F., Lanfranchini, M.E., Etcheverry, R.O. y Recio, C. 2013. Zonación mineral vinculada a procesos geoquímicos en el skarn San Miguel, Sierras Septentrionales de la provincia de Buenos Aires. Revista de la Asociación Geológica Argentina 70: 402-412.

Lajoinie, M.F., Etcheverry, R.O., Lanfranchini, M.E. y Cábana, M.C. 2014. Geología, geoquímica y génesis de diques proterozoicos del área de San Miguel, Sierras Septentrionales de la provincia de Buenos Aires. Revista de la Asociación Geológica Argentina 71: 404-415.

Lema, H. y Cucchi, R. 1981. Hallazgo de metavulcanitas en el Cerro Tandileufú, Provincia de Buenos Aires. Revista de la Asociación Geológica Argentina 36: 1-103.

Le Maitre, R. W. 2002. Igneous Rocks: a Classification and Glossary of Terms: recommendations of the International Union of Geological Sciences Subcommission on the Systematics of Igneous Rocks. Cambridge University, 236 p., Cambridge.

London, D., Morgan, G.B. y Wolf, D. 1996. Boron in granitic rocks and their contact aureoles. En Grew, E.S. y Anovitz, L.M. (eds). Boron. Mineralogy, petrology and geochemistry. Reviews in Mineralogy. Mineralogical Society of America, Virginia 33: 299-330.

Middlemost, E.A.K. 1994. Naming materials in magma/igneous rock system. Earth Science Review 37: 215-224.

Pearce, J.A. y Cann, J.R. 1973. Tectonic setting of basic volcanic rocks determined using trace element analyses. Earth and Planetary Science Letters 19: 290300.

Pearce, J.A., Harris, B.W. y Tindle, A.G. 1984. Trace Element Discrimination Diagrams for the Tectonic Interpretation of Granitic Rocks. Journal of Petrology 25: 956-983.

Peccerillo A. y Taylor, S.R. 1976. Geochemistry of Eocene cal-alkaline volcanic Rocks from the Kastamonu area, Northern Turkey. Contributions to Mineralogy and Petrology 58: 63-81. 
Peng, Q.M. y Palmer, M.R. 1995. The palaeoproterozoic boron deposits in eastern Lianing, China: a metamorphosed evaporite. Precambrian Research 72: 185197.

Pesquera, A. y Velasco, F. 1997. Mineralogy, geochemistry and geological significance of tourmaline-rich rocks from the Paleozoic Cinco Villas massif (western Pyrenees, Spain). Contributions to Mineralogy and Petrology 129: 53-74.

Quartino, B. y Villar Fabre, J. 1967. Geología y petrología del basamento de Tandil y Barker, provincia de Buenos Aires, a la luz del estudio de localidades críticas. Revista de la Asociación Geológica Argentina 22: 223-251.

Rapela, C.W., Pankhurst, R,J., Casquet, C., Fanning, C.M., Baldo, E.G., GonzálezCasado, J.M., Galindo, C. y Dahlquist, J. 2007. The Río de la Plata Craton and the assembly of SW Gondwana. Earth Science Reviews 83: 49-82.

Rollinson, H. 1993. Using geochemical data: evaluation, presentation, interpretation. 352 p. Longman Scientific and Technical.

Schilling, J.G., Meyer, P.S. y Kingsley, R.H. 1983. Rare earth geochemistry of Iceland Basalts: spatial and temporal variations in structure and development of Greenland Scotland Ridge. En Bott, M.H.P. y Saxov, S. (eds.) Plenum Press, 319-342. New York and London.

Shand, S. J. 1927. The Eruptive Rocks. John Wiley, 360 p., New York.

Slack, J.F. 1993. Models for tourmalinite formation in the Middle Proterozoic Belt and Purcell supergroups (Rocky Mountains) and their exploration significance. Current Research, Canada Geologic Survey 93: 33-40.

Siivola, J. y Schmid, R. 2007. List of Mineral Abbreviations. Recommendations by the IUGS Subcommission on the Systematics of Metamorphic Rocks: Web version 01.02.07. www. bgs.ac.uk/scmr/home.html.

Sun, S. y McDonough, W.F. 1989. Chemical and isotopic systematic of oceanic basalts: implications for mantle composition and processes. En Saunders A.D. y Norry, M.J. (eds.) Magmatism in the Ocean Basins. Blackwell Scientific: 313-345, Boston.

Taylor, S.R. y McLennan, S.M. 1981. The composition and evolution of the continental crust: rare earth element evidence from sedimentary rocks. Philosophical Transactions of the Royal Society of London 301: 381-399.

Teixeira, W., Pinese, J., Iacumin, M., Girardi, V., Piccirillo, E., Echeveste, H., Ribot, A, Fernández, R., Renne, P.R. y Heaman, L.M. 2002. Calc-alkaline and 
tholeiitic dyke swarms of Tandilia, Rio de la Plata Craton, Argentina: U-Pb, $\mathrm{Sm}-\mathrm{Nd}$, and $\mathrm{Rb}-\mathrm{Sr}{ }^{40} \mathrm{Ar} /{ }^{39} \mathrm{Ar}$ data provide new clues for intraplate rifting shortly after the Transamazonian orogeny. Precambrian Research 119: 329353.

Teruggi, M.E., Kilmurray, J.O., Rapela, C.W. y Dalla Salda, L.H. 1974. Diques básicos en las Sierras de Tandil. Revista de la Asociación Geológica Argentina 24: 41-60.

Teruggi, M.E., Leguizamón, M.A. y Ramos, V.A. 1988. Metamorfitas de bajo grado con afinidades oceánicas en el basamento de Tandil: su implicancia geotectónica, Provincia de Buenos Aires. Revista Asociación Geológica Argentina 43: 366-374.

Villar Fabre, J.F. 1955. Resumen geológico de la Hoja 32p, Sierras del Azul, Provincia de Buenos Aires. Revista Asociación Geológica Argentina 10:75-99.

Villar Fabre, J. y Quartino, B. 1966. Exomorphic and endomorphic effects from marble-contaminated granite contacts in the "San Miguel" quarry, Barker, Province of Buenos Aires, Argentina. American Journal of Science 264: 310320.

Wood, D.A., Joron, J.L. y Treuil, M. 1979. A re-appraisal of the use of trace elements to classify and discriminate between magma series erupted in different tectonic settings. Earth and Planetary Science Letters 50: 326-336. 


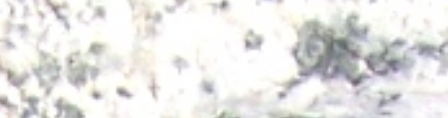

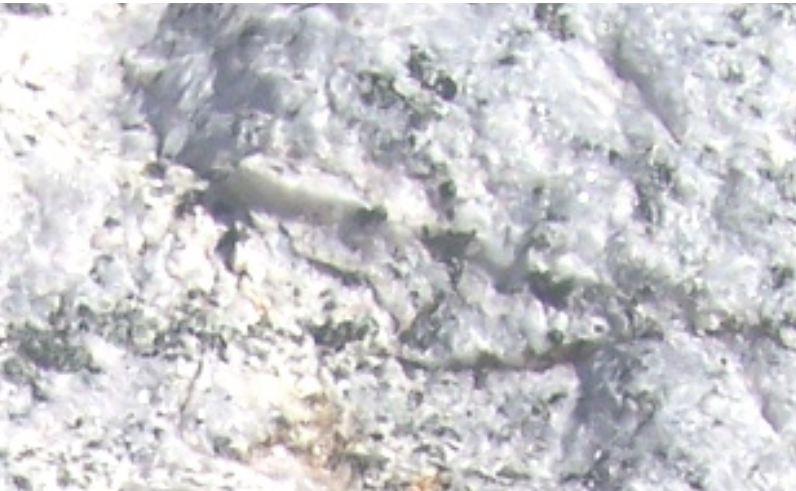

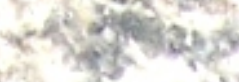

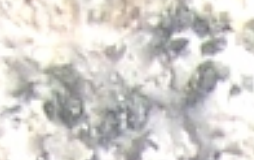

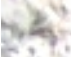
2. 3 .

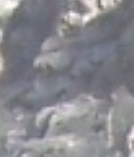
CAPITULO 4 is

\section{SKARN-SAN MIGUEL}
CARACIRERISTICAS GEOLÓGICAS,

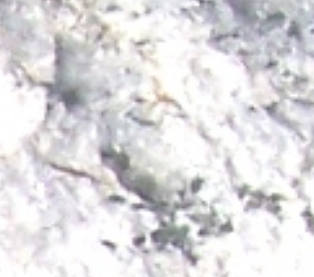

\section{MINERALÓGICAS Y QUUMICAS}

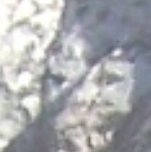

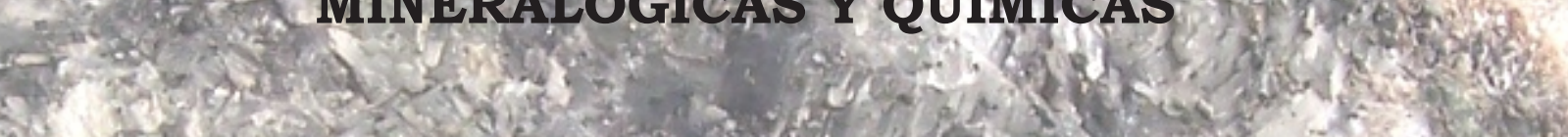

15.

in.

$\log _{10}$

. 5 r.
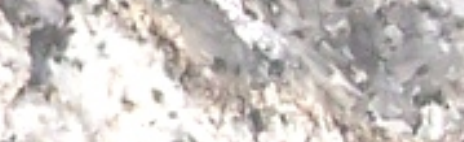

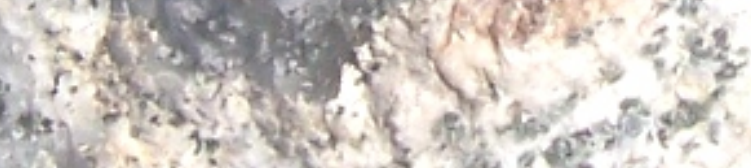

WAs.

s.s.

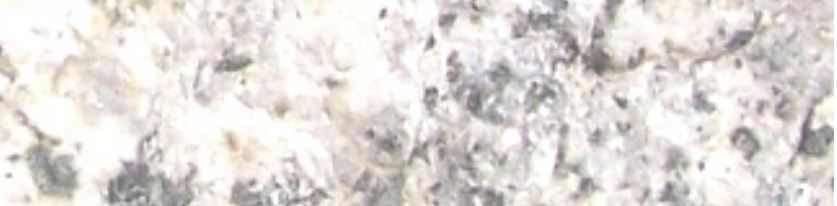

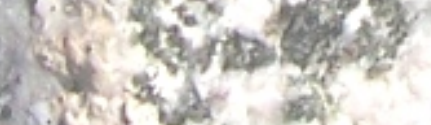

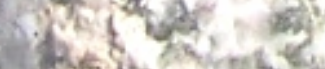

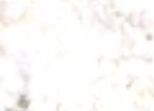

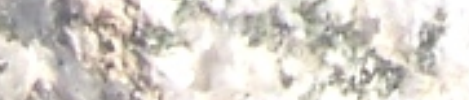

$e^{2}+x^{2}=$

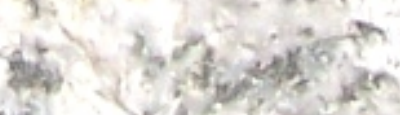

$\log ^{2}$

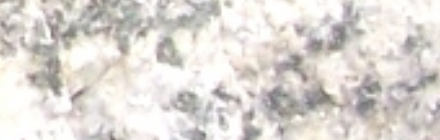
a toras 


\subsection{INTRODUCCIÓN}

El término skarn define a la roca constituida principalmente por silicatos de $\mathrm{Ca}$ y $\mathrm{Mg}$ (rica también en $\mathrm{Fe}$, Al y posiblemente $\mathrm{Mn}$ ), formada a temperaturas relativamente altas por el reemplazo de una roca carbonática. Dicho proceso puede generarse a través de varios mecanismos: reacción metasomática entre diferentes litologías como rocas arcillosas y carbonáticas (skarn de reacción), metasomatismo generado por la infiltración de fluidos hidrotermales de origen ígneo o metamórfico (skarn de infiltración), o inclusive por la reacción isoquímica de un carbonato con impurezas silíceas tras un episodio de metamorfismo regional. Esta última definición es poco aceptada, siendo el skarn de infiltración el que se ajusta más a las definiciones mundialmente reconocgidas, dado que la mayor cantidad de estos depósitos coincide con este tipo.

En Argentina, los depósitos tipo skarn, afloran principalmente en el ámbito de las Sierras Pampenas, Precordillera, Cordillera Andina y en ciertos sectores de la Cuenca Neuquina. En estos ambientes geológicos la mayor ocurrencia de protolitos carbonáticos en conjunto con la acción de procesos generadores de fluidos silíceos promueve las condiciones necesarias para la formación de este tipo de depósito.

En el basamento de las Sierras Septentrionales los skarns representan una rareza, debido principalmente a la escasez de rocas carbonáticas identificadas hasta el momento. Solo se han citado dos ejemplos de este tipo de rocas: el skarn Punta Tota (Delpino 2000 y Delpino y Dristas 2008), situado en las cercanías de la ciudad de Balcarce y el skarn San Miguel, ubicado $7 \mathrm{~km}$ al norte de la localidad de Barker (Fig. 2.3). Este último, cuenta con pocos antecedentes bibliográficos de estudios geológicos (Villar Fabre y Quartino 1966 y Quartino y Villar Fabre 1967), lo que incentivó la realización de la presente Tesis Doctoral.

Este capítulo tiene como finalidad brindar una descripción geológica detallada de la distribución de las diferentes paragénesis minerales que 
componen el skarn junto con la caracterización química de estos minerales. Además se presentan análisis químicos de las distintas paragénesis con el fin de definir los procesos metasomáticos responsables de la formación del skarn.

\subsection{SKARN SAN MIGUEL}

El skarn San Miguel fue identificado, inicialmente en dos destapes ubicados en la estancia homónima (Fig. 4.1). En estos se han reconocido las características mineralógicas, texturales y estructurales más importantes, que permitieron determinar una "zonación mineral" para el skarn, la cual se corresponde con la aparición o desaparición de ciertas fases minerales (Lajoinie et al. 2013a). Estas zonas también se clasifican de acuerdo a su posición, siendo las facies de endoskarn aquellas zonas que se desarrollan sobre el intrusivo y las de exoskarn aquellas constituidas sobre el protolito carbonático.

Utilizando las paragénesis minerales identificadas como guía de prospección, se pudieron reconocer durante el desarrollo de la presente tesis, tres nuevos afloramientos de skarn en las siguientes estancias limitrofes entre sí: San Miguel (al sur de los afloramientos antes mencionados, Fig. 4.2), la Concordia y Siempre Verde (Fig. 4.3a y b). Los correspondientes a éstos últimos presentan características que coinciden con una o dos "zonas" de las definidas en los afloramientos principales. 


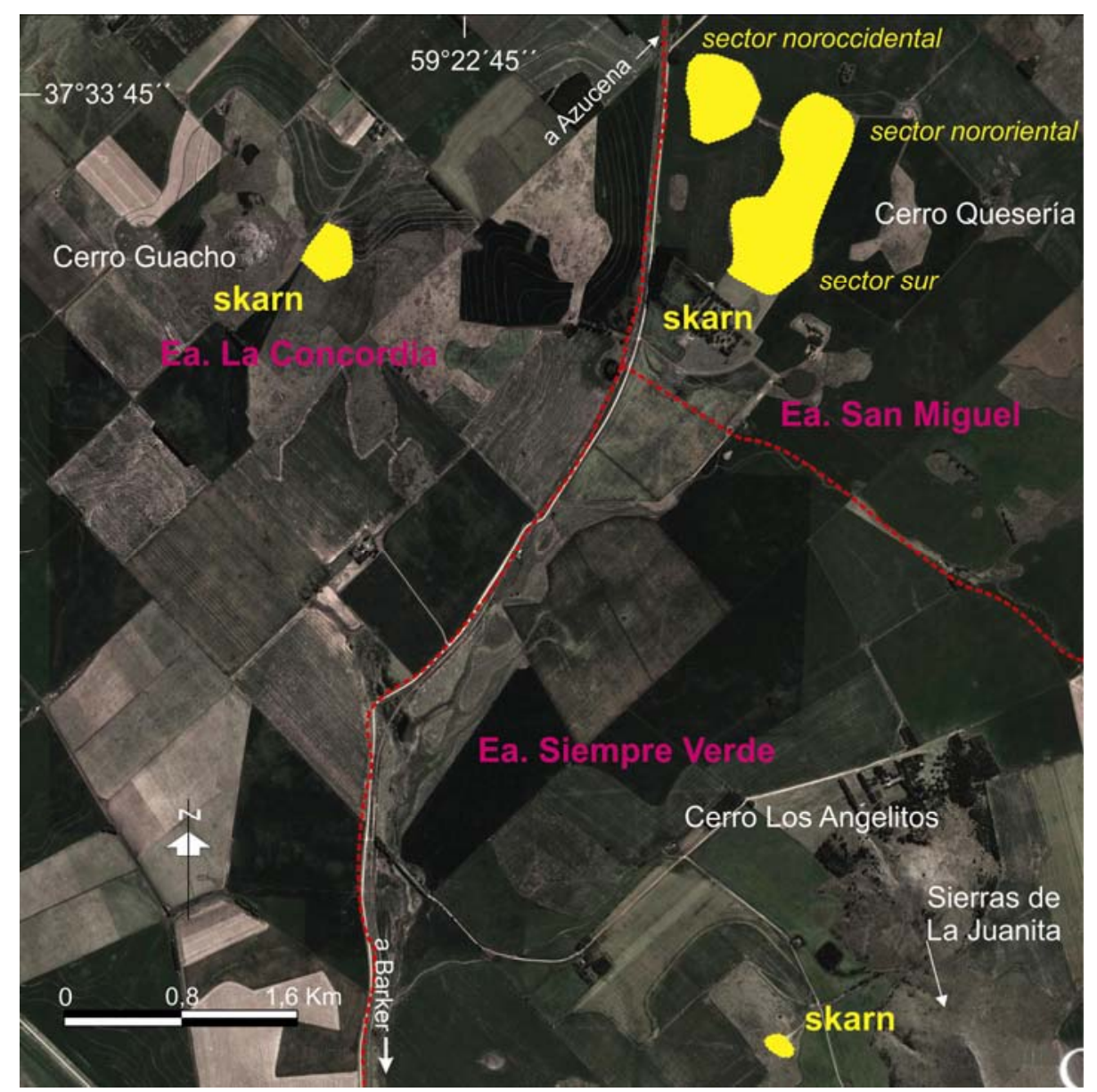

Figura 4.1: Mapa de ubicación de los tres sectores donde aflora el skarn San Miguel.

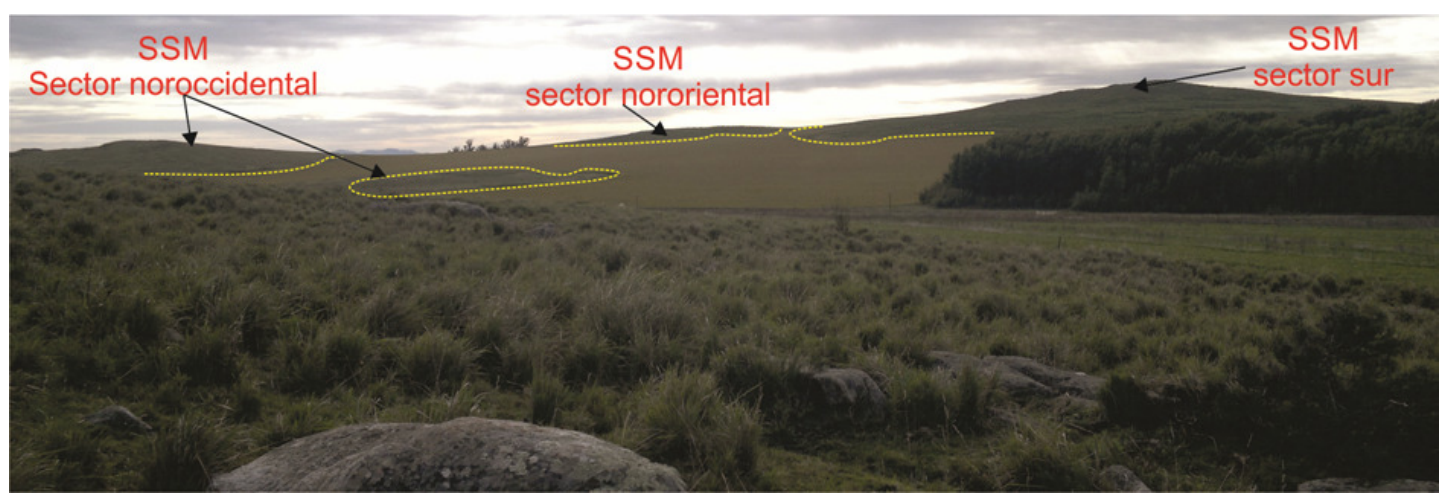

Figura 4.2: Fotografia tomada desde el Cerro Guacho, donde se observan los tres afloramientos principales del skarn San Miguel (SSM) que se exponen en la estancia homónima. 


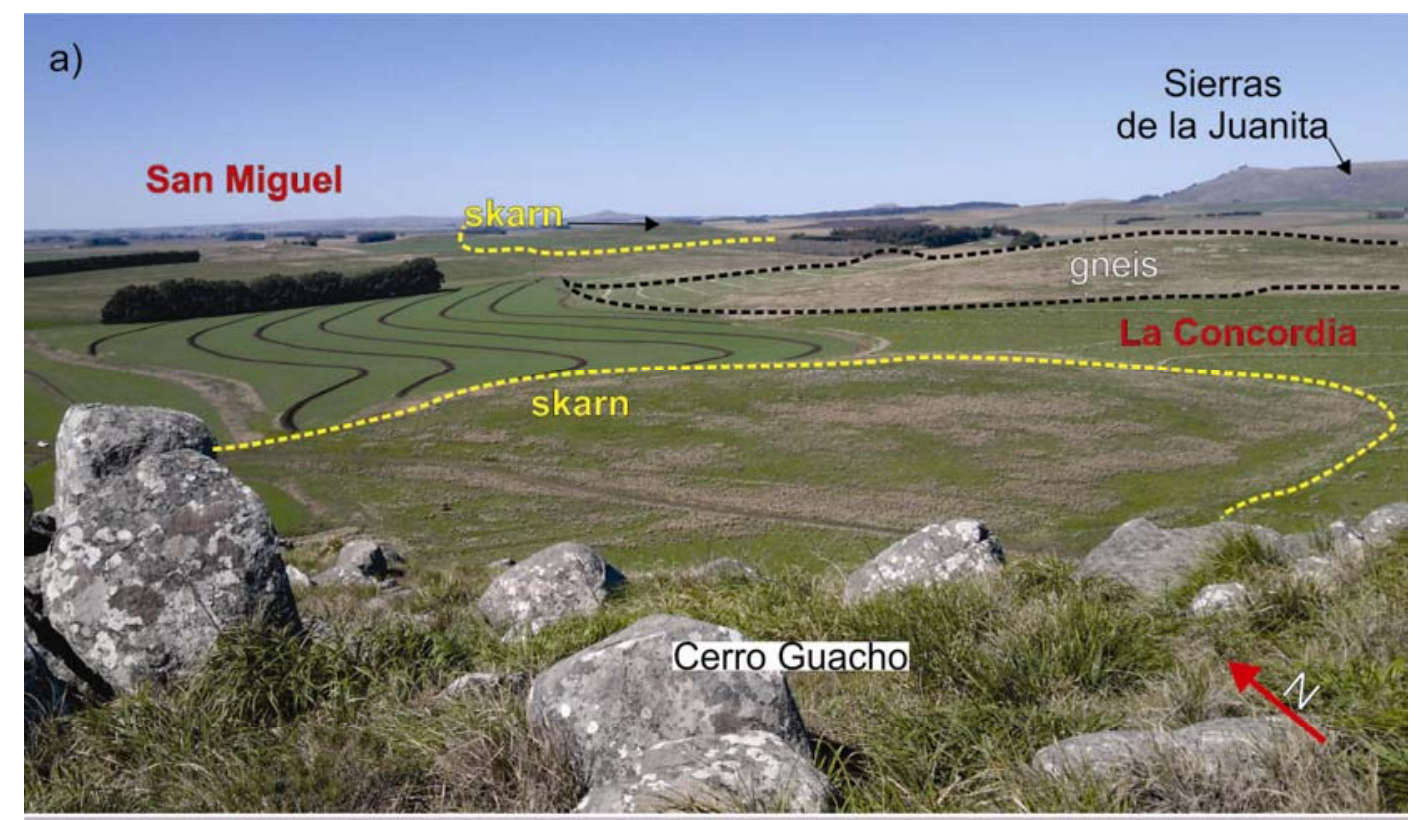

b)

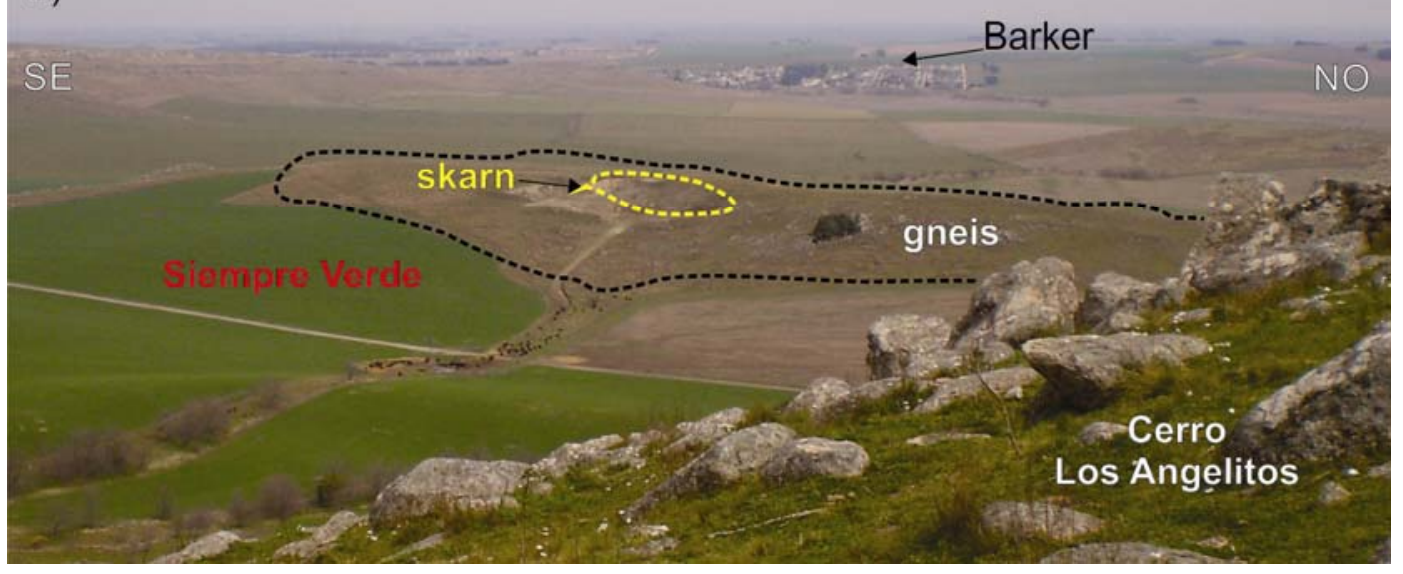

Figura 4.3: Afloramiento del skarn San Miguel en las estancias: a) La Concordia; se observan de fondo los afloramientos ubicados en la Ea. San Miguel y en las Sierras de la Juanita. Fotografia tomada desde el Cerro Guacho. b) Siempre Verde, el skarn se exhibe en contacto con uno de los afloramientos del gneis biotítico migmático. La fotografia fue tomada desde el Cerro Los Angelitos y puede observarse de fondo la ciudad de Barker.

\subsubsection{Estancia San Miguel: sectores noroccidental y nororiental}

En estos sectores (Fig. 4.4) asoman núcleos de mármol calcítico con coloraciones que van de gris oscuro a blanco y tamaño de grano medio a grueso entre 1 y 3 centímetros de diámetro máximo. Estos núcleos de 
mármol están constituidos por tres lentes de mayor espesor, los cuales poseen entre 1 metro y 50 centímetros, y varios cuerpos más finos dispuestos con una inclinación que varía entre subhorizontal y $20-30^{\circ}$ al SO (Fig. 4.5a).

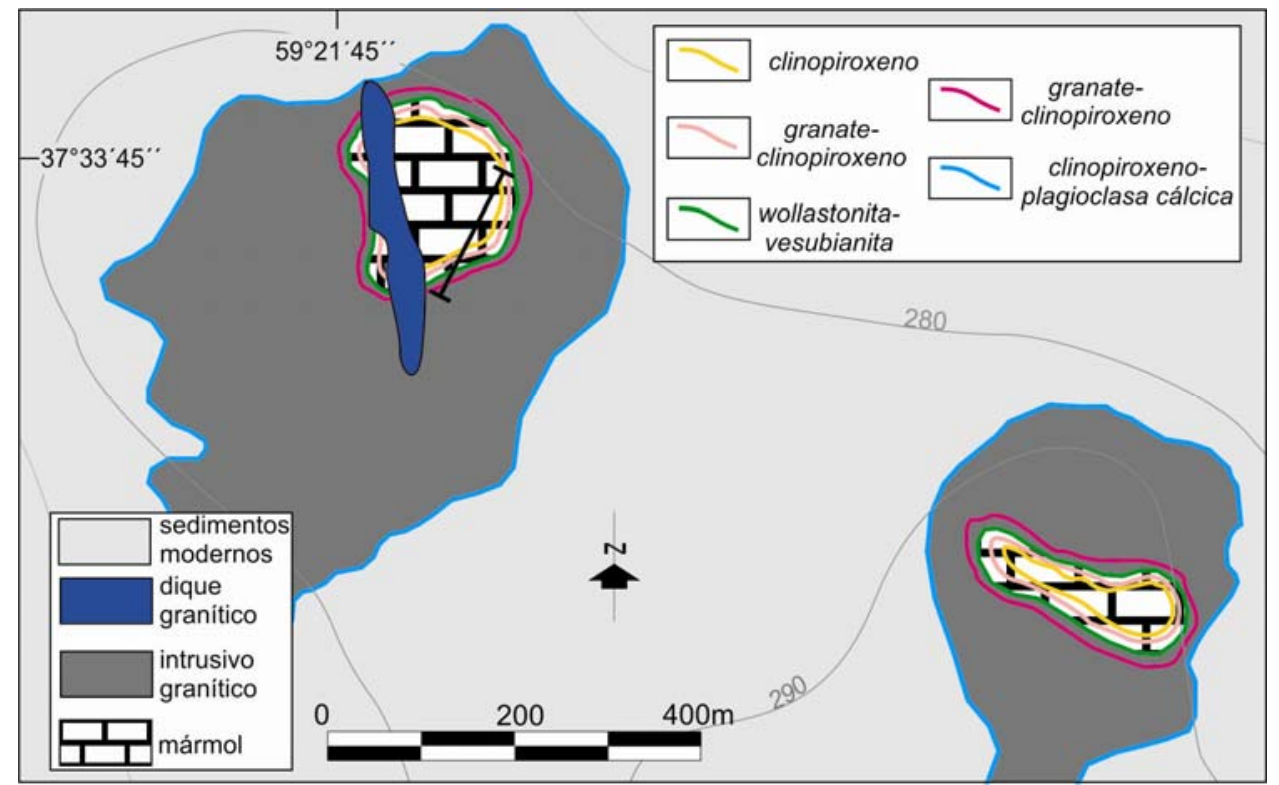

Figura 4.4: Ea. San Miguel, mapa geológico de detalle de los sectores noroccidental y nororiental. En el mismo se indica en forma esquemática la ubicación de las "zonas" definidas en cada uno de los afloramientos y la traza del perfil de la Fig.4.5.

Concordantemente con esta inclinación se intercalan entre las lentes de carbonato, filones graníticos de coloración blanquecina, de variado espesor (Fig. 4.5a y b), con tamaño de grano medio y una textura variable entre granular y porfirica. Si bien el contacto entre estos filones y otras rocas graníticas de la zona no se encuentra expuesto, es de destacar que las rocas más cercanas son el gneis biotítico migmático y los leucosomas de las migmatitas o leucogranitos, con los cuales presentan similitudes en sus características texturales y mineralógicas. En la zona de contacto entre las lentes de mármol y los filones graníticos, se ha identificado una serie de asociaciones minerales que corresponde al denominado skarn San Miguel. Dichas asociaciones fueron clasificadas en zonas que se determinaron sobre 
la base de la "aparición de determinados minerales". Dado que esta zonación se genera en los contactos entre los sucesivos filones que intruyen al carbonato, la misma se repite en forma vertical en cada intrusión granítica. Esto genera una complejidad en las relaciones espaciales entre las diferentes zonas, las cuales se encuentran bien representadas en el frente de la cantera principal del sector noroccidental (Fig. 4.5a y b).

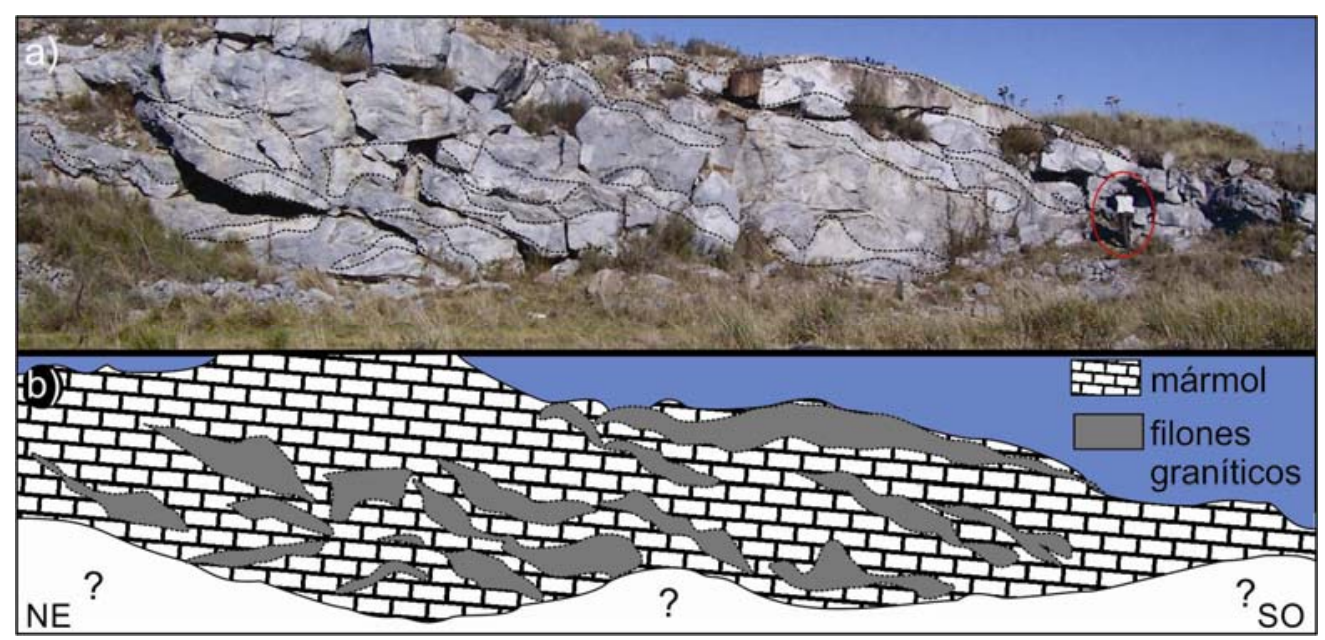

Figura 4.5: a) Frente de la cantera principal donde aflora el skarn San Miguel, en el sector nororiental. b) Perfil esquemático con la ubicación de las lentes de mármol y los filones graníticos.

Zona de exoskarn con wollastonita y vesubianita (1): Se desarrolla principalmente en el borde de reacción mármol-roca granítica (Figs. 4.4 y 4.6a) y presenta un espesor promedio de 1 centímetro. Está representada por la paragénesis wollastonita + vesubianita \pm clinopiroxeno. La wollastonita es el mineral más abundante (aproximadamente 70-80\%), es fibrosa y se desarrolla perpendicularmente a los contactos (Fig. 4.7a y b). Los cristales de vesubianita son escasos, poseen color castaño verdoso y hábito prismático poco desarrollado (Fig. 4.7c). Su composición química general fue determinada mediante microsonda electrónica, y los resultados se presentan en el Cuadro 4.1. El clinopiroxeno tipo diópsido-hedenbergita (Cuadro 4.2) conforma entre el 20 y el $30 \%$ del volumen total, es de color verde oscuro, 
hábito prismático y se encuentra ubicado aleatoriamente entre las fibras de wollastonita (Fig. 4.7d). Además, se observa muy poca cantidad de calcita y cuarzo de grano muy fino, dispuestos intersticialmente entre las fibras de wollastonita (Fig. 4.7c y d).

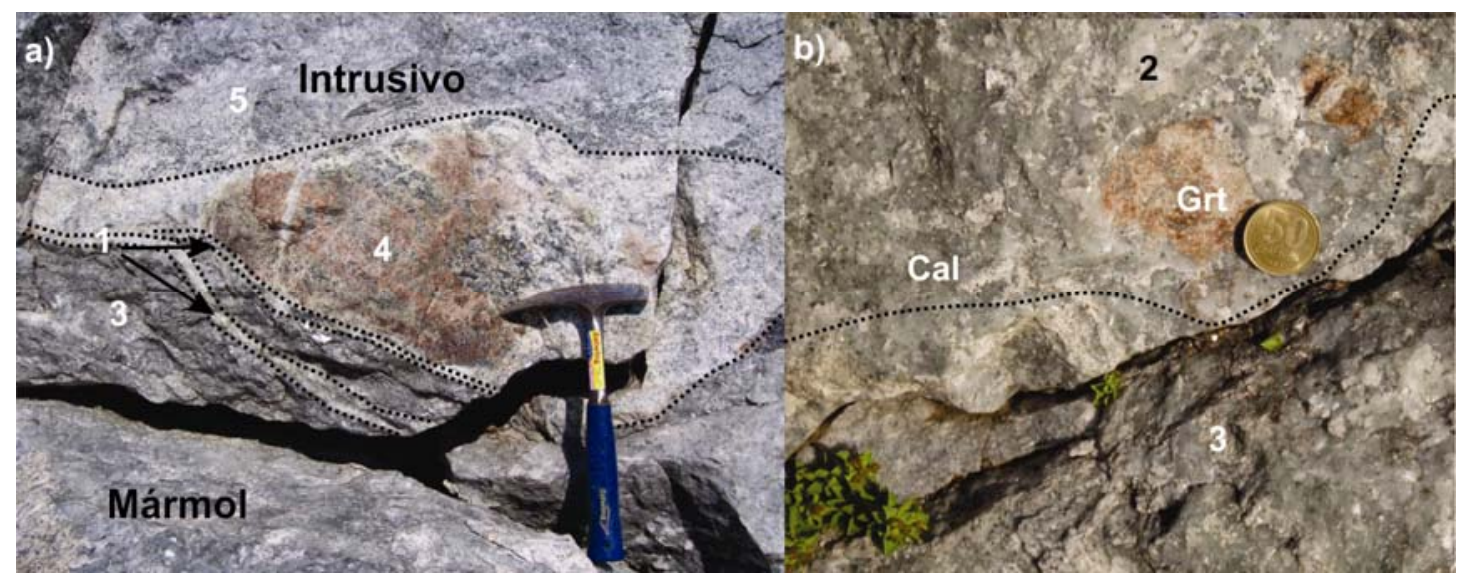

Figura 4.6: a) Disposición de las "zonas" sobre el frente principal de la cantera en relación a uno de los filones graníticos. Zonas del exoskarn: (1) wollastonitavesubianita y (3) clinopiroxeno. Zonas del endoskarn: (4) granate-clinopiroxeno y (5) clinopiroxeno-plagioclasa cálcica. b) Detalle de la zona (2) granate-clinopiroxeno la cual aparece solo en ciertos lugares del exoskarn. Abreviaturas minerales según Siivola y Schmid (2007).

Zona de exoskarn con granate y clinopiroxeno (2): Presenta un desarrollo discontinuo, de hasta un metro de espesor (Fig. 4.6b). Fue sólo reconocida en el sector noroccidental, por este motivo, en algunos sitios la ausencia de esta zona deja en contacto a las zonas de exoskarn con wollastonitavesubianita y la de exoskarn con clinopiroxeno (Fig. 4.6a). Está compuesta por granate, clinopiroxeno, calcita y cuarzo (Fig. 4.8a y b). 

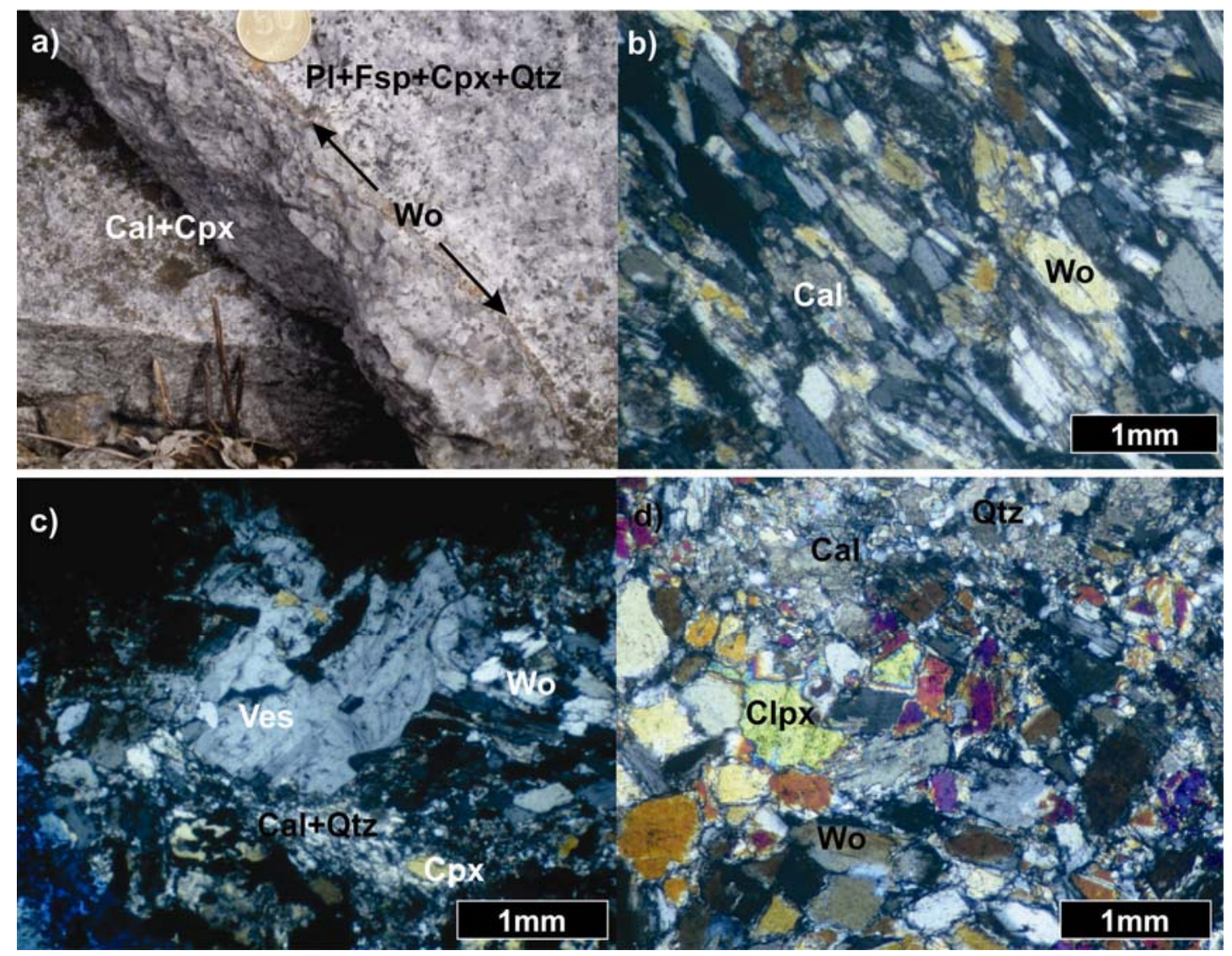

Figura 4.7: Zona de wollastonita-vesubianita. a) Vista mesoscópica en afloramiento. b) Apariencia microscópica, con analizador, donde se observa la orientación de las fibras de wollastonita y calcita intersticial. c) Cristal de vesubianita rodeado de wollastonita, calcita y cuarzo, con analizador. d) Cristal de clinopiroxeno rodeado de wollastonita con calcita y cuarzo intersticial. Abreviaturas minerales según Siivola y Schmid (2007).

\begin{tabular}{|c|c|c|c|c|c|}
\hline Óxido & $\%$ & Óxido & $\%$ & Óxido & $\%$ \\
\hline $\mathrm{SiO}_{2}$ & 36,99 & MnO & 0,13 & $\mathrm{CaO}$ & 36,09 \\
\hline $\mathrm{TiO}_{2}$ & 0,21 & MgO & 0,29 & $\mathrm{BaO}$ & 0,00 \\
\hline $\mathbf{A l}_{2} \mathbf{O}_{3}$ & 19,23 & NiO & 0,00 & $\mathbf{P}_{2} \mathbf{O}_{5}$ & 0,22 \\
\hline $\mathrm{Cr}_{2} \mathrm{O}_{3}$ & 0,02 & $\mathbf{K}_{\mathbf{2}} \mathbf{O}$ & 0,00 & $\mathbf{F}$ & 0,56 \\
\hline $\mathrm{FeO}$ & 6,22 & $\mathrm{Na}_{2} \mathrm{O}$ & 0,00 & Cl & 0,02 \\
\hline
\end{tabular}

Cuadro 4.1: Composición química promedio de la vesubianita, obtenida mediante un análisis por microsonda electrónica (se asume al hierro total como $\mathrm{FeO}$ ). 


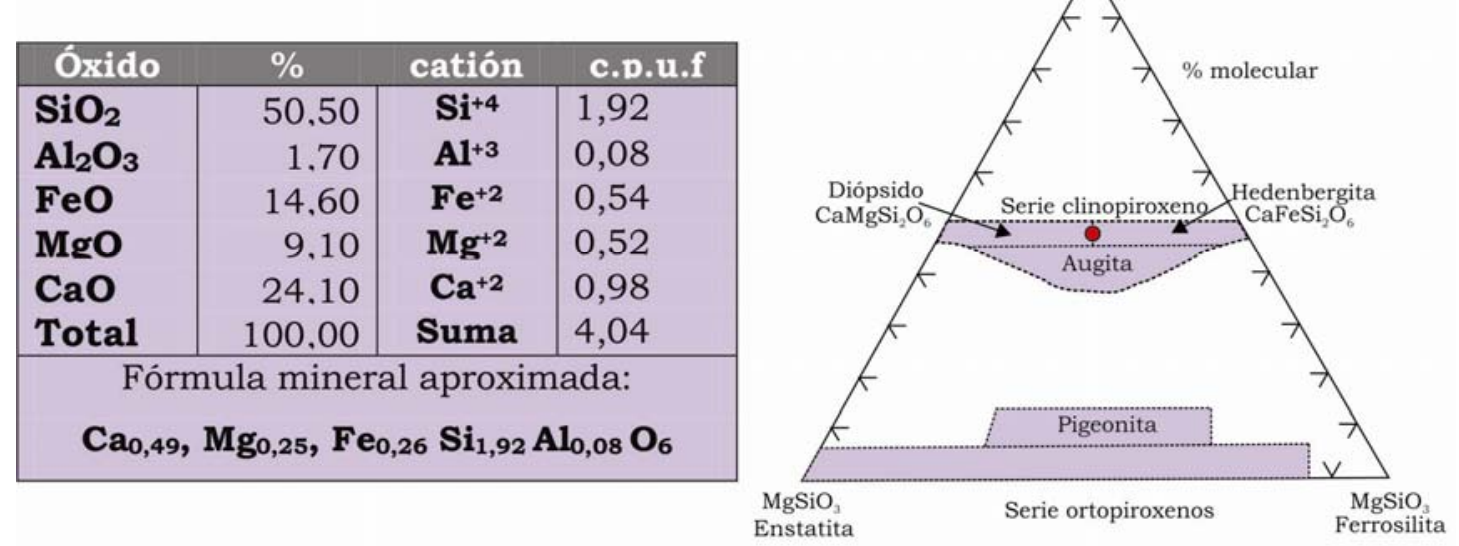

Cuadro 4.2: Composición química promedio y fórmula mineral aproximada de cristales de clinopiroxeno de la zona de exoskarn con wollastonita y vesubianita. La composición se obtuvo mediante un análisis EDAX y se asumió al hierro total como $\mathrm{FeO}$. Complementariamente, su gráfica (punto rojo) en el diagrama triangular (Klein y Hurlbut 1999) que se encuentra a la derecha del cuadro, indicó similares proporciones de diópsido y hedenbergita.

$\mathrm{El}$ granate es de color castaño rojizo y forma pequeños agregados granulares o grandes agregados con morfología esférica, con tamaños que varían entre 1 centímetro y 5 a 10 centímetros de diámetro máximo (Fig. 4.8a). Su composición rica en grosularia se indica en el Cuadro 4.3. Los cristales de clinopiroxeno poseen color verde oscuro, tienen un tamaño máximo de 2 milímetros, se encuentran entre los cristales de granate (Fig. 4.9a y b) y también diseminados en la calcita (Fig. 4.8b). Son predominantemente diópsidos de acuerdo a las composiciones que se muestran en el Cuadro 4.4. 


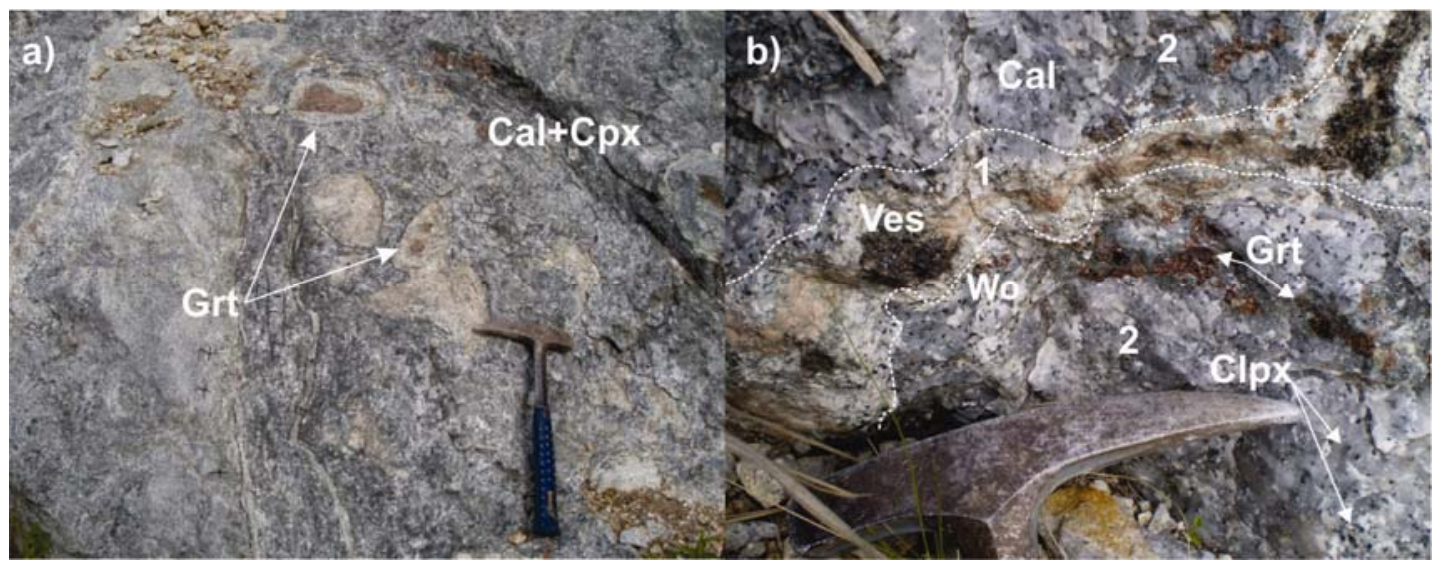

Figura 4.8: Zona granate-clinopiroxeno. a) morfología de la zona en uno de los sectores con mejor desarrollo, donde se observan los agregados de granate rodeados por cristales de calcita y clinopiroxeno. b) Detalle de esta zona en contacto con la correspondiente a wollastonita-vesubianita. En la fotografia pueden apreciarse pequeños cristales de granate de color pardo-rojizos, calcita grisácea e individuos pequeños de clinopiroxeno verde oscuro. Abreviaturas minerales según Siivola y Schmid (2007).

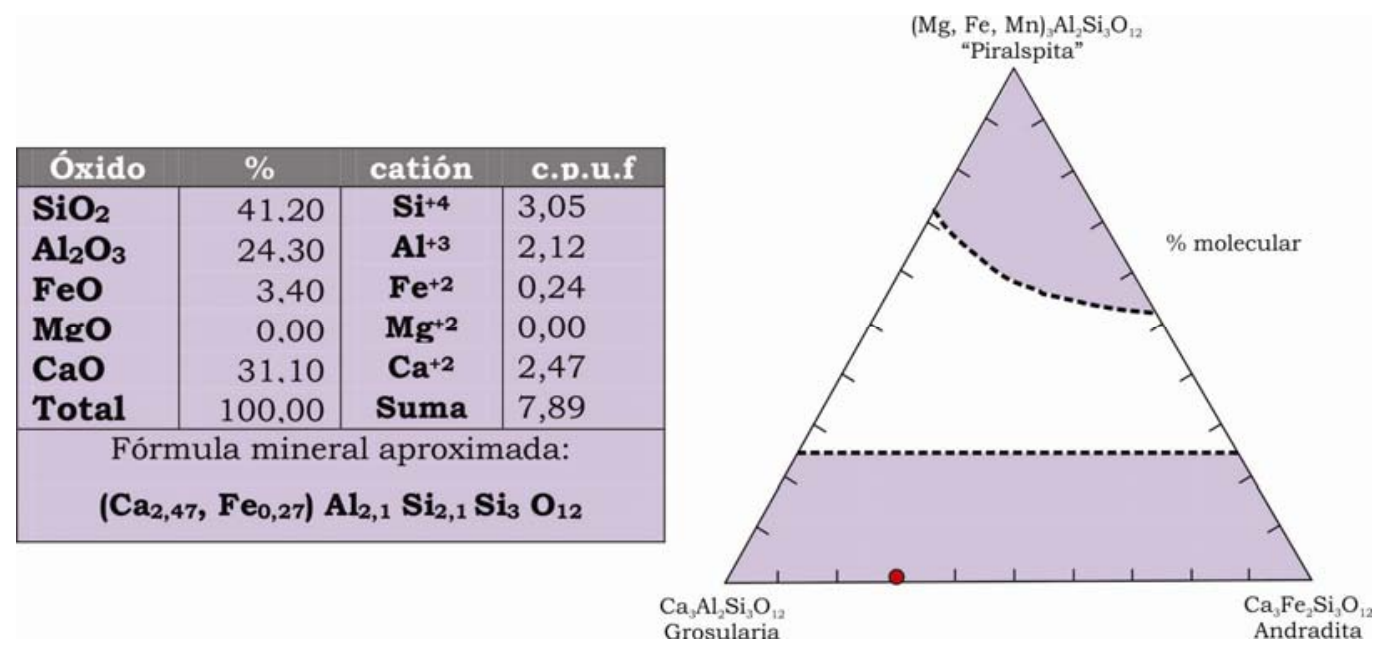

Cuadro 4.3: Composición química promedio y fórmula mineral aproximada de cristales de granate de la zona de exoskarn con granate y clinopiroxeno. Dicha composición fue obtenida mediante un análisis EDAX y se asumió al hierro total como FeO. Complementariamente, fue graficada (punto rojo) en el diagrama triangular (Klein y Hurlbut 1999) que se encuentra a la derecha del cuadro. En el mismo se observa que el granate corresponde a la serie grosularia-andradita (mayoritariamente grosularia). 


\begin{tabular}{|c|c|c|c|}
\hline Óxido & $\%$ & catión & c.p.u.f \\
\hline $\mathrm{SiO}_{2}$ & 52.62 & $\mathbf{S i}^{+4}$ & 1,99 \\
\hline $\mathrm{Al}_{2} \mathrm{O}_{3}$ & 0.99 & $\mathbf{A l}^{+3}$ & 0,04 \\
\hline FeO & 5.30 & $\mathbf{F e}^{+2}$ & 0,19 \\
\hline MgO & 15.25 & $\mathbf{M g}^{+2}$ & 0,83 \\
\hline $\mathrm{CaO}$ & 23.84 & $\mathrm{Ca}^{+2}$ & 0,93 \\
\hline Total & 100.00 & Suma & 3,99 \\
\hline \multicolumn{4}{|c|}{ Fórmula mineral aproximada: } \\
\hline \multicolumn{4}{|c|}{$\mathrm{Ca}_{0,48} \mathrm{Mg}_{0,43} \mathrm{Fe}_{0,09} \mathrm{Si}_{1,99} \mathrm{Al}_{0,01} \mathrm{O}_{6}$} \\
\hline
\end{tabular}

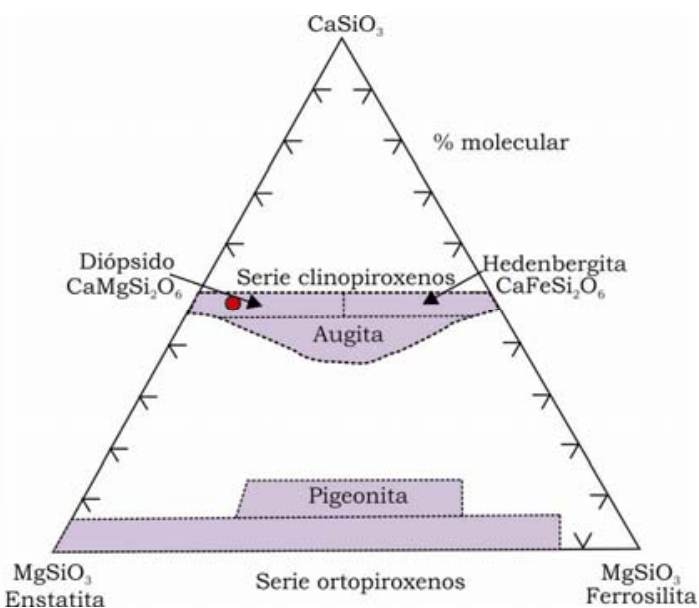

Cuadro 4.4: Composición química promedio y fórmula mineral aproximada de cristales de clinopiroxeno de la zona de exoskarn con granate y clinopiroxeno. Esta composición se obtuvo mediante un análisis EDAX y se asumió al hierro total como FeO. Complementariamente, fue graficada (punto rojo) en el diagrama triangular (Klein y Hurlbut 1999) ubicado a la derecha del cuadro, donde puede observarse que el piroxeno es mayoritariamente diópsido.

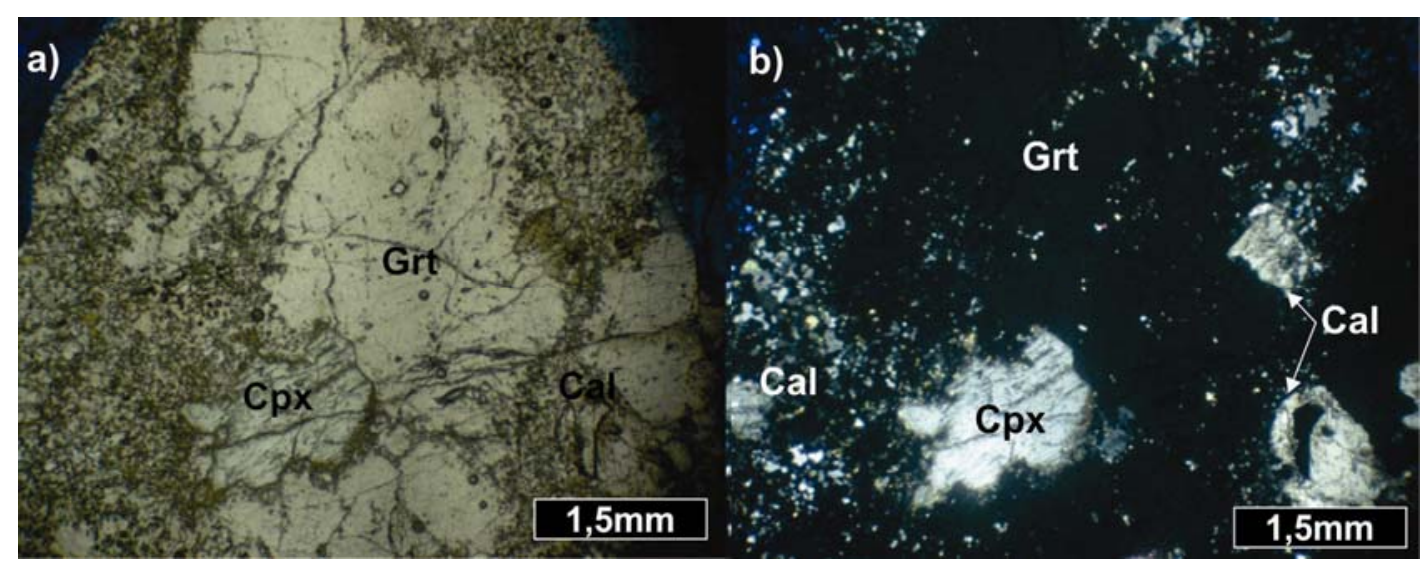

Figura 4.9: a y b) Vista microscópica de los cristales de granate y clinopiroxeno rodeados de calcita, sin analizador y con analizador, respectivamente. Abreviaturas minerales según Siivola y Schmid (2007).

La calcita es el mineral mayoritario, tiene color gris y varía su granulometría de fina a gruesa. Posee inclusiones sólidas de color gris oscuro y brillo metálico, que por su reducido tamaño, son de difícil identificación al microscopio (Fig. 4.10). Análisis por difracción de rayos $\mathrm{X}$ 
permitieron clasificar preliminarmente las inclusiones como esfalerita (Fig. 4.11).

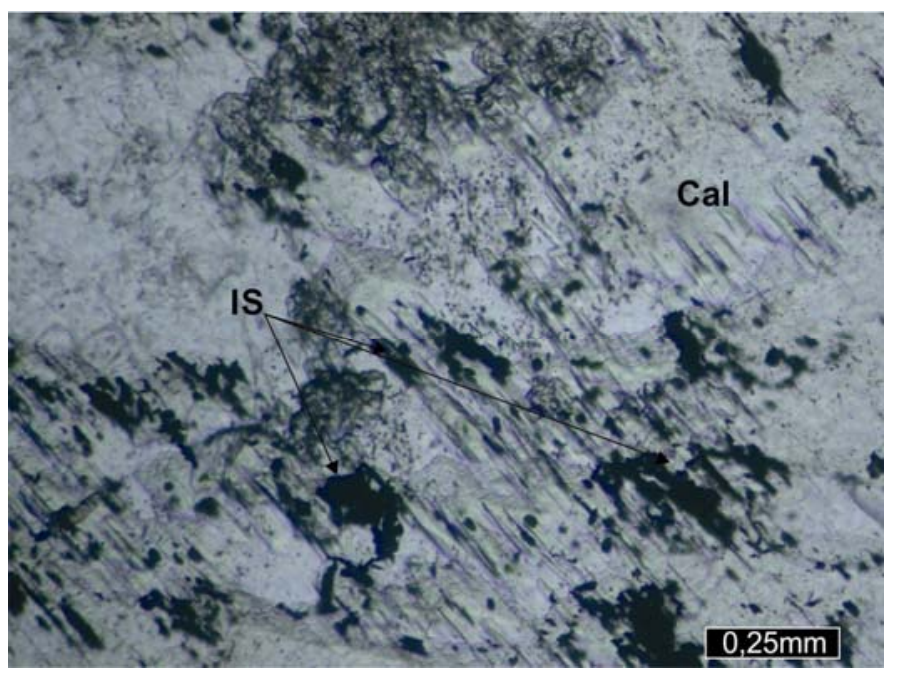

Figura 4.10: Vista de cristal de calcita, al microscopio, con inclusiones sólidas (IS) de posible esfalerita.

El cuarzo es gris, escaso y se encuentra alojado dentro de los agregados de cristales de granate y en pequeñas vetillas (Fig. 4.12). Se identificó además clinozoisita formando coronas sobre cristales de granate como evidencia de retrogradación (Fig. 4.12).

Zona de exoskarn con clinopiroxeno (3): Presenta entre 10 y 20 centímetros de espesor y se desarrolla a continuación de la zona anterior por la desaparición del granate (Fig. 4.6a y b). Está constituida, principalmente, por cristales de calcita de grano grueso a medio (5 a 10 milimetros) de iguales características que la calcita de la zona de exoskarn con granate y clinopiroxeno (Fig. 4.13a y b). La paragénesis mineral reconocida es: calcita + clinopiroxeno. Los cristales de clinopiroxeno comprenden alrededor del $20 \%$ del volumen total y tienen una distribución homogénea. Desarrollan tamaños de hasta 2 milimetros y son de color verde claro, en general translúcidos a ligeramente transparentes (Fig. 4.13a y b). 

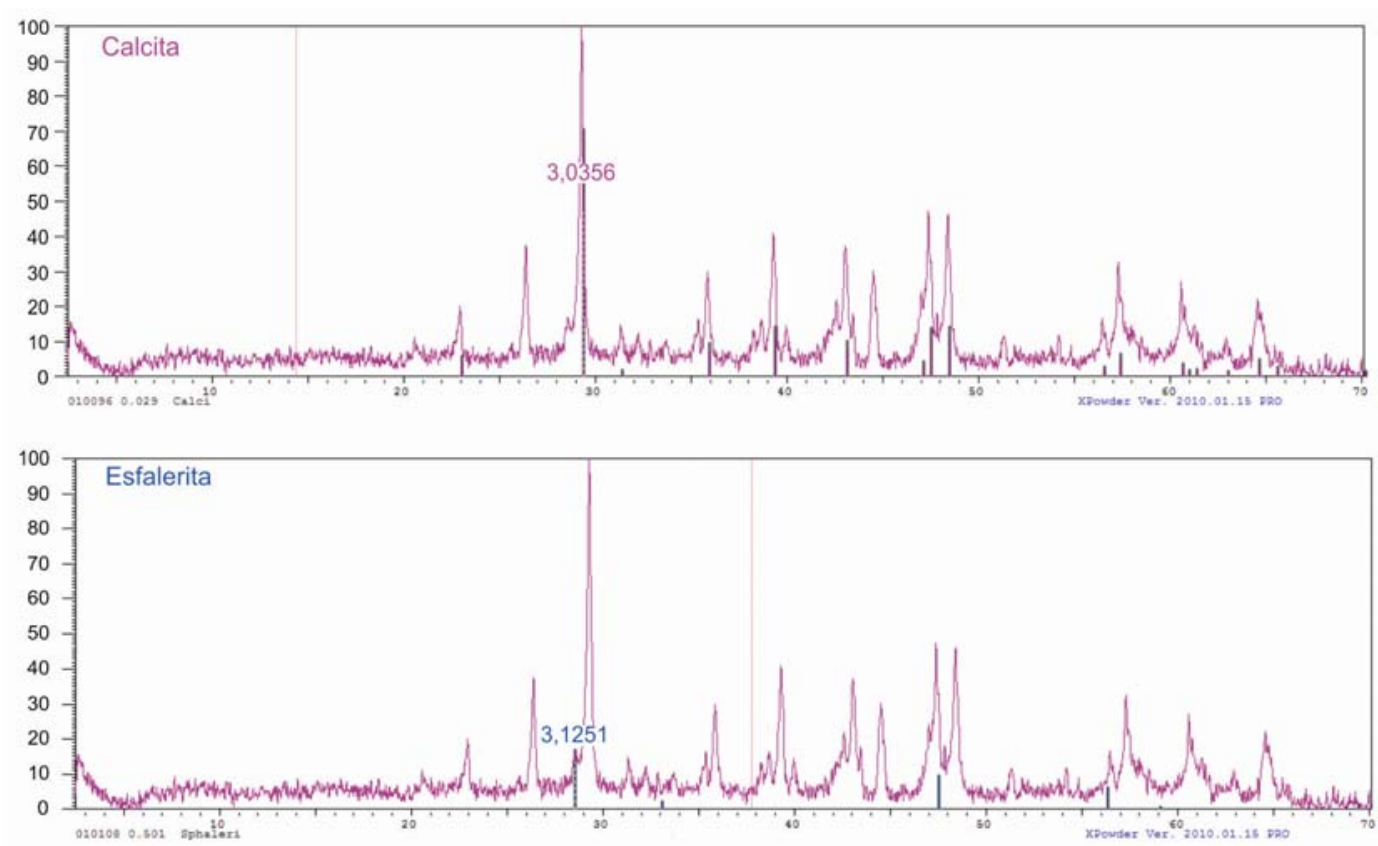

Figura 4.11. Difractogramas: ambos corresponden a la muestra SM-26, en el primero se indican los picos de la calcita, mucho más intensos y en el segundo los picos de la esfalerita con menor expresión. Los difractogramas fueron procesados con el programa XPowder (versión 2010.01.02, Martin 2004).

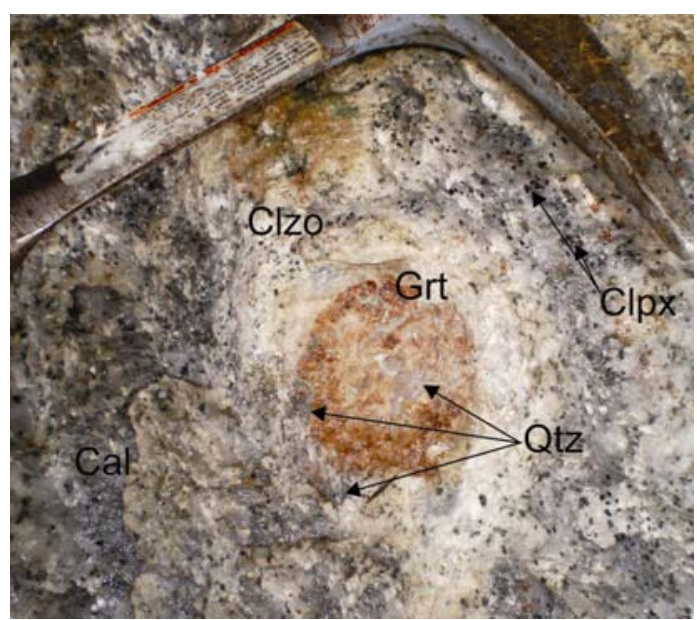

Figura 4.12: Vista mesoscópica de un agregado de cristales de granate con morfología "esférica", y con desarrollo de una corona de clinozoisita, rodeados de calcita, clinopiroxeno y cuarzo. Abreviaturas minerales según Siivola y Schmid (2007). 

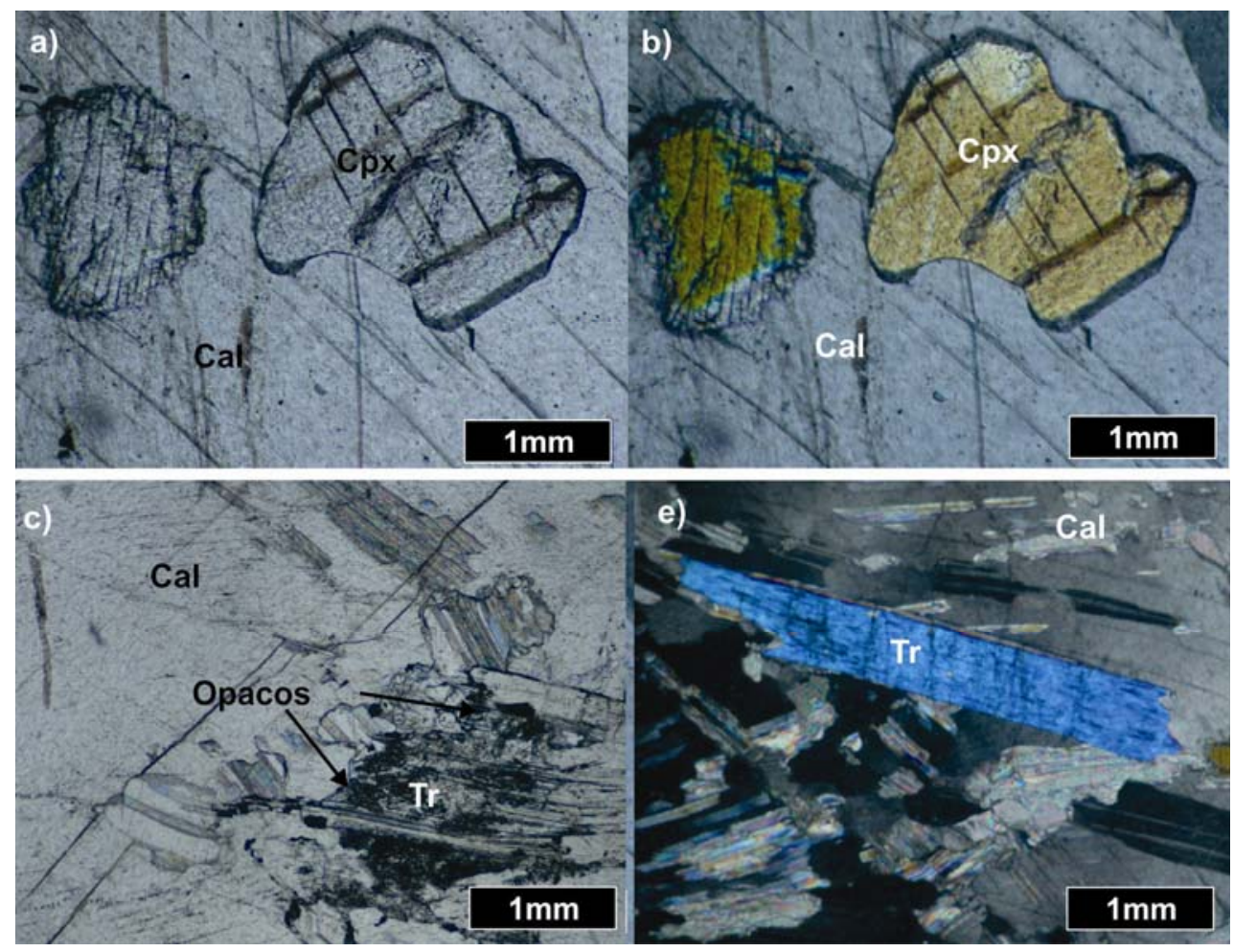

Figura 4.13: Zona de clinopiroxeno. a y b) Vista al microscopio de cristales de clinopiroxeno rodeados por cristales de calcita, sin y con analizador. c y d) Cristales de tremolita con inclusiones de minerales opacos, rodeados por calcita. Abreviaturas minerales según Siivola y Schmid (2007).

Estas características diferencian estos clinopiroxenos de los del mármol (ya estudiados en el apartado 3.A.2), principalmente porque estos últimos no presentan reemplazos pseudomórficos por minerales retrógrados como anfiboles de tipo tremolita-actinolita o por clorita. Y como se pudo determinar en el capítulo 3.A, la signatura isotópica entre ambos clinopiroxenos es muy diferente. Su composición química, determinada en forma semicuantitativa, es muy similar a la de los clinopiroxenos del mármol e indica un alto porcentaje de diópsido (Cuadro 4.5). Se han reconocido pequeños cristales de actinolita rodeada por minerales opacos de similar apariencia que las inclusiones sólidas de esfalerita encontradas en los cristales de calcita (Fig. 4.13a y b). 


\begin{tabular}{|c|c|c|c|}
\hline Óxido & $\%$ & catión & c.p.u.f \\
\hline $\mathrm{SiO}_{2}$ & 51.80 & $\mathbf{S i}^{+4}$ & 1,92 \\
\hline $\mathbf{A l}_{2} \mathbf{O}_{3}$ & 1.00 & $\mathbf{A l}^{+3}$ & 0,04 \\
\hline $\mathrm{FeO}$ & 4.50 & $\mathrm{Fe}^{+2}$ & 0,16 \\
\hline MgO & 15,00 & $\mathrm{Mg}^{+2}$ & 0,83 \\
\hline $\mathrm{CaO}$ & 27.70 & $\mathrm{Ca}^{+2}$ & 1,10 \\
\hline Total & 100.00 & Suma & 4,06 \\
\hline \multicolumn{4}{|c|}{$\begin{array}{l}\text { Fórmula mineral aproximada: } \\
\mathbf{C a}_{\mathbf{0}, \mathbf{5 4}} \mathbf{M g}_{0, \mathbf{4 0}} \mathbf{F e}_{0,07} \mathbf{S i}_{\mathbf{1}, \mathbf{2}} \mathbf{A l}_{0,04} \mathbf{O}_{\mathbf{6}}\end{array}$} \\
\hline
\end{tabular}



Cuadro 4.5: Composición química promedio y fórmula mineral aproximada de cristales de clinopiroxeno de la zona de exoskarn con clinopiroxeno. Dicha composición fue obtenida mediante un análisis EDAX y se asumió al hierro total como $\mathrm{FeO}$. Complementariamente, se la graficó (punto rojo) en el diagrama triangular (Klein y Hurlbut 1999), que se ubica a derecha del cuadro. Como se observa la composición del piroxeno es mayoritariamente diópsido.

Zona de endoskarn con granate y clinopiroxeno (4): Presenta morfologias similares a lóbulos, cuyos espesores varían entre unos pocos centímetros y 1 a 2 metros (Fig. 4.6a y b). La asociación prógrada reconocida en esta zona es: granate + clinopiroxeno + plagioclasa cálcica \pm vesubianita. Los minerales predominantes son granate y clinopiroxeno que desarrollan cristales desde pocos milímetros hasta 6-7 centímetros de tamaño. Si bien el granate no presenta zonación, su composición varía entre grosularia76-99, andradita0-16 y almandino0-8, en tanto que los componentes restantes (piropo+espesartina+uvarovita) no superan el 0,77\% (Cuadro 4.6a y b). Posee color castaño rojizo y forma agregados de tamaño variable, desde pocos centímetros hasta 50 centímetros de diámetro (Fig. 4.14a). Al microscopio, estos agregados están compuestos por pequeños cristales euhédricos de grosularia, algunos con bordes anisótropos (Fig. 14b). En otros sectores, forman agregados macizos junto con el clinopiroxeno (Fig. 4.14a). En ocasiones el granate presenta una corona de coloración rosa pálida, que corresponde a clinozoisita retrógrada (Fig. 4.14a). 


\begin{tabular}{|c|c|c|c|c|c|c|c|c|}
\hline \multicolumn{9}{|c|}{ Granate 1291a (Endoskarn granate-clinopiroxeno) } \\
\hline \%peso & P1 & $\mathbf{P 2}$ & P3 & P4 & P5 & P6 & P7 & P8 \\
\hline $\mathrm{SiO}_{2}$ & 39,59 & 40,26 & 38,95 & 38,74 & 38,36 & 39,51 & 39,75 & 39,64 \\
\hline $\mathrm{TiO}_{2}$ & 0,04 & 0,00 & 0,51 & 0,62 & 0,57 & 0,26 & 0,22 & 0,24 \\
\hline $\mathbf{A l}_{2} \mathbf{O}_{3}$ & 22,12 & 24,71 & 20,51 & 19,42 & 18,14 & 20,82 & 20,92 & 20,73 \\
\hline $\mathrm{Cr}_{2} \mathrm{O}_{3}$ & 0,00 & 0,00 & 0,00 & 0,00 & 0,00 & 0,00 & 0,00 & 0,00 \\
\hline $\mathrm{Fe}_{2} \mathrm{O}_{3 \mathbf{r}}$ & 0,56 & 0,00 & 3,32 & 3,73 & 5,49 & 1,62 & 1,85 & 1,13 \\
\hline $\mathrm{FeO}_{\mathrm{r}}$ & 0,00 & 3,11 & 0,23 & 2,01 & 3,16 & 0,99 & 0,67 & 1,33 \\
\hline MnO & 0,02 & 0,00 & 0,09 & 0,07 & 0,14 & 0,03 & 0,02 & 0,02 \\
\hline MgO & 0,08 & 0,01 & 0,08 & 0,04 & 0,06 & 0,19 & 0,17 & 0,17 \\
\hline $\mathrm{CaO}$ & 37,24 & 30,28 & 35,80 & 34,77 & 33,21 & 36,17 & 36,59 & 36,07 \\
\hline NiO & 0,00 & 0,00 & 0,00 & 0,00 & 0,00 & 0,00 & 0,00 & 0,00 \\
\hline $\mathbf{N a}_{2} \mathbf{O}$ & 0,00 & 0,00 & 0,00 & 0,00 & 0,00 & 0,00 & 0,00 & 0,00 \\
\hline $\mathbf{K}_{2} \mathbf{O}$ & 0,00 & 0,00 & 0,00 & 0,00 & 0,00 & 0,00 & 0,00 & 0,00 \\
\hline $\mathbf{P}_{2} \mathbf{O}_{5}$ & 0,41 & 0,24 & 0,36 & 0,32 & 0,35 & 0,34 & 0,37 & 0,39 \\
\hline Total & 100,06 & 98,61 & 99,85 & 99,72 & 99,48 & 99,93 & 100,56 & 99,72 \\
\hline
\end{tabular}

\begin{tabular}{|c|c|c|c|c|c|c|c|c|}
\hline \multicolumn{9}{|c|}{ ationes por unidad de fórmula, sobre la base de 12 oxígenos } \\
\hline Si & 2,98 & 3,06 & 2,97 & 2,98 & 2,98 & 2,99 & 2,99 & 3,01 \\
\hline $\mathbf{P}$ & 0,01 & 0,01 & 0,01 & 0,01 & 0,01 & 0,01 & 0,01 & 0,01 \\
\hline Al & 0,01 & 0,00 & 0,02 & 0,01 & 0,01 & 0,00 & 0,00 & 0,00 \\
\hline $\mathbf{F e}^{+3}$ & 0,00 & 0,00 & 0,00 & 0,00 & 0,00 & 0,00 & 0,00 & 0,00 \\
\hline Suma & 3,00 & 3,07 & 3,00 & 3,00 & 3,00 & 3,00 & 3,01 & 3,02 \\
\hline $\mathbf{T i}$ & 0,00 & 0,00 & 0,03 & 0,04 & 0,03 & 0,02 & 0,01 & 0,01 \\
\hline Al & 1,90 & 2,71 & 1,82 & 1,74 & 1,65 & 1,86 & 1,86 & 1,86 \\
\hline $\mathbf{F e}^{+3}$ & 0,09 & 0,00 & 0,19 & 0,22 & 0,33 & 0,09 & 0,11 & 0,06 \\
\hline $\mathrm{Fe}^{+2}$ & 0,00 & 0,19 & 0,01 & 0,13 & 0,21 & 0,06 & 0,04 & 0,08 \\
\hline Mn & 0,00 & 0,00 & 0,01 & 0,00 & 0,01 & 0,00 & 0,00 & 0,00 \\
\hline Mg & 0,01 & 0,00 & 0,01 & 0,00 & 0,01 & 0,02 & 0,02 & 0,02 \\
\hline $\mathrm{Ca}$ & 3,00 & 1,98 & 2,92 & 2,86 & 2,76 & 2,94 & 2,95 & 2,93 \\
\hline $\mathbf{N i}$ & 0,00 & 0,00 & 0,00 & 0,00 & 0,00 & 0,00 & 0,00 & 0,00 \\
\hline $\mathbf{N a}$ & 0,00 & 0,00 & 0,00 & 0,00 & 0,00 & 0,00 & 0,00 & 0,00 \\
\hline $\mathbf{K}$ & 0,00 & 0,00 & 0,00 & 0,00 & 0,00 & 0,00 & 0,00 & 0,00 \\
\hline Suma & 5,00 & 4,88 & 4,99 & 4,99 & 5,00 & 4,99 & 4,99 & 4,96 \\
\hline Total & 8,00 & 7,95 & 7,99 & 7,99 & 8,00 & 7,99 & 8,00 & 7,98 \\
\hline \multicolumn{9}{|c|}{ Porcentajes moleculares } \\
\hline Grs & 95,19 & 91,09 & 89,38 & 84,25 & 75,93 & 92,42 & 92,55 & 93,08 \\
\hline Ad & 4,48 & 0,00 & 9,51 & 11,08 & 16,46 & 4,74 & 5,35 & 3,36 \\
\hline Alm & 0,00 & 8,79 & 0,50 & 4,33 & 6,97 & 2,08 & 1,41 & 2,78 \\
\hline $\mathbf{P}+\mathbf{S}+\mathbf{U}$ & 0,33 & 0,12 & 0,61 & 0,34 & 0,64 & 0,77 & 0,68 & 0,77 \\
\hline Total & 100,00 & 100,00 & 100,00 & 100,00 & 100,00 & 100,00 & 100,00 & 100,00 \\
\hline
\end{tabular}

Cuadro 4.6a: Valores representativos de análisis químicos por microsonda electrónica de cristales de granate del endoskarn de granate-clinopiroxeno. El contenido de $\mathrm{Fe}$ en granate $\left(\mathrm{Fe}^{+2}\right.$ y $\left.\mathrm{Fe}^{+3}\right)$ fue recalculado según Droop (1987). Referencias: $\mathrm{P}=$ piropo, $\mathrm{S}=$ espesartina y $\mathrm{U}=$ uvarovita. 


\begin{tabular}{|c|c|c|c|c|c|c|c|c|}
\hline \multicolumn{9}{|c|}{ Granate 1291b (Endoskarn granate-clinopiroxeno) } \\
\hline \%peso & P9 & P10 & P11 & P12 & P13 & P14 & P15 & P16 \\
\hline $\mathrm{SiO}_{2}$ & 39,78 & 39,84 & 39,97 & 40,09 & 39,87 & 39,86 & 39,97 & 39,57 \\
\hline $\mathrm{TiO}_{2}$ & 0,22 & 0,27 & 0,23 & 0,08 & 0,28 & 0,25 & 0,20 & 0,18 \\
\hline $\mathbf{A l}_{2} \mathbf{O}_{3}$ & 20,78 & 20,80 & 20,71 & 21,22 & 21,31 & 20,81 & 20,89 & 20,63 \\
\hline $\mathrm{Cr}_{2} \mathrm{O}_{3}$ & 0,00 & 0,00 & 0,04 & 0,00 & 0,00 & 0,00 & 0,00 & 0,00 \\
\hline $\mathrm{Fe}_{2} \mathrm{O}_{3 \mathrm{r}}$ & 1,68 & 1,28 & 0,99 & 0,70 & 0,55 & 1,52 & 1,09 & 1,53 \\
\hline $\mathrm{FeO}_{\mathrm{r}}$ & 0,81 & 1,22 & 1,51 & 1,63 & 2,04 & 1,05 & 1,41 & 0,99 \\
\hline MnO & 0,01 & 0,03 & 0,01 & 0,03 & 0,04 & 0,00 & 0,00 & 0,08 \\
\hline MgO & 0,17 & 0,15 & 0,19 & 0,16 & 0,17 & 0,19 & 0,17 & 0,18 \\
\hline $\mathrm{CaO}$ & 36,52 & 36,18 & 35,86 & 36,17 & 35,61 & 36,24 & 36,23 & 35,93 \\
\hline NiO & 0,01 & 0,05 & 0,02 & 0,00 & 0,00 & 0,00 & 0,00 & 0,02 \\
\hline $\mathrm{Na}_{2} \mathrm{O}$ & 0,03 & 0,01 & 0,07 & 0,00 & 0,02 & 0,04 & 0,02 & 0,03 \\
\hline $\mathbf{K}_{2} \mathbf{O}$ & 0,01 & 0,00 & 0,02 & 0,01 & 0,02 & 0,00 & 0,01 & 0,00 \\
\hline $\mathbf{P}_{2} \mathbf{O}_{5}$ & 0,35 & 0,38 & 0,33 & 0,36 & 0,35 & 0,38 & 0,37 & 0,34 \\
\hline Total & 100,37 & 100,21 & 99,92 & 100,45 & 100,25 & 100,34 & 100,38 & 99,48 \\
\hline \multicolumn{9}{|c|}{ Cationes por unidad de fórmula, sobre la base de 12 oxígenos } \\
\hline Si & 3,00 & 3,01 & 3,03 & 3,02 & 3,01 & 3,01 & 3,02 & 3,01 \\
\hline $\mathbf{P}^{+5}$ & 0,01 & 0,01 & 0,01 & 0,01 & 0,01 & 0,01 & 0,01 & 0,01 \\
\hline Al & 0,00 & 0,00 & 0,00 & 0,00 & 0,00 & 0,00 & 0,00 & 0,00 \\
\hline $\mathrm{Fe}^{+3}$ & 0,00 & 0,00 & 0,00 & 0,00 & 0,00 & 0,00 & 0,00 & 0,00 \\
\hline Suma & 3,01 & 3,02 & 3,04 & 3,03 & 3,02 & 3,02 & 3,03 & 3,02 \\
\hline $\mathbf{T i}$ & 0,01 & 0,02 & 0,01 & 0,00 & 0,02 & 0,01 & 0,01 & 0,01 \\
\hline Al & 1,85 & 1,85 & 1,85 & 1,88 & 1,90 & 1,85 & 1,86 & 1,85 \\
\hline $\mathrm{Fe}^{+3}$ & 0,10 & 0,07 & 0,06 & 0,04 & 0,03 & 0,09 & 0,06 & 0,09 \\
\hline $\mathrm{Fe}^{+2}$ & 0,05 & 0,08 & 0,10 & 0,10 & 0,13 & 0,07 & 0,09 & 0,06 \\
\hline $\mathbf{C r}$ & 0,00 & 0,00 & 0,00 & 0,00 & 0,00 & 0,00 & 0,00 & 0,00 \\
\hline Mn & 0,00 & 0,00 & 0,00 & 0,00 & 0,00 & 0,00 & 0,00 & 0,00 \\
\hline Mg & 0,02 & 0,02 & 0,02 & 0,02 & 0,02 & 0,02 & 0,02 & 0,02 \\
\hline $\mathrm{Ca}$ & 2,95 & 2,93 & 2,91 & 2,92 & 2,88 & 2,93 & 2,93 & 2,93 \\
\hline $\mathbf{N i}$ & 0,00 & 0,00 & 0,00 & 0,00 & 0,00 & 0,00 & 0,00 & 0,00 \\
\hline $\mathbf{N a}$ & 0,01 & 0,00 & 0,01 & 0,00 & 0,00 & 0,01 & 0,00 & 0,00 \\
\hline $\mathbf{K}$ & 0,00 & 0,00 & 0,00 & 0,00 & 0,00 & 0,00 & 0,00 & 0,00 \\
\hline Suma & 4,99 & 4,98 & 4,96 & 4,97 & 4,98 & 4,98 & 4,97 & 4,98 \\
\hline Total & 8,00 & 8,00 & 8,00 & 8,00 & 8,00 & 8,00 & 8,00 & 8,00 \\
\hline \multicolumn{9}{|c|}{ Porcentajes moleculares } \\
\hline Grs & 92,73 & 93,03 & 93,06 & 93,92 & 93,41 & 92,60 & 93,18 & 92,52 \\
\hline Adr & 4,92 & 3,80 & 2,96 & 2,08 & 1,63 & 4,47 & 3,24 & 4,55 \\
\hline Alm & 1,70 & 2,55 & 3,16 & 3,37 & 4,25 & 2,21 & 2,94 & 2,10 \\
\hline $\mathbf{P}+\mathbf{S}+\mathbf{U}$ & 0,65 & 0,63 & 0,82 & 0,63 & 0,71 & 0,72 & 0,64 & 0,83 \\
\hline Total & 100,00 & 100,00 & 100,00 & 100,00 & 100,00 & 100,00 & 100,00 & 100,00 \\
\hline
\end{tabular}

Cuadro 4.6b: Valores representativos de análisis químicos por microsonda electrónica de cristales de granate del endoskarn de granate-clinopiroxeno. El contenido de $\mathrm{Fe}$ en granate $\left(\mathrm{Fe}^{+2}\right.$ y $\left.\mathrm{Fe}^{+3}\right)$ fue recalculado según Droop (1987). Referencias: $\mathrm{P}=$ piropo, $\mathrm{S}=$ espesartina y $\mathrm{U}=$ uvarovita. 

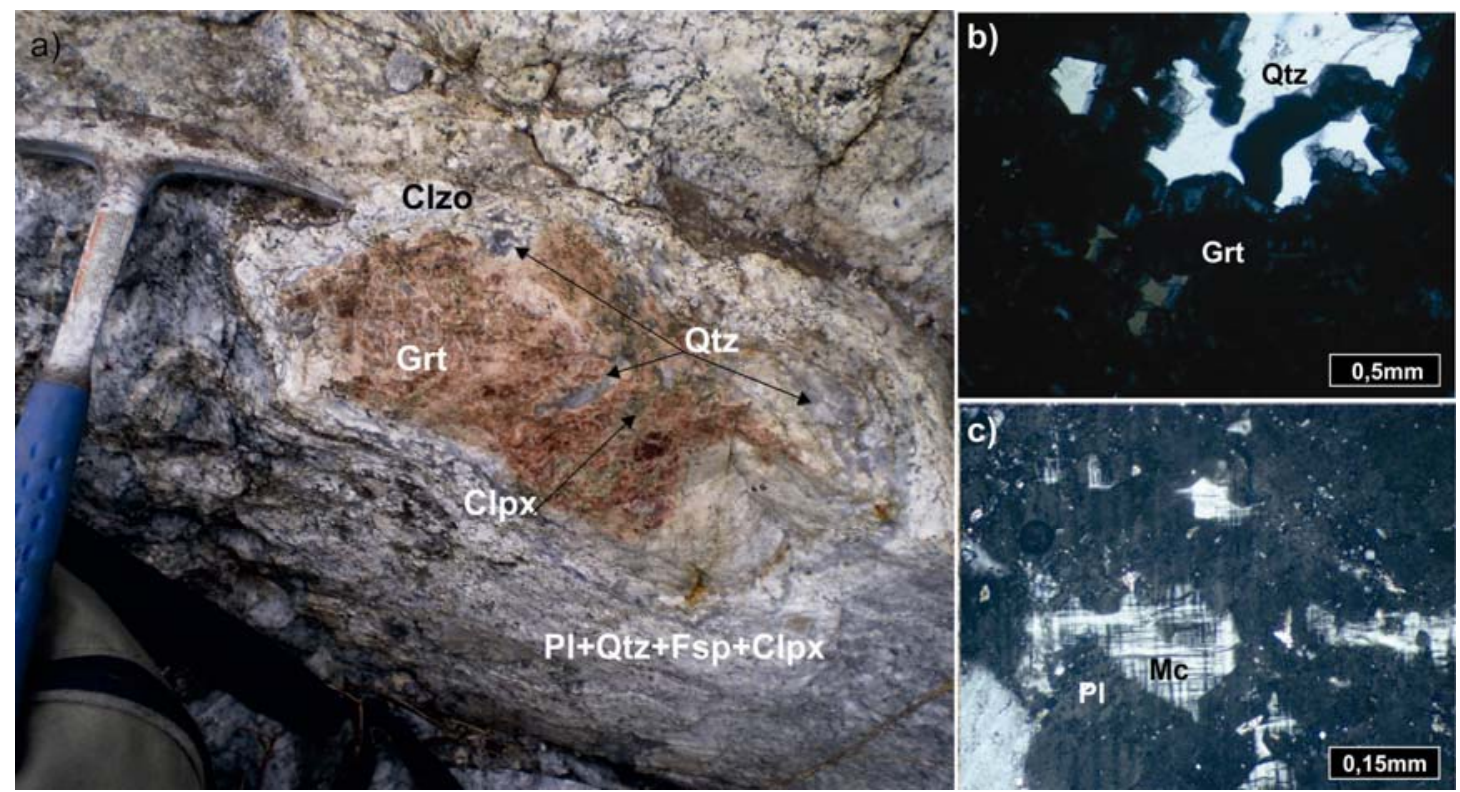

Figura 4.14: Zona granate-clinopiroxeno. a) Vista mesoscópica de un agregado de granate con corona de clinozoisita y clinopiroxeno, con cuarzo intersticial, rodeado de plagioclasa, cuarzo, feldespato potásico y clinopiroxeno. b) Vista al microscopio del agregado con analizador, donde se observan los cristales de granate con bordes parcialmente anisótropos. c) Cristales de microclino reemplazando a cristales de plagioclasa, con analizador. Abreviaturas minerales según Siivola y Schmid (2007).

En muestra de mano el clinopiroxeno posee, en general, hábito prismático y color verde, diferenciándose uno de color verde muy claro poco translúcido y otro de color verde oscuro translúcido. El primero tiene una composición que varía entre diópsido52-67 y hedenbergita33-47, con valores inferiores a $0,50 \%$ de johannsenita, sin zonación composicional (Cuadro 4.7a y b) y forma parte de los agregados macizos junto con granate. El piroxeno verde oscuro (de aspecto similar al clinopiroxeno del exoskarn) se asocia a cuarzo, plagioclasa (anortita50-60) y escaso microclino (Fig. 4.14a).

Al microscopio se observa que algunos cristales de plagioclasa evidencian reemplazos por microclino en su interior, en relación pseudomórfica (Fig. 4.14c). Además, se identificaron escasos cristales de vesubianita, incluidos en los cristales de grosularia. El cuarzo es abundante y se encuentra rodeando al granate, formando parte del granitoide que fue modificado por los procesos de metasomatismo, y en forma intersticial entre 
los agregados de granate-piroxeno (Fig. 4.14a). En ambos casos se trata de un cuarzo translúcido de color gris (Fig. 4.14a y b).

\begin{tabular}{|c|c|c|c|c|c|c|c|c|}
\hline \multicolumn{9}{|c|}{ Clinopiroxeno 1-1291b (Endoskarn granate-clinopiroxeno) } \\
\hline \%peso & P1 & P2 & P3 & P4 & P5 & P6 & P7 & P8 \\
\hline $\mathrm{SiO}_{2}$ & 51,44 & 51,32 & 52,52 & 51,78 & 52,43 & 52,22 & 52,30 & 52,12 \\
\hline $\mathrm{TiO}_{2}$ & 0,10 & 0,07 & 0,02 & 0,00 & 0,00 & 0,00 & 0,00 & 0,00 \\
\hline $\mathbf{A l}_{2} \mathbf{O}_{3}$ & 0,83 & 0,92 & 0,17 & 0,11 & 0,08 & 0,08 & 0,11 & 0,13 \\
\hline $\mathrm{Cr}_{2} \mathrm{O}_{3}$ & 0,00 & 0,00 & 0,00 & 0,00 & 0,00 & 0,00 & 0,00 & 0,00 \\
\hline $\mathrm{FeO}_{\mathbf{r}}$ & 11,23 & 11,08 & 9,53 & 13,88 & 10,35 & 10,82 & 11,75 & 11,83 \\
\hline $\mathrm{Fe}_{2} \mathrm{O}_{3 \mathrm{r}}$ & 1,38 & 1,57 & 0,73 & 0,68 & 0,66 & 0,76 & 0,57 & 0,69 \\
\hline MnO & 0,12 & 0,13 & 0,04 & 0,15 & 0,09 & 0,08 & 0,08 & 0,02 \\
\hline MgO & 9,94 & 10,00 & 11,78 & 9,00 & 11,25 & 10,87 & 10,44 & 10,33 \\
\hline $\mathrm{CaO}$ & 24,91 & 24,48 & 25,06 & 24,76 & 25,22 & 25,26 & 25,06 & 24,97 \\
\hline NiO & 0,01 & 0,07 & 0,00 & 0,10 & 0,00 & 0,00 & 0,06 & 0,04 \\
\hline $\mathrm{Na}_{2} \mathrm{O}$ & 0,19 & 0,25 & 0,11 & 0,08 & 0,08 & 0,07 & 0,05 & 0,09 \\
\hline $\mathbf{K}_{2} \mathbf{O}$ & 0,00 & 0,00 & 0,00 & 0,00 & 0,00 & 0,00 & 0,00 & 0,00 \\
\hline $\mathbf{P}_{2} \mathbf{O}_{5}$ & 0,15 & 0,17 & 0,14 & 0,11 & 0,16 & 0,13 & 0,18 & 0,16 \\
\hline Total & 100,30 & 100,06 & 99,90 & 100,65 & 100,32 & 100,29 & 100,60 & 100,38 \\
\hline \multicolumn{9}{|c|}{ Cationes por unidad de fórmula, sobre la base de 6 oxigenos } \\
\hline $\mathbf{S i}$ & 1,96 & 1,96 & 1,98 & 1,98 & 1,98 & 1,98 & 1,98 & 1,98 \\
\hline $\mathbf{P}$ & 0,00 & 0,00 & 0,00 & 0,00 & 0,00 & 0,00 & 0,00 & 0,00 \\
\hline Al & 0,03 & 0,03 & 0,01 & 0,01 & 0,01 & 0,01 & 0,01 & 0,01 \\
\hline $\mathrm{Fe}^{+3}$ & 0,01 & 0,01 & 0,01 & 0,01 & 0,01 & 0,01 & 0,01 & 0,01 \\
\hline Suma & 2,00 & 2,00 & 2,00 & 2,00 & 2,00 & 2,00 & 2,00 & 2,00 \\
\hline $\mathbf{T i}$ & 0,00 & 0,00 & 0,00 & 0,00 & 0,00 & 0,00 & 0,00 & 0,00 \\
\hline Al & 0,00 & 0,01 & 0,00 & 0,00 & 0,00 & 0,00 & 0,00 & 0,00 \\
\hline $\mathbf{C r}$ & 0,00 & 0,00 & 0,00 & 0,00 & 0,00 & 0,00 & 0,00 & 0,00 \\
\hline $\mathrm{Fe}^{+2}$ & 0,36 & 0,35 & 0,30 & 0,44 & 0,32 & 0,33 & 0,37 & 0,37 \\
\hline $\mathrm{Fe}^{+3}$ & 0,04 & 0,05 & 0,02 & 0,02 & 0,02 & 0,02 & 0,02 & 0,02 \\
\hline Mn & 0,00 & 0,00 & 0,00 & 0,00 & 0,00 & 0,00 & 0,00 & 0,00 \\
\hline Mg & 0,57 & 0,57 & 0,66 & 0,51 & 0,63 & 0,62 & 0,59 & 0,59 \\
\hline $\mathbf{C a}$ & 1,02 & 1,00 & 1,01 & 1,02 & 1,02 & 1,03 & 1,02 & 1,01 \\
\hline $\mathbf{N i}$ & 0,00 & 0,00 & 0,00 & 0,00 & 0,00 & 0,00 & 0,00 & 0,00 \\
\hline $\mathbf{N a}$ & 0,01 & 0,02 & 0,01 & 0,01 & 0,01 & 0,00 & 0,00 & 0,01 \\
\hline $\mathbf{K}$ & 0,00 & 0,00 & 0,00 & 0,00 & 0,00 & 0,00 & 0,00 & 0,00 \\
\hline Suma & 2,00 & 2,00 & 2,00 & 2,00 & 2,00 & 2,00 & 2,00 & 2,00 \\
\hline Total & 4,00 & 4,00 & 4,00 & 4,00 & 4,00 & 4,00 & 4,00 & 4,00 \\
\hline \multicolumn{9}{|c|}{ Porcentajes moleculares } \\
\hline $\mathbf{D i}$ & 58,35 & 58,45 & 67,14 & 52,18 & 64,43 & 62,49 & 60,02 & 59,52 \\
\hline Hd & 41,25 & 41,13 & 32,73 & 47,34 & 35,29 & 37,25 & 39,71 & 40,40 \\
\hline Jh & 0,40 & 0,42 & 0,13 & 0,48 & 0,28 & 0,26 & 0,27 & 0,08 \\
\hline Total & 100,00 & 100,00 & 100,00 & 100,00 & 100,00 & 100,00 & 100,00 & 100,00 \\
\hline
\end{tabular}

Cuadro 4.7a: Valores representativos de análisis químicos por microsonda electrónica de cristales de clinopiroxeno del endoskarn de granate-clinopiroxeno. El contenido de $\mathrm{Fe}$ en piroxeno $\left(\mathrm{Fe}^{2+}\right.$ y $\left.\mathrm{Fe}^{3+}\right)$ fue recalculado según Droop (1987). 


\begin{tabular}{|c|c|c|c|c|c|c|c|c|}
\hline \multicolumn{9}{|c|}{ Clinopiroxeno 2-1291b (Endoskarn granate-clinopiroxeno) } \\
\hline \%peso & P9 & P10 & P11 & P12 & P13 & P14 & P15 & P16 \\
\hline $\mathrm{SiO}_{2}$ & 52,82 & 53,87 & 53,12 & 53,16 & 53,25 & 52,05 & 52,63 & 53,08 \\
\hline $\mathrm{TiO}_{2}$ & 0,00 & 0,02 & 0,04 & 0,00 & 0,04 & 0,07 & 0,00 & 0,02 \\
\hline $\mathbf{A l}_{2} \mathbf{O}_{3}$ & 0,63 & 0,53 & 0,63 & 0,70 & 0,66 & 0,31 & 0,63 & 0,17 \\
\hline $\mathrm{Cr}_{2} \mathrm{O}_{3}$ & 0,01 & 0,04 & 0,03 & 0,02 & 0,00 & 0,00 & 0,00 & 0,03 \\
\hline $\mathrm{FeO}_{\mathrm{r}}$ & 6,99 & 5,39 & 5,48 & 6,62 & 5,37 & 10,93 & 8,65 & 8,79 \\
\hline $\mathrm{Fe}_{2} \mathbf{O}_{3 \mathrm{r}}$ & 1,71 & 1,15 & 1,68 & 1,65 & 1,43 & 0,76 & 1,66 & 0,93 \\
\hline MnO & 0,01 & 0,05 & 0,04 & 0,06 & 0,02 & 0,08 & 0,00 & 0,04 \\
\hline MgO & 12,85 & 14,25 & 13,84 & 13,16 & 14,02 & 10,89 & 11,63 & 12,39 \\
\hline NiO & 0,03 & 0,00 & 0,07 & 0,00 & 0,00 & 0,06 & 0,00 & 0,01 \\
\hline $\mathrm{CaO}$ & 25,34 & 25,65 & 25,74 & 25,70 & 25,59 & 24,78 & 25,76 & 25,61 \\
\hline $\mathrm{Na}_{2} \mathrm{O}$ & 0,21 & 0,19 & 0,16 & 0,17 & 0,18 & 0,09 & 0,18 & 0,08 \\
\hline $\mathbf{K}_{2} \mathbf{O}$ & 0,03 & 0,04 & 0,01 & 0,00 & 0,00 & 0,01 & 0,01 & 0,03 \\
\hline $\mathbf{P}_{2} \mathbf{O}_{5}$ & 0,16 & 0,17 & 0,14 & 0,11 & 0,18 & 0,17 & 0,14 & 0,21 \\
\hline Total & 100,79 & 101,35 & 100,97 & 101,35 & 100,74 & 100,20 & 101,28 & 101,38 \\
\hline \multicolumn{9}{|c|}{ Cationes por unidad de fórmula, sobre la base de 6 oxigenos } \\
\hline Si & 1,96 & 1,97 & 1,96 & 1,96 & 1,97 & 1,98 & 1,96 & 1,97 \\
\hline $\mathbf{P}$ & 0,00 & 0,00 & 0,00 & 0,00 & 0,00 & 0,00 & 0,00 & 0,00 \\
\hline Al & 0,03 & 0,02 & 0,03 & 0,03 & 0,03 & 0,01 & 0,03 & 0,01 \\
\hline $\mathrm{Fe}^{+3}$ & 0,01 & 0,00 & 0,01 & 0,01 & 0,00 & 0,01 & 0,01 & 0,02 \\
\hline Suma & 2,00 & 2,00 & 2,00 & 2,00 & 2,00 & 2,00 & 2,00 & 2,00 \\
\hline Ti & 0,00 & 0,00 & 0,00 & 0,00 & 0,00 & 0,00 & 0,00 & 0,00 \\
\hline Al & 0,00 & 0,00 & 0,00 & 0,00 & 0,00 & 0,00 & 0,00 & 0,00 \\
\hline $\mathrm{Cr}$ & 0,00 & 0,00 & 0,00 & 0,00 & 0,00 & 0,00 & 0,00 & 0,00 \\
\hline $\mathbf{F e}^{+3}$ & 0,05 & 0,03 & 0,04 & 0,04 & 0,04 & 0,02 & 0,05 & 0,02 \\
\hline $\mathrm{Fe}^{+2}$ & 0,21 & 0,16 & 0,16 & 0,20 & 0,16 & 0,34 & 0,27 & 0,26 \\
\hline Mn & 0,00 & 0,00 & 0,00 & 0,00 & 0,00 & 0,00 & 0,00 & 0,00 \\
\hline Mg & 0,71 & 0,78 & 0,76 & 0,72 & 0,77 & 0,62 & 0,65 & 0,69 \\
\hline $\mathbf{N i}$ & 0,00 & 0,00 & 0,00 & 0,00 & 0,00 & 0,00 & 0,00 & 0,00 \\
\hline $\mathbf{N a}$ & 0,02 & 0,01 & 0,01 & 0,01 & 0,01 & 0,01 & 0,01 & 0,01 \\
\hline $\mathbf{K}$ & 0,00 & 0,00 & 0,00 & 0,00 & 0,00 & 0,00 & 0,00 & 0,00 \\
\hline $\mathrm{Ca}$ & 1,01 & 1,01 & 1,02 & 1,02 & 1,01 & 1,01 & 1,03 & 1,02 \\
\hline suma & 2,00 & 2,00 & 2,00 & 2,00 & 2,00 & 2,00 & 2,00 & 2,00 \\
\hline Total & 4,00 & 4,00 & 4,00 & 4,00 & 4,00 & 4,00 & 4,00 & 4,00 \\
\hline \multicolumn{9}{|c|}{ Porcentajes moleculares } \\
\hline Di & 72,76 & 79,60 & 77,77 & 74,10 & 78,85 & 62,32 & 67,08 & 69,46 \\
\hline Hd & 27,21 & 20,23 & 22,12 & 25,71 & 21,08 & 37,43 & 32,92 & 30,40 \\
\hline Jh & 0,03 & 0,17 & 0,12 & 0,19 & 0,08 & 0,25 & 0,00 & 0,14 \\
\hline Total & 100,00 & 100,00 & 100,00 & 100,00 & 100,00 & 100,00 & 100,00 & 100,00 \\
\hline
\end{tabular}

Cuadro 4.7b: Valores representativos de análisis químicos por microsonda electrónica de cristales de clinopiroxeno del endoskarn de granate-clinopiroxeno. El contenido de $\mathrm{Fe}$ en piroxeno $\left(\mathrm{Fe}^{2+}\right.$ y $\left.\mathrm{Fe}^{3+}\right)$ fue recalculado según Droop (1987).

Entre los minerales retrógrados se reconocieron anfiboles de tipo tremolita-actinolita, cloritas, clinozoisita y apatita. Los anfiboles y las 
cloritas, son escasos y se encuentran reemplazando a cristales de clinopiroxeno, como coronas o en forma de "parches" generados por reemplazos pseudomórficos (Fig. 4.15a). La clinozoisita también se presenta como coronas de reemplazo de los cristales de granate (Fig. 4.14a). Los individuos de apatita se observan con buen desarrollo y dispuestos en forma irregular como minerales neoformados entre la mineralogía antes descripta (Fig. 4.15b).

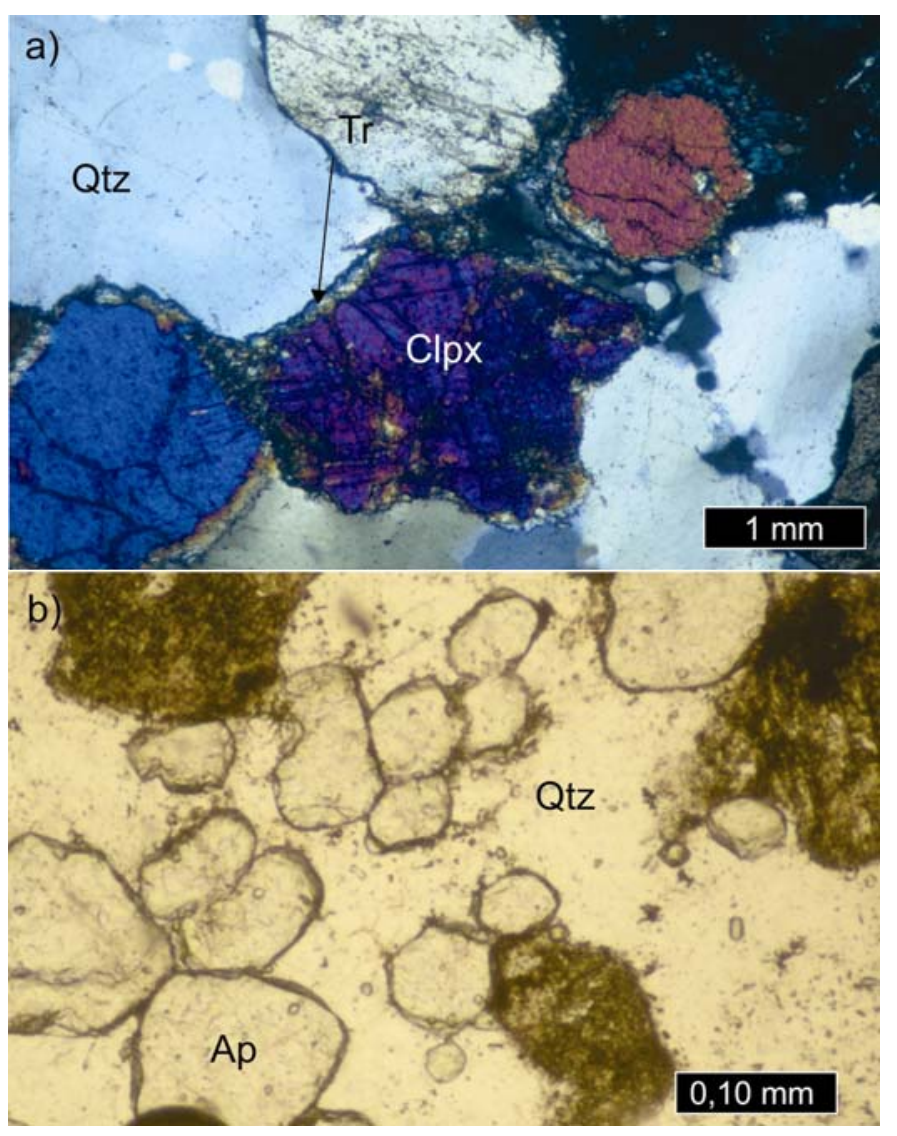

Figura 4.15: a) Cristales de clinopiroxeno con desarrollo de coronas de tremolitaactinolita, rodeados por cuarzo, con analizador. b) Cristales de apatita con alto relieve, rodeados por cuarzo y cristales de clinopiroxeno reemplazados por clorita, sin analizador. Abreviaturas minerales según Siivola y Schmid (2007).

Zona de endoskarn con clinopiroxeno y plagioclasa cálcica (5): Su mineralogía comprende una asociación típica de una roca ígnea de composición 
granodioritica, en la que se reconoce la siguiente paragénesis mineral de endoskarn: plagioclasa cálcica + clinopiroxeno acompañados de cuarzo y feldespato potásico intersticial (Fig. 4.16a, b y c). El espesor total de la zona no pudo ser determinado, ya que parte de los afloramientos están interrumpidos por la cubierta moderna, pero se estima que el mismo ronda los 5-10 metros.

Los minerales más abundantes son las plagioclasas y el feldespato potásico. Las plagioclasas, presentan un amplio rango composicional (anortita40-60), donde las más cálcicas se encuentran parcialmente reemplazadas por feldespato potásico (Fig. 4.16d). El clinopiroxeno de tipo diópsido-hedembergítico (Cuadro 4.8) es escaso y se distribuye en forma homogénea. Presenta coloración verdosa y va disminuyendo su tamaño y cantidad, a medida que aumenta la distancia al contacto con el mármol. En algunos afloramientos se encuentra casi totalmente reemplazado por cloritas y teñido por óxidos e hidróxidos de hierro, que le otorgan una coloración anaranjada.

Entre los minerales retrógrados se identificaron además de clorita, escasos cristales de anfiboles formando coronas y bordes de retrogradación y abundante titanita. Esta última posee color castaño, tiene una granulometría variada que aumenta hacia el contacto con la roca carbonática, donde alcanza 2-3 milímetros de longitud (Fig. 4.16b y c).

\section{Vetillas tardias}

En los afloramientos antes descriptos se da la ocurrencia de vetillas de colores rosa (Fig. 4.17a y b) y gris oscuro (Fig. 4.18a y b) cuyos espesores varian entre 3-4 centímetros y 20-30 centímetros, respectivamente. Estas vetillas cortan las zonas antes descriptas evidenciando una clara posterioridad. En general son subhorizontales, aunque se han encontrado algunas con inclinaciones de $45^{\circ}$ hacia el norte. Las vetillas rosadas se encuentran constituidas casi en su totalidad por clinozoisita que se identifica claramente al microscopio por su color azul anómalo y su alto 
relieve, aunque en algunas de estas vetillas se han identificado cristales relícticos de granate de igual apariencia que el granate descripto en las paragénesis prógradas, que corresponden a grosularia mayormente (Fig. 4.17b).
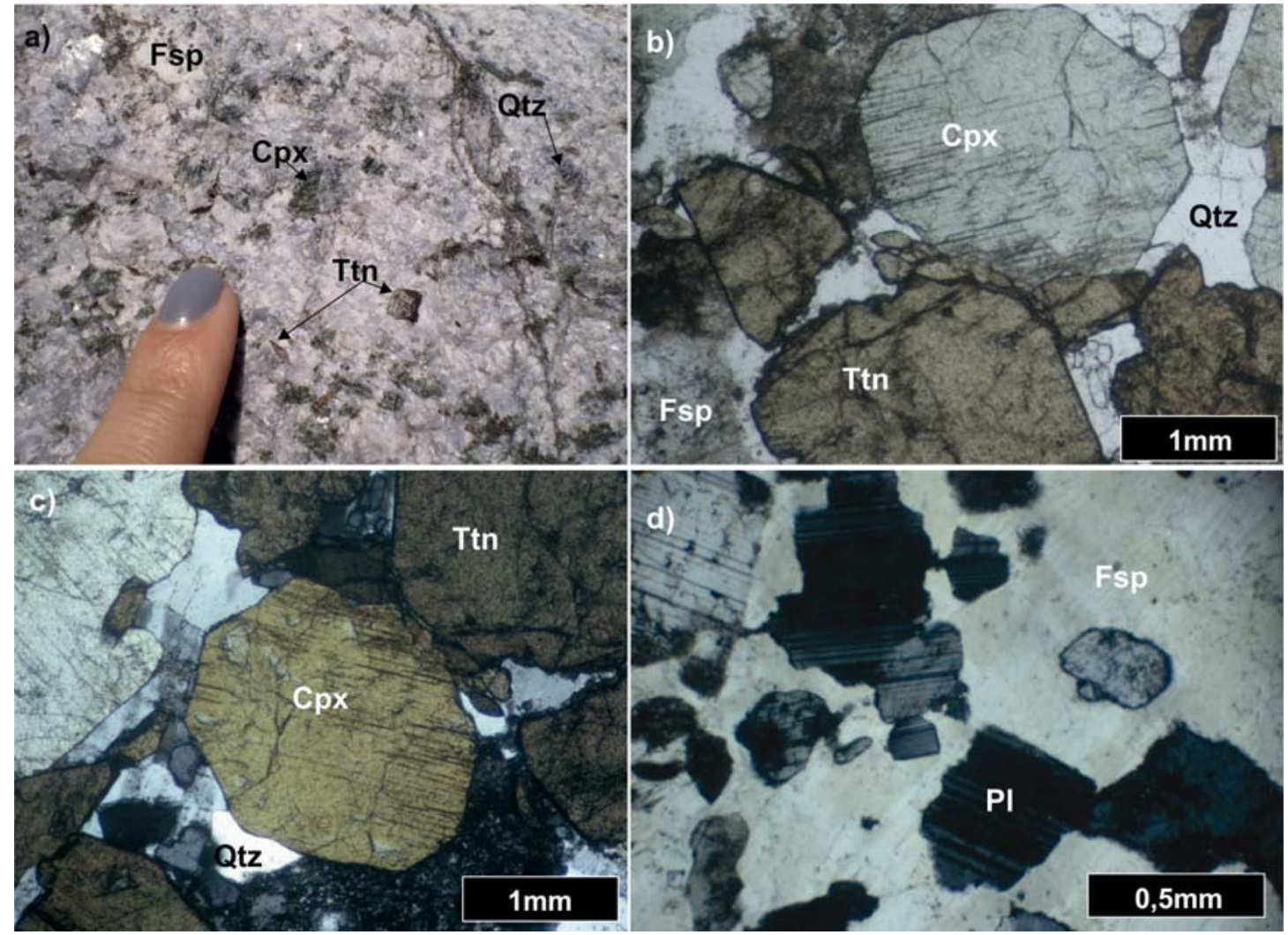

Figura 4.16: Zona de clinopiroxeno-plagioclasa cálcica. a) Detalle de la zona en vista mesoscópica, donde se aprecia el desarrollo de los cristales de clinopiroxeno y titanita. b y c) Vista al microscopio de la mineralogía compuesta por clinopiroxeno, feldespato potásico, cuarzo y titanita, sin y con analizador respectivamente. d) Cristales de plagioclasas reemplazados parcialmente por feldespato potásico. Abreviaturas minerales según Siivola y Schmid (2007). 


\begin{tabular}{|c|c|c|c|c|c|c|c|}
\hline \multicolumn{8}{|c|}{ Clinopiroxeno 21026 (Endoskarn clinopiroxeno-plagioclasa cálcica) } \\
\hline$\%$ peso & P1 & P2 & P3 & P4 & P5 & P6 & P7 \\
\hline $\mathrm{SiO}_{2}$ & 51,91 & 51,80 & 51,34 & 52,70 & 51,13 & 51,33 & 52,40 \\
\hline $\mathrm{TiO}_{2}$ & 0,00 & 0,00 & 0,00 & 0,00 & 0,01 & 0,01 & 0,00 \\
\hline $\mathbf{A l}_{2} \mathbf{O}_{3}$ & 0,20 & 0,13 & 0,18 & 0,11 & 0,18 & 0,37 & 0,10 \\
\hline $\mathrm{Cr}_{2} \mathrm{O}_{3}$ & 0,03 & 0,00 & 0,04 & 0,00 & 0,02 & 0,01 & 0,02 \\
\hline $\mathrm{Fe}_{2} \mathrm{O}_{3 \mathrm{r}}$ & 0,45 & 1,09 & 0,94 & 1,20 & 1,04 & 1,22 & 0,54 \\
\hline $\mathrm{FeO}_{\mathrm{r}}$ & 12,16 & 12,13 & 13,47 & 8,46 & 14,89 & 12,96 & 11,85 \\
\hline MnO & 0,07 & 0,10 & 0,06 & 0,07 & 0,10 & 0,10 & 0,13 \\
\hline MgO & 9,92 & 10,07 & 8,78 & 12,29 & 8,16 & 9,35 & 10,59 \\
\hline $\mathrm{CaO}$ & 24,78 & 24,96 & 25,04 & 25,45 & 24,56 & 24,56 & 24,83 \\
\hline NiO & 0,00 & 0,00 & 0,00 & 0,08 & 0,08 & 0,10 & 0,00 \\
\hline $\mathrm{Na}_{2} \mathrm{O}$ & 0,12 & 0,09 & 0,11 & 0,09 & 0,12 & 0,12 & 0,07 \\
\hline $\mathbf{K}_{2} \mathbf{O}$ & 0,01 & 0,03 & 0,05 & 0,05 & 0,03 & 0,00 & 0,01 \\
\hline $\mathbf{P}_{2} \mathbf{O}_{5}$ & 0,16 & 0,15 & 0,20 & 0,13 & 0,16 & 0,13 & 0,15 \\
\hline Total & 99,79 & 100,54 & 100,21 & 100,63 & 100,48 & 100,26 & 100,71 \\
\hline \multicolumn{8}{|c|}{ Cationes por unidad de fórmula, sobre la base de 6 oxígenos } \\
\hline Si & 1,99 & 1,97 & 1,98 & 1,97 & 1,97 & 1,97 & 1,99 \\
\hline $\mathbf{P}$ & 0,00 & 0,00 & 0,00 & 0,00 & 0,00 & 0,00 & 0,00 \\
\hline Al & 0,01 & 0,01 & 0,01 & 0,00 & 0,01 & 0,02 & 0,00 \\
\hline $\mathbf{F e}^{+3}$ & 0,00 & 0,02 & 0,01 & 0,02 & 0,01 & 0,01 & 0,01 \\
\hline Suma & 2,00 & 2,00 & 2,00 & 2,00 & 2,00 & 2,00 & 2,00 \\
\hline Ti & 0,00 & 0,00 & 0,00 & 0,00 & 0,00 & 0,00 & 0,00 \\
\hline Al & 0,00 & 0,00 & 0,00 & 0,00 & 0,00 & 0,00 & 0,00 \\
\hline $\mathrm{Cr}$ & 0,00 & 0,00 & 0,00 & 0,00 & 0,00 & 0,00 & 0,00 \\
\hline $\mathrm{Fe}^{+3}$ & 0,01 & 0,03 & 0,03 & 0,03 & 0,03 & 0,03 & 0,02 \\
\hline $\mathbf{F e}^{+2}$ & 0,39 & 0,37 & 0,42 & 0,25 & 0,47 & 0,41 & 0,37 \\
\hline Mn & 0,00 & 0,00 & 0,00 & 0,00 & 0,00 & 0,00 & 0,00 \\
\hline Mg & 0,57 & 0,57 & 0,50 & 0,69 & 0,47 & 0,53 & 0,60 \\
\hline $\mathrm{Ca}$ & 1,02 & 1,02 & 1,03 & 1,02 & 1,02 & 1,01 & 1,01 \\
\hline $\mathbf{N i}$ & 0,00 & 0,00 & 0,00 & 0,00 & 0,00 & 0,00 & 0,00 \\
\hline $\mathrm{Na}$ & 0,01 & 0,01 & 0,01 & 0,01 & 0,01 & 0,01 & 0,01 \\
\hline $\mathbf{K}$ & 0,00 & 0,00 & 0,00 & 0,00 & 0,00 & 0,00 & 0,00 \\
\hline Suma & 2,00 & 2,00 & 2,00 & 2,00 & 2,00 & 2,00 & 2,00 \\
\hline Total & 4,00 & 4,00 & 4,00 & 4,00 & 4,00 & 4,00 & 4,00 \\
\hline \multicolumn{8}{|c|}{ Porcentajes moleculares } \\
\hline Di & 58,23 & 57,50 & 52,01 & 69,43 & 47,63 & 53,99 & 60,12 \\
\hline Hd & 41,55 & 42,18 & 47,78 & 30,35 & 52,04 & 45,70 & 39,44 \\
\hline Jh & 0,23 & 0,32 & 0,21 & 0,21 & 0,32 & 0,31 & 0,43 \\
\hline Total & 100,00 & 100,00 & 100,00 & 100,00 & 100,00 & 100,00 & 100,00 \\
\hline
\end{tabular}

Cuadro 4.8: Valores representativos de análisis químicos por microsonda electrónica de cristales de clinopiroxeno del endoskarn de clinopiroxeno-plagioclasa cálcica. El contenido de $\mathrm{Fe}$ en piroxeno $\left(\mathrm{Fe}^{+2}\right.$ y $\left.\mathrm{Fe}^{+3}\right)$ fue recalculado según Droop (1987). 


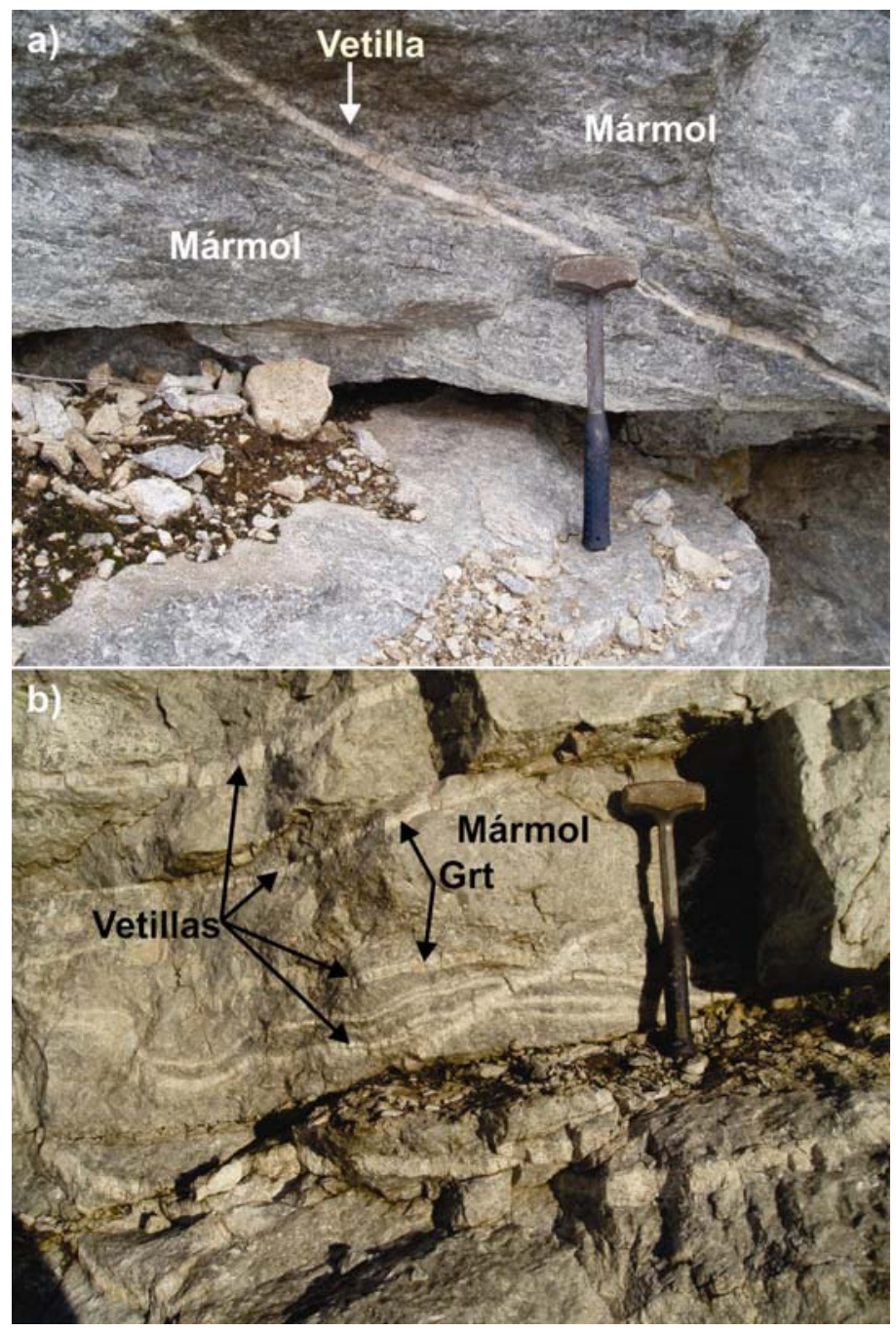

Figura 4.17: Vetillas rosadas. a) Con una inclinación de $45^{\circ}$, atravesando el mármol y la zonas del exoskarn. b) Horizontales con cristales relícticos de granate.

En ciertos sectores, las vetillas se inician en el contacto con algunos filones graníticos, sugiriendo que estas podrian haberse formado a partir de dichos filones. No pudieron tomarse rumbo de estas vetillas ya que sólo afloran en los frentes de la cantera principal de la Estancia San Miguel.

Las vetillas de color gris oscuro (Fig. 4.18a), presentan menores espesores que las anteriores, no superan los 3 centímetros y también se 
encuentran cortando las paragénesis prógradas del skarn, especialmente las que se desarrollan en el endoskarn.

En general tienen bordes más irregulares que las vetillas rosadas y poseen rumbo $\mathrm{N} 60^{\circ} \mathrm{O}$ e inclinan $70^{\circ}$ hacia el $\mathrm{NE}$. Su coloración se debe a que están enteramente compuestas por cuarzo de tipo ahumado (Fig. 4.18b), que en algunos sectores se torna azulado, posiblemente debido a procesos de deformación (Fig. 4.18b).

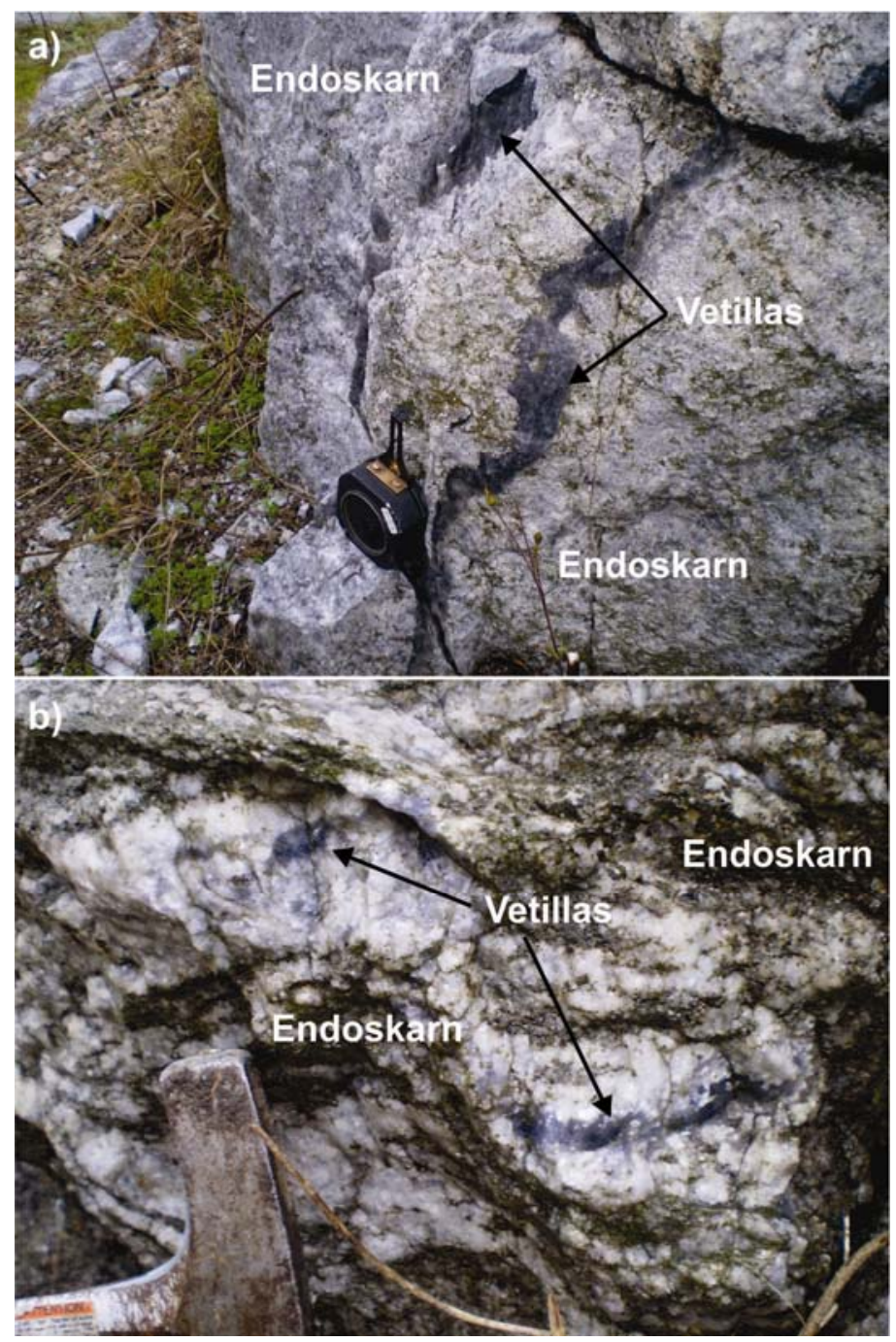

Figura 4.18: a) Vetilla de color gris oscuro cortando en forma casi vertical la paragénesis del endoskarn clinopiroxeno-plagioclasa cálcica. b) Vetilla gris azulada con disposición sub-horizontal. 


\subsubsection{Estancia San Miguel: sector sur}

En este sector, ubicado al sur de los anteriores (Fig. 4.19), la presencia de grandes cristales de granate y clinopiroxeno (Fig. 4.20a) indica la acción de procesos metasomáticos a pesar de no haberse identificado aún afloramientos de mármol calcítico ni de exoskarn. Estos calcosilicatos están rodeados por plagioclasa (anortita45-55), feldespato potásico y gran cantidad de cuarzo, completando la paragénesis de endoskarn zona de granateclinopiroxeno (Fig. 4.19). Asociado a clinopiroxeno se han encontrado pequeños cristales de ilmenita de color gris oscuro y brillo metálico (Fig. 4.20b). Al microscopio calcográfico presentan reflectancia moderada, no desarrollan un hábito definido y en general se encuentran dispuestos en forma intersticial entre los cristales de cuarzo (Fig. 4.21). Su determinación final se realizó mediante microsonda electrónica, dichos resultados se observan en la Cuadro 4.9.

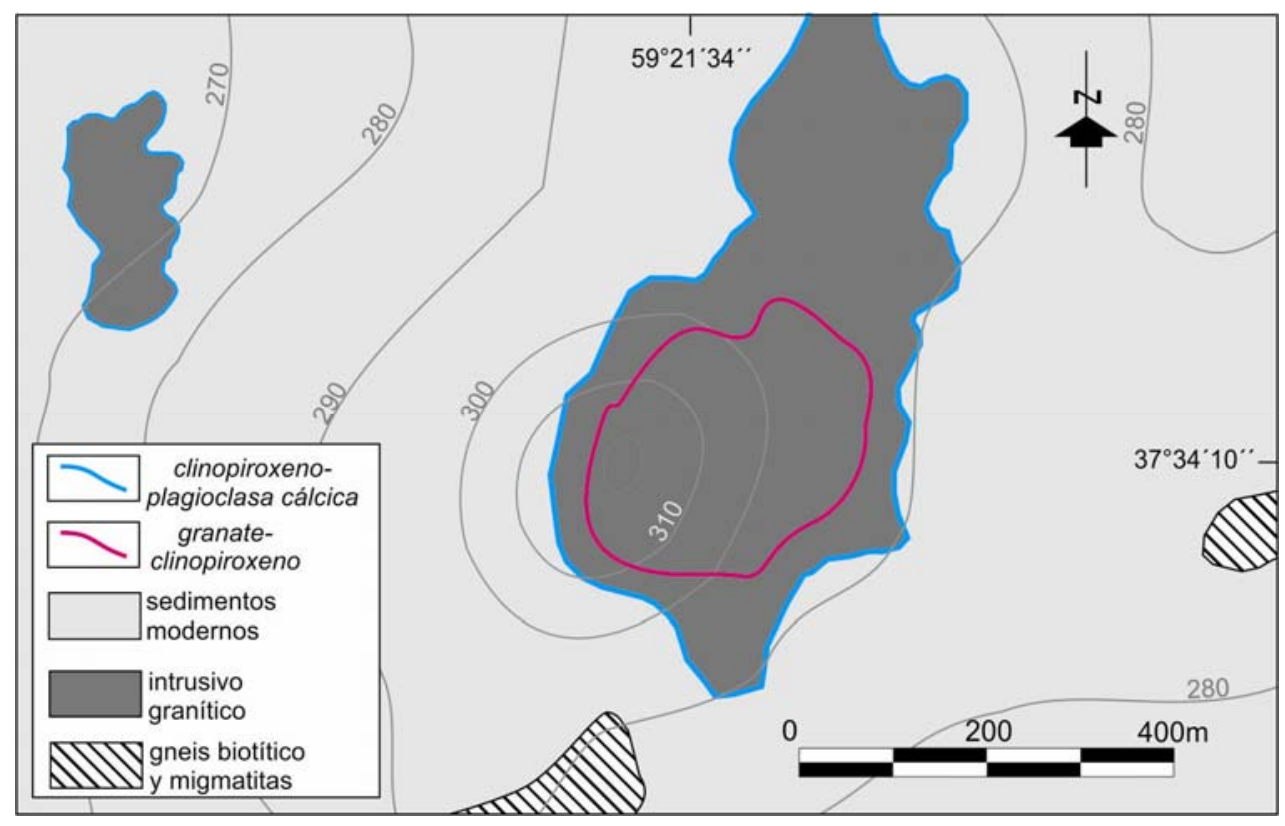

Figura 4.19: Estancia San Miguel: detalle del mapa geológico del sector sur en el que se indica en forma esquemática la ubicación de las "zonas" reconocidas en este afloramiento. 
Los cristales de granate presentan una composición grosularia92-93, andradita $_{2-6}$ y almandino5-2, con cantidades menores a $0,86 \%$ de piropo+espesartina+uvarovita. Dicha composición fue determinada por microsonda electrónica y se muestra en el Cuadro 4.10. Desarrollan tamaños mayores a los 5 centímetros, presentan coronas de retrogradación y reemplazos pseudomórficos de clinozoisita y se encuentran rodeados por abundante cuarzo ahumado.

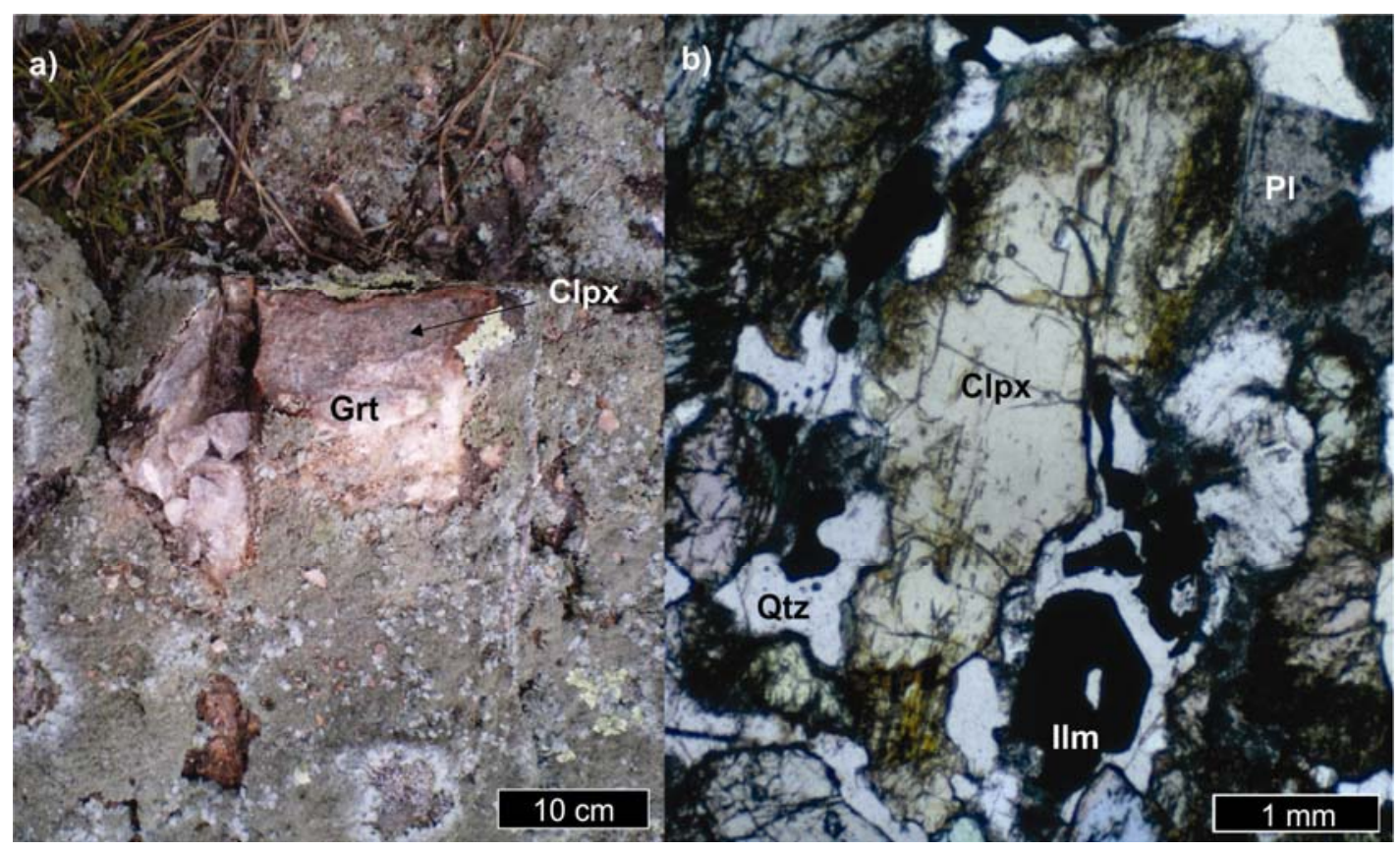

Figura 4.20: Sector sur. a) Vista en afloramiento de cristales de granate. b) Vista microscópica de cristales de clinopiroxeno asociados a ilmenita rodeados por cristales de cuarzo y plagioclasas. Abreviaturas minerales según Siivola y Schmid (2007). 


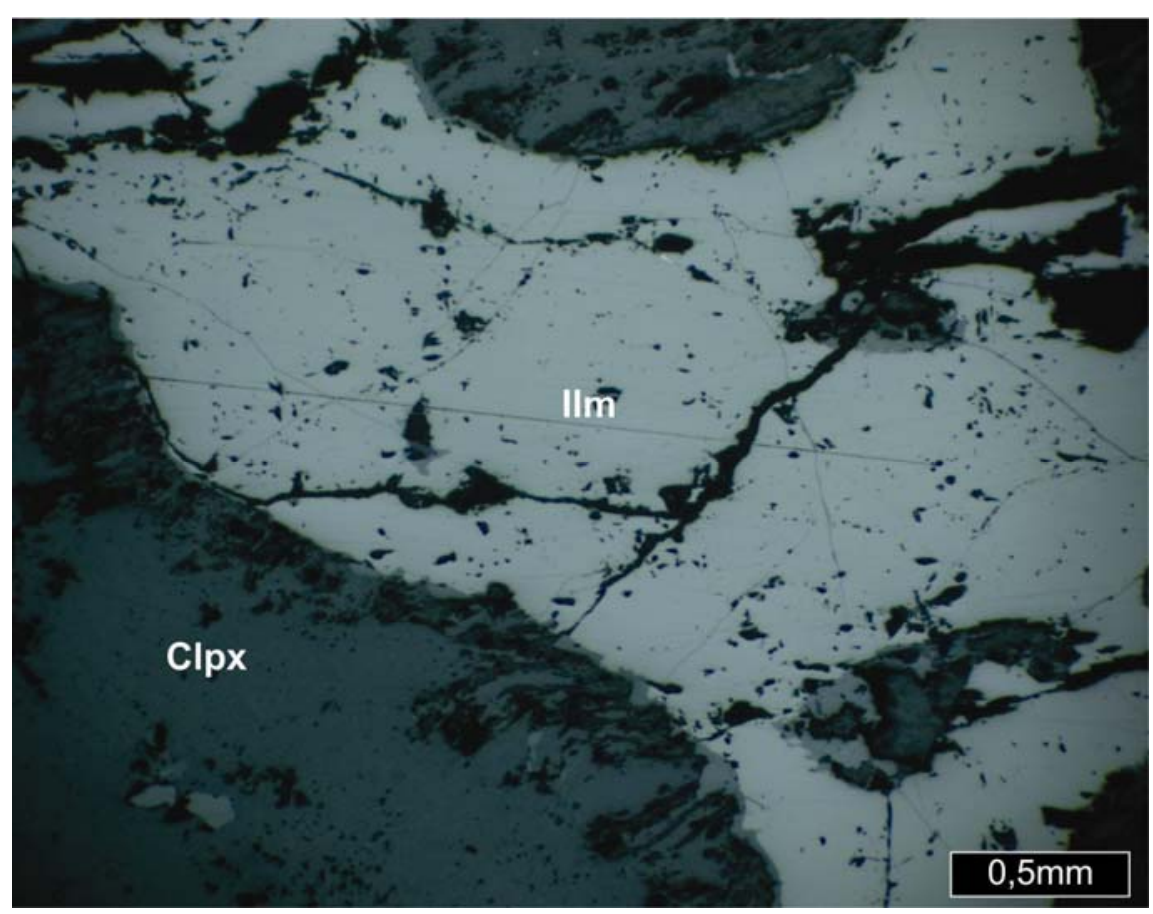

Figura 4.21: Vista al microscopio calcográfico de los cristales opacos asociados a clinopiroxeno, identificados como ilmenita. Abreviaturas minerales según Siivola y Schmid (2007).

Si bien en este sector la zonación mineral no se expresa de forma clara, hacia los sectores más periféricos de este afloramiento desaparece el granate y predomina el piroxeno de tipo diópsido-hedenbergita (Cuadro 4.11) asociado a plagioclasa, cuarzo y microclino completando la paragénesis determinada para la zona de clinopiroxeno-plagioclasa cálcica (Fig. 4.19). Al microscopio se observan también en este sector los reemplazos de plagioclasa (anortita60-70) por microclino. 


\begin{tabular}{|c|c|c|c|c|c|c|c|c|}
\hline \multicolumn{9}{|c|}{ Ilmenita-21001A (San Miguel Sur) } \\
\hline$\%$ peso & P1 & P2 & P3 & P4 & P5 & P6 & P7 & P8 \\
\hline $\mathrm{TiO}_{2}$ & 52,73 & 53,18 & 52,73 & 52,41 & 52,40 & 53,76 & 53,49 & 53,32 \\
\hline $\mathbf{S i O}_{2}$ & 0,00 & 0,07 & 0,01 & 0,02 & 0,04 & 0,03 & 0,02 & 0,03 \\
\hline $\mathrm{Fe}_{2} \mathrm{O}_{3 \mathbf{r}}$ & 6,97 & 6,86 & 6,91 & 6,99 & 6,90 & 6,94 & 6,93 & 6,87 \\
\hline $\mathrm{Cr}_{2} \mathrm{O}_{3}$ & 0,04 & 0,00 & 0,00 & 0,00 & 0,01 & 0,00 & 0,04 & 0,03 \\
\hline $\mathbf{A l}_{2} \mathbf{O}_{3}$ & 0,00 & 0,00 & 0,01 & 0,01 & 0,00 & 0,00 & 0,00 & 0,00 \\
\hline $\mathbf{F e O}_{\mathbf{r}}$ & 39,49 & 38,89 & 39,15 & 39,64 & 39,09 & 39,30 & 39,25 & 38,93 \\
\hline MnO & 0,88 & 0,89 & 1,09 & 1,07 & 1,05 & 0,99 & 0,71 & 0,73 \\
\hline MgO & 0,13 & 0,12 & 0,10 & 0,10 & 0,13 & 0,11 & 0,09 & 0,09 \\
\hline $\mathrm{CaO}$ & 0,00 & 0,01 & 0,03 & 0,08 & 0,04 & 0,00 & 0,05 & 0,02 \\
\hline NiO & 0,00 & 0,03 & 0,03 & 0,00 & 0,01 & 0,03 & 0,01 & 0,00 \\
\hline Zno & 0,04 & 0,00 & 0,05 & 0,00 & 0,00 & 0,05 & 0,00 & 0,00 \\
\hline $\mathrm{Na}_{2} \mathrm{O}$ & 0,02 & 0,03 & 0,01 & 0,00 & 0,00 & 0,00 & 0,01 & 0,01 \\
\hline $\mathbf{K}_{2} \mathbf{O}$ & 0,00 & 0,00 & 0,00 & 0,00 & 0,01 & 0,00 & 0,02 & 0,01 \\
\hline Total & 100,30 & 100,09 & 100,13 & 100,33 & 99,68 & 101,20 & 100,60 & 100,03 \\
\hline
\end{tabular}

Cationes pon unidad de fórmula, sobre la base de $\mathbf{6}$ oxígenos

\begin{tabular}{|lllllllll|}
\hline $\mathbf{T i}$ & 1,96 & 1,52 & 1,97 & 1,50 & 1,96 & 1,98 & 1,98 & 1,98 \\
$\mathbf{S i}$ & 0,00 & 0,00 & 0,00 & 0,00 & 0,00 & 0,00 & 0,00 & 0,00 \\
$\mathbf{F e}$ & 0,26 & 1,11 & 0,26 & 1,12 & 0,26 & 0,26 & 0,26 & 0,26 \\
$\mathbf{C r}$ & 0,00 & 0,00 & 0,00 & 0,00 & 0,00 & 0,00 & 0,00 & 0,00 \\
$\mathbf{A l}$ & 0,00 & 0,00 & 0,00 & 0,00 & 0,00 & 0,00 & 0,00 & 0,00 \\
$\mathbf{F e}$ & 1,63 & 1,25 & 1,62 & 1,26 & 1,63 & 1,61 & 1,62 & 1,61 \\
$\mathbf{M n}$ & 0,04 & 0,03 & 0,05 & 0,03 & 0,04 & 0,04 & 0,03 & 0,03 \\
$\mathbf{M g}$ & 0,01 & 0,01 & 0,01 & 0,01 & 0,01 & 0,01 & 0,01 & 0,01 \\
$\mathbf{C a}$ & 0,00 & 0,00 & 0,00 & 0,00 & 0,00 & 0,00 & 0,00 & 0,00 \\
$\mathbf{N i}$ & 0,00 & 0,00 & 0,00 & 0,00 & 0,00 & 0,00 & 0,00 & 0,00 \\
$\mathbf{Z n}$ & 0,00 & 0,00 & 0,00 & 0,00 & 0,00 & 0,00 & 0,00 & 0,00 \\
$\mathbf{N a}$ & 0,00 & 0,00 & 0,00 & 0,00 & 0,00 & 0,00 & 0,00 & 0,00 \\
$\mathbf{K}$ & 0,00 & 0,00 & 0,00 & 0,00 & 0,00 & 0,00 & 0,00 & 0,00 \\
\hline
\end{tabular}

Cuadro 4.9: Valores representativos de análisis químicos por microsonda electrónica de cristales de Ilmenita del sector San Miguel Sur. El contenido de Fe en Ilmenita $\left(\mathrm{Fe}^{+2}\right.$ y $\left.\mathrm{Fe}^{+3}\right)$ fue recalculado según Droop (1987). 


\begin{tabular}{|c|c|c|c|c|c|c|c|c|}
\hline \multicolumn{9}{|c|}{ Granate 21047 (San Miguel Sur) } \\
\hline \%peso & P1 & P2 & P3 & P4 & P5 & P6 & P7 & P8 \\
\hline $\mathrm{SiO}_{2}$ & 39,87 & 39,86 & 39,97 & 39,57 & 39,90 & 39,37 & 39,46 & 40,02 \\
\hline $\mathrm{TiO}_{2}$ & 0,28 & 0,25 & 0,20 & 0,18 & 0,26 & 0,23 & 0,22 & 0,24 \\
\hline $\mathbf{A l}_{2} \mathbf{O}_{3}$ & 21,31 & 20,81 & 20,89 & 20,63 & 20,64 & 20,66 & 20,72 & 20,78 \\
\hline $\mathrm{Cr}_{2} \mathrm{O}_{3}$ & 0,00 & 0,00 & 0,00 & 0,00 & 0,00 & 0,01 & 0,00 & 0,01 \\
\hline $\mathrm{Fe}_{2} \mathrm{O}_{3 \mathbf{r}}$ & 0,55 & 1,52 & 1,09 & 1,53 & 1,93 & 2,03 & 1,34 & 0,76 \\
\hline $\mathrm{FeO}_{\mathbf{r}}$ & 2,04 & 1,05 & 1,41 & 0,99 & 0,65 & 0,56 & 1,09 & 1,84 \\
\hline MnO & 0,04 & 0,00 & 0,00 & 0,08 & 0,00 & 0,05 & 0,05 & 0,03 \\
\hline MgO & 0,17 & 0,19 & 0,17 & 0,18 & 0,17 & 0,19 & 0,19 & 0,18 \\
\hline $\mathrm{CaO}$ & 35,61 & 36,24 & 36,23 & 35,93 & 36,10 & 35,99 & 35,91 & 36,02 \\
\hline $\mathrm{NiO}$ & 0,00 & 0,00 & 0,00 & 0,02 & 0,00 & 0,01 & 0,00 & 0,00 \\
\hline $\mathrm{Na}_{2} \mathrm{O}$ & 0,02 & 0,04 & 0,02 & 0,03 & 0,04 & 0,05 & 0,04 & 0,00 \\
\hline $\mathbf{K}_{2} \mathbf{O}$ & 0,02 & 0,00 & 0,01 & 0,00 & 0,01 & 0,03 & 0,01 & 0,02 \\
\hline $\mathbf{P}_{2} \mathbf{O}_{5}$ & 0,35 & 0,38 & 0,37 & 0,34 & 0,37 & 0,40 & 0,32 & 0,38 \\
\hline Total & 100,25 & 100,34 & 100,38 & 99,48 & 100,08 & 99,60 & 99,35 & 100,29 \\
\hline \multicolumn{9}{|c|}{ Cationes por unidad de fórmula, sobre la base de 12 oxigenos } \\
\hline Si & 3,01 & 3,01 & 3,02 & 3,01 & 3,02 & 3,00 & 3,01 & 3,02 \\
\hline $\mathbf{P}$ & 0,01 & 0,01 & 0,01 & 0,01 & 0,01 & 0,01 & 0,01 & 0,01 \\
\hline Al & 0,00 & 0,00 & 0,00 & 0,00 & 0,00 & 0,00 & 0,00 & 0,00 \\
\hline $\mathbf{F e}^{+3}$ & 0,00 & 0,00 & 0,00 & 0,00 & 0,00 & 0,00 & 0,00 & 0,00 \\
\hline Suma & 3,02 & 3,02 & 3,03 & 3,02 & 3,03 & 3,01 & 3,02 & 3,04 \\
\hline Ti & 0,02 & 0,01 & 0,01 & 0,01 & 0,01 & 0,01 & 0,01 & 0,01 \\
\hline Al & 1,90 & 1,85 & 1,86 & 1,85 & 1,84 & 1,85 & 1,86 & 1,85 \\
\hline $\mathrm{Cr}$ & 0,00 & 0,00 & 0,00 & 0,00 & 0,00 & 0,00 & 0,00 & 0,00 \\
\hline $\mathbf{F e}^{3+}$ & 0,03 & 0,09 & 0,06 & 0,09 & 0,11 & 0,12 & 0,08 & 0,04 \\
\hline $\mathbf{F e}^{2+}$ & 0,13 & 0,07 & 0,09 & 0,06 & 0,04 & 0,04 & 0,07 & 0,12 \\
\hline Mn & 0,00 & 0,00 & 0,00 & 0,00 & 0,00 & 0,00 & 0,00 & 0,00 \\
\hline Mg & 0,02 & 0,02 & 0,02 & 0,02 & 0,02 & 0,02 & 0,02 & 0,02 \\
\hline $\mathrm{Ca}$ & 2,88 & 2,93 & 2,93 & 2,93 & 2,93 & 2,93 & 2,93 & 2,92 \\
\hline $\mathbf{N i}$ & 0,00 & 0,00 & 0,00 & 0,00 & 0,00 & 0,00 & 0,00 & 0,00 \\
\hline $\mathbf{N a}$ & 0,00 & 0,01 & 0,00 & 0,00 & 0,01 & 0,01 & 0,01 & 0,00 \\
\hline $\mathbf{K}$ & 0,00 & 0,00 & 0,00 & 0,00 & 0,00 & 0,00 & 0,00 & 0,00 \\
\hline Suma & 4,98 & 4,98 & 4,97 & 4,98 & 4,96 & 4,99 & 4,98 & 4,96 \\
\hline Total & 8,00 & 8,00 & 8,00 & 8,00 & 7,99 & 8,00 & 8,00 & 8,00 \\
\hline \multicolumn{9}{|c|}{ Porcentajes moleculares } \\
\hline Grs & 93,41 & 92,60 & 93,18 & 92,52 & 92,30 & 92,01 & 92,93 & 93,11 \\
\hline Alm & 4,25 & 2,21 & 2,94 & 2,10 & 1,39 & 1,20 & 2,31 & 3,82 \\
\hline Adr & 1,63 & 4,47 & 3,24 & 4,55 & 5,66 & 5,93 & 3,97 & 2,29 \\
\hline $\mathbf{P}+\mathbf{U}+\mathbf{S}$ & 0,71 & 0,72 & 0,64 & 0,83 & 0,65 & 0,86 & 0,80 & 0,78 \\
\hline Total & 100,00 & 100,00 & 100,00 & 100,00 & 100,00 & 100,00 & 100,00 & 100,00 \\
\hline
\end{tabular}

Cuadro 4.10: Valores representativos de análisis químicos por microsonda electrónica de cristales de granate del sector San Miguel Sur. El contenido de Fe en granate $\left(\mathrm{Fe}^{2+}\right.$ y $\mathrm{Fe}^{3+}$ ) fue recalculado según Droop (1987). Referencias: $\mathrm{P}=$ piropo, $\mathrm{S}=$ espesartina y $\mathrm{U}=$ uvarovita. 


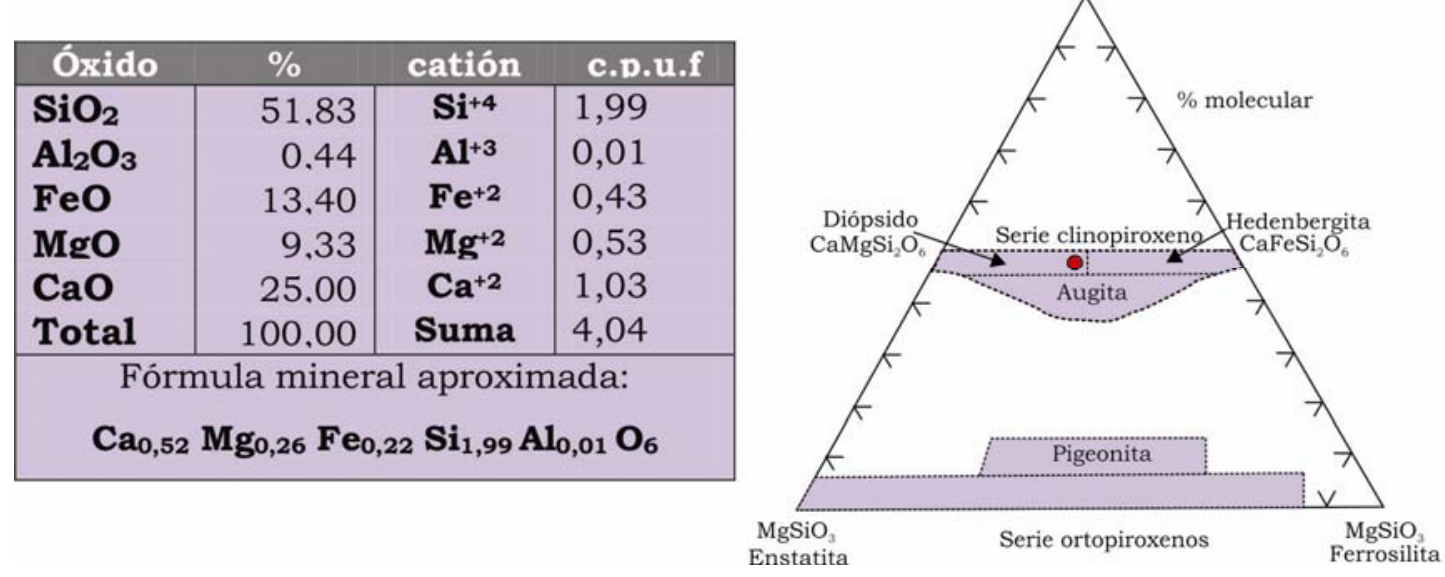

Cuadro 4.11: Composición química promedio y fórmula mineral aproximada de cristales de clinopiroxeno de la Ea. San Miguel sector sur. La composición fue obtenida mediante un análisis EDAX y se asumió al hierro total como $\mathrm{FeO}$. Adicionalmente, fue graficada en el diagrama triangular de Klein y Hurlbut (1999), ubicado a la derecha del cuadro. El punto rojo indica que el clinopiroxeno es mayoritariamente diópsido.

\subsubsection{Estancia La Concordia}

El área de esta estancia presenta suave relieve, en general, y comprende una superficie total aproximada de $70 \mathrm{~km}^{2}$ (Fig. 4.22). Asoman en este sector el gneis biotítico migmático, un cuerpo granítico que constituye el Cerro Guacho (Lajoinie et al. 2013b) y en forma minoritaria rocas del skarn. Estas últimas, presentan coloración blanquecina, tamaño de grano medio a grueso y textura granosa a porfiroide. Su mineralogía está compuesta por clinopiroxeno, plagioclasa (anortita50-55), microclino, clorita, cuarzo y escasa titanita. Esta mineralogía se repite en todo el afloramiento. Al microscopio la roca presenta textura inequigranular con cristales de clinopiroxeno que presentan de 1 a 3 milimetros de longitud, rodeados por cristales con formas irregulares de microclino y plagioclasa (Fig. 4.23a y b). Los cristales de clinopiroxeno presentan las mismas características ópticas que los cristales de este mismo mineral encontrado en los otros afloramientos por lo que se estima que su composición al igual que los otros 
corresponde mayoritariamente a diópsido. En muchos sectores del afloramiento los cristales de diópsido se encuentran casi totalmente reemplazados por clorita y óxidos (Fig. 4.23a y c).

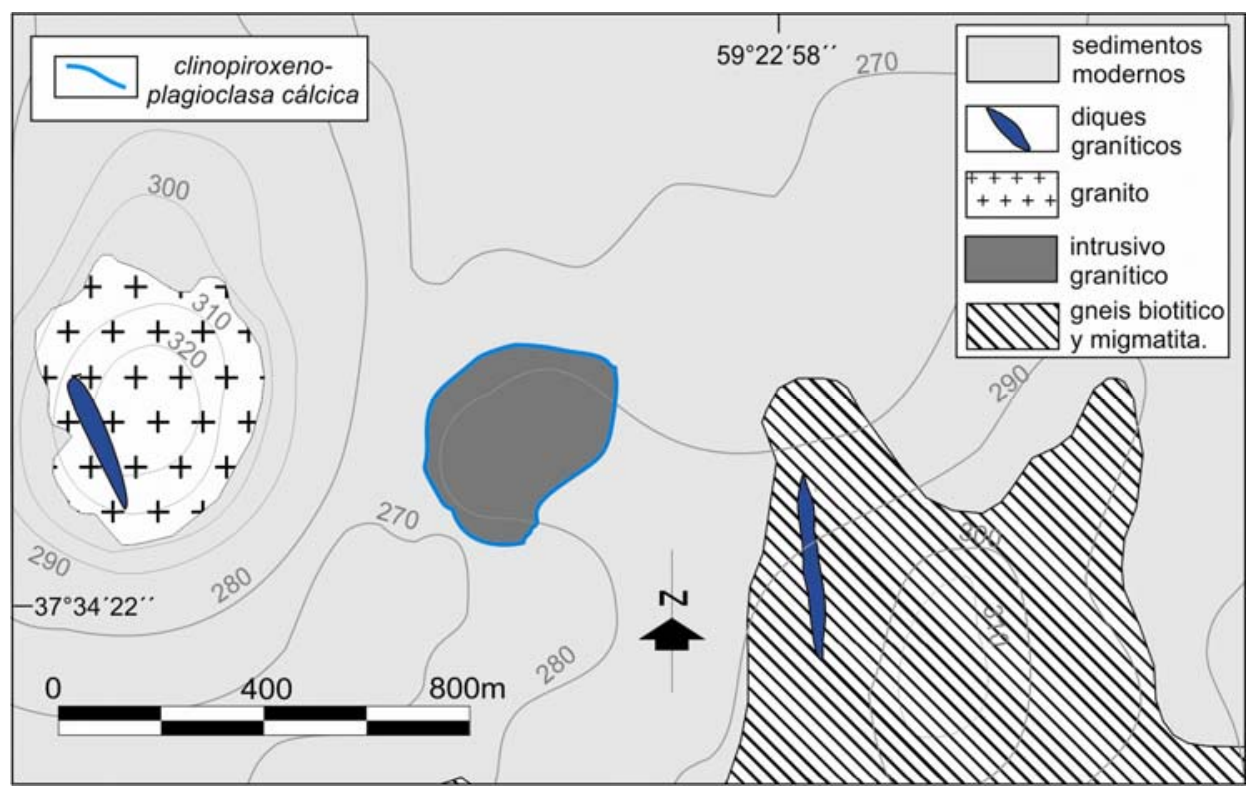

Figura 4.22: Estancia La Concordia: detalle del mapa geológico del sector donde aflora el skarn. La línea azul limita de forma esquemática, como indica la referencia, la zona clinopiroxeno-plagioclasa cálcica reconocida en este afloramiento.

Los cristales de microclino presentan su típico maclado en enrejado y los de plagioclasa maclado polisintético con ahusamiento por deformación intracristalina (Fig. 4.23b). Otro mineral retrógrado, además de la clorita, es la titanita, cuyos cristales se observan con muy buen desarrollo (alrededor de 1 milímetro de longitud), frescos y con secciones rómbicas típicas (Fig. 4.23d). Crecen aleatoriamente sobre los minerales mencionados anteriormente.

En términos generales la mineralogía de este sector se puede comparar con la de la zona de clinopiroxeno-plagioclasa cálcica (Fig. 4.22). Este afloramiento no presenta laboreos por lo que no se descarta que el resto de las zonas del skarn se presenten en forma completa en profundidad. 

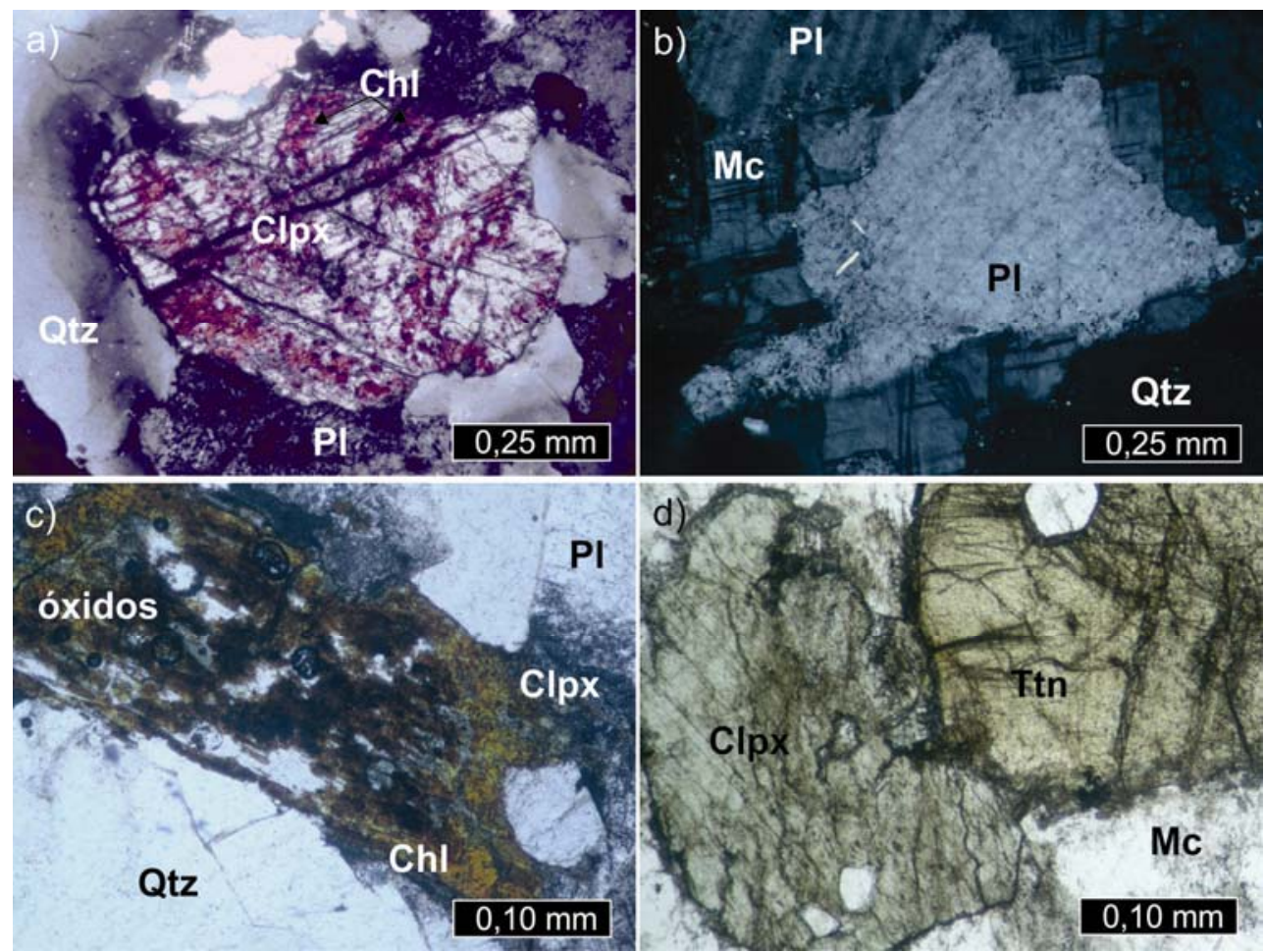

Figura 4.23: Afloramiento estancia La Concordia. a) Aspecto miscroscópico de la mineralogia, con analizador, donde se observa un cristal de clinopiroxeno fracturado y reemplazado parcialmente por clorita, rodeado de cuarzo con extinción ondulosa y plagioclasa levemente alterada. b) Cristales anhedrales de plagioclasa rodeados de cristales irregulares de microclino. c) Detalle de cristal de clinopiroxeno casi totalmente reemplazado por clorita y óxidos, en contacto con cuarzo y plagioclasa alterada a arcillas, con analizador. d) Cristal de clinopiroxeno bien conservado en contacto con un cristal de titanita de gran desarrollo, rodeados por microclino, sin analizador. Abreviaturas minerales según Siivola y Schmid (2007).

\subsubsection{Estancia Siempre Verde}

El skarn aflora sobre la pared sur de una cantera de la que se extrae material para refuerzo de caminos locales (Fig. 4.24a). El cuerpo presenta una morfología general trapezoidal de 6 metros de alto y 20 metros de ancho máximo en la parte superior (Fig. $4.24 \mathrm{a}$ y b). Se encuentra en contacto con el gneis biotítico que presenta numerosos xenolitos máficos (descriptos en el 
apartado 3.A.1) que en este caso son redondeados debido al avanzado estado de meteorización (Figs. 4.25a y b).

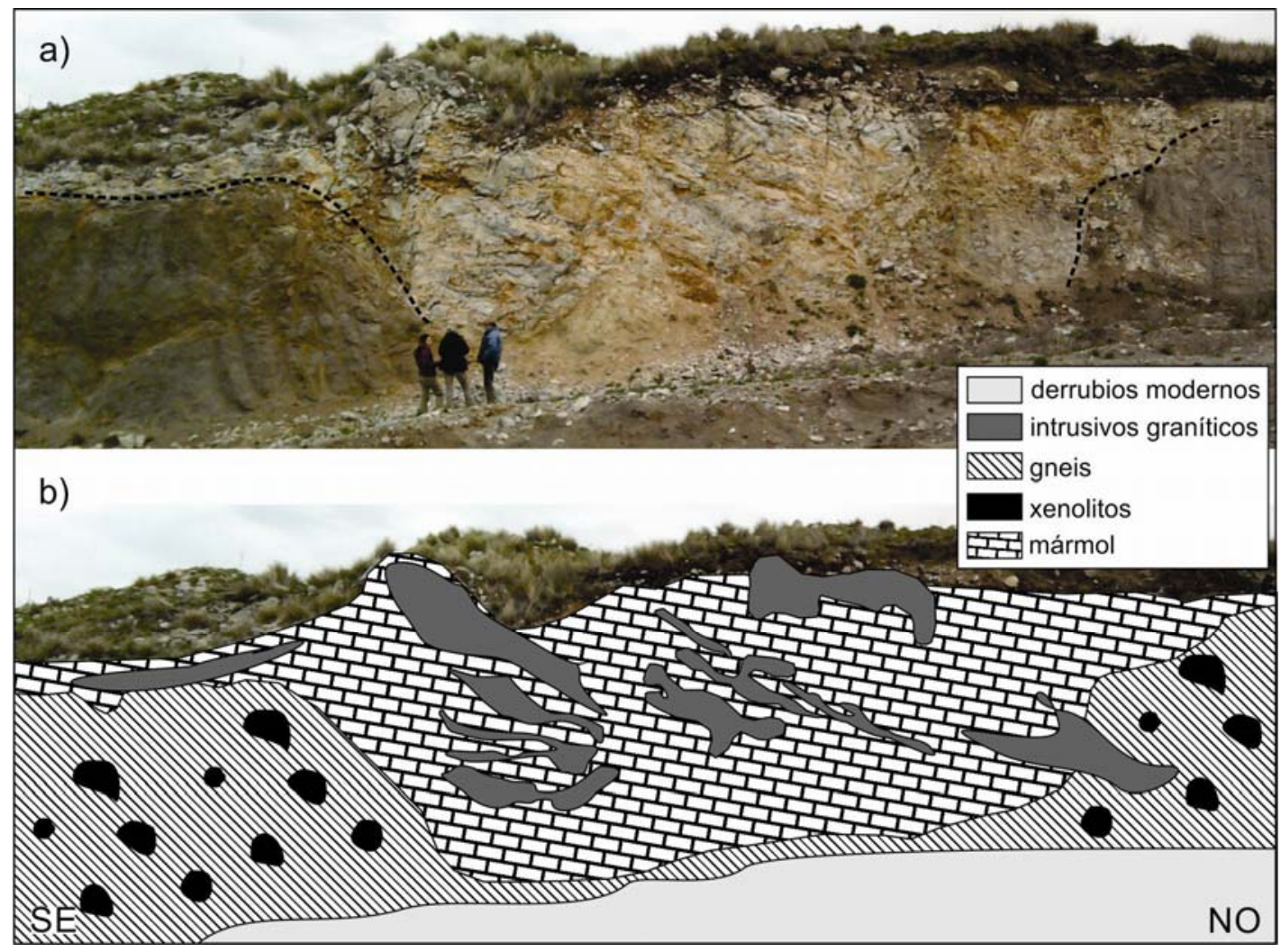

Figura 4.24: Afloramiento de skarn, estancia Siempre Verde. a) Pared sur de la cantera donde aflora el skarn. b) Perfil esquemático donde se observa la morfología del skarn en contacto con el gneis biotítico con xenolitos máficos y los principales filones graníticos.

Se reconocen numerosos filones subhorizontales con espesores variables entre un metro y algunos centímetros, poseen color blanquecino y están intercalados con una roca de aspecto pulverulento y coloración castaña debido a la intensa alteración meteórica, que corresponde a la roca carbonática (Figs. 4.24a y 4.25b). A pesar de los efectos de la alteración pueden observarse en el carbonato cristales relícticos de piroxeno de color verde, que debido al estado en el que se encontraron no fue posible determinar si corresponden al mármol o al proceso metasomático. 

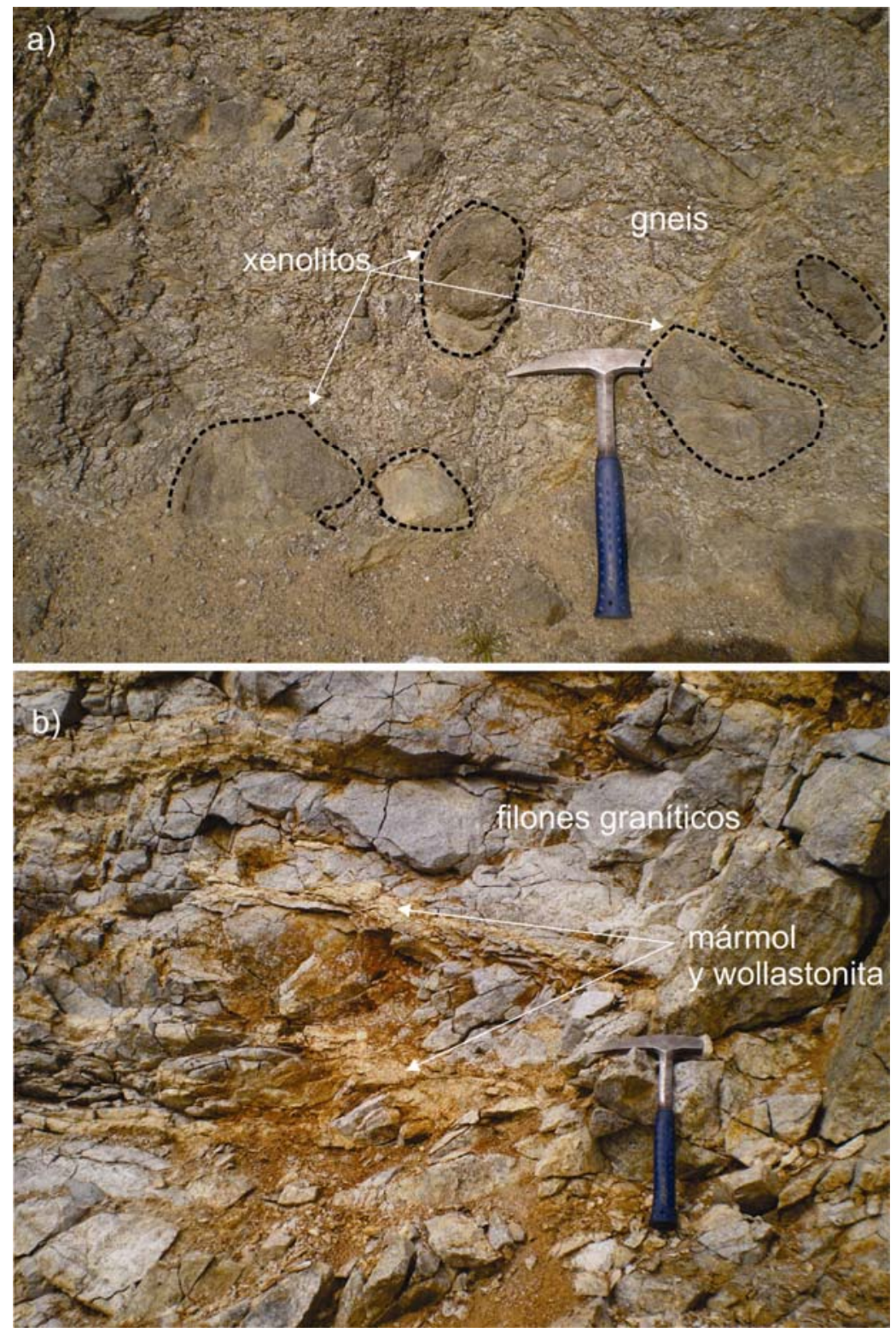

Figura 4.25. Afloramiento de skarn de la estancia Siempre Verde. a) El gneis biotítico migmático presenta xenolitos máficos que resaltan debido al avanzado estado de alteración que este presenta. b) Los filones graníticos de coloración blanquecina se encuentran intercalados con sectores carbonáticos intensamente alterados. En los mismos también se distinguen relictos de cristales de wollastonita y clinopiroxeno. 
Todos los filones presentan la misma mineralogía compuesta por: plagioclasa (anortita50-64), feldespato potásico, clinopiroxeno y cuarzo, (Fig. 4.26a y b) comparable con la zona de endoskarn con clinopiroxenoplagioclasa cálcica (Fig. 4.27). Cabe destacar que este fue el único sector de skarn en el que pudo realizarse un estudio petrográfico. En el contacto con la roca carbonática se desarrolla una zona constituida por wollastonita y clinopiroxeno similar a la zona de exoskarn con wollastonita pero sin vesubianita, también con avanzado reemplazo por acción de la meteorización. No se han identificado en este sector cristales de granate al igual que en el afloramiento de skarn de la estancia La Concordia.
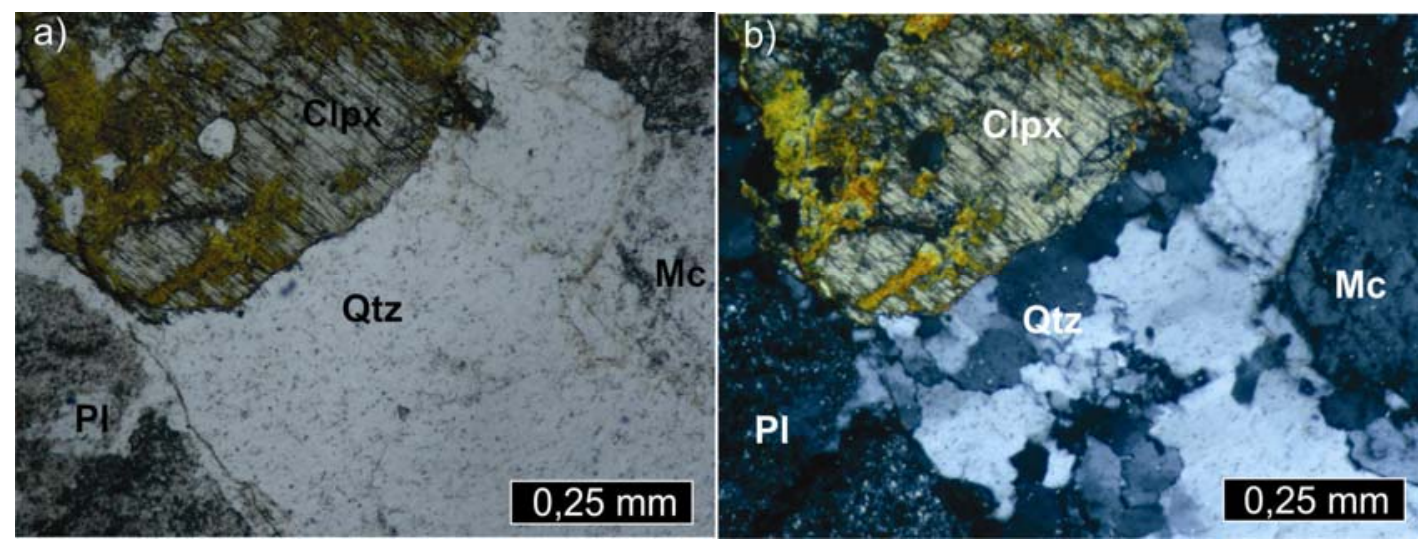

Figura 4.26: a y b) Vista al microscopio de la mineralogía de los filones sin y con analizador, respectivamente. En las fotografias puede observarse que los cristales de clinopiroxeno se encuentran reemplazados por óxidos y las plagioclasas por minerales arcillosos. Los cristales de cuarzo presentan además evidencias de deformación, recuperación y recristalización como es la presencia de subgranos y granos recristalizados. Abreviaturas minerales según Siivola y Schmid (2007). 


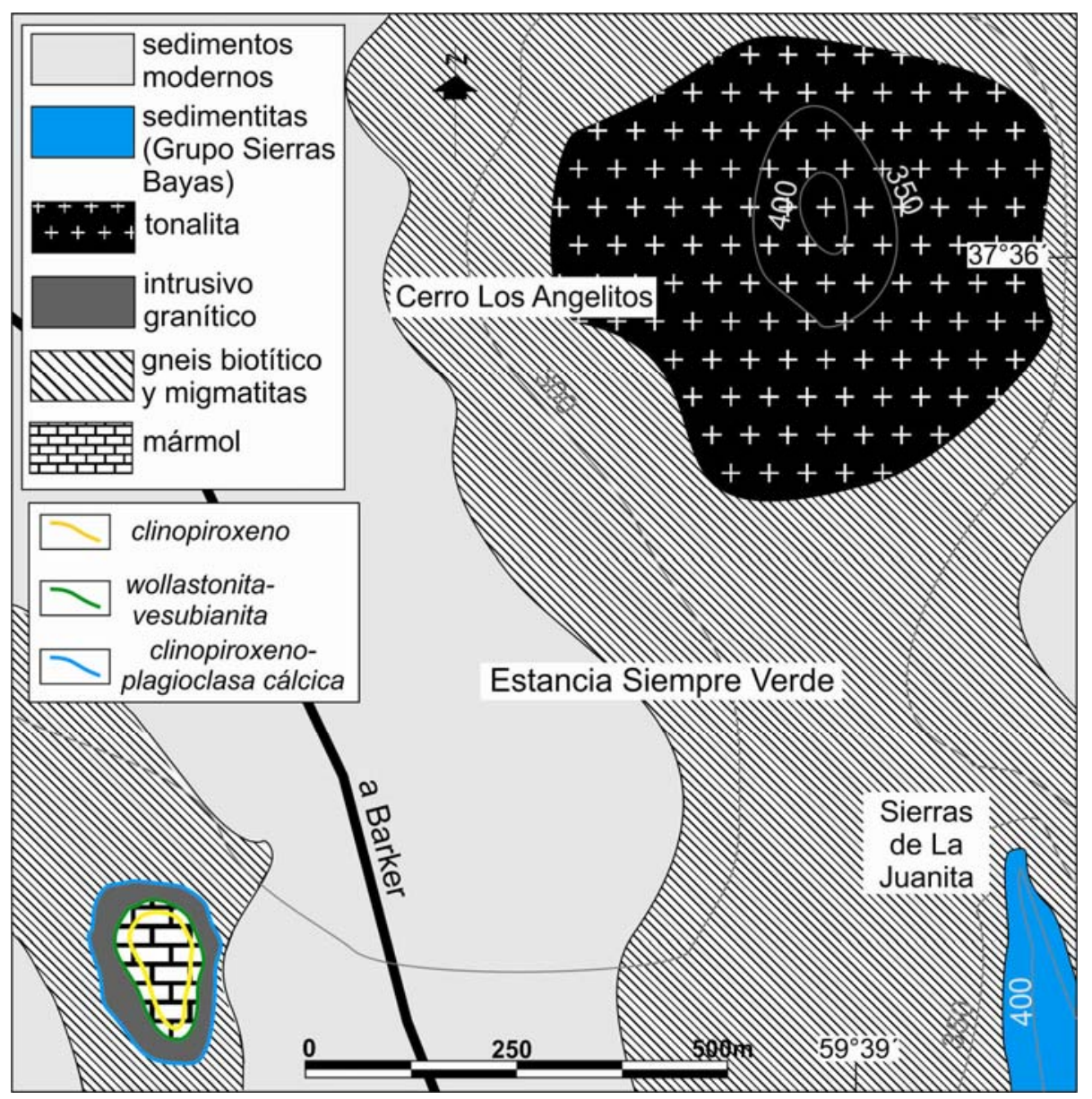

Figura 4.27: Estancia Siempre Verde: detalle del mapa geológico del sector ubicado en esta estancia, donde se identificó uno de los afloramientos de skarn. En el mismo se indican en forma esquemática las "zonas" identificadas.

\subsection{GEOQUÍMICA DEL SKARN SAN MIGUEL}

Sobre la base de la zonación mineral tipo, observada en la cantera principal de la estancia San Miguel, se extrajeron las muestras correspondientes a las zonas determinadas en el skarn a saber: SM-26 (zona clinopiroxeno-plagioclasa cálcica-5), SM-33 (zona granate-clinopiroxeno-4), SM-05 (zona wollastonita-vesubianita-1) y SM-403 (que incluye dos zonas del exoskarn granate-clinopiroxeno-2 y clinopiroxeno-3, ya que no fue posible establecer el limite entre ambas zonas con precisión) como se observa en la 
Fig. 4.28. Además se incluyeron las muestras SM-20 y SM-15 que corresponden a las rocas graníticas localizadas más distales al contacto con el mármol. También se obtuvo una muestra del skarn que aflora en la Ea. La Concordia (LC-12) y otra de la zona de los filones del skarn de la Ea. Siempre Verde (SV-516), del sector menos afectado por la meteorización. Asimismo, se incluyeron dos muestras que corresponden a las vetillas rosadas (vr) y grises (vg). A partir de estas muestras seleccionadas se realizaron análisis químicos de elementos mayoritarios, traza y Tierras Raras, cuyos resultados se observan en el Cuadro 4.12.

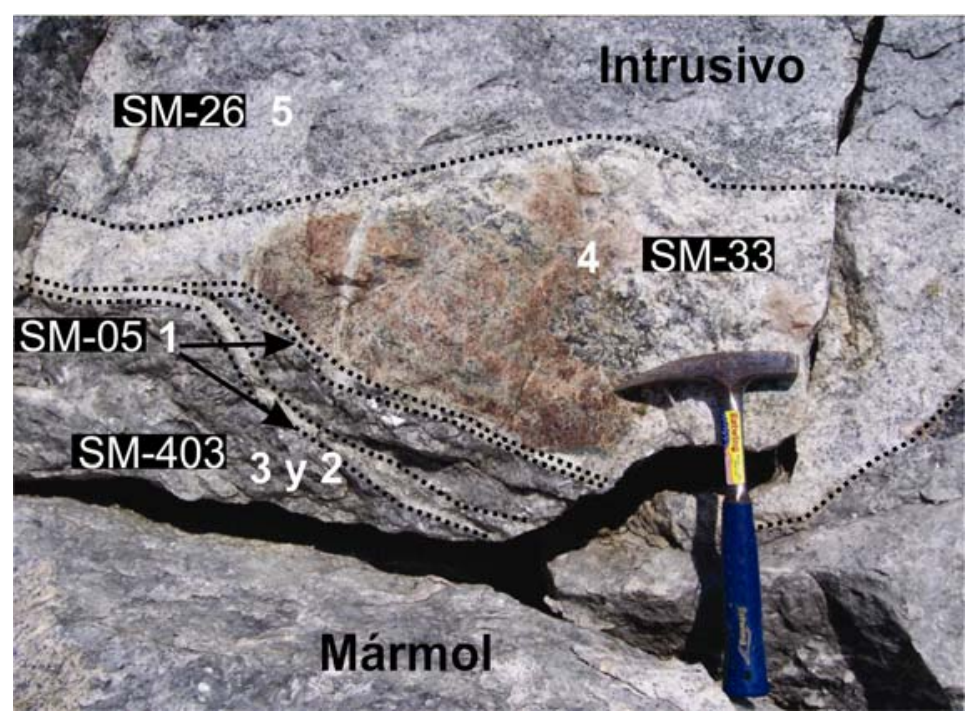

Figura 4.28: Ubicación de las muestras de las diferentes "zonas" analizadas del skarn San Miguel.

\subsubsection{Elementos mayoritarios y trazas}

Para la clasificación general de las rocas que constituyen cada una de las zonas se utilizó el diagrama $\left(\mathrm{Na}_{2} \mathrm{O}+\mathrm{K}_{2} \mathrm{O}\right)$ vs $\mathrm{SiO}_{2}$ (Le Maitre 2002), en éste (Fig. 4.29) se observa que las muestras de las rocas que se ubican en forma distal al contacto con el mármol (SM-15 y SM-20) corresponden a granitos y a cuarzo-dioritas (plagioclasa, feldespato potásico y cuarzo), igual que la muestra SM-26 correspondiente a la zona de clinopiroxeno-plagioclasa cálcica. 


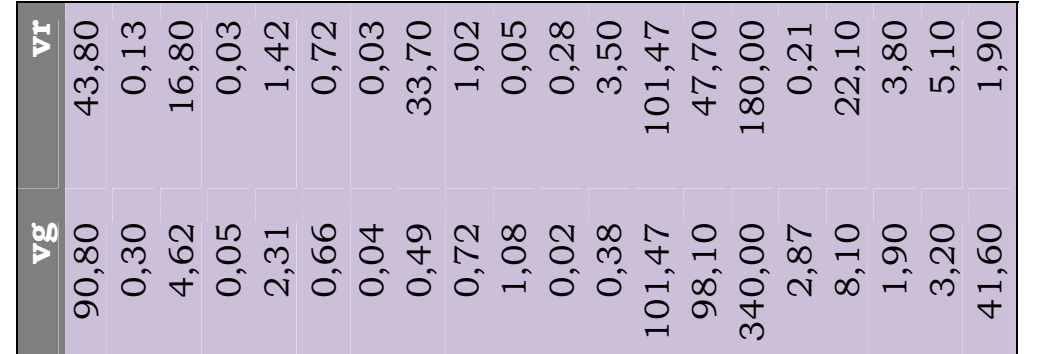

굥요 गु

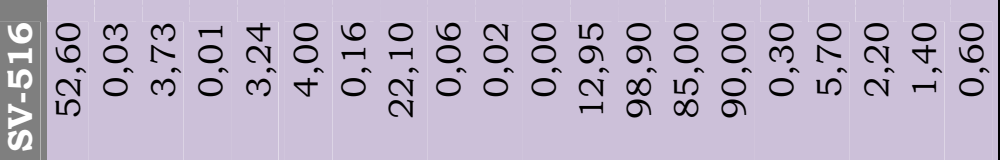

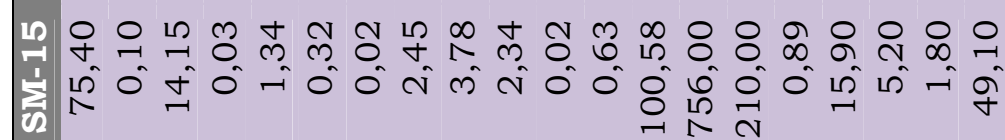

$n$
0
0
0
0
0
0
0
0
0
0
0
0

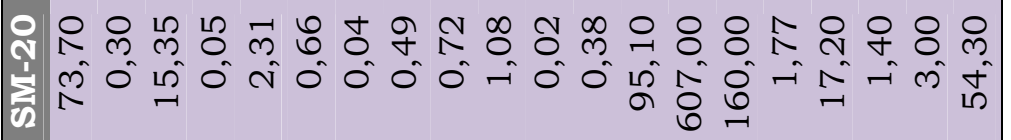

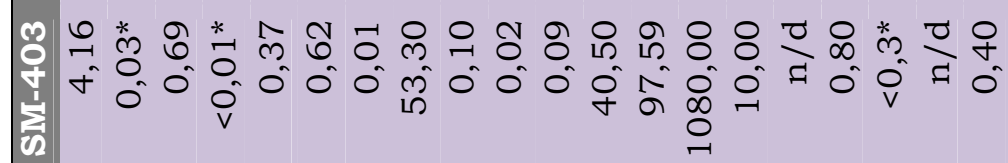

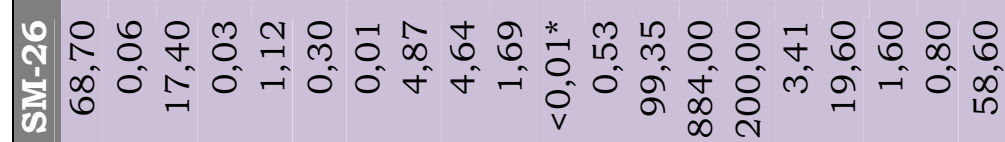

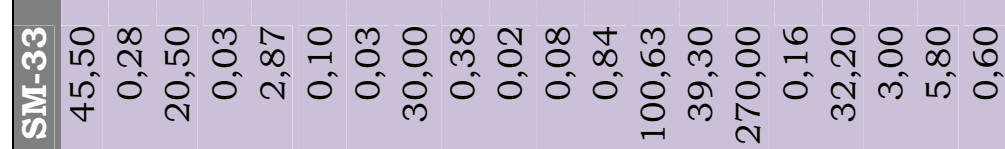

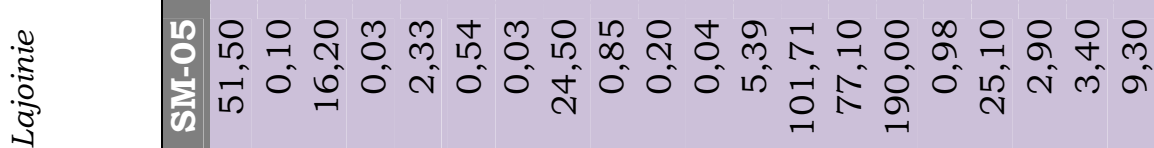

0
0
0
0
0
$\frac{1}{1}$
0
0
$\frac{1}{2}$

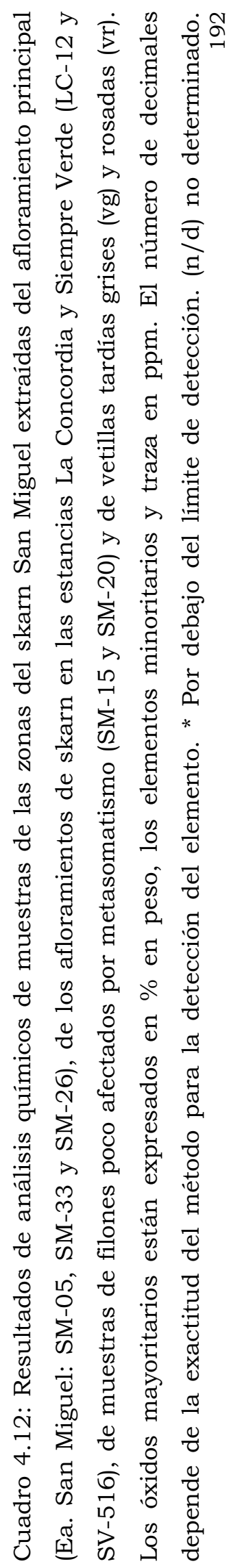




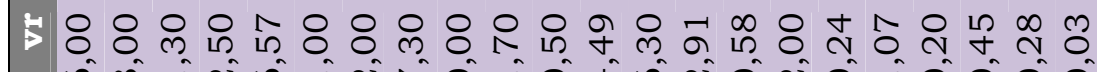

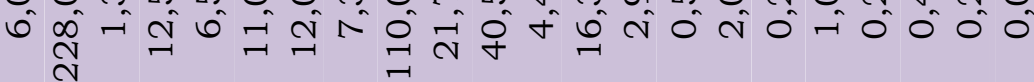

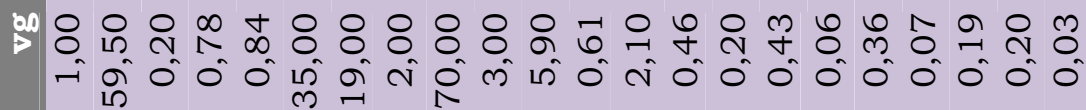

ง ะ 을 गं एं

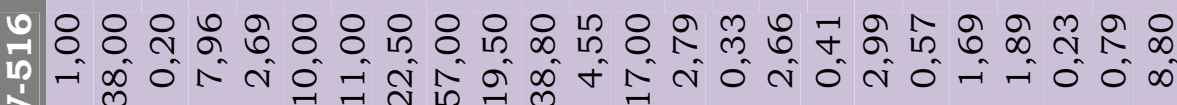

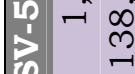

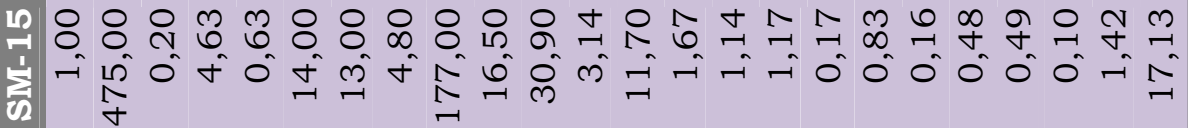

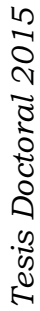

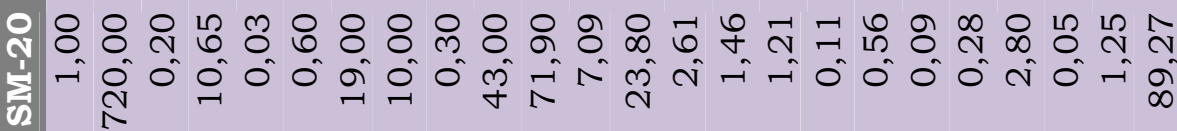

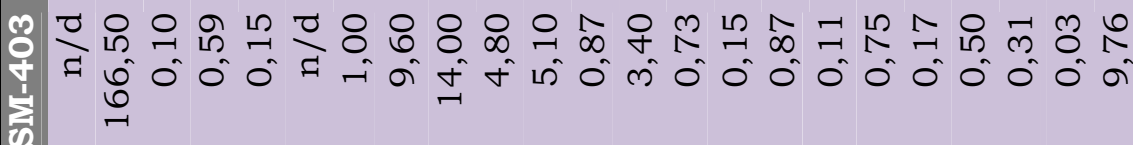

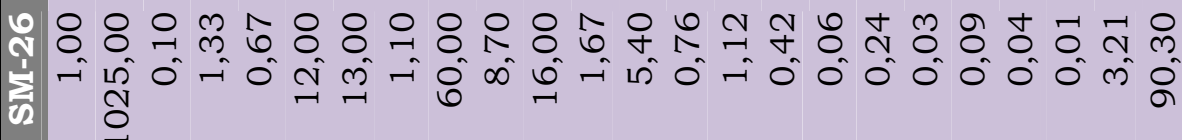

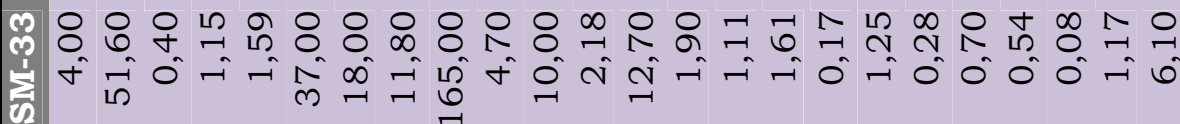

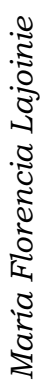

i⿱ 8 은

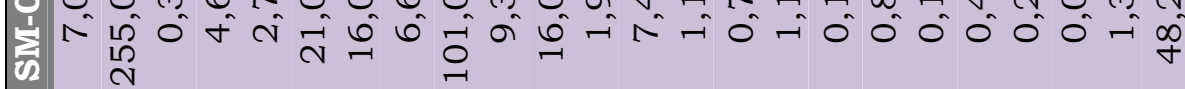


Por otro lado las muestras SM-05 y SM-33 que corresponden a la zona de wollastonita-vesubianita y granate-clinopiroxeno (endoskarn), respectivamente, presentan bajos porcentajes de $\mathrm{SiO}_{2}, \mathrm{~K}_{2} \mathrm{O}$ y $\mathrm{Na}_{2} \mathrm{O}$ que las ubican cercanas al campo de los gabros. Esto último indica que el contenido de los óxidos analizados se asemeja a los presentes en estas rocas, pese a que genéticamente no se trate de gabros. En este último campo quedan comprendidas también las muestras correspondientes a los afloramientos de skarn de las estancias Siempre Verde (SV-516) y La Concordia (LC-12). La muestra SM-403 no fue ploteada en el diagrama anterior ya que sólo cuenta con un $4,16 \% \mathrm{SiO}_{2}$.
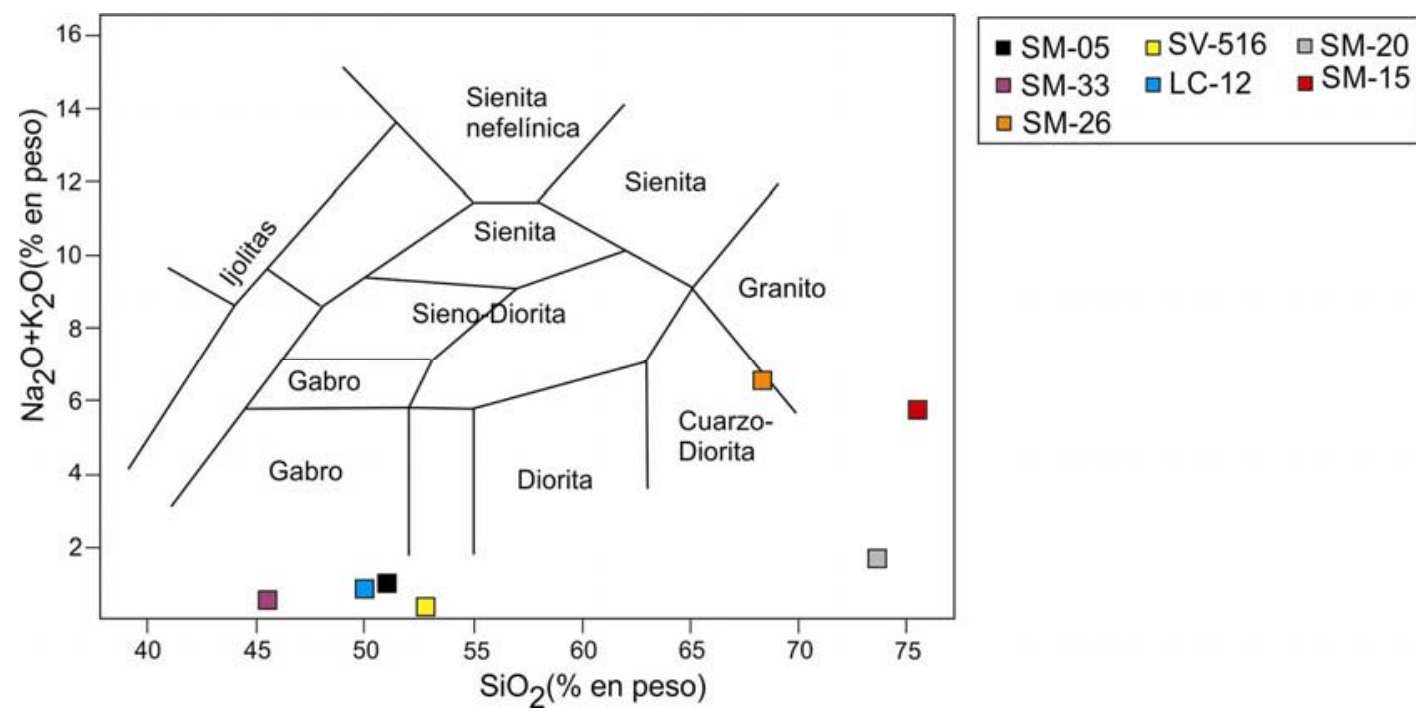

Figura 4.29: Clasificación general de las muestras, diagrama $\left(\mathrm{Na}_{2} \mathrm{O}+\mathrm{K}_{2} \mathrm{O}\right)$ vs $\mathrm{SiO}_{2}$ (Le Maitre 2002).

Se realizaron "diagramas tipo Harker", con el fin de observar la evolución del proceso de intercambio metasomático. En relación al CaO (Fig. 4.30a) que es uno de los óxidos más variables junto con el $\mathrm{SiO}_{2}$ en los procesos de formación de los skarns, se destaca que el enriquecimiento del mismo se da en la zona de granate-clinopiroxeno, muestra SM-33 (30\%), donde además el $\mathrm{SiO}_{2}$ se encuentra en menor proporción $(45,5 \%)$. Con valores similares se presenta la zona de wollastonita-vesubianita (muestra 
SM-05) cuyo contenido en $\mathrm{CaO}$ es $24,5 \%$ y en $\mathrm{SiO}_{2} 51,5 \%$. Finalmente en la muestra de la zona de clinopiroxeno-plagioclasa (SM-26) comienza a notarse un importante descenso en el contenido de $\mathrm{CaO}(4,87 \%)$, mientras que el $\mathrm{SiO}_{2}$ aumenta (68,7\%). Las muestras SM-15 y SM-20, más distales aún al contacto con el mármol son las que presentan los menores contenidos de $\mathrm{CaO}$ de 2,45 y 0,49\%, y mayores de $\mathrm{SiO}_{2}$ de 75,4 y 73,7\% respectivamente. En este mismo diagrama (Fig. 4.30a) también se puede observar que las muestras de los afloramientos de skarn de las estancias Siempre Verde y La Concordia, a pesar de presentar ambos una paragénesis comparable con la zona de clinopiroxeno-plagioclasa cálcica, registran valores de $\mathrm{CaO}$ de 22,1 y $27,9 \%$ y de $\mathrm{SiO}_{2}$ de 50 y 52,6\%, los primeros notoriamente más elevados y los segundos más bajos que dicha zona representada por la muestra SM-26. La tendencia general de las muestras es negativa a mayor porcentaje de $\mathrm{SiO}_{2}$ menor de $\mathrm{CaO}$. Finalmente es de esperar que los valores más altos de $\mathrm{CaO}$ $(54,5 \%)$ se registren en la muestra SM-403 que comprende rocas de las zonas de exoskarn.

El mismo análisis puede hacerse con el $\mathrm{Fe}_{2} \mathrm{O}_{3}$ que presenta la misma tendencia que el CaO para todas las muestras menos para la SM-403 que en este caso registra los valores más bajos de $0,13 \%$ (Fig. 4.30b). También existe una diferenciación en el contenido de este óxido en las muestras distales donde la SM-20 presenta valores más elevados, 2,31\% respecto a $1,34 \%$ que presenta la muestra SM-15. En la muestra SV-516 se observa el contenido más alto de este óxido igual a 3,24\%. En cuanto a $\mathrm{Na}_{2} \mathrm{O}$ (Fig. 4.30c) y $\mathrm{K}_{2} \mathrm{O}$ (Fig. 4.30d), las muestras correspondientes al afloramiento principal tienen una tendencia positiva donde el aumento de los mismos se da junto con el incremento en $\mathrm{SiO}_{2}$. Nuevamente se destaca la diferenciación de las muestras SV-516 y LC-12, respecto de la SM-26, donde las primeras contienen un menor porcentaje de $\mathrm{Na}_{2} \mathrm{O}(0,32$ y $0,06 \%)$ y $\mathrm{K}_{2} \mathrm{O}(0,29$ y $0,02 \%)$ que esta última $\left(4,64 \% \mathrm{Na} 2 \mathrm{O}\right.$ y $\left.1,69 \% \mathrm{~K}_{2} \mathrm{O}\right)$. De la misma forma vuelven a identificarse diferencias, aunque mucho más marcadas entre las muestras periféricas al skarn siendo la SM-20 la que posee menor contenido de $\mathrm{Na}_{2} \mathrm{O}$ $(0,71 \%)$ y de $\mathrm{K}_{2} \mathrm{O}(1,08 \%)$ respecto a la muestra $\mathrm{SM}-15\left(3,78 \% \mathrm{Na}_{2} \mathrm{O}\right.$ y $2,34 \%$ 
$\mathrm{K}_{2} \mathrm{O}$ ). La muestra SM-403 presenta los menores valores de $\mathrm{Na}_{2} \mathrm{O}$ y $\mathrm{K}_{2} \mathrm{O}$ iguales a $0,04 \%$ y $0,01 \%$, respectivamente. $\mathrm{El} \mathrm{Al}_{2} \mathrm{O}_{3}$ (Fig. 4.30e) presenta un enriquecimiento muy marcado en la muestra SM-33 que corresponde a la zona de granate-clinopiroxeno y en contraposición la muestra SV-516 es la que presenta el menor contenido de este óxido, dentro de las muestras que corresponden a zonas del endoskarn, dado que la muestra SM-403 registra tan sólo un $0,06 \%$ de $\mathrm{Al}_{2} \mathrm{O}_{3}$.

Algunos óxidos como $\mathrm{MgO}$ y $\mathrm{MnO}$ (Fig. 4.30f y g), se registran en valores muy bajos, pero presentándose enriquecidos en las muestras LC-12 (el primero) y SV-516 (el segundo). $\mathrm{El} \mathrm{TiO}_{2}$ (Fig. 4.30h) no fue determinado en la muestra SM-403, pero sí en el resto de las muestras, aunque en baja proporción, con un máximo de $0,3 \%$ en la muestra SM-20. El $\mathrm{P}_{2} \mathrm{O}_{5}$ (Fig. 4.30i) no se registró en la muestra SM-26 y en el resto se observa en baja proporción y sin variaciones importantes. $\mathrm{El} \mathrm{Cr}_{2} \mathrm{O}_{3}$ (Fig. 4.30j) se encuentra en menor proporción en la muestra SM-403 y en mayor proporción en la SM20, mientras que en el resto de las muestras registra contenidos bajos y similares cercanos al 0,03\%.

Además de los óxidos mayoritarios, también se graficaron elementos traza como $\mathrm{Ba}, \mathrm{Rb}$ y $\mathrm{Sr}$ (Fig. 4.31a, b y c respectivamente), los cuales muestran un comportamiento similar al de los álcalis, es decir aumenta su contenido junto con el aumento de $\mathrm{SiO}_{2}$. Por el contrario el $\mathrm{Zr}$ muestra una pendiente negativa que indica una disminución en su contenido junto con el aumento en el porcentaje de $\mathrm{SiO}_{2}$, a excepción de la muestra $\mathrm{SM}-15$ que presenta un contenido de $177 \mathrm{ppm}$ de $\mathrm{Zr}$ y 75,4\% de $\mathrm{SiO}_{2}$ (Fig. 4.31b) y la SM-403 que se aparta de la distribución que siguen las demás. 
a)

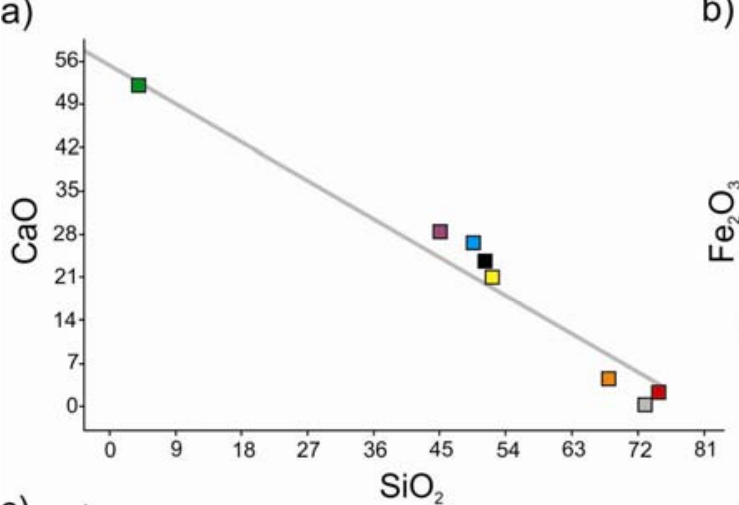

c)

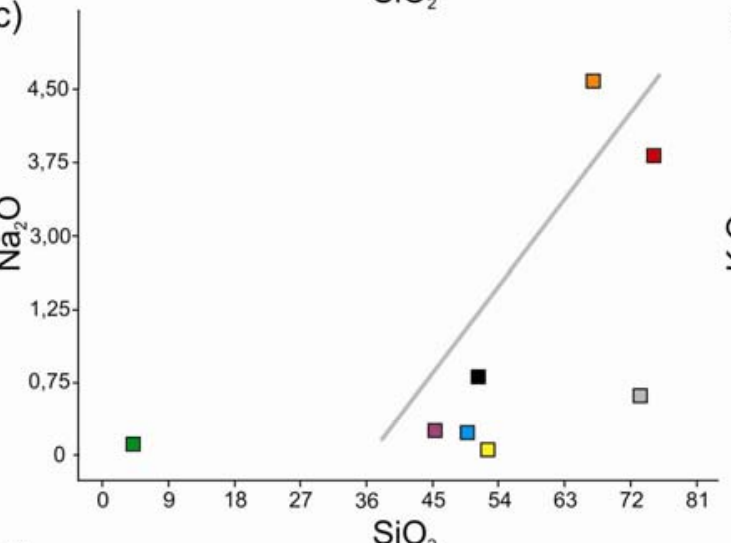

e)

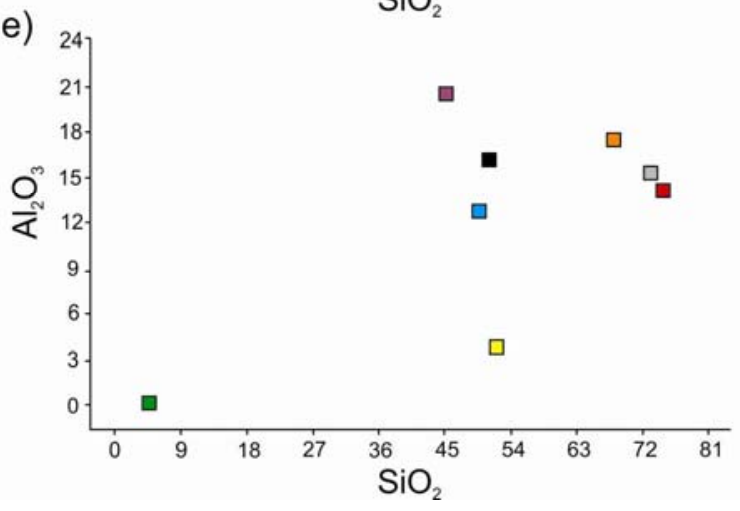

b)

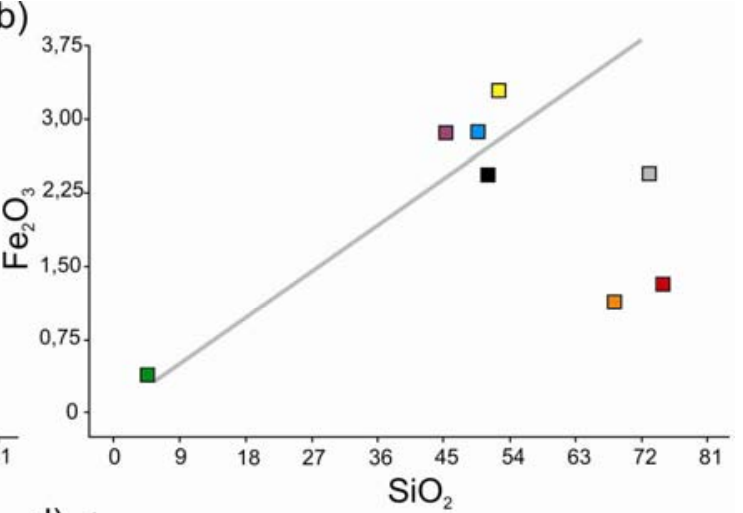

d)

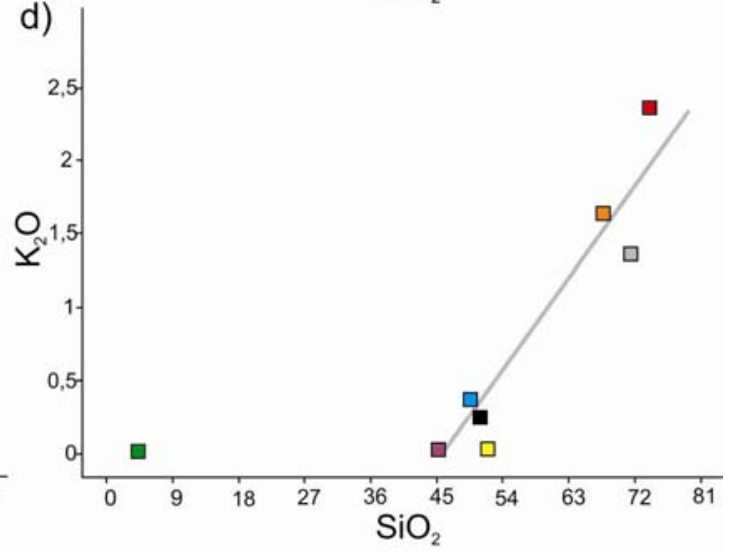

Figura 4.30: Diagramas tipo "Harker". En el mismo se han incluido muestras de las zonas del skarn del área de San Miguel (SM-05, SM-33, SM-26 y SM-403), de los filones graníticos distales al contacto con el mármol del afloramiento del sector nororiental (SM-15 y SM-20) y de los afloramientos de skarn de las estancias La Concordia (LC-12) y Siempre Verde (SV-516). 

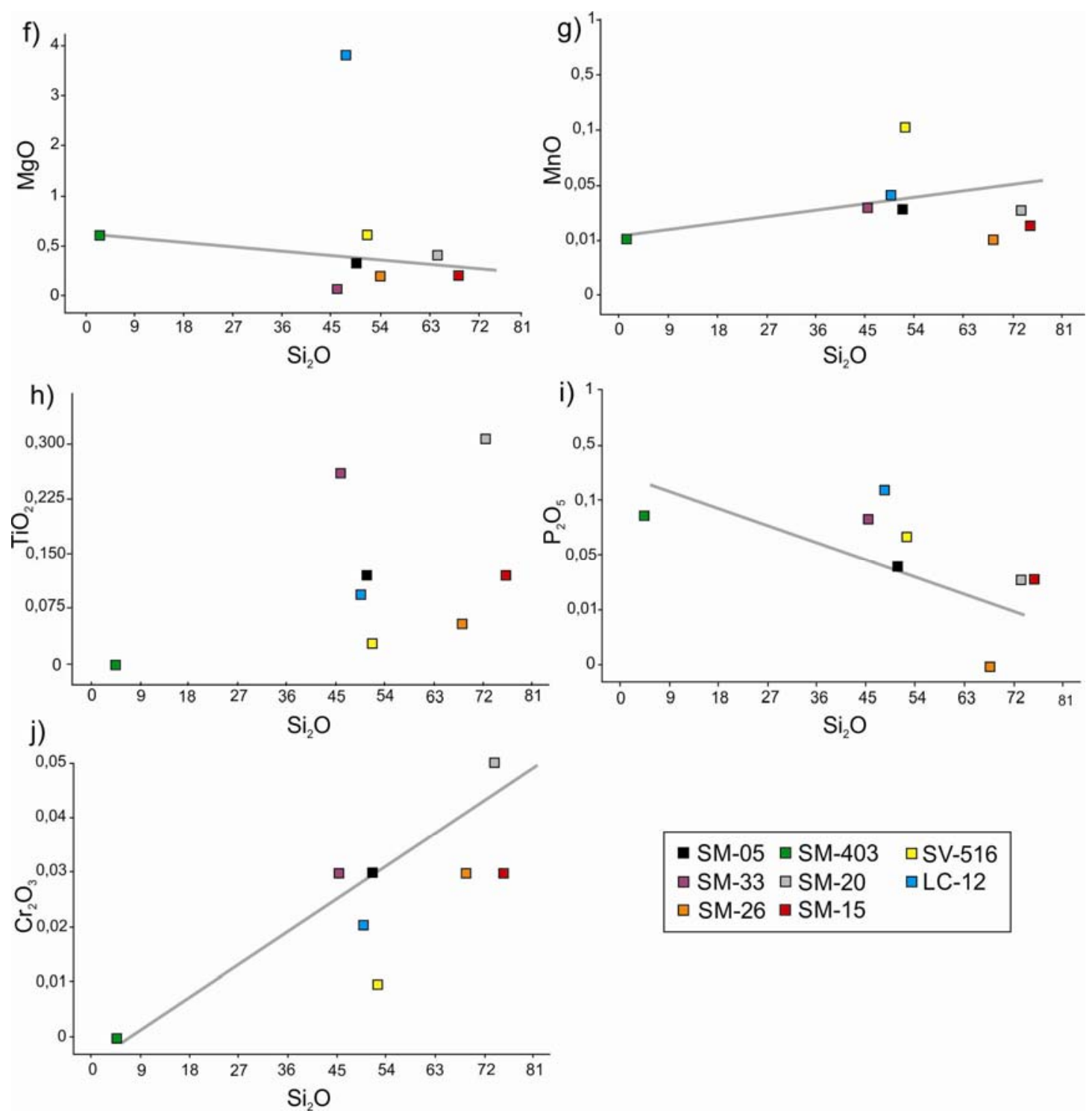

- SM-05 $\mathrm{SM}-403$ 口SV-516

$\square$ SM-33 $\square$ SM-20 LC-12

$\square \mathrm{SM}-26 \backsim \mathrm{SM}-15$

Figura 4.30 continuación. 



Figura 4.31: Diagrama $\mathrm{SiO}_{2}$ vs. elementos traza que mostraron variaciones significativas. Nótese que estas variaciones presentan tendencias positivas o negativas bien marcadas. Referencias en la Fig. 4.30.

\subsubsection{Tierras Raras}

En este estudio los contenidos de Tierras Raras (REE) fueron normalizados a condrito según Sun y McDonought (1989) y se graficaron en un diagrama tipo "spider" (Fig. 4.32). A grandes rasgos todas las muestras presentan diseños con pendientes negativas, con un ligero enriquecimiento en LREE y un empobrecimiento en HREE. Además, todas poseen anomalias positivas o levemente positivas de Eu (con excepción de SM-403), calculadas según la fórmula $\mathrm{Eu}_{\mathrm{N}} / \mathrm{Eu}^{*}$, donde $\mathrm{Eu}^{*}=\left(\mathrm{Sm}_{\mathrm{N}}+\mathrm{Gd}_{\mathrm{N}}\right) / 2$. Dichas anomalías se muestran en el Cuadro 4.12 donde se observa que dentro de las muestras de las zonas del skarn, la SM-26 (zona clinopiroxeno-plagioclasa cálcica), es la que posee la anomalía positiva más elevada, también respecto de LC-12 y 
SV-516 (las tres poseen igual paragénesis pero corresponden a diferentes afloramientos del skarn). Las muestras de la roca granítica periférica al skarn, más distales aún que la SM-26, también presentan anomalías positivas y elevadas. El fraccionamiento total de REE se calculó con la fórmula $\mathrm{La}_{\mathrm{N}} / \mathrm{Lu}_{\mathrm{N}}$, estos valores también se encuentran en el Cuadro 4.12. En cuanto a las muestras que corresponden a las zonas del skarn, la SM-26 y la SM-20 son las que presentan mayores fraccionamientos con relaciones LaN/LuN de 90,30 y 89,26, respectivamente, 5,91 para SM-33, 48,26 para SM-05 y 17,12 para SM-15. La muestra SV-516 presenta una relación $\mathrm{La}_{\mathrm{N}} / \mathrm{Lu}_{\mathrm{N}}$ de 8,80 y LC-12 de 60,41. Cabe destacar que SM-403 presenta valores bajos en el contenido de todas las tierras raras y presenta anomalias negativas de Ce y de Eu.

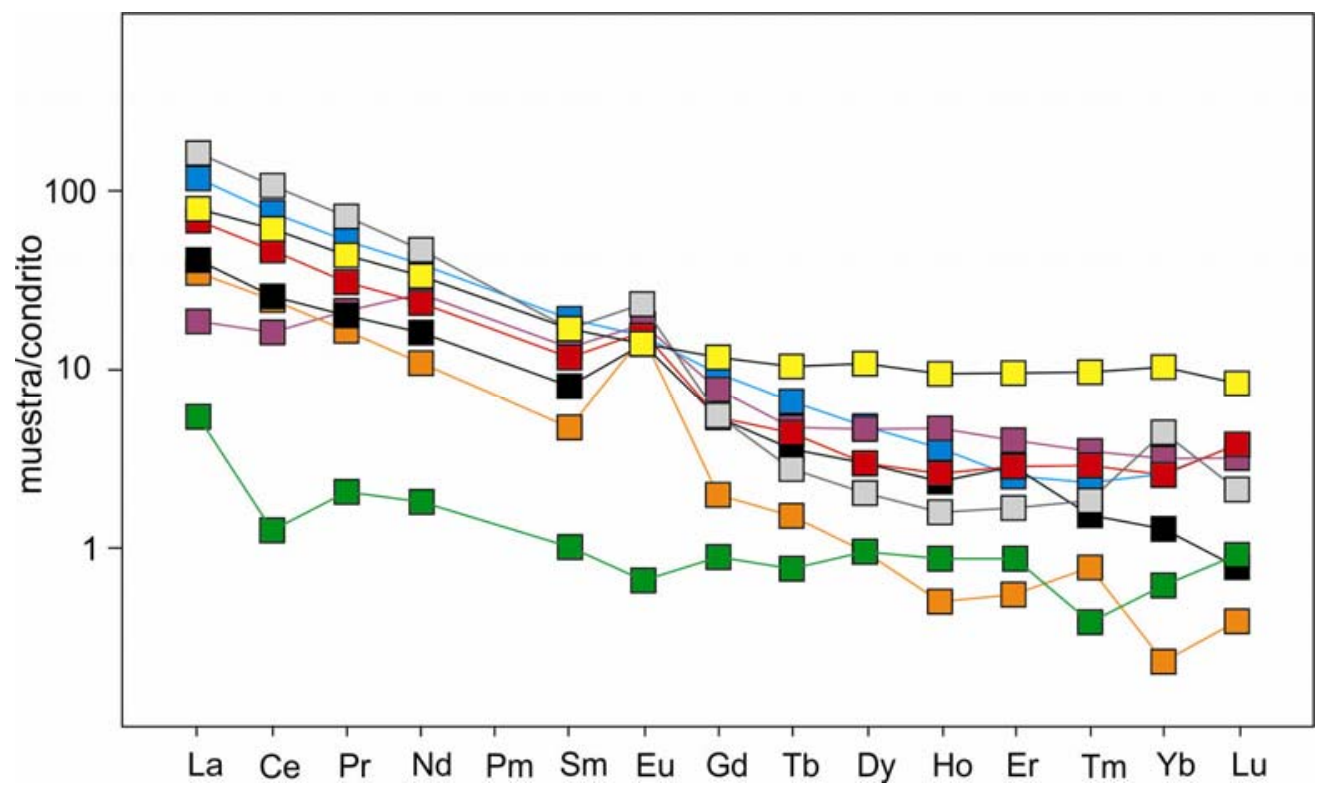

Figura 4.32: Diagrama tipo "spider" de Tierras Raras, normalizado a condrito según Sun y Mc Donought (1989). Se destaca la similitud entre los patrones de todas las zonas del skarn incluyendo las muestras de los afloramientos ubicados en las estancias La Concordia y Siempre Verde, especialmente teniendo en cuenta la fuerte anomalía positiva para todas las muestras. La SM-403 presenta las diferencias esperadas ya que se trata de un mármol modificado. Referencias en la Fig. 4.30. 
En un diagrama spider similar al anterior (Fig. 4.33) se graficaron además algunas muestras de los leucosomas de las migmatitas que afloran próximos al skarn (tratados en el apartado 3.A.1), observándose importantes similitudes en los contenidos de REE de estas respecto a las muestras correspondientes al skarn sobre todo las más periféricas (SM-15 y SM-20). Todas poseen anomalía marcadamente positiva de Eu y pendientes negativas con un ligero enriquecimiento en LREE respecto de HREE. Es interesante la complementariedad entre las anomalias de $\mathrm{Yb}$ de las muestras SM-26 y SM20, negativa en la primera y positiva en la segunda.

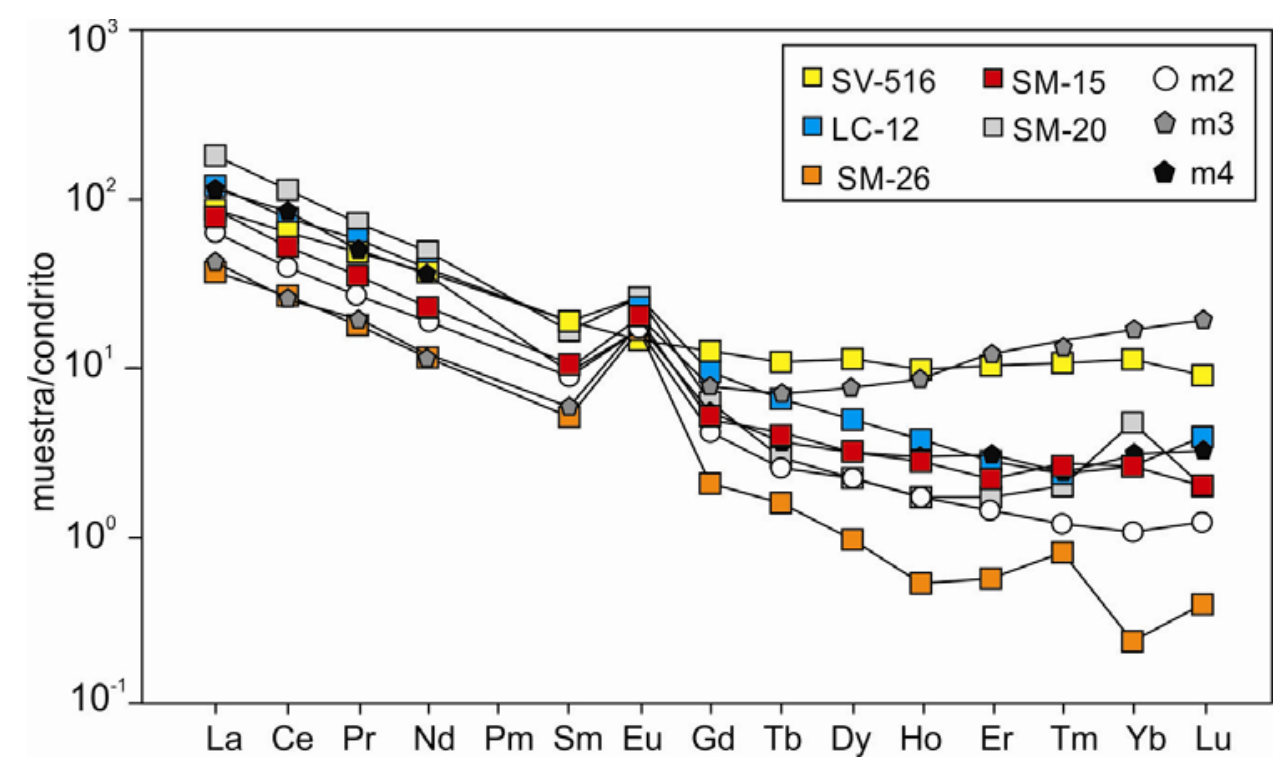

Figura 4.33: Diagrama de Tierras Raras normalizadas a condrito (Sun y Mc Donought 1989), similar al anterior (Fig. 4.32), donde se graficaron además muestras de los leucosomas de las migmatitas que afloran próximos al skarn (tratados en el apartado 3.A.1). Obsérvense las similitudes que se registran en los contenidos de REE de éstas respecto a las muestras correspondientes al skarn sobre todo con las más periféricas (SM-15 y SM-20).

También se realizaron diagramas de elementos traza normalizados a la composición de la corteza superior (Taylor y McLennan 1981). En el primero de los gráficos (Fig. 4.34a) de incluyeron sólo muestras correspondientes a 
las zonas del skarn, si bien es de esperar que el metasomatismo modifique ciertos contenidos y que la muestra SM-403 presente diferencias significativas, en términos generales el resto de las muestras denota una distribución similar con coincidentes anomalías negativas en $\mathrm{Tb}$ y anomalias positivas en Sr. Se destaca que las mayores similitudes en los contenidos de los elementos traza se observa entre las muestras SM-33 y SM-05. En el diagrama de la Fig. 4.34b, se graficaron las correspondientes a los resultados obtenidos de los afloramientos de skarn de las estancias La Concordia (LC-12) y Siempre Verde (SV-516). En el mismo se observa una importante similitud entre los contenidos de elementos traza de ambas muestras, sólo difiriendo notoriamente en los contenidos de $\mathrm{Rb} \mathrm{y} \mathrm{K}$, elementos que por su elevado potencial iónico tienden a ser mucho más móviles ante la acción de los procesos geológicos.

También se compararon los contenidos de estos elementos traza entre las dos muestras de los filones graníticos ubicados más distalmente al skarn (SM-15 y SM-20), que no presentan evidencias mineralógicas ni químicas (en cuanto a elementos mayoritarios según lo visto anteriormente en los diagramas tipo "Harker") de modificaciones generadas por metasomatismo, y la muestra de skarn (SM-26) de la zona clinopiroxeno-plagioclasa cálcica, que corresponde a la zona más externa que evidencia metasomatismo. De acuerdo a este diagrama (Fig. 4.34c) podemos indicar similitudes importantes como las coincidentes anomalias negativas en $\mathrm{Nb}, \mathrm{P}$ y $\mathrm{Tb}$ y las anomalias positivas en $\mathrm{Ba}, \mathrm{K}$ y Sr. Como diferencia significativa la muestra SV-20 se encuentra fuertemente empobrecida en U.

Finalmente en el diagrama de la Fig. 4.34d, se realizó también la comparación entre los valores de elementos traza de las muestras de los leucosomas estudiados en el capítulo 3.A y las muestras correspondientes a los tres sectores con las asociaciones clinopiroxeno-plagioclasa cálcica: SM26, LC-12 y SV-516. En términos generales puede observarse una similitud entre los contenidos de elementos traza de los leucosomas y de las zonas más periféricas del skarn, más aún si tenemos en cuenta que estas tres 
últimas muestras deberian registrar modificaciones por el proceso de metasomatismo y posible asimilación parcial o total del mármol.
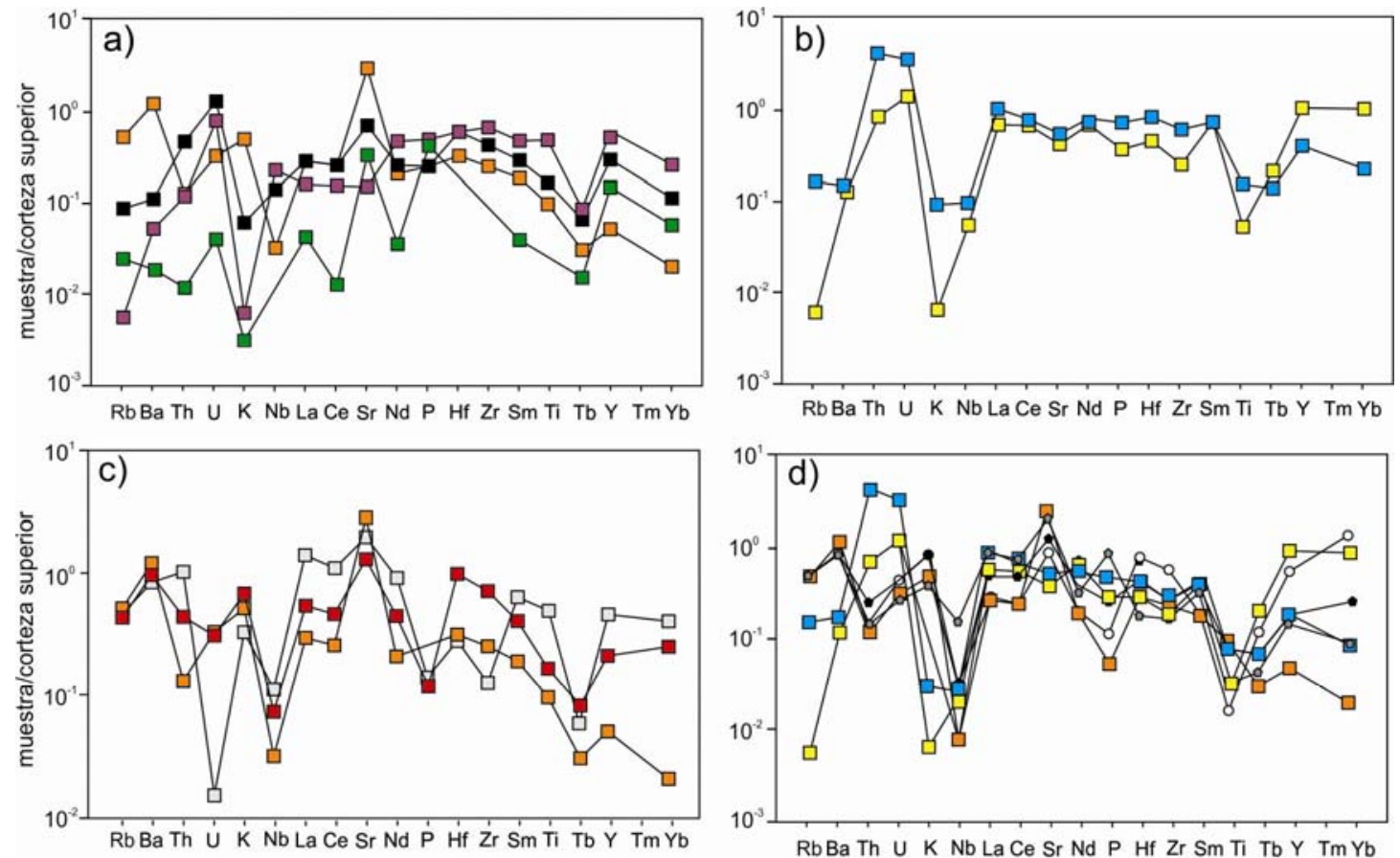

$$
\begin{aligned}
& \text { - SM-05 घ SM-403 口SV-516 ○ } 2 \\
& \square \mathrm{SM}-33 \text { 口 } \mathrm{SM}-20 \quad \square \mathrm{LC}-12 \circ \mathrm{m} 3 \\
& \square \mathrm{SM}-26 \square \mathrm{SM}-15 \quad \cdot \mathrm{m} 4
\end{aligned}
$$

Figura 4.34: Diagramas de elementos traza normalizados a la composición de la corteza superior (Taylor y Mac Lennan 1981). a) Muestras correspondientes a las zonas del skarn. b) Muestras procedentes de los afloramientos de las estancias La Concordia y Siempre Verde. c) Muestra SM-26, correspondiente a la zona clinopiroxeno-plagioclasa cálcica, comparada con las muestras de filones más distales, a los efectos de analizar el metasomatismo. d) Comparación entre los leucosomas y las muestras SM-26, LC-12 y SV-516. En todas las gráficas se resaltan similitudes en los contenidos de elementos traza.

\subsubsection{Balance de masas}

Las ganancias y las pérdidas relativas de elementos químicos durante el proceso metasomático respecto de los protolitos medianamente frescos, fueron evaluadas mediante la confección de isoconas de acuerdo al método 
de Gresens (1967). Éste consiste en emplear un gráfico binario "x-y" donde en el eje " $x$ " se grafica la concentración de elementos químicos medidos en la roca precursora y en el eje " $y$ " la concentración de elementos medidos en la roca modificada. Sobre este gráfico, se busca visualmente o por medios estadísticos, una correlación entre los elementos que han tenido inmovilidad o que fueron inertes (argumento principal del método) durante el fenómeno geológico de alteración. De esta forma se elige la línea de isocona que se traza a través del origen $(0,0)$ y los elementos inertes elegidos. El campo por encima de la línea de isocona incluye o abarca los elementos que sufrieron enriquecimiento elemental, mientras que los del campo inferior a la isocona indican empobrecimiento. Si bien esta metodología es muy utilizada para el estudio de alteraciones hidrotermales en depósitos tipo skarn pueden aplicarse los mismos criterios antes mencionados para conocer las ganancias y pérdidas de elementos que ocurren durante el metasomatismo (Lentz 2005). Las tablas y gráficos realizados fueron confeccionados con el programa EASYGRESGRANT y los resultados analíticos pueden observase en el Cuadro 4.13a y b.

En este estudio se tomó como protolito fresco una muestra de la composición química del mármol calcítico (muestra 21032 b capítulo 3.A.2, Cuadro 3.A.3), esta muestra fue comparada con las correspondientes a facies del exoskarn: SM-403 y SM-05. La dificultad radica en el reconocimiento del protolito granítico fresco, dado que existe una desvinculación entre los afloramientos del skarn y aquellos correspondientes a otras rocas graníticas del área. Esta desvinculación se debe principalmente a la escasez de afloramientos por la extensa cobertura de suelos. Si bien son los gneises y migmatitas las rocas espacialmente más cercanas, para esta comparación se utilizó una de las muestras del sector granítico más periférico al contacto con la roca carbonática (SM-20), que sobre la base de la petrografía y geoquímica presentan una composición poco modificada por la acción de los procesos de metasomatismo y de asimilación. Esta muestra fue utilizada para evaluar los cambios de masa ocurridos sobre las muestras SM-33 y SM-26. Cabe destacar que la utilización de muestras de los 
leucosomas más cercanos m3 y m4 (capítulo 3.A) arrojaron similares resultados a los expuestos en el Cuadro 4.13b.

\begin{tabular}{|c|c|c|c|c|c|c|c|}
\hline Muestra & $21032 \mathrm{~b}$ & SM-403 & $\Delta \mathrm{Ci} / \mathrm{Ci}_{0}$ & $\Delta \mathrm{Ci}$ & SM-05 & $\Delta \mathrm{Ci} / \mathrm{Ci}_{0}$ & $\Delta \mathrm{Ci}$ \\
\hline $\mathrm{SiO}_{2}$ & 1,62 & 4,16 & 1,57 & 2,54 & 51,50 & 30,79 & 49,88 \\
\hline $\mathrm{TiO}_{2}$ & 0,01 & 0,03 & 4,00 & 0,02 & 0,10 & 19,00 & 0,09 \\
\hline $\mathrm{Al}_{2} \mathrm{O}_{3}$ & 0,06 & 0,69 & 10,50 & 0,63 & 16,20 & 269,00 & 16,14 \\
\hline $\mathrm{Fe}_{2} \mathrm{O}_{3}$ & 0,13 & 0,37 & 1,85 & 0,24 & 2,33 & 16,92 & 2,20 \\
\hline $\mathrm{MnO}$ & 0,01 & 0,01 & 0,00 & 0,00 & 0,03 & 2,00 & 0,02 \\
\hline $\mathrm{MgO}$ & 0,65 & 0,62 & $-0,05$ & $-0,03$ & 0,50 & $-0,17$ & $-0,11$ \\
\hline $\mathrm{CaO}$ & 54,50 & 53,30 & $-0,02$ & $-1,20$ & 24,50 & $-0,55$ & $-30,00$ \\
\hline $\mathrm{Na}_{2} \mathrm{O}$ & 0,04 & 0,10 & 1,50 & 0,06 & 0,85 & 20,25 & 0,81 \\
\hline $\mathrm{K}_{2} \mathrm{O}$ & 0,01 & 0,02 & 1,00 & 0,01 & 0,20 & 19,00 & 0,19 \\
\hline $\mathrm{P}_{2} \mathrm{O}_{5}$ & 0,07 & 0,09 & 0,29 & 0,02 & 0,04 & $-0,43$ & $-0,03$ \\
\hline $\mathrm{Rb}$ & 0,10 & 0,40 & 3,00 & 0,30 & 9,30 & 92,00 & 9,20 \\
\hline $\mathrm{Ba}$ & 10,40 & 1080,00 & 102,85 & 1069,60 & 77,10 & 6,41 & 66,70 \\
\hline $\mathrm{Sr}$ & 115,00 & 166,50 & 0,45 & 51,50 & 255,00 & 1,22 & 140,00 \\
\hline $\mathrm{Cr}$ & 5,00 & 10,00 & 1,00 & 5,00 & 190,00 & 37,00 & 185,00 \\
\hline $\mathrm{Ga}$ & 0,05 & 0,80 & 15,00 & 0,75 & 25,10 & 501,00 & 25,05 \\
\hline U & 0,08 & 0,15 & 0,88 & 0,07 & 2,70 & 32,75 & 2,62 \\
\hline $\mathrm{Zr}$ & 1,00 & 14,00 & 13,00 & 13,00 & 101,00 & 100,00 & 100,00 \\
\hline $\mathrm{Hf}$ & 0,10 & 0,15 & 0,50 & 0,05 & 2,90 & 28,00 & 2,80 \\
\hline Y & 3,30 & 9,60 & 1,91 & 6,30 & 6,60 & 1,00 & 3,30 \\
\hline $\mathrm{Ta}$ & 0,05 & 0,10 & 1,00 & 0,05 & 0,30 & 5,00 & 0,25 \\
\hline Th & 0,12 & 0,59 & 3,92 & 0,47 & 4,68 & 38,00 & 4,56 \\
\hline $\mathrm{La}$ & 1,20 & 4,80 & 3,00 & 3,60 & 9,30 & 6,75 & 8,10 \\
\hline $\mathrm{Ce}$ & 0,80 & 5,10 & 5,38 & 4,30 & 16,00 & 19,00 & 15,20 \\
\hline $\operatorname{Pr}$ & 0,20 & 0,87 & 3,35 & 0,67 & 1,92 & 8,60 & 1,72 \\
\hline $\mathrm{Nd}$ & 0,90 & 3,40 & 2,78 & 2,50 & 7,40 & 7,23 & 6,50 \\
\hline $\mathrm{Sm}$ & 0,16 & 0,73 & 3,56 & 0,57 & 1,15 & 6,19 & 0,99 \\
\hline $\mathrm{Eu}$ & 0,04 & 0,15 & 2,75 & 0,11 & 0,79 & 18,75 & 0,75 \\
\hline Gd & 0,19 & 0,87 & 3,58 & 0,68 & 1,14 & 5,00 & 0,95 \\
\hline $\mathrm{Tb}$ & 0,03 & 0,11 & 2,67 & 0,08 & 0,13 & 3,34 & 0,10 \\
\hline Dy & 0,27 & 0,75 & 1,78 & 0,48 & 0,80 & 1,96 & 0,53 \\
\hline Ho & 0,05 & 0,17 & 2,40 & 0,12 & 0,13 & 1,60 & 0,08 \\
\hline $\mathrm{Er}$ & 0,15 & 0,50 & 2,33 & 0,35 & 0,45 & 2,00 & 0,30 \\
\hline $\mathrm{Tm}$ & 0,01 & 0,06 & 5,00 & 0,05 & 0,04 & 3,00 & 0,03 \\
\hline $\mathrm{Yb}$ & 0,11 & 0,31 & 1,82 & 0,20 & 0,22 & 1,00 & 0,11 \\
\hline $\mathrm{Lu}$ & 0,01 & 0,03 & 5,00 & 0,03 & 0,02 & 3,00 & 0,01 \\
\hline
\end{tabular}

Cuadro 4.13a: Resultados del balance de masa realizados sobre muestras (SM-403 y SM-05) del exoskarn. Como protolito fresco se utilizó la muestra 21032b correspondiente al mármol. 


\begin{tabular}{|c|c|c|c|c|c|c|c|}
\hline Muestra & SM-20 & SM-33 & $\Delta C_{i} / C_{i}{ }^{0}$ & $\Delta C_{i}$ & SM-26 & $\Delta \mathrm{Ci} / \mathrm{CiO}$ & $\Delta \mathrm{Ci}$ \\
\hline $\mathrm{SiO}_{2}$ & 73,70 & 45,50 & $-0,38$ & $-28,20$ & 68,70 & $-0,07$ & $-5,00$ \\
\hline $\mathrm{TiO}_{2}$ & 0,30 & 0,28 & $-0,07$ & $-0,02$ & 0,06 & $-0,80$ & $-0,24$ \\
\hline $\mathrm{Al}_{2} \mathrm{O}_{3}$ & 15,35 & 20,50 & 0,34 & 5,15 & 17,40 & 0,13 & 2,05 \\
\hline $\mathrm{Fe}_{2} \mathrm{O}_{3}$ & 2,31 & 2,87 & 0,24 & 0,56 & 1,12 & $-0,52$ & $-1,19$ \\
\hline $\mathrm{MnO}$ & 0,04 & 0,03 & $-0,25$ & $-0,01$ & 0,01 & $-0,75$ & $-0,03$ \\
\hline $\mathrm{MgO}$ & 0,66 & 0,10 & $-0,85$ & $-0,56$ & 0,30 & $-0,55$ & $-0,36$ \\
\hline $\mathrm{CaO}$ & 0,49 & 30,00 & 60,22 & 29,51 & 4,87 & 8,94 & 4,38 \\
\hline $\mathrm{Na}_{2} \mathrm{O}$ & 0,71 & 0,38 & $-0,46$ & $-0,33$ & 4,64 & 5,54 & 3,93 \\
\hline $\mathrm{K}_{2} \mathrm{O}$ & 1,08 & 0,02 & $-0,98$ & $-1,06$ & 1,69 & 0,56 & 0,61 \\
\hline $\mathrm{P}_{2} \mathrm{O}_{5}$ & 0,02 & 0,08 & 2,33 & 0,06 & 0,01 & $-0,79$ & $-0,02$ \\
\hline $\mathrm{Rb}$ & 54,30 & 0,16 & $-1,00$ & $-54,14$ & 58,60 & 0,08 & 4,30 \\
\hline $\mathrm{Ba}$ & 607,00 & 39,30 & $-0,94$ & $-567,70$ & 884,00 & 0,46 & 277,00 \\
\hline $\mathrm{Sr}$ & 720,00 & 51,60 & $-0,93$ & $-668,40$ & 1025,00 & 0,42 & 305,00 \\
\hline $\mathrm{Cr}$ & 160,00 & 270,00 & 0,69 & 110,00 & 200,00 & 0,25 & 40,00 \\
\hline V & 0,60 & 37,00 & 60,67 & 36,40 & 12,00 & 19,00 & 11,40 \\
\hline $\mathrm{Ga}$ & 17,20 & 32,20 & 0,87 & 15,00 & 19,60 & 0,14 & 2,40 \\
\hline U & 0,03 & 1,59 & 52,00 & 1,56 & 0,67 & 21,33 & 0,64 \\
\hline $\mathrm{Zr}$ & 0,30 & 165,00 & 549,00 & 164,70 & 60,00 & 199,00 & 59,70 \\
\hline $\mathrm{Hf}$ & 1,40 & 3,00 & 1,14 & 1,60 & 1,60 & 0,14 & 0,20 \\
\hline Y & 10,00 & 11,80 & 0,18 & 1,80 & 0,04 & $-0,99$ & $-9,96$ \\
\hline $\mathrm{Nb}$ & 3,00 & 5,80 & 0,93 & 2,80 & 0,08 & $-0,97$ & $-2,92$ \\
\hline $\mathrm{Ta}$ & 0,20 & 0,40 & 1,00 & 0,20 & 0,10 & $-0,50$ & $-0,10$ \\
\hline Th & 10,65 & 1,15 & $-0,89$ & $-9,50$ & 1,33 & $-0,88$ & $-9,32$ \\
\hline $\mathrm{La}$ & 43,00 & 4,70 & $-0,89$ & $-38,30$ & 8,70 & $-0,80$ & $-34,30$ \\
\hline $\mathrm{Ce}$ & 71,90 & 10,00 & $-0,86$ & $-61,90$ & 16,00 & $-0,78$ & $-55,90$ \\
\hline $\mathrm{Pr}$ & 7,09 & 2,18 & $-0,69$ & $-4,91$ & 1,67 & $-0,76$ & $-5,42$ \\
\hline $\mathrm{Nd}$ & 23,80 & 12,70 & $-0,47$ & $-11,10$ & 5,40 & $-0,77$ & $-18,4$ \\
\hline $\mathrm{Sm}$ & 2,61 & 1,90 & $-0,27$ & $-0,71$ & 0,76 & $-0,71$ & $-1,85$ \\
\hline Eu & 1,46 & 1,11 & $-0,24$ & $-0,35$ & 1,12 & $-0,23$ & $-0,34$ \\
\hline $\mathrm{Gd}$ & 1,21 & 1,61 & 0,33 & 0,40 & 0,42 & $-0,65$ & $-0,79$ \\
\hline $\mathrm{Tb}$ & 0,11 & 0,17 & 0,55 & 0,06 & 0,06 & $-0,45$ & $-0,05$ \\
\hline Dy & 0,56 & 1,25 & 1,23 & 0,69 & 0,24 & $-0,57$ & $-0,32$ \\
\hline Ho & 0,09 & 0,28 & 2,11 & 0,19 & 0,03 & $-0,67$ & $-0,06$ \\
\hline Er & 0,28 & 0,70 & 1,50 & 0,42 & 0,09 & $-0,68$ & $-0,19$ \\
\hline $\mathrm{Tm}$ & 0,05 & 0,09 & 0,80 & 0,04 & 0,02 & $-0,60$ & $-0,03$ \\
\hline $\mathrm{Yb}$ & 2,80 & 0,54 & $-0,81$ & $-2,26$ & 0,04 & $-0,98$ & $-2,76$ \\
\hline $\mathrm{Lu}$ & 0,05 & 0,08 & 0,60 & 0,03 & 0,01 & $-0,80$ & $-0,04$ \\
\hline
\end{tabular}

Cuadro 4.13b: Resultados del balance de masa realizados sobre muestras (SM-33 y SM-26) del endoskarn. Como protolito fresco se utilizó la muestra SM-20 correspondiente a los sectores de los filones graníticos con escaso o nulo metasomatismo.

En términos generales puede observarse una movilización importante de elementos en todas las zonas. En la muestra SM-403 (Fig. 4.35a) la 
pérdida de $\mathrm{CaO}$ es sólo del -2,00\% y la $\mathrm{MgO}-5,00 \%$ (son los elementos más inmóviles junto con $\mathrm{MnO}_{2} \quad \mathrm{y} \quad \mathrm{P}_{2} \mathrm{O}_{5}$ ). Las mayores incorporaciones corresponden a $\mathrm{Al}_{2} \mathrm{O}_{3}(1050 \%)$ y $\mathrm{TiO}_{2}(500 \%)$ y las menores a $\mathrm{Fe}_{2} \mathrm{O}_{3}, \mathrm{SiO}_{2}$, $\mathrm{Na}_{2} \mathrm{O}$ y $\mathrm{K}_{2} \mathrm{O}$ (Fig. 4.35b). Estas variaciones son consistentes con la cristalización de grosularia y diópsido en esta zona. En cuanto a los elementos traza, si bien todos presentan un enriquecimiento general en su contenido, la incorporación más importante corresponde a Ba, Ga y Zr (Fig. 4.35c). También todos los elementos de las Tierras Raras presentan enriquecimientos entre un 200 y 500\% (Fig. 4.35d). La SM-05 es la más modificada de las zonas (Fig. 4.35e), con una importante incorporación de óxidos mayoritarios sobre todo $\mathrm{Al}_{2} \mathrm{O}_{3}$ (> a 2000\%), $\mathrm{SiO}_{2}$ (307,90\%), $\mathrm{TiO}_{2}$ (190\%) y $\mathrm{Fe}_{2} \mathrm{O}_{3}(169,2 \%)$ y una pérdidas de $\mathrm{CaO}$ de $-5,50 \%$ y $\mathrm{MgO}$ de $-1,70 \%$, siendo nuevamente estos dos últimos óxidos junto con $\mathrm{P}_{2} \mathrm{O}_{5}$ los más inmóviles (Fig. 4.35f). Teniendo en cuenta la cristalización de wollastonita, vesubianita y clinopiroxeno tipo diópsido-hedenbergítico, estos enriquecimientos son acordes a lo esperado. En cuanto a las trazas se observa un incremento en todas con una importante incorporación de $\mathrm{Ga}$, $\mathrm{Zr}, \mathrm{Rb}$, Th y Cr (Fig. 4.35g). Los elementos de Tierras Raras también se enriquecen aunque en menor proporción (Fig. 4.35h). Para las muestras correspondientes al endoskarn (que fueron comparadas con una de las muestras de los sectores de roca granítica más periféricos al skarn), se observa que la SM-33 (zona granate-clinopiroxeno, Fig. 4.36a), presenta pérdidas poco significativas en la mayoría de los óxidos mayoritarios $\left(\mathrm{SiO}_{2}\right.$, $\mathrm{TiO}_{2}, \mathrm{MnO}, \mathrm{MgO}, \mathrm{Na}_{2} \mathrm{O}$ y $\mathrm{K}_{2} \mathrm{O}$ ), salvo en $\mathrm{CaO}$ donde registra un incremento muy importante del 602,20\%. También registra incrementos, aunque en menor proporción, de $\mathrm{P}_{2} \mathrm{O}_{5}$ 23,30\%, $\mathrm{Al}_{2} \mathrm{O}_{3} 3,40 \%$ y $\mathrm{Fe}_{2} \mathrm{O}_{3}$ 2,40\% (Fig. 4.36b). Este incremento en $\mathrm{CaO}$ y en menor proporción de $\mathrm{Al}_{2} \mathrm{O}_{3}$ y $\mathrm{Fe}_{2} \mathrm{O}_{3}$, posibilitó la cristalización de grosularia y en menor proporción clinopiroxeno diópsidohedenbergítico. En cuanto al contenido de elementos traza, si bien se registra poca movilidad general, puede observarse un importante enriquecimiento en $\mathrm{Zr}$, Ga y U (Fig. 4.36c). Elementos del grupo de las Tierras Raras que se ven empobrecidos son Ce, La y Nd, mientras que el 
resto no presenta importantes modificaciones (Fig. 4.36d). La muestra SM26 (Fig. 4.36e), en cuanto a los elementos mayoritarios, presentan poca movilidad aunque con ganancias significativas en $\mathrm{CaO}(89,4 \%)$ y $\mathrm{NaO}_{2}$ $(55,4 \%)$, Fig. 4.36f. El calcio incorporado ha cristalizado en forma de plagioclasa cálcica y clinopiroxeno de tipo diópsido; el sodio también formó plagioclasa. Los elementos traza presentan poca movilidad, en general, aunque se registra importantes enriquecimientos en $\mathrm{Zr}$, U y V, Fig. 4.36g. Se observa una pérdida de todos los elementos del grupo de las Tierras Raras, aunque en baja magnitud, Fig. $4.36 \mathrm{~h}$. 


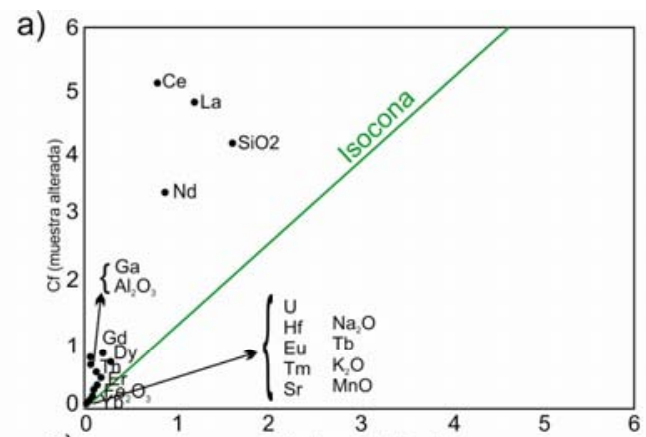

b)
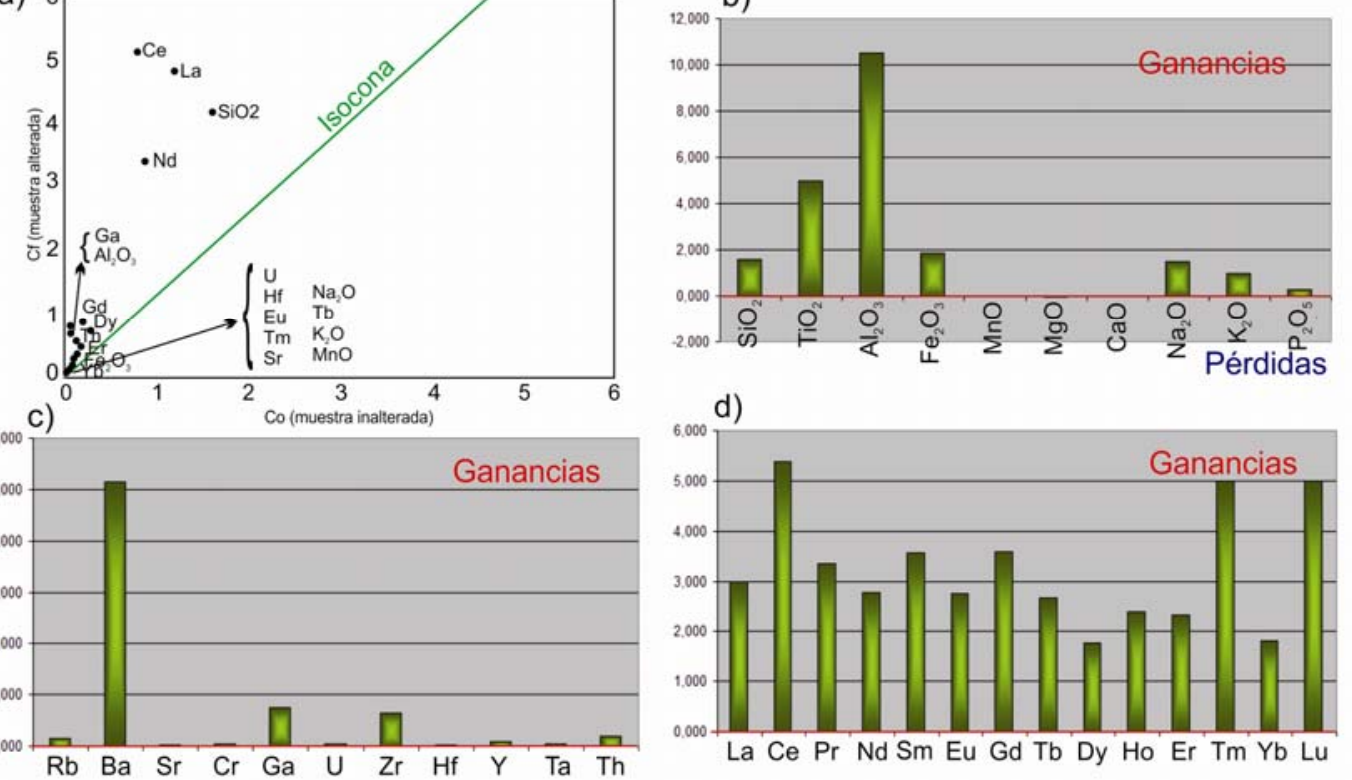

e)
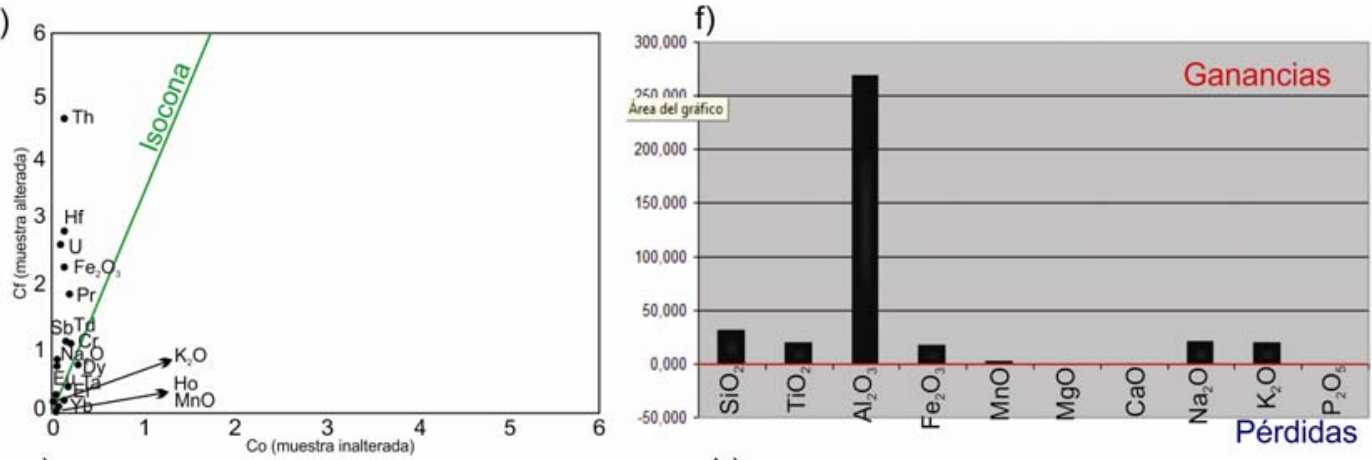

g)
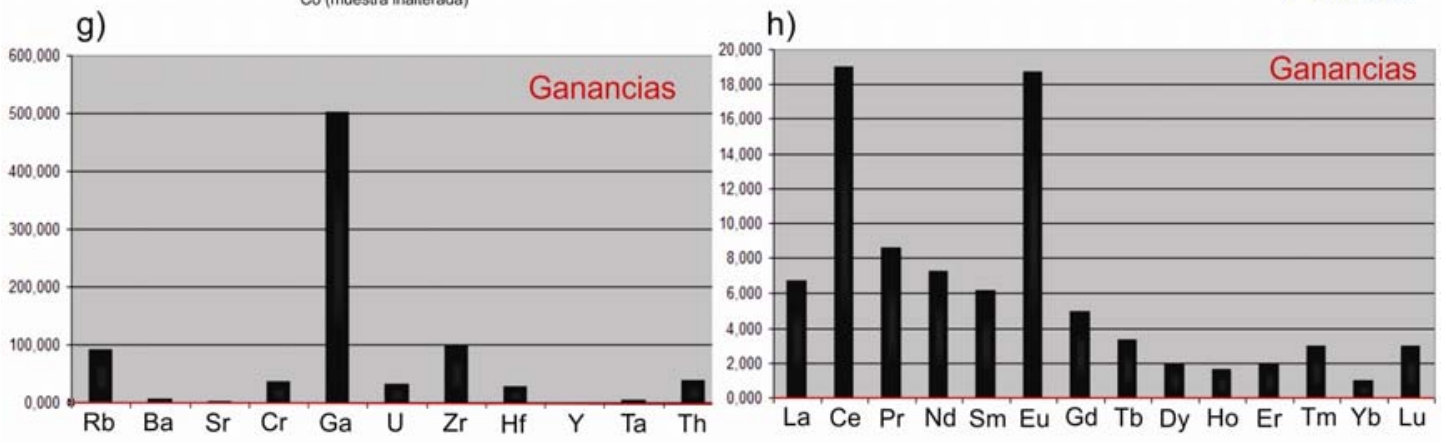

Figura 4.35: Balance de masas del exoskarn. Muestra SM-403. a) Isocona, comparación con 21032 b. Gráficos de barras de pérdidas y ganancias. b) Elementos mayoritarios. c) Elementos traza. d) Tierras Raras. Muestra SM-05. e) Isocona, comparación con 21032b. Gráficos de barras de pérdidas y ganancias. f) Elementos mayoritarios. g) Elementos traza. h) Tierras raras. Los elementos mayoritarios están expresados en \% en óxido y trazas y Tierras Raras en ppm. 
a)

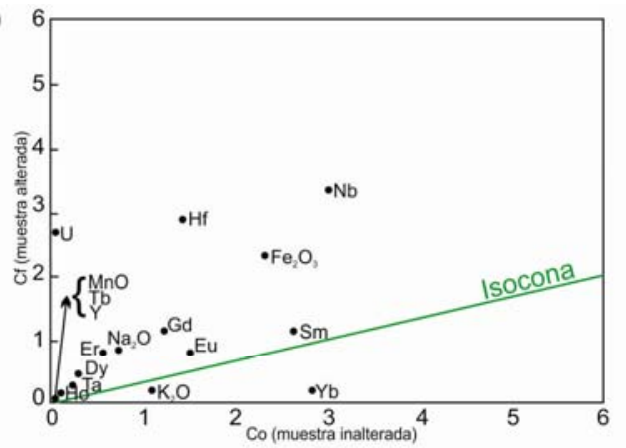

c)

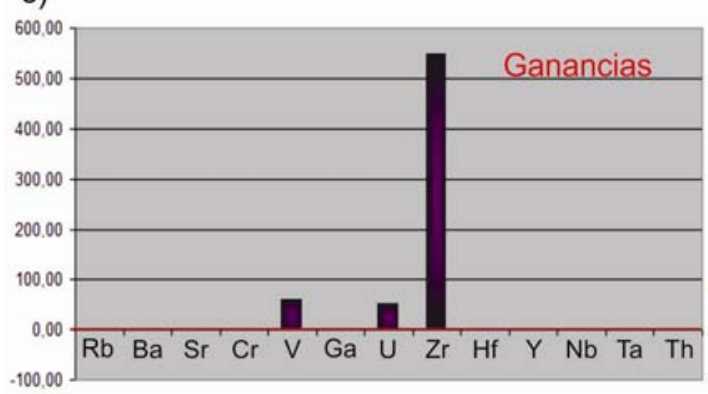

e)

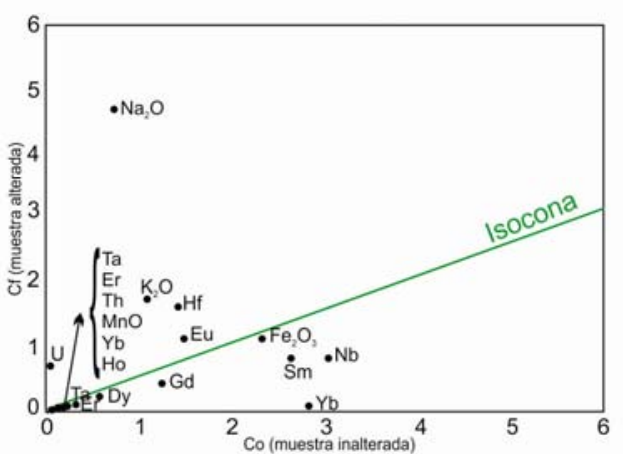

g)

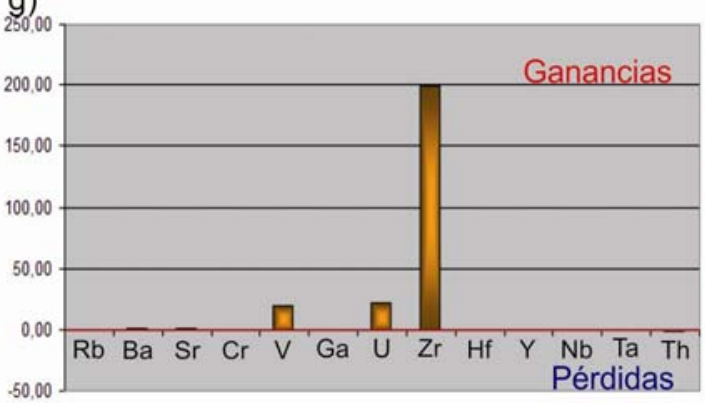

b)

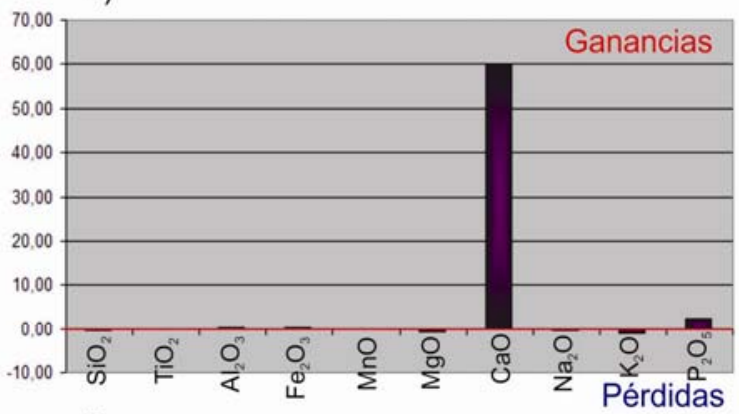

d)

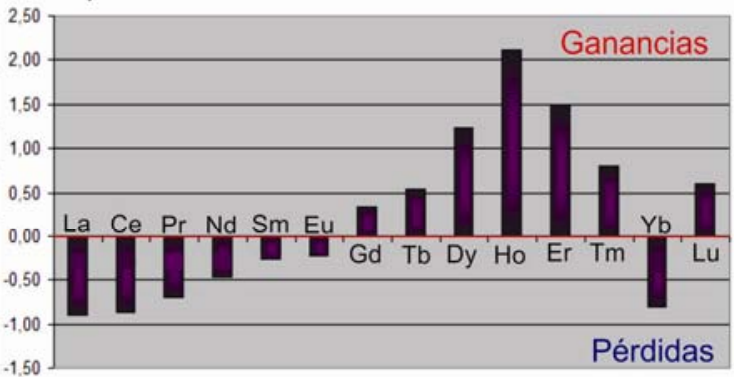

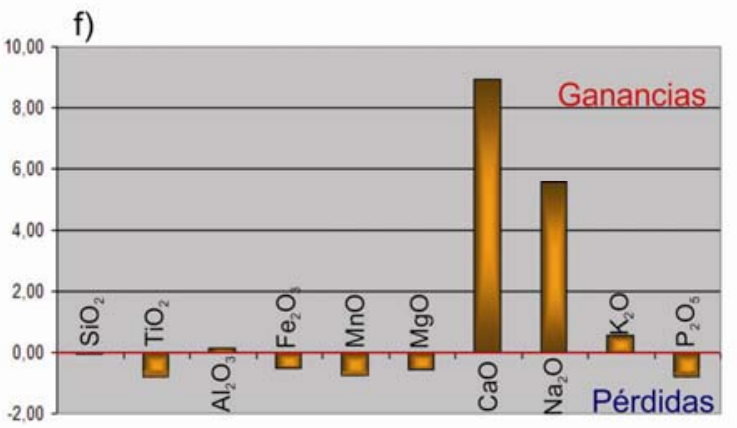

h)

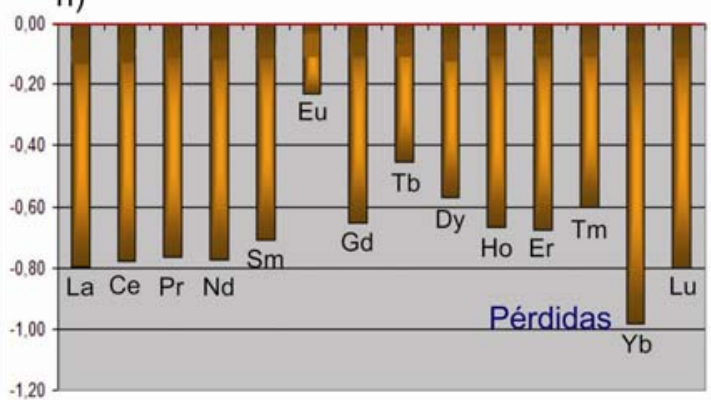

Figura 4.36: Balance de masas del endoskarn. Muestra SM-33. a) Isocona, comparación con SM-20. Gráficos de barras de pérdidas y ganancias. b) Elementos mayoritarios. c) Elementos traza. d) Tierras Raras. Muestra SM-26. e) Isocona de comparación con SM-20. Gráficos de barras de pérdidas y ganancias. f) Elementos mayoritarios. g) Elementos traza. h) Tierras raras. Los elementos mayoritarios están expresados en \% en óxido y trazas y Tierras Raras en ppm. 


\subsubsection{Composición química de las vetillas}

En términos generales los resultados de la composición química de elementos mayoritarios de las vetillas descriptas con anterioridad (Cuadro 4.12), concuerdan con la mineralogía identificada. Las vetillas rosadas presentan altos contenidos de $\mathrm{SiO}_{2}$ (43, 8\%), $\mathrm{CaO}(33,7 \%)$ y $\mathrm{Al}_{2} \mathrm{O}_{3}(16,8 \%)$, bajos en $\mathrm{Fe}_{2} \mathrm{O}_{3}(1,42 \%)$ y $\mathrm{Na}_{2} \mathrm{O}(1,01 \%)$, en tanto que el resto de los óxidos mayoritarios no supera el $0,2 \%$. Por otro lado, las vetillas grises cuentan con una predominancia en $\mathrm{SiO}_{2}$ de $90,8 \%$, muy por debajo le siguen $\mathrm{Al}_{2} \mathrm{O}_{3}$ $(4,62 \%)$ y $\mathrm{Fe}_{2} \mathrm{O}_{3}(2,31 \%)$ y el resto de los demás óxidos no supera el 0,71\%. E1 análisis de Tierras Raras y de elementos traza indica que estas vetillas están empobrecidas en dichos elementos, siendo las vetillas grises las más empobrecidas. Por este motivo no se realizaron diagramas normalizados de, pero sí de elementos traza normalizados a la composición de la corteza continental superior (Taylor y McLennan 1981). Si bien muchos de los elementos traza presentan valores iguales a cero, en este diagrama (Fig. 4.37) puede observarse y corroborarse que las vetillas grises presentan valores bajos y menores en todos los elementos analizados que las vetillas rosadas, a excepción de los contenidos de $\mathrm{Rb}$ y $\mathrm{Ba}$, que son mucho menores en estas últimas. Además, las vetillas rosadas presentan una anomalía positiva en el contenido de U y una anomalía negativa en el contenido de $\mathrm{Nb}$.

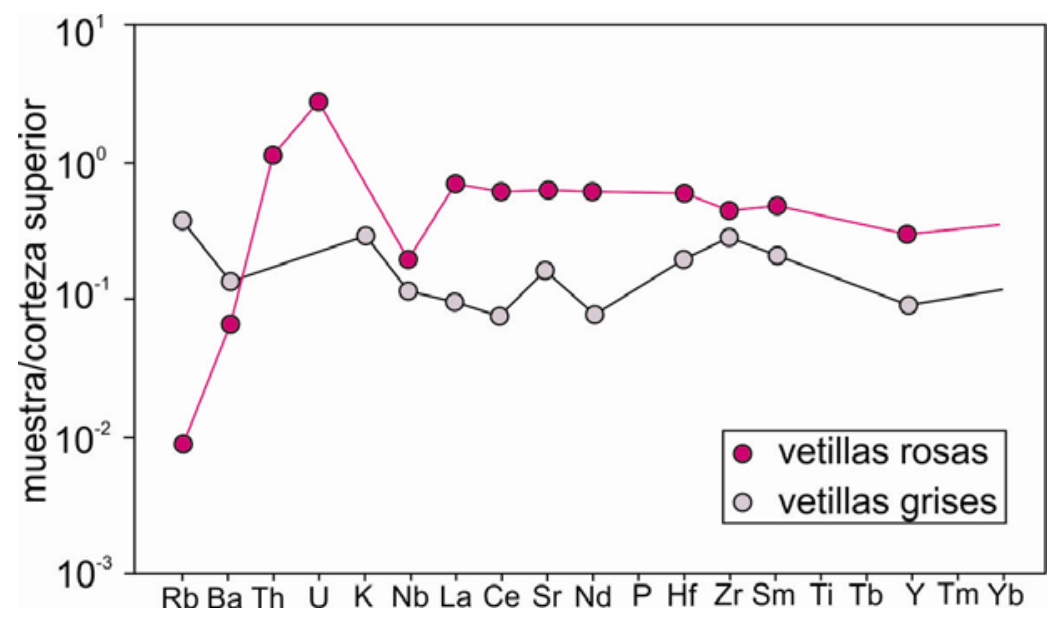

Figura 4.37: Diagrama de elementos traza, normalizados a la composición de la corteza superior (Taylor y Mac Lennan 1981) de las vetillas retrógradas identificadas en el skarn San Miguel. 


\subsubsection{Clasificación del skarn San Miguel}

Ciertas clasificaciones de skarn son sumamente útiles en el intento de determinar, a partir de sus características, las condiciones de su formación. Sobre la base de la distancia al intrusivo que genera la alteración calcosilicática se definen los skarns proximales, cuando la alteración es inmediata al intrusivo, y los distales, cuando los fluidos migran distancias considerables a través de planos estructurales o contactos litológicos antes de cristalizar. Por otro lado, teniendo en cuenta las paragénesis minerales presentes, podemos ubicar a los skarns en dos clases mayores: los cálcicos y los magnésicos. Los primeros se forman por el reemplazo de una roca carbonática compuesta predominantemente por calcita y produce la asociación dominada por granate + clinopiroxeno + wollastonita \pm vesubianita. Los magnésicos son el resultado del reemplazo de una dolomía y genera asociaciones dominadas por la presencia de olivina, flogopita, espinela, serpentina, ortopiroxeno y minerales del grupo de las humitas, además de minerales más comunes como clinopiroxenos, granates, anfiboles y talco. De acuerdo a la mineralogía hasta aquí descripta y en concordancia con los estudios realizados por de Barrio et al. (2009) el skarn San Miguel es un skarn cálcico.

En forma complementaria con la anterior clasificación, el uso de la mineralización o metal económico dominante para determinar las características de formación del skarn, permite ubicar a un depósito estudiado en una de las siete subclases mayores: hierro, cobre, molibdeno, wolframio, zinc-plomo, estaño y oro (Knopf 1942, Einaudi et al. 1981, Orris et al. 1987, Meinert 1988 y 1989, Ettlinger y Ray 1989, Ray et al. 1990 Theodore et al. 1991). A continuación se utilizan una serie de gráficas que se basan en diferentes relaciones para establecer la afinidad de un determinado skarn en estudio con alguno de los correspondientes a las subclases definidas. Si bien el skarn San Miguel no presenta mineralizaciones metalifferas reconocibles, esta clasificación se empleará para determinar su afinidad con alguno de los depósitos caracterizados. 
Los principales minerales formadores de skarns como granates, piroxenos y anfiboles, constituyen herramientas muy útiles para su clasificación, especialmente los dos primeros, debido a que su composición química permite vincularlos a diferentes subclases de skarn, definidas sobre la base de su metal predominante (Zharicov 1970, Burt 1972 y Einaudi et al. 1981). Los diagramas triangulares de la Fig. 4.38a, muestran la variación composicional típica de los extremos composicionales de granates grosularia-andradita-piralspita (sumatoria de piropo, almandino y espesartina) y piroxenos diópsido-hedenbergita-johansenita, en las diferentes subclases. En los mismos, se han graficado las composiciones químicas de dichos minerales obtenidas por microsonda electrónica (Cuadros 4.6 y 4.7) para el skarn San Miguel (Fig. 4.38b). La mayor cantidad de puntos que corresponde a la composición de los granates coincide con los campos determinados para los skarns de $\mathrm{Au}$, y en menor medida de $\mathrm{Fe}$ y $\mathrm{Zn}$, en cambio los puntos correspondientes a los piroxenos, al tener poca variación composicional podrian asignarse tentativamente, por lo menos a cinco tipos de skarn: $\mathrm{Cu}, \mathrm{Fe}, \mathrm{Au}, \mathrm{Sn}$ y W.

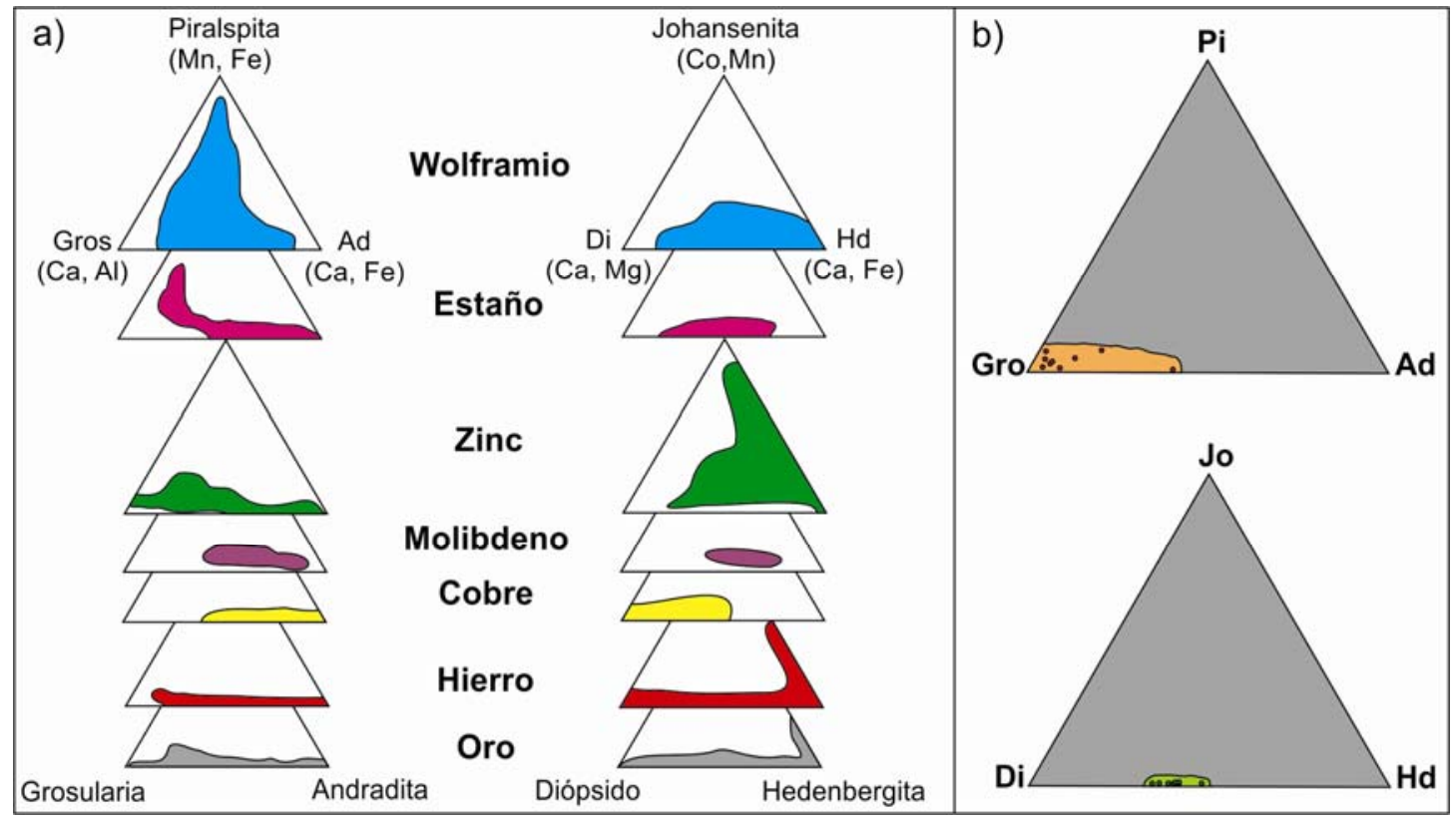


Figura 4.38: a) Diagramas triangulares que muestran la composición de granates y piroxenos y su variación, para las distintas subclases de skarn (Zharicov 1970, Burt 1972 y Einaudi et al. 1981). b) Composición de los granates y piroxenos del skarn San Miguel. Los valores graficados, se detallan en los Cuadros 4.6 y 4.7.

Con este mismo fin, se emplearon los diagramas de óxidos mayoritarios (Fig. 4.39a, Church (1975) y de álcalis vs sílice (Fig. 4.39b, Ray Webster 1991) de las rocas silíceas involucradas en la formación de un skarn. Debido a que en el skarn San Miguel este cuerpo intrusivo fresco no está totalmente definido, se utilizaron los análisis de los sectores menos alterados de los filones graníticos SM-20 y SM-15. En términos generales las gráficas muestran afinidades con los skarns de W-Sn, que coincide con la composición general de los piroxenos, pero no con la totalidad de la composición de los granates.

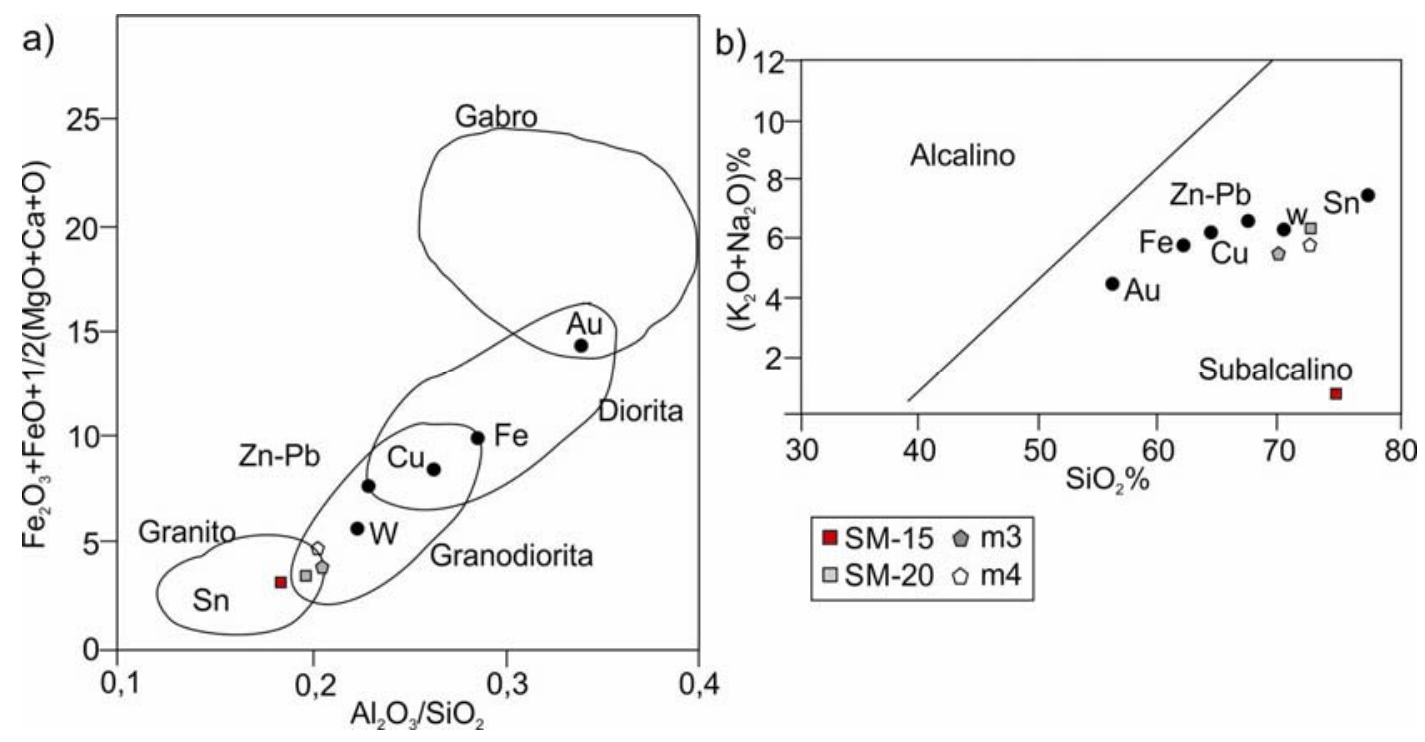

Figura 4.39: Diagramas de clasificación de skarn, sobre la base de la composición del intrusivo. a) Diagrama binario con la composición de óxidos mayoritarios, Church (1975). b) Diagrama modificado de álcalinis vs. sílice (Ray y Webster 1991) en el que se grafica la composición de los filones graníticos (SM-15 y SM-20) y de los leucosomas (m3 y m4). 


\subsection{DISCUSIÓN Y ANÁLISIS DE LOS RESULTADOS}

El progresivo incremento de $\mathrm{CO}_{2}$ en los fluidos graníticos acuosos involucrados en la formación de un skarn, que deriva de la reacción entre éstos y una roca de caja carbonática, y los gradientes en las actividades de los elementos químicos (por ejemplo la $a\left(\mathrm{Ca}^{+2}\right)$ ), suelen ser las principales causas del desarrollo de las típicas zonaciones minerales reconocidas en diversos skarns (Bowman 1998). En el skarn San Miguel, las interpretaciones geoquímicas indican que las paragénesis progradas reconocidas se desarrollaron tras la intrusión de un fundido granítico, que liberó fluidos acuosos ricos en $\mathrm{Si}, \mathrm{Fe}, \mathrm{Al} \mathrm{y} \mathrm{Mg}$. Estos reaccionaron con el $\mathrm{CaCO}_{3}$ formando wollastonita y liberando $\mathrm{CO}_{2}$ (primeras reacciones de descarbonatación), en la zona más cercana al contacto roca ígnea-roca carbonática. Esto es acorde a los análisis químicos de las zonas del skarn que indican un enriquecimiento en $\mathrm{CaO}$ a medida que el $\mathrm{SiO}_{2}$ es más bajo. La paulatina incorporación de $\mathrm{CO}_{2}$ en los fluidos, favoreció la pronta formación de vesubianita, constituyendo así la paragénesis wollastonitavesubianita (Bowman 1998). Las pérdidas y ganancias de elementos pueden identificarse en los gráficos de barras de los distintos balances de masa realizados sobre las zonas del skarn. De las zonas desarrolladas sobre el mármol (exoskarn), la zona wollastonita-vesubianita presenta una ganancias de masa generada fundamentalmente por la incorporación de grandes cantidades de $\mathrm{Al}_{2} \mathrm{O}_{3}, \mathrm{TiO}_{2}$ y $\mathrm{SiO}_{2}$, con poca movilidad de $\mathrm{CaO}, \mathrm{MnO}$ yMgO y también un incremento en casi todos los elementos de las Tierras Raras. Esto es esperable dado que esta zona se desarrolla en el contacto roca granítica-mármol donde el "flujo metasomático" es mayor. La circulación de soluciones a través de planos de debilidad preexistentes, produce la intensificación del flujo, facilitando la movilización de elementos como $\mathrm{Si}, \mathrm{Fe}$, Al y en menor proporción Mg (Meinert et al. 2005), como se observa en los diagramas tipo "Harker". Esta intensificación de la llegada de fluido favoreció la cristalización de granate grosularítico, contribuyendo con un mayor enriquecimiento en $\mathrm{CO}_{2}$, que inhibió las condiciones de formación de 
wollastonita (Bowman y Essene 1984). Por este motivo, la zona de exoskarn con wollastonita-vesubianita quedó restringida a unos pocos milímetros en los contactos con los filones graníticos. Este mayor incremento en $\mathrm{CO}_{2}$ y $\mathrm{Ca}^{2+}$ en los fluidos silíceos portadores de $\mathrm{Fe}$ y $\mathrm{Mg}$ (aunque en menor cantidad), propició la cristalización de clinopiroxeno diseminado en el exoskarn (Bowman y Essene 1984). Si bien el Mg es poco variable en las distintas zonas como se observa en los diagramas tipo "Harker", la muestra correspondiente a los afloramientos de skarn en la estancia Siempre Verde presenta un porcentaje mayor de este óxido. Ésta y la correspondiente a la de la estancia La Concordia registran además mayor enriquecimiento en $\mathrm{CaO}$ como producto de la asimilación del mármol, por lo que no se descarta la posibilidad de que la roca carbonática también haya contribuido con algo de Mg. En este sentido, es de señalar que los análisis químicos realizados sobre muestras del mármol (presentados en el capítulo 3 A) indican contenidos de óxido de $\mathrm{Mg}$ de $0,15 \%$. Por otra parte también, se formaron granate (grosularia82-99-andradita0-16-almandino0-8) y clinopiroxeno (diópsido52-67-hedenbergita33-47) en el endoskarn junto con plagioclasa anortítica (Villar Fabre y Quartino 1966). Esta plagioclasa se generó partir de un fundido granítico, que en su intrusión, se fue enriqueciendo paulatinamente en $\mathrm{Ca}^{2+}$, como resultado de la asimilación de parte del exoskarn, que determinó una diferenciación en su composición. La cristalización de plagioclasa, determinó en esta zona una concentración de ciertos elementos traza, sobre en todo en $\mathrm{Sr}$ y $\mathrm{Ba}$, que son retenidos por esta fase mineral. Además, se registró la formación de microclino a expensas de la plagioclasa, que podría indicar un proceso de feldespatización por incorporación de nuevo fundido proveniente de los cuerpos graníticos (Page et al. 1992), incorporando más $\mathrm{Na}_{2} \mathrm{O}$ y $\mathrm{K}_{2} \mathrm{O}$.

La asimilación del carbonato fue menor en la zona de clinopiroxenoplagioclasa cálcica del afloramiento principal del skarn, donde los procesos que predominaron fueron los metasomáticos. Por el contrario, y como se mencionó anteriormente, en los afloramientos de skarn de las estancias La Concordia y Siempre Verde (que poseen igual paragénesis que la zona 
anterior), los análisis químicos indican un alto enriquecimiento en $\mathrm{CaO}$ (mayor al 20\%). Esto mismo se observa claramente en el diagrama de clasificación de Le Maitre (2002) donde la roca de la muestra SM-26 corresponde a un granito o cuarzo diorita, mientras que las de LC-12 y SV516 poseen composiciones semejantes a gabros. Cabe destacar que en estos afloramientos el mármol no ha sido identificado (La Concordia) o se encuentra en menor proporción (estancia Siempre Verde). Esta mayor predominancia de los procesos de asimilación respecto de los metasomáticos podría estar relacionada con la ausencia de granate en ambos afloramientos.

A partir del balance de masa de elementos traza y Tierras Raras puede interpretarse que el mármol original se encuentra deprimido en estos elementos respecto del fundido granítico, ya que las zonas del exoskarn presentan sólo ganancias en estos elementos, mientras que las zonas del endoskarn evidencian pérdidas de estos elementos. Vale decir que los filones serian los que aportaron estos elementos mayoritariamente.

El análisis de los elementos traza y de Tierras Raras, indica similitudes en cuanto a sus patrones en las distintas zonas del skarn (aunque con variaciones esperables en un proceso metasomático) especialmente en los filones distales, como así también en los afloramientos de skarn en las estancias La Concordia y Siempre Verde. Además, la comparación de elementos traza y Tierras Raras de los filones y de los leucosomas de las migmatitas, analizadas en el capítulo 3.A, junto con evidencias de emplazamiento y disposición en el campo sugieren que la migmatización se encuentra asociada genéticamente a la formación del skarn San Miguel.

Las fases retrógadas se manifiestan como reemplazos de minerales de las paragénesis progradas del siguiente modo: diópsido por tremolita y clorita y granate por clinozoisita, desarrollando texturas de desequilibrio térmico como coronas y pseudomorfismo, y apatita, titanita y escasos cuarzo y calcita como minerales intersticiales o neoformados. La retrogradación también se observa en el desarrollo de vetillas compuestas por cuarzo (vetillas grises) y clinozoisita (vetillas rosadas) que cortan a las zonas 
primarias o prógradas y representan la circulación de los últimos fluidos silíceos y acuosos remanentes del sistema. La presencia de granate rico en grosularia, vesubianita y wollastonita en la etapa prógrada de la formación de un skarn y la de clinozoisita en la retrógrada es un indicador de que los fluidos involucrados fueron mayormente acuosos (Bowman 1998). De todas formas, el reemplazo de minerales por hidratación fue poco intenso indicando escasez de fluidos en el fundido durante la etapa retrograda. Esto podría deberse a que el sistema no funcionó como enteramente cerrado a la escala de observación, por lo que fue más fácil para los fluidos trasladarse lateralmente a lo largo de los contactos, que acceder al interior de los mármoles. Esto último, podría ser una de las causas de la casi inexistente mineralización metalífera en el skarn San Miguel, a excepción del hallazgo de pequeños cristales de ilmenita y esfalerita asociados a clinopiroxeno. Aun así no se descarta que en un futuro análisis de los fluidos mineralizantes se develen otras causas adicionales. No obstante, las composiciones químicas de granates y piroxenos (Meinert 1992) han permitido realizar una estimación de la afinidad que el skarn posee con aquellos skarns mineralizados explotados a nivel mundial. Según la composición de estos minerales indicadores, que son predominantemente grosularia y diópsidohedenbergita, el skarn San Miguel posee afinidad con los skarns de Sn-W y de Fe-Au. Los skarns de Fe-Au suelen asociarse a cuerpos de composición básica a intermedia (Einaudi et al. 1981, Ray et al. 1996), mientras que los skarns de $\mathrm{W}$ suelen asociarse a los de Sn que se forman a partir de cuerpos con signaturas tipo S, con baja ley y bajo contenido en sulfuros, y alta en óxidos como ilmenita (Newberry 1998). Esto sería consistente con la idea de que el skarn se formó a partir de la intrusión de los leucosomas generados por anatexis y también con la falta de mineralización, ya que los fluidos podrian haber sido estériles en su génesis.

Por último, y de acuerdo a las paragénesis minerales identificadas, a su modo de emplazamiento y a los procesos antes mencionados, el skarn San Miguel puede clasificarse como un skarn cálcico, proximal de 
infiltración con estadios de asimilación del protolito carbonático por parte de un fundido granítico.

\subsection{COMPARACIÓN CON EL SKARN PUNTA TOTA}

\subsubsection{Descripción del Skarn Punta tota}

A continuación se detallan las características más importantes del skarn Punta Tota, tomando como base el trabajo de Delpino (2000) correspondiente a su Tesis Doctoral.

El skarn Punta Tota aflora en la zona de la Sierra de Bachicha, partido de Balcarce (Fig. 4.40) y pertenece a la unidad conocida como Complejo Buenos Aires (Marchese y Di Paola 1975). Fue estudiado en detalle por Delpino (2000) y Delpino y Dristas (2008).

Dicho skarn se asocia a un mármol que se presenta como finas intercalaciones dentro de una secuencia conformada por anfibolitas, gneises, migmatitas, granulitas y pegmatitas. Este mármol fue clasificado como dolomítico con impurezas de $\mathrm{Si}, \mathrm{Fe}$ y $\mathrm{Al}$, de acuerdo a la asociación mineral forsterita + espinelo + dolomita + calcita. Esta asociación, fue identificada en las capas más internas del mármol y corresponde al pico metamórfico en facies anfibolita alta - facies granulita. Este pico fue estimado en una temperatura mínima de $710^{\circ} \mathrm{C}$ a una presión de $4,8 \mathrm{Kbars}$.

En los sectores más externos del mármol, que se encuentran en contacto con las anfibolitas, Delpino (2000) indica una asociación diópsido + calcita + dolomita \pm forsterita. Esta asociación, corresponde a la reacción ocurrida entre la roca de caja silícea (anfibolita) y las intercalaciones de capas carbonáticas durante la etapa prógrada del metamorfismo que condujo a la formación de un skarn de reacción. 


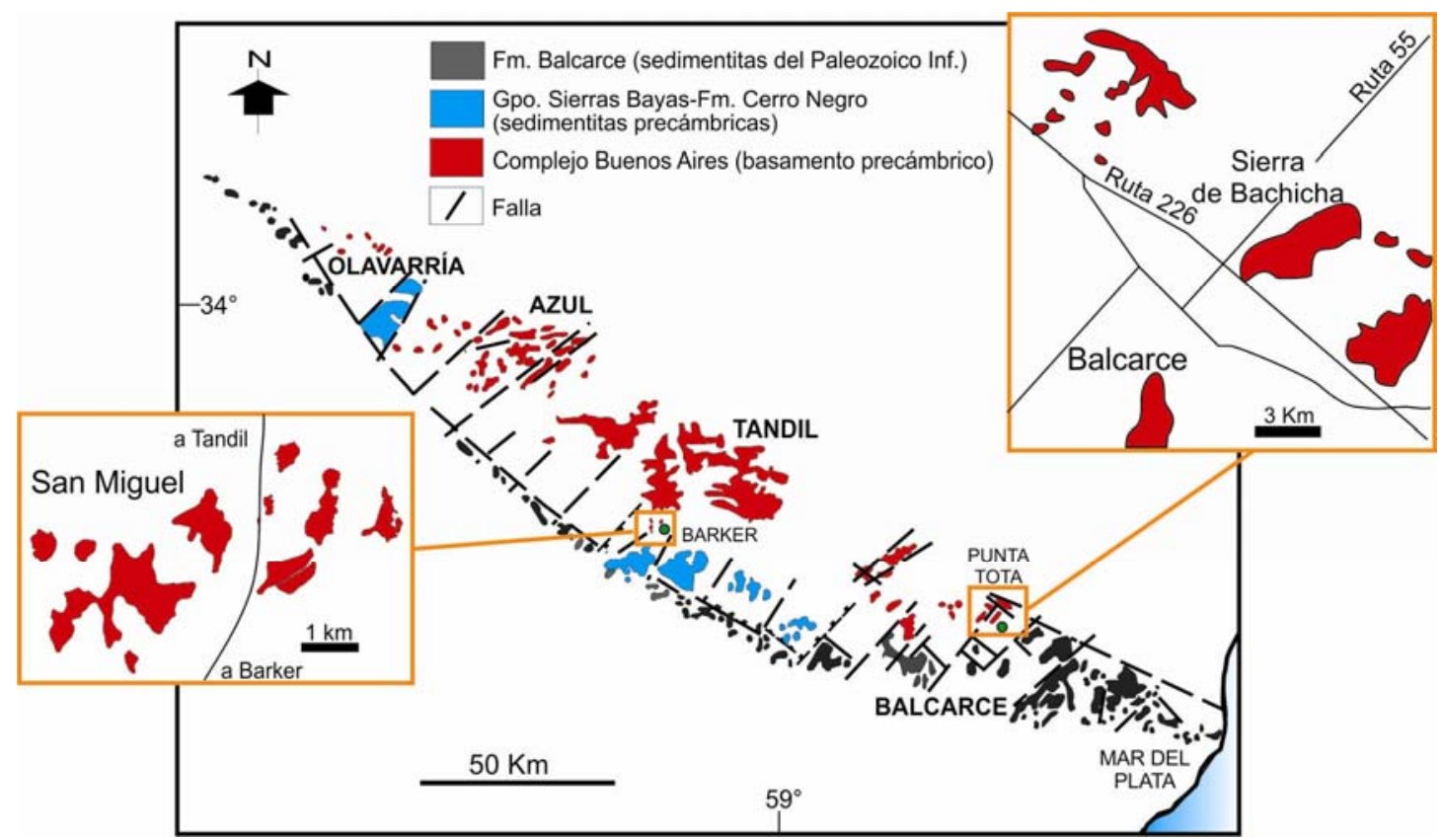

Figura 4.40: Ubicación de los skarns San Miguel y Punta Tota en el ámbito de las Sierras Septentrionales de la provincia de Buenos Aires, modificado de Delpino (2000).

La asociación antes mencionada se encuentra intensamente reemplazada por una mineralogía de menor temperatura generada por cambios en las condiciones ambientales y un aumento en la actividad del agua, constituida por: diópsido + tremolita + cuarzo + calcita +dolomita. Cabe destacar que tanto esta asociación como la anterior (prógrada) indican ambientes con alta $\mathrm{Xco}_{2}$. La cuantificación de P-T de esta asociación de menor temperatura fue estimada en $<623{ }^{\circ} \mathrm{C}$ a una $\mathrm{P}$ de $5 \mathrm{Kbars}$. La aparición de talco manifiesta condiciones de menor temperatura aún y finalmente la serpentinización (variedad antigorita), además de evidenciar este descenso de temperatura, indica un aumento importante en la actividad del agua y un descenso de la $\mathrm{Xco}_{2}$. Estas asociaciones manifiestan una etapa retrógrada del metamorfismo y la consecuente formación de un skarn de infiltración asociado.

También se identificó la asociación clinozoisita + grosularia + cuarzo+ anortita + calcita, como producto de la retrogradación ocurrida en la roca de 
caja constituyendo de esta forma un skarn adyacente. La aparición de grosularia y clinozoisita-zoisita, es también evidencia de la disminución en la $\mathrm{Xco}$. Finalmente, otras fases que cristalizaron en el mármol como flogopita y clorita, indican que además de agua, ingresó al sistema Al y K. La presencia de clinocloro (clorita magnésico - aluminica) es una de las consecuencias que produce típicamente la presencia de $\mathrm{Al}_{2} \mathrm{O}_{3}$ en dolomitas silíceas metamorfizadas (Winkler 1979). Si el potasio está también presente, se formará flogopita en lugar de clinocloro (Winkler 1979).

Los procesos de retrogradación y los skarns asociados se generaron como consecuencia del ingreso de grandes cantidades de agua al sistema. Siendo que toda la secuencia fue producto de un metamorfismo regional ocurrido, de acuerdo a edades radiométricas disponibles, entre los 2200$1700 \mathrm{Ma}$, se estima que grandes cantidades de fluidos fueron liberados como producto del emplazamiento y cristalización de los neosomas generados en las migmatitas infrayacentes.

\subsubsection{Comparación de los skarns Punta Tota y San Miguel}

Del análisis y comparación entre estos dos skarns presentes en el basamento de las Sierras Septentrionales surgen características en común y diferencias importantes que contribuyen a la definición de los ambientes geológicos en los cuales se formaron.

Ambos skarns se desarrollaron en ambientes netamente metamórficos y bajo el régimen de un metamorfismo regional ocurrido durante el Ciclo Transamazoniano (Stipanicic y Linares 1969). Durante este período (2.200$1.700 \mathrm{Ma}$ ) carbonatos de origen marino fueron transformados en mármoles, siendo predominantemente dolomítico el de Punta Tota (Delpino 2000 y Delpino y Dristas 2008) y calcítico el de San Miguel. El primero con una asociación mineral forsterita + espinelo + dolomita + calcita que indica un grado metamórfico en facies anfibolitas alta a granulitas y el segundo con una asociación diópsido + calcita \pm tremolita que corresponde a facies anfibolitas. En ambos casos el clinopiroxeno es de tipo diópsido. 
En el skarn Punta Tota se reconocieron dos tipos de skarns: uno de reacción, generado por reacción entre la roca de caja y el mármol (metamorfismo prógrado) y otro de infiltración, por la intrusión de grandes cantidades de fluidos durante la etapa retrógrada del metamorfismo. Mientras que en San Miguel se observa el desarrollo de un típico skarn de infiltración pero durante una etapa prógrada, cuyas asociaciones minerales son predominantes y desarrollan una zonación mineral debido a la evolución del proceso metasomático. En cambio, durante la etapa retrógrada sólo se produjo el reemplazo parcial de algunos minerales por otros de menor temperatura junto con el desarrollo de vetas de cuarzo y zoisita que cortan al skarn prógrado.

Cabe destacar que la evolución inicial del skarn Punta Tota se da en un ambiente con alta $\mathrm{Xco}_{2}$, evidenciada por las paragénesis minerales mencionadas y por los estudios de inclusiones fluidas. Esta condición restringe la formación de grosularia recién a las últimas etapas de formación del skarn (etapa retrógrada) donde sobre la base de la cristalización de talco y especialmente de serpentina se interpreta el aumento en la actividad de agua y el descenso de la $\mathrm{Xco}_{2}$. En cambio en el skarn San Miguel la identificación de la paragénesis wollastonita, grosularia, vesubianita a la que finalmente se suma la clinozoisita indica que los fluidos formadores del skarn fueron predominantemente acuosos. 


\subsection{BIBLIOGRAFÍA}

Bowman, J.R. 1998. Basic aspects and applications of phase equilibria in the analysis of me-tasomatic Ca-Mg-Al-Fe-Si Skarns. En Lentz, D.R. (ed.) Mineralized Intrusion Related Skarn Systems. Mineralogical Association of Canada. Short Course 26: 1-49, Québec.

Bowman, J.R. y Essene. E.J. 1984. Contact skarn formation at Elkhorn Montana. I. P-T-component activity conditions of early skarn formation. American Journal of Science 284: 597-650.

Burt, D.M. 1972. Mineralogy and Geochemistry of Ca-Fe-Si skarn deposits. P.H.D. thesis. Harvard University, 256 p.

Church, B.M. 1975. Quantitative classification and chemical composition of common volcanic rocks. Geological Society of America 86: 257-263.

de Barrio, R.E., Lanfranchini, M.E., Etcheverry, R.O., Martín-Izard, A., Tessone, M.O. y Paz, M. 2009. Geological and geochemical evolution of the San Miguel skarn, Tandilia Belt, Buenos Aires Province, Argentina, 24th International Applied Geochemistry Symposium, Fredericton, 281-284, Canada.

Delpino, S.H. 2000. Evolución metamórfica del sector nororiental del basamento de Tandilia, Argentina: metamorfismo en facies granulita y anatexis cortical. Tesis Doctoral, Universidad Nacional del Sur (inédita), 180 p., Bahía Blanca.

Delpino, S.H. y Dristas, J.A. 2008. Dolomitic marbles and associated calc-silicates, Tandilia belt, Argentina: Geothermobarometry, metamorphic evolution, and PT path. Journal of South American Earth Sciences, 23: 147-175.

Droop, G.T.R. 1987. A general equation for estimating $\mathrm{Fe}+3$ concentration in ferromagnesian silicates and oxides from microprobe analysis, using stoichiometric criteria. Mineralogical Magazine 51: 431-435.

Einaudi, M.T., Meinert, L.D. y Newberry, R.J. 1981. Skarn Deposits. En Skinner, B.J y Cloke, P.L. (eds.) Seventy-fifth Anniversary 1906-1980. Economic Geology 317-391.

Ettlinger, A.D. y Ray, G.E. 1989. Precious Matal-Enriched Skarn in British Columbia: An overview and Geological study. Ministry of Energy. Mines and Petroleum Resource 3, 128 p.

Gresens, R.L. 1967. Composition-volume relationships of metasomatism. Chemical Geology 2: 47-55.

Klein, C. y Hurlbut, C.S. 1999. Manual of Mineralogy (after Dana J.D., 21th edition), John Wiley \& Sons, 681p., New York. 
Knopf, A. 1942. Ore Deposition in the Pyrometasomatic Deposits. En Newhouse, W.H. (ed.) Ore Deposits as Related to Structural Features. Princeton University Press: 67-72.

Lajoinie, M.F., Lanfranchini, M.E., Etcheverry, R.O. y Recio, C. 2013a. Zonación mineral vinculada a procesos geoquímicos en el skarn San Miguel, Sierras Septentrionales de la provincia de Buenos Aires. Revista de la Asociación Geológica Argentina 70: 390-400.

Lajoinie, M.F., Canafoglia, M.E., Lanfranchini, M.E. y Etcheverry. 2013b. Estudio de turmalinas y su implicancia genética en cuerpos pegmatoideos del cerro Guacho, Sierras Septentrionales de la provincia de Buenos Aires. $11^{\circ}$ Congreso de Mineralogía y Metalogenia. San Juan.

Le Maitre, R.W. 2002. Igneous Rocks. A Classification and Glossary of Terms. Recommendations of the International Union of Geological Sciences Subcommission on the Systematics of Igneous Rocks, 2nd ed. Cambridge University Press 236 p. Cambridge, New York, Melbourne.

Lentz, D.R. 2005. Mass-balance analysis of mineralized skarn systems: Implications for replacement processes, carbonate mobility, and permeability evolution. Mineral Deposit Research: 421-424.

Marchese, H.G. y Di Paola, E. 1975. Miogeosinclinal Tandil. Revista de la Asociación Geológica Argentina 30: 161-179.

Martin, J.D. 2004. Using XPowder: A software package for powder X-ray diffraction analysis. www.xpowder.com D.L. GR 1001/04. ISBN 84 - 609-1497-6. España, 105 p.

Meinert, L.D. 1988. Gold in Skarn Deposits. A preliminary Overview. Proceedings of the Seventh Quadrennial IAGOD Symposium.

Meinert, L.D. 1989. Gold Skarn Deposits. Geology and Eploration Criteria. En The Geology of Gold Deposits. The perspective in 1988. Economic geology. Monograph 6: 537-552.

Meinert, L.D. 1992. Skarns and skarn deposits. Geoscience Canada 19.

Meinert, L.D., Dipple, G. y Nicolescu, S. 2005. Wold Sarn deposits. Economic Geology 100 th Aniversary Volume, 299-336.

Newberry, R.J. 1998. W and Sn-Skarn deposits: a 1998 Status Report. En Lentz, D. (ed.) Mineralized Intrusion-Related Skarn Systems. Mineralogical Association of Canada. Short Course 26: 289-335. 
Orris, G.D., Bliss, J.D., Hammarstrom, J.M. y Theodore, T.G. 1987. Description and Grades and Tonnages of Gold-bearing Skarns. United States Geological Survey. Open files reports 87, $273 \mathrm{p}$.

Page, S., Page, R.F.N. y Viruel de Ramirez, M. 1992. El basamanto de la Sierra de Fiambalá, provincia de Catamarca. Revista de la Asociación Geológica Argentina 47: 373-388.

Quartino, B. y Villar Fabre, J. 1967. Geología y petrologia del basamento de Tandil y Barker, provincia de Buenos Aires, a la luz del estudio de localidades críticas. Revista de la Asociación Geológica Argentina 22: 223-251.

Ray, G.E. y Webster, I.C.L. 1991. Geology and Mineral Occurrences of the Merry Widow Skarn Camp, Northern Vancouver Island, 92L/6: B.C. Ministry og Energy, Mines and Petroleum Resouces. Open Files 191-8.

Ray, G.E., Ettlinger, A.d. y Meinert, L.D. 1990. Gold Skarn: their Distribution, Characteristics and Problems in Classification. Geological Fieldwork, Ministry of Energy, Mines and Petroleum Resouces 1990-1: 237-246.

Ray, G.E., Dawson, G.L. y Webster, I.C.L. 1996. The stratigraphy of the Nicola Group in the Hedley district, British Columbia and the chemistry of its intrusions and Au skarns. Canadian Journal of Earth Science 33: 11051126.

Siivola, J. y Schmid, R. 2007. List of Mineral Abbreviations. Recommendations by the IUGS Subcommission on the Systematics of Metamorphic Rocks: Web version 01.02.07. www. bgs.ac.uk/scmr/home.html.

Stipanicic, P.N. y Linares, E. 1969. Edades radimétricas determinadas para la República Argentina y su significado geológico. Boletín de la Academia Nacional de Ciencias Córdoba 157, 1.

Sun, S.S. y McDonough, W.F. 1989. Chemical and isotopic systematics of oceanic basalts: implications for mantle composition and processes. En Saunders, A.D. y Norry, M.J. (eds.) Magmatism in the ocean basins. Geological Society of London 42: 313-345.

Taylor, S.R. y McLennan, S.M. 1981. The Composition and Evolution of the Continental Crust: Rare-Earth Element Evidence from Sedimentary Rocks. Philosophical Transactions of the Royal Society of London 301: 381-399.

Theodore, T.G., Hammarstrom, J.M. y Bliss, J.D. 1991. Gold Bearing Skarn. Unite States Geological Survey. Bulletin 1930, 61 p. 
Villar Fabre, J. y Quartino, B. 1966. Exomorphic and endomorphic effects from marble-contaminated granite contacts in the "San Miguel" quarry, Barker, Province of Buenos Aires, Argentina. American Journal of Science 264: 310320.

Winkler, H.G.F., 1979. Petrogénesis de Rocas Metamórficas. H. Blume Ediciones, 346 p. Madrid.

Zharicov, V.A. 1970. Skarns. International Geological Review 12: 541-559, 619-647, 760-775. 


\section{CAPÍTULO 5}

\section{NATURALEZA DE LOS FLUIDOS}

\section{FORMADORES DEL SKARN: COMPOSICIÓN}

\section{Y CONDICIONES P-T}




\subsection{INTRODUCCIÓN}

En el presente capítulo se exponen los resultados de los estudios microtermométricos de inclusiones fluidas (IF), de isótopos estables (C y O) y geotermométricos (granate-clinopiroxeno) realizados sobre silicatos y carbonatos del skarn San Miguel. Además, se presenta el estudio de la especie vesubianita a través de varias técnicas analíticas. La finalidad de todas estas determinaciones es definir los parámetros físico-químicos de los fluidos involucrados en la formación del skarn.

\subsection{CARACTERIZACIÓN Y ANÁLISIS DE LAS INCLUSIONES FLUIDAS}

El estudio de inclusiones fluidas (IF) en minerales específicos de cuerpos tipo skarn son particularmente útiles para registrar la variación en la evolución espacial y temporal de los fluidos formadores de los mismos, siendo además una herramienta de medición directa de los cambios de temperatura y salinidad entre eventos progradantes y retrógrados.

\subsubsection{Petrografia de inclusiones fluidas}

La petrografia de las IF, se realizó en diferentes secciones de minerales que corresponden al exo y endoskarn. Para su clasificación genética se utilizó la nomenclatura de Roedder (1984), que las separa en primarias (P), secundarias (S) y pseudosecundarias (PS) y se empleó el criterio de Nash (1976) para establecer el número de fases reconocidas en cada una de ellas: monofásicas, bifásicas, trifásicas y polifásicas.

En el exoskarn se realizó el estudio de cristales de vesubianita y granate, los cuales presentan numerosas IF primarias, aunque muchas de ellas son de tamaños reducidos $(<10 \mu \mathrm{m})$ y no pudieron ser analizadas. En el endoskarn se efectuaron análisis sobre cristales de granate, clinopiroxeno y cuarzo intersticial. En este último se estudiaron IF primarias y secundarias, aprovechando el amplio rango de estabilidad del cuarzo, el cual podría registrar eventos tempranos y tardios sin alterarse. Todas las inclusiones 
utilizadas registran tamaños mayores a $10 \mu \mathrm{m}$ y contienen dos o más fases. En términos generales, se identificaron seis tipos de IF primarias, que fueron denominadas teniendo en cuenta su morfología y número de fases (Fig. 5.1):

i- irregulares-bifásicas

ii- irregulares-trifásicas

iii- ovoides-bifásicas

iv- regulares-bifásicas

v- tabulares-bifásicas

vi- regulares-polifásicas

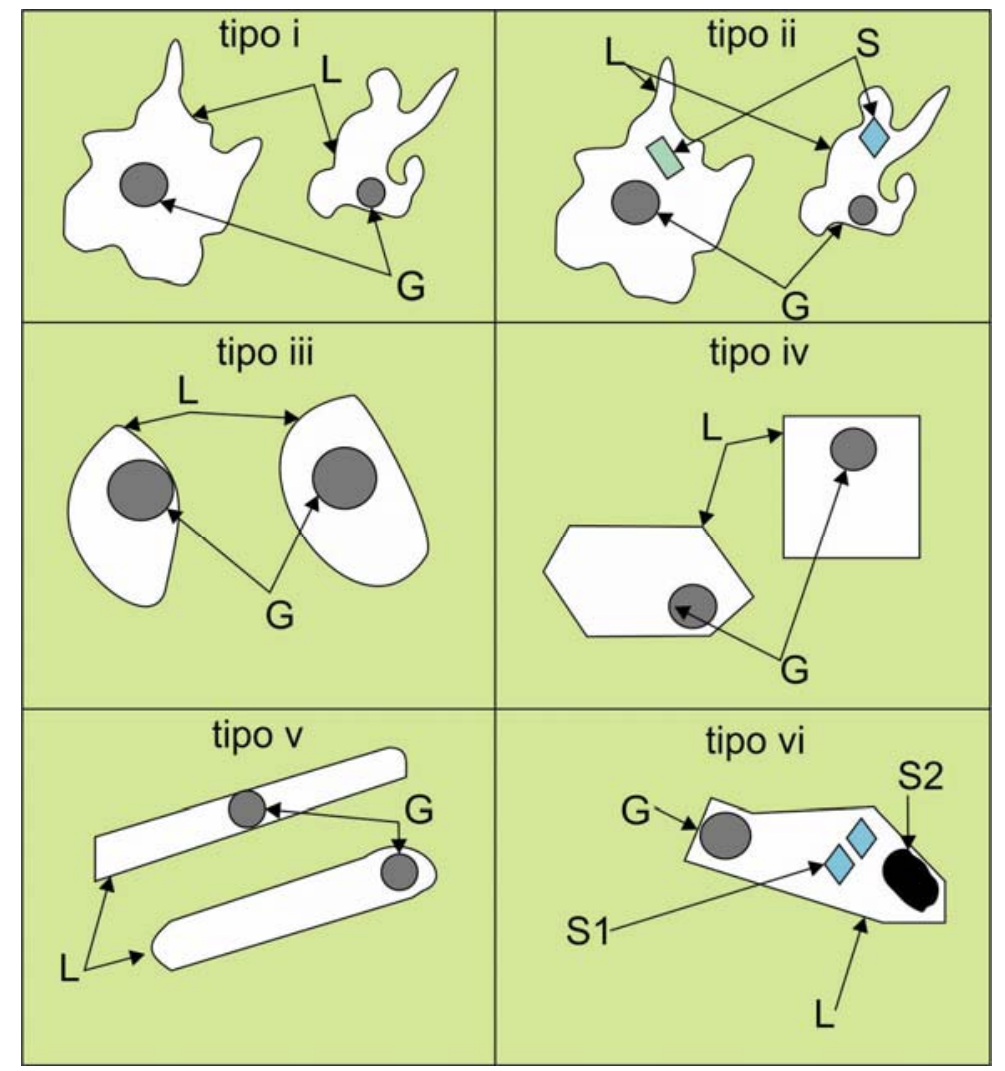

Figura 5.1: Clasificación general de las IF, basada en los criterios de Nash (1976) Roedder (1984) y en su morfología. Tipo i: irregulares bifásicas, tipo ii: irregulares trifásicas, tipo iii: ovoides bifásicas, tipo iv: regulares bifásicas, tipo v: tabulares bifásicas y tipo vi: regulares polifásicas. 
IF en cristales de vesubianita del exoskarn

Los cristales de vesubianita seleccionados poseen numerosas inclusiones fluidas que en su mayoría parecen estar asociadas a modificaciones en las condiciones químicas de los fluidos (Fig. 5.2a) y a pequeñas fracturas (Fig. 5.2b) generadas durante y con posterioridad al crecimiento del cristal. Estas últimas fueron clasificadas como IF pseudosecundarias y desarrollan trenes de inclusiones (Fig. 2b); en su mayoría presentan tamaños menores a los $10 \mu \mathrm{m}$.

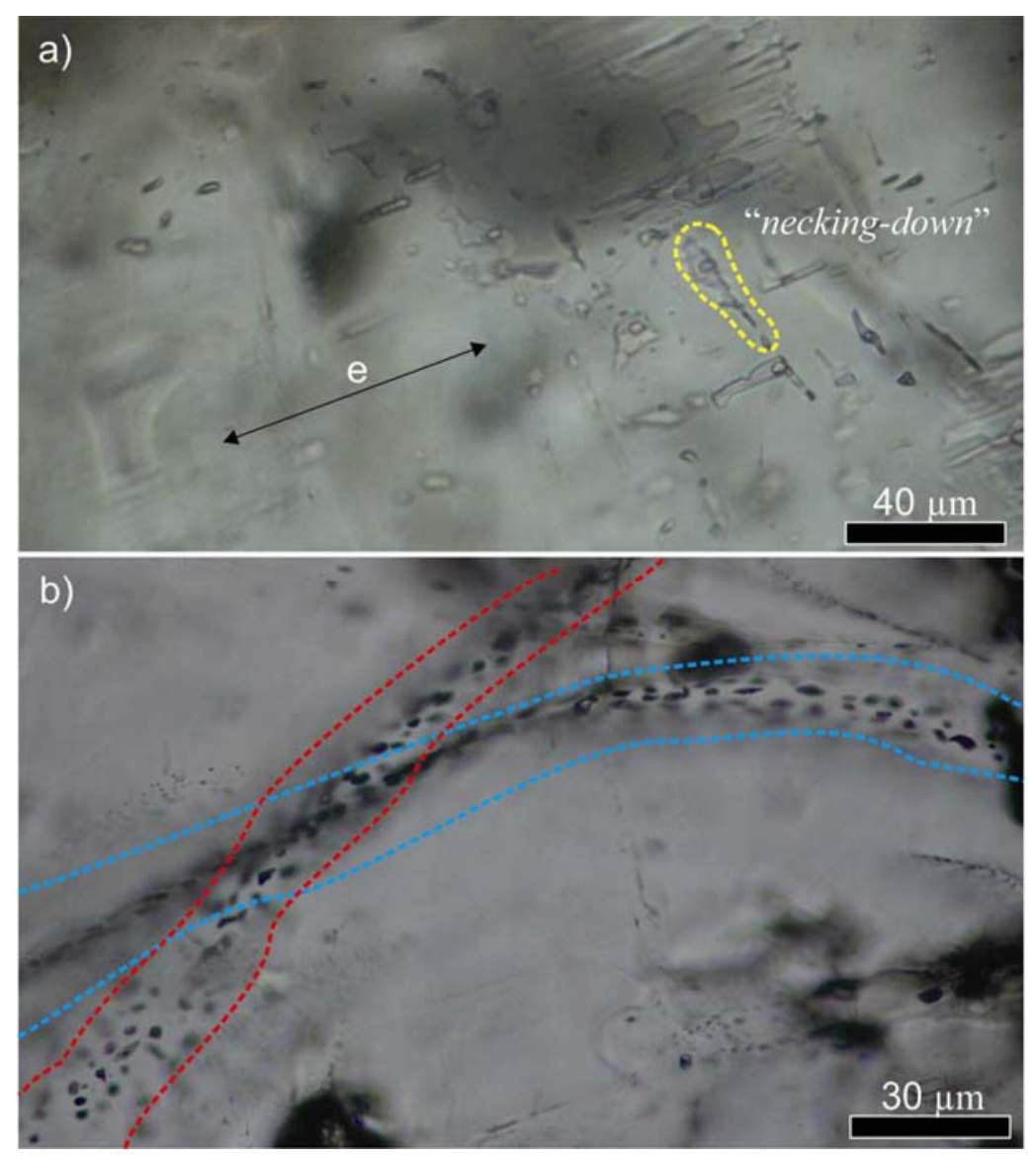

Figura 5.2: a) IF primarias generadas por cambios químicos en el sistema, con crecimiento paralelo a la elongación (e) del cristal (Goldstein y Reynolds 1994). En amarillo se resalta una inclusión estrangulada o mecanismo de "necking down". b) En rojo y en celeste se engloban dos trenes de inclusiones fluidas, secundarias, asociadas a pequeñas fracturas en el cristal.

Las tipo i, son las menos abundantes y su contenido es L (líquido) + G 
(gas), donde la fase líquida es la dominante (Fig. 5.3a). Éstas se encuentran distribuidas por todo el cristal en forma aleatoria. Sus tamaños van desde pocos $\mu \mathrm{m}$ a 15-30 $\mu \mathrm{m}$. Algunas burbujas son bien transparentes, mientras que otras son de color castaño oscuro lo que podría indicar un cambio en la composición química de la fase gaseosa, por eso se utilizó la nomenclatura G que incluye $\mathrm{H}_{2} \mathrm{O}$ y $\mathrm{CO}_{2}$ en lugar de $\mathrm{V}$ (Fig. 5.3b).

Las tipo ii, también son poco abundantes pero poseen tamaños mayores, cercanos a los $30 \mu \mathrm{m}$. Están constituidas por L+G+S (sólido), Fig. $5.3 c$.

Las iii (Fig. 5.3d y e) son las más abundantes junto con las tipo iv (Fig. 5.3e) y tipo $\mathrm{v}$ (Fig. 5.3f). Son todas bifásicas $\mathrm{L}+\mathrm{G}$ y con tamaños comprendidos entre 10 y $20 \mu \mathrm{m}$. En la mayoría, la fase líquida es la predominante, aunque en algunas la relación es 50\% L - 50\% G.

Las IF tipo vi son aparentemente escasas, sólo se ha identificado una con un tamaño de $50 \mu \mathrm{m}$. Dada su dimensión, en su interior se reconocieron dos cristales, ambos de hábito romboidal y dos cristales más pequeños redondeados que corresponderían a uno o dos minerales opacos (Fig. 5.3g). En otra IF tipo vi se reconocieron cristales traslúcidos, uno equidimensional y otro más elongado que no pudieron ser identificados (Fig. 5.3h).

Las IF tipo v y vi se disponen paralelas a la elongación de los cristales de vesubianita, asociadas al crecimiento rápido del cristal. Muchas de estas IF, así como algunas de las inclusiones tipo i presentan múltiples estrangulamientos o "neking-down" (Fig. 5.2a), en las que se modifica la relación inicial líquido/gas, motivo por el cual quedan descartadas para realizar cualquier tipo de determinación microtermométrica. 


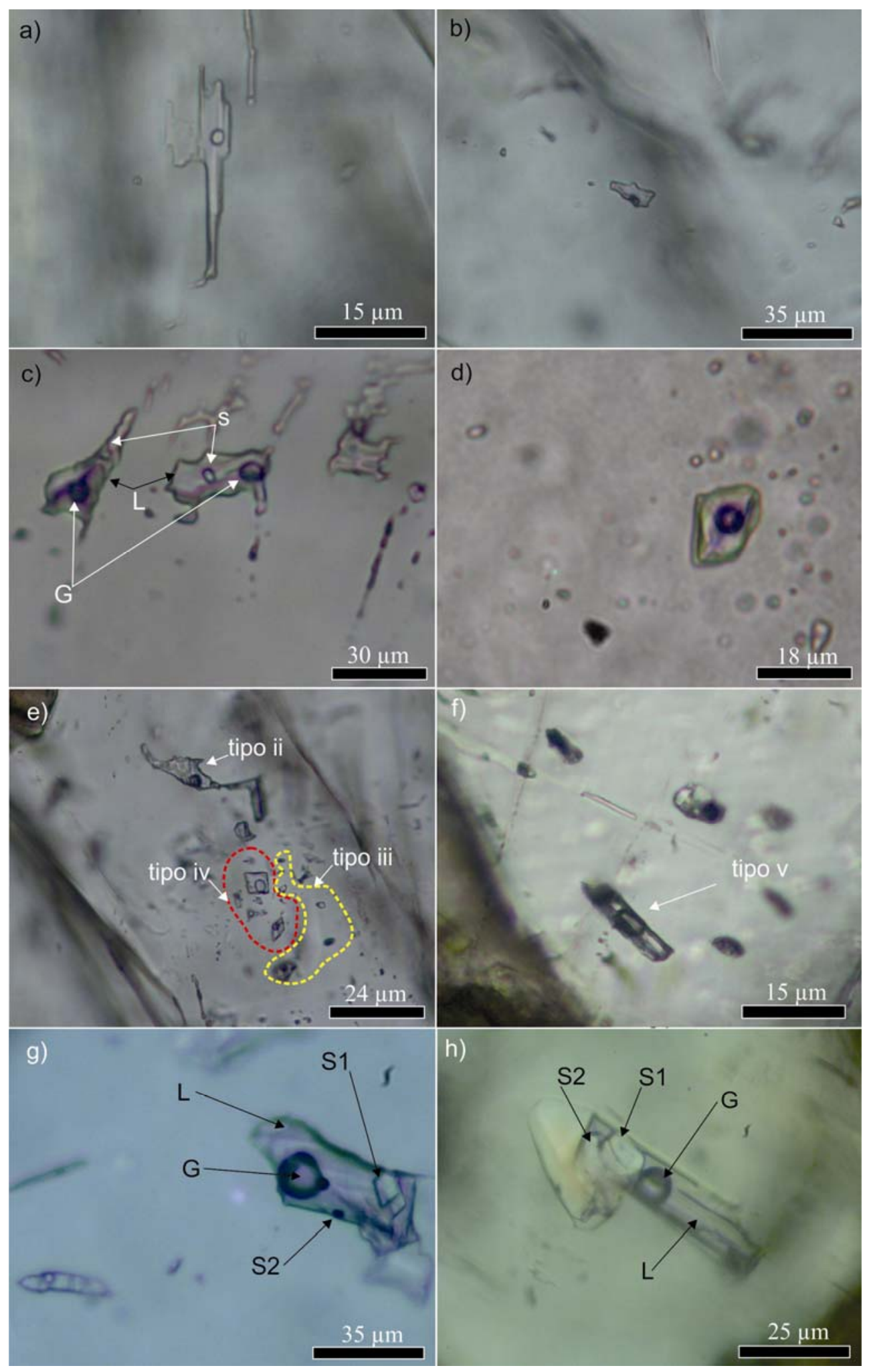

Figura 5.3: IF en cristales de vesubianita del exoskarn. a y b) IF tipo i, con burbujas 
trasparentes y castañas, respectivamente. c) IF tipo ii, con burbuja castaña (G) y pequeño cristal prismático corto y verdoso (S). d) IF tipo iii con morfología ovoide. e) Grupos de IF tipo ii, iii (dentro del campo amarillo) y iv (dentro del campo rojo). f) IF tipo $\mathrm{v}$ tabular bifásica. g y h) IF tipo vi. En g) S1 corresponde a dos cristales rómbicos y S2 a opacos, en h) S1 cristal equidimensional transparente y S2 cristal elongado también transparente.

\section{IF en cristales de granate del exoskarn}

Los cristales de granate del exoskarn presentan numerosos trenes de inclusiones fluidas que estarian asociados a microfracturaciones generadas con posterioridad al crecimiento del cristal. Todas las IF encontradas son secundarias y con tamaños menores a los $10 \mu \mathrm{m}$ (Fig. 5.4a y b). No son aptas para estudios microtermométricos debido a su tamaño y tono oscuro.

\section{IF en cristales de granate del endoskarn}

Al igual que los cristales de granate del exoskarn, los del endoskarn presentan numerosos grupos de IF de tipo secundarias. Las pocas IF primarias reconocidas tienen tamaños $>10 \mu \mathrm{m}$. Las mismas son IF de tipo i (Fig. 5.5a), iii (Fig. 5.5b) y iv (Fig. 5.5c). Algunas IF se encuentran abiertas y con estrangulamientos, por lo que también se descartaron para realizar mediciones (Fig. 5.5d). Se identificaron escasas IF tipo v, con burbujas de color castaño oscuro que podrían contener $\mathrm{CO}_{2}$ (Fig. 5.5e). Asimismo se reconocieron IF trifásicas de pequeño tamaño (Fig.5.5e y f), L+G+S (sólido), las fases sólidas corresponden a un mineral opaco (Fig. 5.5f) y a un cristal transparente de tonalidad verdosa (Fig. 5.5e).

\section{IF en cristales de clinopiroxeno del endoskarn}

Se encontraron escasas IF aptas para microtermometría en los cristales de diópsido dado que la coloración verde y tonalidad oscura de este mineral, sumado a las numerosas inclusiones sólidas presentes, dificultan la tarea de reconocimiento y clasificación. Estas IF son del tipo i (Fig. 5.6a y b), tipo iv $(\mathrm{L}+\mathrm{G}$ ) con tamaños que rondan los 5 a $13 \mu \mathrm{m}$ (Fig. 5.6c) y tipo vi (S + $\mathrm{G}+\mathrm{L})$ (Fig. 5.6d) con gran abundancia de las IF más pequeñas $(<10 \mu \mathrm{m})$, 
que debido a su tamaño no pueden ser utilizadas para realizar mediciones microtermométricas.

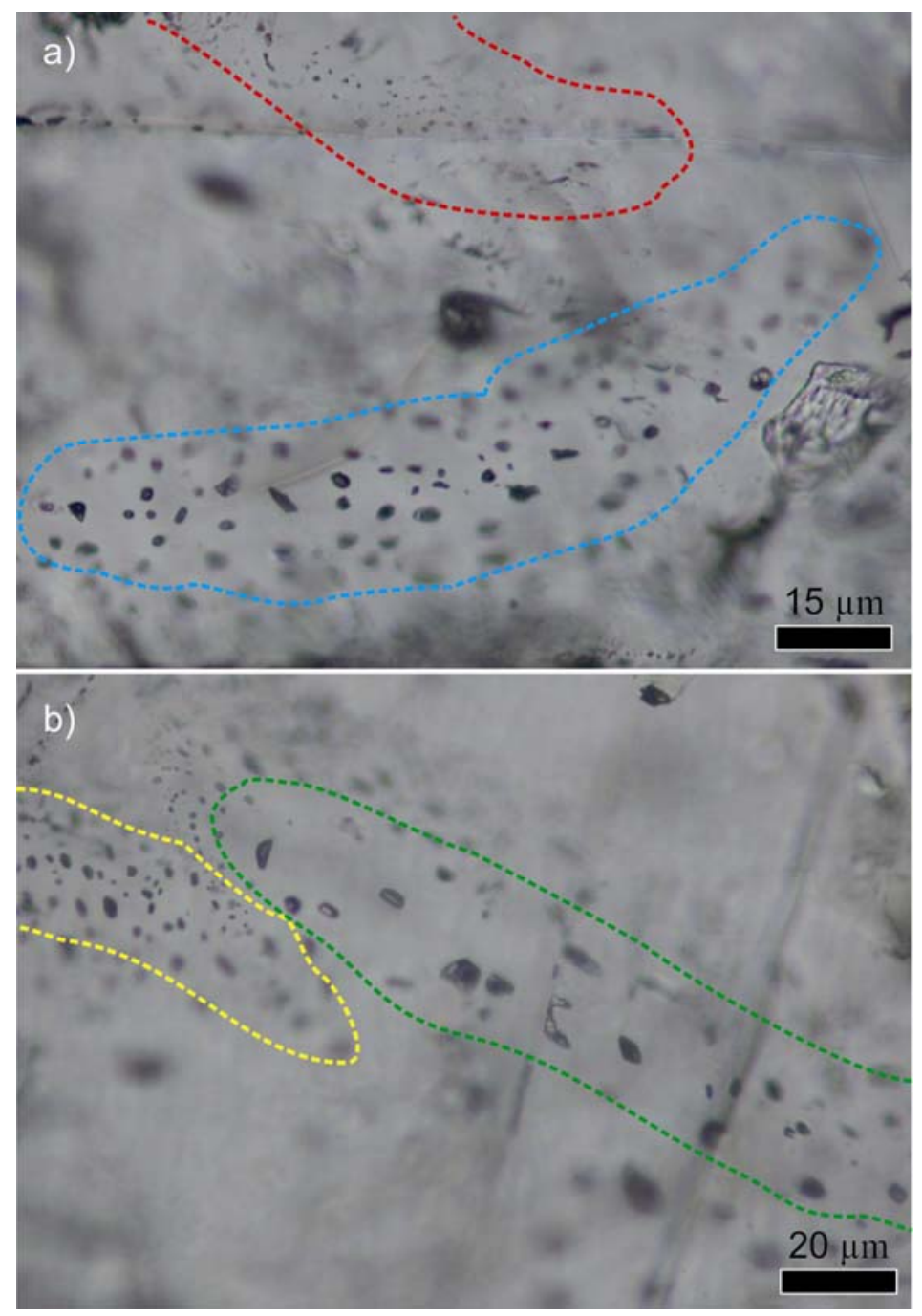

Figura 5.4: a y b) Trenes de inclusiones fluidas en granates del exoskarn (indicados en colores). Como se ve en las imágenes las inclusiones son menores a $10 \mu \mathrm{m}$. Su tono oscuro debido a la profundidad de la inclusión fluida, sumado a su pequeño tamaño, hace que estas IF no sean aptas para microtermometría. 

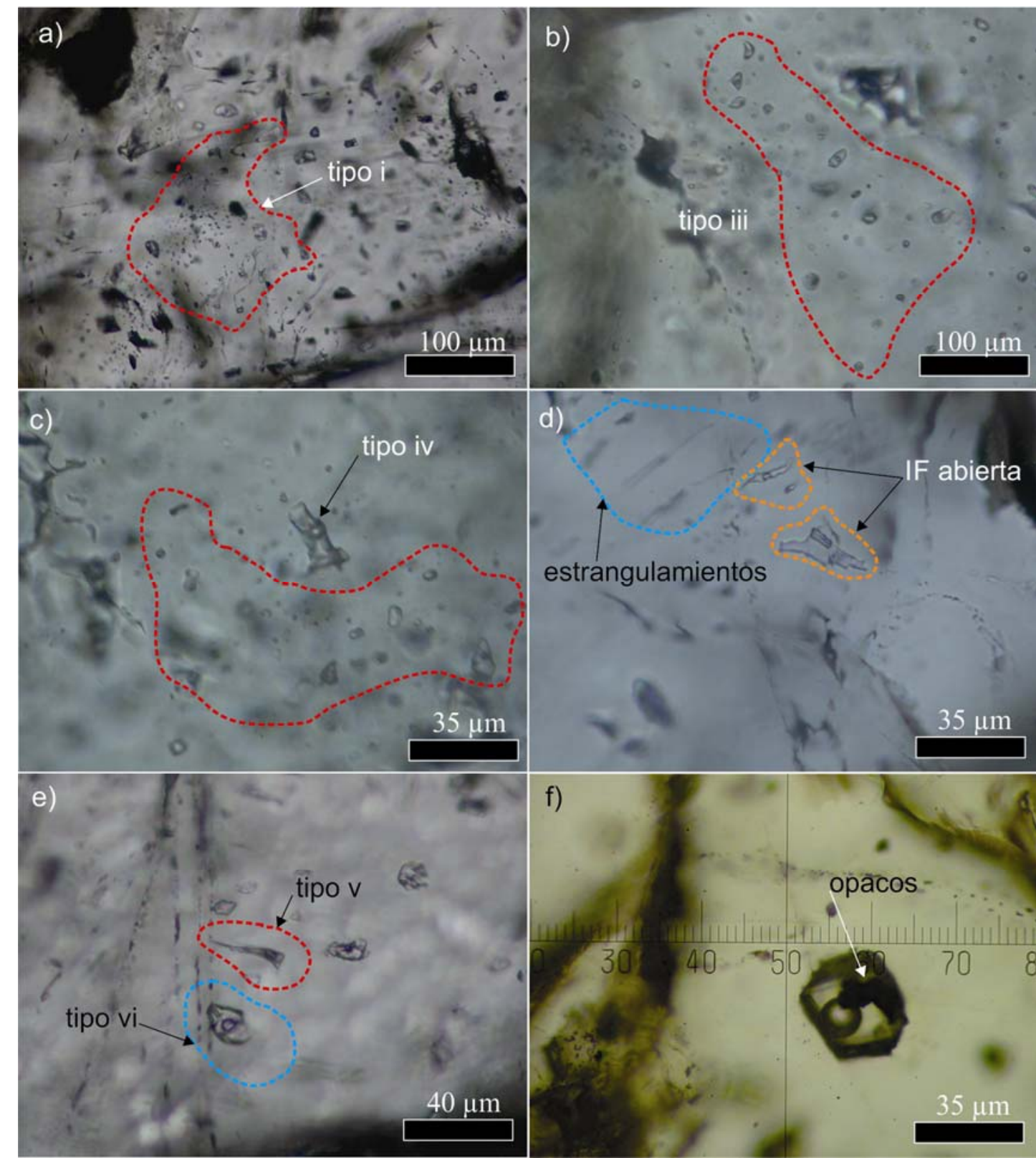

Figura 5.5: Inclusiones fluidas en cristales de granate del endoskarn. a) Grupo de IF tipo i. b) IF tipo iii u ovoides bifásicas. c) En rojo se destaca un campo de IF tipo iii y fuera de este campo inclusión tipo iv de mayor tamaño. d) En el campo celeste: un grupo de inclusiones fluidas que presentan estrangulamiento y en los campos naranjas: dos inclusiones que poseen un extremo abierto. e) En el campo rojo: IF tipo v o tabular y en el celeste IF: regular trifásica (tipo vi). f) Inclusión fluida de importante tamaño tipo vi, los sólidos son minerales opacos. 

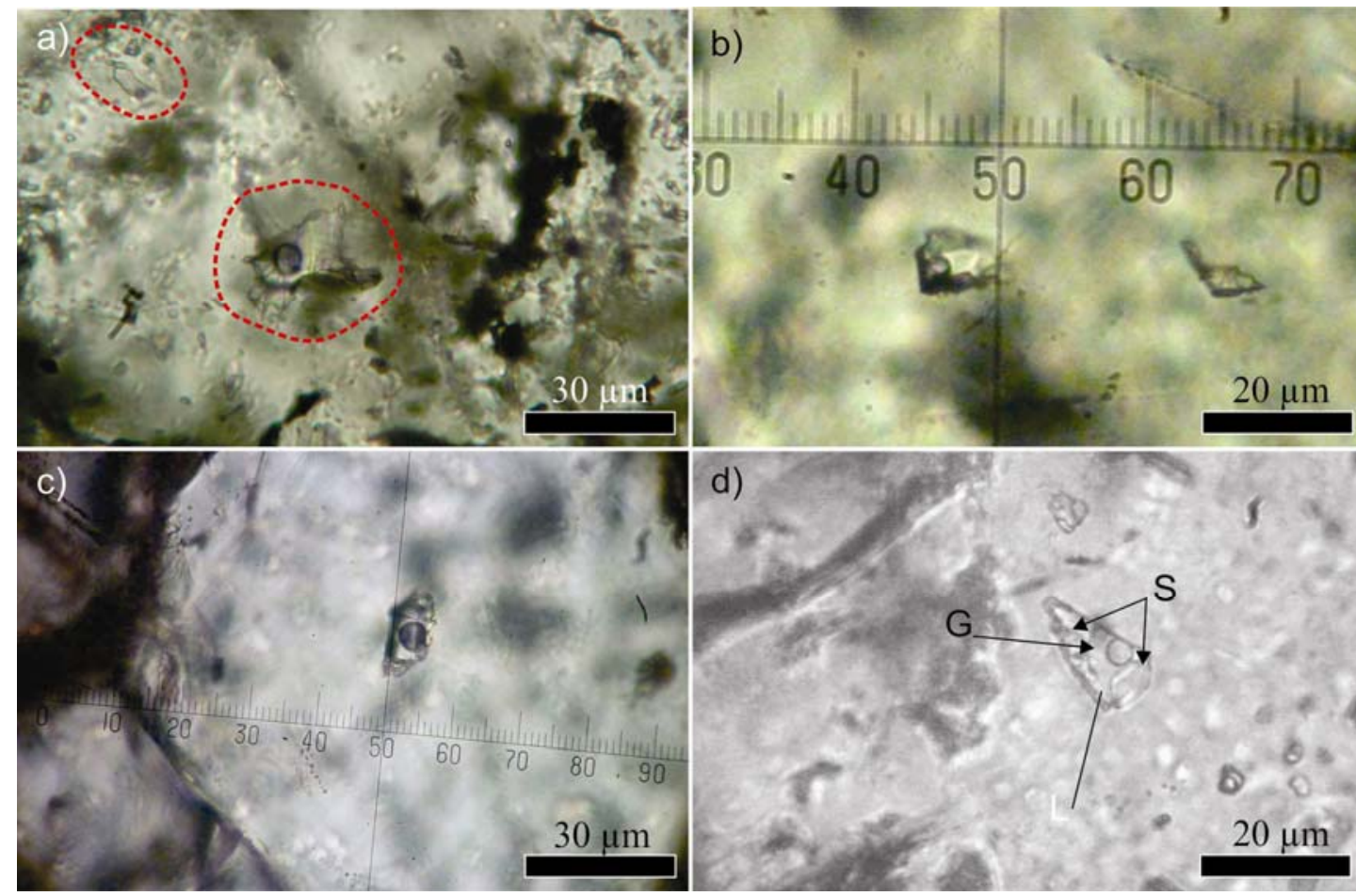

Figura 5.6: Inclusiones fluidas en cristales de clinopiroxeno del endoskarn. a y b) IF irregulares bifásicas (tipo i). Nótese en a) la gran concentración de opacos del lado derecho de la imagen. c) Regular bifásica (tipo iv). d) Regular trifásica (tipo vi).

IF en cristales de cuarzo intersticial del endoskarn

Los cristales de cuarzo intersticial presentan escasas IF primarias y se ubican en aislados sectores de los cristales. En su mayoría se trata de inclusiones de tipo iii y algunas menos abundantes de tipo iv, todas con tamaños que rondan los 10-12 $\mu$ m (Fig. 5.7a). También se han identificado trenes de inclusiones de tipo secundarias, cercanas a fracturas que en algunos sectores se superponen a las IF primarias dificultando su interpretación genética (Fig. 5.7b).

\subsubsection{Microtermometria de inclusiones fluidas}

\subsubsection{Metodología}

Todas las IFs de las muestras fueron inicialmente enfriadas a $-120{ }^{\circ} \mathrm{C}$, donde se determinó Tc o temperatura de congelamiento total de la inclusión 
fluida. Luego, fueron lentamente calentadas para poder medir las temperaturas del punto eutéctico (Te) o de la primera fusión y las temperaturas de fusión final (Tf) de acuerdo a Roedder (1984) y Shepherd et al. (1985). Estas rutinas de enfriamiento permitieron corroborar la ausencia de $\mathrm{CO}_{2}$ (Velasco 2004) en el sistema. Luego de la determinación de Tf, se continuó con el calentamiento hasta conseguir la temperatura de homogeneización líquido-vapor (Th). En las IF de tipo vi, que presentaban probables cristales hijos, se continuó con el calentamiento para determinar la temperatura de fusión de los mismos. Ninguno de los cristales alcanzó la fusión ya que las IF decrepitaron antes.

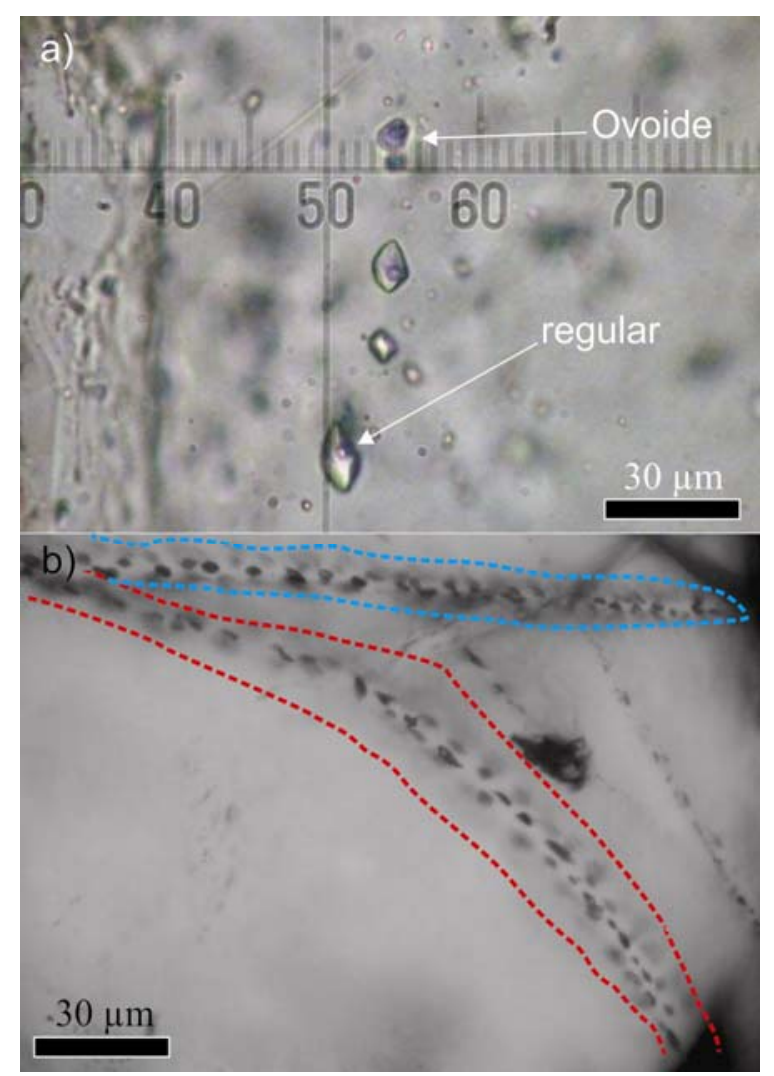

Figura 5.7: Inclusiones fluidas en cristales de cuarzo del endoskarn. a) Tipos de IF más comunes: ovoide y regular, ambas bifásicas L + G. b) Trenes de IF secundarias resaltadas en los campos rojo y celeste. 


\subsubsection{Resultados}

Los resultados obtenidos se presentan en el Cuadro 5.1 y en los diagramas de Temperatura de homogeneización vs Frecuencia y salinidad (\% peso eq. $\mathrm{NaCl}$ ) vs Frecuencia (Figs. 5.8 y 5.9, respectivamente). Dicha salinidad se obtuvo a partir de las Tf que permiten ingresar a la tabla de salinidades de Bodnar (1992).

En los cristales de vesubianita se efectuaron un total de 33 mediciones en IF primarias con tamaños de 17 a $25 \mu \mathrm{m}$ y 7 pseudosecundarias. La mayoría de las IF bifásicas $(L+G)$ son irregulares o regulares prismáticas y poseen un grado de llenado $\left(\mathrm{F}=\mathrm{V}_{\text {liq }} / \mathrm{V}_{\text {total }}\right)$ entre 0,70 y 0,90 . Las pocas mediciones sobre IF trifásicas $(\mathrm{L}+\mathrm{G}+\mathrm{S})$ realizadas, no arrojaron resultados de temperaturas de disolución de los cristales ya que decrepitaron antes. La Th máxima se determinó en $335^{\circ} \mathrm{C}$ y la mayoría de las mediciones quedó comprendida entre 240 y $270{ }^{\circ} \mathrm{C}$ (Fig. 5.8b). La Te determinada varia entre $-21,5$ y $-22,4{ }^{\circ} \mathrm{C}$, indicando un sistema $\mathrm{H}_{2} \mathrm{O}-\mathrm{NaCl} / \mathrm{H}_{2} \mathrm{O}-\mathrm{NaCl}-\mathrm{KCl}$ (Bodnar 1992). Las temperaturas de fusión del hielo (Tf) indican un sistema de baja salinidad entre 2,7 y 3,4 \% en peso eq. $\mathrm{NaCl}$ (Fig. 5.9b). En la Fig. 5.10 se observa una rutina de enfriamiento y calentamiento de una inclusión fluida primaria tipo iv, hospedada en un cristal de vesubianita.

Asimismo se realizaron un total de 30 mediciones en cristales de granate del endoskarn en IF primarias bifásicas (en su mayoría regulares con una relación de fases igual a 0,95; 0,90 y 0,70) y algunas trifásicas todas con tamaños entre 10 y $17 \mu \mathrm{m}$. Las temperaturas de homogeneización (Th) máximas rondan los $358,5{ }^{\circ} \mathrm{C}$, quedando la mayor cantidad de mediciones comprendidas entre los intervalos $248-276$ y $304-332{ }^{\circ} \mathrm{C}$ (Fig. 5.8a) y en todos los casos homogeneizaron a líquido. En pocas IF se midieron las temperaturas del eutéctico (Te), entre $-22,8$ y $-24,2{ }^{\circ} \mathrm{C}$, correspondientes a un sistema "salino-acuoso" $\mathrm{NaCl}-\mathrm{KCl}-\mathrm{H}_{2} \mathrm{O}$ (Shepherd et al. 1985). La medición de Tf indica una salinidad muy baja comprendida entre 2,8 y 3,6 \% en peso eq. $\mathrm{NaCl}$ (Fig. 5.9a). Las IF trifásicas con presencia de sólidos opacos presentan valores similares a los anteriores y decrepitaron antes de disolverse los sólidos. 

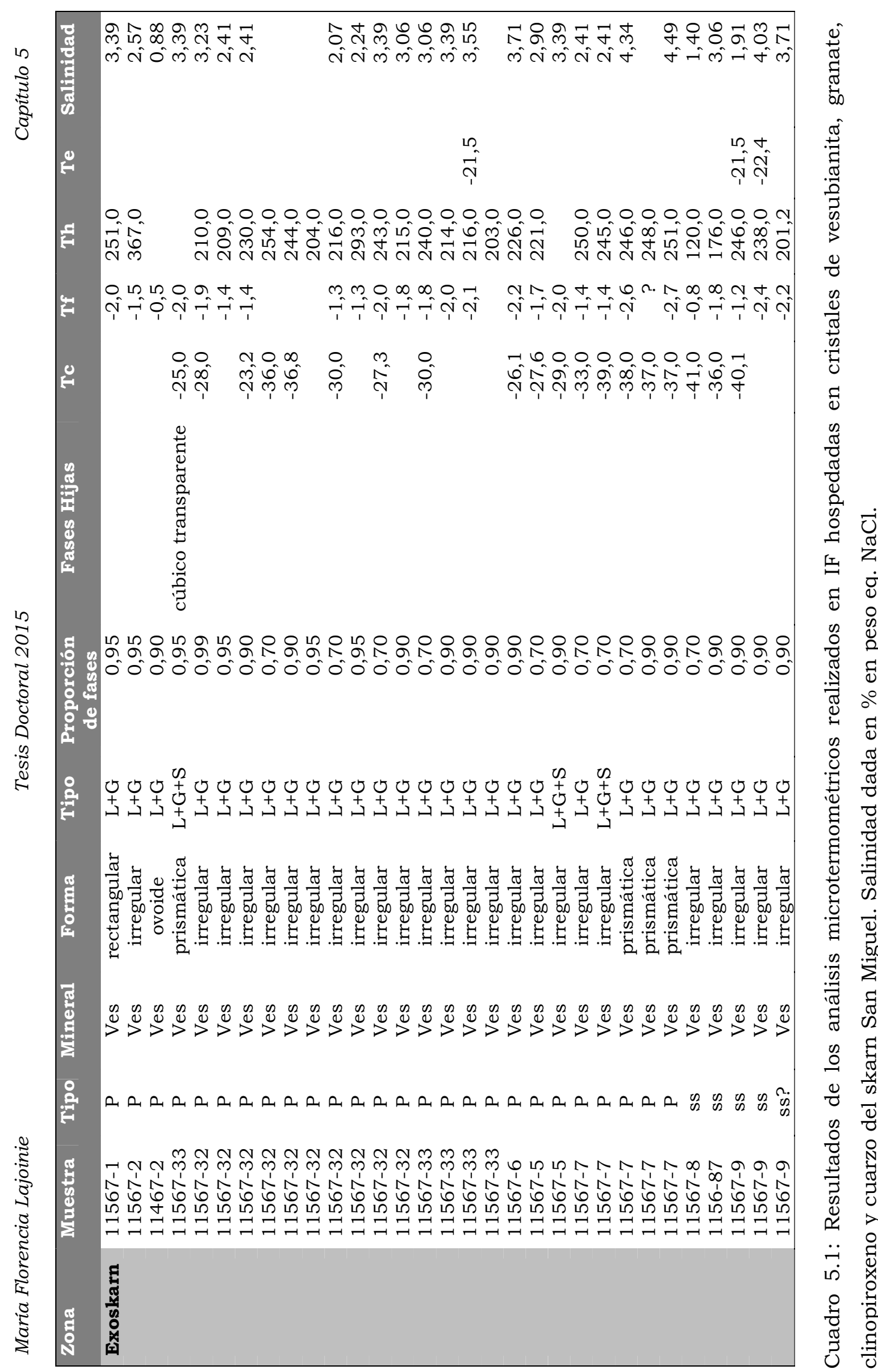

$\stackrel{\infty}{\stackrel{N}{N}}$ 


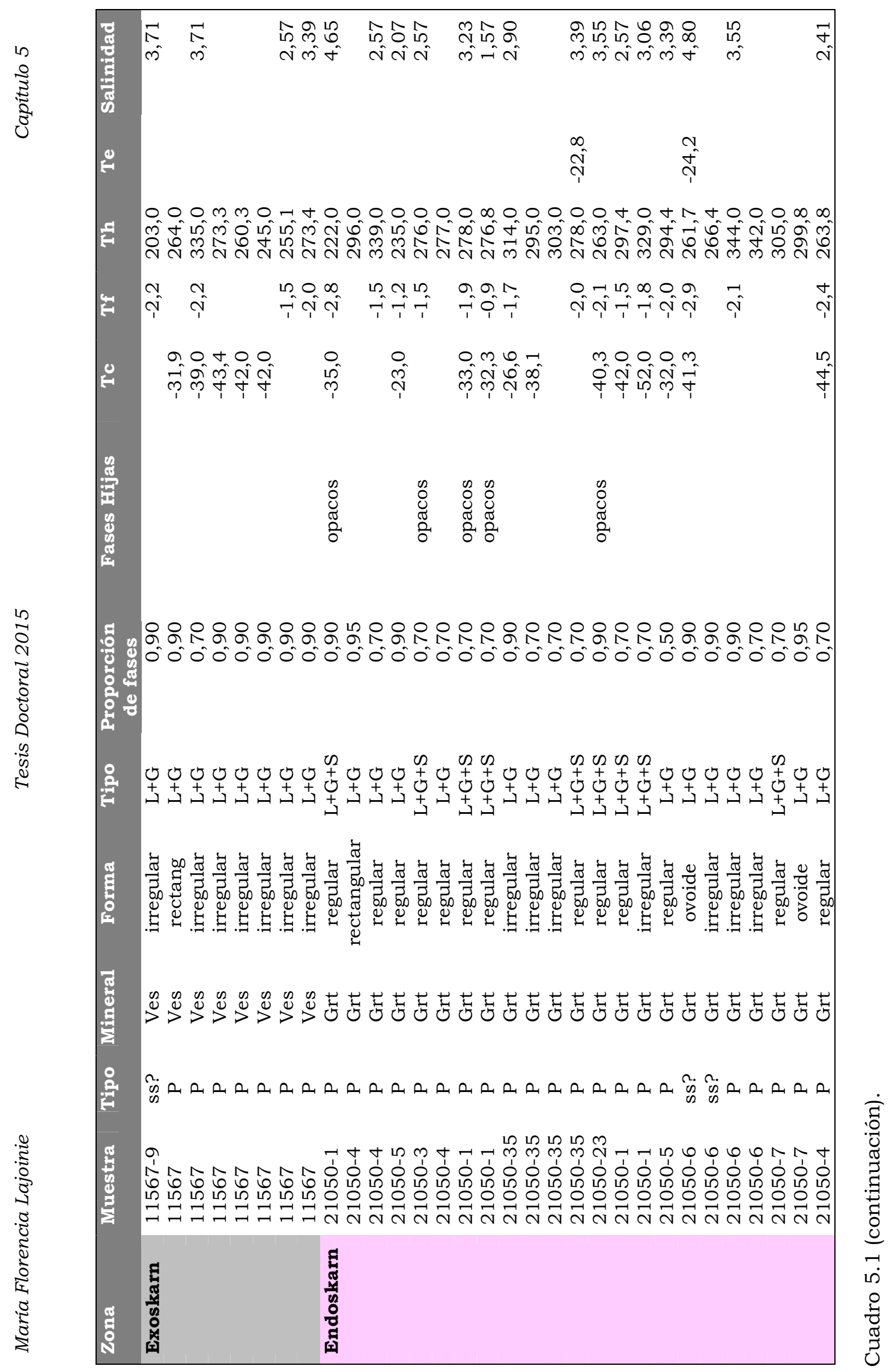


फ की

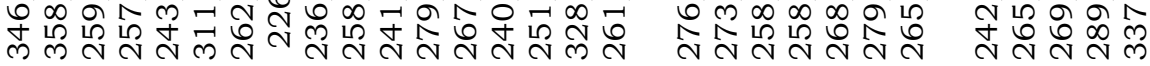

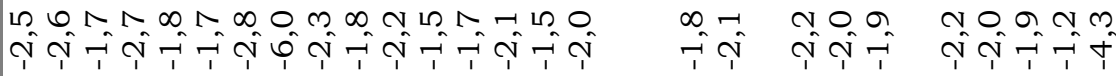

\section{○ ด 0 m 0 เ 06}

नीं

0
$\hat{0}$
1

m $N \infty \infty m-$

$\Lambda+\Lambda m$

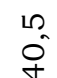

0
0
$\substack{1 \\ 1}$

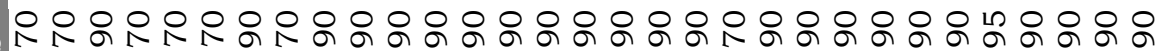

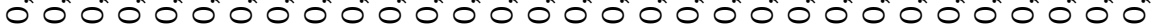
政

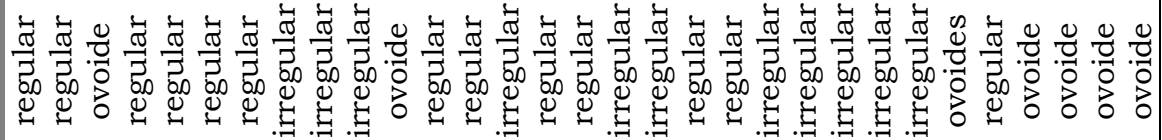

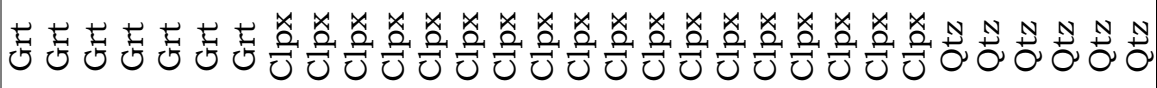

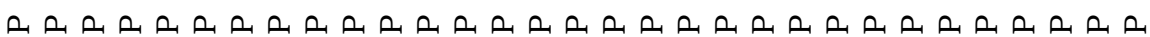

人 O유 0000000000000000000000000000000

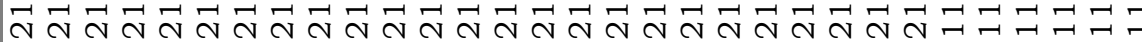




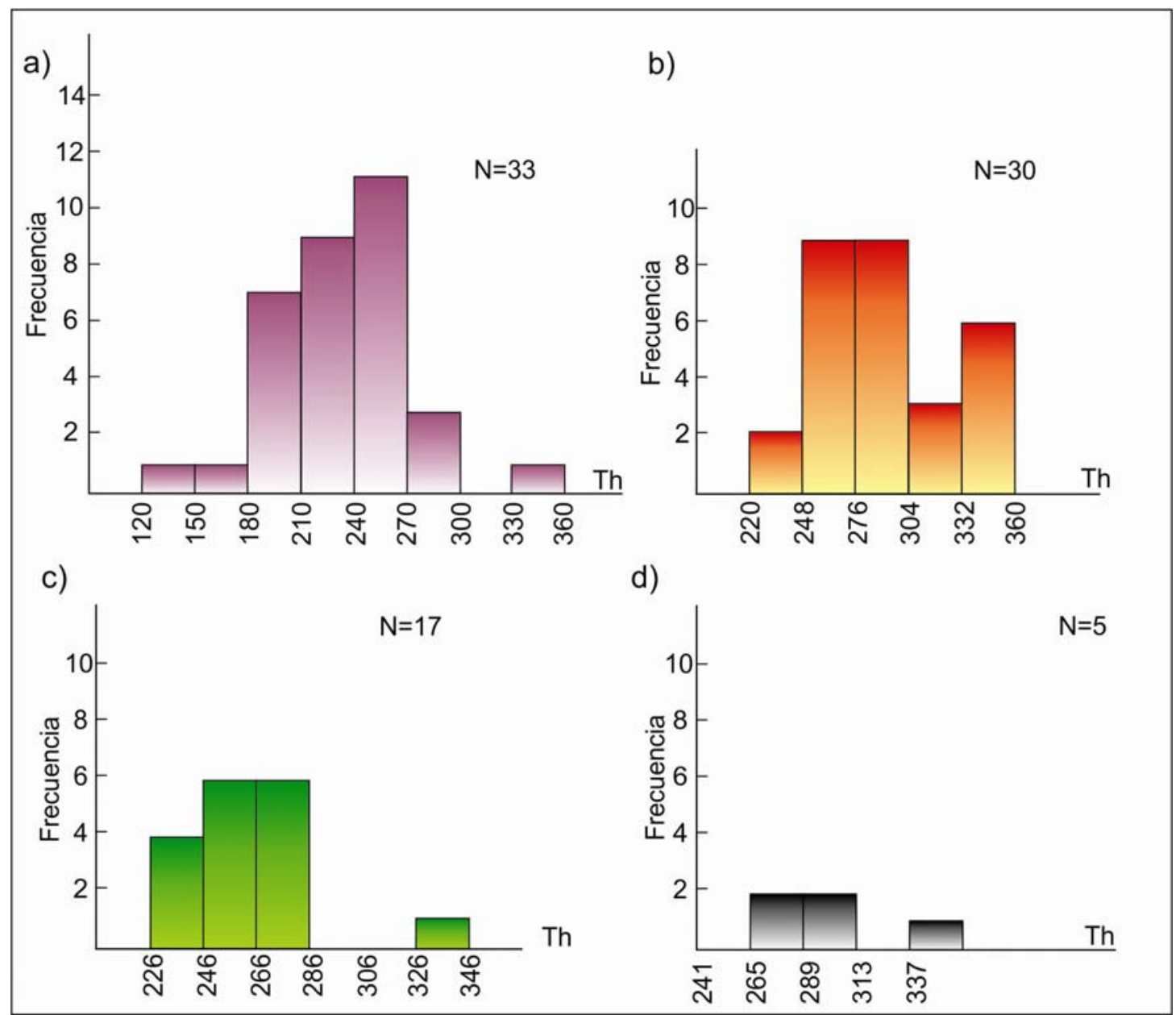

Figura 5.8: Histogramas de Temperatura de homogeneización $\left(\mathrm{en}{ }^{\circ} \mathrm{C}\right)$ vs Frecuencia. Mediciones de IF hospedadas en: a) vesubianita, b) granate, c) clinopiroxeno y d) cuarzo.

Se midieron 17 IF en cristales de clinopiroxeno del endoskarn que cumplieron con las condiciones de tamaño y nitidez para poder ser medidas. Todas ellas son primarias, bifásicas $(\mathrm{L}+\mathrm{G})$ y con $\mathrm{F}$ igual a 0,90 predominantemente. La máxima Th es igual a $328^{\circ} \mathrm{C}$ y la mayoria de las mediciones cae en el rango $246-286^{\circ} \mathrm{C}$ (Fig. 5.8c). La Te es de $-21,5 /-21,8{ }^{\circ} \mathrm{C}$ e indica un sistema $\mathrm{H}_{2} \mathrm{O}-\mathrm{NaCl}$ (Shepherd et al. 1985). Las Tf medidas se condicen con bajas salinidades con una moda comprendida entre 3,0 y 3,7 $\%$ en peso eq. $\mathrm{NaCl}$ (Fig. 5.9c). 


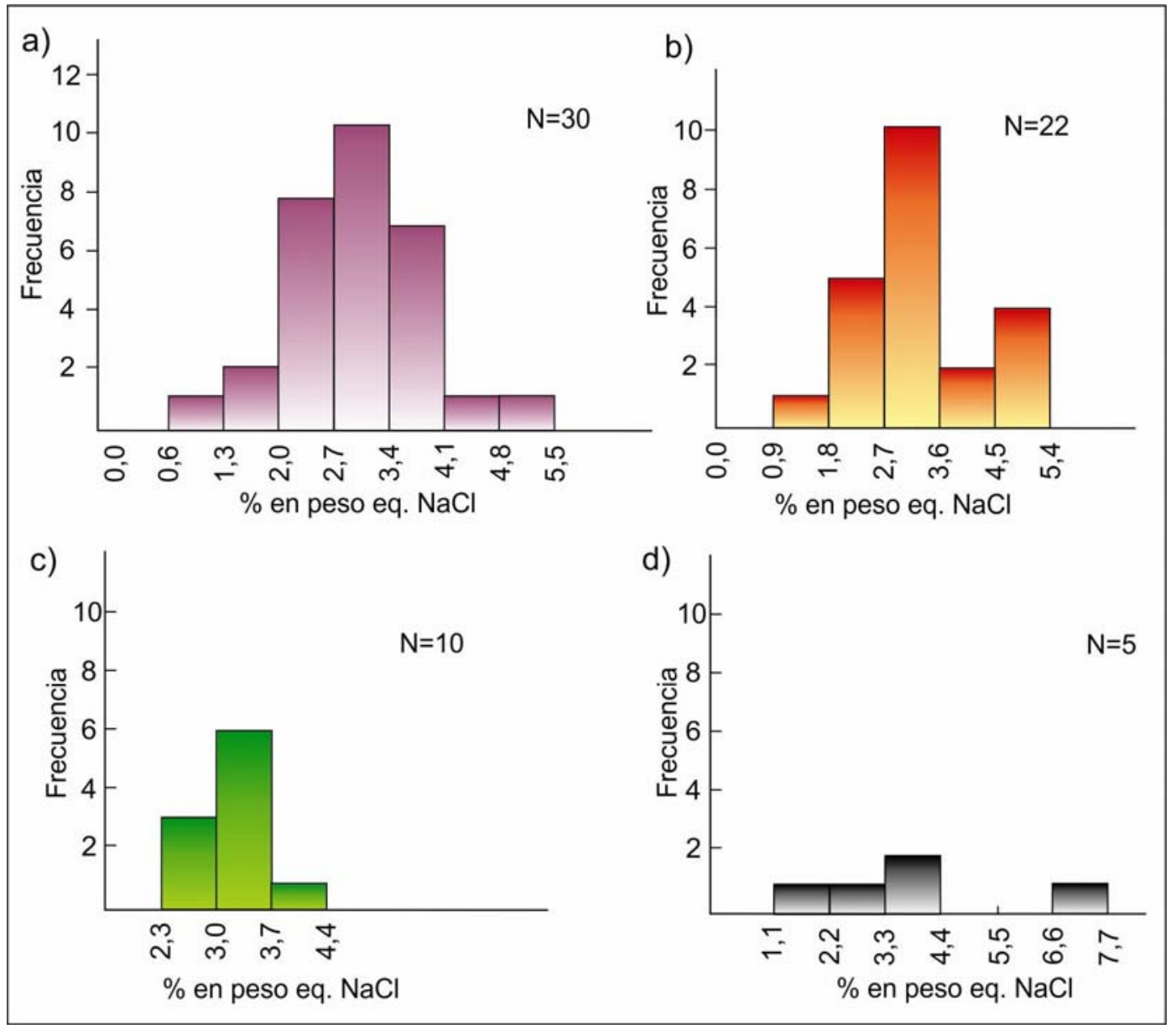

Figura 5.9: Histogramas de salinidades \% en peso eq. $\mathrm{NaCl}$ vs Frecuencia. Mediciones de IF hospedadas en: a) vesubianita, b) granate, c) clinopiroxeno y d) cuarzo.

Finalmente, las IF primarias medidas en cristales de cuarzo intersticial son bifásicas $(L+G)$, ovoides y con $F=0,90$. Las mismas registraron una Th variable entre 241 y $289{ }^{\circ} \mathrm{C}$ (Fig. 5.8d), probablemente por la baja cantidad de mediciones efectuadas no se expresa una moda clara. Las Tf indican salinidades entre 1,1 y 4,4 \% en peso eq. $\mathrm{NaCl}$ (moda poco marcada entre 3,3 y $4,4 \%$ en peso eq. $\mathrm{NaCl}$ ), y sólo una medición quedo por encima de este valor en el intervalo 6,6-7,7 \% en peso eq. $\mathrm{NaCl}$ (Fig. 5.9d). Debido a sus tamaños de $10 \mu \mathrm{m}$ o menos no pudieron determinarse las Te. 

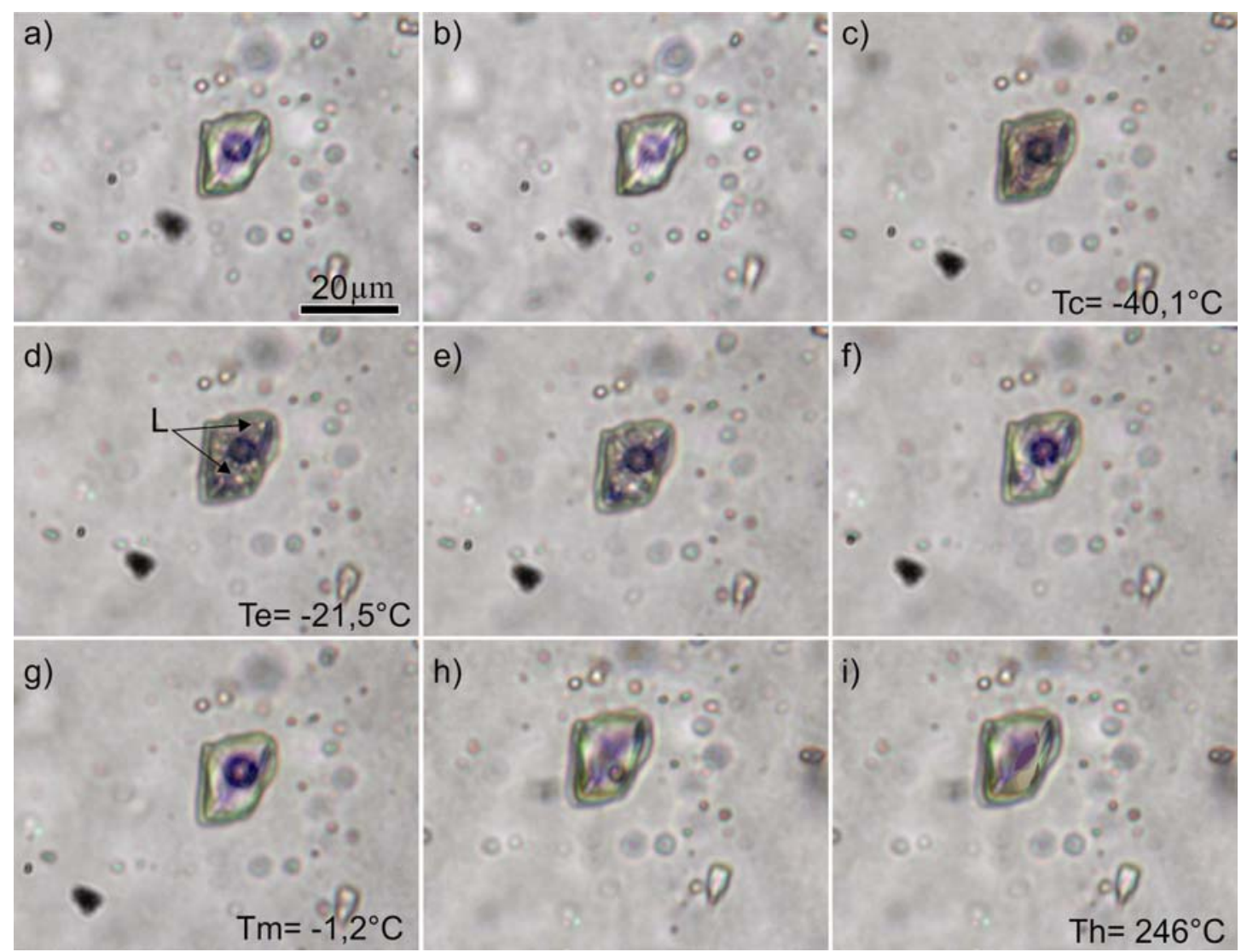

Figura 5.10: Rutina de medición de una IF en cristal de vesubianita. a y b) Enfriamiento de la inclusión fluida. c) Temperatura de congelamiento de la IF. d) En el calentamiento de la misma se detecta la Te (eutéctico) con la aparición de las primeras gotas de líquido. e y f) Calentamiento de la inclusión, nótese como van desapareciendo los cristales de hielo formados durante el enfriamiento. g) Temperatura de la fusión del último cristal del hielo $\left(\mathrm{Tf}=-1,2{ }^{\circ} \mathrm{C}\right)$, indicando una baja salinidad para el fluido. h) Siguiendo con el calentamiento de la IF podemos ver como la burbuja ha disminuido su volumen. i) Temperatura de homogeneización de la IF (Th) a los $246^{\circ} \mathrm{C}$ con la desaparición de la burbuja de gas y homogeneización a líquido.

\subsection{ANÁLISIS DE ISÓTOPOS ESTABLES}

El estudio de isótopos estables se ha convertido en una importante herramienta de caracterización de fluidos y de procesos de la interacción 
fluido-roca. La principal utilidad de los isótopos estables se debe, en gran parte, a que los distintos reservorios de roca y agua son isotópicamente diferentes uno del otro. De esta forma la interacción de dos o más sistemas con características isotópicas distintas generará importantes modificaciones hasta llegar a un equilibrio isotópico entre ellos. Los depósitos tipo skarn son un ejemplo de la interacción de dos sistemas geológicos; el estudio de las variaciones espaciales y temporales de las signaturas isotópicas de los minerales que se generan como producto de esta interacción, nos da la posibilidad de obtener información acerca de las características de los fluidos mineralizantes, del o de los protolitos carbonáticos involucrados y de los procesos físico-químicos acaecidos.

Los análisis de isótopos estables de $\delta^{18} \mathrm{O}_{\text {smow }}$ se realizaron sobre: wollastonita, vesubianita y clinopiroxeno del exoskarn y granate $y$ clinopiroxeno del endoskarn. Además, se incluyeron los resultados de $\delta^{18} \mathrm{O}_{\text {SMOW }}$ obtenidos de los cristales de calcita del mármol del sector más cercano al contacto con los filones graníticos presentados en el capítulo 3.A.

\subsubsection{Resultados}

Los resultados de los análisis realizados se muestran en el Cuadro 5.2. Exoskarn: los cristales de calcita presentan valores de $\delta^{18} \mathrm{O}_{\text {Smow }}$ de $+13,84$ a $+17,12 \%$ o, los de vesubianita de $+10,2 \%$ o, los cristales de wollastonita $+9,4$ y $+9,5 \%$ o y el clinopiroxeno (diópsido) de $+9,4 \%$ o $+14,70 \%$.

Endoskarn: el granate (grosularia) exhibe valores de $+8,0$ y $+8,1 \%$ y el clinopiroxeno de $+9,10$ y +9,40\%o. Cabe destacar que los valores más elevados de $\delta^{18} \mathrm{O}_{\text {SMow }}$ de calcita han sido interpretados en el capítulo 3.A como correspondientes al mármol casi sin modificaciones por metasomatismo y los correspondientes a $\delta^{18} \mathrm{O}_{\mathrm{SMO}} \mathrm{de}+14,70 \%$ on diópsido como los valores de estos minerales que cristalizaron durante el proceso de metamorfismo regional. Sin embargo la incorporación de estos últimos en el diagrama de la Figura 5.11, permite ver el descenso en los valores de O, como producto del metasomatismo, desde las calcitas del mármol hasta los calcosilicatos del exoskarn y finalmente los del endoskarn. 


\begin{tabular}{|cc|}
\hline Minerales & $\mathbf{8 1 8} \mathbf{O}_{\text {(SMow) }} \%$ \\
\hline calcita ** & $+13,84$ \\
calcita ** & $+13,99$ \\
calcita ** & $+13,91$ \\
calcita ** & $+17,12$ \\
diópsido ** & $+14,70$ \\
diópsido ** & $+9,40$ \\
diópsido * & $+9,10$ \\
grosularia * & $+8,10$ \\
grosularia * & $+8,00$ \\
vesubianita ** & $+10,20$ \\
wollastonita ** & $+9,50$ \\
wollastonita ** & $+9,40$ \\
\hline
\end{tabular}

Cuadro 5.2: Resultados de las determinaciones de $\delta^{18} \mathrm{O}$ obtenidas de diferentes minerales que forman el skarn San Miguel. Los valores se expresan en \%oSMOW (Standard Mean OceanWater), *endonskarn, **exoskarn.

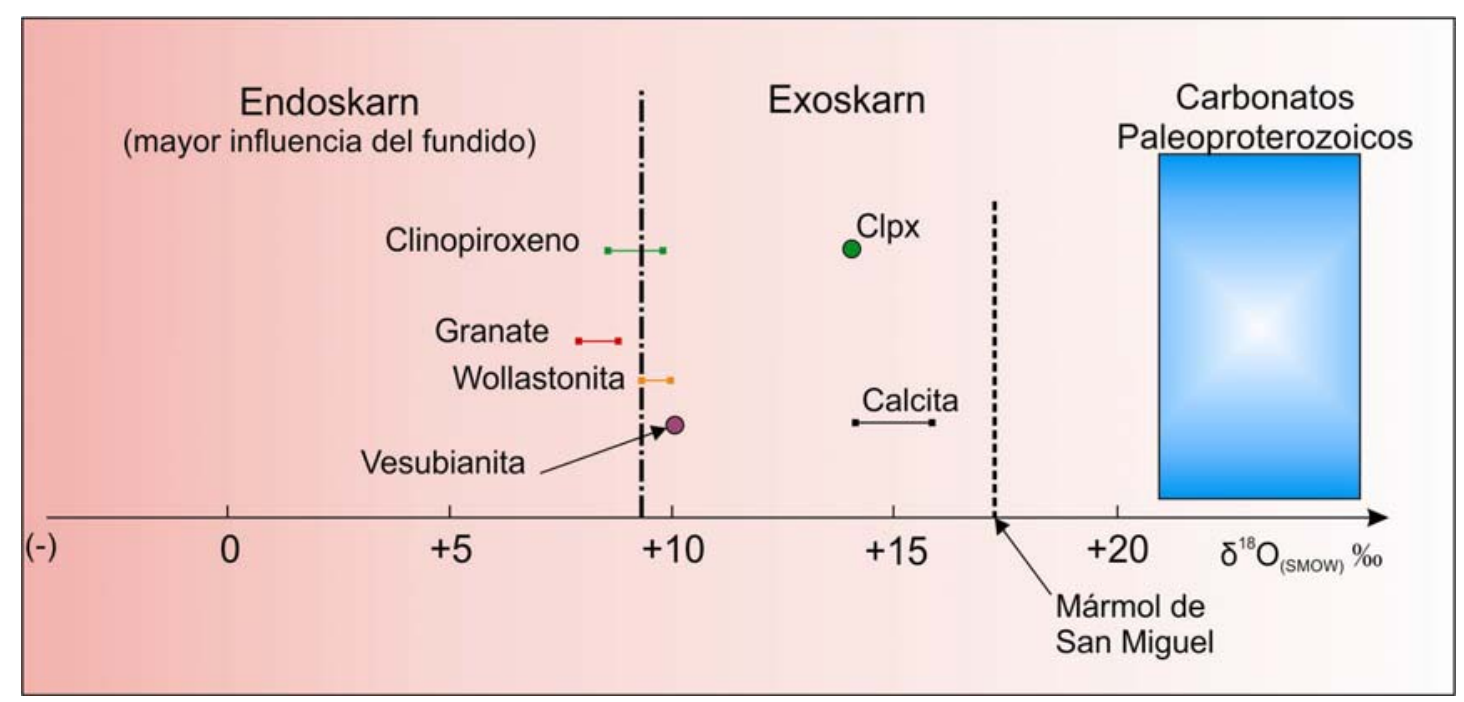

Figura 5.11: Valores $\delta^{18} \mathrm{O}$ de minerales del skarn que indican la evolución del fraccionamiento isotópico entre el mármol y el fluido acuoso durante el metasomatismo. 


\subsubsection{Termometria}

La geotermometría de isótopos estables es una herramienta muy utilizada en la obtención de temperaturas de sistemas de este tipo skarns, dado que el fraccionamiento isotópico es independiente de la presión a diferencia de otros métodos de determinación de temperaturas como el de las IF o los geotermómetros tradicionales.

Las temperaturas del equilibrio isotópico del skarn en estudio se determinaron entre los minerales de la paragénesis reconocida. Los resultados de las temperaturas calculadas según Zheng (1993a y b), se presentan en el Cuadro 5.3. Del par grosularia-diópsido se obtuvieron temperaturas entre 360 y $553^{\circ} \mathrm{C}$ y del par wollastonita-calcita entre 456 y $503^{\circ} \mathrm{C}$. Asimismo, se realizó el cálculo del par calcita-diópsido siguiendo a Zheng (1993a y 1999), que arrojó valores entre 385 y $429^{\circ} \mathrm{C}$, donde queda incluida la temperatura de $451^{\circ} \mathrm{C}$ obtenida en el capítulo 3.A, que fue utilizada para diferenciar poblaciones de diópsidos metamórficos y metasomáticos cristalizados en el mármol. Los pares calcita-vesubianita y wollastonita-vesubianita arrojaron temperaturas mucho más elevadas, del orden de $673^{\circ} \mathrm{C}$ (el primer par) y $890^{\circ} \mathrm{C}$ (el segundo par).

\begin{tabular}{|cc|}
\hline geotermómetro & $\mathbf{T}^{\circ} \mathbf{C}$ \\
\hline grosularia-diópsido & $360-553$ \\
wollastonita-calcita & $456-503$ \\
calcita-diópsido & $385-429$ \\
calcita-vesubianita & 673 \\
wollastonita-vesubianita & 890 \\
\hline
\end{tabular}

Cuadro 5.3: Determinaciones de temperaturas de equilibrio isotópico mediante la utilización de distintos geotermómetros de oxígeno según Zheng (1993a y b). Los resultados de los geotermómetros que incluyen a la vesubianita muestran temperaturas mucho más elevadas que el resto de las determinaciones.

\subsubsection{Estimación del $\delta^{18} \mathrm{O}$ del fluido}

Dado que no se cuenta con mediciones de relaciones de isótopos de $\mathrm{O}$ provenientes de la fuente directa de fluidos, un valor aproximado al $\delta^{18} \mathrm{O}$ de 
los mismos, puede ser calculado indirectamente de acuerdo a Brown et al. (1985):

$$
\frac{W}{R}=\frac{n_{c}}{X_{\Sigma} c} \times \frac{\delta^{13} \mathrm{C} c c^{f}-\delta^{13} \mathrm{C} c c^{i}}{\Delta C_{c c-\Sigma c^{+\delta^{13}} \mathrm{C} c c^{i}-\delta^{13} \mathrm{C} c c^{f}}}
$$

Donde $\frac{W}{R}$ es la relación agua/roca, ne es el número de moles de carbono por mol de calcita, $x_{\Sigma \complement}$ número de moles de carbono en solución por mol de fluido, $8^{18} \operatorname{Ccc}^{t}$ y $8^{19} \mathrm{Cec}^{f}$ corresponden a la composición isotópica de la

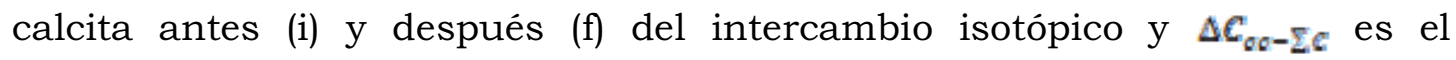
fraccionamiento isotópico entre calcita y la especie de carbono en solución. Para resolver la ecuación (1) se consideró que el número de moles de carbono en solución es menor a 0,1 teniendo en cuenta los datos obtenidos de las IF y sumado a la presencia de ciertos minerales y asociaciones minerales indicadoras de $X_{\mathrm{Co}_{2}}$. La vesubianita es un mineral estable a bajos valores de $X_{\mathrm{CO} 2}$ (Hochella et al. 1982 y Valley et al. 1985), más aún si tenemos en cuenta la asociación vesubianita + grosularia limitada a $x_{\mathrm{CQ2}_{2}<}$ 0,05 y la asociación vesubianita + wollastonita estable hasta $X_{\mathrm{CO} 2}<0,01$; ambas se mencionan en el capítulo 4 durante la descripción de las paragénesis del skarn. También se tuvo en cuenta que si bien la ocurrencia del diópsido no está restringida a fluidos acuosos, su cristalización a temperaturas de $450^{\circ} \mathrm{C}$ o menos, indica valores $x_{\mathrm{coz}}$ menores a 0,11 de acuerdo a la reacción:

$$
\mathrm{Tr}+3 \mathrm{Cc}+\mathrm{Qtz}=5 \mathrm{Di}+3 \mathrm{CO}_{2}+\mathrm{H}_{2} \mathrm{O}
$$

De esta forma se tomó 0,1 como $X_{\Sigma e}$ máximo, $n_{e}$ igual a 1 , $\delta^{13} \mathrm{Cec}^{i}=5,42 \%$ o, $\delta^{13} \mathrm{Cec}^{f}=4,26 \%$ y de acuerdo a la temperatura estimada para este sistema (entre 360 y $451{ }^{\circ} \mathrm{C}$ aproximadamente) la especie de carbono presente en el fluido es $\mathrm{CO}_{2}$ por lo que $\Delta C_{c o-\Sigma e}$ corresponde al 
fraccionamiento calcita- $\mathrm{CO}_{2}$ que es igual a $-2,4 \%$ a $451^{\circ} \mathrm{C}$ (Bottinga 1968). Una vez obtenida la relación agua/roca $\left(\frac{W}{\bar{R}}=9,35\right)$ reemplazamos en la ecuación (2) de Brown et al. (1985).

$$
\frac{W}{R}=\frac{\delta^{18} O_{R f}-\delta^{1 \theta^{1}} O_{R i}}{\delta^{18} O_{W i}-\delta^{18} O_{R f}+\Delta O_{F C-H 2 O}}
$$

Donde $\delta^{18} O_{\text {EI }}$ y $\delta^{18} O_{\text {IU }}$ corresponden a las composiciones isotópicas de la roca (mármol) antes (Ri) y después (Rf) de la interacción con el fluido acuoso, dichos valores son $17,12 \%$ y $13,84 \%$ o respectivamente y $\Delta 0_{\sigma \varepsilon-\mu 20}$ que es el fraccionamiento calcita-agua es igual a $3,5 \%$ o también a $451^{\circ} \mathrm{C}$ (Brown et al. 1985).

De la ecuación (2) se obtiene que $\delta^{18} \mathcal{Q}_{w i}$, que corresponde a la composición isotópica inicial para el fluido, tiene un valor estimado de $+9,99 \%$.

\subsection{VESUBIANITA COMO ESTIMADOR DE TEMPERATURA}

\subsubsection{Introducción}

La vesubianita o idocrasa es un mineral de fórmula y estructura compleja perteneciente a un grupo mixto de silicatos de tipo $\mathrm{SiO}_{4}^{-4} \mathrm{y} \mathrm{Si}_{2} \mathrm{O}_{7}{ }^{-6}$. Fue descripto por primera vez por Werner (1975), en xenolitos dolomíticos incluidos en lavas del Monte Vesubio, Italia. Su apariencia óptica varía considerablemente y su coloración típica es verde-marrón. En su formación intervienen procesos químicos en los que se destaca la gran movilidad de iones que origina una serie de sustituciones acopladas. De esta manera, esta especie presenta importantes variaciones en su composición química (Groat et al. 1992). Además, las variables del medio físico (presión y temperatura), reinantes en el momento de su formación, influyen fundamentalmente en el tipo estructural que puede presentar la vesubianita (Groat y Hawthorne 1998). 
Su fórmula general se expresa:

$\mathbf{X}_{\mathbf{1 9}} \mathbf{Y}_{\mathbf{1 3}} \mathbf{T}_{\mathbf{0 - 5}} \mathbf{Z}_{\mathbf{1 8}} \mathbf{O}_{\mathbf{6 8}} \mathbf{W}_{\mathbf{1 0}}$ (Groat et al. 1992)

Donde, $\mathrm{X}$ es un catión $\left(\mathrm{Na}^{+}, \mathrm{K}^{+}, \mathrm{Ca}^{+2}, \mathrm{Ba}^{+2}\right)$ de coordinación cúbica. $\mathrm{Y}$ es un catión cuyo radio varía entre 0,5 y $0,8 \AA\left(\mathrm{Mn}^{+2}, \mathrm{Ni}^{+2}, \mathrm{Mg}^{+2}, \mathrm{Fe}^{+2}, \mathrm{Cr}^{+3}\right.$, $\mathrm{Al}^{+3}, \mathrm{Ti}^{+4}$ ) ubicado en coordinación octaédrica. $Z$ corresponde a $\mathrm{Si}^{+4} \mathrm{y}$ ocasionalmente $\mathrm{Al}^{+3}$ en coordinación tetraédrica, en tanto que $\mathrm{T}$ a especies $\mathrm{B}$ o P en coordinación trigonal planar y tetraédrica respectivamente, si bien no está perfectamente especificado en la fórmula. W corresponde a grupos aniónicos $\left(\mathrm{OH}^{-}, \mathrm{F}^{-}, \mathrm{Cl}^{-}\right)$.

La vesubianita está asociada a rocas de tipo skarn, aunque también se las ha descripto en rocas calcosilicatadas producto de un metamorfismo regional. En Argentina, la mayoria de las citas bibliográficas acerca de este mineral corresponde a los ámbitos de Sierras Pampeanas y Cordillera Andina, donde dichas rocas son más frecuentes. Los cristales de vesubianita que aquí se estudian y que provienen del skarn San Miguel, corresponden a la primera investigación de este mineral realizado en el ámbito de las Sierras Septentrionales de la provincia de Buenos Aires.

El conocimiento de su composición química, mediante la reconstrucción de la fórmula mineral, y la interpretación de su estructura cristalina, permiten inferir el rango de temperatura de formación de este mineral, contribuyendo a esclarecer las condiciones de formación del skarn San Miguel.

\subsubsection{Resultados}

En los espectros de DRX obtenidos (Fig.5.12) se han identificado tres señales de máxima intensidad: $34,52^{\circ}$ (100\%); 56,58 (100\%); 32,44 $(70 \%)$. Dichas señales concuerdan con el patrón de vesubianita correspondiente al PDF 38-474. 


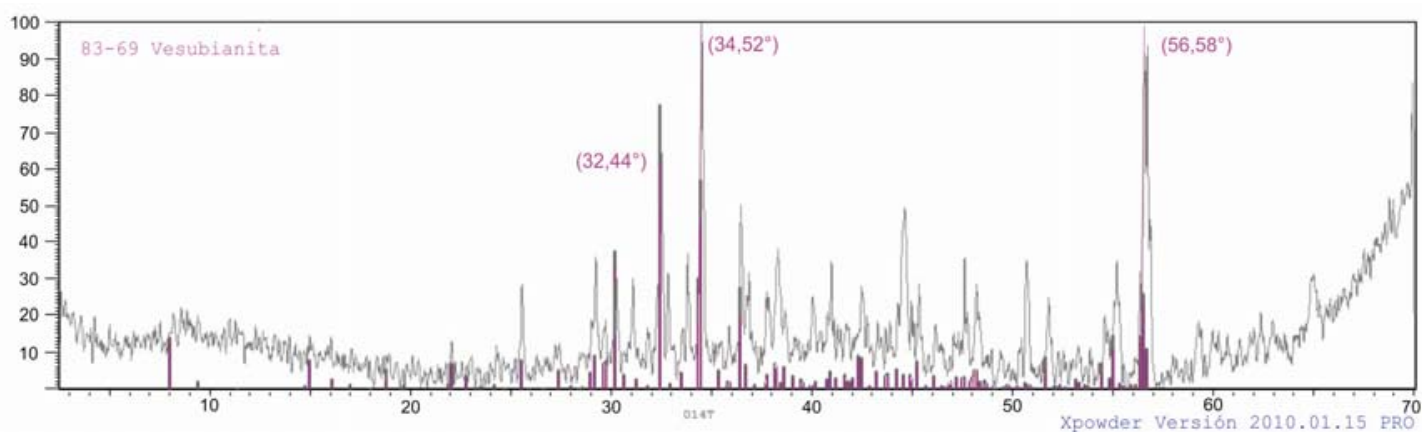

Figura 5.12: Espectro DRX de la vesubianita. El mismo fue obtenido mediante el programa XPowder.

Para observar la influencia de las sustituciones catiónicas sobre los enlaces químicos se empleó el método FTIR (Fourier transform infrared spectroscopy). El espectro resultante se observa en la Fig. 5.13 y se caracteriza por las débiles bandas 3854 y $3738 \mathrm{~cm}^{-1}$ y otra ancha banda centrada en $3428 \mathrm{~cm}^{-1}$. Las dos primeras se asignan a grupos $(\mathrm{OH})^{-}$y la restante a puentes de $\mathrm{H}$ del $\mathrm{H}_{2} \mathrm{O}$. La señal en $1622 \mathrm{~cm}^{-1}$ se corresponde a la deformación angular del $\mathrm{H}_{2} \mathrm{O}$. Los estiramientos de los enlaces Si-O (grupos $\mathrm{SiO}_{4}{ }^{-4}$ aislados y condensados $\mathrm{Si}_{2} \mathrm{O}_{7}{ }^{-6}$ ) se localizan en la zona $1200-1000$ $\mathrm{cm}^{-1}$, destacándose las bandas de los grupos terminales (1211-1100 $\left.\mathrm{cm}^{-1}\right)$. El hombro localizado en $932 \mathrm{~cm}^{-1}$ se puede relacionar con los grupos Al-O-H. Por otra parte la presencia de los enlaces $\mathrm{P}-\mathrm{O}$ del grupo tetraédrico $\mathrm{PO}_{4}{ }^{-3}$ $\left(1030 \mathrm{~cm}^{-1}\right)$, se encuentra solapada e incluida dentro de la envolvente de los silicatos. La zona inferior a $900 \mathrm{~cm}^{-1}$, es la más compleja de asignar con precisión, dado que en ella se encuentran las señales de las deformaciones angulares de las especies de $\mathrm{Si}$, los estiramientos del enlace $\mathrm{M}-\mathrm{O}$ (particularmente $\mathrm{Al}$ en coordinación octaédrica), las libraciones del $\mathrm{H}_{2} \mathrm{O}$ y grupos OH, así como los modos de red (Farmer 1974).

Finalmente se obtuvieron los contenidos promedio expresados en porcentaje en óxidos, dichos resultados se presentan en el Cuadro 5.4. Los mismos se corresponden con los valores esperados para este mineral, pero se destaca el tenor elevado de $\mathrm{F}$ de $0,55 \%$. 


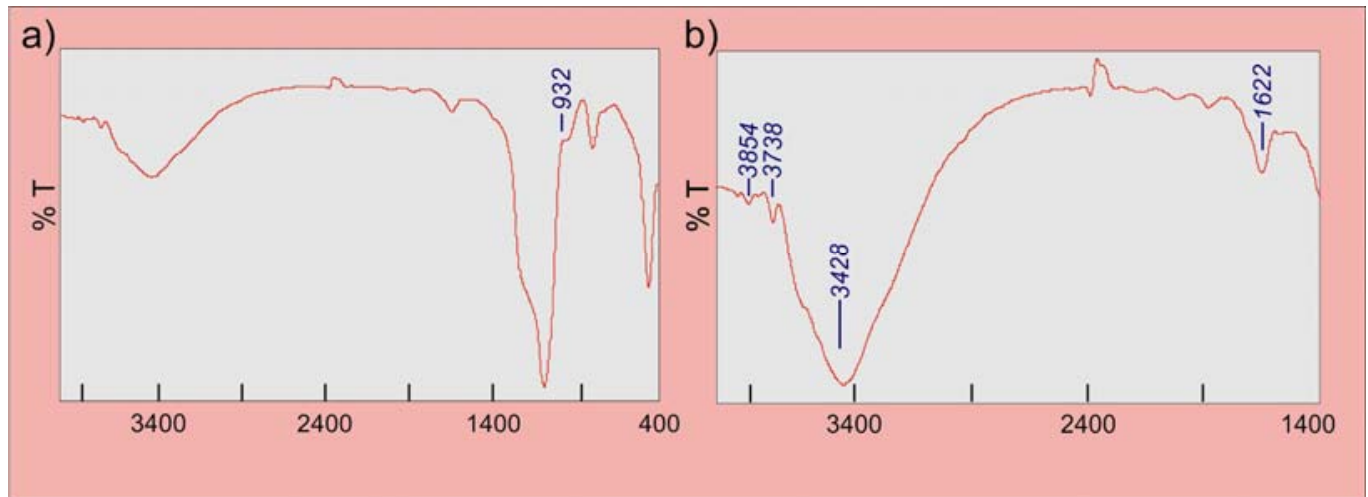

Figura 5.13:a) Espectro FTIR de la vesubianita, en el cual se observa la influencia de las sustituciones catiónicas sobre los enlaces químicos. b) Detalle de la zona alta del espectro comprendida entre 4000 y $1400 \mathrm{~cm}^{-1}$.

\begin{tabular}{|ll|ll|ll|}
\hline $\mathbf{O}_{x i d o}$ & $\%$ & Óxido & $\%$ & Oxido & $\%$ \\
\hline $\mathbf{S i O}_{2}$ & 36,85 & $\mathbf{M n O}$ & 0,09 & $\mathbf{C a O}$ & 36,86 \\
$\mathbf{T i O}_{2}$ & 0,30 & $\mathbf{M g O}$ & 0,90 & $\mathbf{B a O}$ & 0,09 \\
$\mathbf{A l}_{2} \mathbf{O}_{3}$ & 18,60 & $\mathbf{N i O}$ & 0,02 & $\mathbf{P}_{\mathbf{2}} \mathbf{O}_{5}$ & 0,20 \\
$\mathbf{C r}_{2} \mathbf{O}_{3}$ & 0,02 & $\mathbf{K} \mathbf{O}$ & 0,03 & $\mathbf{F}$ & 0,55 \\
$\mathbf{F e O}$ & 5,46 & $\mathbf{N a} \mathbf{O}$ & 0,01 & $\mathbf{C l}$ & 0,13 \\
\hline
\end{tabular}

Cuadro 5.4: Composición química promedio de la vesubianita, obtenida mediante un análisis EDAX (se asume al hierro total como $\mathrm{FeO}$ ).

\subsubsection{Discusión y conclusiones parciales}

De acuerdo a Gnos y Armbruster (2006) existe una total dependencia entre el grupo espacial o de simetría de la vesubianita y la temperatura de cristalización de la misma. Según estos mismos autores existen tres tipos de simetría en la cual cristaliza la vesubianita: P4nc dominante, corresponde a cristales formados a menos de $300{ }^{\circ} \mathrm{C} ; \mathrm{P} 4 / \mathrm{n}$ dominante, indica temperaturas de formación entre 300 y $500{ }^{\circ} \mathrm{C}$ y $P 4 / n n c$, que predomina en cristales formados a más de $500{ }^{\circ} \mathrm{C}$. A partir de los datos de DRX puede afirmarse que la vesubianita de San Miguel pertenece al grupo espacial P4/nnc (Warren y Modell 1931 y Groat y Hawthorne 1998), por lo que se habría formado a temperaturas mayores a los $500{ }^{\circ} \mathrm{C}$. Esta afirmación también es respaldada por los estudios de FTIR, donde la comparación del espectro obtenido con los 
citados en reportes bibliográficos revela semejanzas con los de vesubianitas de mayor temperatura (Warren y Modell 1931).

El microanálisis obtenido, permitió definir la siguiente expresión general de su fórmula:

$$
(\mathrm{Na}, \mathrm{K}, \mathrm{Ca}, \mathrm{Ba})_{19}(\mathrm{Mn}, \mathrm{Ni}, \mathrm{Mg}, \mathrm{Fe}, \mathrm{Cr}, \mathrm{Al}, \mathrm{Ti})_{13}\left(\mathrm{PO}_{4}\right)_{0,2} \mathrm{Si}_{18} \mathrm{O}_{68}(\mathrm{~F} ; \mathrm{Cl}, \mathrm{OH})_{10}
$$

$\mathrm{X}=\mathrm{Na}_{0,67} \mathrm{~K}_{0,02} \mathrm{Ca}_{18,88} \mathrm{Ba}_{0,04}$

$\mathrm{Y}=\mathrm{Mn}_{0,04} \mathrm{Ni}_{0,01} \mathrm{Mg}_{0,62} \mathrm{Fe}_{1,92} \mathrm{Cr}_{0,05} \mathrm{Al}_{10,26} \mathrm{Ti}_{0,10}$

$\mathrm{T}=\left(\mathrm{PO}_{4}\right)^{-3} 0,2$

$\mathrm{Z}=\mathrm{Si}_{18}$

$\mathrm{W}=\mathrm{F}_{0,9} \mathrm{Cl}_{0,1} \mathrm{OH}_{9}$

En términos generales, los resultados químicos obtenidos concuerdan con los valores esperados para esta especie, aunque se destaca su contenido de $\mathrm{F}$ cercano al 1\%, lo que indica que es una vesubianita rica en flúor. Este elemento puede ser incorporado en la estructura de la vesubianita en $\mathrm{O}(11)$ $\mathrm{H}(1)$, este sitio corresponde a uno de los grupos del OH (Groat et al. 1995). Si consideramos las posibles transconfiguraciones de $\mathrm{O}(11)-\mathrm{H}(1)$, existen tres arreglos posibles entre $\mathrm{F}$ y OH: OH-OH, OH-F y F-F (Groat et al. 1995). De acuerdo a evidencias de estudios espectroscópicos, de estos arreglos, el segundo muestra la configuración favorable en vesubianitas ricas en flúor.

Concluyendo, la vesubianita del skarn San Miguel es una vesubianita rica en flúor que de acuerdo a su ordenamiento espacial $P 4 / n n c$ y su espectro FTIR, se formó a una temperatura mayor a $500{ }^{\circ} \mathrm{C}$.

\subsection{GEOTERMÓMETRO GRANATE-CLINOPIROXENO}

Existen muchos geotermómetros que han sido calibrados con fines termobarométricos en los últimos años. Muchos de ellos permiten obtener buenos resultados, en tanto se apliquen dentro de los límites P-T-X de la calibración. Obtener buenos resultados implica, por lo tanto, conocer las bases conceptuales de las calibraciones para poder juzgar sus limites de aplicabilidad. 
La identificación del equilibrio en una asociación de fases es un aspecto de importancia fundamental que debe ser considerado previamente a cualquier intento de alcanzar soluciones termobarométricas. Es incuestionable que los resultados numéricos obtenidos en rocas donde no exista equilibrio entre todas o parte de las fases que las forman carecen de significado geológico alguno. Los criterios que pueden utilizarse para juzgar el requisito fundamental de equilibrio son texturales, composicionales y teóricos.

Existen muchos casos en que estos requisitos son cumplidos y las aplicaciones termobarométricas tienen validez geológica. En otros, si bien estos métodos no deben ser forzados pueden ser utilizados de forma estimativa o complementaria con otras técnicas para calcular P y/o T.

Con este fin, se utilizaron los datos de composición de granates y clinopiroxenos del skarn San Miguel, obtenidos mediante microsonda electrónica y se aplicó el geotermómetro de Krogh Ravna (2000) que considera el intercambio de $\mathrm{Fe}$ y $\mathrm{Mg}$ entre granate y clinopiroxeno, a través de la ecuación:

$$
\begin{aligned}
& \mathrm{T}\left({ }^{\circ} \mathrm{C}\right)=\left[\left(1939,9+3270 \mathrm{X}^{\mathrm{Grt}} \mathrm{Ca}^{-} 1396\left(\mathrm{X}^{\mathrm{Grt}} \mathrm{Ca}\right)^{2}+3319 \mathrm{X}^{\mathrm{Grt}} \mathrm{Mn}-3535\right.\right. \\
& \left(\mathrm{X}^{\mathrm{Grt}}{ }_{\mathrm{Mn}}\right) 2+1105 \mathrm{X}^{\mathrm{Grt}}{ }_{\mathrm{Mg}^{*}}-3562\left(\mathrm{X}^{\mathrm{Grt}} \mathrm{Mg}^{\star}\right)^{2}+2324\left(\mathrm{X}^{\mathrm{Grt}}{ }_{\mathrm{Mg}^{\star}}\right)^{3}+169,4 P \\
& \left.\left.(\mathrm{GPa})) /\left(\ln K_{D}+1,223\right)\right]\right]-273
\end{aligned}
$$

Donde:

$\mathrm{K}_{\mathrm{D}}=\left(\mathrm{Fe}^{+2} / \mathrm{Mg}\right)^{\mathrm{Grt}} /\left(\mathrm{Fe}^{+2} / \mathrm{Mg}\right)^{\mathrm{Clpx}}$

$\mathrm{Mg}^{*}=100 \times \mathrm{Mg} /\left(\mathrm{Mg}+\mathrm{Fe}^{+2}\right)$

$\mathrm{X}_{\mathrm{Ca}}=\mathrm{Ca} /(\mathrm{Ca}+\mathrm{Mn}+\mathrm{Fe}+\mathrm{Mg})$ en granate

$\mathrm{X}_{\mathrm{Mn}}=\mathrm{Mn} /(\mathrm{Ca}+\mathrm{Mn} / \mathrm{Mn}+\mathrm{Fe}+\mathrm{Mg})$ en granate

$\mathrm{X}_{\mathrm{Mg}^{*}}=\mathrm{Mg} /(\mathrm{Fe}+\mathrm{Mg})$ en granate

Como datos de presión se utilizaron las determinadas por Delpino (2000) para el área de Balcarce de 0,50 y 0,75 GPa, como presiones mínima y máxima. Los resultados se muestran en el Cuadro 5.5. Como se observa, estos valores se encuentran entre 402,17 y $575,89^{\circ} \mathrm{C}$, encontrándose en un rango aceptable para este sistema, aún considerando que el método no está calibrado para ambientes metasomáticos. 




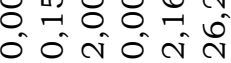

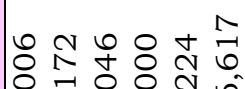

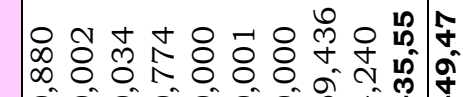

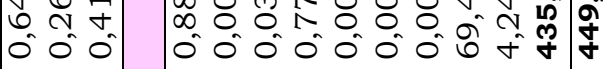

$\sqrt{2}$

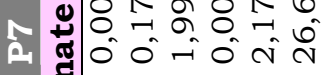

疍

은

는

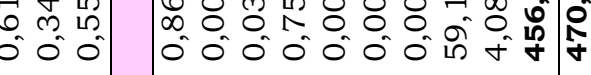

น

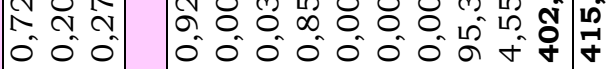

는

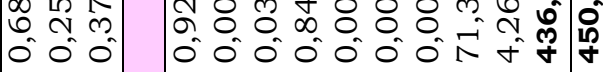

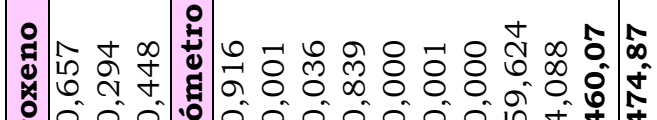

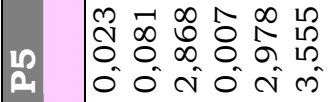

no m 혼

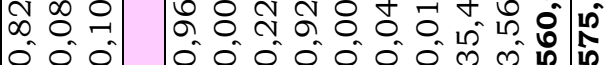

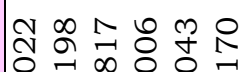

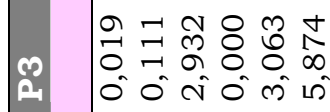

르 $\begin{array}{ccc}\infty & -1 & -1 \\ 0 & 0 & 0\end{array}$

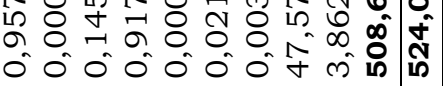

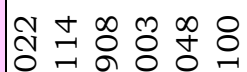




\subsection{DISCUSIÓN}

Se realizaron mediciones de inclusiones fluidas hospedadas en vesubianita del exoskarn y en granate, clinopiroxeno y cuarzo del endoskarn. Las temperaturas de homogeneización medidas en estas inclusiones fluidas, indican que dichos minerales se formaron a partir de un fluido con moderada a elevada temperatura, entre 250 y $320{ }^{\circ} \mathrm{C}$. En términos generales, si bien estos minerales se disponen en paragénesis zonales (Capítulo 4), la temperatura se ha mantenido relativamente constante a lo largo de la cristalización de los mismos. Otra característica de este fluido es su baja salinidad (< al 7\% en peso eq. de $\mathrm{NaCl}$ ), por lo que las fases sólidas encontradas dentro de algunas inclusiones fluidas corresponderian a cristales entrampados en el momento de la formación de la IF y no de cristales hijos, ya que no se trata de un fluido saturado como para generar la precipitación de minerales. Las Te medidas entre -24,2 y -21,5, indican en todos los casos un sistema acuoso predominantemente $\mathrm{NaCl}-\mathrm{H}_{2} \mathrm{O} / \mathrm{NaCl}-\mathrm{KCl}$ $\mathrm{H}_{2} \mathrm{O}$, correspondiente a un fluido de origen magmático-metamórfico (Roedder 1971, Bodnar 1995, Meinert et al. 2005). Esto sumado a que no se ha encontrado $\mathrm{CO}_{2}$ como gas inmiscible dentro de las inclusiones fluidas analizadas, indicaría que el $\mathrm{CO}_{2}$ generado durante las reacciones de descarbonatación ha sido eliminado del sistema o ha sido diluido por el ingreso de más fluido acuoso, manteniendo su concentración baja y relativamente constante o con poca variación.

Las determinaciones de $\delta^{18} \mathrm{O}$ (\%o SMOW) obtenidas a partir de diferentes minerales como clinopiroxeno y granate del endoskarn y vesubianita, wollastonita, clinopiroxeno y calcita del exoskarn, muestran una gama de variación generada por la interacción del fluido acuoso y el mármol calcítico. Dicha variación está fuertemente asociada, en parte, a la posición que ocupan estos minerales respecto de las dos fuentes de oxígeno antes mencionadas (fluido y mármol), ya que los valores más bajos se han registrado en granates y en algunos clinopiroxenos ubicados en el endoskarn (con fuerte control de la fuente del fluido acuoso) y en wollastonita y 
vesubianita ubicados en la zona intermedia entre el mármol y el intrusivo. Los valores más elevados se registraron, fundamentalmente en calcita, donde claramente la fuente que controla la signatura isotópica es el mármol. Por otro lado, también podemos decir que esta diferencia tan marcada entre los valores de oxígeno del mármol y los calcosilicatos se genera por el bajo efecto que tuvo el protolito carbonático en la cristalización de los calcosilicatos ya que, como se señaló anteriormente, no se ha registrado $\mathrm{CO}_{2}$ en las IF. En este sentido, la estimación del valor de $\delta^{18} \mathrm{O}$ del fluido realizada previamente por métodos empíricos (sección 5.3.1.2) en 9,9\%o sería bastante acorde al valor esperado, aunque algo más elevado, teniendo en cuenta que el $\delta^{18} \mathrm{O}$ de los granates es entre 8,0 y $8,1 \%$.

Por otro lado, la utilización de estos valores de $\delta^{18} \mathrm{O}$ permitió la aplicación de diferentes pares minerales geotermométricos a partir de los cuales se arribó a temperaturas de equilibrio isotópico del orden de 351 a $553{ }^{\circ} \mathrm{C}$. Éstas se encuentran por encima de las temperaturas de homogeneización de las inclusiones fluidas medidas pero si tenemos en cuenta que la cristalización de los minerales analizados se produjo, de acuerdo al contexto geológico, bajo un régimen de metamorfismo regional, esta diferencia podría deberse a que las IF no fueron corregidas por la presión del sistema (Roedder y Bodnar 1980), mientras que los equilibrios isotópicos no son sensibles a la presión. De todas formas, la pérdida de $\mathrm{CO}_{2}$ que indicaría una despresurización del sistema, sumado al hecho de que los valores más elevados $\left(456-503^{\circ} \mathrm{C}\right)$ se registraron en el par wollastonitacalcita (Zheng 1993a y 1999), minerales de los cuales no se cuenta con datos de inclusiones fluidas, podríamos decir que la corrección sería mayor a $100^{\circ} \mathrm{C}$ aproximadamente en este caso.

Con el fin de corregir las temperaturas de homogeneización de las IF y acercarnos más a la temperatura de entrampamiento, se realizaron las isocoras correspondientes a vesubianita, granate, clinopiroxeno y cuarzo, (Fig. 5.14.a, b, c y d) según la metodología propuesta por Zhang y Frantz (1987). En las mismas se utilizó como factor de corrección la presión mínima estimada por Delpino (2000) para una porción de basamento del área de 
Balcarce y las temperaturas de los pares termométricos calculados en este capítulo (en los casos de vesubianita, granate y clinopiroxeno).

Como podemos observar que la mayoría de los casos las correcciones rondan $\operatorname{los} 400^{\circ} \mathrm{C}$ y las temperaturas de entrampamiento alrededor de los 660-690 ${ }^{\circ} \mathrm{C}$ (Fig. 5.14.a, b c, y d)
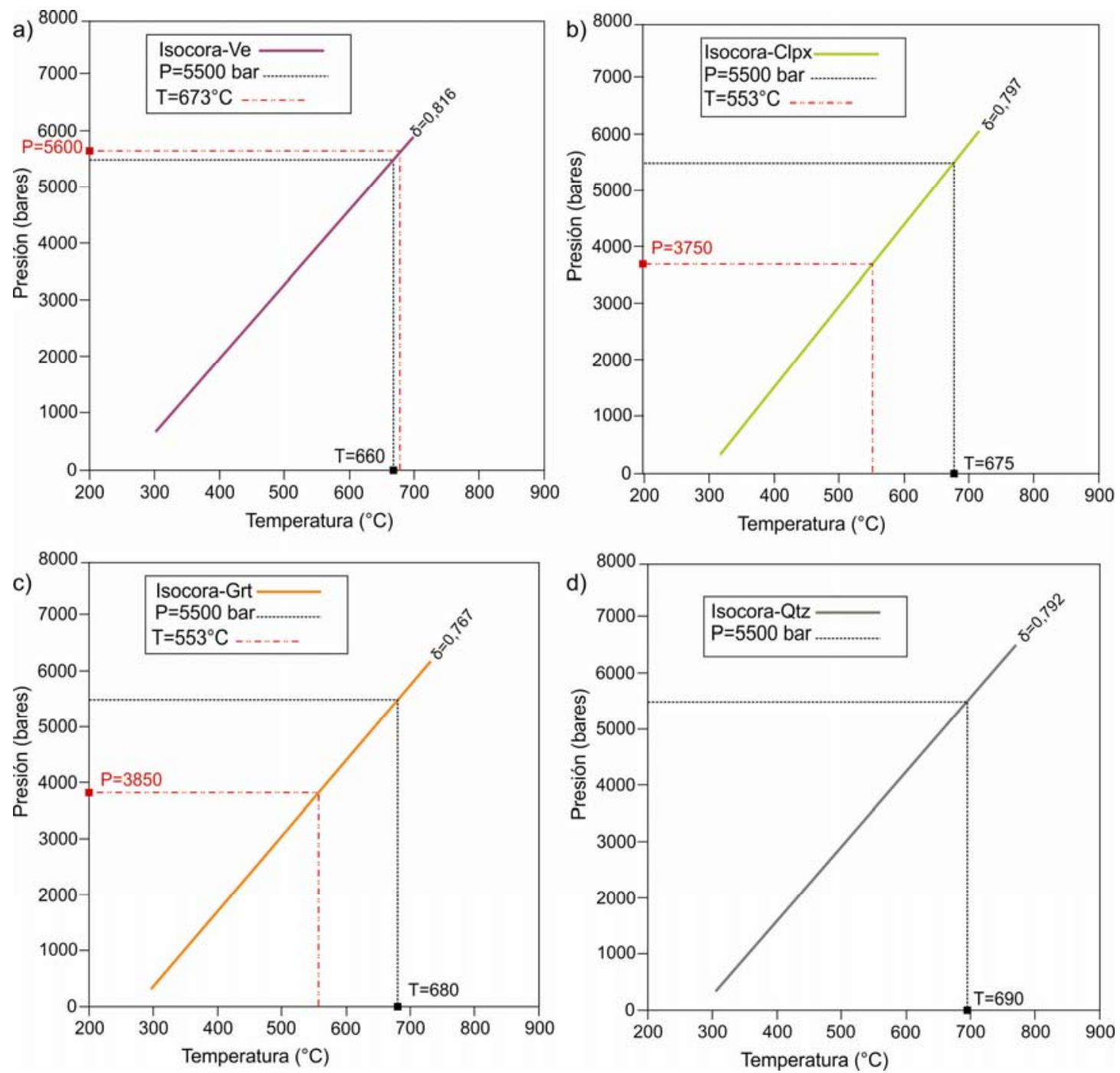

Figura 5.14: Isocoras para las IF medidas en a) Vesubianita, para una Th de $245^{\circ} \mathrm{C}$ y una salinidad de $3,05 \%$ en peso eq. $\mathrm{NaCl}$; b) Clinopiroxeno para una Th de $258^{\circ} \mathrm{C}$ y una salinidad de $3,06 \%$ en peso eq. $\mathrm{NaCl}$; c) Granate, Th de $276^{\circ} \mathrm{C}$ y salinidad de $3,06 \%$ en peso eq. $\mathrm{NaCl}$ y d) Cuarzo, Th de $269^{\circ} \mathrm{C}$ y una salinidad de $3,41 \%$ en peso eq. $\mathrm{NaCl}$. 
Si bien las temperaturas de los equilibrios isotópicos son algo menores y de esta forma determinaron menores presiones, las mismas, suelen ser generalmente más bajas que las temperaturas de cristalización (Hoef, 1987).

Cabe señalar que los geotermómetros de vesubianita arrojaron valores más elevados $\left(600-800^{\circ} \mathrm{C}\right)$, esto podría deberse a que este mineral alcanzó el equilibrio isotópico con su par antes que la cristalización de las otras fases minerales medidas. Independientemente de esto, el estudio de la vesubianita suma una importante información a la caracterización de los fluidos involucrados en la formación del skarn San Miguel. Por un lado, la vesubianita es un mineral estable a bajos valores de $\mathrm{CO}_{2}$ (Hochella et al. 1982 y Valley et al. 1985), más aún si tenemos en cuenta la asociación vesubianita + grosularia limitada a $X_{\mathrm{CO}_{2}}<0,05$ y la asociación vesubianita + wollastonita estable hasta $X_{\mathrm{CO2}}<0,01$. Esto estaría en concordancia con los datos aportados por las IF y con los valores $\delta^{18} \mathrm{O}$ obtenidos de los calcosilicatos. Además, la determinación de su simetría $P 4 / n n c$ junto con su contenido de $\mathrm{F}$ de aproximadamente $1 \%$, indica que la misma se formó a una temperatura mayor a los $500^{\circ} \mathrm{C}$ (Warren y Modell 1931, Groat y Hawthorne 1998 y Borovikova y Kurazhkovskaya 2005). Como se indicó en el capítulo 4, la vesubianita es uno de los primeros minerales en formarse junto con la wollastonita, cuyo par temométrico arrojo un valor de $503^{\circ} \mathrm{C}$, por lo que dicha temperatura podría corresponder a la temperatura del inicio del proceso metasomático.

Finalmente y como método complementario-experimental se aplicó el geotermómetro granate-clinopiroxeno de Krogh Ravna (2000), las temperaturas obtenidas son del orden de $\operatorname{los} 402,17$ y $575,89^{\circ} \mathrm{C}$ y se consideran aceptables para la formación del skarn, aunque no podrían haber sido interpretadas como datos aislados ya que este geotermómetro no ha sido calibrado para estas composiciones de granate y clinopiroxenos. 


\subsection{CONCLUSIONES}

Los métodos analíticos abordados en el presente capítulo indican que el skarn San Miguel comenzó a formarse a una temperatura estimada en del orden de los $660-690^{\circ} \mathrm{C}$ con la cristalización de wollastonita y vesubianita. La cristalización de estos minerales se produjo como consecuencia de la interacción del protolito carbonático con un fundido cuya fase fluida es acuosa y de baja salinidad y que fue generado por los procesos de migmatización del gneis biotítico ocurrido durante el metamorfimo regional correspondiente al ciclo Tansamazoniano. De acuerdo a Kornprobst (1994) los fluidos derivados de series metapeliticas que pertenecen a facies esquistos verdes y anfibolitas (grado metamórfico determinado para las rocas del área de estudio) son particularmente ricos en agua, mientras que los de las rocas que han cristalizado en facies granulitas son, por el contrario, muy pobres en agua pero ricos en $\mathrm{CO}_{2}$. 


\subsection{BIBLIOGRAFÍA}

Bodnar, R.J. 1992. Revised equation and table for freezing point depressions of $\mathrm{H}_{2} \mathrm{O}$-salt fluid inclusions (abstract): PACROFI IV, 4th biennial Pan-American Conference on Research on Fluid Inclusions, Program and Abstracts 15p., Lake Arrwhead.

Bodnar, R.J. 1995. Fluid-inclusion evidence for magmatic source for metals in porphyry copper deposits. Mineralogical Association of Canada Short Course Series 23: 139-152.

Borovikova, E.Y. y Kurazhkovskaya, E.S. 2005. Infrared spectra and factor group analysis of vesuvianites in OH region. Vibrational Spectroscopy 39: 95-98.

Bottinga, Y. 1968. Calculation of fractionation factors for carbonand oxygen isotopic exchange in the system calcite-carbon dioxide-water. Journal of Physical Chemistry 72: 800-808.

Brown, P.E., Bowman, J.R. y Kelly, W. 1985. Petrologic and Stable Isotope Constraints on the Source and Evolution of Skarn-Forming Fluids at Pine Creek, California. Economic Geology 80: 72-95.

Delpino, S.H. 2000. Evolución metamórfica del sector nororiental del basamento de Tandilia, Argentina: Metamorfismo en facies granulita y anatexis cortical. Tesis Doctoral, Universidad Nacional del Sur (inédita), 180p., Bahía Blanca.

Farmer, V. C. 1974. The layer silicates. En Farmer, V. C. (ed.) The Infrared Spectra of Minerals. Mineralogical Society, London: 331-363.

Gnos, E. y Armbruster, T. 2006. Relationship between metamorphic grade, vesuvianite "rod polytypism", and vesuvianite composition. American Mineralogist 91: 862-870.

Goldstein, R.H. y Reynolds, T.J. 1994. Are fluid inclusions representative samples of diagenetic fluids? and Fluid inclusion microthermometry. En Systematics of fluid inclusions in diagenetic minerals. SEPM short course 31. Society for Sedimentary Geology. 43-63 y 87-121, Tulsa, Oklahoma.

Groat, L.A. y Hawthorne, F.C. 1998. Diffuse reflections and the symmetry of vesuvianite. Phase Transitions 67: 137-151.

Groat, L.A., Hawthorne, F.C. y Ercit, T.S. 1992. The role of fluorine in vesuvianite: a crystal structure study. Canadian Mineralogist 30: 1065-1075. 
Groat, L.A., Hawthorne, F.C., Rossman, G.R. y Ercit, T.S. 1995. The infrared spectroscopy of vesuvianite in the $\mathrm{OH}$ region. Canadian Mineralogist 33: 609626.

Hochella, M.F., Liou, J.G., Keskinen, M.J. y Kim, H.S. 1982. Synthesis and stability relations of magnesium idocrase. Economic Geology 77: 798-808.

Hoef, J. 1987. Stable Isotope Geochemistry. Verlín, Springer-Verlag, $3^{\circ}$ edición, $241 \mathrm{p}$.

Kornprobst, J. 1994. Les roches métamorphiques et leur signification géodynamique: Précis de pétrologie. Enseignement des sciences de la terre, Masson, 245 p., París.

Krogh Ravna, E. 2000. The garner-clinopyroxene $\mathrm{Fe}^{+2}-\mathrm{Mg}$ geothermometer: an updated calibration. Journal of Metamorphic Geology 18: 211-219.

Meinert, L., Dipple, G. y Nicolescu, S. 2005. World Skarn Deposits. Economic Geology, 100th Aniversary Volume: 299-336.

Nash, J.T. 1976. Fluid inclusion petrology-data from porphyry copper deposits and application to exploration. U. S. Geology Survey Paper 907-D.

Roedder, E. 1971. Metastability in fluid inclusions. Society of Mining Geology of Japan, Special Issue 3: 327-334.

Roedder, E. 1984. Fluid Inclusions. Mineralogy Society of America. Reviews in Mineralogy 12, $644 \mathrm{p}$.

Roedder, E. y Bodnar, R.J. 1980. Geologic pressure determinations from fluid inclusion studies. Annual Review of Earth and Planetary Sciences 8: 263301.

Shepherd, T.J., Rankin, A.H. y Alderton, D.H. 1985. A practical guide to fluid inclusion studies. Glasgow, Blackie and Son, 239 p.

Valley, J.W., Peacor, D.R., Bowman, J.R., Essene, E.J. y Allard, M.J. 1985. Crystal chemistry of a Mg-vesuvianite and implications of phase equilibria in the system CaO-MgO- $\mathrm{Al}_{2} \mathrm{O}_{3}-\mathrm{SiO}_{2}-\mathrm{H}_{2} \mathrm{O}-\mathrm{CO}_{2}$. Journal of Metamorphic Geology 3: 132-153.

Velasco, F. 2004. Introducción al estudio de inclusiones fluidas. En UNESCO y SEG (eds.) 23 Curso de Metalogenia 98 p., Mendoza.

Warren, B.E. y Modell, D.I. 1931. The structure of vesuvianite $\mathrm{Ca}_{10} \mathrm{Al}_{4}(\mathrm{Mg}, \mathrm{Fe})_{2} \mathrm{Si}_{9} \mathrm{O}_{34}(\mathrm{OH}) 4$. Zeitschrift für Kristallographie78: 422-432.

Werner, A.G. 1795. Über Vesuvian. Klaproth`s Beiträge: 1-34. 
Zhang, Y.G. y Frantz, J.D. 1987. Determination of homogenization temperatures and densities of supercritical fluids in the system $\mathrm{NaCl}-\mathrm{KCl}-\mathrm{CaCl} 2-\mathrm{H} 2 \mathrm{O}$ using synthetic fluid inclusions. Chemical Geology 64 : 335-350.

Zheng, Y.F. 1993a. Calculation of oxygen isotope fractionation in anhydrous silicate minerals. Geochimica et Cosmochimica Acta 57: 1079-1091.

Zheng, Y.F. 1993b. Calculation of oxygen isotope fractionation in hydroxyl-bearing silicates. Earth Planet Science Letter 120: 247-263.

Zheng, Y.F. 1999. Oxygen isotope fractionation in carbonate and sulfate minerals. Geochemical Journal 33:19-126. 
CAPÍTULO 6

\section{DISCUSIÓN Y CONCLUSIONES FINALES}
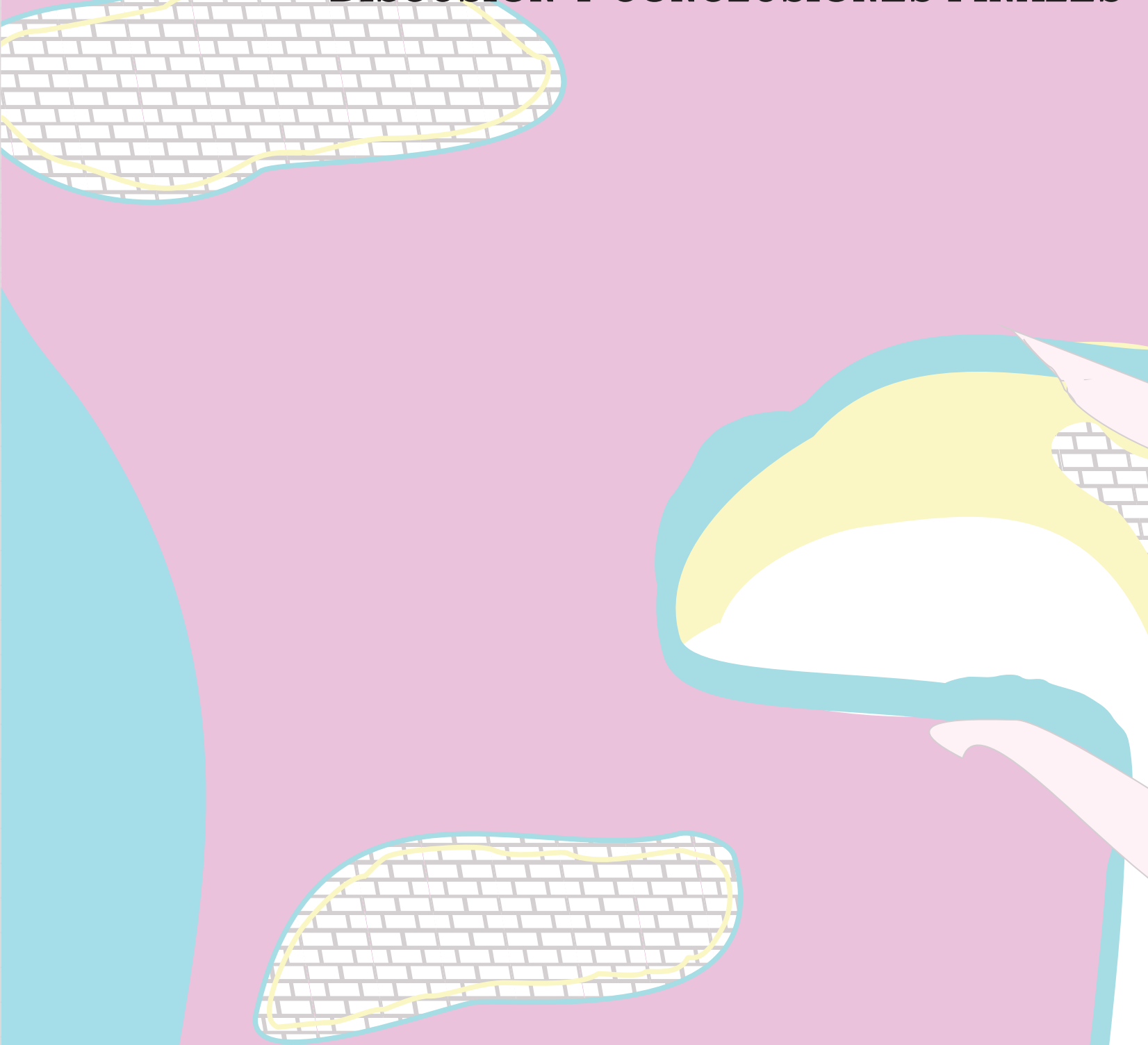


\subsection{INTRODUCCIÓN}

En el presente capítulo se realiza un análisis de los resultados de los estudios geológicos, petrológicos, mineralógicos y geoquímicos de las rocas que afloran en el área de San Miguel. El objetivo principal es reconstruir su historia geológica, vinculando los diversos procesos que dieron origen a los distintos tipos de rocas, en especial al skarn San Miguel. Para este último, se plantea un modelo evolutivo que fue delineado a partir de las condiciones físico-químicas del fluido y de las características del protolito carbonático involucrado.

\subsection{DISCUSIÓN}

\subsubsection{Evolución del basamento del área de San Miguel}

En el área de San Miguel, afloran principalmente rocas del basamento denominado Complejo Buenos Aires (Marchese y Di Paola 1975), entre las que se destacan gneises biotíticos migmáticos, migmatitas, anfibolitas, mármoles y un skarn asociado, además de un conjunto de rocas ígneas. Estas últimas litologías están representadas por un cuerpo granítico que constituye el Cerro Guacho, otro de composición tonalítica que aflora en el casco de la Ea. San Miguel y en el Cerro Los Angelitos (Ea. Siempre Verde) y dos tipos de diques: granítico y andesítico-basáltico.

Los procesos del metamorfismo regional que afectaron al área de estudio ocurrieron durante el ciclo Transamazoniano ya que la edad obtenida por otros autores (Halpern et al. 1970, Halpern 1972, Rapela et al. 2007 y Cingolani 2010) para las rocas formadas por estos procesos, rondan los 2.200 Ma. Los resultados de los análisis geoquímicos (fundamentalmente de Tierras Raras y de isótopos estables) indican que estas rocas metamórficas, derivan principalmente de protolitos sedimentarios. Dichas 
rocas habrian sido grauvacas o wackes y carbonatos, las que posteriormente fueron transformadas en un gneis biotítico y en un mármol, respectivamente.

La presencia de una importante anomalía positiva de $\delta^{13} \mathrm{C}$ identificada en este mármol, indica que el carbonato del cual deriva, se habría depositado en un ambiente marino durante un período caracterizado por un aumento en la producción de carbono orgánico en los océanos, conocido como "Evento Lomagundi-Jatuli" (Schidlowski et al. 1975 y 1976, Karhu y Holland 1996). Dicho evento fue registrado en diversas unidades carbonáticas pertenecientes a distintos cratones y se estima que ocurrió entre los 2.450 y 2.060 Ma aproximadamente (Karhu y Holland 1996, Melezhik et al. 2005 y 2007 y Bekker et al. 2008).

Por otro lado, el mármol se encuentra englobado por el gneis biotítico migmático, esto último manifiesta que luego de la depositación del carbonato, se produjo un cambio que generó una importante sedimentación clástica que constituyó los wackes o grauvacas. Este tipo de rocas sedimentarias "con gran cantidad de fragmentos líticos, generalmente de rocas plutónicas y volcánicas” (Boggs 2009), es un indicador de ambientes tectónicos inestables o activos ya que poseen una baja madurez textural y composicional. Cabe destacar que durante el Arqueno-Proterozoico se registra una importante depositación de grauvacas ya que las áreas emergidas eran esencialmente arcos volcánicos (Alonso Zarza 2010). En concordancia con esto último, Chernicoff et al. (2014) proponen el inicio de un período de subducción entre los 2.230 y los $2.166 \mathrm{Ma}$, teniendo en cuenta las edades más jóvenes obtenidas a partir de circones magmáticos procedentes de rocas gneísicas del Complejo Buenos Aires obtenidas por Cingolani et al. (2002). Dicha zona de subducción, buzante hacia el sur (Teruggi et al. 1988), generó la formación de un arco magmático en la margen norte de las Sierras Septentrionales (Varela et al. 1988, Teruggi et al. 1988, Ramos et al. 1990 y Ramos 1999).

Durante esta etapa, dichas rocas clásticas fueron intruidas por 
cuerpos subvolcánicos de composición básica. Estos cuerpos tipo filón capa fueron descriptos también por Quartino y Villar Fabre (1967) en el cerro Centinela (Tandil) y por Delpino (2000) en la Sierra de Bachicha y Cerro el Triunfo (Balcarce). En el área de estudio, los mismos fueron fragmentados como consecuencia de la deformación de la secuencia sedimentaria, conformando así xenolitos máficos, al mismo tiempo que la generación de anomalias térmicas promovieron procesos metamórficos asociados.

En este contexto, el metamorfismo regional provocó la deshidratación de la secuencia sedimentaria clástica y la formación de un gneis biotítico, constituido además por feldespato potásico, plagioclasas y cuarzo, con una fábrica anisótropa planar de tipo bandeado gnéisico con rumbo $\mathrm{N} 35^{\circ} \mathrm{E}$. Dicha orientación es coincidente con el dominio tectónico B propuesto por Teruggi et al. (1973 y 1974), desarrollado en gran parte hace 2.000 Ma. Este período es interpretado como un episodio de colisión entre Tandilia y el terreno de Buenos Aires (Ramos 1999) o proto-cratón del Río de la Plata (Cingolani 2010), que interrumpió la actividad del arco magmático generado por subducción (Ramos et al. 1990). Esta colisión produjo deformación y metamorfismo, alcanzando el nivel de facies anfibolitas de acuerdo al grado determinado para las rocas de la región. Durante la deformación, los xenolitos máficos se hidrataron como consecuencia de la interacción con los fluidos provenientes de la deshidratación de los protolitos sedimentarios, y de esta forma, fueron afectados también por las nuevas condiciones de $\mathrm{P}$ y $\mathrm{T}$, desarrollando la siguiente asociación mineral: hornblenda + plagioclasa \pm titanita \pm apatita \pm minerales opacos, característica de una anfibolita en facies anfibolitas.

Al mismo tiempo, los fragmentos del carbonato se metamorfizaron, constituyendo un mármol cuya asociación mineral es calcita + diópsido, que indica un grado metamórfico en facies anfibolitas, en concordancia con el resto de las rocas metamórficas de la región. Además de los estudios de isótopos estables que determinaron la procedencia del protolito de este mármol y por este medio una estimación de su edad, la aplicación de un 
geotermómetro de oxígeno calcita-diópsido, (Valley 2003) determinó una temperatura de $716{ }^{\circ} \mathrm{C}$ para este metamorfismo, acorde a una transición entre facies anfibolita y granulita.

La evolución del proceso metamórfico generó la fusión parcial del gneis a través de la deshidratación de la biotita (Thompson 1982, Le Breton y Thompson 1988 y Patiño Douce y Johnston 1991) y la consecuente formación de migmatitas en las que pudieron diferenciarse leucosomas con y sin granate. Estas migmatitas se formaron inicialmente aún bajo el mismo régimen deformacional, ya que se desarrollaron estructuras estromáticas (Mehnert 1968) de igual orientación que el bandeado composicional del gneis. El aumento de la fusión parcial y la acción de las presiones externas generó la migración de los leucosomas, que comenzaron a intruirse dentro del gneis biotítico como cuerpos leucocráticos más voluminosos, muchos con granate predominantemente almandínico (Prp $\operatorname{Pr}_{13} \mathrm{Alm}_{72} \mathrm{Sp}_{12}$ Gro3) y también dentro de los cuerpos de mármol. Los grandes cristales de calcita del mármol propiciaron la formación de planos de debilidad (a través de la orientación de los planos de clivaje), por los que se infiltraron los fluidos y también los fundidos anatécticos. Esta intrusión en forma de filones (o de forma más irregular cuando no lo hace a través de estos planos) generó las condiciones necesarias para el inicio del proceso de metasomatismo y consecuente formación del skarn San Miguel.

La colisión también provocó la intrusión de cuerpos ígneos que se formaron como producto del reciclado de la corteza continental. Si bien este tipo de procesos es más importante en sectores ubicados al norte del área de estudio, como en las Sierras de Tandil, Sierras del Tigre y Sierra Alta de Vela (Dalla Salda et al. 2005), el granito del Cerro Guacho, la tonalita de la Ea. San Miguel y Cerro Los Angelitos, y los diques graníticos son ejemplos de estos cuerpos. En el Cerro Guacho aflora un granito de grano medio a fino que se intruyó en el gneis biotítico arrastrando en su ascenso xenolitos máficos y fragmentos de gneis. Si bien el granito no presenta un bandeamiento o deformación visible a escala mesoscópica, en el estudio 
petrográfico se identificaron microestructuras generadas por deformación y recuperación.

Dado que, para litologías de esta antigüedad, la tarea de clasificación de rocas de origen ígneo y metamórfico resulta en algunos casos sumamente dificultosa, el hallazgo de cuerpos pegmatoideos portadores de turmalina, fue de mucha utilidad en la definición del origen ígneo del granito del Cerro Guacho. Su clasificación tectónica, mediante estudios geoquímicos, es similar a la del resto de los granitos estudiados por Dalla Salda y Franzese (1989), que poseen características transicionales entre granitos sincolisionales y de arco volcánico. Según estos autores esto se debe a que los procesos de anatexis cortical se produjeron sobre una corteza que había sido previamente re-trabajada tras la formación del arco magmático durante el cierre de la cuenca que mantuvo separado al terreno de Tandil del resto del Cratón del Río de la Plata.

La tonalita que aflora en el Cerro Los Angelitos y en el casco de la Ea. San Miguel, se pone de manifiesto a través de las relaciones de corte, como una formación posterior al gneis y a los leucosomas. Su tamaño de grano es medio a grueso y en algunos sectores presenta foliación que junto con la vinculación a los leucosomas de las migmatitas, indican un ambiente meso a catazonal. Tanto la tonalita como el granito antes mencionado no presentan relaciones de contacto en afloramiento con el skarn San Miguel. Geoquímicamente, la tonalita también posee características transicionales entre los granitos sincolisionales y de arco volcánico. Esta roca podría estar asociada a la anatexis de cuerpos básicos o, a la fusión parcial en la corteza inferior-media (protolitos mixtos máficos-gneísicos) que también genera magmas de composición intermedia (González Menéndez et al. 2006).

Adicionalmente, se definió un conjunto de diques integrados por cuerpos granítico-granodioríticos y un dique andesítico-basáltico. Estos cuerpos intruyen a todas las unidades antes descriptas por lo que representan el evento más joven dentro de la evolución ígneo-metamórfica del basamento del área de estudio. 
Los primeros corresponden a granitos calco-alcalinos, metaluminosos con tendencia a la peraluminosidad, con una signatura geoquímica que los ubica en un zona de transición entre los granitos sin-colisionales y de arco volcánico, en coincidencia con los granitos de Tandil. Estas características son concordantes con la de los granitoides de alta $\mathrm{SiO}_{2}$ que son los últimos residuos en cristalizar y tienen además de agua, volátiles ricos en aluminio. Análisis petrográficos y geoquímicos, especialmente de Tierras Raras, revelaron importantes similitudes, indicando que estos diques podrian derivar del mismo fundido granítico que se emplazó a través de un sistema de fallas de rumbo NO-SE. Dicha orientación coincide con la determinada para el dominio tectónico C (Teruggi et al. 1973) y corresponde a planos estructurales que han controlado la inyección de diques de composición básica y en reducidos sectores también de composición ácida.

Los diques graníticos del sector corresponden a la primera mención de este tipo de cuerpos en el ámbito de las Sierras Septentrionales, aunque los mismos poseen similitudes petrográfico-geoquímicas con los filones capa de igual composición, emplazados en la foliación de gneises biotíticos que afloran en el Cerro Centinela (Quartino y Villar Fabre 1967). Esto podría deberse a que los fundidos que formaron ambos tipos de cuerpos, derivan de la anatexis y reciclado de la corteza continental, aunque su modo de emplazamiento sea diferente.

Por otra parte el dique básico (andesítico-basáltico) es calcoalcalino de potasio medio y se emplazó en una zona de cizalla, con una actitud similar a la de los diques graníticos, siendo sometido a un proceso de deformación frágil-dúctil evidenciado por la presencia porfiroclastos de plagioclasa con bordes deformados y una matriz con planos de disolución por presión y planos de diaclasamiento. Según las relaciones geoquímicas $(\mathrm{La} / \mathrm{Yb})_{\mathrm{N}}$ y $(\mathrm{La} / \mathrm{Sm})_{\mathrm{N}}$ obtenidas, este dique posee afinidad con los correspondientes a la suite calcoalcalina para la cual Teixeira et al. (2002) determinaron una edad de aproximadamente $2.000 \mathrm{Ma}$. En este sentido, Iacumin et al. (2001), propusieron que este tipo de diques calcoalcalinos derivaron de la fusión 
parcial de material mantélico, posteriormente afectado por metasomatismo, a partir de la interacción con material cortical.

Los procesos antes descriptos que determinaron la formación de las rocas que afloran en el área de San Miguel, pueden ser explicados teniendo en cuenta además los estudios realizados por otros autores, en el contexto tectónico de una cuenca de retro-arco asociada a una subducción corteza oceánica-corteza continental.

De acuerdo al esquema de evolución tectónica propuesto para las Sierras Septentrionales (Teruggi et al. 1988, Ramos et al. 1988, Ramos 1999 y Cingolani 2010), las rocas del área de San Miguel corresponderían al relleno de uno de los depocentros de una cuenca marginal formada a partir de un rift en el retro-arco (Fig. 6.1a).

La extensión en estos sistemas de rift, se forman en respuesta a cambios en la tasa de subducción o a un "empinamiento" de la capa subductante (Uyeda y McCabe 1983, Tamaki y Honza 1991 y Honza 1993), que genera adelgazamiento de la litósfera con el consecuente levantamiento pasivo de la astenósfera (Turcotte y Oxburgh 1973; Coblentz et al. 1994). Este fenómeno genera fallamiento de la corteza superior, acompañado por un ascenso de la astenósfera y un calentamiento de la litósfera. Este tipo de cuencas puede progresar y provocar la separación de la corteza y la apertura de cuencas oceánicas limitadas, sin embargo, como las tasas de convergencia de placas que chocan son variables en el tiempo, dichas cuencas son generalmente de corta duración. Tras un nuevo aumento de las tasas de convergencia, los sistemas extensivos de retro-arco son propensos a la destrucción por esfuerzos de compresión (Uyeda y McCabe 1983, Cloetingh et al. 1989, Jolivet et al. 1989, Ziegler y Cloetingh 2004, Letouzey et al. 1991, Nikishin et al 2001). En este sentido, la evolución de una cuenca oceánica al norte de la zona de estudio, interpretada a partir de los estudios realizados sobre la Formación El Cortijo (Teruggi et al. 1988, Ramos et al. 1990 y Chernicoff et al. 2014) y la posterior generación del arco magmático de Tandil como consecuencia del inicio de la subducción de dicha corteza 
oceánica (Varela et al. 1988, Teruggi et al. 1988, Ramos et al. 1990 y Ramos 1999), concuerdan con la posibilidad de la existencia de una cuenca de retro-arco con depositación de rocas sedimentarias de ambiente marino en las áreas de San Miguel y Punta Tota (Delpino 2000) y la intrusión de cuerpos básicos subvolcánicos (Fig. 6.1a y b). Estas áreas podrian haber constituido inicialmente depocentros separados, lo que justificaría las diferencias composicionales de los protolitos de las rocas metamórficas y el estado de deformación de los afloramientos.

El calor generado por el ascenso astenosférico, sumado al emplazamiento de cuerpos ígneos en la zona del arco magmático generó deformación y metamorfismo de las rocas de la secuencia sedimentaria (Fig. 6.1c) formándose asî los gneises biotíticos, mármoles y anfibolitas (Fig. 6.1d). Finalmente tras la colisión se constituye la estructuración final de los gneises, y asociado a la fusión parcial de los mismos, la formación de migmatitas. La interacción de estos leucosomas o leucogranitos con los mármoles provocó metasomatismo y la formación del skarn San Miguel (Fig. $6.1 \mathrm{e})$.

El reciclado de la corteza continental tras la colisión de Tandilia por el cierre de la cuenca oceánica (Dalla Salda et al. 1992), ocasionó el ascenso de cuerpos ígneos como el granito que aflora en el Cerro Guacho y la tonalita del Cerro Los Angelitos y del casco de la Ea. San Miguel (Fig. 6.1f). El mismo proceso podría atribuirse a la intrusión de diques graníticos tardíos que se emplazaron a través de un sistema de fallas con rumbo NO-SE, mientras que el dique intermedio-básico (andesítico-basáltico) aprovechó posteriormente uno de estos planos de falla para emplazarse (Fig. 6.1g).

A continuación se presenta el esquema evolutivo propuesto para la región, en particular del sector San Miguel, el cual fue construido sobre la base de la investigación realizada, y complementada por la información de otras contribuciones bibliográficas consultadas. 

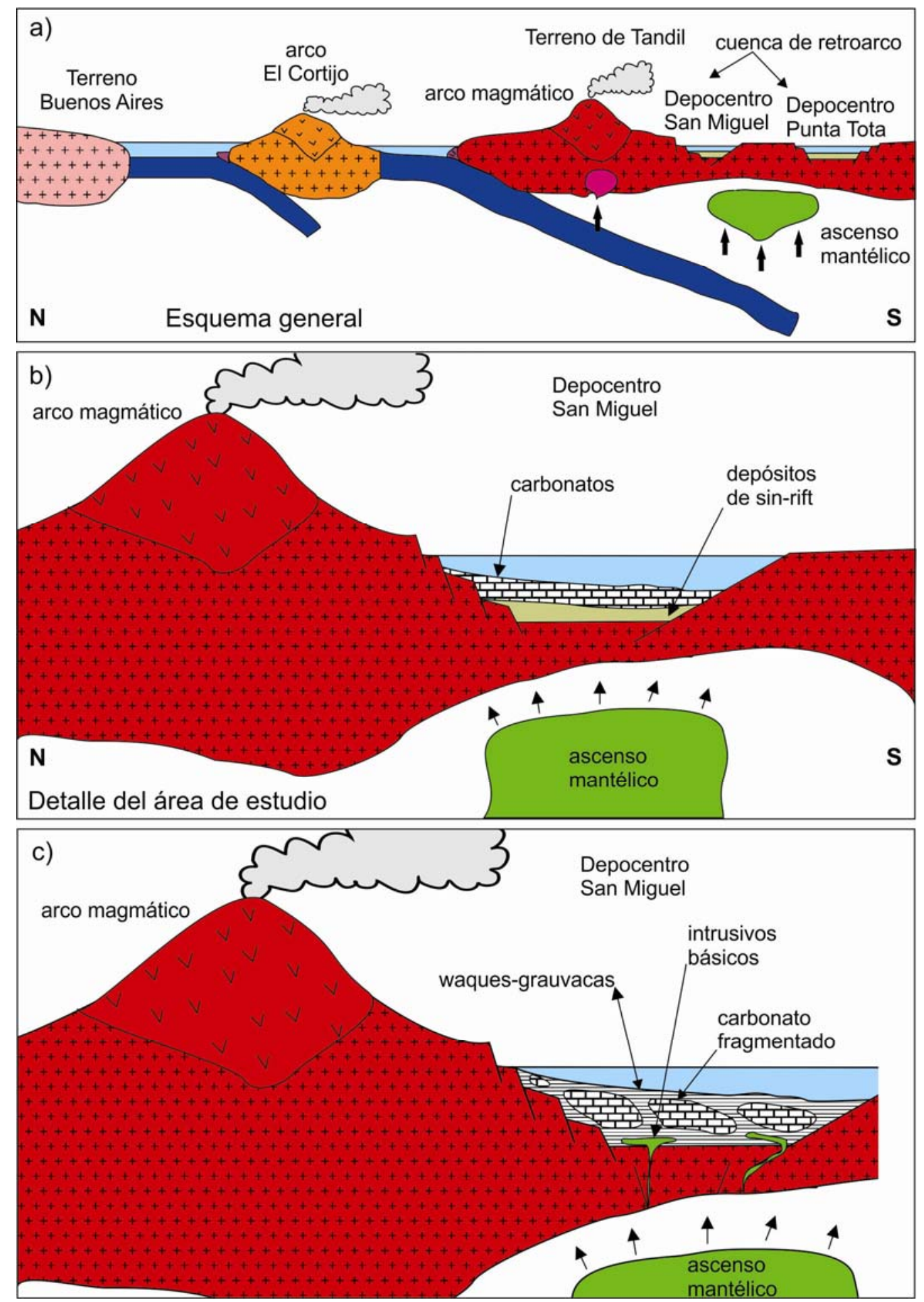


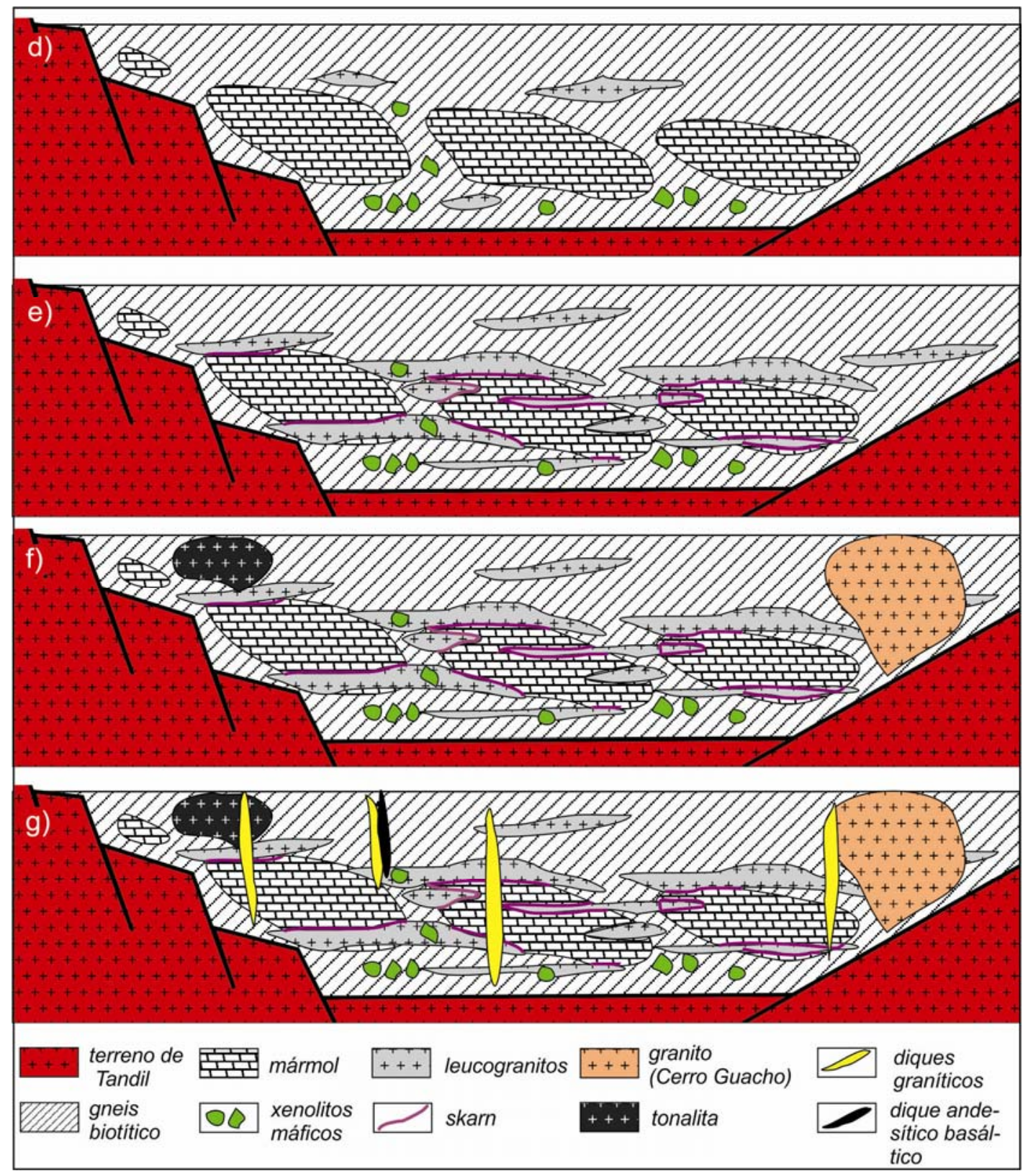

Figura 6.1: Evolución del área de San Miguel en contexto con el ambiente tectónico propuesto por Teruggi et al. (1988), Ramos et al. (1990), Dalla Salda et al. (1992), Ramos (1999), Dalla Salda et al. (2005) y Cingolani (2010), para las Sierras Septentrionales de la provincia de Buenos Aires.

Evolución detallada:

a) Esquema de evolución de Tandilia, donde se observa que el área de San Miguel correspondería a un posible depocentro de una cuenca de retro-arco, 
generada por un proceso de extensión asociado a la formación del arco magmático de Tandil con anterioridad a los 2.200 Ma.

b) Tras los depósitos de sin-rift se depositó el carbonato que actuó como protolito del mármol. De acuerdo a los valores $\delta^{13} \mathrm{C}$ obtenidos, esto ocurrió durante el "Evento Lomagundi-Jatuli" entre 2.450 y 2.060 Ma aproximadamente.

c) Los cambios en el régimen de sedimentación provocaron la depositación de gran cantidad de sedimentos clásticos (principalmente de rocas ígneas) que formaron wackes o grauvacas; durante esta etapa también se intruyeron cuerpos ígneos básicos provenientes de la fusión parcial del manto superior.

d) Dentro de la cuenca la anomalia térmica, generada por el ascenso de material mantélico, propició las condiciones para el desarrollo de procesos metamórficos y la transformación de carbonatos y wackes en mármoles y gneises; el agua liberada por estos protolitos hidrató los cuerpos básicos que fueron transformados en anfibolitas.

e) La evolución del metamorfismo generó fusión parcial del gneis y la formación de migmatitas, cuyos leucosomas se intruyeron en el mármol en forma de leucogranitos, generando la formación del skarn San Miguel.

f) Como resultado del reciclado de la corteza, producto de la colisión, se formaron cuerpos ígneos graníticos y tonalíticos.

g) Material granítico, generado también como resultado del proceso anterior, se intruyó a través de un sistema de fallas con rumbo NO-SE, conformando los diques graníticos. Finalmente, un dique calcoalcalino andesíticobasáltico se intruyó en una zona de cizalla con una actitud similar a la de los diques graníticos, durante una etapa transtensiva en el ciclo Transamazoniano.

\subsubsection{Modelo genético del skarn San Miguel}

El skarn San Miguel se formó a partir de la intrusión de los leucosomas generados por la fusión parcial del gneis biotítico (leucogranitos), 
en los núcleos de mármol calcítico (Fig. 6.2a). Dicho origen es acorde con el determinado por Delpino (2000) para el skarn que aflora en Punta Tota, Balcarce.

Estos fundidos de origen anatéctico, de composición graníticagranodiorítica, liberaron tras su intrusión fluidos acuosos ricos en $\mathrm{Si}, \mathrm{Fe}, \mathrm{Al}$ y Mg. En este sentido, el análisis de inclusiones fluidas determinadas indican un sistema acuoso predominantemente $\mathrm{NaCl}-\mathrm{H}_{2} \mathrm{O} / \mathrm{NaCl}-\mathrm{KCl}-\mathrm{H}_{2} \mathrm{O}$, con baja salinidad < al $7 \%$ en peso eq. de $\mathrm{NaCl}$, y temperaturas de homogeneización entre 250 y $320^{\circ} \mathrm{C}$ para la mayoria de las paragénesis minerales identificadas. Sin embargo, estudios de isótopos estables permitieron, a través de la aplicación de geotermómetros de $\delta^{18} \mathrm{O}$, la obtención de temperaturas mayores, indicando que el proceso de metasomatismo se inició alrededor de los $553^{\circ} \mathrm{C}$. Sumado a esto la corrección de las Th mediante la realización de isocoras y la utilización de una presión de 5,5 Kbares (Delpino 2000), indica temperaturas de cristalización del orden de los $660-690^{\circ} \mathrm{C}$.

Este skarn posee un marcado dominio de las paragénesis prógradas que se distribuyen en cinco zonas identificadas en los afloramientos de las canteras de la estancia San Miguel (sectores noriental y noroccidental). Las mismas corresponden a las zonas de wollastonita-vesubianita (Fig. 6.2b), granate-clinopiroxeno (Fig. 6.2c) y clinopiroxeno (Fig. 6.2d) en el exoskarn, y granate-clinopiroxeno (Fig. 6.2e) y clinopiroxeno-plagioclasa cálcica (Fig. 6.2f), en el endoskarn.

Esta zonación se explica a partir de las modificaciones en los gradientes de las actividades de cationes como $\mathrm{Si}^{+4}, \mathrm{Ca}^{+2}, \mathrm{Mg}^{+2}, \mathrm{Fe}^{+2}, \mathrm{Fe}^{+3}$ y $\mathrm{Al}^{+3}$ que son transportados por la fase fluida que reacciona con el $\mathrm{CaCO}_{3}$ (Bowman 1998). En la zona más cercana al contacto roca ígnea-roca carbonática, se genera el "frente estacionario de reacción" (Dipple y Gerdes 1998), donde la producción de fluidos acuosos junto con la elevada $a\left(\mathrm{Ca}^{+2}\right)$, promueve las condiciones necesarias para la formación de wollastonita, a través de las primeras reacciones de descarbonatación. En este sentido los diagramas de actividades para sistemas acuosos $a\left[\left(\mathrm{Ca}^{+2} /\left(\mathrm{H}^{+}\right)\right]\right.$vs 
$a\left[\left(\mathrm{Al}^{+3}\right) /\left(\mathrm{H}^{+}\right)\right]$y $a\left[\left(\mathrm{Ca}^{+2} /\left(\mathrm{H}^{+}\right)\right]\right.$vs $a\left[\left(\mathrm{Mg}^{+3}\right) /\left(\mathrm{H}^{+}\right)\right]$(Bowers et al. 1984) muestran como elevados valores de $a\left[\left(\mathrm{Ca}^{+2} /\left(\mathrm{H}^{+}\right)\right]\right.$son requeridos para estabilizar la reacción de formación de wollastonita (Fig 6.3a y b).
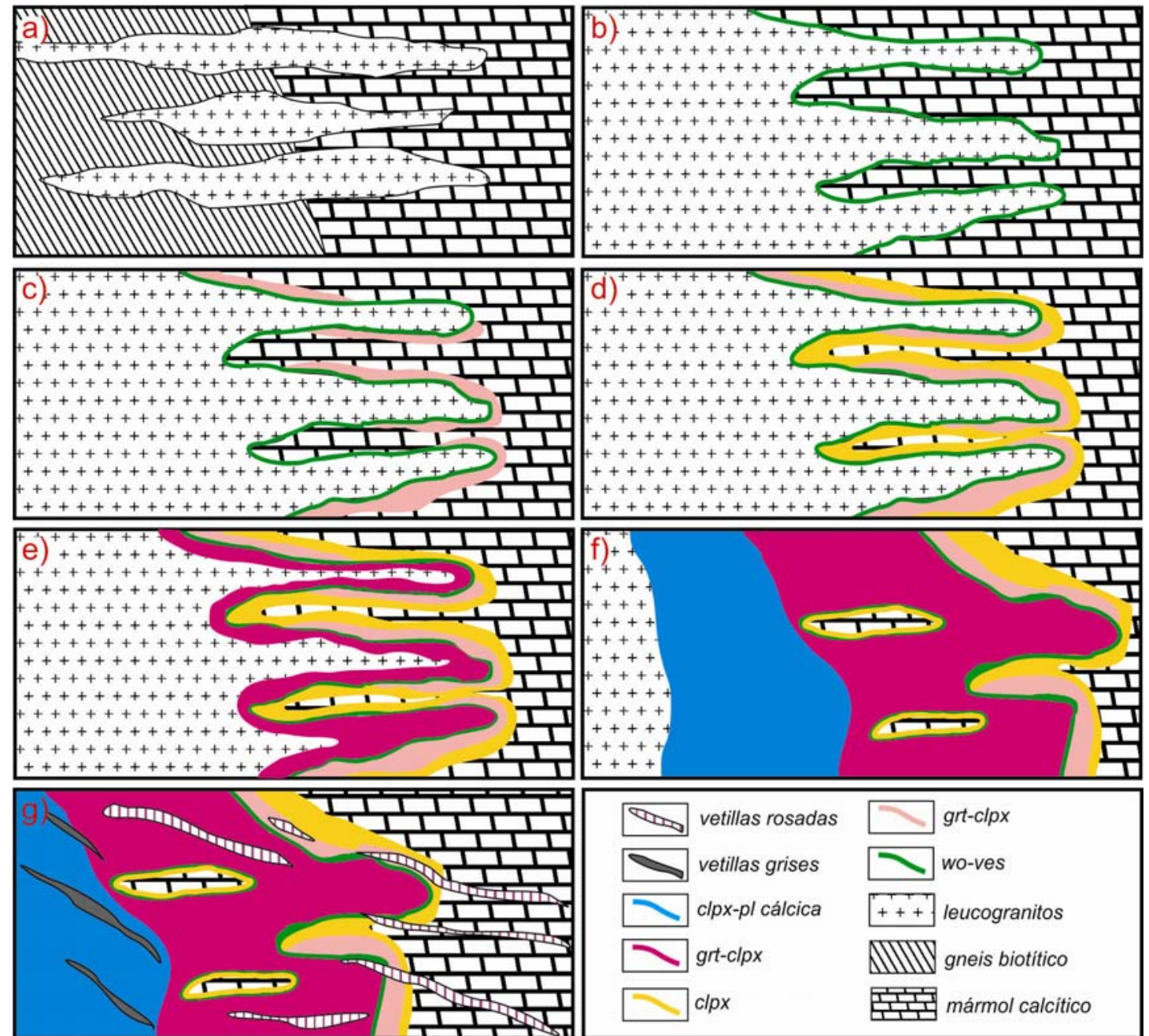

Figura 6.2: Esquema evolutivo de formación del skarn San Miguel, donde se grafica el desarrollo de las diferentes zonas minerales. Detalles:

a) Leucosomas producidos por la fusión parcial del gneis intruido (leucogranitos) en el mármol. Exoskarn: b) Desarrollo de la zona de wollastonita-vesubianita (en verde). c) Aparición de la zona de granate-clinopiroxeno (en rosa claro). d) Desarrollo de la zona de clinopiroxeno (en amarillo).

Endoskarn: e) Zona de granate-clinopiroxeno (rosado intenso). f) Desarrollo de la zona de clinopiroxeno. g) Etapa de retrogradación con desarrollo de vetillas grises y 
rosadas conformadas por clinozoisita y cuarzo respectivamente. Durante esta misma etapa se desarrollan coronas de clinozoisita sobre granate, pseudomorfismo de clinopiroxeno por anfiboles y la cristalización de apatita y titanita.

La paulatina incorporación de $\mathrm{CO}_{2}$ al fluido junto con el aumento en las actividades de iones como $\mathrm{Al}^{+3}, \mathrm{Fe}^{+2 /+3} \mathrm{y} \mathrm{Mg}^{+2}$, que poseen velocidades de difusión menores que el Si (Meinert et al. 2005), propició la formación de vesubianita que completó la paragénesis wollastonita-vesubianita (Bowman 1998). El análisis de las IF identificadas en vesubianita indican que este fluido era acuoso y de baja salinidad, evidenciando la falta de fases inmiscibles de $\mathrm{CO}_{2}$ (generado en las reacciones de descarbontación). Este debió haber sido eliminado en su mayoría del sistema o fue diluido en el fluido acuoso ingresante. En concordancia con lo anterior, la asociación vesubianita + wollastonita a $500{ }^{\circ} \mathrm{C}$ (temperatura determinada para su formación), sólo es estable hasta una $X_{\mathrm{CO}_{2}}<0,01$, ya que a mayores valores de $X_{c \notin 2}$ a esta asociación se suman minerales como granate o clinopiroxeno.
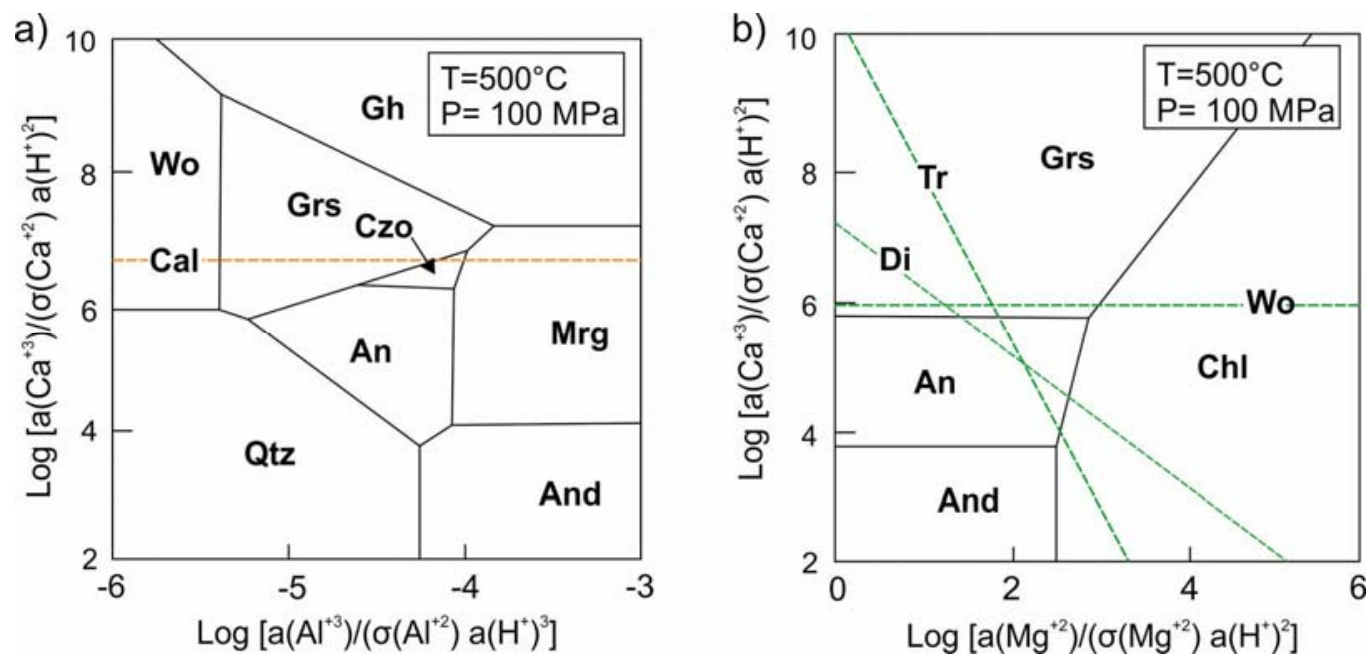

Figura 6.3: Diagramas de actividad de Bowers et al. (1984). a) $a\left[\left(\mathrm{Ca}^{+2} /\left(\mathrm{H}^{+}\right)\right]\right.$vs $a\left[\left(\mathrm{Al}^{+3}\right) /\left(\mathrm{H}^{+}\right)\right]$y b) $a\left[\left(\mathrm{Ca}^{+2} /\left(\mathrm{H}^{+}\right)\right]\right.$vs $a\left[\left(\mathrm{Mg}^{+3}\right) /\left(\mathrm{H}^{+}\right)\right]$.

La intensificación del flujo incrementó la movilización de $\mathrm{Si}, \mathrm{Fe}, \mathrm{Mg}$ y Al (Meinert et al. 2005), lo que permitió la cristalización de granate 
grosularítico predominantemente, contribuyendo con un mayor enriquecimiento en $\mathrm{CO}_{2}$, que inhibió las condiciones de formación de wollastonita (Bowman y Essene 1984). Este enriquecimiento fue menor a $x_{\mathrm{CO}_{2}}<0,05$, límite de estabilidad de la asociación vesubianita + grosularia.

Finalmente el incremento en $\mathrm{CO}_{2}$ y $\mathrm{Ca}^{2+}$ en los fluidos silíceos, que son portadores de $\mathrm{Fe}$ y de $\mathrm{Mg}$, favoreció la cristalización de clinopiroxeno de tipo diópsido (mayoritariamente) diseminado en el exoskarn (Bowman y Essene 1984). Aún en estas condiciones la $X_{\mathrm{Co} 2}$ sería menor a 0,11 , sin embargo evidencias de campo y petrográficas indican que en parte la zona de endoskarn clinopiroxeno-plagioclasa cálcica se formó a partir de la asimilación del mármol y no por procesos metasomáticos. Esta asimilación también provocó la incorporación mecánica de cristales de diópsido que se encontraban en el mármol (Quartino y Villar Fabre 1967).

La zonación descripta no fue identificada de manera completa en la totalidad de los afloramientos, como por ejemplo en San Miguel Sur y La Concordia, probablemente debido a la falta de destapes. Sin embargo para el afloramiento de la estancia Siempre Verde, esta explicación no es aceptable, ya que en la cantera donde aflora, se observa una sección posiblemente completa del skarn, y en ella no se identificaron ni cristales de granate ni de vesubianita. Cabe aclarar que este último es el afloramiento más afectado por los procesos de alteración meteórica. De esta forma la causa de la ausencia de estos minerales podría atribuirse a algunas de las siguientes situaciones, que están directamente relacionadas a la concentración de $\mathrm{CO}_{2}$ del fluido, considerando que granate y vesubianita son minerales que se forman, como ya se mencionó, con baja $x_{\mathrm{eaz}}$ :

1) Un estadio más avanzado del proceso metasomático en el cual el $\mathrm{CO}_{2}$ liberado en las reacciones de descarbonatación no hayan sido evacuadas del sistema y se hayan incorporado a los fluidos en mayor cantidad.

2) Predominio de procesos de asimilación respecto de los metasomáticos, generado por un mayor volumen de fundido anatéctico o porque el núcleo de mármol era de dimensiones más reducidas. En este 
sentido, análisis químicos de los afloramientos de skarn ubicados en las estancias La Concordia y Siempre Verde, revelan un alto enriquecimiento en Ca (mayor al 20\%), indicando que la composición original ha sido completamente obliterada.

A esta etapa prógrada se le superpone una leve retrogradación que consiste fundamentalmente en el reemplazo parcial de los minerales antes descriptos por tremolita, clinozoisita, apatita, titanita y escasas clorita y calcita. Dichos reemplazos consisten en el desarrollo de coronas de clinozoisita sobre granate y pseudomorfismo de diópsido por tremolita y clorita. Los últimos fluidos en circulación, dentro de esta etapa retrógrada, desarrollaron vetillas compuestas por cuarzo (vetillas grises) y clinozoisita (vetillas rosadas) que cortan a las zonas primarias o prógradas (Fig. 6.2g).

El escaso reemplazo de las paragénesis progradantes por minerales de menor temperatura da cuenta de la baja circulación de fluidos durante el enfriamiento del skarn. Esto, sumado a la baja salinidad estimada a partir del análisis de inclusiones fluidas podría ser la causa de la ausencia de mineralizaciones en el skarn San Miguel, más allá de pequeños cristalizados de ilmenita y esfalerita asociados a los cristales de clinopiroxeno, aunque por el tipo de intrusito (leucogranitos), no se descarta que el mismo haya sido estéril en su génesis.

El desarrollo del skarn San Miguel, muestra importantes diferencias con el que aflora en Punta Tota, Balcarce. En primer, lugar el protolito cabonático de San Miguel fue clasificado como calcítico mientras que el de Punta Tota, como dolomítico con una asociación mineral forsterita + espinelo + dolomita + calcita, indicando además un grado metamórfico en facies granulita (Delpino 2000 y Delpino y Dristas 2008), a diferencia del skarn San Miguel que se formó en facies anfibolita. Esto implica que el skarn Punta Tota se desarrolló en un ambiente con alto $\mathrm{Xco}_{2}$, esta condición restringió la formación de minerales como vesubianita y grosularia. Este último mineral cristaliza en los estadios retrógrados donde la serpentinización evidencia el aumento en la actividad del agua (Delpino 2000). En el skarn San Miguel la cristalización de wollastonita, grosularia, 
vesubianita y finalmente clinozoisita indica que los fluidos mineralizantes fueron predominantemente acuosos con $\mathrm{Xco}_{2}<0,1$ (Bowman 1998).

\subsection{CONCLUSIONES}

A partir de la información obtenida a través de los sucesivos estudios geológicos y geoquímicos ejecutados sobre las rocas que afloran en el área de San Miguel, se concluye que:

1- La porción de basamento del área de San Miguel representa una parte importante de la evolución del basamento de las Sierras Septentrionales, denominado Complejo Buenos Aires, que se extiende desde el Neoarqueno hasta el Paleoproterozoico tardío (1.700 Ma).

2- De acuerdo a los estudios de campo y análisis petrográficos y geoquímicos las rocas metamórficas (gneis y mármol) derivan de protolitos sedimentarios de origen marino, que se depositaron en una cuenca de retroarco, asociada a la formación del arco magmático de Tandil.

3- Sobre la base de los estudios de isótopos estables $\delta^{13} \mathrm{C}$ y $\delta^{18} \mathrm{O}$ realizados sobre el mármol, los carbonatos que actuaron como protolito se depositaron en un ambiente marino durante el "Evento Lomagundi-Jatuli", en el Paleoproterozoico temprano (2.450-2.060 Ma).

4- Análisis geoquímicos de Tierras Raras indican que el gneis biotítico se formó a partir de una grauvaca.

5- La orientación de la foliación del gneis $\mathrm{N} 35^{\circ} \mathrm{E}$ coincide con la dirección del Dominio tectónico B (Teruggi et al. 1973 y 1974) que se vincula con el evento de metamorfismo regional más importante para la formación de las Sierras Septentrionales. Este evento se desarrolló durante el Ciclo Transamazoniano, por la colisión del terreno de Tandil con el terreno de Buenos Aires o proto-Cratón del Río de la Plata y cierre de la cuenca sedimentaria. Dicho evento alcanzó un grado metamórfico de facies anfibolitas, acorde con el grado determinado para las rocas del área de 
estudio: diópsido + calcita para el mármol y hornblenda + plagioclasa \pm titanita \pm apatita \pm minerales opacos, para los xenolitos máficos. Respaldando lo anterior, el geotermómetro de oxígeno calcita-clinopiroxeno, indica una temperatura de $716^{\circ} \mathrm{C}$ para el proceso metamórfico.

6- La evolución del proceso metamórfico generó la fusión parcial del gneis biotítico con la consecuente formación de migmatitas con leucosomas y leucosomas granatiferos.

7- El granito que constituye el Cerro Guacho es el resultado de la anatexis de la corteza continental provocada por los efectos térmicos de la colisión entre los terrenos de Tandil y Balcarce durante el Ciclo Transamazoniano.

8- Los cuerpos tonaliticos podrian haberse formado por anatexis de cuerpos básicos o por la fusión parcial de protolitos mixtos máfico-gnéisicos que también pueden generar magmas de composición intermedia durante el mismo episodio metamórfico.

9- Los estudios de campo, petrográficos y geoquímicos indican que los diques graníticos poseen una relación genética entre sí y que se habrian formado a partir de la fusión parcial de la corteza continental. El fundido granítico generado se emplazó a través de un sistema de fallas cuya orientación NO-SE coincide con el Dominio tectónico C (Terrugi et al. 1973 y 1974).

10- El dique andesítico-basáltico presenta afinidad con los correspondientes a la suite calcoalcalina de edad paleoproterozoica.

11- El skarn San Miguel se formó a partir de la intrusión de los leucosomas o leucogranitos en el mármol calcítico.

12- Según los estudios de inclusiones fluidas de minerales del skarn los fluidos liberados de estos leucosomas tienen una salinidad < al $7 \%$ en peso equivalente de $\mathrm{NaCl}$ y corresponden a un sistema acuoso predominantemente $\mathrm{NaCl}-\mathrm{H}_{2} \mathrm{O} / \mathrm{NaCl}-\mathrm{KCl}-\mathrm{H}_{2} \mathrm{O}$.

13- La zonación mineral identificada en el skarn responde a la 
evolución química del mismo fluido acuoso a medida que fue interactuando con el mármol. Así, el fluido fue incorporando $\mathrm{CO}_{2}$ (aunque en bajas proporciones) y $\mathrm{Ca}$, que junto con la difusión de $\mathrm{Si}, \mathrm{Fe}, \mathrm{Mg}$ y $\mathrm{Al}$, determinaron la cristalización de wollastonita, vesubianita, grosularia y diópsido.

14- Los estudios termométricos indican que el skarn prógrado se formó en un intervalo de temperatura entre los $353-553^{\circ} \mathrm{C}$, según los geotermómetros de oxígeno, y entre 660 y $690^{\circ} \mathrm{C}$, según estudios de inclusiones fluidas, teniendo en cuenta la corrección por la presión sel sistema.

15- La ausencia de mineralizaciones metálicas en el skarn San Miguel estaría asociada al carácter estéril de los fundidos y fluidos provenientes de los procesos anatécticos. 


\subsection{BIBLIOGRAFÍA}

Alonso Zarza, A.M. 2010. Rocas detríticas. Componentes y caracterización de los distintos tipos. Reduca (Geología). Serie Petrología Sedimentaria 2: 57-79.

Bekker, A., Holmden, C., Beukes, N.J., Kenig, F., Eglington, B. y Patterson, W.P. 2008. Fractionation between inorganic and organic carbon during the Lomagundi (2.22-2.1Ga) carbon isotope excursion. Earth Planet. Science Letter 271: 278-291.

Boggs, S. Jr. 2009. Petrology of Sedimentary Rocks. Cambridge University Press, 600 pp., Cambridge.

Bowers, T.S., Jackson, K.L y Helgenson, H.C. 1984. Equilibrium Activity Diagrams. Springer-verlag, 397 pp., Berlín.

Bowman, J.R. y Essene, E.J. 1984. Contact skarn formation at Elkhorn Montana I. P-T-component activity conditions of early skarn formation. American Journal of Science 284: 597-650.

Bowman, J.R. 1998. Basic aspects and applications of phase equilibria in the analysis of metasomatic Ca-Mg-Al-Fe-Si Skarns. En Lentz, D.R. (ed.) Mineralized Intrusion Related Skarn Systems. Mineralogical Association of Canada. Short Course 26: 1-49, Québec.

Chernicoff, C.J., Zappettini, E.O. y Peroni, J. 2014. The Rhyacian El Cortijo suture zone: aeromagnetic signature and insights for the geodynamic evolution of the southwestern Rio de la Plata craton, Argentina. Geoscience Frontiers 5: 43-52.

Cingolani, C.A., Hartmann, L.A., Santos, J.O.S. y McNaughton, N.J. 2002. U-Pb SHRIMP dating of zircons from the Buenos Aires Complex of the Tandilia Belt, Río de la Plata Craton, Argentina. 15 Congreso Geológico Argentino 1: 149154.

Cingolani, C.A. 2010. The Tandilia System of Argentina as a southern extension of the Río de La Plata craton: An overview. International Journal of Earth Science 100: 221-242.

Cloetingh, S., Wortel, R. y Vlaar, N.J. 1989. On the Initiation of Subduction Zones. Pure and Applied Geophys 129: 7-25.

Coblentz, D.D., Richardson, R.M. y Sandiford, M. 1994. On the gravitational potential of the Earth's lithosphere. Tectonics 13: 929-945. 
Dalla Salda, L.H. y Franzese, J.R. 1989. Los granitoides de Tandil. Primeras Jornadas Geológicas Bonaerenses, Actas 1: 845-861, Buenos Aires.

Dalla Salda, L., Franzese, J. y Posadas V. 1992. The 1.800 m.y. Mylonite-anatetic granitoid association in Tandilia, Argentina. En Mason, R. (ed.) Basement Tectonics, Kluwer Academic Publishers 7: 161-174. Canadá.

Dalla Salda, L.H., de Barrio, R.E., Echeveste, H. y Fernández, R. 2005. El basamento de las Sierras de Tandilia. En de Barrio R.E., Etcheverry R., Caballé M.F. y Llambías E.J. (eds.) Geologia y Recursos minerales de la Provincia de Buenos Aires, Relatorio del $16^{\circ}$ Congreso Geológico Argentino: 32-50, La Plata.

Delpino, S.H. 2000. Evolución metamórfica del sector nororiental del basamento de Tandilia, Argentina: metamorfismo en facies granulita y anatexis cortical. Tesis Doctoral, Universidad Nacional del Sur (inédita), 180p., Bahía Blanca.

Delpino, S.H. y Dristas, J.A. 2008. Dolomitic marbles and associated calc-silicates, Tandilia belt, Argentina: Geothermobarometry, metamorphic evolution, and PT path. Journal of South American Earth Sciences 23: 147-175.

González Menéndez, L., Azor, A., Pereira, M.D. y Acosta, A. 2006. Petrogénesis de Santa Eulalia (Alto Alentejo, Portugal). Revista de la Sociedad Geológica de España 19: 1-2.

Dipple, G.M. y Gerdes, M.L. 1998. Reaction-Infiltration feedback and hidrodynamics at the skarn front. En Lentz, D. (ed.) Mineralizated intrusion-related skarn systems. Mineralogical Association of Canada. Short course series volume 26: 71-90, Québec.

Halpern, M. 1972. Geochronologic Evolution of Southern South America. Simposio Internacional de Sistemas Carbonifero e Permiano America do Sul. Academia Brasileira de Ciencias 44: 149-160, San Pablo, Brasil.

Halpern, M., Umpierre Urquhart, M. y Linares, E. 1970. Radiometric ages of crystalline rocks from southern South America, as relate to Gondwana and Andean geologic provinces. 4th Upper Mantle Symposium, Petrologia y Volcanismo: 345-356, Buenos Aires.

Honza, E. 1993. Spreading mode of backarc basins in the western Pacific. Tectonophysics 251: 139-152.

Iacumin, M., Piccirillo, E., Girardi, V., Teixeira, W., Bellieni, G., Echeveste, H., Fernández, R., Pinese, J. y Ribot, A. 2001. Early Proterozoic Calc-Alkaline and Middle Proterozoic Tholeiitic Dyke Swarms from Central-Eastern Argentina. Petrology, Geochemistry, Sr-Nd Isotopes and Tectonic Implications, Journal of 
Petrology 42: 2109-2143.

Jolivet, L., Huchon, P. y Rangin, C. 1989. Tectonic setting of Western Pacific marginal basins. Tectonophysics 160: 23-47.

Karhu, J.A. y Holland, H.D. 1996. Carbon isotopes and rise of the atmospheric oxygen. Geology 2: 6-9.

Le Breton, N. y Thompson, A.B. 1988. Fluid-absent (deshydration) melting of biotite in metapelites in the early stages of crustal anatexis. Contributions to Mineralogy and Petrology 99: 226-237.

Letouzey, J., Werner, P. y Marty, A. 1991. Fault reactivation and structural inversion. Backarc intraplate compressive deformations. Examples of the eastern Sunda shelf (Indonesia). Tectonophysics 183, 341-362.

Marchese, H.G. y Di Paola, E. 1975. Miogeosinclinal Tandil. Revista de la Asociación Geológica Argentina 30: 161-179.

Mehnert, K. R. 1968. Migmatites and the origin of granitic rocks, 391 p., Amsterdam.

Meinert, L.D., Dipple, G. y Nicolescu, S. 2005. Wold Sarn deposits. Economic Geology 100 th Aniversary Volume: 299-336.

Melezhik, V.A., Fallick, A.E. y Kuznetsov, A.B. 2005. Palaeoproterozoic, rift-related, ${ }^{13} \mathrm{C}$-rich, lacustrine carbonates, NW Russia-Part 2: Global isotope signal recorded in the lacustrine dolostones. Transactions of the Royal Society of Edinburgh Earth Science 95: 423-444.

Melezhik, V.A., Huhma, H., Condon, D.J., Fallick, A.E. y Whitehouse, M.J. 2007. Temporal constraints on the Paleoproterozoic Lomagundi-Jatuli carbon isotopic event. Geology 35: 655-658.

Nikishin, A.M., Ziegler, P.A., Panov, D.I., Nazarevich, B.P., Brunet, M-F., Stephenson, R.A., Boloyov, S.N., Korotaev, M.V. y Tikhomirov, P.L. 2001. Mesozoic and Cainozoic evolution of the Scythian Platform-Black SeaCaucasus domain. En Ziegler, P.A., Cavazza, W., Robertson, A.H.F. y Crasquin-Soleau, S (eds.) Peri-Tethys Memories 6: Peri-Tethyan Rift/Wrench Basins and Passive Margins. Memoires du Museum national d'Histoire naturelle, Paris 186: 295-346.

Patiño Douce, A.E. y Johnston, A.D. 1991. Phase equilibria and melt productivity in the pelitic system: implications for the origin of peraluminous granitoids and aluminous granulites. Contributions to Mineralogy and Petrology 107: 202218. 
Quartino, B. y Villar Fabre, J. 1967. Geología y petrología del basamento de Tandil y Barker, provincia de Buenos Aires, a la luz del estudio de localidades críticas. Revista de la Asociación Geológica Argentina 22: 223-251.

Ramos, V.A. 1999. Rasgos estructurales del territorio argentino. 1 Evolución Tectónica de la Argentina. En Caminos, R. (ed.) Geología Argentina, Anales 29-24: 715-784. Instituto de Geoligía y Recursos Minerales, Subsecretaria de Minería, Buenos Aires.

Ramos, V.A., Leguizamón, A., Kay, S.M. y Teruggi, M. 1990. Evolución tectónica de las Sierras de Tandil (provincia de Buenos Aires). $11^{\circ}$ Congreso Geológico Argentino. Actas 2: 357-360, San Juan.

Rapela, C.W., Pankhurst, R,J., Casquet, C., Fanning, C.M., Baldo, E.G., GonzálezCasado, J.M., Galindo, C. y Dahlquist, J. 2007. The Rio de la Plata craton and the assembly of SW Gondwana. Earth Science Reviews 83: 49-82.

Schidlowski, M., Eichmann, R. y Junge, C.E. 1975. Precambrian sedimentary carbonates: carbon and oxygen isotope geochemistry and implications for the terrestrial oxygen budget. Precambrian Research 2: 1-69.

Schidlowski, M., Eichmann, R. y Junge, C.E. 1976. Carbon istope geochemintry of the Precambrian Lomagundi carbonate province, Rhodesia. Geochemical et Cosmochemical Acta 40: 449-455.

Tamaki, K. y Honza, E. 1991. Global tectonics and the formation of marginal basins: Role of the western Pacific. Episodes 14: 224-230.

Teixeira, W., Pinese, J., Iacumin, M., Girardi, V., Piccirillo, E., Echeveste, H., Ribot, A, Fernández, R., Renne, P.R. y Heaman, L.M. 2002. Calc-alkaline and tholeiitic dyke swarms of Tandilia, Rio de la Plata craton, Argentina: U-Pb, $\mathrm{Sm}-\mathrm{Nd}$, and $\mathrm{Rb}-\mathrm{Sr}{ }^{40} \mathrm{Ar} /{ }^{39} \mathrm{Ar}$ data provide new clues for intraplate rifting shortly after the TransAmazonian orogeny. Precambrian Research 119: 329353.

Teruggi, M.E., Kilmurray, J.O. y Dalla Salda, L.H. 1973. Los dominios tectónicos de la región de Tandil. Anales de la Sociedad Científica Argentina, 295, 81-94.

Teruggi, M. E., Kilmurray, J.O., Rapela, C.W. y Dalla Salda, L.H., 1974. Diques básicos en las Sierras de Tandil, Revista de la Asociación Geológica Argentina 24: 41-60.

Teruggi, M.E., Leguizamón, M.A. y Ramos, V.A. 1988. Metamorfitas de bajo grado metamórfico con afinidades oceánicas en el basamento de Tandil: su implicancia geotectónica, provincia de Buenos Aires. Revista de la asociación 
Geológica Argentina 43: 366-374.

Thompson, A.B. 1982. Deshydration melting of pelitic rocks and the generation of $\mathrm{H} 2 \mathrm{O}-$ undersaturated granitic liquids. American Journal of Science 282: 1567-1595.

Turcotte, D.L. y Oxburgh, E.R. 1973. Mid-plate tectonics. Nature 244: 337-339.

Uyeda, S. y McCabe, R., 1983. A possible mechanism of episodic spreading of the Philippine Sea. En Hashimoto, M. y Uyeda, S. (eds.) Accretion tectonics in the Circum-Pacific regions. Terra Scientific Publ. Co., Tokyo y D. Reidel Publ. Co. Dordrecht Boston London, 291-306.

Valley, J.W. 2003. Oxygen isotopes in zircon. En Hanchar, J.M. y Hoskin, P.W.O. (eds.) Zircon, Reviews in Mineralogy and Geochemistry 53: 343-385.

Varela, R., Cingolani, C. y Dalla Salda, L. 1988. Geocronología Rubidio-Estroncio en granitoides del basamento de Tandil, provincia de Buenos Aires, Argentina. Jornadas Geológicas Bonaerenses. Actas: 291-304, Bahía Blanca.

Ziegler, P.A y Cloetingh, S. 2004. Dynamic processes controlling evolution of rifted basins. Earth-Science Review 64: 1-50. 
ANEXOS 


\section{Abreviaturas minerales utilizadas}

Siivola y Schdmit (2007) y Kretz (1983):

$\mathbf{A b}=$ albita

Act $=$ actinolita

$\mathbf{A d r}=$ andradita

$\mathbf{A l m}=$ almandino

$\mathbf{A m}=$ anfiboles *

$\mathbf{A n}=$ anortita

$\mathbf{A p}=$ apatita

$\mathbf{B t}=$ biotita

Cal $=$ calcita

Chl $=$ clorita

$\mathbf{C l p x}=$ clinopiroxeno*

Clzo $=$ clinozoicita

$\mathbf{D i}=$ diópsido

$\mathbf{E p}=$ epidoto

Fsp $=$ feldespato*

Grs= grosularia

Grt $=$ granate

Hbl= hornblenda

$\mathbf{H d}=$ hedenbergita

Ilm= ilmenita

$\mathbf{J h}=$ johansenita

$\mathbf{M c}=$ microclino

$\mathbf{O p}=$ mineral opaco*

$\mathbf{O r}=$ ortosa

$\mathbf{P 1}=$ plagioclasa

Prp $=$ piropo

Qtz= cuarzo

Ser $=$ sericita ${ }^{*}$

$\mathbf{S p}=$ esfalerita

$\mathbf{T r}=$ tremolita

$\mathbf{T t n}=$ titanita

Tur $=$ turmalina

Uvt $=$ uvarovita *

Ves $=$ vesubianita

$\mathbf{W o}=$ wollastonita

* Exclusivo Siivola y Schdmit (2007). 